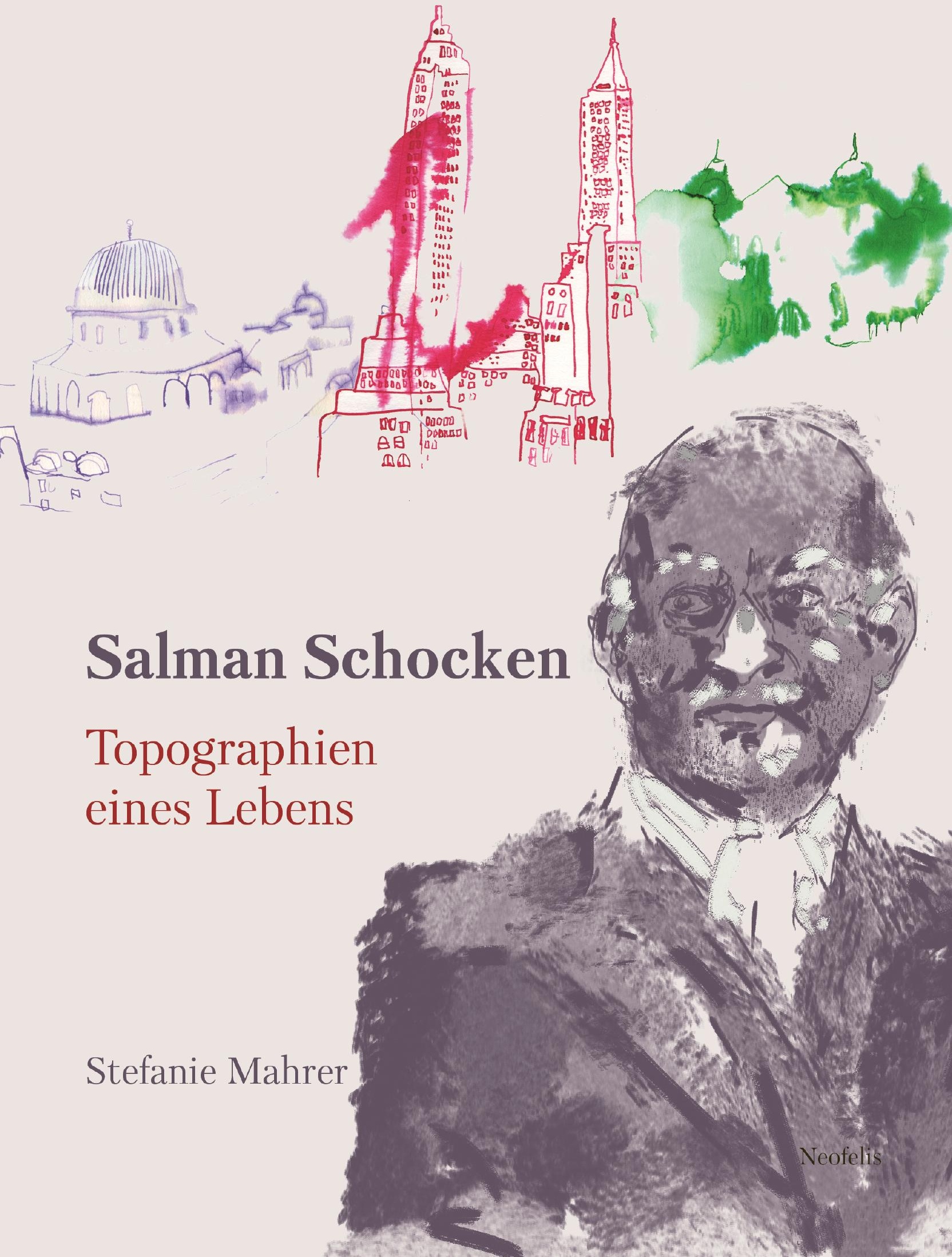


Stefanie Mahrer

Salman Schocken

Topographien eines Lebens

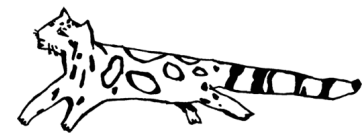




\section{Jüdische Kulturgeschichte in der Moderne \\ hrsg. von Joachim Schlör}

Band 24

Stefanie Mahrer (Prof. Dr.) ist Assistenzprofessorin für Neuere und Neueste Allgemeine Geschichte, sie forscht und lehrt an den Universitäten Bern und Basel zur Geschichte und Kultur der Juden in der Schweiz, in Deutschland und im britischen Mandatsgebiet Palästina/ Israel des 19. und 20. Jahrhunderts. Sie legt den Fokus ihrer Forschung auf Fragen zu Antisemitismus und Vertreibung, Migration, Biographie, Kultur- und Wissenstransfer sowie auf transnationale Netzwerke. 
Stefanie Mahrer

\title{
Salman Schocken
}

\author{
Topographien eines Lebens
}

Neofelis 

Für Ella und Leo 



\section{Inhalt}

Vorwort

1. Einleitung

1.1 Ziel, Fragestellung und Aufbau der Arbeit

1.2 Topographien eines Lebens theoretisch-methodische Überlegungen

1.3 Forschungsstand und Quellenlage

Teil I: Deutschland (1898-1933)

2. Migration von Posen über Berlin nach Zwickau Ein kurzer biographischer Abriss

3. Der Kaufmann 41

3.1 „Wir machen keinen Ausverkauf!“ - der Kaufmann Salman Schocken 43

3.2 Ein moderner Patron das System hinter dem Denken und Handeln Schockens

4. Jüdisches und Zionistisches. Aufbau eines Netzwerkes 63

4.1 Schockens zionistisches Denken $\quad 71$

4.2 Palästina und seine Wirtschaft 74

4.3 Zehn Jahre im Dienste des Zionismus $\quad 85$

5. „The book as a force of change“. Perspektiven auf

Salman Schocken, den Schocken Verlag und seine Bücher 89

5.1 Zionistische Initiativen und Ambitionen die Förderung jüdischer Literatur vor der Verlagsgründung 94

5.2 Der Schocken Verlag - eine historische Skizze 111

5.3 Das Buch im Netzwerk 136

5.4 Text - das Buch als Widerstand 150

5.5 Fazit 184 
TEIL II: JeRUSALEM (1933-1940)

6. Jerusalem als Zufluchtsort. Einleitende Überlegungen

7. Das Haus mit Rosengarten und die Bibliothek der geretteten Bücher Schockens deutsche Enklave in Jerusalem

7.1 Deutsche Kultur in Palästina:

Rechavia und seine Bewohner - eine Einleitung 197

7.2 Zwei deutsch-palästinensische Häuser in Rechavia 201

7.3 Deutsche und hebräische Bücher vereint unter einem Dach die Schocken-Bibliothek in Jerusalem

7.4 Vortragsreihen und Kaffee und Kuchen das bürgerliche Leben in den zwei Häusern

8. Salman Schocken in Jerusalem und sein Beitrag zum Aufbau der jüdischen Zivilgesellschaft

8.1 Hebräische Universität 280

8.2 Der Publizist: Ein deutsches Programm in hebräischer Sprache 303

9. Zwischen zwei Realitäten. 1933 bis 1940

9.1 Schocken in Palästina, Schocken in Europa ein Leben auf zwei Kontinenten

9.2 Weiterleben dank Schocken: Finanzielle und organisatorische Unterstützung für die Flucht aus Deutschland

9.3 Angekommen und doch verloren. Die Unterstützung für mittellose Dichter*innen und Künstler*innen in Palästina

10. Abreise ohne Abschied 


\section{TEIL III: NEW YORK}

11. Reise und Ankunft. Erste Schritte in den USA 371

11.1 Palästina - Neuseeland - Amerika 371

11.2 Im Auftrag der Universität:

Die Schockens in der New Yorker Society 374

11.3 Der unausgesprochene Entschluss, zu bleiben: Ein Fazit 385

12. Neuanfang mit Blick zurück 389

12.1 Schocken Books New York 391

12.2 Schocken / Merkur. Ein kurzes Gastspiel in Deutschland 417

12.3 Die Erfüllung eines Traums: Die Schocken-Baruch-Type 423

12.4 Bruch mit Palästina - ein Schluss 427

13. Blicke auf Verpasstes. Ein Epilog 433

14. Schlusswort 437

Dank 439

ANHANG

Abbildungsverzeichnis $\quad 444$

Abkürzungsverzeichnis $\quad 445$

Glossar $\quad 446$

Veröffentlichungen der Schocken Books New York 1946-1957 449

Literatur- und Quellennachweise

Ungedruckte Quellen, Bestandsverzeichnisse und Archivsiglen 455

Gedruckte Quellen $\quad 460$

Forschungsliteratur 466

$\begin{array}{ll}\text { Index } & 486\end{array}$ 



\section{Vorwort}

Am Anfang dieser Forschung stand die Idee, das kaufmännische Denken des Kaufhausgründers Salman Schocken zum Thema meiner Habilitationsschrift zu machen. Im Sommer des Jahres 2012 aber, im Lesesaal des Archivs der Israelischen Nationalbibliothek, einem damals noch eher unscheinbaren Raum im Untergeschoss des Gebäudes, tat sich mir dann eine ganz andere Welt auf, nicht jene des Wirtschaftsmannes Schocken, sondern jene des Kulturförderers und Verlegers, dieser stand mit sämtlichen wichtigen Autorinnen und Autoren, Wissenschaftlern und Wissenschaftlerinnen sowie zionistischen Persönlichkeiten seiner Zeit in Kontakt. Viele seiner Ideen, Pläne, Hoffnungen, Versprechen und Enttäuschungen erschlossen sich mir in diesem Sommer. Vier Wochen lang saß ich tagtäglich über den zahlreichen Briefen, die in den Nachlässen der Wissenschaftler*innen und Autor*innen zugänglich sind. Ich tauchte in ein Netzwerk von Menschen ein, die in den 1920er Jahren in Deutschland eine jüdische Welt aufbauten, die in den 1930er Jahren von den Nationalsozialisten erst erschüttert und dann zerstört wurde. Teile davon konnten mit der Emigration nach Palästina transferiert werden. Diese Welt ließ mich über fünf Jahre nicht mehr los. Zu den im Sommer 2012 erfassten Briefen kamen Tausende mehr Dokumente, die ausgewertet und analysiert werden sollten. Sie bildeten die Basis für diese Arbeit.

Es geht in dieser Studie nicht darum, die Lebensgeschichte zu psychologisieren; ohne Verweise auf Schockens Charakter ließ sich die Geschichte seines Lebens jedoch nicht erzählen. Denn auch bei einer wissenschaftlichen Biographie wie 
der vorliegenden, die sich den Anforderungen der historischen Forschung in allen Belangen verpflichtet fühlt, handelt es sich um eine Erzählung. Über zehntausend Briefe und Protokolle sind in diese Biographie eingeflossen, eine Auswahl davon ist in den Text aufgenommen worden. Diese Dokumente haben mir einen Einblick in die Persönlichkeit Salman Schockens gewährt, sie halfen mir, die Geschichte von Schockens Leben zu rekonstruieren, das Netz zu weben. Die Einbettung der Lebensgeschichte in die politischen und gesellschaftlichen Umstände und die Darstellung der wechselseitigen Beziehungen zwischen Makro- und Mikroebene führten schließlich zu der Biographie, wie sie hier vorliegt. Trotz der Fülle des Materials ließ sich jedoch eine gewisse Distanz zu Schocken nicht überwinden. Durch den geschäftlichen Ton, den er unabhängig von den Adressat ${ }^{*}$ innen in sämtlichen seiner Briefe pflegte, kam so etwas wie Nähe nie auf. Selbst in der Korrespondenz mit seiner Frau und seinen Kindern scheinen keine Gefühle durch und selbst wenn es um Bücher geht, die vielleicht das Wichtigste in seinem Leben ausmachten, ist kaum Begeisterung oder Leidenschaft spürbar. Am deutlichsten wird Schockens kühle Distanziertheit aber wohl in seiner Korrespondenz mit Else Lasker-Schüler. ${ }^{1}$ Die überschwängliche Sprache der Dichterin, ihre Ehr- und Freundschaftsbezeugungen werden kontrastiert in Schockens knapp und förmlich gehaltenen Antwortschreiben. Diese analysierende Kälte machte vielen seinen Wegefährt ${ }^{*}$ innen den Umgang mit ihm schwierig, tiefe Freundschaften blieben ihm daher Zeit seines Lebens verwehrt. So verwundert es kaum, dass S.J. Agnon seinen lebenslangen Förderer, dem er in seinem posthum erschienenen Roman Herrn Lublins Laden ein Denkmal setzte, bei der Verleihung des Nobelpreises mit keinem Wort erwähnte. ${ }^{2}$

Diese fehlende Nähe wird auch in dieser Biographie spürbar, sie ist daher nicht dem Versuch der Verfasserin geschuldet, eine rigide wissenschaftliche Distanz zum Protagonisten herzustellen, sondern der Tatsache, dass Salman Schocken keine Nähe zuließ. Der Blick auf Schocken und seine Lebenswelt bleibt daher ein kritisch-distanzierter, aber keinesfalls ein kritisierender.

1 Vgl. Kap. 9.3.1. Der publizierte Briefwechsel findet sich hier: Else Lasker-Schüler: ,Was soll ich hier?'. Exilbriefe an Salman Schocken. Heidelberg: Lambert Schneider 1986.

2 Shmuel Yosef Agnon: Herrn Lublins Laden, aus d. Hebr. v. Inken Kraft. Leipzig: Kiepenheuer 1993. 
Das vorliegende Werk stellt die leicht überarbeitete Fassung meiner 2018 abgeschlossenen Habilitationsschrift dar, die im Herbstsemester 2019 von der philosophisch-historischen Fakultät der Universität Basel im Fach Neuere und Neuste Allgemeine Geschichte angenommen wurde.

Im folgenden Text werden zahlreiche Personen, Orte und Institutionen genannt. Von vielen gibt es unterschiedliche Schreibweisen. Während in den Originalzitaten auf eine Angleichung verzichtet wurde, wurde in der Nennung im Lauftext auf Einheitlichkeit geachtet, dabei wurde meist die im Deutschen gebräuchliche Schreibweise oder die von der Person bevorzugte Variante gewählt. Fremdsprachliche Begriffe wurden entweder eingedeutscht, oder die gebräuchliche Transliteration verwendet. 



\section{Einleitung}

\subsection{Ziel, Fragestellung und Aufbau der Arbeit}

„Salman Schocken war eine kompliziert geschliffene Persönlichkeit mit einer Fülle von Facetten“, schrieb Kurt Blumenfeld in seinem Nachruf auf Schocken, „wer ihn beleuchten will, muss jedes Mal Blick und Stellung ändern. Es gilt, seine Vielseitigkeit zu erfassen und gleichzeitig zu versuchen, in das Rät-

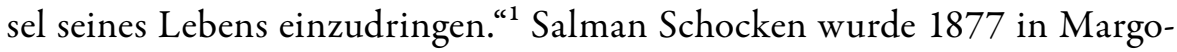
nin in der Provinz Posen als zehntes Kind einer einfachen und frommen jüdischen Familie geboren. Als er 1959 in einem Nobelhotel in Pontresina starb, war er ein reicher Mann, der sich als Kaufhausbesitzer, Kulturzionist, Verleger und Mäzen auf drei Kontinenten einen Namen gemacht hatte. Wer war dieser Mann, dessen beruflicher Aufstieg äußerst steil war, und der zeitweilig das Zentrum eines der wichtigsten deutsch-jüdischen Netzwerke war? Was hat ihn angetrieben, seine Heimat zu verlassen und seiner Herkunft den Rücken zu kehren - und ein Leben in der und für die Öffentlichkeit zu leben? Woher kam sein unstillbares Interesse für die jüdische Buchkultur und Wissenschaft? Was bedeutete für ihn die Emigration aus Deutschland, wie ging er mit dem Ausschluss aus der deutschen Gesellschaft um? Warum geriet ein Mann wie Schocken nach seinem Tod in Vergessenheit? Dies sind einige der Fragen, die meine Forschungsarbeit anleiteten und die in der Folge beantwortet werden sollen.

1 Kurt Blumenfeld: Erlebte Judenfrage. Ein Vierteljahrhundert deutscher Zionismus. Stuttgart: DVA 1962, S. 99. 
Diese Fragen sind dem Interesse an Salman Schockens Biographie geschuldet; dennoch liegt mit dieser Untersuchung keine klassische Biographie vor, die sich darauf beschränkt, den Lebensweg eines Einzelnen nachzuzeichnen. Vielmehr folge ich dem Verständnis Hannah Arendts, die über das Genre der Biographien schrieb:

Es geht in ihnen darum, ein Leben und dessen literarische Manifestationen in seine Zeit hineinzustellen und unter Berücksichtigung der jeweils besonderen gesellschaftlichen, politischen, geschichtlichen Umstände zu verstehen. Die (exemplarischen) Berührungspunkte von individuell gelebtem Leben und politisch-geschichtlicher Zeit sind es, welche vornehmlich interessieren. ${ }^{2}$

Die wissenschaftliche Biographik interessiert sich für die Singularität eines Lebens und die individuelle Erfahrung des einzelnen Subjektes im Kontext seiner gesellschaftlichen und politischen Umgebung. In den 1970er Jahren sah sie sich als rein hermeneutisches Verfahren der Fundamentalkritik der nunmehr verstärkt theoriegeleiteten Geschichtswissenschaft ausgesetzt. Mit Blick auf die neuen Fragen nach den Strukturen der menschlichen Geschichte wurden die angeblich theoriefeindliche Biographik und ihr Verfahren der Rekonstruktion eines singulären Lebens von der Sozialgeschichte als überholt und erkenntnisfrei kritisiert. ${ }^{3}$ Erst das aufkommende Unbehagen an der menschenleeren Strukturgeschichte weckte ein Jahrzehnt später neues Interesse am Leben und Erleben des historischen Subjekts.

Pierre Bourdieu verdeutliche, so Reinhard Sieder in seinem Aufsatz zur Sozialgeschichte auf dem Weg zu einer historischen Kulturwissenschaft, dass die von der Sozialgeschichte ins Zentrum gerückten „sozial-strukturellen Tatsachen“ erst durch die Aneignung durch einen Handelnden, einen historischen Akteur, „soziale Wirklichkeit“ werden. ${ }^{4}$ Die erneuerte Biographik, die eng mit dem aus

2 Hannah Arendt: Menschen in finsteren Zeiten. München / Zürich: Piper 1989, S. 8.

3 Vgl. Ulrich Herbert: Über Nutzen und Nachteil von Biographien in der Geschichtswissenschaft. In: Beate Böckem / Olaf Peters / Barbara Schellewald (Hrsg.): Die Biographie Mode oder Universalie? Zu Geschichte und Konzept einer Gattung in der Kunstgeschichte. Berlin: de Gruyter 2015, S.3-15; Simone Lässig: Die historische Biographie auf neuen Wegen? In: Geschichte in Wissenschaft und Unterricht 10 (2009), S. 540-553.

4 Vgl. Reinhard Sieder: Sozialgeschichte auf dem Weg zu einer historischen Kulturwissenschaft. In: Geschichte und Gesellschaft. Zeitschrift für historische Sozialwissenschaft 20,3 (1994), S. 446-468. 
der Soziologie stammenden Konzept der ,Lebenswelt' verbunden ist, bedeutet daher keinesfalls ein Zurückfallen in theoriefreie Betrachtung und führt auch keineswegs zu einer hagiographischen Überhöhung des Individuellen. Vielmehr wird fremdes Leben in einer Weise nachgezeichnet, dass der dazugehörige Inszenierungs- und Konstruktionscharakter ebenfalls Bestandteil der Beschreibung ist. Im Unterschied zur alten Biographik des Historismus begreift somit die moderne Forschung das Verhältnis zwischen Individuum und Gesellschaft nicht länger dichotom ${ }^{5}$; sie geht vielmehr von einem „soziologischen Begriff der historischen Persönlichkeit “6 aus. Ein isoliertes Betrachten des historischen Subjektes stellt sich aus dieser Perspektive als ebenso unbefriedigend dar wie eine Strukturgeschichte, der die Menschen abhandengekommen sind. Es geht vielmehr darum, den Menschen im Netzwerk seiner Beziehungen sowie im Gefüge von Zeit und Raum zu verstehen.

Nicht nur, aber besonders im Kontext von Migration und Flucht sind darüber hinaus Bourdieus Hinweise auf die Nichtlinearität der menschlichen Identität relevant. Nur gerade der Eigenname sei noch

als bleibende und dauerhafte soziale Identität gesetzt, [...] [der] für die Identität des biologischen Individuums in all den möglichen Feldern einsteht, in die es als Akteur hineingerät, das heißt in allen seinen möglichen Lebensgeschichten. ${ }^{7}$

Das, was der Eigenname bezeichnet, ist immer nur eine sich ständig verändernde Sammlung an biologischen und sozialen Eigenschaften, die nur in den Grenzen eines Raumes Gültigkeit hat. ${ }^{8}$

5 Vgl. Jürgen Oelkers: Biographik - Überlegungen zu einer unschuldigen Gattung. In: Neue politische Literatur 19,3 (1974), S.296-309; Hagen Schulze: Die Biographie in der ,Krise der Geschichtswissenschaft'. In: Geschichte in Wissenschaft und Unterricht 29,8 (1978), S. 508-518.

6 Hans Erich Bödeker: Biographie. Annäherung an den gegenwärtigen Forschungs- und Diskussionsstand. In: Ders. (Hrsg.): Biographie schreiben. Göttingen: Wallstein 2003, S.9-63, hier S. 20.

7 Pierre Bourdieu: Die biographische Illusion. In: Ders.: Praktische Vernunft. Zur Theorie des Handelns, aus d. Franz. v. Hella Beister. Frankfurt am Main: Suhrkamp 1998, S.75-83, hier S.78.

8 Ebd., S. 80. 
Die wissenschaftliche Biographik vermag es, wie Margit Szöllösi-Janze bemerkt, durch die Integration verschiedener Ansätze und Themenfelder, Geschichte in all ihren Schattierungen darzustellen. ${ }^{9}$ Dies genau ist das Ziel der vorliegenden Studie.

Durch den Einbezug der historischen Migrationsgeschichte, der Buchgeschichte, der Institutionsgeschichte und der Netzwerkanalyse wird die Geschichte der kulturellen und zionistischen Elite des deutschen Judentums aufgearbeitet. Es sind die Berührungspunkte zwischen Salman Schockens Erleben und dem Politisch-Historischen, die auf einer übergeordneten Ebene interessieren. Dabei steht die Biographie Schockens im Zentrum. Anhand der wichtigsten Stationen und Themen seines Lebens sollen die „Facetten seiner Persönlichkeit“, um Blumenfeld nochmals zu zitieren, im Kontext seiner Zeit beleuchtet werden. Damit verfolgt die Studie erstens das Ziel, eine der zentralen deutsch-jüdischen Persönlichkeiten der ersten Hälfte des 20. Jahrhunderts wieder vermehrt ins Bewusstsein zu bringen, und zweitens, einen Beitrag zur Geschichte und Kultur der Juden Deutschlands vor dem Nationalsozialismus, aber auch nach ihrer Vertreibung und Emigration zu leisten. Zwar gelang es den Nationalsozialisten durch die Ausgrenzung der Juden aus dem Wirtschafts-, Kultur- und Geistesleben Deutschlands, durch ihre Entrechtung und schließlich durch ihre Ermordung, das jüdische Leben in Deutschland zu vernichten. Sie vermochten aber nicht, die deutsch-jüdische Kultur auszulöschen. Durch die Vertreibung und Emigration entstanden neue Zentren, eines davon in Jerusalem. Daran war Salman Schocken nicht unbeteiligt. Im Folgenden geht es daher auch darum, wie sich der Kulturraum des deutschen Judentums nach 1933 außerhalb Deutschlands konstituierte und veränderte. Im Zentrum steht dabei das Netzwerk um Salman Schocken.

Die Gliederung der Studie folgt konsequenterweise den Lebensstationen Schockens und rollt die Geschichte chronologisch auf, wobei keine lückenlose Darstellung seiner Lebensgeschichte angestrebt wird, sondern einzelne Topographien vertieft und analysiert werden.

9 Vgl. Margit Szöllösi-Janze: Lebens-Geschichte - Wissenschafts-Geschichte. Vom Nutzen der Bigraphie für Geschichtswissenschaft und Wissenschaftsgeschichte. In: Berichte zur Wissenschaftsgeschichte 23 (2000), S. 17-35, hier S. 21. 


\subsection{Topographien eines Lebens - theoretisch-methodische Überlegungen}

„Geschichte spielt nicht nur in der Zeit, sondern auch im Raum “10, so eröffnet Karl Schlögel sein monumentales Werk Im Raume lesen wir die Zeit, in dem er die Historikerzunft dazu aufruft, sich vermehrt wieder dem Raum zu widmen. Denn Geschichte ist, so der Autor, geprägt durch die Orte, an denen sie stattfindet. Er plädiert dafür, Ort, Zeit und Handlung als Einheit zu denken: ,spacing history ${ }^{11}$ nennen dies die US-amerikanischen Kolleginnen und Kollegen.

Der Spatial Turn, der die ,Raumvergessenheit in den Sozial- und Kulturwissenschaften kritisierte, setzte Ende der 1980er Jahre ein, als er das erste Mal vom amerikanischen Humangeographen Edward W. Soja ${ }^{12}$ in einer Zwischenüberschrift verwendet wurde. ${ }^{13}$ Soja rief in seinem Text zu einer Neubewertung des Werkes des französischen Soziologen Henri Lefebvre auf, der eine Theorie der Produktion des Raumes entworfen hatte. Lefebvre eröffnete die Perspektive, unterschiedliche räumliche Phänomene gesellschaftstheoretisch zu analysieren und zu erklären. Seine Theorie ist auch für die sozial- und kulturwissenschaftliche Forschung von Interesse, da sie kulturelle, sprachliche, politische, soziale und ökonomische Aspekte der Raumproduktion zu erfassen mag. ${ }^{14}$ Soja postulierte ebenso wie ein anderer Vertreter der postmodernen Geographie, Derek Gregory, einen Paradigmenwechsel vom Historischen zum Räumlichen. In seinem 1996 publizierten Werk Thirdspace kam Soja auf den Begriff des Spatial Turn zurück, und bezeichnete ihn im (selbstverfassten) Klappentext ${ }^{15}$ des erwähnten Buches als

10 Karl Schlögel: Im Raume lesen wir die Zeit. Über Zivilisationsgeschichte und Geopolitik. Frankfurt am Main: Fischer 2016, S.9.

11 Vgl. ebd., S. 10.

12 Edward W. Soja: Postmodern Geographies. The Reassertion of Space in Critical Social Theory. New York: Verso 1989.

13 Vgl. Jörg Döring/ Tristan Thielmann: Einleitung. Was lesen wir im Raume? Der Spatial Turn und das geheime Wissen der Geographen. In: Dies. (Hrsg.): Spatial Turn. Das Raumparadigma in den Kultur- und Sozialwissenschaften. Bielefeld: Transcript 2008, S.9-45, hier S. 9 .

14 Christian Schmid: Stadt, Raum und Gesellschaft. Henri Lefebvre und die Theorie der Produktion des Raumes. Wiesbaden: Steiner 2005, S. 10.

15 Vgl. Döring/Thielmann: Einleitung. Was lesen wir im Raume?, S. 9. 
one of the most important intellectual und political developments in the late twentieth century, [when] scholars have begun to interpret space and the spatiality of human life with the same critical insight and emphasis that has traditionally be given to time and history on the one hand, and to social relations and society on the other. ${ }^{16}$

Die Beschäftigung mit dem Raum als Kategorie, die lange Zeit in gesellschaftstheoretischen Überlegungen marginalisiert war, wurde sehr bald von Soziologen wie Pierre Bourdieu aufgegriffen. ${ }^{17}$

Das Interesse an Raum als kulturwissenschaftlichem Konzept ist jedoch lange vor dem eigentlichen Spatial Turn festzumachen. Bereits in den ersten zwei Jahrzehnten des 20. Jahrhunderts haben Émile Durkheim ${ }^{18}$ und Oswald Spengler ${ }^{19}$ darauf hingewiesen, dass Raum historisch und gesellschaftlich konstituiert sei. Jedoch erst der aus der postmodernen Geographie stammende Begriff des Spatial Turn löste ein Nachdenken über die Kategorie Raum in den unterschiedlichsten Disziplinen aus. Allerdings werden in der Regel, so Döring und Thielmann, die Diskussionen innerhalb der einzelnen Disziplinen geführt, sodass es bis heute keine überfachliche Verständigung darüber gibt, was das neue, durch die sogenannte Wende herbeigeführte räumliche Paradigma denn eigentlich bedeuten soll. Inzwischen ist eine verbreitete Skepsis gegenüber dem Begriff des Spatial Turn zu beobachten, die auf eine inflationäre Verwendung des Begriffs Turn in den Kulturwissenschaften seit den 1980er Jahren zurückgeht. Es soll in der vorliegenden Arbeit nicht um eine weitere theoretische Abhandlung zur räumlichen Wende in der Kultur- und Geschichtswissenschaft gehen. Vielmehr sollen die Diskussionen vor und nach dem Spatial Turn anregen, darüber nachzudenken, inwiefern die Kategorie Raum für die historisch-wissenschaftliche Aufarbeitung einer Biographie nutzbar gemacht werden kann.

16 Edward W. Soja: Thirdspace. Journeys to Los Angeles and Other Real-and-Imagined Places. Oxford: Blackwell 1997.

17 Vgl. Schmid: Stadt, Raum und Gesellschaft, S.62.

18 Émile Durkheim: Die elementaren Formen des religiösen Lebens, aus d. Franz. v. Ludwig Schmidts. Frankfurt am Main: Suhrkamp 1981, S. 591-593.

19 Oswald Spengler: Die Symbolik des Weltbildes und das Raumproblem. In: Ders.: Der Untergang des Abendlandes. Umrisse einer Morphologie der Weltgeschichte, Bd.2: Welthistorische Perspektiven. München: dtv 1972, S.231-234. 
Der Historiker Schlögel weist in seiner Einleitung darauf hin, dass der

Ort ein Vetorecht gegen die von der Disziplin und der arbeitsteiligen Forschung favorisierte Parzellierung und Segmentierung des Gegenstands [hatte]. Der Ort [hielt] den Zusammenhang aufrecht und verlangte geradezu die gedankliche Reproduktion des Nebeneinanders, der Gleichzeitigkeit der Ungleichzeitigkeit. ${ }^{20}$

Der Raum wird hier als Klammer verstanden, der eine histoire totale ermöglicht. Im Raum muss die Geschichte nicht mehr in ihren Einzelteilen in einer chronologischen Abfolge der Ereignisse gelesen, sondern kann in ihrer Gesamtheit in den Blick genommen werden. Soziale Beziehungen, politische Ereignisse, kulturelle Ausdrücke und gesellschaftliche Normen lassen sich im Raum in ihren Beziehungen zueinander studieren. Dies gibt für die historische Biographik wichtige Anstöße, den Menschen in seinen Verflechtungen wahrzunehmen, führt aber durch das noch sehr reale Verständnis von Raum zu einer Verengung des Blickwinkels. Schlögel versteht den Raum zwar als ein offenes, dynamisches Konzept, interessiert sich jedoch vornehmlich für urbane Räume und vernachlässigt einerseits das „Dazwischen“, also die Reise durch den Raum, und andererseits die „Verräumlichung des Sozialen“. ${ }^{21}$

Für das Verstehen der Biographie Salman Schockens ist dieses ,Dazwischen fundamental. Die Erfahrung des Dazwischen hat 1974 auch der französische Schriftsteller Georges Perec in seinem Text Espèces d'espaces ausgelotet, indem er die „Selbstverständlichkeit ${ }^{\text {“22 }}$ des realen Raumes in Frage stellte. Er verstand die Lebenswelt eines jeden vielmehr als zusammengesetzt aus einer Vielzahl von Räumen, die „sich vermehrt geteilt und aufgelockert [haben]. Es gibt heute Räume in allen Größen und von allen Sorten, für jeden Gebrauch und für alle Funktionen. Leben heißt, von einem Raum zum anderen zu gehen [...].“23 Perecs Konzept der Gleichzeitigkeit von Räumen ist für die vorliegende Arbeit zentral. Salman Schocken bewegte sich in mehreren sozialen, politischen,

20 Schlögel: Im Raume lesen wir die Zeit, S. 10.

21 Albrecht Weisker: Rezension zu: Karl Schlögel: Im Raume lesen wir die Zeit. Über Zivilisationsgeschichte und Geopolitik. München 2003. In: H-Soz-Kult, 13.03.2004. www. hsozkult.de/publicationreview/id/reb-4847 (Zugriff am 12.02.2020).

22 Georges Perec: Träume von Räumen, aus d. Franz. v. Eugen Helmlé. Zürich: Diaphanes 2013, S. 13.

23 Ebd. 
kulturellen und geographischen Räumen gleichzeitig. Diese Räume berührten und überschnitten sich. Michel Foucault schrieb in seinem für die kulturwissenschaftliche Raumforschung zentralen Aufsatz Des espaces autres, dass „wir [...] in einem Moment [sind], wo sich die Welt weniger als ein Großes sich durch die Zeit entwickelndes Leben erfährt, sondern eher als ein Netz, das seine Punkte verknüpft und sein Gewirr durchkreuzt. ${ }^{\text {"24 }}$ Wie genau ein historisches Subjekt sein Leben erfahren hat, ist aus der Perspektive der Geschichtswissenschaft nur schwer nachvollziehbar. Wir können uns über die überlieferten Quellen zwar ein Bild eines Lebens machen, in die Gefühlswelt eines Menschen einzudringen, scheint jedoch kaum möglich. Dennoch müssen wir im Sinne einer lebensweltlichen Geschichtsschreibung nach der Sinnstiftung des Individuums fragen.

Das Interesse am „Bewusstseinsleben des historischen Subjekts “25 ist in den letzten drei Jahrzehnten gewachsen. Das Konzept der Lebenswelt, das ursprünglich über die Phänomenologie Edmund Husserls ${ }^{26}$ von Alfred Schütz ${ }^{27}$ in die empirische Sozialwissenschaft eingeführt und später intensiv durch Jürgen Habermas $^{28}$ rezipiert wurde, erfuhr in den Arbeiten von RudolfVierhaus ${ }^{29}$ und Heiko Haumann $^{30}$ eine Wende zu einer historisch-kulturwissenschaftlichen Methode. In seiner Lebenswelt deutet der Akteur seine Umwelt, in ihr findet die

24 Michel Foucault: Andere Räume, aus d. Franz. v. Walter Seitter. In: Karlheinz Barck / Peter Gente / Heidi Paris / Stefan Richter (Hrsg.): Aisthesis. Wabrnehmung heute oder Perspektiven einer anderen Ästhetik. Essais. Leipzig: Reclam 1992, S.34-46, hier S.34.

25 Alfred Schütz: Strukturen der Lebenswelt, hrsg. v. Thomas Luckmann. Stuttgart: UTB 2003, S. 100.

26 Edmund Husserl: Die Phänomenologie der Lebenswelt. Ausgewählte Texte II. Überarb. Aufl. Stuttgart: Reclam 2007.

27 Vgl. Schütz: Strukturen der Lebenswelt.

28 Jürgen Habermas: Theorie des kommunikativen Handelns. Zur Kritik der funktionalistischen Vernunft. Frankfurt am Main: Suhrkamp 1981, insb. S. 190-209, 222-228.

29 Rudolf Vierhaus: Die Rekonstruktion historischer Lebenswelten. Probleme moderner Kulturgeschichtsschreibung. In: Hartmut Lehmann (Hrsg.): Wege zu einer neuen Kulturgeschichte. Göttingen: Wallstein 1995, S. 6-28.

30 Heiko Haumann: Geschichte, Lebenswelt, Sinn. Über die Interpretation von Selbstzeugnissen. In: Brigitte Hilmer / Georg Lohmann / Tilo Wesche (Hrsg.): Anfang und Grenzen des Sinns. Weilerswist: Velbrück Wissenschaft 2006, S.42-54; ders.: Lebensweltlich orientierte Geschichtschreibung in den Jüdischen Studien. Das Basler Beispiel. In: Klaus Hödl (Hrsg.): Jüdische Studien. Reflexionen und Praxis eines wissenschaftlichen Feldes. Innsbruck: Studienverlag 2003, S. 105-122. 
Sinnstiftung statt und zwar im kommunikativen Netz von objektiven Strukturen, Gesellschaft und Individuum. ${ }^{31}$ Diese Überlegungen hatten großen Einfluss auf die historische Biographik, ein publikumswirksames, aber gleichzeitig eines der schwierigsten Genres des wissenschaftlichen Schreibens. „Der Mensch lebt nicht nur ein persönliches Leben als Einzelperson, sondern, bewusst oder unbewusst, das seiner Epoche und Zeitgenossenschaft", schrieb Thomas Mann im Zauberberg, und erfasste damit, was die wissenschaftliche Biographik erst Jahrzehnte später zu verstehen begann, nämlich, dass eine Lebensgeschichte auch immer die Geschichte ihrer Epoche ist. Dies bedeutet jedoch gleichzeitig, dass die gesellschaftlichen und sozialen Zustände von Menschen geprägt werden. Durch das wechselseitige Einwirken von Individuen und Strukturen entsteht Geschichte. Das gilt auch, nachdem der Poststrukturalismus zentrale Grundlagen der bisherigen Geschichtsschreibung in Frage stellte, denn auch die poststrukturalistische Geschichte rekonstruiert Strukturen. „Allerdings“, so schreibt Reinhard Sieder, „denkt sie [die poststrukturalistische Geschichtsschreibung, Anm. d. Verf.] diese Strukturen nicht mehr als die zähen Determinanten des Handelns und Deutens, sondern ,strukturell' ist eine Eigenschaft

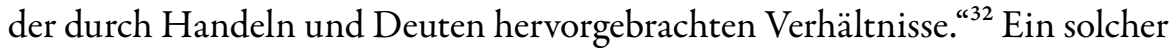
Zugang zu Geschichte und zur historischen Biographik ermöglicht es, die Lebensgeschichte eines Menschen zu erzählen, auch wenn nur wenige Quellen überliefert sind, da nicht die lückenlose Chronik eines Lebens das Ziel ist. Vielmehr wird untersucht, wie das historische Subjekt in seiner Epoche sein Leben gestaltete, welche Entscheidungen es traf und wie diese von den Umständen der Zeit beeinflusst wurden. Es geht dabei auch darum, den Eigensinn der jeweiligen Akteure im Blick zu behalten, und danach zu fragen, wo Neues geschaffen wurde und inwiefern sie sich gegen die vorherrschenden gesellschaftlichen Erwartungen und Normen auflehnten.

Salman Schockens Leben war geprägt von freiwilligen und unfreiwilligen Migrationen, von sozialem Aufstieg und von professionellen Umschichtungen. Er bewegte sich zwischen und in unterschiedlichen Welten, geographischen Räumen, Lebenswirklichkeiten und sozialen Räumen. Diese kulturellen, geographischen und sozialen Topographien sollen in der vorliegenden Arbeit

31 Vgl. Stefanie Mahrer: Handwerk der Moderne. Jüdische Ubrmacher und Uhrenunternehmer im Neuenburger Jura 1800-1914. Köln: Böhlau 2012, S. 29.

32 Sieder: Sozialgeschichte auf dem Weg zu einer historischen Kulturwissenschaft, S. 452. 
ausgelotet werden. Es gilt dabei, die unterschiedlichen Räume zu beschreiben und gleichzeitig die zahlreichen Verbindungen zwischen ihnen, die durch ein Geflecht von Beziehungen entstehen, zu fassen. Das Beziehungsgeflecht, in dem Schocken sich bewegte, war niemals statisch. Vielmehr war es beeinflusst von unterschiedlichen Abhängigkeiten, persönlichen Freundschaften wie politischen Entwicklungen und ständig in Bewegung. In diesem mehrschichtigen Netzwerk manifestieren sich Zwischenräume, die für das Verstehen der Biographie zentral sind.

Daher versteht sich diese Untersuchung sehr viel mehr in der Tradition des von der deutschen Literatur- und Kulturwissenschaftlerin Sigrid Weigel geprägten Begriffs des ,topographical turn' als in der des Spatial Turn. Weigels Konzept wird gemeinhin als europäischer Beitrag zum bis dahin amerikanisch geprägten Raumdiskurs verstanden. Anders als ihre amerikanischen Kolleginnen und Kollegen, beruft sie sich auf die europäische Tradition, Raum als philosophisches, soziologisches und anthropologisches Konzept zu verstehen. ${ }^{33}$ Methodologisch bedeutet dies, dass Weigel sich auf das gráphein, also das Schreiben und Zeichnen, das in ,Topographie` enthalten ist, einlässt.

Der Raum ist hier nicht mehr Ursache oder Grund, von der oder dem die Ereignisse oder deren Erzählung ihren Ausgang nehmen, er wird vielmehr als eine Art Text betrachtet, dessen Zeichen oder Spuren semiotisch, grammatologisch oder archäologisch zu entziffern sind. ${ }^{34}$

Um Raum als Text zu lesen, müssen wir, ganz praktisch gesehen, erst definieren, was wir überhaupt als Raum verstehen. Wie bereits erwähnt, wird in der vorliegenden Studie mit einem weiten Raumbegriff gearbeitet, der in der europäischen Tradition des Raumdiskurses soziale Räume, wie sie unter anderem von Pierre Bourdieu eingeführt wurden, sowie kulturelle, politische und geographische Räume gleichermaßen beachtet. „Topographien eines Lebens“, der Untertitel der vorliegenden Untersuchung, verweist darauf, dass der Zugang über die Kategorie Raum es erlaubt, eine Biographie nicht als chronologische Abfolge von Ereignissen zu erzählen, sondern als Bewegung eines Menschen

33 Vgl. Döring/Thielmann: Einleitung. Was lesen wir im Raume?, S. 16.

34 Sigrid Weigel: Zum ,topographical turn'. Kartographie, Topographie und Raumkonzepte in den Kulturwissenschaften. In: KulturPoetik 2,2 (2002), S. 151-165, hier S. 160. 
(auch) im Netzwerk seiner Beziehungen. Die vorliegende Arbeit versteht sich daher als Beitrag zur Erschließung des Raumkonzepts für die Biographieforschung und erprobt hierfür auch methodologisch ein mögliches Fundament.

Während in den Kulturwissenschaften die Kategorie Raum durch den Spatial Turn breite Beachtung fand und ein Feld schuf, das intensiv bearbeitet wurde, existiert in der Migrationsforschung bislang kaum eine Auseinandersetzung mit Raum als sozialem Konstrukt. ${ }^{35}$ So besteht nach Elisabeth Scheibelhofer bis heute das bereits zu Beginn der 1970er Jahre von Wilbur Zelinsky prägnant formulierte Problem, dass „, $[\mathrm{t}]$ hroughout migrational literature, space is almost always treated as an absolute, with distances between point reckoned as constant. ${ }^{\text {“36 }}$ Für die Forschung kann es schwierig sein, die sozialen Beziehungen und Migrationsbewegungen zu verstehen, da die entscheidenden Faktoren oft in komplexen räumlichen, politischen, historischen und sozialen Zusammenhängen stehen. Ein raumtheoretischer Zugang kann dabei helfen, empirisch beobachtete Realitäten adäquater zu erfassen. ${ }^{37}$ Die empirische Forschung hat gezeigt, dass Migranten häufig in sozialen Zusammenhängen leben, die territorial betrachtet die Grenzen eines Nationalstaates überschreiten. ${ }^{38}$ Migrationsforschung, die auf einem nationalstaatlichen Paradigma beruht, nimmt jedoch „ein[en] nationale[n] Rahmen für soziale Beziehungen “ ${ }^{39}$ an; daher würden Beziehungen zum Herkunftsland wie auch die Pflege der Herkunftssprache als Hindernis für eine gelungene Integration verstanden. Scheibelhofer plädiert daher für eine Reflexion der gängigen Raumannahmen in der Migrationsforschung, da multiple Zugehörigkeiten und eine eindeutige Positionierung im ,Dazwischen' auch positive Aspekte haben könnten. ${ }^{40}$

Die vorliegende biographische Studie zu Salman Schocken wird damit von mehreren methodisch-theoretischen Zugängen beeinflusst. Sie verortet sich in der neuen historischen Biographieforschung, nimmt aber auch Anstöße aus der

35 Vgl. Elisabeth Scheibelhofer: Raumsensible Migrationsforschung. Methodologische Überlegungen und ihre empirische Relevanz für die Migrationssoziologie. Wiesbaden: Spinger VS 2011, S. 13.

36 Wilbur Zelinsky: The Hypothesis of the Mobility Transition. In: Geographical Review 60,2 (2003), S. 219-249, hier S. 226.

37 Vgl. Scheibelhofer: Raumsensible Migrationsforschung, S. 12.

38 Vgl. ebd., S. 10-11.

39 Ebd., S. 11.

40 Vgl. ebd. 
Raumtheorie, aus der Soziologie Pierre Bourdieus und aus der neueren Migrationsforschung auf.

\subsection{Forschungsstand und Quellenlage}

Salman Schocken wird in einschlägigen Werken zur Geschichte von Warenhäusern, des Verlagswesens, zu den Anfangsjahren der Hebräischen Universität, der Migration deutscher Juden in den 1930er Jahren usw. erwähnt. Dies geschieht jedoch nie in einer Ausführlichkeit, die seiner Rolle entspricht. Bisher führte das dazu, dass die konzeptionellen Ansätze Schockens, die in mancherlei Hinsicht die Bildung der Netzwerke und Spezifizierungen kultureller Ausrichtungen beeinflussten, in ihrer gestalterischen Relevanz nicht beachtet wurden. Die Darstellung seiner Rolle im jüdischen Kulturleben Deutschlands und im Aufbau des deutsch-jüdischen Lebens in Jerusalem ist deshalb ein Forschungsdesiderat.

Kurt Blumenfeld ${ }^{41}$, Gershom Schocken ${ }^{42}$ und weitere Persönlichkeiten verfassten nach dem Tod von Salman Schocken persönliche Erinnerungen an ihn, die in (wissenschaftlichen) Zeitschriften publiziert wurden. Es liegt eine biographische Studie zu Salman Schocken von Anthony David ${ }^{43}$ vor, die, wie u. a. Michael Brenner festhält, zwar literarisch ansprechend sei, aber wissenschaftlichen Standards nicht genüge. ${ }^{44}$ Die Angaben in Davids Werk sind unzuverlässig, an manchen Stellen schlicht falsch und können daher für das vorliegende Werk nicht hinzugezogen werden.

Von allen, die sich bislang mit dem Leben Schockens beschäftigten, wurden die Erinnerungen des ältesten Sohnes Gershom an den Vater herangezogen. ${ }^{45}$ Der dem Vater gegenüber durchaus kritische Aufsatz diente auch der bisherigen

41 Kurt Blumenfeld: Erinnerung an Salman Schocken. In: Mitteilungsblatt der Hitachduth Olej Merkas Europa, 11.09.1959, S.3-4.

42 Gershom Schocken: Salman Schocken. Ich werde seinesgleichen nicht mehr sehen. In: Der Monat 242 (1968), S. 15.

43 Anthony David: The Patron. A Life of Salman Schocken, 1877-1959. New York: Metropolitan Books 2003.

44 Vgl. Michael Brenner: Rezension zu: Anthony David. The Patron: A Life of Salman Schocken, 1877-1959. In: Jewish Quarterly Review 96,3 (2006), S. 457-460.

45 Schocken: Salman Schocken. 
biographischen Forschung zu Schocken als Grundlage, wobei die Angaben meist unreflektiert übernommen wurden.

Des Weiteren wurden von der Forschung stets Teilaspekte von Schockens Wirken in den Blick genommen. Volker Dahm beschäftigte sich in seinem zweiteiligen Werk Das jüdische Buch im Dritten Reich ausführlich mit Schocken in seiner Funktion als Verleger. ${ }^{46}$ Die Geschichte des Verlages wurde vor allem von ihm sehr detailliert aufgearbeitet. ${ }^{47}$ Die Verlagsgeschichte des deutschen Schocken Verlages (1931-1938) kann damit als weitgehend bearbeitet gelten. Auch der Sammelband Dem suchenden Leser unserer Tage leistete einen wichtigen Beitrag zur Erforschung der Verlagsgeschichte. ${ }^{48}$ Die Herausgeber dokumentieren in diesem Band u. a. das Programm des Verlages (Claude Weber) ${ }^{49}$, den Inhalt der Bücher (Katalog, Herausgeber) und die Persönlichkeit Salman Schockens (Volker Dahm) ${ }^{50}$. Saskia Schreuders Beitrag „Inmitten von Not und aller Angriffe‘. Der Schocken Verlag im Spiegel der jüdischen Kritik “" ${ }^{1}$ ist hervorzuheben, da die Autorin mit ihrer Analyse gegenüber den meist deskriptiven, stark psychologisierenden Arbeiten heraussticht. Silke Schaeper befasste sich in ihrer nichtpublizierten Masterarbeit ${ }^{52}$ an der Hebräischen Universität Jerusalem, die Niederschlag in einigen kürzeren Artikeln fand, mit der Bibliothek des Bibliophilen Salman Schocken. ${ }^{53}$

46 Vgl. Volker Dahm: Das jüdische Buch im Dritten Reich. Frankfurt am Main: BuchhändlerVereinigung 1979.

47 Vgl. ebd.; Volker Dahm: Salman Schocken. In: Saskia Schreuder / Claude Weber (Hrsg.): Der Schocken-Verlag/Berlin. Jüdische Selbstbehauptung in Deutschland 1931-1938. Essayband zur Ausstellung ,Dem suchenden Leser unserer Tage' der Nationalbibliothek Luxemburg. Berlin: Akademie 1994, S. 15-35.

48 Vgl. Schreuder/Weber (Hrsg.): Der Schocken-Verlag/Berlin.

49 Vgl. Claude Weber: ,Halt und Richte. In: Ders. / Schreuder (Hrsg.): Der Schocken-Verlag/ Berlin, S.39-54.

50 Vgl. Dahm: Salman Schocken.

51 Saskia Schreuder: ,Inmitten aller Not und aller Angriffe‘. In: Dies. / Weber (Hrsg.): Der Schocken-Verlag/Berlin, S. 377-395.

52 Silke Schaeper: The History of the Book Collection of Salman Schocken. Unveröffentlichte Masterarbeit, Hebrew University Jerusalem, 1995.

53 Vgl. Silke Schaeper: Goldadern wertvollen jüdischen Lebens. Salman Schocken und seine Hebraica-Sammlung. In: Jakob Hessing (Hrsg.): Jüdischer Almanach 1995. Frankfurt am Main: Jüdischer Verlag 1995, S. 328-330; dies.: Von Zwickau nach Jerusalem. Der Kulturzionist Salman Schocken. In: Heiko Haumann (Hrsg.): Der Erste Zionistenkongress von 1897. Ursachen, Bedeutung, Aktualität. Basel: Karger 1997; dies.: Bibliophilie als kultureller 
Seit 2013 lässt sich ein wachsendes Interesse an Salman Schocken beobachten: In diesem Jahr widmete sich eine internationale Konferenz in Chemnitz dem Leben und Wirken Salman Schockens und Erich Mendelsohns. Die Veranstaltung stieß auf reges Interesse. Im dazu erschienenen Sammelband wurden die Beiträge, die sich unterschiedlicher Aspekte von Schockens Schaffen annahmen, veröffentlicht. ${ }^{54}$ Zwei Jahre später fand am Israel Museum in Jerusalem eine große, von Ada Wardi kuratierte Ausstellung zur neuen hebräischen Typographie statt. Salman Schocken, der sich vor allem in Deutschland, aber auch in Palästina im Buchdruck hervorgetan hatte, nahm in dieser Ausstellung einen wichtigen Platz ein. In den zwei die Ausstellung begleitenden Katalogen wurde Schockens Verdienst um die hebräische Buchgestaltung mit mehreren Artikeln Rechnung getragen. ${ }^{55}$

Die deutsch-jüdische Geschichte, die Geschichte der Judenpolitik während des Nationalsozialismus, die Geschichte der Emigration und Emigrationserfahrung deutschsprachiger Juden, sowie der Beitrag der deutschen Juden am Aufbau eines jüdischen Gemeinwesens in Palästina sind der Referenzrahmen dieser Forschung. Die relevanten Untersuchungen dazu sowie weitere Forschungsliteratur zu spezifischen Fragestellungen und Kontexten werden an geeigneter Stelle benannt.

Die hier vorliegende Biographie basiert zu weiten Teilen auf der Arbeit mit archivalischen, also nicht publizierten Quellen. Lange Archivrecherchen in Jerusalem, New York und Berlin förderten eine kaum zu bewältigende Menge an Briefen, Protokollen, Notizen und Berichten zutage. Über 10.000 Dokumente wurden ausgewählt, erfasst und analysiert; sie erlaubten mir, die Biographie Salman Schockens zu rekonstruieren. Die wichtigsten Bestände sollen hier vorgestellt werden.

Auftrag. In: Schreuder / Weber (Hrsg.): Der Schocken-Verlag/Berlin, S. 347-360; dies.: S'ridei Schocken. ,Einbandfragmente' of Hebrew Incunabula at the Schocken Institute for Jewish Reserach. In: Judit Targarona Borrás / Angel Sáenz-Badillos (Hrsg.): Jewish Studies at the Turn of the $20^{\text {th }}$ Century. Proceedings of the $6^{\text {th }}$ EAJS Congress Toledo 1998. Leiden /Boston / Köln: Brill 1999, S.627-635.

54 Antje Borrmann / Doreen Mölders / Sabine Wolfram (Hrsg.): Konsum und Gestalt. Leben und Werk von Salman Schocken und Erich Mendelsohn vor 1933 und im Exil. Berlin: Hentrich \& Hentrich 2016.

55 Ada Wardi (Hrsg.): New Types. Three Pioneers of Hebrew Graphic Design. Jerusalem: Israel Museum Jerusalem 2016. 
Der größte und für die Arbeit wichtigste Bestand liegt im Schocken Archiv, das in der Schocken-Bibliothek in Jerusalem untergebracht ist. Das Archiv ist bis heute im Besitz der Familie Schocken, die über den Zugang zu den Dokumenten entscheidet. Das Privatarchiv umfasst die private Korrespondenz von Salman Schocken und seiner Familie, Fotografien, Ausschnitte aus Tagebüchern, Manuskripte von Reden und Ansprachen, aber auch die Akten des Schocken-Konzerns und einen Teil der Akten des Schocken Verlages Berlin, sämtliche Dokumente zur Emigration aus Deutschland, Unterlagen zu Reisen, Bauakten, Protokolle von geschäftlichen Verhandlungen, die Unterlagen aus Schockens Tätigkeiten in Verbänden und Gremien, Akten der Hebräischen Universität, Akten zur,Wiedergutmachung nach dem Zweiten Weltkrieg sowie Zeitungsartikel zu Salman Schocken und seinen Tätigkeiten. Die Bestände wurden in den 1950er Jahren grob mit Schreibmaschine katalogisiert, blieben aber in ihrer ursprünglichen Ablageordnung. Die Masse der Dokumente im Schocken Archiv und ebenso, dass zahlreiche Akten mehrfach in Kopien abgelegt sind, gestaltete die Arbeit zeitaufwändig. Zugleich ermöglichen die Dokumente einen detailreichen Einblick in Schockens Arbeit, sein Handeln und Denken. Viele von ihnen weisen handschriftliche Notizen von Salman Schocken auf, die Rückschlüsse auf seine Überlegungen erlauben. Keine bisherige Arbeit zu Salman Schocken hat die Akten des Schocken Archivs in dieser Breite gesichtet und ausgewertet.

Von großer Bedeutung sind darüber hinaus die Bestände des Archivs der Nationalbibliothek Israels (NLI) in Jerusalem. Dort lagern die Nachlässe vieler wichtiger Wissenschaftler*innen, Autor*innen und Zionist*innen, etliche von ihnen standen mit Schocken in jahrelangem Kontakt. Die Auswertung der Korrespondenz ermöglichte die Rekonstruktion von Schockens Rolle im Netzwerk der deutsch-jüdischen Intellektuellen und Zionisten sowohl in Deutschland wie auch später in Palästina und den USA. Gesichtet und verwendet wurden die Briefwechsel Salman Schockens mit Martin Buber, Gershom Scholem, Else Lasker-Schüler $^{56}$, Samuel Joseph Agnon ${ }^{57}$ und Hugo Bergmann. Darüber hinaus wurden auch die Korrespondenzen zwischen Martin Buber und Simon Weltsch, zwischen Ernst Simon und dem Schocken Verlag, zwischen Lambert

56 Die Originale liegen im Schocken Archiv unter Verschluss, daher musste mit den Kopien in der NLI gearbeitet werden.

57 Auch diese Originale liegen im Schocken Archiv unter Verschluss. 
Schneider und Gershom Scholem, zwischen Gershom Scholem und Hannah Arendt, zwischen Werner Senator und Gershom Scholem sowie zwischen Martin Buber und Moritz Spitzer bearbeitet und analysiert.

Ebenfalls in Jerusalem befindet sich das Central Zionist Archive. Aus dessen Beständen wurden die Unterlagen zu Salman Schockens Engagement für die Zeitschrift Der Jude herangezogen. Im Leo Baeck Archiv Jerusalem wurde der Nachlass von Ernst Markowicz gesichtet und analysiert. Dieser ermöglichte profunden Einblick in Salman Schockens Emigrationshilfe für die Mitarbeiterinnen und Mitarbeiter des Schocken-Konzerns in den 1930er Jahren. Im Archiv der Hebräischen Universität wurden die Akten zu Schockens Amtszeit als administrativer Leiter der Hochschule gesichtet, diese waren deckungsgleich mit jenen, die im Schocken Archiv gefunden wurden. Und schließlich ist der Nachlass von Franzisca Baruch zu nennen, der im Archiv des Israel Museums in Jerusalem liegt und ein Verständnis für die Zusammenarbeit der Schriftkünstlerin mit Salman Schocken und seinem Jerusalemer Verlag ermöglicht. Zur Rekonstruktion der Anfangsgeschichte der Schocken Books New York und von Schockens Rolle während dieser ersten Jahre wurden die Akten im Verlagsarchiv gesichtet und ausgewertet. Das Archiv wurde bei der Übernahme des Verlages durch Random House aufgelöst. Teile davon wurden in das Firmenarchiv aufgenommen, vieles aber vernichtet. Schocken Books konnte einen kleinen Bestand, vor allem jene Dokumente zu den Rechten an den Texten Franz Kafkas, für sich beanspruchen. Unter diesen Akten befand sich weiterführende Korrespondenz aus den Anfangsjahren des Verlages, vieles in deutscher Sprache.

Im Leo Baeck Archiv New York war vor allem die Sammlung von Zeitungsauschnitten zum Leben, der Arbeit und zum Tod Salman Schockens wichtig. Im Bundesarchiv in Berlin liegen die Akten der Reichsschrifttumskammer, die den Umgang dieser Behörde mit dem Schocken Verlag rekonstruierbar machen. Diese Akten wurden komplett gesichtet und ausgewertet.

Zwei Oral-history-Interviews, eines mit Racheli Edelman, der heutigen Besitzerin des Schocken Verlages Tel Aviv und Enkelin Salman Schockens, sowie eines mit Dvorah Schocken, der Witwe von Gideon Schocken und damit Schwiegertochter Salman Schockens, vermittelten einen Einblick in die Charakterzüge von Salman und seiner Frau Lili Schocken. Beide Interviewpartnerinnen gaben der Autorin dieser Studie wichtige Hinweise und vermochten Eindrücke, die in der Auseinandersetzung mit den Quellen gewonnen wurden, zu bestärken. 
Zu den für die vorliegende Forschung relevanten publizierten Quellen zählt auch die publizierte Korrespondenz von Weggefährten und Bekannten Salman Schockens. Zudem wurden Zeitungsartikel zu Schockens Leben und Wirken herangezogen, um sich der zeitgenössischen Außenwahrnehmung der Person Schocken anzunähern. 



\section{Teil I \\ Deutschland (1898-1933)}


DIE HAUPTVERWALTUNGS - GEBÄUDE DES SCHOCKEN-KONZERNS, ZWICKAU - SA.

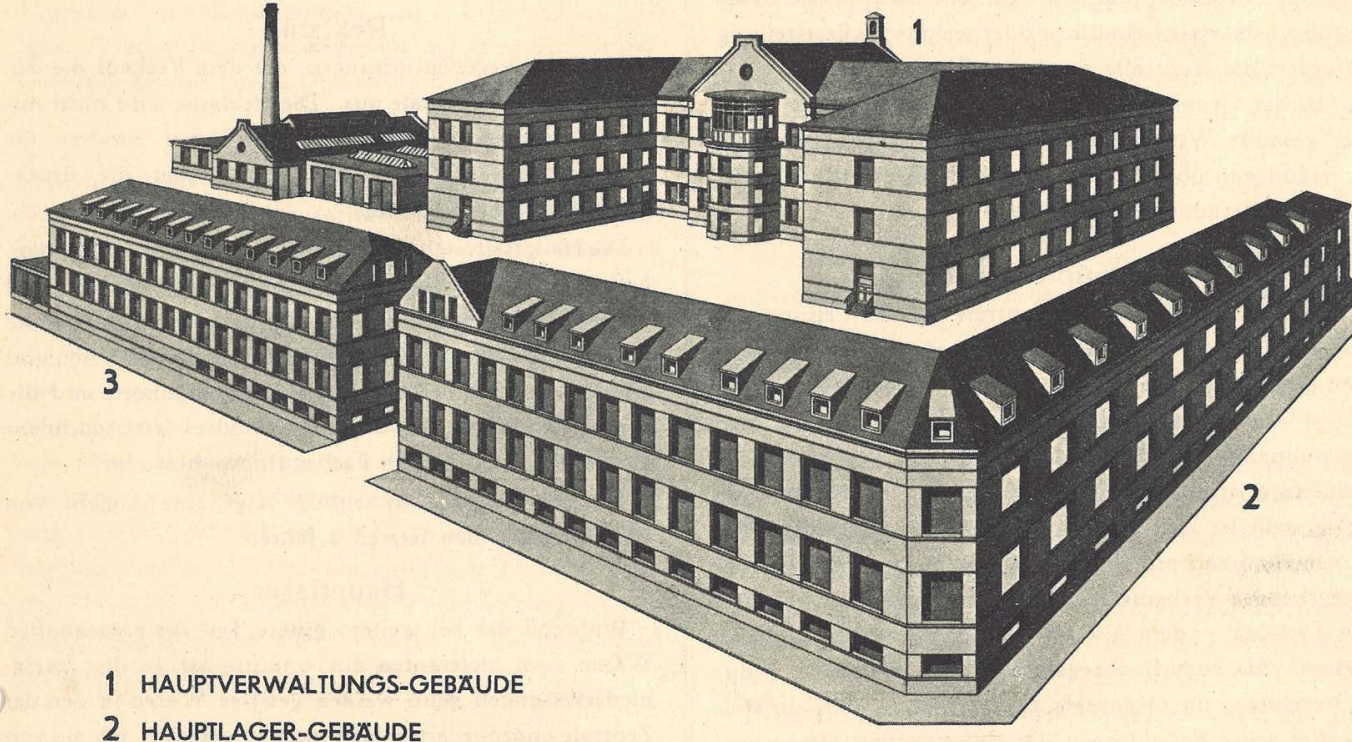

3 WERKSTATTEN-GEBAUDE

Abb. 1: Die Hauptverwaltungs-Gebäude des Schocken Konzerns, Zwickau S. A. 


\section{2 \\ Migration von Posen über Berlin nach Zwickau \\ Ein kurzer biographischer Abriss}

Über Salman Schockens Jugendjahre ist nur wenig bekannt. Entwürfe zu diversen biographischen Artikeln in Lexika nennen stichpunktartig die wichtigsten Daten. Geboren am 30. Oktober 1877 in Margonin ${ }^{1}$, einem kleinen Ort in der Provinz Posen, wuchs er als jüngstes Kind von zehn Geschwistern in einem traditionell-jüdischen Elternhaus auf. Der Vater, Isaak Schocken, ein gelernter Schneider, war Besitzer eines Manufakturwarengeschäftes, seine Mutter Eva war Hausfrau. Die Familie Schocken unterschied sich damit wenig von den meisten anderen jüdischen Familien in Posen. Handwerksberufe und Kleinhandel waren unter der jüdischen Bevölkerung ebenso verbreitet wie die deutsche Sprache. ${ }^{2}$ Die finanziellen Möglichkeiten der Familie, die zwar nicht arm, aber nicht vermögend war, ließen es nicht zu, dass Salman das Gymnasium besuchte. So beschränkte sich seine Schulbildung auf wenige Jahre deutsche Grundschule und seine religiöse Bildung auf ein paar Jahre im Cheder. Er verschwieg diese Tatsache nie, sondern gab sie bei passender Gelegenheit fast schon etwas kokett - so erinnern sich zumindest seine Weggefährten - und anekdotisch zum Besten. ${ }^{3}$

1 Kreis Kolmar, heute Chodzieski.

2 Vgl. Bernhard Breslauer: Die Abwanderung der Juden aus der Provinz Posen. Denkschrift im Auftrage des Verbandes der Deutschen Juden gefertigt von seinem ersten Schriftführer. Berlin: Berthold Levy 1909, S.3.

3 Vgl. z. B. Moritz Spitzers Nachruf auf Salman Schocken bei Radio Berlin, Typoskript, 20.01.1960. SchA, Verlag, 303. 
Entgegen seines eigentlichen Wunsches, an einer Hochschule zu studieren, absolvierte Salman Schocken eine kaufmännische Lehre und trat nach zweijähriger Lehrzeit eine Aushilfsstelle in Gnesen an. Seine nächste Stelle führte ihn nach Berlin und schließlich nach Leipzig. Leipzig wies eine der größten Gemeinschaften osteuropäischer Juden im Kaiserreich auf. Nach dem DreiBigjährigen Krieg arrivierte die Messestadt zu einem der wichtigsten Handelsplätze für Pelze in Europa. Der Handel mit Rauchwaren, das heißt, den zwar bereits gegerbten, aber noch nicht weiterbearbeiteten Tierfellen, wurde seit dem 18. Jahrhundert von jüdischen Familien aus Polen bestritten. Mit steigender Nachfrage nach Pelzprodukten im Westen sowie der Verlagerung der Pelzverarbeitung nach Leipzig, wurde die sächsische Stadt zum Magneten für polnisch-jüdische Facharbeiter und Händler. ${ }^{4}$ Um 1900 waren 60 Prozent der ungefähr 10.000 Personen zählenden jüdischen Gemeinde Leipzigs Ausländerinnen und Ausländer, dies im Vergleich zum Durchschnitt von 7 Prozent im gesamten Kaiserreich. ${ }^{5}$ Schocken fand in Leipzig ein Milieu vor, das ihm nicht fremd war. Zahlreiche junge jüdische Männer aus Osteuropa versuchten ihr Glück im Westen und die bereits ansässigen jüdischen Händler in Leipzig boten genügend Arbeitsstellen für diese Neuimmigranten.

Schocken ruhte sich in seiner Anstellung nicht aus: Sowohl in Berlin wie auch in Leipzig besuchte er Abendvorlesungen an den jeweiligen Universitäten, unter anderem in Literatur- und Allgemeiner Geschichte sowie in Philosophie. ${ }^{6}$ Der junge Schocken, dem der Zugang zu einem ordentlichen Studium an der Universität wegen fehlender Hochschulreife verschlossen geblieben war, bildete sich neben seiner kaufmännischen Tätigkeit als Autodidakt weiter.

Salman Schocken erwähnte später immer wieder, dass er nicht nur in diesen Jahren seine knapp bemessene Freizeit mit Büchern und mit Lesen verbracht habe. Auch der erwachsene Schocken war ein unermüdlicher und kritischer Leser, der nie ohne mehrere wertvolle Bücher, die er oft als spezielle

4 Vgl. Adolf Diamant: Chronik der Juden in Leipzig. Chemnitz: Heimatland Sachsen 1993.

5 Vgl. Tobias Brinkmann: Migration und Transnationalität. Paderborn: Schöningh 2012.

6 Vgl. Entwurf einer biographischen Skizze von Lucie Birnbaum (Büroleiterin des SchockenKonzerns in Berlin) nach einem Diktat von Gustav Schocken, 12.09.1937. SchA, Privates, $807 / 2$. 
Handausgaben beschneiden und in weiches Leder binden lies, reiste. ${ }^{7}$ Als über Siebzigjähriger und längst ein Mann des Buches ließ Schocken die Anfänge seiner Bibliothek rekonstruieren. Die ersten Bücher in seinem Besitz waren zwei Bände Nevi'im in der Ausgabe Krotoschin von 1840. ${ }^{8}$ Die Bücher waren ein Geschenk von Blume Silber, einer Großtante väterlicherseits. Schocken erinnerte sich, dass er auf Anraten seiner Mutter vor allem in Jirmijahu und den kleinen Propheten gelesen hätte, meist in der deutschen Übersetzung. Während seiner Lehrzeit las er John Steward Mills Über die Freiheit, System der Nationalökonomie und Ansicht über die soziale Frage sowie Zur Arbeiterfrage von Friedrich Albert Lange und Treitschkes Historische und Politische Schriften. Ein Teil dieser Bücher, die aus dem Elternhaus stammten, verblieben in Schockens Besitz und wurden beim Export der Bibliothek nach Jerusalem mitverschifft. Ab 1898 begann Schocken, eigene Bücher zu erwerben, meist günstige Reclam-Bändchen, die bei einem der Umzüge verloren gegangen sind. Ungefähr 100 Bände umfasste diese erste Sammlung, darunter Schopenhauer, Spinoza und Kant, des Weiteren einen Band mit Gedichten von Goethe, der ebenfalls verloren gegangen ist. Nach Abschluss der kaufmännischen Lehre erlegte sich der noch nicht zwanzigjährige Schocken laut eigener Aussage ein striktes wöchentliches Lektürepensum auf: Neben philosophischen, historischen und ökonomischen Büchern las er mehrere Zeitschriften wie Die Nation, den Grenzboten, Wilhelm Foersters Ethische Kultur, die Zukunft, die Preußischen Jabrbücher sowie die Deutsche Rundschau. ${ }^{10}$

Hier zeichnet sich eine Selbstdarstellung als ein junger Mann ab, der seine wenige Freizeit nicht einfach mit Lesen verbringt, sondern mit diszipliniertem und systematischem Erarbeiten der wirtschaftswissenschaftlichen Grundlagenliteratur sowie der literarischen und philosophischen Klassiker. Vielleicht

7 Vgl. Schaeper: Bibliophilie als kultureller Auftrag, S.351. Silke Schaeper war langjährige Bibliothekarin der Schocken-Bibliothek in Jerusalem und ist eine der besten Kennerinnen der Sammlung und ihrer Geschichte.

8 Vgl. Zur Geschichte der Schocken-Bibliothek, Typoskript, 04.12.1949; Zur Geschichte der Bibliothek nach Angaben von Herrn S. Schocken, Typoskript, 20.08.1956. SchA, Privates, 870.

9 Vgl. Kap. 7.3.2 sowie Stefanie Mahrer: 'Much More Than Just Another Private Collection'. The Schocken Library and Its Rescue From Nazi Germany in 1945. In: Naharaim. Zeitschrift für deutsch-jüdische Literatur und Kulturgeschichte 9,1 (2015), S.4-24.

10 Vgl. Zur Geschichte der Schocken-Bibliothek, Typoskript, 04.12.1949. SchA, Privates, 870. 
glaubte er, sich gegenüber dem Kreis der universitär Gebildeten, in dem er sich später bewegen wird, als Mensch legitimieren zu müssen, der sich eine weitreichende Bildung dank diszipliniertem Selbststudium erarbeitete. Dies deutet einerseits darauf hin, dass er den fehlenden universitären Abschluss als Makel empfand, zum anderen macht die Selbstdarstellung aus der Ex-postPerspektive deutlich, wie wichtig ihm die Zugehörigkeit zum Kreis der Gebildeten war. Trotz seiner vielen Erfolge und seiner unbestrittenen Zugehörigkeit zum Netzwerk deutsch-jüdischer Intellektueller und Autoren scheint es ihm auch im hohen Alter noch ein Bedürfnis gewesen zu sein, auf seine Bildung hinzuweisen.

Die niedergeschriebenen Erinnerungen an die ausgiebige Lektüre und den Besuch von Abendvorlesungen neben der täglichen Arbeit dürfen jedoch nicht nur als Konstruktion verstanden werden, die auf Zugehörigkeit zielte. Sie reflektieren ebenso Schockens Studieneifer und seine Wissbegierde, seine Disziplin und Zielgerichtetheit - Charaktereigenschaften, die sein Leben und Schaffen prägen werden. Zudem sind die Erinnerungen auch Zeugnis seiner Liebe zu Büchern, die sich bereits in den Jahren 1896 bis 1898 abzeichnete, als er als zweiter Bibliothekar der Bibliothek des Vereins junger Kaufleute amtete. Diese Bibliothek umfasste mehrere Tausend Bücher, „alles gute Bände der modernen Literatur“, über deren Anschaffung er „,in den Jahren 1897/98 selbständig entschieden habe. ${ }^{\text {"11 }}$ Auch dieser Hinweis bindet seine spätere Sammeltätigkeit an sein frühes Leben zurück. Es scheint, als unterlege er aus der Perspektive des alten Mannes seinem Leben eine lineare Entwicklung. Man darf vermuten, dass er nach dem zweiten großen Bruch in seiner Biographie, der Emigration von Jerusalem nach New York, seinem Leben im Rückblick trotz allem eine Kontinuität geben wollte. ${ }^{12}$

Die Welt, aus der Schocken stammte, war eine fundamental andere als jene, in der er sich später bewegen würde. Das Leben in der Kleinstadt Margonin war stark jüdisch geprägt. Glaube und Tradition wurden gelebt, ohne sich von weltlichen Belangen abzugrenzen. Im letzten Jahrzehnt vor der Wende zum 20. Jahrhundert begann sich diese Welt jedoch langsam zu verändern. Durch Industrialisierung und moderne Transportmittel erweiterten sich die

11 Zur Geschichte der Schocken-Bibliothek, Typoskript, 04.12.1949. SchA, Privates, 870.

12 Zur Migration nach New York im Jahr 1940 vgl. Kap. 11. 
Erwerbsmöglichkeiten. Zugleich geriet das Handwerk durch die technisierte Herstellung von Gütern unter starken Druck und durch vermehrten Straßenund Eisenbahnbau setzte eine Abwanderung zuerst von ländlichen Orten in die Städte und dann Richtung Westen ein, was den Händlern ihre Einkommensgrundlage entzog. ${ }^{13}$ Amtliche Erhebungen ${ }^{14}$ zeigen, dass ein nicht unbedeutender Teil der deutschsprachigen, jüdischen wie auch christlichen Bevölkerung die Provinz Posen im Laufe des 19. Jahrhunderts verließ. Neben den wirtschaftlichen Gründen nennt Breslauer vor allem das Fehlen eines kulturellen Lebens als Grund für die Emigration. „Nichts“ sei, so der Verfasser, „von der Regierung geschehen, um das Leben in der Provinz Posen einigermaßen erträglich zu machen. Weder war der Kunst eine Grundlage geschaffen, noch war für Verschönerung und Verbesserung der natürlichen Anlagen gesorgt. ${ }^{\text {"15 }}$ Es sei unter diesen Umständen

nicht wunderbar, dass diejenigen, welche sich dem ruhigen Leben hingeben wollten, der Provinz - in der ihnen nichts, gar nichts zur Bildung von Herz und Gemüt, zur Erholung und zur Zerstreuung geboten wurde, - den Rücken kehrten, und dass darunter auch eine gewisse Anzahl Deutscher jüdischen Glaubens war. ${ }^{16}$

Oft verließen, wie in der Familie Schocken, die Söhne als Erste die Provinz, nicht selten folgten darauf die Eltern.

Salman Schocken verließ im Alter von 15 Jahren Margonin, als sein Vater ihn ins knapp 70 Kilometer entfernte Samter (heute Szamotuły) in die Lehre schickte. Nach Abschluss der Ausbildung blieb er vorerst weitere zwei Jahre in der Provinz Posen. Als 19-Jähriger verließ er schließlich die Region. Anhand der Lektüre der Akten wird nicht deutlich, warum der junge Schocken die Heimat seiner Eltern und Großeltern verließ; ausgehend vom weiteren Verlauf seines Lebens, dem schier unstillbaren Wissensdurst und seiner Schaffenskraft ist die Annahme naheliegend, dass es ihm in der beschaulichen Provinz zu eng wurde.

13 Vgl. Breslauer: Die Abwanderung der Juden aus der Provinz Posen, S. 10.

14 Die Darstellung von Breslauer aus dem Jahr 1909 basierte auf amtlichen Zahlen und wertete die Abwanderungsbewegung in den Jahren 1793 bis 1905 aus. Die vorliegende Arbeit bezieht sich auf Breslauers Angaben.

15 Ebd., S. 10.

16 Ebd. 
Mit dem Wegzug ließ Salman Schocken aber nicht nur seine Heimat, sondern auch die jüdische Tradition zurück. Las er als Junge noch jüdische Texte, waren diese für einige Jahre nicht Bestandteil seiner Lektüre. Erst Jahre später wird Salman Schocken wieder zu seiner religiösen Herkunft zurückfinden. 


\section{3 \\ Der Kaufmann}

Salman Schocken war Kaufmann: Als solcher wurde er ausgebildet, als solcher begann er seine berufliche Karriere als erwachsener Mann, und als solcher dachte und handelte er. Das Kaufmännische war tief in seiner Persönlichkeit verankert, auch wenn er sich später in ganz anderen Berufs- und Betätigungsfeldern bewegte. Das Abwägen von Kosten und Nutzen, das Prüfen von Machbarkeit und Nachhaltigkeit, das strenge Messen und Kontrollieren - kaufmännisches Denken also - prägten das Leben dieses außergewöhnlichen Menschen. Auch wenn der Fokus des Buches nicht auf dem Schocken-Konzern liegt, zu dem bereits eine umfassende Studie vorliegt, ${ }^{1}$ muss dessen Geschichte hier aufgearbeitet werden, um den Charakter Schockens zu verstehen. Eine Biographie versucht, das Leben eines Menschen zu verstehen. Dafür gilt es, die Herkunft eines Menschen zu kennen, zu wissen, was ihn in jungen Jahren prägte, von was er sich zu lösen versuchte, was er ablehnte, was er neu erfand und welche Richtung er seinem Dasein geben wollte. Ohne dieses Verständnis schwebt das Spätere im luftleeren Raum.

Dieses Kapitel soll die wichtigsten biographischen Eckpunkte des jungen Schocken in aller Kürze darlegen. Viel bekannt ist nicht über Schockens junge Jahre, die wenigen Angaben reichen aber aus, seine Herkunft kursorisch zu skizzieren. Der größte Teil des Kapitels widmet sich der Geschichte des Konzerns und

1 Vgl. Konrad Fuchs: Ein Konzern aus Sachsen. Das Kaufhaus Schocken als Spiegelbild deutscher Wirtschaft und Politik 1901 bis 1953. Stuttgart: DVA 1990. 
Salman Schockens Selbstverständnis als Patron und Wirtschaftsmann. Dabei geht es weniger um den Konzern, als vielmehr um die Art und Weise, wie Schocken den Betrieb aufbaute und leitete, denn - wie immer wieder deutlich werden wird -, seine kaufmännischen und unternehmerischen Grundsätze sollten sein weiteres Leben maßgeblich bestimmen.

Ebenso bestimmend für sein Leben war auch die 1910 geschlossene Ehe mit Zerline Ehrmann, einer zu diesem Zeitpunkt 20-jährigen Frau aus einer jüdischen Familie in Hamburg. Lili, wie sich Zerline nannte, und Salman hatten eine Tochter, Eva (später Chava) ${ }^{2}$, und vier Söhne, Gustav (später Gershom), ${ }^{3}$ Theodor, ${ }^{4}$ Gideon ${ }^{5}$ und Micha ${ }^{6}$.

2 Eva (Chava) (1918-1982) wurde in Zwickau geboren. Sie migrierte in den 1930er Jahren in die USA, wo sie den Verleger Theodore Herzl Rome heiratete, der 1965 starb. Rome stand bis zu seinem Tod dem amerikanischen Verlag Schocken Books New York vor. In zweiter Ehe war sie mit Julius S. Glazer vermählt. Eva Schocken hatte vier Kinder. Eva Schocken war seit dem Tod ihres Vaters Lektorin bei Schocken Books New York und stand dem Verlag nach dem Tod ihres Bruders im Jahr 1975 als Präsidentin vor.

3 Gustav (1912-1990) nannte sich nach seiner Emigration nach Palästina 1933 Gershom. 1939 setzte sein Vater ihn als Herausgeber der Tageszeitung Haaretz ein, die er bis zu seinem Tod maßgeblich prägte. Von 1955 bis 1959 war er zudem Abgeordneter der Miflaga Progresivit (Progressive Partei). Unter dem Pseudonym Robert Pozen veröffentlichte er Gedichte auf Deutsch, Englisch und Hebräisch. Er war verheiratet mit Shulamit Parsitz, mit der er drei Kinder hatte. Sein Sohn Amos ist der derzeitige Herausgeber von Haaretz, seine Tochter Racheli Edelman die Leiterin des israelischen Schocken Verlages.

4 Theodor (1914-1975) war im Vorstand des Berliner Schocken Verlages sowie des SchockenKonzerns und leitete nach der Emigration des Vaters dessen Geschäfte. 1938 migrierte er in die USA, wo er an der Harvard University einen Master in Betriebswirtschaft erwarb. 1941 diente er in der amerikanischen Armee. Nach der Emigration seiner Eltern nach New York war er mitbeteiligt an der Gründung und dem Aufbau der Schocken Books New York. Nach dem Tod Herzl Romes leitete er das Verlagshaus. Theodor Schocken war mit Dora Landauer, der früheren Sekretärin seines Vaters verheiratet. Das Paar hatte drei Kinder.

5 Gideon (1919-1981) migrierte 1934 zusammen mit seinen Eltern nach Palästina, er besuchte das Gymnasium Rehavia in Jerusalem. 1936 trat er in die Haganah, die zionistische paramilitärische Untergrundorganisation in Palästina ein. Während des Weltkrieges diente er als Major in der britischen Armee und nach der Gründung des Staates Israel als General in der israelischen Armee (Israel Defense Forces). Gideon war verheiratet mit Dvorah Cohen, die er auf dem Gymnasium kennengelernt hatte. Das Paar hatte drei Kinder.

6 Micha (1923-1982) war der jüngste Sohn der Familie, er migrierte gemeinsam mit seinen Eltern nach Jerusalem, wo er wie sein älterer Bruder die Schule besuchte. Er war Ingenieur und arbeitete in verschiedenen Druckereien, u. a. in der familieneigenen Druckerei der Haaretz. Micha war verheiratet und hatte zwei Kinder. 


\section{1 „Wir machen keinen Ausverkauf!“ - der Kaufmann Salman Schocken}

Nach wenigen Jahren Berufserfahrung als Angestellter in kleineren Geschäften in Leipzig folgte Salman Schocken im Jahr 1902 der Bitte seines älteren Bruders Simon, diesen in der Leitung des Warenhauses Ury in Zwickau zu unterstützen. ${ }^{7}$ Simon Schocken gründete das Haus im März 1901 als Tochtergesellschaft des gleichnamigen Mutterhauses in Leipzig. Bereits zwei Jahre später gründete Salman sein eigenes Warenhaus in Oelsnitz und bewies damit für einen noch nicht dreißigjährigen Mann ein beachtliches Maß an Selbständigkeit und Unternehmergeist. ${ }^{8}$ Der Erfolg des Schocken'schen Konzepts - ein gutes Warenangebot zu erschwinglichen Preisen anzubieten - veranlasste ihn, ein zweites Haus nach demselben Muster zu errichten. Es herrschte bei den Brüdern Schocken die zu dieser Zeit noch kaum verbreitete Politik, Waren zu festen Preisen anzubieten. Zudem wurde darauf verzichtet, auf Kredit zu verkaufen, dafür bestand ein verbrieftes Rückgaberecht bei Nichtgefallen der Ware.' Salman Schocken wird diesen Grundsätzen bis zur erzwungenen Aufgabe des Konzernes Ende 1938 treu bleiben. In Oelsnitz entwickelte Salman Schocken seine Verkaufsstrategien weiter. ${ }^{10}$

Bereits wenige Jahre nach der geschäftlichen Trennung der zwei Brüder schlossen sie sich Anfang des Jahres 1907 wieder zusammen, indem sie die Firma I. Schocken Söhne Zwickau (I.S.S.) gründeten. Mit dem I. im Namen ehrten die beiden Brüder ihren Vater Isaak. Die Firma schloss die zwei Kaufhäuser Zwickau und Oelsnitz sowie eine neugegründete Einkaufszentrale ein. Mit der Gründung der Zentrale wurde der Grundstein für den nach dem Ersten Weltkrieg stark zentralisierten Schocken-Konzern gelegt, der bis dahin aus den zwei genannten Kaufhäusern sowie einer stetig wachsenden Anzahl sogenannter „Anschlussgeschäfte "11 bestand, die ihre Waren über die Einkaufszentrale bezogen.

7 Vgl. Entwurf einer biographischen Skizze von Lucie Birnbaum (Büroleiterin des SchockenKonzerns in Berlin) nach einem Diktat von Gustav Schocken, 12.09.1937. SchA, Privates, $807 / 2$.

8 Für eine detaillierte Darstellung der Geschichte des Schocken-Konzernes vgl. Fuchs: Ein Konzern aus Sachsen.

9 Vgl. Flugblatt anlässlich der Eröffnung am 21.10.1904. SchA, Konzern, 111/1187.

10 Vgl. Siegfried Moses: Salman Schocken. His Economic and Zionist Activities. In: LBIYB

5,1 (1960), S.73-104, hier S. 77.

11 Fuchs: Ein Konzern aus Sachsen, S. 36. 
Noch vor dem Ersten Weltkrieg kam es, zusätzlich zu den bereits vor der Gründung der I.S.S. im Besitz der Brüder befindlichen Kaufhäuser in Bremerhaven, Oelsnitz und Zwickau, zur Eröffnung von elf weiteren Häusern. ${ }^{12}$ Der Krieg, die Inflation und Weltwirtschaftskrise der 1920er Jahre ${ }^{13}$ setzten dem Konzern zwar zu und beeinträchtigten vorübergehend sein Wachstum, dennoch verzeichneten Salman und Simon Schocken auch in den Krisenjahren ein langsames Wachstum: Das Kaufhaus Schocken in Auerbach wurde im November 1919 gegründet und nur wenige Tage später kam es zur Gründung der Liga AG für kaufmännische Versicherungen. Im Januar 1920 eröffnete die I. S. S. ein spezielles Einkaufhaus für Strumpfwaren, einige Monate später eröffnete das Kaufhaus Regensburg. Im gleichen Jahr wurden Personalbibliotheken in den Kaufhäusern eingerichtet, ein eigenes Baubüro gegründet und eine Textilwerkstatt eröffnet. ${ }^{14}$ Ab Februar 1921 wurden Gardinen und Halbstores in Eigenfertigung hergestellt und in Chemnitz eine eigene Strumpffabrikation eingerichtet. Im Herbst 1922 wurde mit dem Aufbau von eigenen Buchabteilungen begonnen. ${ }^{15}$

Dieses beachtliche Wachstum zwischen Kriegsende und Beginn der Festwährung, die Salman Schocken als „Rückschlag " ${ }^{\text {"16 }}$ bezeichnete, wird von der eigentlichen Expansionsphase in den Schatten gestellt. ${ }^{17}$ Diese Phase setzte bereits kurz nach der Währungsstabilisierung im November 1923 ein.

Der Schocken-Konzern war der am stärksten zentralisierte Warenhauskonzern Deutschlands seiner Zeit. Sämtliche Entscheidungen wurden in der Zwickauer Zentrale gefällt; dies betraf Verkaufsmethoden, Schaufensterdekoration,

12 Vgl. Wichtige Daten aus der Entwicklung des Schocken-Konzerns. SchA, Konzern, 111/191. 13 Vgl. für das Jahr 1920: Turnowsky-Pinner, M[argarete]: Die wirtschaftliche Entwicklung der Firma I. Schocken Söhne Zwickau im Jahre 1920. Unveröffentlichtes Typoskript, 28.03.1931. Sch A, Konzern, 112/113.

14 Die I. S. S. übernahm die Firma Tobias in Zwickau. Vgl. Wichtige Daten aus der Entwicklung des Schocken-Konzerns. SchA, Konzern, 111/191.

15 Alle Angaben laut: Wichtige Daten aus der Entwicklung des Schocken-Konzerns. SchA, Konzern, 111/191.

16 Salman Schocken: Zur Eröffnung des Kaufhauses Schocken in Nürnberg. Ansprache des Herrn Salman Schocken an die Gäste am 11.10.1926. In: Aus früheren Schocken Hauszeitungen, 1926. SchA, Konzern, 121/714. Es handelt sich dabei um eine gedruckte „Hauszeitung“, weitere bibl. Angaben sind nicht verfügbar.

17 Für eine chronologische Darstellung der Kaufhausentwicklung vgl. SchA, Konzern, 111/191. 
Einkauf ebenso wie Werbung. Salman Schocken war für die Verkaufs- und Einkaufsstrategien verantwortlich. ${ }^{18}$ Noch heute findet man im Schocken Archiv in Jerusalem Mappen mit Fotografien thematisch eingerichteter Beispielschaufenster, nach deren Muster die Dekorateure sämtliche Auslagen zu gestalten hatten. ${ }^{19}$ In den Jahren bis zur Machtergreifung der Nationalsozialisten wuchs der Konzern weiterhin rasant. Zahlreiche Häuser wurden neu gegründet, darunter die in die Architekturgeschichte eingehenden Bauten von Erich Mendelsohn in Nürnberg (Eröffnung 1926), Stuttgart (1928) und Chemnitz $^{20}$ (1930). Die bestehenden Kaufhäuser wurden vergrößert und modernisiert, neue Abteilungen geschaffen und die interne Organisation weiter gestrafft und professionalisiert.

Zur Geschäftsstrategie gehörte auch eine eigene wissenschaftliche Warenprüfstelle, in der wichtige Produkte auf ihre physikalischen Eigenschaften und chemische Zusammensetzung untersucht wurden. Diese interne Kontrollstelle, sowie der vollständige Verzicht auf Sonderverkäufe, Lockartikel, Konsumfinanzierung und Gratiszugaben ${ }^{21}$ machten den Schocken-Konzern einzigartig. Das Unternehmen, das nach dem Unfalltod von Simon Schocken im Oktober 1929 an Salman Schocken überging, ${ }^{22}$ bestand aus mehreren Gesellschaften mit verschiedenen Rechtsformen: Die I. Schocken Söhne, Zwickau als offene Handelsgesellschaft, die nach dem Tod Simon Schockens als Einzelhandelsfirma geführt wurde; die Einkaufszentrale I. Schocken Söhne GmbH, Zwickau; die Schocken Kommanditgesellschaft auf Aktien, Zwickau; die Geschäftshaus

18 Vgl. Überblick über Geschichte und Aufbau des Konzerns. Exposé Dr. Landauer, Typoskript, 1937. SchA, Konzern, 115/244.

19 Vgl. Beispielfotos zur Dekorierung der Schaufenster. SchA, „blaue Schachtel“ (Wandschrank, Büchersaal).

20 Zur Geschichte des „Chemnitzer Schocken“ vgl. Tilo Richter / Evangelisches F. Chemnitz (Hrsg.): Erich Mendelsohns Kaufhaus Schocken. Jüdische Kulturgeschichte in Chemnitz. Leipzig: Passage-Verlag 1998. Das Warenhaus in Chemnitz ist der einzige heute noch erhaltene Bau des Architekten für Schocken in Deutschland. Im halbrunden Gebäude ist seit Frühjahr 2015 das Staatliche Museum für Archäologie (Sachsen) untergebracht. Bevor der Bau fachgerecht restauriert wurde, stand er lange leer. Drei Ausstellungsbereiche sind der Geschichte des Kaufhauses, seinem Besitzer und dem Architekten gewidmet. Vgl. die Webseite des Museums unter: http://smac.sachsen.de (Zugriff am 29.05.2014).

21 Exposé Dr. Landauer. Überblick über Geschichte und Aufbau des Konzerns, Typoskript 1937, S.4. SchA, Konzern, 115/224.

22 Zum genauen Erbablauf vgl. Fuchs: Ein Konzern aus Sachsen, S. 184-186. 
GmbH, Zwickau; die Liga AG für kaufmännische Versicherung, Zwickau und die Terrain-Gesellschaft „Westestadt“ GmbH, Zwickau. ${ }^{23}$

Im letzten Jahr vor der nationalsozialistischen Herrschaft erwirtschaftete Salman Schocken mit den 19 Warenhäusern 82.638.000 Reichsmark. ${ }^{24}$ Als Reingewinn werden für dasselbe Jahr 6.270.000 Reichsmark ausgewiesen. Der Konzern blieb bis zum erzwungenen Verkauf im Jahr 1938 rentabel und wies für das Geschäftsjahr 1937 einen Nettogewinn von ca. 3,5 Millionen Reichsmark aus. Damit war zwar ein Absatzrückgang zu verzeichnen, deutlich wird aber auch, dass die Käufer trotz Boykottmaßnahmen, vorübergehenden Geschäftsschließungen, Beschränkung der Belieferung und einschüchternder Propaganda gegen jüdische Geschäfte den Schocken Warenhäusern treu blieben. ${ }^{25}$

Die nicht nachlassenden Schikanen gegen den Konzern führten aber dazu, dass ab 1933 sämtliche leitenden jüdischen Angestellten das Unternehmen verließen. Die Geschäftsleitung wurde an den katholischen Volkswirtschaftler Wilhelm Fonk, einen ehemaligen Abgeordneten der Zentrumspartei im Reichstag übertragen, der den Konzern gemeinsam mit den nunmehr ausschließlich nichtjüdischen Vorstandsmitgliedern im Sinne Salman Schockens führte. Salman Schocken versuchte zudem im September, durch die Überführung einer Aktienmehrheit an eine englische Gruppe, das heißt in dem Fall in „arische Hand “26, dem Staat und der Partei deutlich zu machen, dass der Konzern nunmehr arisiert sei. Dieser Schachzug vermochte die Lage vorübergehend zu beruhigen, so waren Zeitungen wieder bereit, Inserate der Schocken Warenhäuser zu drucken, ${ }^{27}$ langfristig ließ sich ein Verkauf des Konzerns aber nicht mehr aufhalten. Salman Schocken verließ Deutschland bereits im Jahr 1933. Der zweitälteste Sohn Theodor Schocken führte die Geschäfte im Sinne seines Vaters weiter, bis er im Herbst 1937 alle seine Ämter niederlegte und Deutschland ebenfalls verließ.

23 Vgl. Wichtige Daten aus dem Schocken-Konzern. SchA, Konzern, 111/191.

24 Vgl. Exposé Dr. Landauer. Überblick über Geschichte und Aufbau des Konzerns, Typoskript 1937. SchA, Konzern, 115/224, S.6.

25 Vgl. Konrad Fuchs: Zur Geschichte des Warenhaus-Konzerns I. Schocken Söhne. Unter besonderer Berücksichtigung der Jahre seit 1933. In: Zeitschrift für Unternehmensgeschichte 33,4 (1988), S. 232-252, hier S. 236.

26 Fuchs: Ein Konzern aus Sachsen, S. 231.

27 Vgl. ebd., S.232-233. 
Angesichts des wachsenden Drucks vonseiten der Nationalsozialisten trieben Salman Schocken und Wilhelm Fonk im Laufe der ersten Hälfte des Jahres 1938 die Arisierung des Betriebes voran. Die verbliebenen jüdischen Mitarbeiterinnen und Mitarbeiter sollten finanziell entschädigt werden und dann ausscheiden. Ab April 1938 arbeiteten keine jüdischen Angestellten mehr in den Schocken-Warenhäusern. Allein in der Zwickauer Zentrale sowie im Berliner Büro waren zu diesem Zeitpunkt noch zwölf Jüdinnen und Juden beschäftigt, ${ }^{28}$ und auch diese sollten nach den Plänen von Salman und Gershom Schocken sowie Wilhelm Fonks bis Ende des Jahres aus dem Konzern ausscheiden. ${ }^{29}$ Schockens Hoffnung, er könne durch die ,freiwillige‘ Arisierung des Konzerns an seinem Besitz festhalten, erfüllte sich nicht. Die Repressionen nahmen drastische Züge an, sodass die Firma beispielsweise ab April 1938 kein industriell gefertigtes Fett mehr beziehen konnte. Rohmaterial für Berufs- und Sportkleidung wurde bereits ab Januar desselben Jahres nicht mehr an Schocken geliefert und ab Anfang April wurde den Kaufhäusern verboten, Butter zu verkaufen. ${ }^{30}$ Die Schikane in Form von Beschränkung der zum Einkauf erlaubten Waren, die bereits genannten Boykottaktionen und die Einschüchterung der Kundschaft machten es unmöglich, die Wirtschaftlichkeit des Konzerns aufrechtzuerhalten. Trotz aller Bemühungen wurde die Firma als ,nichtarisches Unternehmen' eingestuft.

So rang sich Schocken im August 1938 nach langem Zögern dazu durch, seinen Konzern und damit sein bisheriges Lebenswerk zu verkaufen. Durch die Vermittlung der beiden in Amsterdam ansässigen Bankhäuser Rhodius, Koenigs \& Co. und Hollandsche Koopmansbank wurden die Aktien und Anteile an eine deutsche Bankengruppe unter Führung der Deutschen Bank und der Reichskredit-Gesellschaft verkauft. Ohne die Zahlen im Detail aufzuschlüsseln, kann gesagt werden, dass die Gesellschafter große Verluste ${ }^{31}$ beim Verkauf des

28 Vgl. Theodor Schocken an Salman Schocken, 25.06.1938. SchA, Konzern, 115/255/2.

29 Vgl. Notiz „Jüdische Angestellte“, 05.03.1938. SchA, Konzern, 115/216/7.

30 Vgl. Fuchs: Zur Geschichte des Warenhaus-Konzerns I. Schocken Söhne, S.235-236, sowie die Akten in: SchA, Konzern, 115/215.

31 Der Bilanzwert des Konzerns betrug Ende Februar 193820 Millionen Mark. Zur Auszahlung an Salman Schocken kamen 800.000 Holländische Gulden sowie der Verkaufswert der Aktien. Die exakten Zahlen für Abgaben, Zölle, aber auch für die transferierten Beträge sind in den Quellen nicht zu finden. Vgl. auch Fuchs: Ein Konzern aus Sachsen, S. 257, Anm. 242. 
Konzernes machten. ${ }^{32}$ Zudem wurden die jüdischen Verkäufer durch fiskalische Nötigungsmaßnahmen wie die Reichsfluchtsteuer, strenge Devisenbestimmungen und Sonderabgaben auch nach dem Verkauf noch systematisch beraubt. ${ }^{33}$ Die unfreiwilligen Verkäufe und Liquidationen jüdischer Gewerbe und Konzerne setzten in hohem Maß Mittel frei, die nun kaum mehr vor dem Zugriff der NS-Behörden geschützt werden konnten. Raul Hilberg, Benno Nietzel und Martin Dean verstehen daher die Enteignung als Prozess mit einer strukturellen Abfolgelogik. ${ }^{34}$ Die Verdrängung aus dem Berufsleben, die Vernichtung von Gewerbe und schließlich die Beschlagnahmung von Vermögen stehen in einem Kausalzusammenhang, wobei diese Maßnahmen bis 1938 teilweise auch parallel stattfanden. ${ }^{35}$ Auch Salman Schocken verlor einen großen Teil seines Vermögens durch die Zwangsabgaben, denen er sich nicht zu entziehen vermochte.

Käufer waren ein deutsches Bankenkonsortium und mit dem Namenswechsel vom 16. Februar 1939 von „Schocken Aktiengesellschaft“ zu „Merkur-Aktiengesellschaft“ fand die erfolgreiche Ära des Schocken-Konzerns nach außen hin ein Ende. Der Verkauf führte aber, was Organisation und Personal anbelangte, zu keinen Veränderungen. Die Mitglieder der Geschäftsleitung, die von Salman Schocken als Vertrauensleute eingesetzt wurden, informierten den ehemaligen Besitzer über die unternehmensinternen Vorgänge, so lange dies möglich war, zudem verhinderten sie, dass nationalsozialistische Funktionäre aufgenommen wurden. ${ }^{36}$

32 Vgl. Fuchs: Ein Konzern aus Sachsen, S. 256-257.

33 Vgl. Frank Bajohr: ,Arisierung' in Hamburg. Die Verdrängung der jüdischen Unternehmer in Hamburg 1933-1945. Hamburg: Christians 1998, S. 198-216.

34 Vgl. Benno Nietzel: Die Vernichtung der wirtschaftlichen Existenz der deutschen Juden 1933-1945. Ein Literatur- und Forschungsbericht. In: Archiv für Sozialgeschichte 49 (2009), S. 561-613, hier S. 585-586.

35 Vgl. ebd., S. 585; Raul Hilberg: Die Vernichtung der europäischen Juden, Bd. 1, aus d. Amer. v. Christian Seeger / Harry Maor / Walle Bengs / Wilfried Szepan. 9. erw. Aufl. Frankfurt am Main: Fischer 1998, S. 85-163; Martin Dean: Robbing the Jews. The Confiscation of Jewish Property in the Holocaust 1933-1945. New York: Cambridge UP 2008, S. 3.

36 Vgl. Fuchs: Zur Geschichte des Warenhaus-Konzerns I. Schocken Söhne, S. 236-237. 


\subsection{Ein moderner Patron - das System hinter dem Denken und Handeln Schockens}

Salmann [sic] Schocken ist der seltene Fall eines Mannes, in dem das meist Gegensätzliche sich schöpferisch bindet: eine starke Persönlichkeit mit der altruistischen Fähigkeit restloser Hingabe dieser Persönlichkeit an fremde, übergeordnete Interessen, ein ausgeprägter, sogar comerciell geschulter Sinn für das Wirkliche mit einer reinen Leidenschaft für das Abstracte - höchste Aktivität also in durchaus geistige, durchaus moralische Richtung gewandt. Männer solcher durchaus ungewöhnlicher Doppelseitigkeit sind zu Organisatoren gleichsam von innen her vorausbestimmt, weil beide Lebenssphären, die active und die denkerische auf persönlich-einmalige Weise bindend $[\ldots] .^{37}$

Mit diesen Worten beschrieb Stefan Zweig im Jahr 1937 Salman Schocken, den er wohl hauptsächlich durch dessen Wirken kannte. Die „Doppelseitigkeit“ in Schockens Charakter, die Verbindung eines höchst ausgeprägten Wirklichkeitssinns mit einer Leidenschaft für das Theoretische und Abstrakte, schienen dem Schriftsteller bemerkenswert. Auch Siegfried Moses hat viele Jahre später in seinem Nachruf auf Schocken zwei sehr verschiedene Züge bei Schocken bemerkt. Der promovierte Jurist Moses war ein langjähriger Weggefährte Schockens und einer der führenden deutschen Zionisten, er hatte ab 1933 die Stellungen des Vorsitzenden der Zionistischen Vereinigung für Deutschland (ZVfD) und des Vizepräsidenten der Reichsvertretung der deutschen Juden inne. Von 1923 bis 1929 war er Direktor im Schocken-Konzern und blieb für Salman Schocken auch nach seinem Ausscheiden aus dem Konzern und der darauffolgenden Etablierung als selbständiger Rechtsanwalt als Rechtsberater und -vertreter tätig. Zudem waren die beiden verbunden durch ihre langjährige gemeinsame zionistische Arbeit. Auch nach der Emigration der beiden Männer nach Palästina (Schocken im Jahr 1933, Moses vier Jahre später) konnte Schocken auf Moses als Berater zählen. ${ }^{38}$ Die Beziehung blieb trotz zeitweiliger Spannungen und Probleme eng. Schocken beschrieb im Oktober 1945

37 Stefan Zweig: Salman Schocken - 70 Jahre. In: Mitteilungsblatt der Alijah Chadaschah 11,44 (1947), S. 5-6.

38 Vgl. Grundbetrachtung zu einem Gespräch [von Salman Schocken] mit Herrn [Moschwa] Goldmann, Jerusalem, 03.05.1939. SchA, Privates, 844/2, Bd. 5. 
sein Verhältnis zu Moses folgendermaßen: „Siegfried Moses ist mir seit mehr als 25 Jahren nächster Mitarbeiter und Freund, und ich kenne wenige Menschen so

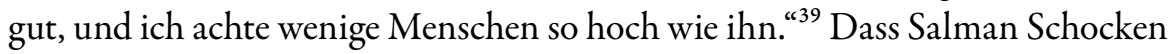
ihn als Freund bezeichnete, lässt auf die tatsächlich enge Bindung zwischen den zwei Männern schließen. In den Tausenden für diese Arbeit gesichteten Briefen bezeichnet er nur zwei weitere Menschen als seine Freunde. ${ }^{40}$

Siegfried Moses beschrieb, ähnlich wie Stefan Zweig, Schocken als Menschen, der zwei sehr unterschiedliche Charakterzüge in sich vereinte: Dieser wüsste, so Moses, ,in einem ganz außerordentlichen Masse Verstand und Instinkt zu koordinieren. “41 Er besitze „einen Verstand von ungewöhnlicher Klugheit, geschult durch das Studium von philosophischen Schriften und eine wachsam beobachtende und systematisch kontrollierte Lebenserfahrung. ${ }^{\text {“42 }}$

Moses führt weiter aus, dass sich Schocken von seinem Instinkt führen ließ, wenn es darum ging, welchen Gebieten er sich zuwenden solle. ${ }^{43}$ Da Salman Schockens Tagebücher nicht zugänglich sind, ${ }^{44}$ kann dies aus heutiger Perspektive kaum verifiziert werden. Deutlich wird aber, dass Schocken, wenn er sich einem Bereich zugewandt hatte, diesen systematisch erschloss. Sorgsame Analysen und fundiertes Abwägen von Für und Wider gingen allen Handlungen voraus. Insofern lag Siegfried Moses vermutlich richtig, wenn er dieses systematische Analysieren - und es handelte sich dabei tatsächlich nicht um einen Charakterzug, sondern um ein Vorgehen - als wesentliche Ursache des großen Erfolgs Salman Schockens sah, der weit über das Wirtschaftliche hinausging. ${ }^{45}$

39 Salman Schocken an M. Plaut, 17.10.1945. SchA, Privates, 844/2, Bd. 5.

40 Neben Moses ist es das Ehepaar Ticho, mit dem er in Jerusalem eine enge Beziehung einging. Vgl. Salman Schocken an John Rewald, 18.04.1953. SchA, Privates, 844/2, Bd.6.

41 Siegfried Moses: Salman Schocken. Seine Betätigung in der Wirtschaft und als Zionist. In: Bulletin des Leo Baeck Instituts (Tel Aviv) 13,4 (1961b), S. 1-43, hier S. 1. Original in englischer Sprache erschienen unter Siegfries Moses: Salman Schocken. His Economic and Zionist Activities. In: LBIYB 5,1 (1960), S.73-104.

42 Moses: Salman Schocken, S. 1-2.

43 Vgl. ebd., S. 2.

44 Im Katalog des Schocken Archives sind Tagebücher vermerkt. Es war der Autorin aber nicht möglich, diese zu erhalten. Lediglich die Aufzeichnungen zu seinen frühen Palästinareisen, die unter derselben Signatur wie die Tagebücher geführt sind, waren zugänglich. Es bleibt deshalb unklar, wie ausführlich die Tagebücher überhaupt sind, und ob sie tatsächlich noch im Archiv gelagert sind.

45 Siegfried Moses: Salman Schocken, S.2. 
Es sollen nun in Folge die Grundzüge dieses Denken, das ,System Schocken“ dargelegt werden und zwar vorerst auf den Bereich des Konzerns beschränkt. ${ }^{46}$ Die Fokussierung auf diesen Bereich liegt darin begründet, dass die Analyse des reichen Quellenkorpus zur These führte, dass Schocken in seiner Rolle als Konzernleiter diese Denkmuster erst entwickelt hat: Es wird davon ausgegangen, dass deren Entwicklung durch die Erfahrungen im Konzern und die Möglichkeiten, die er bot, ermöglicht und gefördert wurde.

Wissbegierde, Analyse, Kontrolle und pädagogisches Sendungsbewusstsein diese vier Stichworte können als Grundpfeiler sämtlicher Entscheidungen und Handlungen Schockens zählen. Angetrieben durch ein unendliches Interesse an den Dingen der Welt, schlug er in vielen Gebieten neue Wege ein, förderte und forderte Neuentwicklungen und war mit Althergebrachtem selten zufrieden. Der Schocken-Konzern ist vielleicht das herausstechende Beispiel dafür. Die Schocken-Brüder waren nicht die Erfinder des modernen Warenhauses. Das Konzept kam vielmehr aus dem Frankreich des 19. Jahrhunderts, von wo aus es vor allem in den Vereinigten Staaten schnell Verbreitung fand. ${ }^{47}$ Was den Schocken-Konzern von seiner Konkurrenz abhob, waren die klaren betriebswirtschaftlichen Richtlinien und kaufmännischen Strategien. Das Bedürfnis der Kunden stand an erster Stelle. Die Produkte hatten von bester Qualität zu sein - dafür sorgten firmeninterne Testlabors und Warenprüfstellen - und sollten gleichzeitig zu erschwinglichen Preisen weitergegeben werden.

Die Prüfstellen waren für Deutschland einzigartig und stehen für Schockens Wunsch nach Analyse und Kontrolle. Auf wissenschaftlicher Basis waren Spezialisten unter anderem damit beschäftigt, Textilien auf ihre Reißfestigkeit und Waschmittel auf ihre chemische Wirkung zu testen. Auf Grundlage der Ergebnisse wurden mit Produzenten Einkaufspreise verhandelt oder Verbesserungen gefordert. In dem Streben, den Kunden nicht nur qualitativ einwandfreie, sondern vielmehr die bestmögliche Ware anzubieten, schwang auch ein gewisses $\mathrm{Maß}$ an erzieherischem Impetus mit. Zwar kamen in den Prüfstellen wissenschaftliche Methoden zum Zug, dennoch wurde von Schocken bestimmt, was als gut und was als schlecht zu gelten hatte.

46 Es wird im Laufe dieser Untersuchung in unterschiedlichen Kontexten explizit und implizit auf das ,System Schocken' verwiesen.

47 Vgl. u.a. Hrant Pasdermadjian: Das Warenhaus. Entstehung, Entwicklung und wirtschaftliche Struktur. Köln / Opladen: Westdeutscher Verlag 1954. 
Der Schocken-Konzern war einem eindeutigen Modernitätskurs verschrieben. Von der Architektur und Inneneinrichtung über Verkaufsstrategien in den Geschäften bis zum Ausschluss von Warengattungen wurde erzieherisch auf die Kundschaft eingewirkt. Sein Sohn Gershom Schocken beschrieb den zugrundeliegenden Wunsch ausführlich in seinen publizierten Erinnerungen an seinen Vater, der „die Hebung des Kulturniveaus und des Geschmackes seiner Kunden “48 anstrebte. Die Einrichtung von Bücherabteilungen in den Kaufhäusern hatte zum Ziel, der Kundschaft gute Literatur - wie z. B. Goethe ${ }^{49}-$ zu günstigen Preisen anzubieten. Schon fast legendär wurde auch Salman Schockens Kampf gegen lange Männerunterhosen. Er empfand diese als derart unästhetisch und altmodisch, dass er sie aus seinen Geschäften verbannte. ${ }^{50}$

Wenn man Schockens schriftlichen Nachlass - Aufsätze, Reden und Dienstanweisungen, aber auch Briefe - liest, kommt man bald zum Schluss, dass es sich bei dem Verfasser um einen ausgesprochenen Machtmenschen mit großem Sendungsbewusstsein handeln muss. Kundschaft, Angestellte, Freunde und selbst Familienmitglieder sind Teil von Schockens Erziehungsbestrebungen. ${ }^{51}$ Für das 19. Jahrhundert war dies nicht unüblich: Familiengeführte Unternehmen verstanden die Belegschaft als erweiterte Familie. Das Familienoberhaupt und gleichzeitiger Inhaber der Firma hatte seinen Angestellten gegenüber ähnliche Rechte und Verpflichtungen wie gegenüber seinen Familienmitgliedern. Tatsächlich sind im Schocken-Konzern zahlreiche Spuren des Patronagesystems des vorangehenden Jahrhunderts vorhanden. Dazu gehören erzieherische Maßnahmen gegenüber seinen Angestellten wie Bibliotheken für Angestellte, die eingerichtet wurden, lange bevor die Kundschaft in Genuss von günstigen

48 Schocken: Salman Schocken, S. 19.

49 Schocken stellte in einer Anthologie Gedichte und Sprüche von Goethe zusammen, die die Lebensweisheiten und Betrachtungen der Welt des Dichters wiedergaben. Der Band wurde unter dem Titel Goethe-Gedichte. Eine Auswabl. Leben und Welt 1932 veröffentlicht. Der Vertrieb erfolgte nur über die Buchabteilungen des Konzerns. Der Band wurde nicht in das Verlagsprogramm aufgenommen. Vgl. Lambert Schneider: Salman Schocken. In: Imprimatur. Ein Jahrbuch für Bücherfreunde 6 (1969), S. 189-202, hier S. 193-194; Dahm: Das jüdische Buch im Dritten Reich, S. 475.

$50 \mathrm{Zu}$ Salman Schocken und der Frage der Ästhetik vgl. Stefanie Mahrer: Tradition and Modernity. In: Wardi (Hrsg.): New Types, S. 58-71.

51 Vgl. u. a. Fünfzehn Leitsätze für Verkaufspersonal der Kaufhäuser Schocken. In: Aus früheren Schocken Hauszeitungen, 1926. SchA, Konzern, 121/714. 
Buchausgaben in den Warenhäusern kam. ${ }^{52}$ Die Bücher sollten „das Fachwissen fördern, die volkswirtschaftliche Einsicht und die Bedeutung [der] Tagesarbeit festigen, und [...] auch die geistigen und seelischen Werte guter Dichtungen vermitteln. ${ }^{\text {"53 }}$

Die Leitsätze für das Verkaufspersonal verstärken das Bild des Erzieherischen, so heißt es z. B. im Leitsatz Nummer sieben: „Wer ohne zersplitterte Ablenkung bei seiner Aufgabe ist, der wird von seinem Gedächtnis nicht im Stich gelassen. Je mehr man sich für eine Sache interessiert, umso stärker wird die Gedächtnis-

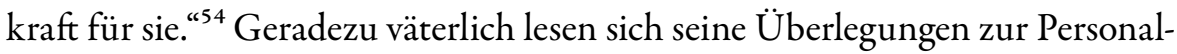
entwicklung und -führung:

In den Jahren, in denen ich mich praktisch mit der Personalerziehung beschäftigen konnte, habe ich jedem jungen Menschen Zeit gelassen, wenn ich sah, dass er sich mit Gedanken plagte oder mit Zweifeln, sei es an sich, am Beruf, oder an den Menschen überhaupt. Und ich habe gute Erfolge gehabt. ${ }^{55}$

Der Schocken-Konzern machte es sich zur Aufgabe, Mitarbeiter, und bis zu einem gewissen Grad auch Mitarbeiterinnen, ${ }^{56}$ im Betrieb aus- und weiterzubilden, ihnen Entwicklungsmöglichkeiten zu bieten und sie so langfristig im Betrieb zu halten. Schocken verglich die Ausbildungsmöglichkeiten im modernen Großbetrieb, zu denen der Schocken-Konzern zu zählen war, mit der Tradition der Wanderjahre, in denen die Gesellen mehrere Jahre lang von

52 Vgl. Wichtige Daten aus der Entwicklung der Firma I. Schocken G. m. b. H. SchA, Konzern, 111/191.

53 Der Schocken-Konzern, Typoskript, o. D. [geschätzt vor 1931]. SchA, Konzern, 111/191.

54 Fünfzehn Leitsätze für Verkaufspersonal der Kaufhäuser Schocken. In: Aus früheren Schocken Hauszeitungen, 1926. SchA, Konzern, 121/714. Schocken bezog dies auch auf sich selbst. So antwortete er laut Moses, wenn er auf sein erstaunliches Gedächtnis angesprochen wurde, mit dem Satz: „Wo das Interesse ist, da ist Gedächtnis“ (Moses: Salman Schocken, S.3).

55 Fragen der Personalerziehung. Nach stenographischer Niederschrift aus Vorträgen von Salman Schocken anlässlich der Informationskurse Mai-Juni 1926. In: Aus früheren Schocken Hauszeitungen, 1926. SchA, Konzern, 121/714.

56 Für die Mitarbeiterinnen gab es keine spezifischen Weiterbildungskurse im Sinne einer Karriereförderung. Frauen waren als Verkäuferinnen und Sekretärinnen, nicht aber in leitenden Stellen vorgesehen. Vgl. Fragen der Personalerziehung. 
Meister zu Meister zogen, um ihr Können zur perfektionieren. ${ }^{57}$ Das Durchlaufen von mehreren Berufsstationen innerhalb des Konzernes biete, so Schocken, eine vergleichbare Ausbildung. Ein Großteil der führenden Angestellten wurde tatsächlich aus dem selbst ausgebildeten Personal rekrutiert. Laut Landauer hatten über 50 Prozent aller Angestellten im Konzern gelernt, dies bei einem Wachstum der Beschäftigten von 1.200 im Jahr 1924 auf knappe 5.500 im Jahr $1937^{58}$

Die Konzernleitung forderte ein hohes Maß an Einsatz und Perfektion von seinen Mitarbeitenden, sorgte aber im Gegenzug auch für diese. Der SchockenKonzern gewährte den Angestellten, unabhängig von ihrer Stellung, ab 1908 ein Urlaubsgeld sowie zwei Urlaubstage mehr als rechtlich vorgeschrieben waren. ${ }^{59}$ Bereits 1917, anlässlich des zehnjährigen Bestehens der Firma I.S.S., wurde eine Stiftung als Grundlage des Angestellten-Wohlfahrtsfonds gegründet. 1934 wird in Rautenkranz ein Personalerholungsheim eingerichtet, 1926 werden der Unterstützungskasse der Angestellten 100.000 Reichsmark und der Stadt Zwickau 50.000 Reichsmark für das Bauen von Kleinwohnungen übergeben. Das Erholungsheim in Rautenkranz bot der Belegschaft Gelegenheit, einen kostenfreien Urlaub zu genießen. Für Angestellte, die ihre arbeitsfreie Zeit nicht im konzerneigenen Ferienheim verbrachten, wurde eine finanzielle Urlaubsbeihilfe für jeden Ferientag gewährt. ${ }^{60}$ Rückblickend am bedeutendsten war jedoch die Hilfe, die Schocken seinen 250 jüdischen Angestellten für die Emigration aus Hitlerdeutschland anbot. Im Frühjahr 1935 setzte er eine Kommission ein, die jüdische Auswanderungswillige, unabhängig davon, in welcher Position sie im Konzern angestellt waren, bei der Emigration logistisch, praktisch und finanziell unterstützen sollte. ${ }^{61}$

Dieser Umgang mit dem Personal vereinte zwei unterschiedliche, jedoch nicht gezwungenermaßen gegenläufige Tendenzen: Ein paternalistisches, noch fast

57 Vgl. Fragen der Personalerziehung, S. 8.

58 Vgl. Exposé Dr. Landauer. Überblick über Geschichte und Aufbau des Konzerns, Typoskript 1937. SchA, Konzern, 115/224.

59 Vgl. Die sozialen Einrichtungen im Schocken-Konzern. Termine der Einführung. SchA, Konzern, 175/281.

60 Vgl. Eröffnungsdaten und wichtige Ereignisse der Geschäftsentwicklung, 1901-1931. SchA, Konzern, 111/191.

61 Vgl. dazu genauer Kap. 9.2. 
im 19. Jahrhundert verhaftetes Personalverständnis wurde gekoppelt an ein modernes Sozialsystem, das Erholung, Bildung sowie Absicherung für Notlagen vorsah. Dabei wurden einfache Hilfskräfte behandelt wie leitende Angestellte. Schocken war in diesem System ein Patron der alten Schule, der nach modernen Gesichtspunkten handelte. Als Gegenleistung für die großzügige Unterstützung, die der Belegschaft zuteilwurde, verlangte Schocken Loyalität und Perfektion. Zudem sorgten weitreichende Kontrollmaßnahmen für die Einhaltung der Vorgaben.

Die Kontrollmechanismen dienten jedoch nicht nur zur Überprüfung der geleisteten Arbeiten, sondern auch der statistischen Erfassung sämtlicher Vorgänge und Transaktionen. Das hausinterne ,statistische Bureau' diente der Untersuchung der internen Abläufe des Unternehmens und ermöglichte eine zuverlässige Übersicht, so nachzulesen in den Konzernakten. ${ }^{62}$ Ab 1922 wurden unter der Leitung des Statistikers Moschwa Goldmann in der Zwickauer Zentrale sämtliche Rohstoffs-, Einkaufs- und Verkaufspreise erfasst. Anhand der Daten konnten saisonale Schwankungen im Absatz vorausgesagt und Einkaufspreise verglichen werden. Weiterhin erhob die statistische Abteilung Daten zur Kaufkraft der Bevölkerung, die in die Preisgestaltung einflossen. ${ }^{63}$ Die statistische Abteilung war Teil der Zwickauer Zentrale, den zweihundert Mitarbeitenden der Konzernzentrale oblag die Verwaltung des Gesamtunternehmens. Die horizontale Organisationsstruktur verlangte nach einer zentralen Verwaltung.

In der Zentrale wurden „viele Hunderte Formulare und Arbeitsanweisungen “64 entworfen und an die entsprechenden Abteilungen versandt. „In diesen Formularen“, so beschrieb es Schocken,

schlagen sich die Ergebnisse einer jahrzehntelangen, sorgfältigen Gedankenarbeit nieder, mit der die Mittel gesucht wurden, aus dem Alltagsleben des Betriebes jede

62 Vgl. Eröffnungsdaten und wichtige Ereignisse der Geschäftsentwicklung, 1901-1931. SchA, Konzern, 111/191.

63 Vgl. Salman Schocken: Zwischen Produktion und Konsum. Ein Vortrag gehalten am 12. November 1931 in der Hauptversammlung des Verbandes Deutscher Waren- und Kaufhäuser. In: Das Kaufhaus Schocken im Jahre 1926, S. 31-48, hier S. 41-42.

64 Aus früheren Schocken Hauszeitungen, 1926. SchA, Konzern, 121/714. 
Unordnung, alles Undurchsichtige und Zweifelhafte hinauszufegen, bis der klare, einfachste Weg dazu gefunden war, der nun täglich mit offenkundigem Erfolg begangen wird. ${ }^{\text {"6s }}$

Die statistische Auswertung der Daten, die erfassten Kundenwünsche, die zentrale Buchhaltung und die Analyse von Arbeitsberichten floss in die Arbeitsanweisungen ein. Die Tages-, Wochen- und Monatsberichte stammten aus unterschiedlichen Abteilungen und hatten standardisiert zu erfolgen. Die Formulare dazu wurden in Absprache mit den Abteilungsleitern, zuständigen Bearbeitern in der Zentrale und Salman Schocken entworfen. Und die Analyse dieser Formulare führte wiederum zur Optimierung von Abläufen und neuen Dienstanweisungen. In der Zentrale kam es also täglich zu einem Wechselspiel zwischen Anordnungen und Berichten, die sich gegenseitig beeinflussten. Es war Salman Schocken, der dieses System entwickelte, beaufsichtigte und verbesserte. Für ihn waren diese „Hunderte Formulare und Arbeitsanweisungen [keine] tote Pappe und Papier“, vielmehr wird das Papier „in der Hand der Angestellten lebendig [...]. ${ }^{“ 66}$ Die ständige Optimierung der betrieblichen Abläufe durch die Objektivierung menschlichen Handelns war damit im Schocken-Konzern eine, wenn nicht die zentrale Unternehmensstrategie. Dies war Salman Schockens Persönlichkeit geschuldet, der in einer Konferenz im Jahr 1933 selber feststellte:

Ich war mein Leben lang ein Mensch, der auf theoretische Methoden angewiesen war. Ich habe sicherlich oft versagt im Augenblick, weil mir das Papier als Unterlage fehlte, das ich erst sehen musste, um mir ein Bild machen zu können. ${ }^{67}$

Der Schocken-Konzern war damit wahrscheinlich der am stärksten von innen analysierte Konzern seiner Zeit. Über die Zwickauer Zentrale war Salman Schocken jederzeit über sämtliche Entwicklungen und Vorkommnisse informiert und konnte bei Bedarf einschreiten. Sein Bedürfnis nach Kontrolle konnte in einem Großbetrieb wohl nur durch die zentrale Verwaltung gestillt werden, zudem war er längst nicht mehr nur Kaufmann, sondern betätigte sich

65 Aus früheren Schocken Hauszeitungen, 1926. SchA, Konzern, 121/714.

66 Ebd.

67 Zit. n. Moses: Salman Schocken, S.2. 
auf zahlreichen weiteren Feldern. Das von ihm angeregte und ständig verbesserte System der Kontrolle entstand im Schocken-Konzern. Es wird sich aber zeigen, dass jeder wichtigen Entscheidung Schockens ein kompliziertes Analyseverfahren vorausging: Die Grundsätze des Handelns, die er als Kaufmann ausgebildet und die er als Inhaber des Schocken-Konzernes perfektioniert hatte, würden sein gesamtes Leben bestimmen.

Diese Grundsätze als rein kaufmännisches Denken zu bezeichnen, wäre verkürzend. Zwar wollte er mit dem Konzern, wie jeder Kaufmann, Gewinn erzielen, sein Denken ging jedoch weiter. In ihm verschränkte sich das Bestreben, erzieherisch auf die Kundschaft wie auf das Personal einzuwirken. Sein Denken verband ein paternalistisches Menschenbild mit ästhetischem, sozialem und wirtschaftlichem Modernitätsstreben. Diese unterschiedlichen Bestrebungen versuchte er durch analytisches Vorgehen zu vereinbaren. Die Zwickauer Zentrale, das Rückgrat des Konzerns, spiegelt dieses Denken wider.

Der Schocken-Konzern war auch auf eine weitere Weise ausschlaggebend für seine späteren Betätigungen. Die Konzernorganisation war nicht nur Ausdruck von Schockens Denken, der Konzern sorgte nicht nur für die finanzielle Grundlage, sondern bot ebenfalls die nötige Infrastruktur, das Personal sowie das Fachwissen, das für Salman Schockens kulturelle und zionistische Aktivitäten unabdingbar war.

Das ,System Schocken', so wie es sich in den Quellen präsentiert, meint Salman Schockens Denksystem, also sein bis ins letzte Detail durchdachtes Ordnungsund Kontrollsystem, das eine Infrastruktur basierend auf seinem Netzwerk nach sich zog.

Mit dem Konzern schuf sich Salman Schocken eine Infrastruktur, auf die er nach Bedarf zurückgreifen konnte. Der Großkonzern verfügte neben den Warenhäusern, Produktionswerkstätten und der Einkaufszentrale unter anderem über ein eigenes Baubüro, eine Rechtsabteilung und eine Hausdruckerei. In den Abteilungen waren zahlreiche Sachbearbeiter und Sekretärinnen beschäftigt, die sich um die Alltagsgeschäfte des Konzerns, aber auch um Schockens andere Unternehmungen kümmerten. Eine strikte Trennung zwischen Geschäftlichem und Privatem fand dabei nicht statt. So waren die Sekretariate in Zwickau und Berlin, und ab 1934 auch jenes in Jerusalem, einerseits für den Konzern und dessen Unterabteilungen, andererseits für den Privatmann Schocken in seinen unterschiedlichen Funktionen tätig. Ein Netzwerk 
von Mitarbeitenden ermöglichte es Schocken, auf zahlreichen Feldern erfolgreich tätig zu sein.

Salman Schocken betätigte sich neben seiner beruflichen Funktion als Inhaber eines Großkonzerns in zahlreichen Verbänden und Gremien. Ab 1908 gehörte er dem deutschen Warenhausverband an, später auch der Hauptgemeinschaft des deutschen Einzelhandels und dem Reichsbund des Textileinzelhandels. Seine Tätigkeit für Wirtschaftsverbände erreichte in den Jahren 1918 bis 1922 ihren Höhepunkt. Er verfolgte das Ziel, so Siegfried Moses, den Einzelhandel und seine Organisationen dahingehend zu stärken,

dass der Einzelhandel nicht das Objekt der Preisforderungen des Produzenten sein sollte, sondern dass der organisierte Einzelhandel den Fabrikantenverbänden als gleichwertiger Kontrahent gegenüberstehen könnte. ${ }^{68}$

Fast gleichzeitig mit seinem Engagement in Wirtschaftsverbänden nahm Schocken seine zionistische Betätigung auf, die ihn schnell zeitlich fordern würde. Während die spezialisierten Abteilungen des Konzerns, also die Bau-, Einkaufs-, Export- und Rechtsabteilung, für die jeweiligen Sachfragen hinzugezogen wurden, waren die Sekretariate für eine reibungslose Organisation der Korrespondenz, der Anfragen und der Reisen zuständig. Dabei entstand ein ausgeklügeltes System der Kommunikation zwischen den unterschiedlichen Abteilungen in Zwickau, Berlin und Jerusalem. Da Salman Schocken sämtliche Entscheidungen persönlich fällen oder zumindest absegnen wollte, begleitete ihn auf allen Reisen eine Sekretärin oder ein Sekretär. Damit Dokumente und Briefe nicht verloren gingen, wurden Kopien und Durchschläge angefertigt, die bis 1933 in Berlin und Zwickau und nach 1933 in Jerusalem archiviert wurden. Die Korrespondenz, die im heutigen Schocken Archiv gelagert ist, gibt daher einen genauen Einblick in dieses faszinierende Kommunikationssystem.

Ein Brief vom Februar 1939 gibt Auskunft, wie die Sekretariate ihre Kommunikation untereinander regelten:

68 Moses: Salman Schocken, S. 15. 
Da Sie [gemeint ist Dora Landauer ${ }^{69}$ ] um Rat- und Verbesserungsvorschläge in technischer Hinsicht bitten, möchte ich die Gelegenheit ausnutzen und Sie bitten, unsere Antwortbriefe nur für die Beantwortung darin enthaltener Fragen - und zwar in der gleichen Weise die Punkte nummeriert - zu benutzen. Bodenheimer z. B. hätte auf einen Extrazettel gehört. ${ }^{70}$

Dora Landauer war zu diesem Zeitpunkt neu als Sekretärin eingestellt und begleitete das Ehepaar Schocken nach Amsterdam, wo sich Salman Schocken einer dringenden Augenoperation unterziehen musste. ${ }^{71} \mathrm{Zu}$ diesem Zeitpunkt befand sich der Schocken-Konzern im Verkauf und der Berliner Verlag, der im August 1938 strukturell aus dem Konzern ausgegliedert worden war, ${ }^{72}$ in Liquidation - eine schwierige Zeit also. Schocken musste sich in dieser Situation, in der er nicht vor Ort sein konnte und darüber hinaus gesundheitlich stark angeschlagen war, auf seine Mitarbeiter*innen und Vertrauten verlassen können. Über Dora Landauer kommunizierte er mit den betreffenden Stellen in Berlin und Jerusalem, die im Sinne von Salman Schocken die Geschäfte abwickelten. Im Konzern waren Theodor Schocken und die Direktoren federführend, im Verlag waren es Theodor Schocken sowie Moritz Spitzer. Das Kommunikationssystem zwischen den Sekretärinnen war zu diesem Zeitpunkt derart ausgereift, dass die Liquidation, die für alle Beteiligten emotional schwierig und

69 Dora Landauer (geb. 1916) war eine entfernte Verwandte von Salman Schocken. Sie trat als Sekretärin von Moritz Spitzer in den Schocken Verlag ein, migrierte nach Jerusalem und trat dort nach einiger Zeit eine Stelle als private Sekretärin von Salman Schocken an. Sie begleitete ihn und seine Frau auf einigen Reisen als Sekretärin, bevor sie in die USA migrierte. Später heiratete sie Theodor Schocken, den zweitältesten Sohn von Lili und Salman. Vgl. Korrespondenz in SchA, Privates, 844/2, Bd.4; Dahm: Das jüdische Buch im Dritten Reich, S. 422 .

70 Lucie Birnbaum an Dora Landauer, 24.02.1939. SchA, Privates, 844/2, Bd. 4.

71 Vgl. Kap. 9.1.

72 Die Ausgliederung des Verlages aus dem Konzern wurde bereits im Herbst 1936 beschlossen, da die Funktionäre des Konzerns gegen die jüdische Verlagsabteilung opponierten. Sie befürchteten verstärkte Repressionen. Diese Pläne wurden dann aber erst im August 1937 wieder aufgegriffen, als ein Schreiben des Sonderreferates Hinkel eintraf, das die Fortführung des Betriebes als ,jüdischer Buchverlag' vorübergehend genehmigte. Wegen dieser Deklarationspflicht war man übereingekommen, dass die Ausgliederung schnellstmöglich vollzogen werden müsse. Die Ausgliederung wurde schließlich im März 1938 im Rahmen des Verkaufs des Konzerns vorgenommen. Vgl. SchA, Verlag, 331/91; Dahm: Das jüdische Buch im Dritten Reich, S.309-315. 
organisatorisch komplex war, bewältigt werden konnte. Eine wichtige Rolle spielte zu dieser Zeit seine Familie, an erster Stelle Theodor, der zweitälteste Sohn von Lili und Salman Schocken.

Theodor (1914-1975) war ab 1933 Leiter der Zwickauer Filiale und ab 1935 Teilhaber des Schocken Verlages. Er blieb, als die Familie 1933 nach Jerusalem emigrierte, in Deutschland zurück und führte als engster Vertrauter seines Vaters die Geschäfte weiter. Obwohl auch Theodor Schocken häufig geschäftlich verreiste, war er in Deutschland eine wichtige Stütze für seinen Vater und fungierte als Bindeglied zwischen dem Schocken Direktorium, dem Verlag und Salman Schocken. Theodor migrierte später in die USA, wo er gemeinsam mit seinem Vater den Verlag Schocken Books in New York begründete.

Es war aber nicht nur Theodor, der im System seines Vaters als Sohn, als Direktor eines Warenhauses, als Geschäftsführer des Verlages in Berlin, als Mitbegründer des New Yorker Verlagshauses und später als Ehemann der ehemaligen Sekretärin Schockens mehrere Rollen einnahm. Viele leitende Angestellte und Direktoren im Konzern, Sekretärinnen und Bibliothekare waren für Schocken in unterschiedlichen Funktionen tätig und viele blieben ihm auch nach seiner Emigration verbunden, entweder in ähnlichen Positionen oder als Berater und freie Mitarbeiter. Die Loyalität war gegenseitig. Salman Schocken galt als schwieriger und eigensinniger Patron, der von seinen Mitarbeitenden äußerste Perfektion verlangte; er zeigte sich ihnen gegenüber aber auch großzügig, wenn Hilfe notwendig war.

Bei Schockens Ausreise im Jahr 1933 war das System von Mitarbeitenden bereits so weit gefestigt, dass es ohne die persönliche Anwesenheit Schockens weiter funktionierte. Zudem war das Jerusalemer Büro - das zu Beginn in einer angemieteten Privatwohnung im Haus neben dem in den ersten Jahren ebenfalls gemieteten Familienwohnsitz untergebracht war -, mit ehemaligen Mitarbeitenden aus Deutschland besetzt, was die Zusammenarbeit vereinfachte. Zum Zeitpunkt des erzwungenen Verkaufes des Konzerns war dieses System so eingespielt, dass es auch ohne den Rahmen des Konzerns weiterlief. In den Jahren zwischen der Emigration der Familie Schocken und dem endgültigen Ende aller Geschäftstätigkeit in Deutschland baute Schocken sein privates und öffentliches Leben in Palästina kontinuierlich auf. Er ließ von Erich Mendelsohn die Familienvilla sowie das Bibliotheksgebäude bauen und dann den Hausrat, die Bibliothek und das Archiv nach Palästina verschiffen. Während seine Geschäfte in Deutschland zunächst weitergingen - so baute er unter 
anderem den Verlag in Berlin auf ${ }^{73}$-, begann Schocken sich zunehmend auch in Palästina zu betätigen, wozu unter anderem der Erwerb der Zeitung Haaretz und die Mitarbeit in der zionistischen Organisation gehörten. All dies wäre ohne das ,System Schocken' nicht möglich gewesen. Davon profitierten seine Familienmitglieder ebenso wie jene Körperschaften und Organisationen, in deren Dienst Schocken sich stellte. Die Hebräische Universität z. B. hatte mit Schocken nicht nur einen versierten Wirtschaftsmann und Förderer der Wissenschaften gewonnen, sondern auch ein System von gut vernetzten und professionell organsierten Mitarbeiterinnen und Mitarbeitern.

Es ist schwierig, in diesem System Salman Schocken als Privatmenschen zu finden. Indem über ihn vor allem Quellenmaterial vorliegt, das im Rahmen seiner beruflichen und politischen Aktivitäten entstand, jedoch z. B. keine Tagebücher zur Verfügung stehen, wird seine private Existenz weniger sichtbar als seine berufliche. Durch den hohen Grad an Mobilität und die teilweise langen Kommunikationswege zwischen Europa und Palästina wurden Entscheidungen immer wieder von seinen leitenden Mitarbeitern gefällt, ohne dass mit ihm Rücksprache gehalten wurde. Dies missfiel Schocken, der sich wiederholt beklagte, dass über seinen Kopf hinweg entschieden würde. Denn obwohl er seinen Leuten vertraute, bestand er darauf, in alle Entscheidungen einbezogen zu werden, auch wenn dies den Prozess stark verlangsamte. Da für ihn die zeitintensive, ausführliche Analyse die Basis jeder Entscheidung bildete, setzten sich seine Geschäftsführer in Situationen, in denen schnell gehandelt werden musste, über ihn hinweg. Das monierte er jeweils sehr scharf. So muss also trotz seiner Direktive, ihn an allen Entscheidungen persönlich zu beteiligen und die Kontrolle über sein Unternehmen bei ihm zu belassen, gefragt werden, ob Geschäftsvorgänge und -entscheidungen von Schocken als Person oder vom ,System Schocken' gefällt wurden.

Wir können aber festhalten, dass der wirtschaftliche Erfolg als Geschäftsmann das kulturelle und verlegerische Schaffen Schockens ermöglichte. Ohne die Mittel, die er erwirtschaftete, hätte er weder seinen Lebensstil noch seine kulturellen und zionistischen Projekte finanzieren können. Darüber hinaus bot der Konzern die organisatorische Grundlage seiner zahlreichen Unternehmungen.

73 Zur Villa und zum Bibliotheksgebäude vgl. Kap. 7; zur Rettung der Bibliothek 7.3.2; zur Haaretz Kap. 8.2; zu seiner Funktion an der Universität Kap. 8.1; zum Schocken Verlag in Palästina Kap. 8.2 und zum Berliner Verlagshaus Kap. 5. 
Mit dem Konzern schuf sich Schocken einen professionellen Verwaltungsapparat, auf den er zu jeder Zeit zurückgreifen konnte. Ohne das von ihm geschaffene Netzwerk von Mitarbeitenden wären seine zionistischen, verlegerischen und privaten Unternehmungen nicht möglich gewesen. Schocken konnte jederzeit auf die vielseitigen Kompetenzen seiner zahlreichen Mitarbeitenden zurückgreifen, die sein mobiles Leben und seine zahlreichen Geschäfts- und Privatunternehmungen organisierten. 


\section{4 \\ Jüdisches und Zionistisches \\ Aufbau eines Netzwerkes}

Durch Ihr Rabbi Nachman Buch bin ich vor Jahren stark beeindruckt worden. Seitdem habe ich Ihr Schaffen in Verehrung verfolgt. Seitdem bin ich wieder zum lebenden Juden geworden. [... $]^{1}$

Diese Zeilen, die Salman Schocken am 4. Februar 1914 an Martin Buber schrieb, werden von Vielen zitiert, wenn es darum geht, Schockens ,Rückkehr zum Judentum zu beschreiben. Dass sich alle auf diesen einen Brief stützen, hat den einfachen Grund, dass es das einzige Dokument ist, in dem Schocken selbst auf die Gründe für sein - dem Zitat zufolge neuerwachtes - Interesse am Judentum zu sprechen kommt. Er wird wahrscheinlich auch darum so häufig zitiert, weil der Brief nicht an irgendjemanden, sondern an den einflussreichen Religionsphilosophen Martin Buber gerichtet ist. Buber war bereits zu dem Zeitpunkt, als Schocken den Brief schrieb, durch seine Veröffentlichungen und seine verlegerischen Tätigkeiten bekannt.

Tatsächlich wandte sich Schocken schon einige Jahre vor dem vielzitierten Brief wieder dem Judentum zu. Ab März 1911 war er Mitglied im Zionistischen

1 Salman Schocken an Martin Buber, 04.02.1914. NLI, Buber Archiv, Arc. Ms. Var. 350/705, Bd. 1. Der Brief wurde in Bubers publiziertem Briefwechsel abgedruckt, dort jedoch mit einer Umstellung der Satzstruktur. Vgl. Martin Buber: Briefwechsel aus sieben Jahrzehnten. In drei Bänden, Bd. 1: 1897-1918, hrsg. v. Grete Schaeder. Heidelberg: Lambert Schneider 1972, S.356. 


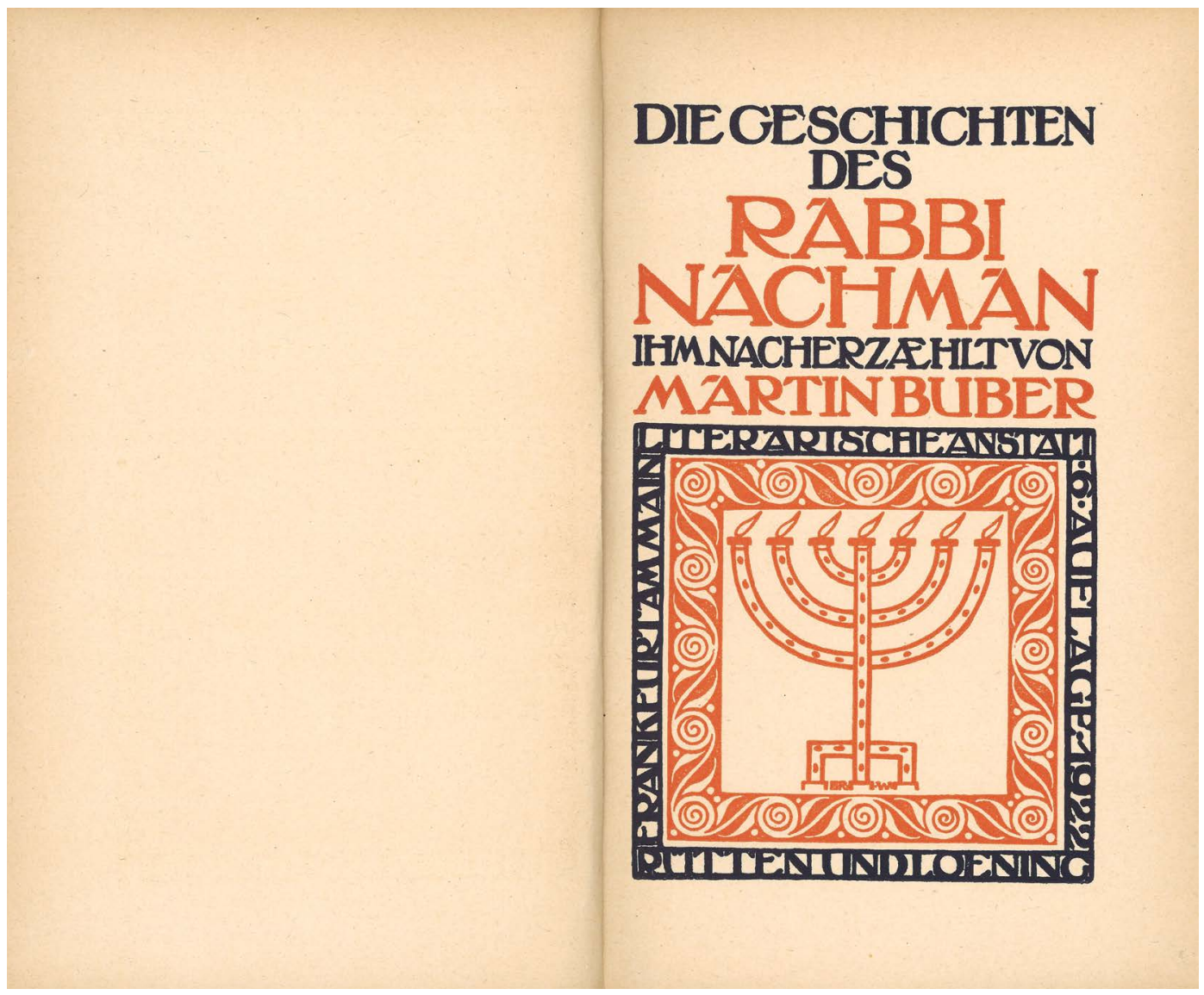

Abb.2: Martin Buber: Die Geschichten des Rabbi Nachman. Frankfurt am Main: Rütten \& Loening 1906.

Komitee und Ende November desselben Jahres trat die ZVfD mit dem Vorschlag an ihn heran, in Zwickau eine Ortsgruppe zu bilden. ${ }^{2}$ Vor diesem Hintergrund scheint es fraglich, ob die Lektüre in der Tat einen „Wendepunkt ${ }^{\text {“3 }}$

2 Vgl. M[iriam] Nussbaum: Chronologische Darstellung der jüdischen und zionistischen Tätigkeiten des Herrn Salman Schockens, 1911 bis 1932. SchA, Katalog zu 5: Jüdisches und Zionistisches. Chronologische Darstellungen wie diese finden sich zu unterschiedlichen Themen und wurden aus den Akten selbst zusammengestellt. Miriam Nussbaum war Archivarin im Schocken Archiv und für die endgültige Ordnung der Akten verantwortlich. Zu Nussbaum vgl. Stephen M. Poppel: Writing and Reading About Salman Schocken. In: MedaonMagazin für jüdisches Leben in der Forschung und Bildung 8,14 (2014), S. 1-15, hier S.7.

3 Schocken: Salman Schocken, S. 21. 
darstellte, wie es erstmals in Gershom Schockens Erinnerungen formuliert wurde, und in der Folge von Vielen übernommen wurde. Wahrscheinlich wäre es richtiger zu sagen, dass das Interesse am Judentum nach dem Verlassen des Elternhauses in eine Art Schlummerzustand versetzt worden war und allmählich wieder zum Vorschein kam. ${ }^{4}$

Der junge Schocken, der bekanntlich eine traditionelle jüdische Ausbildung genoss, war wie viele junge Juden seiner Zeit nach der Emigration aus Posen mit Dingen beschäftigt, die das traditionelle und religiöse Leben in Vergessenheit geraten ließen. Konfrontiert mit den wirtschaftlichen Möglichkeiten und fasziniert vom Lebensstil des jüdischen Bürgertums in Deutschland, rückte das traditionelle Judentum Posens in den Hintergrund. In Leipzig traf Schocken unter den deutschen Juden auf ein bürgerliches Religionsverständnis ${ }^{5}$, das ihm fremd erschienen sein musste. Dieses Selbstverständnis stellte zugleich eine Abgrenzung dar von den als arm und rückständig geltenden ,Ostjuden', ein pejorativer Begriff, mit dem sich die assimilierten deutschen Juden von den aus dem Osten zugewanderten Glaubensgenossen distanzierten. Es kann vermutet werden, dass der Lebensstil des jüdischen Bürgertums sowie die wirtschaftlichen und gesellschaftlichen Möglichkeiten, die damit verbunden waren, zunächst eine Anziehung auf den jungen Schocken ausübten. ${ }^{6}$ Und es scheint gerade der Kontakt mit dem anfänglich attraktiven jüdischen Bürgertum gewesen zu sein, der Schockens jüdisches Bewusstsein aufweckte.

Einige Faktoren spielen hier zusammen, die als Anhaltspunkte für dieses Wiedererwachen berücksichtigt werden müssen. So attraktiv das jüdische Bürgertum für Schocken auch gewesen sein mag - ein schneller Eintritt war ihm nicht möglich. Wie Simone Lässig in ihrer Studie zur Verbürgerlichung der deutschen Juden im 19. Jahrhundert eindrücklich gezeigt hat, vollzog sich der

4 Eine publizierte Aussage vom März 1914 untermauert dies. So schreibt er: „Studiert man aber die Werke Hermann Cohens, wie ich es seit langen Jahren tue [...].“ (Salman Schocken: Philosophie und Politik. Hermann Cohen und der Zionismus. In: Jüdische Rundschau, 20.03.1914, S. 124.) Die Auseinandersetzung mit dem Judentum scheint nie gänzlich abgebrochen zu sein.

5 Zur Verbürgerlichung der Religion im 19. Jahrhundert vgl. u. a. Simone Lässig: Jüdische Wege ins Bürgertum. Kulturelles Kapital und sozialer Aufstieg im 19. Jahrbundert. Göttingen: Vandenhoeck \& Ruprecht 2004, S. 243-441.

6 Schocken wird später trotz seiner vehementen Ablehnung des, Assimilationsjudentums einen großbürgerlichen Lebensstil pflegen. Vgl. SchA, Privates, 821-823. 
soziale Aufstieg der Juden in Deutschland als kollektives Phänomen, da sie sich in eine einzige Referenzgruppe der Mehrheitsgesellschaft, nämlich in das Bürgertum, integrierten. ${ }^{7}$ Als Neuzuwanderer aus dem Osten, dazu als weitgehend mittelloser, ohne akademische Bildung und ohne familiäre oder anderweitige Vernetzung in Deutschland, brachte Schocken denkbar schlechte Voraussetzungen mit, Teil des Bürgertums zu werden. ${ }^{8}$

Es greift jedoch zu kurz, nur äußere Umstände für die Hinwendung zu jüdischen Themen heranzuziehen. Schocken war ein Mensch, der aktiv mitgestalten wollte: Wie im vorherigen Kapitel deutlich wurde, spielte er in allen Gebieten, in denen er tätig war, eine leitende Rolle. Den Wunsch, Neues zu schaffen, konnte er im Rahmen der zionistischen Arbeit am besten verwirklichen. Die zionistischen Organe, Gruppierungen und Vereine waren die Kampfplätze der jungen Generation, die sich gegen das etablierte Bürgertum ihrer Eltern auflehnte. Der Zionismus - das Schreckgespenst der verbürgerlichten Juden Deutschlands - war zu diesem Zeitpunkt eine junge Bewegung in ihrer Entwicklung, die offen für Neuzugewanderte war. Damit bot sie, anders als die etablierten Organe des deutschen Judentums wie der Central-Verein, Schocken die Möglichkeit, aktiv zu werden, mitzugestalten und sich ein Netzwerk aufzubauen.

Als dritter und letzter Faktor ist Schockens tief verankertes Interesse am Judentum, seiner Kultur und Geschichte, zu nennen, das zu Beginn des Jahrhunderts in seinen Reden und seinem Handeln immer deutlicher hervortrat. Schockens Interesse am Jüdischen ging weit über sein privates Leben hinaus. Es war sein Wunsch, das Judentum zu verstehen und dessen Geschichte mit der Gegenwart zu verknüpfen. Woher dieses Interesse kam, ist aus heutiger Perspektive kaum mehr zu eruieren. Ein möglicher Erklärungsansatz kann in der Familie vermutet werden. Sein Bruder Simon, mit dem er geschäftlich verbunden war,

7 Vgl. Lässig: Jüdische Wege ins Bürgertum, S. 17-18. Der Publikation liegt Lässigs Habilitationsschrift zugrunde, in der sie sich in erster Linie auf die Entwicklungen in drei Regionen resp. Staaten, nämlich Dessau, Böhmen und Sachsen, konzentrierte.

8 Vgl. dazu auch die Kapitaltheorie bei Pierre Bourdieu: Die feinen Unterschiede. Kritik der gesellschaftlichen Urteilskraft, aus d. Franz. v. Bernd Schwibs / Achim Russer. Frankfurt am Main: Suhrkamp 1987; ders.: Die verborgenen Mechanismen der Macht, aus d. Franz. v. Jürgen Bolder. Hamburg: VSA 2005, und dazu Lässig: Jüdische Wege ins Bürgertum, S. 26-34; sowie Mahrer: Handwerk der Moderne. 
war seit der Gründung der jüdischen Gemeinde Zwickau im Jahr $1904^{9}$ im Gemeindevorstand und von 1911 bis zu seinem Tod 18 Jahre lang deren Vorsteher. ${ }^{10}$ Inwiefern die weiteren Geschwister Interesse am Judentum bezeugten, ist nicht überliefert. Aus einem Brief von Salman Schocken an Agnon wissen wir, dass sein Bruder Julius zwar Palästina bereiste, zionistisch aber nicht interessiert war. ${ }^{11}$

Dass die Lektüre von Bubers Rabbi Nachman die Wende hervorgerufen hat, bleibt damit fraglich. Eine schöne Geschichte ist es jedoch allemal. Vor allem ist die Anekdote aber wichtiger Teil von Schockens Selbstinszenierung als Mann, der gerne selber denkerisch gearbeitet hätte, aufgrund von familiären Gegebenheiten jedoch den Beruf als Kaufmann ergreifen musste, dem auf dem Weg in den Westen sein Judentum verloren ging, welches er durch die Lektüre des Buches wiederfand und der fortan an vorderster Front für ein lebendiges und stolzes Judentum kämpfte. Diese Inszenierung gibt ihm auch in dem Netzwerk intellektueller Zionisten die nötige Glaubhaftigkeit: Sämtliche wichtigen Zionisten dieser Generation grenzten sich durch den Zionismus von der Generation ihrer Väter ab, indem sie sich entweder im Gegensatz zu ihnen oder auf gänzlich andere Weise positiv auf ihr Judentum bezogen. Schocken kam aus einem traditionell religiösen Elternhaus, fügte sich aber mit dem Bild des sich das Judentum ,zurückerobernden' Mannes in dieses Narrativ ein. Indem er sich in diesen Diskurs einordnete, entweder berechnend oder intuitiv, handelte er geschickt. Um als Zionist erfolgreich zu sein, brauchte er ein tragfähiges Netzwerk, denn die zionistische Bewegung wurde zwar geprägt durch starke Charaktere, war aber schließlich eine Gruppenbewegung, in der individualistische Einzelkämpfer nur bedingt erfolgreich sein konnten.

Neuere netzwerkanalytische Theorieansätze aus der Soziologie bieten, vor allem wenn man sie mit weiteren theoretischen Ansätzen verknüpft, interessante Erklärungsmuster hinsichtlich des komplexen Wechselspiels zwischen Akteuren, Interaktionen und Strukturen. ${ }^{12}$ Es ist Ziel der Netzwerkforschung,

9 Vgl. Adolf Diamant: Zur Chronik der Juden in Zwickau. Dem Gedenken einer kleinen jüdischen Gemeinde in Sachsen. Frankfurt am Main: Selbstverlag 1971, S. 11.

10 Vgl. Nachruf des Zwickauer Gemeinderabbiners im Mitteilungsblatt des sächsischen israelitischen Gemeindeverbandes. In: Diamant: Zur Chronik der Juden in Zwickau, S. 26.

11 Vgl. Salman Schocken an S. J. Agnon, 28. 02.1929. NLI, Agnon Archive, Arc. 41270.

12 Vgl. Dorothea Jansen: Einführung in die Netzwerkanalyse. Grundlagen, Methoden, Forschungsbeispiele. 3. überarb. Aufl. Wiesbaden: VS 2006, S. 24. 
Mikro- und Makroebenen in Verbindung zu bringen. „Im Netzwerk wird der Zusammenhang zwischen den Strukturen und dem Handeln einzelner Akteure“, so Jansen und Diaz-Bone, „mit dem Begriff des sozialen Kapitals erfasst. “13 Der Begriff des „sozialen Kapitals“ geht auf Pierre Bourdieu zurück, und bezieht sich auf die dritte Ressource (neben der ökonomischen und kulturellen), auf die der Akteur im sozialen Feld zurückgreifen kann.

Das Sozialkapital ist die Gesamtheit der aktuellen und potenziellen Ressourcen, die mit dem Besitz eines dauerhaften Netzes von mehr oder weniger institutionalisierten Beziehungen gegenseitigen Kennens oder Anerkennens sind; oder, anders ausgedrückt es handelt sich dabei um eine Ressource, die auf der Zugehörigkeit zu einer Gruppe beruht. ${ }^{14}$

Das soziale Kapital ist demzufolge abhängig von den Beziehungen, die ein Akteur zu anderen Akteuren im Netzwerk unterhält, und ermöglicht „Zugang zu weiteren Ressourcen und Handlungsmöglichkeiten “15. Wenn man nun also die Zionisten in Deutschland - um diese undifferenzierte Sammelbezeichnung für eine schon zu dieser Zeit sehr heterogene Gruppe zu verwenden - und insbesondere deren Führungsliga als Netzwerk begreifen will, stellt sich dieses für Salman Schocken als unabkömmlich dar. Um als Zionist erfolgreich zu sein, galt es, Eintritt in dieses Netzwerk zu finden, denn ohne soziales Kapital wäre sein Handlungsspielraum stark beschränkt geblieben.

Netzwerke sind keine hermetisch abgeschirmten Einheiten, sie sind aber auch nicht einfach für jeden öffentlich zugängig. Folgt man Bourdieus Kapitaltheorie, bedarf es für eine gelungene Integration anderer Formen von Kapital: Für Bourdieu findet soziale Praxis in einem sozialen Raum statt,

13 Dorothea Jansen / Rainer Diaz-Bone: Netzwerkstrukturen als soziales Kapital. In: Johannes Weyer (Hrsg.): Soziale Netzwerke. Konzepte und Methoden der sozialwissenschaftlichen Netzwerkforschung. München: Oldenbourg 2011, S.73-108, hier S. 75; vgl. Jürgen Habermas: Das Konzept der Lebenswelt und der hermeneutische Idealismus der verstehenden Soziologie. In: Ders.: Theorie des kommunikativen Handelns. Zur Kritik der funktionalistischen Vernunft. Frankfurt am Main: Suhrkamp 1995, S. 190-209, 222-228.

14 Bourdieu: Die verborgenen Mechanismen der Macht, S. 63.

15 Jansen / Diaz-Bone: Netzwerkstrukturen als soziales Kapital, S. 75. 
der so konstituiert ist, dass die Verteilung der Akteure oder Gruppen in ihm der Position entspricht, die sich aus ihrer statistischen Verteilung nach zwei Unterscheidungsprinzipien ergibt [...], nämlich das ökonomische Kapital und das kulturelle Kapital. ${ }^{16}$

Er bezieht sich dabei auf das Schema ,Raum der sozialen Positionen' und ,Raum der Lebensstile ${ }^{\text {(17 }}$. Dem kulturellen Kapital in seinen drei Formen - objektiv (kulturelle Erzeugnisse wie Bücher, Gemälde etc.), inkorporiert (Bildung) und institutionalisiert (Diplome u.ä.) - kommt im Gesellschaftsmodell Bourdieus eine wichtige Rolle zu, entsprechend seinem Interesse, die Stabilität von Gesellschaftsgruppen und die Unterschiede zwischen den sozialen Gruppen aufzuzeigen. ${ }^{18}$ Es hat sich als fruchtbar erwiesen, dieses starre Modell zu dynamisieren und es als Integrationssystem zu fassen. ${ }^{19}$

Während es kaum möglich ist, sich innerhalb von kurzer Zeit in eine etablierte Gesellschaftsschicht zu integrieren, da es meist mehr als einer Generation bedarf, um kulturelles und soziales Kapital aufzubauen, ist der Eintritt in eine junge Bewegung, wie es der Zionismus zu Beginn des 20. Jahrhundert war, einfacher. Einerseits waren die Strukturen noch nicht verfestigt, andererseits war die Bewegung daran interessiert, neue Mitglieder und Mitkämpfer zu gewinnen. Es gab zwar bereits einige Führungspersönlichkeiten, dennoch war der Kreis tendenziell offen für Männer ${ }^{20}$, die tatkräftig mitdenken und mitarbeiten wollten. Aber auch in einer jungen Bewegung wie dem Zionismus zählte kulturelles und soziales Kapital, wollte man erfolgreich sein. Anders als in den führenden Eliten des deutschen Judentums spielten weniger die bürgerlichen Werte eine Rolle, auch wenn diese durchaus nicht irrelevant waren, als vielmehr die Unzufriedenheit mit der Trägheit und Assimilation des jüdischen

16 Pierre Bourdieu (Hrsg.): Praktische Vernunft. Zur Theorie des Handelns, aus d. Franz. v. Hella Beister. Frankfurt am Main: Suhrkamp 1998, S. 18.

17 Vgl. Bourdieu: Die feinen Unterschiede, S. 212-213.

18 Vgl. ebd., S. 210-221; Bourdieu: Die verborgenen Mechanismen der Macht, S. 50, 75.

19 Simone Lässig hat das System dynamisiert, indem sie die Konvertierbarkeit der Kapitalsorten umdrehte. Vgl. Lässig: Jüdische Wege ins Bürgertum, S. 31. In meiner eigenen Studie zur Geschichte der jüdischen Uhrmacher und Uhrenunternehmer habe ich das System noch einen Schritt weitergedacht und als eigentliches Integrationssystem verstanden. Vgl. Mahrer: Handwerk der Moderne, S. 115-216.

20 Es gab nur ganz wenige Frauen, die führende Positionen im Zionismus innehatten. 
Bürgertums. Sich als Rückkehrer zur Tradition zu verstehen, war dabei ein wichtiger Aspekt.

Der eingangs zitierte Satz aus dem Brief an Buber erscheint vor diesem Hintergrund in einem völlig neuen Licht: Schocken schreibt sich nicht nur in einen allgemeinen Diskurs ein, sondern schafft sich dabei auch Glaubwürdigkeit und damit soziales Kapital. Der Brief hatte jedoch noch eine weitere Funktion, zur Zeit des Verfassens wohl die wichtigere: sich bei Martin Buber vorzustellen. So endet der Brief mit dem Wunsch, ihn persönlich kennenzulernen.

Herr Leo Hermann [sic], der vor kurzem an meinem Wohnorte - Zwickau/i. Sa. war, sagt mir, dass ich vielleicht Gelegenheit bekommen könnte, Sie persönlich kennen zu lernen. Vor Jahren hatte ich schon die Absicht Sie aufzusuchen; ich mochte aber nicht einem schaffenden arbeitenden Menschen seine Zeit nehmen. Jetzt würde ich mich sehr freuen, wenn ich Ihnen näher treten könnte. ${ }^{21}$

Schocken war ein Meister des Netzwerkens. Mit Bezugnahme auf Leo Herrmann schuf er geschickt eine Verbindung zwischen sich und Buber. Herrmann war ein Journalist aus Böhmen, der als Vorsitzender der Prager Zionisten Buber zu seinem berühmten Vortrag „Drei Reden über das Judentum“"22 einlud. Er war in Prag u. a. Herausgeber der zionistischen Wochenschrift Die Selbstwehr, nach seiner Migration nach Berlin im Jahr 1913 nahm er zuerst den Posten als Sekretär der Zionistischen Weltorganisation wahr und wurde später Chefredaktor der Jüdischen Rundschau. ${ }^{23}$

Dem Brief fügte Schocken zudem die gedruckte Ausgabe der Maccabäerrede ${ }^{24}$ an, die er am 29. Dezember 1913 in Chemnitz gehalten hatte und bei Poeschel \& Trepte in Leipzig drucken ließ, und die einen klaren Einblick in sein zionistisches

21 Salman Schocken an Martin Buber, 04.02.1914. NLI, Buber Archiv, Arc. Ms. Var. 350/705, Bd. 1 .

22 Die Reden wurden 1932 im Schocken Verlag unter dem Titel Reden über das Judentum herausgebracht. Die Erstausgabe erfolgte 1923 bei Rütten \& Loening. Vgl. Dahm: Das jüdische Buch im Dritten Reich, S. 477.

23 Vgl. dazu und zur weiteren Biographie Wilma Iggers: Herrmann, Leo. In: YIVO Encyclopedia of Jews in Eastern Europe, Bd. 1, hrsg. v. Gershon David Hundert. New Haven / London: Yale UP 2008, S.713-714.

24 S[alman] Schocken: Eine Maccabäerrede. Gehalten am 29. Dezember in Chemnitz. Leipzig: Poeschel \& Trepte [1913]. 
Denken gab - Kampf gegen die Assimilation und eine Rückkehr zu „den inneren Quellen" ${ }^{25}$. Die Rückkehr konnte, so Schocken, nur durch ein Bekenntnis zur zionistischen Idee erfolgen. Mit der Verbindung zu Buber schuf sich Schocken einen wichtigen Kontakt im Netzwerk der Zionisten. Ab 1914 zeitigten seine Bemühungen Erfolg: Er wurde allmählich Teil des Netzwerkes der führenden Zionisten. Als Motor zahlreicher Initiativen nahm Schocken in den folgenden Jahren wichtige Funktionen und Schlüsselpositionen auf deutscher wie auf internationaler Ebene ein.

\subsection{Schockens zionistisches Denken}

Ich brauche Ihnen nicht zu sprechen von dem Prozess der Assimilation, des Verschwindens jüdischen Lebens aus der jüdischen Welt, ich brauche Ihnen nicht zu sprechen von der bestehenden breiten Majorität völkisch gleichgültiger Juden, die gern durch schwierige Jongleurkunststückchen und verzwickte Rechenexempel finden möchten, dass [...] Jude gleich Deutscher sei, und dass sie nach dieser Berechnung gar nicht mehr nötig hätten, sich [...] Juden zu nennen, sondern dass sie eigentlich [...] nur Deutsche sind.

Denn wozu sich mit einem Namen belegen, der jahrhundertelang zum Schimpfnamen geworden war, wozu die Last der Abstammung, die Last der Gemeinschaft mit Großen, von schwerer Not zerdrückte Menschenmassen auf sich nehmen, wenn man mit ein paar geschickten Missdeutungen des französischen Gleichheitsideals sich zu Allerweltsmenschen machen kann. ${ }^{26}$

Anstelle des eigentlich geforderten Berichtes über den 11. Zionistenkongress in Wien, lieferte Schocken der zionistischen Ortgruppe Chemnitz, die ihn als ihren Vertreter zum Kongress schickte, eine Brandrede für den Zionismus und gegen die Assimilation. Den Zionisten in Chemnitz brauchte er eigentlich keinen Zionismus zu predigen, also war diese Rede vielmehr als öffentliche Positionierung zu verstehen, oder wie es Dahm formulierte als „das erste Zeugnis seiner zionistischen Gesinnung ${ }^{\text {“27 }}$.

25 Ebd., S. 8.

26 Ebd., S.25-26.

27 Dahm: Dasjüdische Buch im Dritten Reich, S.252. Vgl. dort auch eine detaillierte Zusammenfassung der Rede. 
In der Rede, die er anlässlich des Makkabäerfestes gehalten hatte, verglich er die Situation des assimilierten Judentums der Gegenwart mit der des hellenistischen. So wie die Juden in der griechischen Provinz Judäa, die sich einen „Wettlauf nach der möglichst schnellen Assimilation zum Griechentum“ lieferten, um in „einem hohlen Scheingriechentum zu leben“, verhalte sich das gegenwärtige Judentum. ${ }^{28}$ Er zeichnet das Bild einer hochmütigen und gottlosen jüdischen Herrscherklasse, die ihre Religion verachte, ${ }^{29}$ und durch Reichtum verdorben würde ${ }^{30}$. Dem jüdischen Volk hätte der Untergang gedroht, ${ }^{31}$ wäre nicht Mattatias (der Vater von Judas Makkabäus), ein „obskurer Dorfpriester aus Modein “32 gekommen, der das Volk zum Aufstand gegen die Griechen und zur Umkehr bewogen hätte.

Die Zionisten erscheinen hier, so wird deutlich, als die Makkabäer der Gegenwart. Die Makkabäerbewegung, so Schocken, gab den Juden neuen Lebensinhalt, sie war eine Wiedergeburt jüdischer Größe, ${ }^{33}$ denn den Juden der Gegenwart ging wie den hellenistischen Juden der ,lebendige Zusammenhang mit der

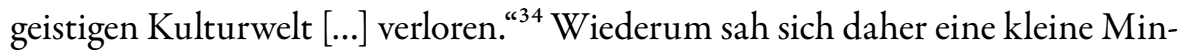
derheit dazu aufgefordert, diese Missstände zu bekämpfen, und die Juden wieder in Kontakt mit ihrer Herkunft zu bringen. Theodor Herzl, zentraler Protagonist in der Auseinandersetzung um die Zukunft, ${ }^{35}$ wird dabei zum Mattatias der Gegenwart. Mattatias war jedoch nur der Initiator des Befreiungskampfes gegen den syrischen König Antiochus IV; es waren seine Söhne, Simon und Judas Makkabäus, die den Aufstand zum Erfolg führten. In diesem Sinne nahmen die zionistischen Führer der post-Herzl'schen Zeit, zu denen sich Schocken wohl auch zählen wollte, die Rolle der Söhne ein: die zweite Generation, die den Kampf gegen das Verschwinden und die Auflösung gewinnen würde. In einer Rede vor dem Jugendbund in Plauen nimmt Schocken dieses Motiv erneut auf. Er bezeichnet die jungen Leute, die das Leugnen des eigenen

28 Schocken: Eine Maccabäerrede, S. 12.

29 Ebd., S. 13.

30 Vgl. ebd., S. 14.

31 Vgl. ebd., S. 16.

32 Ebd., S. 18.

33 Vgl. ebd., S. 20.

34 Ebd., S. 28.

35 Vgl. ebd., S.31-32. 
Jüdisch-Seins ihrer Elterngeneration nicht mehr ertragen könnten, die „dem Aussterben in geistiger und kultureller Beziehung ${ }^{\text {“36 }}$ ein Ende setzen wollen würden, als Soldaten der Bewegung:

Diese junge neue Bewegung ist eben notwendig, um neues Leben hineinzubringen um einen Stamm, der alles was wir glauben Kraft in sich hat zusammenzulegen und zu tragen $[s i c] .[. .$.$] Es ist das erste Mal seit Jahrtausenden, dass eine jüdische Bewe-$ gung möglich ist und besteht, die nicht nur aus Offizieren besteht - es ist unsere jungjüdische Bewegung. Das Erstemal [sic] seit Hunderten von Jahren fühlen hunderttausende wieder als gemeine Soldaten und es ist dafür gesorgt, dass unsere Bewegung Menschenmaterial hat. ${ }^{37}$

Der Zionismus als eine Bewegung der Jungen, als eine Bewegung der Unzufriedenen, so präsentierte ihn Schocken in der Rede vor dem Jugendbund. Diese Rede war zwar deutlich weniger geschliffen als jene vor dem Delegiertenkongress - so verzichtet Schocken auf rhetorische Spielereien und historische Querverbindungen -, weniger kämpferisch war sie jedoch nicht. Auch sie appellierte an einen jüdischen Nationalstolz. Aus Furcht würde, so Schocken, das jüdische Volk geleugnet und aus ihm eine Konfession gemacht, ${ }^{38}$ geblieben sei nichts mehr als eine „rissige Fassadenkultur “39. Dagegen stelle sich die junge Generation und gehe jene Probleme an, die die „Majorität der erwachsenen Juden einfach nicht sehen wolle. ${ }^{\text {40 }}$ Dem wollte Schocken vorangehen, er wollte mithelfen, den Nationalstolz aufzubauen und die Juden „zu ihren Quellen“ zurückzuführen. Das war für ihn die Aufgabe des Zionismus und damit ordnete er sich in die Reihe der Kulturzionisten ein, deren Anliegen in erster Linie die kulturelle Erneuerung des Judentums war.

36 Mitschrift eines Vortrages von Salman Schocken im Jüdischen Jugendbund Plauen, 19.11.1912. SchA, Jüdisches und Zionistisches, 532/1, S.6. Die Mitschrift ist unvollständig, die erste Seite fehlt komplett, im Text selber sind Lücken vermerkt. Das Originalmanuskript ist nicht mehr vorhanden.

37 Ebd., S.7.

38 Vgl. ebd., S.4.

39 Ebd., S.3.

40 Ebd. 
Die zionistische Bewegung war über diese Frage gespalten. Ein großer Teil der zionistisch gesinnten und organsierten Juden stammte aus Osteuropa. Diese Gruppe verfolgte deutlich andere Ziele als die deutschen Zionisten, die mehrheitlich aus einer gebildeten Oberschicht ${ }^{41}$ stammten und in ihrem Land bürgerliche Rechte genossen. Demgegenüber mussten die Juden Osteuropas weiterhin für ihre Rechte kämpfen, waren weiterhin Pogromen ausgesetzt und sahen daher im Zionismus in erster Linie eine praktische Lösung für diese Probleme. Auch innerhalb der ZVfD war die Fraktion der aus Osteuropa stammenden Juden groß. Das Programm der ZVfD nahm sich der Probleme beider Gruppierungen an: der sogenannten Ostjuden und deren Familien, die teilweise noch in den Herkunftsländern lebten, und der deutschen Mitglieder, die die Führungsriege stellten. Das Hauptanliegen der deutschen Zionisten war die kulturelle Erneuerung, um die Assimilation aufzuhalten. Die Schwierigkeit dabei war, dass sich ,jüdische Kultur' nicht einfach definieren ließ, und für einen orthodoxreligiösen Juden aus Galizien eine andere Bedeutung hatte als für einen Universitätsabsolventen aus Berlin.

Schocken war sich zwar durchaus der Probleme der Juden in und aus Osteuropa bewusst und beschäftigte sich später bis zu einem gewissen Grad damit; sein Hauptinteresse lag aber darin, den deutschen Juden einen Zugang zu ihren Wurzeln zu geben. Die „innere Wiedergeburt des jüdischen Menschen“ solle der Zionismus bringen, denn „nur aus dieser Wiedergeburt wird die Zukunft Israels werden können. “42 So schließt die Maccabäerrede, die für Schockens weiteres Handeln programmatisch sein sollte.

\subsection{Palästina und seine Wirtschaft}

"Als erstes kommt Palästina. Als Zweites: das Judesein in der Galuth “43, so Schocken Anfang 1917. Faktisch war Schockens zionistische Arbeit in den Anfangsjahren jedoch auf Deutschland, also auf die Galut, ausgerichtet. Sowohl

41 Vgl. Stephen M. Poppel: Zionism in Germany 1897-1933. The Shaping of a Jewish Identity. Philadelphia: Jewish Publication Society of America 1976, S. 36.

42 Schocken: Eine Maccabäerrede, S. 34.

43 Salman Schocken an unbekannt, 24.02.1917, zit. n. Moses: Salman Schocken, S. 28, Anm. 22. Moses gibt leider nicht an, an wen der Brief adressiert war und wo das Original zu finden ist. 
die Maccabäerrede wie auch jene am Leipziger Delegiertentag im Dezember 1916 stellten die kulturelle Erneuerung des Judentums in den Vordergrund; der Aufbau einer jüdischen Heimstätte hingegen fand keine explizite Erwähnung. Dass für ihn Zionismus aber in der letzten Konsequenz die Schaffung eines jüdischen Gemeinwesens in Palästina bedeutete, klingt wiederholt an und das bereits, bevor er 1921 durch die Wahl in das Direktorium des Keren Kayemeth LeIsrael, des Jüdischen Nationalfonds (KKL), und in den Finanz- und Wirtschaftsrat der Zionistischen Organisation ${ }^{44}$ eine aktive Rolle in der jüdischen Besiedelung Palästina übernahm.

Schocken besuchte 1912 den XIII. Delegiertentag in Posen ${ }^{45}$, bei dem beschlossen wurde, dass die ZVfD sich vom rein politischen Zionismus Herzls lösen und sich dem praktischen Zionismus zuwenden solle. Die Ansiedlung und der Aufbau Palästina rückten damit, zumindest in der Theorie, in den Fokus der Anstrengungen der deutschen Zionisten. Schocken trat in Posen noch nicht als Redner auf, stimmte aber, so Siegfried Moses, für die von Theodor Zlocisti ${ }^{46}$ vorgebrachte und von der Gruppe um Kurt Blumenfeld „verteidigte und sieg-

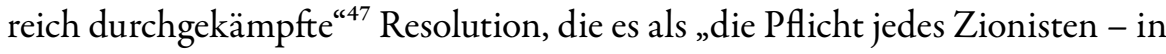
erster Reihe der wirtschaftlich Unabhängigen - [ansieht,] die Übersiedlung nach Palästina in ihr Lebensprogramm aufzunehmen. ${ }^{\text {“48 }}$ Schocken stimmte diesen Forderungen also zu, und meinte gar in einem kurzen, ersten Gespräch mit Blumenfeld am Rande des Delegiertentages: „Auf dieser Tagung sehe ich, dass die Zionisten ihre eigene Sache ernst nehmen. Der Weg zur Durchführung ist weit, aber auch das ist gut. ${ }^{\text {(49 }}$

$44 \mathrm{Vgl}$. Nussbaum, M[iriam]: Mitwirkung des Herrn S. Schocken an dem Aufbau der Palästina-Wirtschaft 1921-1928, 20.10.1957, Typoskript. SchA, Katalog zu 5: Jüdisches und Zionistisches.

45 Zum Posener Delegiertentag vgl. u. a. Poppel: Zionism in Germany 1897-1933, S. 50-67.

46 Der Arzt und Schriftsteller Zlocisti (1874-1943) war deutscher Zionist. Er war 1912 einer der Initiatoren der Resolution, die alle Zionisten dazu aufforderte, nach Palästina auszuwandern. Er selbst verließ 1921 Deutschland und ließ sich in Palästina nieder. Vgl. hierzu die Biographie von Albrecht Spranger: Theodor Zlocisti. Die multiplen Zugehörigkeiten eines Zionisten. Berlin: Neofelis 2020, die als Bd. 23 der Reihe Jüdische Kulturgeschichte in der Moderne erschien.

47 Blumenfeld: Erlebte Judenfrage, S. 90.

48 Zusammenstellung der Anträge, die vom XIII. Delegiertentag zum Beschluss erhoben wurden. In: Jüdische Rundschau, 14.06.1912, S.222.

49 Blumenfeld: Erlebte Judenfrage, S. 92. 
Wie auch in der kulturzionistischen Bewegung um Buber, handelte es sich bei den praktischen Zionisten, die zeitgenössisch als, die Radikalen' bezeichnet wurden, um eine Gruppe junger Männer. Im Gegensatz zur Buber-Gruppe sahen Vertreter der praktischen Zionisten einer Zukunft für Juden in Deutschland kritisch entgegen. Auch wenn die Interessen der zwei Fraktionen keinesfalls deckungsgleich waren, lassen sich Überschneidungen ausmachen. Blumenfeld verwies z. B. auf das Problem, dass die Zionisten über keine oder zu wenig jüdische Bildung verfügten, ${ }^{50}$ was sich mit Schockens Ansichten deckte.

Der Posener und vielmehr noch der Leipziger Delegiertentag im Jahr 1914, der die Posener Resolution bestätigte, zeigten, dass die jüngeren Kräfte innerhalb des ZVfD sich durchsetzen konnten. Der Aufbau Palästinas wurde damit das erklärte Ziel. ${ }^{51}$ Schocken unterstützte zwar formell und ideell die Anliegen der Radikalen, trat aber sonst in dieser Hinsicht nur punktuell in Erscheinung. So kommentierte er gegenüber Blumenfeld das Verteilen der gedruckten Kongressreden mit den Worten:

Hätten die zionistischen Delegierten die Kenntnis der Geschichte des deutschen Judentums vom 18. und 19. Jahrhundert und die Kenntnis der großen deutschen Literatur, so würden sie wissen, dass sie den Fuß in Deutschland nur leicht aufsetzen können. Der Druck der Kongressreden Herzls wird für die Wirkung Herzls vielleicht mehr tun als die konventionellen Reden bei Gedenktagen, die sichtlich unerhört verhallen. ${ }^{52}$

Schocken zeigte damit, dass er sich keinerlei Partei- oder Fraktionsprogrammen verpflichten wollte, denn die Kulturzionisten lehnten ebenso wie die Radikalen den Kongresszionismus Herzl'scher Prägung ab. Für Schocken hatte Herzl jedoch eine andere Bedeutung: Er war der Begründer des politischen Zionismus, in dessen Programm die Besiedlung Palästinas und die Schaffung eines jüdischen Staates durchaus eine Rolle spielten. Mit dem Verteilen der HerzlReden handelte Schocken nach eigenen Grundsätzen und ließ sich weder durch Ideologien, persönliche Beziehungen noch durch politische Gepflogenheiten

50 Vgl. Jehuda Reinharz: Fatherland or Promised Land. The Dilemma of the German Jew, 1893-1914. Ann Arbor: U of Michigan P 1975, S. 167.

51 Vgl. ebd., S. 169.

52 Blumenfeld: Erlebte Judenfrage, S.93-94. 
einschränken. Sein Interesse war die Zukunft des Judentums, die nur durch eine Rückbesinnung auf die eigene Tradition gesichert werden konnte. Dass sich Schocken schließlich den Kulturzionisten anschloss, ist vor diesem Hintergrund nur logisch. Aber auch seine Wahl, den praktischen Zionismus Blumenfelds zu unterstützen, folgte dieser Logik: Vertraten die praktischen Zionisten doch die Meinung, dass der Zionismus in Deutschland eine „postassimilatorische Bewegung ist, die die Problematik erkannte, die Assimilation und Einbürgerung fremder Kulturen und Völker mit sich bringen [...]. ${ }^{153}$ Schockens zionistisches Verständnis führte ihn dazu, von zwei unterschiedlichen Seiten her den für ihn absehbaren Untergang des Judentums durch die Assimilation zu bekämpfen: Einerseits durch kulturellen Aufbau ,aus den Wurzeln', das heißt, durch die Förderung von Literatur und Kultur, und andererseits durch die aktive Arbeit am Aufbau Palästinas.

Faktisch arbeitet Salman Schocken erst im Jahr 1921 aktiv am Aufbau Palästinas mit. Bis dahin hatte er sich, abgesehen von seiner Mitarbeit im Kulturausschuss und seinen verlegerischen Projekten in diesem Rahmen, vor allem im Zentralkomitee in Berlin sowie weiterhin im Verband der jüdischen Gemeinden Sachsen, dem er als Präsident vorstand, betätigt. ${ }^{54}$ Dass er zwischen 1917 und 1921 vergleichsweise wenig in Erscheinung trat, ist sicherlich auch der Tatsache geschuldet, dass er zu dieser Zeit intensiv mit dem Aufbau seines Konzernes sowie den wirtschaftlichen Problemen der Kriegs- und Nachkriegszeit beschäftigt war, und nicht zuletzt seiner Betätigung in deutschen Wirtschaftsund Warenhausverbänden.

Die Wahl in den Finanz- und Wirtschaftsrat der Zionistischen Organisation auf dem 12. Zionistenkongress in Karlsbad, bei dem unter dem Vorsitz von Nachum Sokolow die zionistische Mandatspolitik ratifiziert und ein großzügiges Kolonisationsprogramm beschlossen wurden, sowie die Wahl in das Direktorium des KKL Ende 1921 markieren den Beginn von Schockens praktischer Arbeit für die Besiedelung Palästinas. Gleichzeitig trat er durch diese Ämter in die höchsten Führungsgremien der international agierenden zionistischen Organisationen ein. Schocken hatte sich seit seinen ersten öffentlichen

53 Moses: Salman Schocken, S. 24.

54 Vgl. Nussbaum, M[iriam]: Chronologische Darstellung der jüdischen und zionistischen Tätigkeiten des Herrn Salman Schockens, 1911 bis 1932. SchA, Katalog zu 5: Jüdisches und Zionistisches. 
Auftritten auf der zionistischen Bühne durch seine kulturpolitischen und verlegerischen Tätigkeiten nicht nur einen Namen gemacht, sondern ein wichtiges Netzwerk mit bedeutenden Persönlichkeiten aufgebaut. Zugleich verfügte er über ein hohes Verhandlungsgeschick, was kaum unbemerkt bleiben

konnte. Nicht zuletzt sein Erfolg als Kaufmann, der trotz schwieriger wirtschaftlicher Lage aus dem Nichts einen Konzern aufbaute, empfahl ihn für ein ungleich schwierigeres Unterfangen: den Aufbau Palästinas. Der Ruf, ein genauer, wenn nicht gar pedantischer Analytiker zu sein, der sich nicht scheute, offen auf Missstände hinzuweisen, machte ihn für die Aufgabe perfekt. Schocken war, so wichtig ihm das zionistische Projekt auch war, weder ein Utopist noch ein Idealist. Als Besitzer des Warenhauskonzernes ließ er jedes neue Produkt analysieren, arbeitete an der Verbesserung und Modernisierung der betrieblichen Abläufe wie Produkte, und versuchte, alles Unvorhergesehene auszuschließen. Gleichzeitig verfolgte er jedoch Visionen und war Neuem gegenüber aufgeschlossen.

\subsubsection{Die erste Reise nach Palästina}

Nach diesem System ging er auch seine neuen Aufgaben für den KKL und für den Finanz- und Wirtschaftsrat der Zionistischen Organisation an. Um einen Überblick über die tatsächliche Lage in Palästina zu gewinnen, trat er am 4. März 1922 gemeinsam mit seiner Frau seine erste Palästinareise an. Ein Reisetagebuch, Briefe von Salman und Lili Schocken an die Kinder, ein abschließender Reisebericht sowie mehrere Vorträge nach der Rückkehr am 17. Mai 1922 dokumentieren diese Reise und sind Zeugnis, welche Bedeutung der Besuch Palästinas für Schocken hatte, auch wenn seine Berichte in ähnlich sachlich-analytischer Weise abgefasst waren wie seine Wirtschaftsberichte.

In erster Linie verfolgte Schocken mit der Reise den Zweck, die wirtschaftliche Lage Palästinas zu erfassen und zu analysieren, um dabei auch Möglichkeiten für private wie zionistische Investitionen abzuklären. Das Reisetagebuch verdeutlicht, dass das Ehepaar ebenfalls touristische Ziele auf dem Weg wie die Pyramiden von Gizeh und den Bazar in Kairo besuchten. Vor allem die Briefe und der Reisebericht an die Kinder zeigen, wie aufregend diese erste Reise für Lili und Salman war. ${ }^{55}$ Schon von der Zugreise durch die Schweiz bis nach

55 Vgl. Reisebericht und Briefe Lili Schocken. SchA, Privates, 835/2. 
Genua, wo sie am 8. März nach Alexandria einschifften, schickten sie lange Beschreibungen an die Kinder. In späteren Jahren, als Reisen zu einem Dauerzustand für Salman, aber auch für den Rest der Familie Schocken wurde, ließ die Begeisterung nach, aber diese erste Reise war für das Ehepaar eindrücklich. Die Fahrt durch die Schweiz, entlang von Flüssen und durch zahlreiche Tunnel werden ausführlich beschrieben, ebenso der Speisewagen, eine Droschkenfahrt in Genua und die Schönheit der italienischen Paläste. ${ }^{56}$ Der Reisebericht ist eines der sehr wenigen Dokumente, die einen Einblick in das persönliche Erleben Schockens ermöglichen.

Palästina machte auf beide großen und gleichermaßen einen befremdlichen Eindruck. Nach einer Fahrt „durch das schöne sonnige Land“ über „farbenprächtige Wiesen“, dem Besuch einiger Kolonien, die im Entstehen begriffen waren und in denen „Leute noch in Zelten wohnten "57, einem kurzen Aufenthalt in Tiberias, einer „alten und verfallenen Stadt“, und ein paar Tagen in Jaffa/Tel Aviv, erreichten sie am 24. März 1922 Jerusalem. $^{58}$

Die Stadt liegt $800 \mathrm{~m}$ hoch, mitten in den Bergen. Es war Freitag nachmittag [sic] als wir ankamen. Wir gingen nach den Klagemauern. Durch winklige, dunkle Gässchen, auf holprigen Wegen, schmutzig und düster führte uns der Weg. Die Betenden standen dicht gedrängt an den Mauern; polnische Juden in ihren blau- und gelbsamtenen pelzgefütterten Mänteln mit der Pelzmütze auf dem Kopf, schwarzgekleidete Juden mit langen Schläfenlocken im Kaftan und rundem Hut; Juden von Arabern nicht zu unterscheiden, in arabischen farbigen Gewändern mit dem Fez auf dem Kopf, Frauen mit leuchtenden Kopftüchern, meist ärmlich gekleidet, Kinder, wie Erwachsene angezogen mit klugem Gesichtsausdruck. Einen alten Juden sah ich, der langsam die Mauer entlang schritt mit Feierlichkeit und Inbrunst jeden einzelnen Stein küsste. So

56 Vgl. Salman und Lili Schocken: Reisebericht von Bord der „Esperia“, 12.03.1922. SchA, Privates, 835/2.

57 Gemeint sind die Arbeiter der Gdud ha-Avoda (Arbeiterlegion), die zwischen Haifa und Nazareth und zwischen Zemach, Tiberias und Tabha Straßen bauten. Es handelte sich dabei zum größten Teil um junge Männer und wenige Frauen aus Russland. Die Legion wurde 1920 gegründet und bestand bis 1926. Vgl. genauer Walter Laqueur: A History of Zionism. With a New Preface by the Author. New York: Schocken Books 1989, S. 295-297.

58 Salman und Lili Schocken: Reisebericht von Bord der „Esperia“, 12.03.1922. SchA, Privates, $835 / 2$. 
stehen seit Jahrhunderten tagtäglich Hunderte von Juden vor dieser Mauer und wehklagen über das Leid des Volkes und über ihr eigenes Leid. ${ }^{59}$

Mit einem gewissen Erstaunen beschreibt Lili Schocken die freitagnachmittägliche Szenerie an der Klagemauer. Die bürgerliche Europäerin scheint befremdet: über die Bekleidung aus dem Orient oder aus der ebenso fremden Welt des Schtetls, die Armut und das offensichtliche Leid der Menschen. In ihrer Beschreibung konstruiert Lili Schocken einen deutlichen Gegensatz zwischen den osteuropäischen und den orientalischen Juden an der Klagemauer und den jungen Zionisten, die sie auf ihrer Reise antrafen:

[Wir] fuhren am 3. Tage nach Naizis ${ }^{60}$, um die vom Nationalfonds angekauften neuen Bäder zu besichtigen. Dort fanden wir eine Genossenschaft (Chwuzah) junger Menschen vor, die in gemeinsamer Arbeit den Boden bebauen und besiedeln wollen. Sie sind sich der Schwierigkeit ihrer Aufgabe wohl bewusst, aber sie sind alle frisch und freudig bei ihrer schweren Arbeit. ${ }^{61}$

In Schockens offiziellem Bericht über die palästinensische Wirtschaftspolitik auf der Jahreskonferenz der Zionistischen Organisation in Karlsbad am 22. August 1922 klingt es ähnlich:

Palästina hat in vielem die Eigenschaft eines Koloniallandes. - Ein Kolonialland beherbergt neben den Eingeborenen eine mehr oder minder große Menschengruppe, die ins Land gekommen ist und die aus ihren früheren Wohnländern bestimmte Lebensformen mitbringt; Lebensformen, die eine besondere Art des Konsums bedingen. [...] Wir stehen nun in dem Prozess, dass Palästina für den Juden allmählich diesen Kolonialcharakter verliert. [...] Wir stehen seit zwei Jahren [gemeint ist nach dem Ersten Weltkrieg, S. M.], besonders jetzt nach der Erteilung des Mandats, vor der groBen Aufgabe die Wirtschaft des Landes wieder aufzubauen. ${ }^{62}$

59 Salman und Lili Schocken: Reisebericht von Bord der „Esperia“, 12.03.1922. SchA, Privates, $835 / 2$.

60 Bei Tiberias, vgl. Salman Schocken: Palästinensische Wirtschaftspolitik. Bericht auf der Jabreskonferenz in Karlsbad am 23. August 1922. Zionistische Broschüren-Bibliothek. Berlin: Verlag des Berliner Büros der Zionistischen Organisation 1922.

61 Ebd.

62 Schocken: Palästinensische Wirtschaftspolitik, S.3. 
Während des genau zweimonatigen Aufenthalts in Palästina absolvierte Salman knapp 50 Arbeitstreffen, nahm an Wahlversammlungen und Sitzungen der Universität und des Nationalfonds teil, besichtigte Genossenschaften wie Bauland, und traf Literaten, Politiker und Wirtschaftsfachleute. ${ }^{63}$ Sie seien überall gut aufgenommen worden, schreibt Lili Schocken dazu an die Familie.

Sally ist sehr beschäftigt mit seinen Sitzungen und ich habe viel Aufforderung und Einladungen. Bei dem Präsidenten der Organisation sind wir schon öfters eingeladen gewesen (Ussischkin $\left[{ }^{64}\right]$ ). Er hat uns auch zum Sederabend eingeladen. ${ }^{65}$

Die Reise war sozusagen ein Antrittsbesuch in Palästina mit einer Vielzahl an hochkarätigen Treffen. Schockens Expertise in Wirtschaftsfragen war sowohl in Palästina, wie die zahlreichen Treffen und Sitzungen zeigen, wie auch in Europa gefragt, von wo aus der Aufbau gesteuert und vor allem auch finanziert werden sollte.

Einen Tag nach seiner Abreise veröffentlichte die Haaretz ein Interview mit Schocken, in dem er die ersten Eindrücke und Analysen der Reise wiedergibt. Er äußert darin, dass er „das Land, was die Fülle der Möglichkeiten, die für sein Auferstehen da sind, betrifft, besser gefunden als [er] es [sich] vorgestellt [hatte]. ${ }^{\text {“6 }}$ In den Berichten, die Schocken nach der Rückkehr verschiedenen zionistischen Gremien und Institutionen vorstellte, wird jedoch deutlich, als wie schwierig er den Aufbau einschätzte: Das Land sei arm und klein und daher sei auch der Konsum beschränkt, Waren und Dienste seien überteuert, die Besiedlung habe Kolonialcharakter und daher sei die Lebensführung nicht dem Land angepasst. Die Infrastruktur sei bescheiden und es gäbe kein Staatswesen, das diese aufbauen würde. Es brauche daher große finanzielle Investitionen, um die Infrastruktur wie Hafenbauten, Wasserkraftwerke, Elektrizitätsanlagen und Industrie aufzubauen, aber auch, um die Bodenschätze zu nutzen; es müsse daher eine Bevölkerung geschaffen werden, die dem Land entsprechend lebe.

63 Vgl. 04.03. bis 17.05.1922, Palästinareise. SchA, Privates, 835/2.

64 Menachem Ussischkin (1863-1941), Sekretär des 1. Zionistenkongresses, ab 1929 Vorsitzender der Zionistischen Kommission für Palästina, 1923-1941 Präsident des KKL.

65 Salman und Lili Schocken: Reisebericht von Bord der „Esperia“, 12.03.1922. SchA, Privates, $835 / 2$.

66 של̈ber die Arbeit und die Wirtschaft im Land [Israel]. Ein Gespräch mit H. Schocken]. In: Haaretz, 18.05.1922, S.2. 
Die Landwirtschaft müsse mit "geeignetem Ernst“ nach „wirtschaftlichen Tatsachen" aufgebaut werden. ${ }^{67}$

\subsection{2 „Geeigneter Ernst“ und „wirtschaftliche Tatsachen“: Schockens Pläne für den Wirtschaftsaufbau}

Nach seiner Rückkehr bot Schocken im Finanz- und Wirtschaftsrat der Zionistischen Organisation an,

[v]on Zwickau aus, die Wirtschaftsführung in Palästina zu kontrollieren und zu überführen. Zu diesem Zwecke erklärte er sich bereit, die genauen monatlichen Rechnungsberichte aus Palästina zu prüfen und die aus dieser Prüfung sich ergebenden Vorschläge zwecks Einführung adäquater Arbeitsmethoden in Palästina dem Wirtschaftsrat zu unterbreiten. ${ }^{68}$

Es entsprach Schockens Denken, den wirtschaftlichen Aufbau Palästinas mittels einer systematischen Erfassung und Überprüfung zu begleiten. Wiederum lag ihm die aktive Gremienarbeit weniger als die Analyse der regelmäßigen Berichte aus dem Land und die Entwicklung darauf aufbauender Strategien. Wenngleich Lili und Salman Schocken die jungen Menschen, die enthusiastisch die schwere Arbeit der Besiedelung verrichteten, in ihren Reiseberichten lobten; als Wirtschaftsmann forderte er professionell ausgebildete Arbeiter, die das Land nach einem systematischen Plan erschlossen. Er glaubte, dass „je mehr die Arbeit im Lande sich nach dem Grundsatz der rationellen Wirtschaft organisierte, desto leichter wird es werden, die Unterstützung des ganzen jüdischen Volkes, die sehr nötig ist, zu erreichen. ${ }^{\text {“69 }}$ Die von Schocken geforderte Disziplin und Systematik beim Aufbau des Landes kann als Absage an das Ideal des zionistischen Pioniers, wie es in der dritten Alija bestand, betrachtet werden, denn er forderte nichts Geringeres als eine Neukonzeption des zionistischen Projektes: Stärkung und Professionalisierung der Organisation des Aufbaus,

67 Schocken: Palästinensische Wirtschaftspolitik, S. 3.

68 Sitzung des Finanz- und Wirtschaftsrates 19.06.-23.06.1922, Protokoll, zit. n. M[iriam] Nussbaum: Mitwirkung des Herrn S. Schocken an dem Aufbau der Palästina-Wirtschaft 1921-1928, Typoskript vom 20.10.1957, S.3. SchA, Katalog 5: Jüdisches und Zionistisches.

69 Über die Arbeit und die Wirtschaft im Land. In: Haaretz, 18.05.1922, S. 2. 
systematische Berufsvorbereitung der Einwanderungswilligen, ${ }^{70}$ finanzielle Unterstützung von neuen Betrieben, jedoch nur mit gleichzeitiger enger Überwachung in Form „regelmäßige[r] Sachrevision “71.

Innerhalb des deutschen Sektors der praktischen Zionisten stieß er mit diesen Forderungen auf offene Ohren. Auf dem Delegiertentag der ZVfD im September 1922 sprach er über die Aufgaben, die sich dem deutschen Zionismus in Palästina stellten. Robert Weltsch berichtete darüber in der Jüdischen Rundschau und hob hervor, dass, neben dem Referat von Arthur Ruppin, Schockens Rede den größten Eindruck bei den Delegierten machte. „Schocken, der bis dahin der weiteren zionistischen Öffentlichkeit fast unbekannt gewesen ist, war mit einem Male die populärste Figur der Konferenz. Bei allen Parteien fand sein Referat uneingeschränktes Lob. ${ }^{\text {“72 }}$ Damit stand er nur, gerade acht Jahre nachdem er die nationale zionistische Bühne betrat, in zwei wichtigen Netzwerken im Zentrum: bei den praktischen Zionisten und bei den Kulturzionisten. Ob Schocken mit seinen Plänen erfolgreich war, ist schwer abschätzbar. Als er beim 14. Zionistenkongress im Sommer 1925 in Wien die Schaffung einer Wirtschaftsexekutive forderte - da er glaubte, dass nur ein solches Gremium unabhängig, das heißt, nach wirtschaftlichen Gesichtspunkten ohne Verpflichtungen einer Partei gegenüber entscheiden könne -, gelang es ihm nicht, seine Forderung durchsetzen. ${ }^{73} \mathrm{Ob}$ es daran lag, dass er gleichzeitig die Meinung vertrat, die Arbeiter spielten zwar für den Aufbau Palästinas eine wichtige Rolle, aber dürften keine Entscheidungsgewalt über die Gestaltung der Wirtschaft haben, lässt sich nicht mehr rekonstruieren. Die Tatsache, dass Schockens wirtschaftliche Ideen vor allem innerhalb des deutschen Zionismus zu überzeugen vermochten, weniger im Rahmen des internationalen Zionismus, wie er auf den Zionistenkongressen vertreten war, ist offensichtlich. Der Chalutz-Zionismus

70 Die Familie Schocken war involviert in die Ausbildung junger Jüdinnen und Juden in landwirtschaftlichen Berufen. Simon Schocken, Salmans Bruder, erwarb vermutlich 1922 das Gut Winkel, eine landwirtschaftliche Ausbildungsstätte in Brandenburg. Nach Simons Tod stand Salman Schocken dem Gut vor. Zur Geschichte des Gutes vgl. Ilana Michaeli / Irmgard Klönne (Hrsg.): Gut Winkel. Die schützende Insel. Hachschara 1933-1941. Berlin: Lit 2007.

71 Schocken: Palästinensische Wirtschaftspolitik, S. 10.

72 Robert Weltsch: Schluss der Jahreskonferenz. Erstes Resumé. Von unserem Berichterstatter. In: Jüdische Rundschau, 05.09.1922, S. 467.

73 Vgl. Adolf Böhm: Die Zionistische Bewegung 1918 bis 1925. Jerusalem: Hotza'a Ivrit 1937, S. 563 . 
ließ sich nur schwerlich mit dem systematischen Denken Schockens, das auf allen Seiten Opfer forderte, in Einklang bringen.

Einer der größten Erfolge, die Schocken im Aufbau des Landes verbuchen konnte, war sicherlich der Erwerb der Haifa-Bay, der durch seine Verhandlung zustande kam. Nachdem der KKL den Erwerb des Bodens, der die Bucht von Haifa bis nach Akko umschließt, ursprünglich abgelehnt hatte - der Fokus lag zu dieser Zeit auf dem Erwerb von landwirtschaftlichem Boden -, konnte Schocken 1925 das Direktorium von der Bedeutung des Gebietes für die Entwicklung von Haifa überzeugen. Zuerst konnte der KKL nur einen Viertel des Landes erwerben, als aber deutlich wurde, dass die besitzende Gesellschaft finanziell nicht in der Lage war, das Land zu entwickeln, nahm Schocken die Verhandlungen wieder auf. Mit einem persönlichen Darlehen über $10.000 £$ ermöglichte er die Zahlung der fälligen Hypothekenraten an den Verkäufer. ${ }^{74}$ Schocken zögerte nie, eigene finanzielle Mittel einzusetzen, um Projekte, an die er glaubte, voranzubringen. In der Tat gelang es ihm in den folgenden zwei Jahren, den größten Teil des Geländes für den KKL zu erwerben.

Als Unternehmer folgte er jedoch seinen eigenen Vorgaben, die Industrie in Palästina durch Investitionen aufzubauen, nicht. Er trat mit Vertretern der Privatwirtschaft in Kontakt und klärte Investitionsmöglichkeiten ab, sah jedoch von privaten Investitionen ab. Zwar bemerkte er bis in die erste Hälfte des Jahres 1925 eine erhebliche verstärkte Kapitalbildung und ein wachsendes Vertrauen ausländischer Firmen. ${ }^{75}$ Er selbst entschloss sich aber in keinem Fall für den Einstieg in eine Firma oder eine Eigengründung, auch wenn er jedes Projekt, das ihm vorgeschlagen wurde, sorgfältig prüfte. Schocken unterstützte auch zahlreiche Projekte mit privaten Mitteln in Form von verzinsten oder zinslosen Darlehen. Seine Bindung an Palästina und an die zionistischen Gremien im Land wurde zudem durch nunmehr regelmäßige Reisen enger. Damit blieb er eine zentrale Figur im Wirtschaftszionismus, auch wenn er sich ab Ende der 1920 er Jahre wieder vermehrt innerhalb von Deutschland engagierte.

74 Vgl. Moses: Salman Schocken.

75 Vgl. Salman Schocken: Bericht über die wirtschaftlichen Eindrücke meiner Palästinareise. September / Oktober 1925. SchA, Privates, 835/2. Krediteinschränkungen der AngloPalestine und der Anglo-Egyptian Bank im Oktober 1925 stoppten kurze Zeit später die positive Entwicklung vorerst. 


\subsection{Zehn Jahre im Dienste des Zionismus}

Der Glaube des edlen Menschen an die ewige Fortdauer seiner Wirksamkeit auch auf dieser Erde gründet sich auf der Hoffnung der ewigen Fortdauer des Volkes, aus dem er selber sich entwickelt hat, und der Eigentümlichkeit desselben. ${ }^{76}$

Mit diesen Worten von Johann Gottlieb Fichte ${ }^{77}$ wollte Schocken 1914 in einer Replik auf Hermann Cohens Schrift Deutschtum und Judentum die Differenzen zwischen Zionisten und liberalen Juden ${ }^{78}$ darlegen. ${ }^{79}$ Der Artikel in der Jüdischen Rundschau war nicht der erste, in dem sich Schocken gegen Hermann Cohen als öffentliche Figur der Liberalen richtete. Bereits eineinhalb Jahre zuvor griff Schocken mit einem Aufsatz gegen Cohen in die Diskussion zwischen dem zionistischen und dem liberalen Lager innerhalb des deutschen Judentums ein. ${ }^{80}$ Cohen war einer der Mitverfasser und Mitunterzeichnender einer „Erklärung“ des Antizionistischen Komitees, die am 5. Februar 1914 im Berliner Tagblatt gedruckt wurde. Sie warf den Zionisten vor,

innerhalb des Judentums einen ,national-jüdischen ' Chauvinismus [...] entfachen [zu wollen], der uns in schroffen Gegensatz zu unseren christlichen deutschen Mitbürgern bringen müsste, von denen uns doch nichts unterscheidet als unser Glaube. ${ }^{81}$

76 Salman Schocken: Hermann Cohen. In: Jüdische Rundschau, 05.11.1915, S.361-362, hier S.362. Original in: Johann Gottlieb Fichte: Reden an die deutsche Nation. Berlin: Realschulbuchhandlung 1808 .

77 Schocken zitiert in seinen Reden und Veröffentlichungen oft Autoren, um seine Standpunkte zu untermauern. Vgl. auch Schocken: Salman Schocken, S. 16.

78 Der Begriff, liberal' ist eine zeitgenössische Eigenbezeichnung der jüdischen Mehrheitsgruppe, die sowohl die religiöse Orthodoxie wie auch den Nationalismus der Zionisten ablehnte.

79 Vgl. Jehuda Reinharz: Consensus and Conflict Between Zionists and Liberals in Germany Before World War I. In: Michael A. Fishbane / Paul R. Mendes-Flohr (Hrsg.): Texts and Responses. Studies Presented to Nahum N. Glatzer on the Occasion of His Seventieth Birthday by His Students. Leiden: Brill 1975, S. 226-238.

80 Vgl. Schocken: Philosophie und Politik.

81 Hermann Cohen: Erklärung. In: Handels-Zeitung des Berliner Tagblattes. Beiblatt, 05.02.1914, o.P. 
Dies führe, so Cohen, zu einer tiefen Spaltung des deutschen Judentums, an der die Zionisten Schuld trügen. ${ }^{82}$ Die "Erklärung“ wie auch die Wahl, sie als Annonce in einer nichtjüdischen Zeitung zu platzieren und damit die Zionisten in der breiten Öffentlichkeit zu diskreditieren, rief unter Letzteren große Empörung hervor, die sich unter anderem in zahlreichen Responsen in der Jüdischen Rundschau, dem offiziellen Organ der ZVfD, entlud.

Schockens Artikel über Cohens Schrift Deutschtum und Judentum vom November 1915 war eigentlich eine Fortführung der Debatte von 1914 und als Frontalangriff auf die jüdische Mehrheit in Deutschland zu verstehen. Schocken unterschied in jenem Aufsatz drei Generationen deutscher Juden: Die erste, die Generation Cohens, verlange danach, eine Symbiose zwischen Judenund Deutschtum herzustellen, die zweite habe ihr Judentum fast gänzlich verloren, und erst die dritte Generation, jene, die nach 1870 geboren ist, sei „wiedergewonnen worden für die jüdische Sphäre“, ihre Vertreter seien die „Träger der werdenden Wiedergeburt. ${ }^{\text {"83 }}$

Schocken sah, wie bereits weiter oben deutlich wurde, die Vertreter des Zionismus und damit auch sich selbst, als Träger einer jüdischen Wiedergeburt; auf ihnen ruhe die einzige Hoffnung, die in der „ewige[n] Fortdauer des Volkes“ bestehe. Die von Schocken zitierten und hier eingangs wiedergegebenen Worte Fichtes haben in diesem Kontext eine zweifache Bedeutung - sie sind einerseits als Mittel zur Diffamierung der liberalen Juden zu verstehen, sie sind aber andererseits auch eine Selbstvergewisserung. Es besteht die Hoffnung, so glaubt Schocken, dass das aus der zionistischen Perspektive gefährdete Fortleben des Judentums gesichert werden könne. Entsprechend Schockens Verständnis der Ungleichheit der Menschen - für ihn gab es, so sein Sohn, ,Elitemenschen', Menschen des Geistes und der großen Taten, $-{ }^{84}$ war es seine Pflicht als Elitemensch, die Gesellschaft vorwärts zu bringen. Entsprechend seines Selbstverständnisses als Kaufmann und Patron, erzieherisch auf die Angestellten und Kunden einzuwirken, sah er sich verpflichtet, jüdischen Menschen Zugang zum Judentum zu ermöglichen. Um dies zu verwirklichen, stellte sich Salman Schocken ab 1911 in den Dienst des Zionismus und baute sich in relativ kurzer Zeit mithilfe von persönlichen Begegnungen und wirksamen Auftritten in der

82 Vgl. Cohen: Erklärung.

83 Schocken: Hermann Cohen, S.361-362.

84 Vgl. Schocken: Salman Schocken, S. 15. 
Öffentlichkeit ein Netzwerk von bedeutenden Zionisten auf. Kultur und Wirtschaft, oder genauer: Bücher und Zahlen, waren dabei die Pfeiler seiner zionistischen Arbeit. So hieß es auch in einem biographischen Eintrag in der Palestine Review im Jahr 1936 über Schocken: „His commercial capabilities, combined with concern for cultural and spiritual Judaism, and an organisational talent that is far above the normal, stamp him as an outstanding person. ${ }^{\text {"85 }}$

85 Palestine Personalities. Salmann Schocken. In: Palestine Review, 21.08.1936, S. 375. 



\section{5 \\ „The book as a force of change“ \\ Perspektiven auf Salman Schocken, den Schocken Verlag und seine Bücher}

Bücher waren im Leben Salman Schockens immens wichtig, sie waren sein eigentliches Lebensthema - als Förderer der Wissenschaft und von Autoren, als Verleger, als Sammler und als Leser war er sowohl beruflich wie auch privat in ständigem Kontakt mit ihnen. Bücher waren gleichermaßen bedeutend für den größten Teil seines sozialen Umfeldes, das sich überwiegend aus Verlegern, Autoren, Wissenschaftlern und Lesern zusammensetzte. Keinen anderen Aspekt seines Lebens verfolgte er mit einer derartigen Konstanz. Bücher waren für Schocken die Grundlage jeglicher Kultur und gleichsam Monumente der Geschichte. Zwar las auch er zur Unterhaltung, Anekdoten zu seiner Reisebibliothek gibt es zur Genüge, er maß dem Buch aber eine Funktion zu, die weit darüber hinaus ging. Das folgende Kapitel wird diese kontextgebundenen sozialen und politischen Funktionen aufschlüsseln. Diese Überlegungen stehen nicht im luftleeren Raum, sondern knüpfen an Vorüberlegungen aus den (historischen) Buchwissenschaften an.

Bereits Mitte des 17. Jahrhunderts schrieb John Milton in Verteidigung der Freiheit der Rede, dass Bücher ein Dasein unabhängig von ihrem Verfasser haben, dass sie gleichsam zu ,lebendigen Wesen' über den Text hinaus werden. 
Books are not absolutely dead things, but doe contain a potencie of life in them to be as active as the soule whose progeny they are; nay they do preserve as in a violl the purest efficacie and extraction of that living intellect that bred them. ${ }^{1}$

Und 400 Jahre später bezeichnete Leslie Howsam das Buch als

[...] not so much a category [than] as a process: books happen; they happen to people who read, reproduce, disseminate, and compose them; and they happen to be significant. The book can be a force of change and the history of the book documents that change. ${ }^{2}$

Ähnlich argumentiert Robert Darnton in seiner grundlegenden Arbeit zur Kultur- und Sozialgeschichte des Buches. Ausgehend von einem Missbehagen gegenüber dem üblichen Verständnis des Buches durch die Geschichtsforschung, die das Buch als passive Quelle von Informationen ansieht, definiert er das Buch als aktive Kraft in der Geschichte. ${ }^{3}$ Er unterstreicht vor allem die kommunikative Rolle des Buches. Eng angelehnt an die Annales-Schule ${ }^{4}$ geht es ihm nicht um bibliographische Fragen, die bislang die Buchwissenschaft beschäftigten, sondern um sozioökonomische Fragestellungen nach allgemeinen Mustern in der Buchproduktion und -distribution. ${ }^{5}$ Darnton plädiert für ein Modell (siehe Abb.3) eines Kommunikationskreislaufes, das Autor, Verleger, Drucker, Verkäufer und Leser umfasst. ${ }^{6}$ „[...] The circuit runs full cycle. It transmits messages, transforming them en route, as they pass from thought to

1 John Milton: Areopagitica. A Speech of Mr. John Milton for the Liberty of Unlicens'd Printing. To the Parliament of England. London 1644, zit. n. ders.: Areopagitica, hrsg. mit Einleitung und Anm. v. John M. Hales. Oxford: Clarendon 1904, S. 5. Miltons Worte richteten sich gegen die Einführung der Vorzensur durch das englische Parlament - das zentrale Argument dabei war, dass die Vorzensur die Verbreitung der Wahrheit verhindern würde.

2 Leslie Howsam: Old Books and New Histories. An Orientation to Studies in Book and Print Culture. Toronto: U of Toronto P 2006, S. 5 (Herv. i. Orig.).

3 Vgl. Robert Darnton: What Is the History of Books? In: Deadalus 111,3 (1982), S. 65-83, hier S.65.

4 Vgl. Lucien Febvre / Henri-Jean Martin: L'apparition du livre. Paris: Albin Michel 1958.

5 Vgl. Darnton: What Is the History of Books?, S. 66.

6 Vgl. ebd., S.67. 


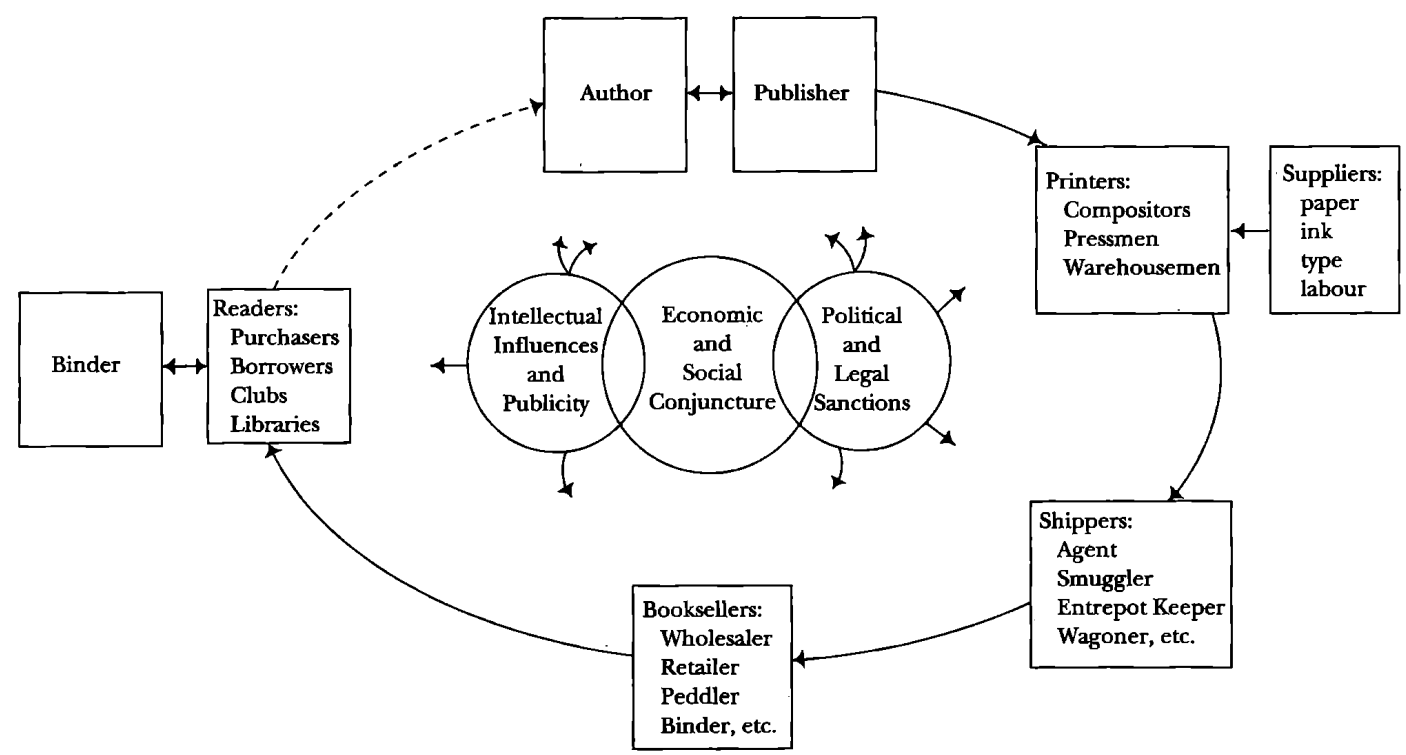

Abb. 3: Darntons Kommunikationskreislauf.

writing to printed characters and back to though again. ${ }^{\text {"7 }}$ Der soziale, ökonomische, politische und intellektuelle Kontext nimmt auf sämtliche Positionen und Aktionen im Kreislauf Einfluss.

Darntons Ansinnen, den Kreislauf der Buchproduktion als Ganzes zu betrachten und die einzelnen Teile in Bezug zueinander zu analysieren, um die Rolle des Buches als Mediator in einem Kommunikationsgefüge zu verstehen, eröffnet neue Zugänge für das Studium von Gesellschaften. Problematisch dabei ist jedoch, dass in diesem Modell der Text, also der Inhalt des Buches, irrelevant scheint. Mit der Ausblendung des Buches als Träger von Kultur und Diskursen geht eine zentrale Funktion des Buches verloren.

Howsams Ansatz ist da ganzheitlicher, wenn sie das Buch als „simultaneously a written text, a material object, and a cultural transaction " ${ }^{* 8}$ bezeichnet. Auch Benedict Anderson weist in Imagined Communities darauf hin, dass Menschen, die dieselben Texte zur ungefähr gleichen Zeit lesen, sich als Gemeinschaft

7 Ebd.

8 Howsam: Old Books and New Histories, S. vii. 
konstituieren, ohne sich dabei persönlich zu kennen. Der Buchhandel ist für Anderson ein „stiller Bazar“" der Produzenten mit Konsumenten des Geschriebenen verbinden und damit Identität hervorrufen kann.

Der Literaturwissenschaftler Peter D. McDonald bringt eine weitere Sichtweise auf das Buch in die Diskussion ein, indem er nach dem soziopolitischen Raum der Literaturproduktion fragt. McDonald schlägt vor, Bourdieus Theorie des literarischen Feldes mit Darntons Konzept des Kommunikationskreislaufes zu verbinden. McDonald kritisiert an Darntons Modell des Kreislaufes, dass die Agenten nur in ihrer Funktion in der materiellen Produktion erscheinen. Damit zeige das Modell sich blind gegenüber anderen Organisationsformen von literarischer Kultur. Er weist darauf hin, dass die Position eines Akteurs nicht nur horizontal anhand seiner Funktion im Kreislauf zu erfassen sei, sondern auch vertikal in Bezug auf seinen Status. ${ }^{10}$

Mit Bourdieus Feldtheorie liegt ein Modell vor, das unsichtbare Strukturen und Relationen erkennbar macht. ${ }^{11}$ Der Begriff des Feldes überwindet den methodologischen Individualismus; das Feld kann sich nur durch die Handlungen der Akteure reproduzieren. Felder sind, so Bourdieu, begrenzt, Zusammenhänge zwischen verschiedenen Feldern sind zwar vorhanden, das Konzept zwingt jedoch, nach den Grenzen wie auch nach den Gemeinsamkeiten einzelner Felder zu fragen.

So stellt auch das literarische Feld einen sozialen Mikrokosmos mit eigenen Strukturen und Gesetzen dar. Die Verbindung zur Außenwelt ist vorhanden, da das literarische Feld von sozialen, wirtschaftlichen, politischen und technologischen Verhältnissen beeinflusst wird. ${ }^{12}$

McDonald schlägt daher eine Erweiterung von Darntons Kommunikationskreislauf durch die Integration von Bourdieus Theorie des Feldes vor.

9 Benedict Anderson: Imagined Communities. Reflections on the Origin and Spread of Nationalism [1983]. London: Verso 2006, S. 77.

10 Vgl. Peter D. McDonald: British Literary Culture and Publishing Practice 1880-1914. Cambridge: Cambridge UP 1997, S. 11-12.

11 Vgl. Joseph Jurt: Die Theorie des literarischen Feldes von Pierre Bourdieu. In: LiTheS. Zeitschrift für Literatur- und Theatersoziologie 1 (2008), S. 5-14, hier S. 8.

12 Zum literarischen Feld vgl. Pierre Bourdieu: Die Regeln der Kunst. Genese und Struktur des literarischen Feldes, aus d. Franz. v. Bernd Schwibs / Achim Russer. Frankfurt am Main: Suhrkamp 2001. 
When rightly conceived, then, the communication circuit should be read both as a map of tangible process of material production and distribution, as Darnton's analysis insists, and as an index of the more elusive process which Bourdieu calls, symbolic production. ${ }^{13}$

Damit schlägt er eine Analyse von Büchern in ihrem Kontext vor, das heißt, der Fokus liegt weder alleinig auf dem Text noch ausschließlich auf dem Autor, gefragt wird nach den Umständen der Entstehung. Die Partizipation des Verfassers in einem Netzwerk bedeutet, dass ein Werk unter bestimmten Voraussetzungen und Einflüssen entstanden ist, die im Text entweder bejaht oder abgelehnt werden, die aber immer in die Struktur des Feldes eingebettet sind. Da diese Strukturen von dem spezifischen Charakter von Ort und Zeit geprägt sind, ist Schreiben ein Teil der Sozialgeschichte. ${ }^{14}$

Für McDonald hat das wichtige methodologische Konsequenzen:

Given that texts are radically situated, for Bourdieu, as material forms with a specific status in the field, the first task of any literary analysis is not to interpret their meaning, but to reconstruct their predicament. Initially, this might involve tracing the text's journey through Darnton's circuit. ${ }^{15}$

McDonalds Konzept, das Darntons Konzept aus literaturwissenschaftlicher Perspektive weiterdenkt, ist nicht nur für die Literaturwissenschaft relevant: Für die vorliegende Untersuchung sind diese Überlegungen anregend und sie ermöglichen zudem eine vertiefende Analyse.

Das Buch, darauf wurde bereits hingewiesen, nahm eine zentrale Stellung in Schockens Leben ein. Versteht man das Buch nun als Akteur in dem Kommunikationskreislauf eines spezifischen sozialen Feldes, kann die Rolle Schockens in eben jenem Feld genauer gefasst werden. Legt man als Folie Darntons Kreislauf mitsamt seinen Funktionen zugrunde, wird deutlich, dass Schocken mehrere davon einnimmt: Er ist Verleger, nimmt gleichzeitig starken Einfluss auf die Ausgestaltung des Buches, hat ein eigenes Vertriebsnetzwerk und ist gleichzeitig Leser. Zudem nimmt er durch seine führende gesellschaftliche und

13 McDonald: British Literary Culture and Publishing Practice 1880-1914, S. 11-12.

14 Vgl. ebd., S. 12.

15 Ebd., S. 13. 
wirtschaftliche Stellung Einfluss auf einige Rahmenbedingungen. Das Feld, das hier in den Blick genommen werden soll, ist nicht im Bourdieu'schen Sinne das literarische, sondern es integriert deutsche, jüdische, zionistische, intellektuelle, literarische und wissenschaftliche Einflüsse. Diese werden im Folgenden Thema und als Feld der deutsch-jüdischen Geistesarbeit beschrieben wie analysiert.

\subsection{Zionistische Initiativen und Ambitionen - die Förderung jüdischer Literatur vor der Verlagsgründung}

Die Suche nach der Identität und dem Wesen des Judentums trieb Schocken zeitlebens an. Ihm zufolge war dessen Erneuerung nötig, die nur durch einen ,Rückbezug auf die Quellen' erfolgen könne. Schocken erwähnt an verschiedenen Stellen, dass die Quellen des Judentums in dessen Texten zu finden seien. So erstaunt es nicht, dass seine erste zionistische Initiative im Dienste des jüdischen Buches und der jüdischen Texte stand. Das geschah, bevor er als Experte für wirtschaftliche Fragen zu Rate gezogen wurde. In einer Rede im März 1937 äußerte er sich zu seinem Antrieb:

Lange, bevor ich Zionist wurde, begann ich, das hebräische Buch zu sammeln. Damals - ganz einfach gesagt - war es der Wunsch, die wichtigsten Elemente unserer Literatur in wichtigsten Exemplaren in unserem Haus zu haben [...]. ${ }^{16}$

Damit nimmt er Bezug auf den Beginn seiner bedeutenden Privatbibliothek, die Ariel Hirschfeld als „eine Art jüdisches Bewusstsein “17 bezeichnete. Es waren Bücher, die Salman Schocken das Judentum von Neuem zugänglich machten, daher war er überzeugt, dass dies auch für andere assimilierte Juden möglich sein sollte.

Traditionell lebende wie auch zionistisch orientierte Juden beklagten seit Ausgang des 19. Jahrhunderts, dass die Juden Deutschlands im Laufe der Assimilation zusehends den Bezug zur jüdischen Tradition verlören. Der Verlust von jüdischer Bildung führe dazu, dass die Überlieferung der Tradition

16 Rede des Herrn Salman Schocken beim Empfang für Erich Mendelsohn am 15.03.1937 in der Schocken-Bibliothek, Typoskript. SchA, Privates, 803/82.

17 Ariel Hirschfeld: Schocken und Agnon. In: Schreuder / Weber (Hrsg.): Der Schocken-Verlag/ Berlin, S. 191-200, hier S. 193. 
abzubrechen drohe. ${ }^{18}$ Gershom Scholem beschrieb dies in seiner Autobiogra-

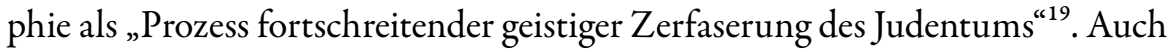
für Schocken war das Problem der jüdischen Existenz in Deutschland in höherem Maße ein kulturell-gesellschaftliches als ein politisches. ${ }^{20}$ Die Lösung dieses Problems lag für ihn in der Bereitstellung von jüdischen Texten - durch jüdische Literatur, Poesie und Geschichte sollte eine Brücke zur Tradition geschlagen werden.

Bücher - und Bücher jüdischer Autor*innen im Besonderen - standen Mittelpunkt von Schockens Interesse, das sich in seiner Bibliothek und seinen späteren Verlagshäusern in Berlin, Jerusalem / Tel Aviv und New York niederschlug. Aber bereits Jahre zuvor begann er Bücher herzustellen und zu vertreiben. Auch unterstützte er Schriftsteller*innen und Wissenschaftler*innen. Im Dienste des Zionismus und in seinem eigenen Interesse, Kultur nicht nur zu fördern, sondern auch weiterzuentwickeln, lancierte er eine Reihe von Initiativen zur Förderung jüdischer Publikationen.

Kurt Blumenfeld erinnerte sich daran, dass Schocken das Fehlen einer zionistischen Literatur beanstandete. „Warum gibt es keine zionistische Literatur?“, fragte Schocken.

Wenn ich [Blumenfeld] entgegenhielt, dass eine Bewegung wie die zionistische entscheidend durch das Lebensmäßige ausgedrückt wird, widersprach er. ,Am Anfang der sozialistischen Bewegung stand ,Das Kapital'. Am Anfang der Französischen Revolution stehen die Enzyklopädisten. Ich [Schocken] kann nicht begreifen, dass eine jüdische Bewegung nur von ein paar Broschüren eingeleitet und begleitet sein kann. Ich sehe darin ein Armutszeugnis. ${ }^{21}$

Entsprechend wählte Schocken für seinen Redebeitrag auf dem außerordentlichen Delegiertentag der ZVfD am 25. und 26. Dezember 1916 als Thema

18 Vgl. Klaus S. Davidowicz: Rückführung zum Judentum. In: Schreuder/ Weber (Hrsg.): Der Schocken-Verlag/Berlin, S. 115-128, hier S. 115.

19 Gershom Scholem: Von Berlin nach Jerusalem. Jugenderinnerungen. Frankfurt am Main: Suhrkamp 1978, S.38.

20 Vgl. Schocken: Salman Schocken, S. 21.

21 Blumenfeld: Erlebte Judenfrage, S. 97. 
die jüdische Kultur, Literatur und Wissenschaft. Er prangerte das Fehlen einer „jüdischen Wissenschaft ${ }^{\text {“22 }}$ sowie fehlende Publikationsmöglichkeiten an.

Es fehlt uns am notwendigsten. Wir haben keine arbeitende Wissenschaft und keine Bücher. [...] Es wird eine Publikationsgesellschaft gegründet werden müssen, deren Aufgabe es sein wird, die jüdische wissenschaftliche Arbeit anzuregen und zu bezahlen; die Herausgabe wissenschaftlicher Werke mit Geldbeiträgen zu fördern und Bücher in eigenem Verlag herauszubringen, deren Herausgabe auf geschäftlicher Basis wegen der geringen Aussicht auf den wirtschaftlichen Erfolg sonst nicht erfolgen würde. ${ }^{23}$

Schocken ließ dieser Fundamentalkritik Taten folgen, indem er begann, gezielt jüdische Schriftsteller zu fördern, und ideell wie finanziell die Publikationen zionistisch orientierter Autoren zu unterstützen.

Bereits zwei Jahre zuvor verteilte er am zionistischen Delegiertentag in Leipzig an alle Teilnehmer eine Ausgabe der Kongressreden Herzls. Damit verlieh er nicht nur seinem Anliegen, zionistische Literatur zu publizieren, Nachdruck, sondern machte auch wirkungsvoll auf seine Person aufmerksam. In

22 Trotz seiner expliziten Aufforderung, jüdische Wissenschaft zu fördern, konnte er sich nicht entschließen, in der Akademie für die Wissenschaft des Judentums mitzuarbeiten. Er nahm als Leiter des Kulturausschusses am Gründungstreffen teil, betätigte sich dann aber nicht weiter. Die Gründe dafür können nur vermutet werden. Es ist möglich, dass er seinen Einfluss als nicht groß genug einschätzte, oder aber es waren persönliche Animositäten, die ihn zur Zurückhaltung drängten. Erst 1929 bekundetet Schocken Interesse an einer Zusammenarbeit zwischen der Akademie und seinem damals in Planung befindlichen Verlagshaus. Vgl. Besprechungsprotokoll zwischen Salman Schocken und Vertreter der Hochschule für die Wissenschaft des Judentums, 03.12.1929. SchA, Privates, 881/35. Erst ab 1935 wurden dann aber Bestände des von der Akademie gegründeten Verlages übernommen. Vgl. Irene AueBen-David: Deutsch-jüdische Geschichtsschreibung im 20. Jabrbundert. Zu Werk und Rezeption von Selma Stern. Göttingen: Vandenhoeck \& Ruprecht 2017, S. 137-138. Zur Geschichte der Akademie liegen bisher kaum Veröffentlichungen vor, zu nennen ist jedoch ein Artikel zum zehnjährigen Bestehen: Julius Guttmann: Jüdische Wissenschaft. Die Akademie für die Wissenschaft des Judentums. In: Der Jude. Eine Monatsschrift 7,7-8 (1923), S. 489-493. Eine Darstellung der Geschichte der Wissenschaft vom Judentum von 19. bis ins 20. Jahrhundert findet sich in Kap. 9: „Jewish Scholarship and Jewish Identity: Their Historical Relationship in Modern Germany". In: Michael A. Meyer: Judaism Within Modernity. Essays on Jewish History and Religion. Detroit: Wayne State UP 2001, S. 127-143.

23 Salman Schocken: Schockens Referat. In: Jüdische Rundschau, 05.01.1917, S. 3. 
EEHRTE Kongreßmitglieder! Als einem der Einberufer

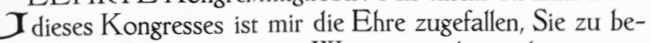
grüßen. Ich will es mit wenigen Worten tun, denn jeder von uns dient der Sache gut, wenn er mit den kostbaren Minuten des Kongresses spart. In drei Tagen haben wir viel Wichtiges zu besorgen. Wir wollen den Grundstein legen zu dem Haus, das dereinst die jüdische Nation beherbergen wird. Die Sache ist so groß, daß wir nur in den einfachsten Worten von ihr sprechen sollen. Soweit es sich jetzt schon beurteilen läßt, wird in diesen dreiTagen eine Übersicht über den gegenwärtigen Stand der Juden= frage geliefert werden. Der gewaltige Stoff gliedert sich unter der Hand unserer Referenten.

W IR werden Berichte hören über die Lage der Juden in den einzelnen Ländern. Sie alle wissen, wenn auch vielleicht nur in einer unbestimmten Weise, daß diese Lage mit wenigen Ausnahmen eine nicht erfreuliche ist. Wir fänden uns wohl kaum zusammen, wenn es anders wäre. Die Gerneinsamkeit unserer Geschicke hat eine lange Unterbrechung erlitten, obwohl die versprengten Teile des jüdischen Volkes allenthalben Ähn= liches erdulden mußten. Erst in unserer Zeit ist durch die neuen Wunder des Verkehrs die Möglichkeit einer Verständigung und Verbindung der Getrennten gegeben. Und in dieser Zeit, die sonst so hoch ist, sehen, fühlen wir uns überall vom alten Haß umgeben. Antisemitismus ist der Ihnen nur zu wohlbekannte moderne Name der Bewegung. Der erste Eind́ruck, den die

Abb.4: Theodor Herzl: Sechs Kongressreden Leipzig: Drugulin 1914.

zahlreichen persönlichen Erinnerungen an Salman Schocken fand diese Aktion Erwähnung. Man muss sich dabei bewusst sein, dass Schocken, der zu dieser Zeit im Vergleich zu anderen auf eine erst kurze zionistische Betätigung zurückschauen konnte, bereits mit zwei Publikationen auf sich aufmerksam machte mit seiner Maccabäerrede und der eben erwähnten Ausgabe der Herzl'schen Kongressreden. ${ }^{24}$

Schocken ließ die sechs Reden Herzls in Leipzig bei der Offizin Drugulin ${ }^{25}$ in 400 Exemplaren drucken. Es war „das erste zionistische Buch, das den höchsten

24 Vgl. ebd.

$25 \mathrm{Zu}$ Drugulin vgl. Anm. 87 in diesem Kap. 
künstlerischen Ansprüchen der modernen Drucktechnik genügte “26, so Blumenfeld. Schocken legte nicht nur besonderen Wert auf den Inhalt, sondern auch auf die äußere Form von Büchern und Drucksachen. ${ }^{27}$

Ebenfalls im Jahr 1914 begann Schocken mit der Förderung des Schriftstellers und späteren Nobelpreisträgers Samuel Joseph Agnon, geborener Samuel Joseph Czaczkes, ${ }^{28}$ und verlieh damit seiner Forderung nach moderner hebräischer Literatur Nachdruck. Die Beziehung zwischen Schocken und Agnon ${ }^{29}$ blieb über Jahrzehnte bestehen und der Briefwechsel zwischen den so unterschiedlichen Männern, die durch das tiefe Interesse am jüdischen Buch verbunden waren, ist Zeugnis einer intensiven Freundschaft. ${ }^{30}$ Der erste Kontakt kam über die mit dem ZVfD verbundene Organisation Tchija zustande, die notleidenden jüdischen Schriftstellern Honorare im Voraus gewährte; Agnon war einer dieser Autoren. Agnon, der 1888 in Ostgalizien geboren wurde, lebte von 1907 bis 1913 in Palästina, migrierte aber ein Jahr vor Beginn des Ersten Weltkrieges verarmt nach Deutschland, wo er sich mit Auftragsarbeiten für den Jüdischen Verlag $^{31}$ und durch Privatunterricht zu finanzieren versuchte.

Ab Beginn des Jahres 1916 standen Schocken und Agnon in direktem Kontakt. Die finanzielle Unterstützung, die ein monatliches Stipendium von 150 RM vorsah, wurde in Form eines Verlagsvertrages geregelt, ohne dass Schocken zu dieser Zeit einen Verlag besessen hätte. Der Vertrag wurde über fünf Jahre

26 Blumenfeld: Erlebte Judenfrage, S. 93.

27 Vgl. Mahrer: Tradition and Modernity.

28 Für die erste Veröffentlichung in Palästina (Agunot, 1908) wählte Czaczkes den Namen Agnon, den er zunächst nur als Künstlernamen, später auch als Familiennamen führte. Im Folgenden wird abgesehen von Originalzitaten der Name Agnon verwendet.

29 Zur Beziehung zwischen Agnon und Schocken vgl. u. a. Hirschfeld: Schocken und Agnon; Dahm: Das jüdische Buch im Dritten Reich, S. 269-273.

30 Der Briefwechsel wurde in Auszügen in hebräischer Sprache publiziert: Shmuel Yosef Agnon / Salman Schocken: ש"י עגנון - ש"ז שוקן: חילופי עגרות (תרש"ו - תש"ט)] [S.J. Agnon Sch.Z. Schocken: Briefwechsel (1916-1958)]. Jerusalem: Schocken 1991.

Die Originale werden im Schocken Archiv verwahrt, sind dort aber nicht zugänglich. Der größte Teil davon liegt im Archiv der Nationalbibliothek in Jerusalem als Kopie. In dieser Untersuchung wird, weil auf die Originale nicht zurückgegriffen werden konnte, mit den Kopien gearbeitet. Diese haben gegenüber der Publikation den Vorteil, dass sie in der deutschen Originalsprache, ausgenommen die hebräischen Briefe von Agnon an Schocken, und vollständiger sind.

31 Zur Geschichte des Jüdischen Verlages vgl. Anatol Schenker: Der jüdische Verlag 1902-1938. Zwischen Aufbruch, Blüte und Vernichtung. Tübingen: Niemeyer 2003, S. 351. 
abgeschlossen und enthielt für Agnon die Verpflichtung, dass er „im Laufe von fünf Jahren ein druckfertiges Manuskript, das etwa 50 Druckbogen stark ist, zu liefern [habe] von dem besprochenen Buche ,Vom Juden ““32 Schocken erwarb laut Vertrag das Recht an der hebräischen Ausgabe (bis 3.000 Exemplare) sowie die Übersetzungsrechte für „Deutsch, Englisch, Russisch und Jüdisch [sic]“. 33 Das Jahr 1916 scheint in der Biographie Schockens als Markstein auf: Der Beginn der langfristigen Förderung Agnons war nur ein Teil der systematische Züge annehmenden Unterstützung jüdischer Geistes- und Kulturarbeit. Anfang Februar desselben Jahres schloss Schocken einen Vertrag mit dem Verlag Richard Löwit zur Übernahme der von Martin Buber gegründeten Zeitschrift Der Jude und am Ende des Jahres initiierte er auf dem Delegiertentag der ZVfD in Berlin den Jüdischen Kulturausschuss. Vor allem die letzten beiden kulturzionistischen Unternehmungen sollten nicht nur für Schockens Biographie bedeutsam sein, sondern auch der jüdischen Kulturarbeit in Deutschland wichtige Impulse geben.

\subsubsection{Die Zeitschrift Der Jude -}

\section{erste Zusammenarbeit mit Martin Buber}

Martin Buber hatte sowohl bei Der Jude ${ }^{34}$ wie auch im Kulturausschuss Schlüsselpositionen inne. Die gemeinsame Arbeit im Dienste einer Wiederbelebung der jüdischen Kultur brachte die beiden unterschiedlichen Männer zusammen. Der Jahrzehnte währende Briefwechsel ${ }^{35}$ zwischen den fast gleich alten Männern gibt einen detaillierten Einblick in die enge Zusammenarbeit, die zuweilen in eine private Freundschaft überging. Schocken war dabei oftmals ein säumiger Korrespondenzpartner, was die Beziehung und Zusammenarbeit zwischen den zweien mitunter auf eine harte Probe stellte. „Unser Briefwechsel“, so Buber an Schocken im April 1918, „hat in den letzten Monaten die Form angenommen, dass meine Mitteilungen und Anfragen sich bei Ihnen ansammeln und

32 Salman Schocken an S.J. Czaczkes, 06.03.1916. NLI, Agnon Archiv, Arc. 4, 1270, Bd. 3.

33 Ebd.

34 Zur Geschichte der Zeitschrift vgl. Eleonore Lappin: Der Jude 1916-1928. Jüdische Moderne zwischen Universalismus und Partikularismus. Tübingen: Mohr Siebeck 2000.

35 Der Briefwechsel liegt zu einem Teil im Archiv der israelischen Nationalbibliothek im Nachlass von Martin Buber, zum anderen im Schocken Archiv, dort ist er über mehrere Bestände zerstreut. 
dann alle paar Wochen einmal von Ihnen zusammenfassend beantwortet werden. ${ }^{136}$ Schocken war sich dieser Schwäche durchaus bewusst, viele seiner Briefe beginnen mit einer Entschuldigung für seine schlechte Schreibmoral. So vermerkte er am Ende seines Lebens in einem Brief: „Ich war und bin von jeher ein schlechter Briefschreiber. ${ }^{437}$ Trotz zeitweiliger Trübung des Verhältnisses zwischen Buber und Schocken war die Zusammenarbeit ab 1916 für einige Jahre sehr intensiv und in einigen Phasen kann man aus den Briefen Ansätze von persönlicher Freundschaft zwischen dem Religionsphilosophen und dem Kaufmann herauslesen.

Der im Buber-Archiv der Jerusalemer Nationalbibliothek liegende Briefwechsel zeigt, wie sich der Kontakt zwischen den beiden nach Schockens Einstieg in das Leitungsgremium des Juden intensivierte. Vor Februar 1916 liegt nur eine Handvoll Briefe vor, nachdem sich Schocken aber endgültig zur finanziellen Beteiligung und aktiven Mitarbeit bei der Herausgabe der Zeitschrift entschloss, stieg die Zahl abrupt an. Schocken erklärte sich bereits im Sommer 1914 bereit, einen größeren Betrag für den Gründungsfonds zu zeichnen. Buber bestand aber darauf, dass die Arbeit erst aufgenommen werden konnte, wenn ein Betrag von mindestens 20.000 RM zur Verfügung stünde, damit verzögerte sich der Arbeitsbeginn um zwei Jahre. ${ }^{38}$

Die Idee einer jüdischen Zeitschrift stammte ursprünglich aus der frühen Phase des Jüdischen Verlages. Chaim Weizmann und Buber schwebte die Gründung einer Zeitschrift zur Verbreitung der Ideen der ,Demokratischen Fraktion' vor. Diese Fraktion wurde 1901 als erste Oppositionsgruppe innerhalb der Zionistischen Weltorganisation gegen den rein politischen Zionismus gegründet. Die Demokratische Fraktion setzte sich über landsmannschaftliche Grenzen hinweg und vereinigte Vertreter aus Osteuropa mit jenen aus Deutschland. Die Fraktion stellte 37 der 287 Delegierten des 5. Zionistenkongresses, der vom 26. bis 30. Dezember 1901 in Basel tagte. Unter den Delegierten für die Demokratische Fraktion waren Chaim Weizmann, Martin Buber, Berthold Feiwel,

36 Martin Buber an Salman Schocken, 12.04.1916. NLI, Buber Archiv, Ms. Var. 350/705I.

37 Salman Schocken an S.J. Agnon, 03.04.1959. NLI, Agnon Archiv, Arc 41270.

38 Bubers Bedenken, die Zeitschrift ohne ausreichende finanzielle Mittel zu gründen, geht auf seine Erfahrungen als Verleger im Jüdischen Verlag zurück, der ohne die erforderlichen Mittel gegründet wurde und dadurch immer wieder gefährdet war. Vgl. Schenker: Der jüdische Verlag 1902-1938. 
Leo Motzkin, Davis Trietsch und Ephraim Moses Lilien. Diese Gruppe wollte verhindern, dass die Kulturfrage an den Rand gedrängt wurde und forderte erfolgreich eine Kulturkommission. Buber und Weizmann, Mitglieder dieser neu gegründeten Kulturkommission, stellten sofort eine Reihe von Forderungen auf wie u. a. die Gründung einer Nationalbibliothek in Jerusalem, ${ }^{39}$ einer jüdischen Hochschule $^{40}$ sowie von Kulturkommissionen in den Landesverbänden. Buber forderte zudem ein Darlehen für den Jüdischen Verlag, den er kurz vor dem Kongress gemeinsam mit Berthold Feiwel, E. M. Lilien, Leo Motzkin, Alfred Nossing, Davis Trietsch und Chaim Weizmann gegründet hatte. Der Kongress billigte sämtliche Forderungen mit Ausnahme des Kredites für den Verlag. ${ }^{41}$ Während sich Weizmann hauptsächlich um die Vorbereitungen zur Gründung einer jüdischen Hochschule kümmerte, engagierte sich Buber für den Jüdischen Verlag. Die Herausgabe einer Zeitschrift als Hausorgan der Demokratischen Fraktion war erklärtes Ziel. Finanzielle Schwierigkeiten, aber auch persönliche Spannungen zwischen den Initianten verhinderten jedoch vorerst das Erscheinen der Zeitschrift. ${ }^{42}$ Schlussendlich scheiterte die Demokratische Fraktion und mit ihr das Hochschul- und Zeitschriftenprojekt. Auch verschiedenen Wiederbelebungsversuchen war in den folgenden Jahren kein Erfolg beschert.

Interessanterweise deckten sich sämtliche Forderungen der Demokratischen Fraktion - die Forderungen nach einer Kulturkommission in den Landesverbänden, einem Verlag für Bücher jüdischer Autorinnen und Autoren, einer Zeitschrift und nach einer jüdischen Hochschule - mit den späteren Interessensund Wirkungsgebieten Salman Schockens, auch wenn er erst gute zehn Jahre später selbst zionistisch aktiv wurde. Viele der Mitglieder der Demokratischen Fraktion spielten in Schockens späterem Leben zudem eine wichtige Rolle. Ein Jahrzehnt nach dem Scheitern des ersten Versuches, eine zionistisch orientierte Zeitschrift zu gründen, wurde 1914 das ursprüngliche Konzept gleich von zwei Gruppen wiederaufgenommen: von einer Gruppe junger Prager um

39 Die heutige Israelische Nationalbibliothek wurde 1925 als Jüdische National- und Universitätsbibliothek gegründet. Vgl. Jacob Barnai: Jüdische National- und Universitätsbibliothek. In: Enzyklopädie jüdischer Geschichte und Kultur (EJGK), Bd.3, hrsg. v. Dan Diner. Stuttgart / Weimar: Metzler 2012, S.249-251.

40 Vgl. dazu auch weiter unten Kap. 8.1.

41 Vgl. Lappin: Der Jude 1916-1928, S. 10-11.

42 Vgl. ebd., S. 14-16. 
Leo Herrmann ${ }^{43}$ (mit der Unterstützung von Martin Buber) und von einer Gruppe junger deutscher Zionisten unter Victor Jacobsohn, einem Mitglied des neugewählten ,Engeren Actions-Comités' der zionistischen Exekutive. Nach Wochen der Konkurrenz beschlossen die Akteure 1914, ihre Kräfte zu bündeln und fusionierten. ${ }^{44}$

Im Juni 1914 wurde ein erstes Rundschreiben verschickt, das auch an Salman Schocken ging. Die Verfasser des Schreibens, Leo Herrmann, Felix Rosenblüth und Martin Buber, formulierten darin die Leitlinien der Zeitschrift und baten um Werbung. ${ }^{45}$

Unsere Zeitschrift soll, von zionistischem Geist getragen, alle Äußerungen des jüdischen Lebens unserer Tage in gründlicher, nicht von einseitigen Parteirücksichten gefesselter Form behandeln. Sie wird in umfassender und objektiver Weise die vielen Probleme des jüdischen Lebens behandeln und darstellen. Aber diese Darstellung soll aus der Erkenntnis heraus dem Zukunftswillen unseres jüdischen Volkes dienen. Wir wollen nicht nur das Gewesene und das Gewordene darstellen, wir wollen auch zum neuen Werden den Weg weisen und die Kräfte stärken. [...] So soll die Zeitschrift aussehen, die wir Der Jude nennen wollen, und die monatlich erscheinen wird. ${ }^{46}$

Salman Schockens Reaktion war mehr als positiv, er zeigte sich bereit, 2.000 Mark für den Garantiefonds zu zeichnen und wollte als Mitherausgeber fungieren. ${ }^{47}$ Gerade vier Monate nach seinem ersten Brief an Buber empfahl sich Schocken damit einer Gruppe von bekannten und untereinander seit langer Zeit vernetzten Kulturzionisten als aktiver Herausgeber. Der Beginn des Ersten Weltkrieges zwanzig Tage nach Schockens Brief verhinderte die Gründung der Zeitschrift abermals. Das Interesse Schockens war zu diesem Zeitpunkt jedoch geweckt, sodass er etwas mehr als ein Jahr später - im Oktober 1915 - von sich aus den

43 Leo Herrmann war jener Journalist, auf den Schocken sich bezog, als er sich erstmals bei Martin Buber persönlich vorstellte.

44 Vgl. Lappin: Der Jude 1916-1928, S. 17-38.

45 Das Schreiben ist weder datiert noch unterschrieben. Anhand eines Sitzungsprotokolls vom 07.05.1914 (Central Zionist Archives, Z3/1128) erkennt Anatol Schenker als Verfasser Hermann, Rosenblüth und Buber als Editoren. Vgl. Schenker: Der jüdische Verlag 1902-1938, S.201, Anm. 310.

46 Rundschreiben, o. D. CZA, Z3/1128.

47 Vgl. Salman Schocken an das Zentralbüro der Exekutive, 08.07.1914. CZA, Z3/1128. 
Versuch unternahm, finanzielle Mittel für Der Jude aufzubringen. Der Krieg war dabei ein großes Hindernis; viele der angefragten Persönlichkeiten konnten keine oder nur sehr beschränkte Mittel beitragen. ${ }^{48}$ Salman Schocken zählte zu diesem Zeitpunkt neben Martin Buber und Victor Jacobsohn zum vorbereitenden Komitee. Da sich abzeichnete, dass es während des Krieges dem Komitee nicht gelingen würde, das nötige Kapital von 20.000 Mark aufzubringen, wurde die Zusammenarbeit mit einem Verlag, der zu einer maßgeblichen Eigenbeteiligung bereit wäre, als notwendige Bedingung der Herausgabe der Zeitschrift angesehen. Der Jüdische Verlag kam dafür nicht in Frage, da man verhindern wollte, „dass die Revue in eine offizielle Verbindung mit dem A.C. [Action Comites] gerät. “49

Es war schließlich Salman Schocken, der nach langwierigen und teilweise unerfreulichen Verhandlungen mit dem Wiener Verlag Richard Löwit am 15. Februar 1916 den Vertrag unterzeichnete. Das Betriebskapital von 30.000 Mark wurde hälftig von beiden Partnern aufgebracht. ${ }^{50}$ Damit wurde Salman Schocken zu einem Hauptakteur im Feld der kulturzionistischen Szene.

Schockens Rolle innerhalb des Herausgeberkreises ist paradigmatisch für seine zukünftige Position im Netzwerk des (Kultur-)Zionismus. Während andere die intellektuelle Arbeit und das Tagesgeschäft übernahmen, kam ihm die Rolle des Initiators und Organisators zu. Die finanzielle Beteiligung war dabei ebenso wichtig wie sein wirtschaftliches Denken, das im kaufmännischen Leben geschulte Verhandlungsgeschick sowie seine Hartnäckigkeit. Die Struktur des Schocken-Konzerns war dabei ein wichtiger Faktor, da vor allem in Krisenzeiten dessen gut funktionierender Verwaltungs-, Einkaufs- und Logistikapparat eine gewisse Stabilität garantierte. Die beschriebene Aufgabenteilung darf aber nicht darüber hinwegtäuschen, dass Schocken - geleitet durch seinen Wunsch, das Judentum durch Rückbesinnung auf dessen kulturelle und literarische Traditionen zu erneuern, - Anspruch auf Mitsprache bei inhaltlichen

48 Vgl. SchA, Jüdisches und Zionistisches, 539/811-814. Wenig bekannt ist, dass auch Salmans Bruder Simon Schocken sich finanziell an den Anfängen der Zeitschrift Der Jude beteiligte. Er steuerte 1.000 Mark bei. Vgl. Julius Berger an Julius Simon, 15.11.1915. CZA, Z3/1129.

49 Victor Jacobsohn an Elias Straus, 22.10.1915. CZA, 3/1129.

50 Vgl. Schenker: Der jüdische Verlag 1902-1938, S. 203-204. 
und ideologischen Fragen erhob. Schocken nahm dadurch mehrere Funktionen ein - eine Tatsache, die enormes Konfliktpotential in sich trug. Dass Schocken seit seinem Einstieg in die Herausgebergruppe von Der Jude eine wichtige Rolle spielte, wird schnell deutlich. Knappe drei Monate bevor das Abkommen zwischen der Zeitschrift und dem Löwit Verlag zustande kam, schloss er einen ersten Vertrag mit Martin Buber ab. Buber wollte zwar noch im Oktober 1915 die Redaktion der Zeitschrift ohne Honorar übernehmen, denn er verstand seine Arbeitsleistung als seinen persönlichen Beitrag an der politischen Arbeit des Zionismus, ${ }^{51}$ aber bereits einen Monat später musste er sich eingestehen, dass seine finanzielle Situation dies nicht zuließ. Es war Salman Schocken, der aus seinem Privatvermögen 200 Mark an Buber bezahlte, die die vorbereitenden Kosten decken sollten. ${ }^{52}$ Als nach Abschluss des Vertrages mit Löwit die Herausgabe der Zeitschrift gesichert war, schloss Schocken einen Herausgebervertrag mit Martin Buber ab, der vorerst ein Jahr gelten sollte. Laut diesem Vertrag standen Buber als leitendem Redaktor monatlich dreihundert Mark Honorar sowie ein Betrag von fünfhundert Mark für die vorbereitenden Arbeiten zu. ${ }^{53}$ Bereits einen Tag später stimmte Buber den von Schocken genannten Bedingungen zu. ${ }^{54}$ Aus dem Vertrag wie auch aus Bubers Schreiben wird deutlich, dass das Honorar privat von Salman Schocken bezahlt wurde, Buber sich aber allen Herausgebern gegenüber verantwortlich zeigte.

Das erste Heft erschien im April 1916. Die überlieferte Korrespondenz zeigt, dass Schocken an dessen Vorbereitung stark beteiligt war. Während Buber von seinem Wohnort Heppenheim aus an den Artikeln arbeitete, waren Leo Herrmann, Julius Berger und Salman Schocken in Berlin mit den technischen Vorarbeiten beschäftigt. Schocken legte dabei besonderen Wert auf die Gestaltung der Hefte ${ }^{55}$ und auf die Qualität des Papiers. Dass Schocken beim Einkauf auf den Schocken-Konzern zurückgreifen konnte, erleichterte das schwierige

51 Vgl. Julius Berger an Julius Simon, 15.10.1915. CZA, Z3/1129; Lappin: Der Jude 1916-1928, S.35.

52 Vgl. Salman Schocken an Martin Buber, 27.11.1915. SchA, Verlag, 312

53 Vgl. Salman Schocken an Martin Buber, 14.02.1916. SchA, Verlag, 312.

54 Martin Buber an Salman Schocken, 15.02.1916. NLI, Buber Archiv, Ms. Var. 350008 $705 \mathrm{I}$.

55 So insistierte er auf typographischen Änderungen: Vgl. Martin Buber an Salman Schocken, 30.03.1916. NLI, Buber Archiv, Ms. Var. 350008 705I. 
Unterfangen, während des Krieges an gutes Papier zu kommen. ${ }^{56}$ Schocken trat auch als Lektor in Erscheinung, so redigierte er, wie aus einem weiteren Brief hervorgeht, gemeinsam mit Buber einen Artikel für das zweite Heft. ${ }^{57}$ Entgegen vieler Versprechungen veröffentlichte Schocken jedoch keinen eigenen Beitrag, dies sehr zum Bedauern und Ärger von Martin Buber, der fest mit einem Artikel rechnete und als Herausgeber über das andauernde Verschieben nicht erfreut war. Eine gewisse Unlust am Schreiben, sowie eine konstante Überbeanspruchung durch vielerlei Verpflichtungen, die sich wiederholt auch in längeren Erkrankungen und Kuraufenthalten bemerkbar machte, trugen wohl dazu bei, dass Schocken, abgesehen von kurzen Artikeln, Zeit seines Lebens kaum publizierte.

Schockens Engagement bei der Zeitschrift dauerte bis ins Jahr $1921 .^{58}$ Aus dem Briefwechsel mit Buber wird deutlich, dass er während der vier Jahre eine zentrale Rolle spielte: Er hatte Einfluss bei der Auswahl von Autoren und Artikeln und übernahm in der Regel die Verhandlungen mit Druckereien. Darüber hinaus übernahm er in Personalfragen Verantwortung. Die Arbeit für Der Jude ließ Buber bald an seine Grenze stoßen, sodass ein weiterer Mitarbeiter in der Redaktion eingestellt werden sollte. Nachdem Bubers Wunschkandidat Siegmund Kaznelson absagte, weil er zum Sekretär der österreichischen Kongressbewegung $^{59}$ gewählt wurde, suchte Buber bei Schocken Rat.

Einen Ersatz für ihn [Kaznelson] weiß ich nicht. Die Sache ist für mich von Bedeutung, da die Arbeit an der Zeitschrift durch die Menge des Einlaufs und der Anfragen aller Art immer aufreibender wird und ich nicht mehr weiß, wie ich ihr gerecht werden soll, ohne entweder meine Gesundheit oder meine schriftstellerische Produktion in Frage zu stellen. ${ }^{60}$

56 Vgl. u.a. Salman Schocken an Martin Buber, 11.03.1916. NLI, Buber Archiv, Ms. Var. 350 008705 .

57 Vgl. Martin Buber an Salman Schocken, 30.03.1916. NLI, Buber Archiv, Ms. Var. 350 008705 I.

58 Vgl. dazu genauer: Lappin: Der Jude 1916-1928, S. 62.

59 Zur österreichischen Kongressbewegung vgl. u. a. Sarah Panter: Jüdische Erfahrungen und Loyalitätskonflikte im Ersten Weltkrieg. Göttingen: Vandenhoeck \& Ruprecht 2014, S.296-301.

60 Martin Buber an Salman Schocken, 04.10.1917. NLI, Buber Archiv, Ms. Var. 350008 $705 \mathrm{I}$. 
Dass Schocken bei der Suche nach einer geeigneten Person für den Posten des ,Subredaktors, wie er von Buber genannt wurde, angefragt wurde, impliziert, dass Schocken nun Teil des Netzwerkes war. Sehr zum Leidwesen von Buber beantwortete Schocken aber genau in dieser Phase seine Briefe kaum. So blieb ein verzweifelter Brief vom 7. November 1917 ebenso unbeantwortet, wie die darauffolgenden, in denen Buber Abraham Robinsohn vorschlug. ${ }^{61}$ Schließlich wurde Helene Hanna Cohn eingestellt, die Buber fortan in der Redaktion unterstützte. ${ }^{62}$ Ende Februar 1920 übersiedelte Siegmund Kaznelson dann doch nach Berlin, um für die Zeitschrift zu arbeiten. ${ }^{63}$

Kurz zuvor kam es zu Spannungen zwischen Max Präger, dem Verleger des Verlages Richard Löwit, und den Herausgebern. Die anhaltend prekäre finanzielle Situation der Zeitschrift, inhaltliche Unstimmigkeiten und die Erweiterung der Redaktion um Kaznelson führten wohl zum Bruch zwischen Präger und der Zeitschrift. ${ }^{64}$ Es war Schocken, der die schwierigen Verhandlungen über den Ausstieg des Verlages aus dem Zeitschriftenprojekt führte. ${ }^{65}$ Zur gleichen Zeit wurde der Jüdische Verlag umstrukturiert und finanziell aufgestockt; damit war die Grundlage geschaffen, dass Der Jude fortan dort erscheinen konnte. ${ }^{66}$ Der anhaltende Streit mit Max Präger, der sich u. a. weigerte, die Adresskartei der Abonnenten dem Jüdischen Verlag zu übergeben, sowie ein großes finanzielles Defizit, das das Fortbestehen der Zeitschrift ernsthaft in Frage stellte, dauerte allerdings durch das Jahr 1920 an. Im Januar 1921 zogen sich schließlich auch die bisherigen Herausgeber zurück und übertrugen die Verantwortung alleinig dem Jüdischen Verlag. ${ }^{67}$ Mit dem Ausstieg des Herausgebergremiums kam auch Schockens Engagement für die Zeitschrift zu einem Ende.

61 Vgl. Briefe Martin Buber an Salman Schocken, 07.11.1917; 18.11.1917, beide in: NLI, Buber Archiv, Ms. Var. 350008 705I.

62 Vgl. Martin Buber an Salman Schocken, 10.12.1917. NLI, Buber Archiv, Ms. Var. 350008 $705 \mathrm{I}$.

63 Vgl. Schenker: Der jüdische Verlag 1902-1938, S. 211.

64 Vgl. ebd., S.210-211.

65 Vgl. Korrespondenz zwischen Salman Schocken, Julius Berger und Max Präger, Februar und März 1920. CZA, Z3/1136.

66 Vgl. Schenker: Der jüdische Verlag 1902-1938, S. 211; Lappin: Der Jude 1916-1928, S. 62-63.

67 Vgl. unsign. Dokument, Januar 1921. SchA, Jüdisches und Zionistisches, 539/85; Schenker: Der jüdische Verlag 1902-1938, S.213. 
Auch wenn Der Jude für Schocken finanziell gesehen kein Erfolg war und die ständige Finanzknappheit das regelmäßige Erscheinen der Zeitschrift verunmöglichte, war die Beteiligung an diesem Projekt aus anderer Perspektive ertragreich. Er verdeutlichte dabei den Wert seines im geschäftlichen Alltag geschulten Verhandlungsgeschickes sowie seiner Kontakte und Ressourcen im Rahmen kulturpolitischer Initiativen. Daneben konnte er in einer wichtigen kulturzionistischen Institution inhaltlich Einfluss nehmen und seinen Vorstellungen Ausdruck verschaffen. Salman Schockens Arbeit im und für Der Jude war ein wichtiger Schritt in der Verwirklichung seiner Vision der kulturellen Erneuerung des deutschen Judentums. Die Publikation der zwei Bände, seiner Maccabäerrede und der Reden Herzls hatten zwar einiges an Aufsehen erregt, um aber bei kulturzionistischen Fragen mitzureden und mitzugestalten, musste er Teil des diskursbestimmenden Netzwerkes werden. Durch die Mitarbeit in der Zeitschrift Der Jude wurde er dies.

\subsubsection{Schockens erste eigene Initiative - der Kulturausschuss der ZVfD}

Die zunehmend wichtige Rolle Schockens im Kulturzionismus und die damit einhergehende Vernetzung in diesem Feld ging jedoch nicht nur auf seine Beteiligung bei Der Jude zurück. 1916 war in einer dritten Hinsicht - neben dem eben dargestellten Einstieg in Bubers Zeitschrift und dem Vertrag mit Agnon ein zentrales Jahr für Schocken. Ende des Jahres gründete er den Kulturausschuss innerhalb der ZVfD und nahm damit eine der Forderungen auf, die die Demokratische Fraktion beim 5. Zionistenkongress in Basel 15 Jahre zuvor gestellt hatte: Eine Kulturkommission in allen Landesverbänden, wenn auch nur innerhalb Deutschlands.

Auf dem außerordentlichen Delegiertentag der ZVfD am 25. und 26. Dezember 1916 forderte Schocken in seinem Referat ${ }^{68}$ einen „Hauptausschuss für jüdische Kulturarbeit.“

Es fehlt uns am Notwendigsten. Wir haben keine arbeitende Wissenschaft und keine Bücher. Es besteht eine Wissenschaft vom Judentum in Deutschland, die von

68 Eine Auswahl der wichtigsten Referate des Delegiertentages wurde leicht gekürzt in der Jüdischen Rundschau veröffentlicht, so auch jenes von Schocken. Die folgenden Zitate stammen alle aus dieser Publikation. Schocken: Schockens Referat. 
liberalen Juden in der ersten Hälfte des 19. Jahrhunderts aufgebaut worden ist. [...] Aus inneren und äußeren Gründen besteht da nur ein spärliches Leben. Wir müssen daran gehen, eine neue jüdische Wissenschaft zu schaffen, die aus unserer Stellung heraus und aus unserem Geiste versucht, unsere Vergangenheit, unser Volkstum, unsere ganze Geisteswelt neu aufzubauen. Männer, die in unserer Bewegung stehen, müssen die Arbeit leisten, unsere Vergangenheit aus unseren Augen neu zu sehen und uns die Geschichte unseres Volkes neu zu erzählen. In den 30.000 Bänden der hebräischen Literatur ruhen unsere Schätze vergraben und unsere Arbeiter können wahrhafte Mekize Nirdamim (Erwecker der Schlummernden) sein, wenn sie die Goldadern wertvollen jüdischen Lebens aus den verschüttenden Büchern hervorholen.

Wiederum forderte er die Wiederbelebung des Judentums aus seinen Quellen, wie er es in der Maccabäerrede zwei Jahre zuvor schon getan hat. Die Schriften des Judentums seien die Goldadern, die es aufzuspüren und auszugraben gelte. Dazu müssten „Publikationsgesellschaften gegründet werden, deren Aufgabe es sein würde, die jüdische wissenschaftliche Arbeit wirtschaftlich zu stützen, wertvolle wissenschaftliche Arbeiten anzuregen und zu bezahlen. ${ }^{\text {“69 }}$ Damit soll auch die Unterstützung oder Gründung eines Verlages einhergehen, darüber hinaus die Herausgabe eines jährlichen literarischen Ratgebers, die Publikation populärwissenschaftlicher Texte und jüdischer Heldensagen für Kinder, die Förderung der hebräischen Sprache und Literatur durch die Herausgabe von Lehrbüchern, die Einrichtung von Vortrags-Zyklen und Seminaren, die Ausbildung von Hebräisch-Lehrern sowie die Bildung von akademischen Vereinigungen und Jugendverbänden. Die Liste von Forderungen war lang - zu lang, als dass sie je vollständig umgesetzt werden konnte. Aber die Gründung des Kulturausschusses wurde am 26. Dezember beschlossen und einen Tag später fand zwischen Salman Schocken, Martin Buber und Moses Calvary das erste Arbeitstreffen in Berlin statt. ${ }^{70}$

Unter der Leitung von Schocken bestand der Kulturausschuss, dem neben Buber und Calvary außerdem Kurt Blumenfeld, Max Brod und Hugo Bergmann angehörten, bis zum Jahre 1927. Misst man den Erfolg des Gremiums an

69 Schocken: Schockens Referat, S.3.

70 Zum Kulturausschuss vgl. auch Dominique Bourel: Martin Buber. Was es heisst, ein Mensch zu sein. Gütersloh: Gütersloher Verlagshaus 2017, S. 424. 
den Ende 1916 formulierten Zielen, scheint er dürftig. Es wurden während des zehnjährigen Bestehens lediglich acht Kinderbücher ${ }^{71}$, ein hebräisches Schulbuch $^{72}$, ein Band mit osteuropäischen Liedern ${ }^{73}$ und ein Werk der hebräischen Phraseologie ${ }^{74}$ fertigstellt respektive publiziert, wobei die Phraseologie lange Zeit ungebunden liegenblieb und erst 1932 bei dem Jerusalemer Verlag Rubin Mass erschien. ${ }^{75}$ Die Bedeutung des Ausschusses an der Menge an publizierten Büchern zu messen, würde jedoch zu kurz greifen, zumal das Gremium durch die schwierige wirtschaftliche und kommunikationstechnische Lage während des Krieges und in der Nachkriegszeit stark eingeschränkt war. Der vergleichsweise bescheidene Output schmälerte keineswegs den größten Erfolg des Ausschusses, dass er nämlich, um es mit Siegried Moses zu formulieren,

71 Jehuda Steinberg: Der Soldat des Zaren. Jüdische Jugendbücherei, Bd. 2. Berlin: Jüdischer Verlag 1920; C[heskel] Z[wi] Klötzel: In Saloniki. Jüdische Jugendbücherei, Bd. 6. Berlin: Jüdischer Verlag 1920; Bath Hillel: In Bene Berak - Und andere Erzählungen. Jüdische Jugendbücherei, Bd. 3. Berlin: Jüdischer Verlag 1920; Karl Glaser: Gibborim. Jüdische Jugendbücherei, Bd.4. Berlin: Jüdischer Verlag 1920; Heinrich Glanz-Sohar: Elisa und Jonadab. Jüdische Jugendbücherei, Bd. 8. Berlin: Jüdischer Verlag 1920; Moses Calvary: Durch Palästina. Jüdische Jugendbücherei, Bd. 5. Berlin: Jüdischer Verlag 1920; Martin Buber/ H[elena] H[anna] Cohn / C [heskel] Z[wi] Klötzel: Drei Legenden. Jüdische Jugendbücherei, Bd. 1. Berlin: Jüdischer Verlag 1920; Elias Auerbach: Joab - Ein Heldenleben. Jüdische Jugendbücherei, Bd.7, hrsg. v. Ausschuss für jüdische Kulturarbeit. Berlin: Jüdischer Verlag 1920. Die Jugendbücher wurden 1922 zusammengefasst in zwei Sammelbänden ein weiteres Mal publiziert. Bände 1, 3, 4, 7 und 8 in: Historien und Legenden. Berlin: Jüdischer Verlag [1922] und die Bände 5 und 6 in: Im Morgenlande. Berlin: Jüdischer Verlag [1922]. Vgl. die Bibliographie der Publikationen des Jüdischen Verlages 1902-1938 in Schenker: Der jüdische Verlag 1902-1938, S. 535-605. Zu jüdischer Kinder- und Jugendliteratur vgl. Annegret Völpel / Ran HaCohen: Deutsch-jüdische Kinder-und Jugendliteratur von der Haskala bis 1945. Die deutsch-und hebräischsprachigen Schriften des deutschsprachigen Raums. Ein bibliographisches Handbuch in zwei Bänden. Stuttgart: Metzler 2016.

72 David Josef Bornstein: Einführung in das Hebräische der Gegenwart. Methodische Texte und Erläuterungen, hrsg. v. d. ZVfD. Berlin: Verlag der Jüdischen Rundschau 1927.

73 Fritz M. Kaufmann (Hrsg.): Die schönsten Lieder der Ostjuden. 47 ausgewählte Volkslieder. Schriften des Ausschusses für jüdische Kulturarbeit. Berlin: Jüdischer Verlag 1920.

74 Baruch Krupnik: Hebräische Phraseologie. Dreitausend Redewendungen, deutsch-hebräisch, hebräisch-deutsch. Berlin: Rubin Mass 1932.

75 Vgl. Stephen M. Poppel: Salman Schocken and the Schocken Verlag. A Jewish Publisher in Weimar and Nazi Germany. In: Harvard Library Bulletin 11,1 (1973), S.20-49, hier S.24. 
„die Grundlage für eine systematische Arbeit der deutschen Zionisten auf dem Gebiet der jüdischen Kultur legte [...]. ${ }^{\text {“76 }}$

Dennoch machte sich unter den Mitgliedern mitunter eine gewisse Desillusionierung breit. Bereits 1917 äußerte sich Buber in einen Brief an Schocken frustriert über die Arbeit des Ausschusses:

Ich erinnere bei dieser Gelegenheit nochmals daran, dass wir in der Zeit unseres Bestehens, man kann wohl schon sagen: in unserem ersten Jahr, so gut wie nichts zustande gebracht haben und dass keinerlei Anlass besteht anzunehmen, dass wir bei unveränderter Organisationsform im zweiten Jahr mehr zustande bringen werden. Es muss meines Erachtens eine organisatorische Umformung [...] vorgenommen werden, wenn wir vor dem nächsten Delegiertentag, vor der Partei überhaupt und vor uns selber in Ehren bestehen wollen. ${ }^{77}$

Schocken äußerte sich interessanterweise niemals derart frustriert über das Gremium, das er begründete und dem er vorstand. Es kann vermutet werden, dass er bis zu einem gewissen Grad erreicht hatte, was ihn persönlich interessierte: das Herausgeben von Büchern. Zudem war ihm am Tagesgeschäft in der Regel wenig gelegen. Er gefiel sich in der Rolle des Ideengebers und des Initiators, zudem zeigte er Geschick in schwierigen Verhandlungen; die zeitraubende und viel Disziplin und Kommunikation fordernde Gremienarbeit interessierte ihn hingegen wenig. Trotz dieser Schwäche, die ihm durchaus bewusst war und mit der er seine Weggefährten wiederholt verärgerte, rückte er durch die Arbeit im Kulturausschuss ins Zentrum des deutschen zionistischen Netzwerkes.

\subsubsection{Fazit}

Ab Mitte der 1910er Jahre begann sich Schocken als Initiator und Förderer jüdischer Kulturarbeit zu profilieren. Das Buch und die Literatur standen dabei eindeutig im Zentrum. Die Förderung von S. J. Agnon und Martin Buber legten den Grundstein für seine spätere systematische Förderung von Autor*innen und Wissenschaftler*innen. Die Verteilung von Büchern an jüdisch-russische Kriegsgefangene, ein Projekt, das er ebenfalls 1916 startete, steht für Schockens

76 Moses: Salman Schocken, S. 27.

77 Martin Buber an Salman Schocken, 18.11.1917. NLI, Buber Archiv, Ms. Var. 350008 $705 \mathrm{I}$. 
Anliegen, gute und vorbildliche Literatur zu verbreiten. Schließlich begann er durch seine Finanzierung der Zeitschrift Der Jude und durch die Initiativen des Kulturausschusses gezielt Publikationsmöglichkeiten für die Texte jüdischer Schriftstellerinnen und Schriftstellerinnen und Denker zu schaffen. Schocken trat in unterschiedlichen Rollen auf: Er war Geldgeber, Initiator, stellte sein Verhandlungsgeschick und sein soziales Kapital als Kaufmann zur Verfügung und arbeitete bis zu einem gewissen Grad inhaltlich mit. Durch diese doch sehr unterschiedlichen Aufgaben nahm er bald eine zentrale Position im Feld der deutsch-jüdischen Geistesarbeit ein. Dass er mit seinem Vermögen viele Initiativen erst ermöglichte, war dabei sicherlich ein wichtiger Faktor. Die Schlussfolgerung, dass er sich damit ein Mitspracherecht auf inhaltlicher Ebene ,erkaufte, würde zu weit führen. Dennoch waren Geld und wirtschaftliches Wissen das Kapital, das er mit seinem Engagement in den Kulturzionismus einbrachte und das ihm den schnellen Aufstieg in der kulturzionistischen Hierarchie bis in die Elite ermöglichte. In den 1920er Jahren ließen die Aktivitäten Schockens in diesem Feld nach. Er war zwar in stetigem Kontakt mit den wichtigen Protagonisten und er versuchte weiterhin, Bücher zu publizieren, sein Fokus lag aber, so wurde im vorherigen Kapitel deutlich, auf wirtschaftszionistischen Fragen. Der enge Kontakt mit Buber und Agnon blieb gleichermaßen bestehen wie der lang gehegte Wunsch, einen von Parteipolitik unabhängigen jüdischen Verlag zu gründen.

\subsection{Der Schocken Verlag - eine historische Skizze}

Die Geschichte des Schocken Verlages wurde in einer Monographie und einem Sammelband detailliert aufgearbeitet. Der zweite Teil von Volker Dahms Das jüdische Buch im Drittem Reich beschäftigt sich ausschließlich mit der Geschichte dieses Verlages und gilt bis heute als Standardwerk und erste Referenz. Der von Saskia Schreuder und Claude Weber herausgegebene Sammelband Der Schocken Verlag/Berlin enthält Einzelstudien zu unterschiedlichen Aspekten der Verlagsgeschichte und zur Biographie Schockens. Mit Studien zu Einzelwerken, zur Beziehung zwischen dem Verleger und einzelnen Autoren, aber auch zur Buchgestaltung liefert er dabei detaillierte Einblicke, die über die Überblicksdarstellung Dahms hinausgehen.

Das vorliegende Kapitel wird die Verlagsgeschichte in groben Zügen nachzeichnen, um für die Analyse des Buches im kulturzionistischen Netzwerk und der 


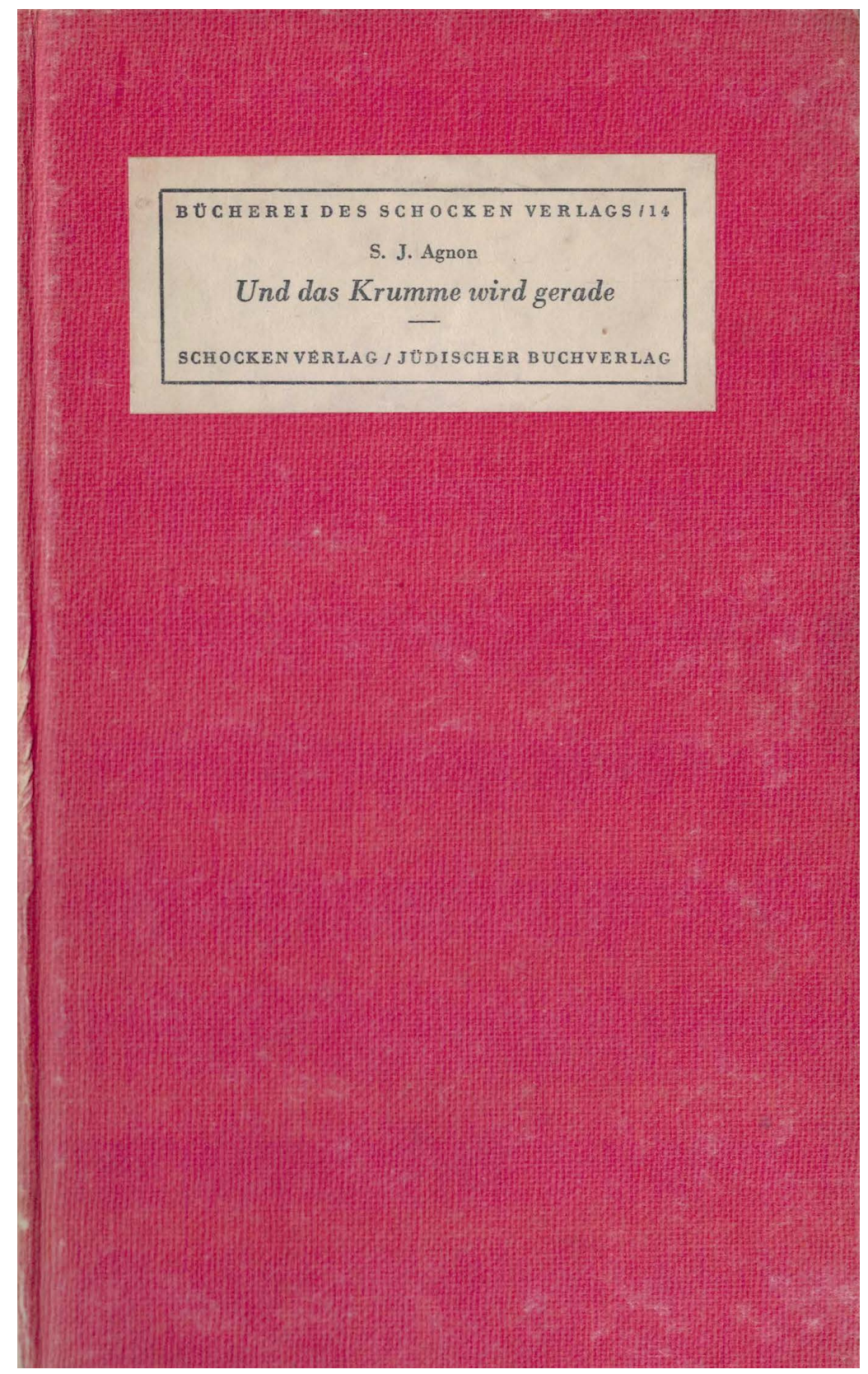

Abb. 5: Beispiele aus der, Schocken-Bücherei', Schocken Verlag Berlin, 1933-1938. 


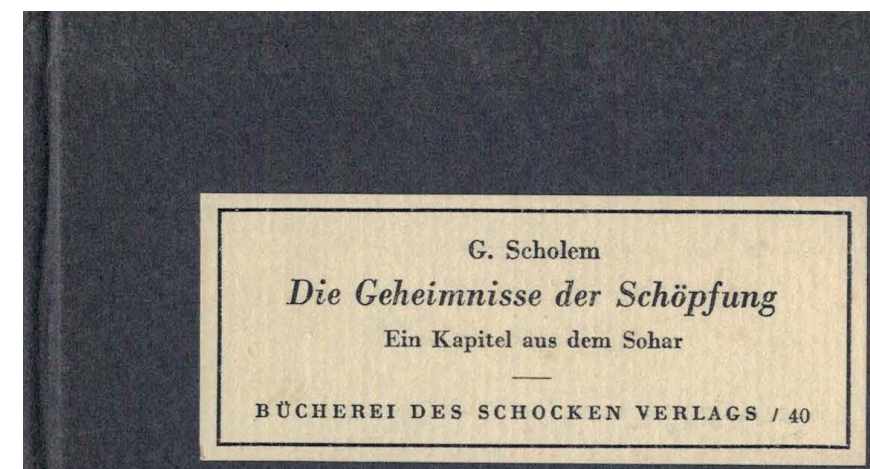




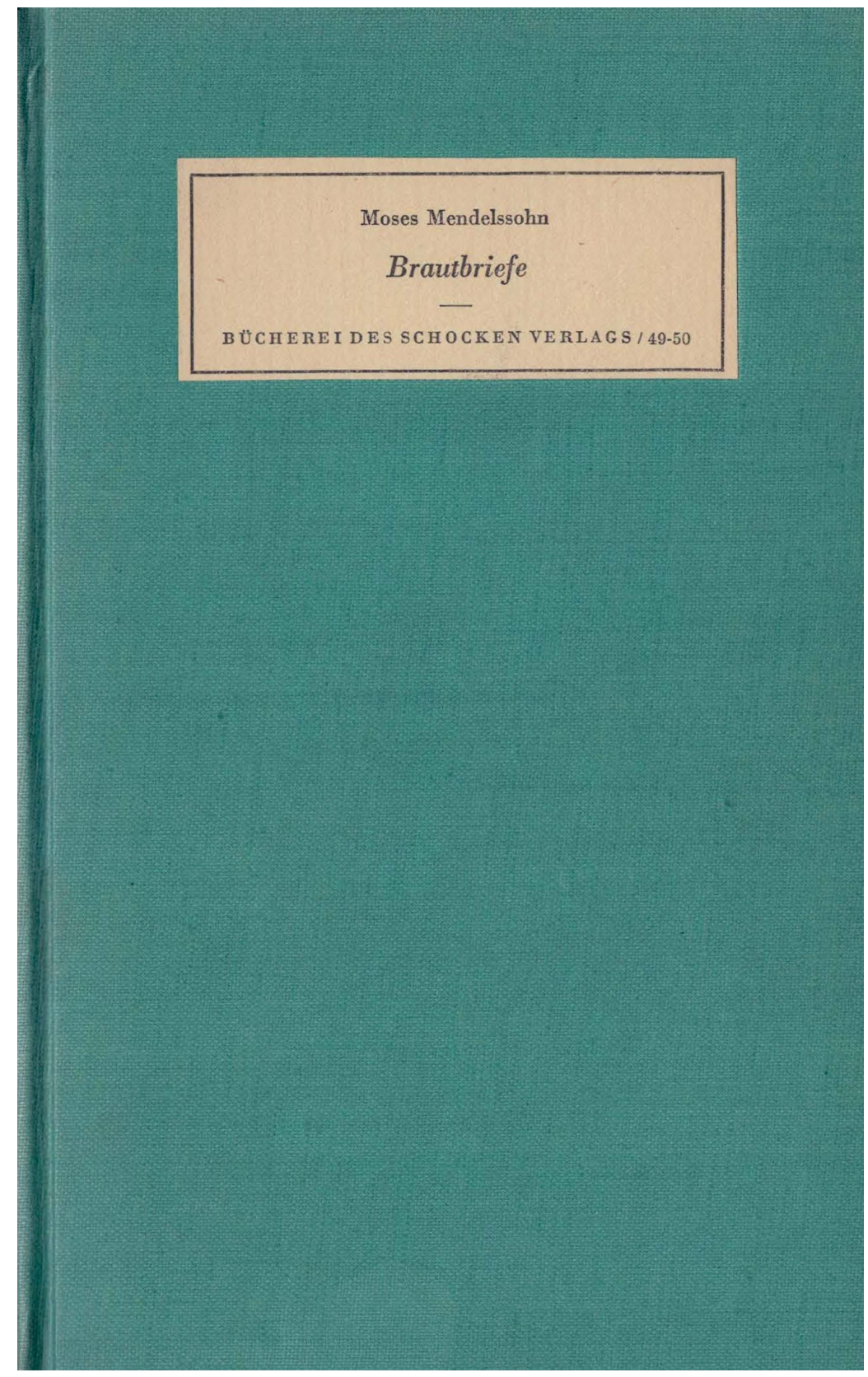




\section{Heine}

Gedicht und Gedanke

Auswahl und Nachwort von Werner Kraft

BÜCHEREI DES SCHOCKEN VERLAGS । 57 
Rolle des Verlages im kulturellen Widerstand gegen den Nationalsozialismus den nötigen Hintergrund zu liefern. Die Darlegung stützt sich auf die beiden oben erwähnten Werke sowie auf die reichhaltigen Akten im Schocken Archiv. ${ }^{78}$

Salman Schocken plante selbst eine Geschichte seines Berliner Verlages zu schreiben - dass dieses Projekt nie richtig begonnen wurde, kann man wohl auf die von ihm selbst deklarierte Schreibfaulheit schieben. Das Projekt hat, obgleich es nicht durchgeführt wurde, Eingang in die Akten des Schocken Archivs gefunden, und zwar in Form von Briefen und Besprechungsprotokollen. Diese Dokumente geben auch Einblick in seine persönliche Sicht auf die Anfangszeiten des Verlages. ${ }^{79}$

\subsubsection{Die Anfänge}

„Wenn ich nun eine Darstellung des eigentlichen Programms des Verlages geben soll, möchte ich zuerst versuchen, einen kurzen geschichtlichen Überblick zu geben. ${ }^{\text {“80 }}$ So beginnt Schocken einen Brief vom Dezember 1945 an seinen Sohn Theodor, der geschichtliche Überblick beginnt jedoch nicht mit dem Gründungsdatum des Verlages im Jahr 1931, sondern mit seinem Referat zur jüdischen Kulturarbeit auf dem Delegiertentag der ZVfD im Dezember 1916. Auch in Moritz Spitzers ${ }^{81}$ Einleitung zu einer leider nie publizierten Bio-Bibliographie des Verlages und seines Verlegers beginnt die Geschichte weit vor 1931.

Das Gründungsjahr des Schocken Verlages ist 1932 [sic], seine Wurzeln aber gehen viel weiter zurück. In seiner Begründung und Führung verdichtet sich, was sich im deutschen Judentum als Erneuerungsbewegung seit Jahrzehnten geistig angebahnt hatte. [...] In dieser Bewegung war Salman Schocken eine zentrale Gestalt. Schon als zu Anfang des Jahres der nunmehr außerordentlich wirksam gewordenen Strömung

78 Das Verlagsarchiv wurde zwar nicht komplett, doch aber in großen Teilen rechtzeitig von Deutschland nach Jerusalem verschickt. Es fehlen aber unter anderem sämtliche Unterlagen zur Zusammenarbeit mit Druckern und Buchbindern.

79 Vgl. Salman Schocken an Theodor Schocken, 10.12.1945. SchA, Verlag, 303; Protokoll, Besprechung des Herrn Salman Schocken mit Herrn Dr. Spitzer, 16.04.1958. SchA, Verlag, 303.

80 Salman Schocken an Theodor Schocken, 10.12.1945. SchA, Verlag, 303.

81 Details zur Biographie von Moritz Spitzer vgl. Kap. 5.2.2. 
[gemeint ist der Kulturzionismus] in der von Martin Buber herausgegebenen Monatsschrift ,Der Jude ein Organ geschaffen wurde, war Salman Schocken eine führende Figur in der Verwirklichung dieses Unternehmens. [...] Schocken war auch unter denjenigen, die zusammen mit Buber auf dem außerordentlichen DelegiertenTag der ZVfD im Dezember 1916 ein Programm für den systematischen Ausbau der jüdischen Erziehungs- und Kulturarbeit durchsetzten. [...] In diesem Zusammenhang war Schockens Hauptmerk schon damals auf die Anregung von Druckwerken didaktischer Absicht gerichtet. Eine Reihe von Publikationen ist, diesem Programm gemäß, vor allem im ,Jüdischen Verlag' und ,Welt Verlag' erschienen. ${ }^{82}$

Die Gründung des Schocken Verlages war in Schockens Selbstverständnis aufs Engste mit seiner zionistischen Arbeit verknüpft. Ebenso wichtig scheinen aber sein genuines Interesse an Literatur und an Büchern, sowie sein Mäzenatentum im Bereich der jüdischen Literatur und Wissenschaft.

Ein Beispiel dafür ist die Beziehung zwischen Schocken und Agnon, die durch den 1916 abgeschlossenen Verlagsvertrag geregelt war und bis 1925 unverändert bestehen blieb, ohne dass Schocken ein Manuskript von Agnon drucken ließ. Das Buch der Buchstaben, das erste von Schocken unterstützte und unter der Schirmherrschaft des Kulturausschusses stehende Buchprojekt Agnons, war ein gemeinsames Werk der Künstlerin Tom Freud ${ }^{83}$ (Illustrationen) und Agnon (Texte). Es konnte aus finanziellen Gründen nicht gedruckt werden. ${ }^{84}$ Das erste Werk Agnons, das Schocken dann unter eigener Herausgeberschaft drucken ließ, war ein unverkäuflicher Privatdruck von Schnei Sugot anlässlich

82 [Moritz Spitzer]: Vorwort [zur Bio-Bibliographie des Schocken Verlages], Typoskript, 25.06.1957. SchA, Verlag, 30.

83 Tom Seidmann-Freud, geb. Martha Freud, war eine dem Jugendstil verpflichtete deutschjüdische Illustratorin und Autorin von Bilderbüchern, die als Fünfzehnjährige den Männernamen Tom annahm. Sie genoss eine Ausbildung in London und Berlin, ihr erstes Buch wurde 1914 im Verlag Reuss \& Pollack veröffentlicht. 1921 heiratete sie den Schriftsteller und Übersetzer Jakob Seidmann. Das Ehepaar gründete gemeinsam der Peregrin-Verlag. 1930, ein Jahr nach dem Selbstmord ihres Mannes, nahm auch sie sich das Leben. Vgl. Barbara Murken: Tom Seidmann-Freud. In: Kinder-und Jugendliteratur. Ein Lexikon. 32. Ergänzungslieferung, hrsg. v. Kurt Franz / Günter Lange / Franz-Josef Payrhuber. Meitinge: Corian 2008, S. 1-21. 84 Das Buch erschien erst posthum 1983 im Schocken Verlag Tel Aviv mit Illustrationen von Yoni Ben-Shalom. S. Y. Agnon: ספר האותיות [Buch der Buchstaben]. Tel Aviv: Schocken 1983. 
der Bar Mitzwa seines ältesten Sohnes Gustav Schocken ${ }^{85}$ im Jahr $1927^{86}$. Im selben Jahre sandte Agnon Manuskripte für die Erzählungen Der Verstoßene und Das Krumme wird gerade an Schocken, der den Druck der zwei Bücher in Deutschland plante.

$\mathrm{Zu}$ dieser Zeit nahm auch Schockens Idee, einen Verlag zu gründen, konkretere Formen an. So schreibt er am 13. September 1928 an Agnon, dass „heute der Auftrag für den Druck Ihrer 3 Bände an die Firma Drugulin $\left[{ }^{87}\right]$ übergeben worden ist. [...] Ich wünsche Ihnen und mir, dass wir an dem ersten wirklich gemeinsamen Werk stets die gleiche Freude haben mögen. ${ }^{88}$ Und fährt dann fort:

Ich nehme an, dass es Sie freut, wenn ich Ihnen mitteile, dass ich mich zu meiner früheren Stellungnahme entschlossen habe, das Werk im eigenen Verlag herauszubringen, und zwar habe ich mich entschlossen, einen jüdischen Verlag zu gründen, der hebräische und deutsche Bücher herausbringt.

Von den deutschen Büchern wird als erstes ein zweibändiges Lesebuch erscheinen, dessen ersten Teil: deutsche Original-Lesestücke Herr Ludwig Strauß zusammengestellt

85 Gustav Schocken (1912-1990) nannte sich nach seiner Emigration nach Palästina Gershom. Laut familiärer Überlieferung nahm er den Namen aus zionistischen Gründen an, da in der Schreibweise des Namens גרשום (Gershom) das hebräische גר שם (dort leben) anklingt. Diese Information stammt von Rabbi Baruch Yonin, dem Bibliothekar des SchockenInstitutes in Jerusalem, der sie in einem Gespräch mit Racheli Edelman, der heutigen Leiterin des Schocken Verlages Jerusalem und Tochter von Gershom Schocken, erhielt.

86 Folgt man dem jüdischen Religionsgesetz, nach dem männliche Jugendliche mit 13 Jahren die religiöse Volljährigkeit erreichen, hätte Gustavs Bar Mitzwa bereits 1923 sein müssen. Im Laufe des 19. Jahrhunderts lehnten sich die Bar Mitzwa-Feiern immer stärker an die protestantische Konfirmation an, die in der Regel im 15. oder 16. Lebensjahr gefeiert wird. Möglicherweise wurde diese bürgerliche Tradition in der Familie Schocken trotz vehementer Ablehnung der Assimilation übernommen. Vgl. u. a. Lässig: Jüdische Wege ins Bürgertum, S.252.

87 Der Schocken Verlag arbeitete während seines ganzen Bestehens eng mit der Offizin Drugulin in Leipzig zusammen. Der größte Teil der hebräischen Drucke wurden von den Spezialisten dort gesetzt und gedruckt. Vgl. zur Beziehung zwischen dem Schocken Verlag und Drugulin: Dahm: Das jüdische Buch im Dritten Reich, S. 393; Schneider: Salman Schocken, S. 198; Stefanie Mahrer: Texts and Objects. The Books of the Schocken Publishing Houses in the Context of Their Time. In: Rachel Seelig / Amir Eschel (Hrsg.): The German-Hebrew. Dialogue Studies of Encounter and Exchange. Berlin: de Gruyter 2017, S. 121-141; sowie Kap. 5.3.3.

88 Salman Schocken an S. J. Agnon, 13.09.1928. NLI, Agnon Archiv, Arc 41270. 
hat; der zweite Band enthält Übersetzungen aus dem Hebräischen, und zwar viel neue, die gemeinsam von Nachum Glatzer und Ludwig Strauß zusammengestellt sind.

Über die weitere Reihe der hebräischen Bücher hätte ich mich gern mit Ihnen beraten, und hoffe, dass sich Gelegenheit finden wird; vielleicht machen Sie mir einmal Vorschläge.

Mein alter Lieblingsgedanke Mussar und Aggada steht an erster Stelle. ${ }^{89}$

Ein halbes Jahr später bat Schocken Agnon abermals, ihm „aufgrund Ihrer Kenntnis der hebräischen Literatur Vorschläge für meinen in Aussicht gestellten jüdischen Verlag zu machen. ${ }^{\text {“90 }}$ Auch Buber wurde in die Verlagspläne einbezogen, Schocken konnte jedoch mit dessen Ideen wenig anfangen.

Ich habe mir die Vorschläge, die Sie mir bei Ihrem letzten Besuch in Berlin gemacht habe, im Zusammenhang mit meinen Verlagsplänen wiederholt durch den Kopf gehen lassen. Freilich komme ich [...] zum Schluss zu dem Ergebnis, dass eigentlich recht wenig Positives für mich aus den Vorschlägen herausspringt.

Praktisch läuft Ihr Vorschlag auf eine Aktion hinaus, durch Vorwegzahlung an Autoren eine Literatur zu schaffen. Die Gefahr, die ich hierin [erblicke], liegt nach meinen praktischen Erfahrungen darin, dass bei solchen Sammelarbeiten leicht Lückenbüßer und leere Stellen entstehen und dass das Gute durch das Mindere leidet. Da lobe ich mir einzelne Bücher, die für sich stehen und für sich wirken können. ${ }^{91}$

Schocken hatte aus den Erfahrungen mit dem Kulturausschuss gelernt, dass Auftragsarbeiten oft nicht zu Ende gebracht wurden. Im selben Brief weist er Buber auch darauf hin, dass er bereits einige fertige Manuskripte vorliegen habe, „z. B. das für den Druck fertig gesetzte Werk von Agnon, ein oder zwei Bände

89 Ebd.

90 Salman Schocken an S. J. Agnon, 14.03.1929. NLI, Agnon Archiv, Arc 41270.

91 Salman Schocken an Martin Buber, 16.07.1929. NLI, Buber Archiv, Ms. Var. 350/705. Volker Dahm ging davon aus, dass dieser Brief verlorengegangen sei, dies führte zu Verfälschungen in der Darstellung der Ereignisse. Dahm schloss aus dem Antwortschreiben Bubers darauf, dass der Vorschlag, Autoren mit Vorauszahlungen zum Verfassen von Manuskripten zu verpflichten, von Schocken stammte. Der hier zitierte Brief macht nun deutlich, dass diese Idee ursprünglich von Buber kam, auch wenn dieser sie später verwerfen wird (vgl. dazu weiter unten). Zum angeblichen Verlust des Briefes vgl. Dahm: Das jüdische Buch im Dritten Reich, S. 288. 
des Lesebuches von Ludwig Strauß und einige kleinere Sachen ${ }^{\text {(992 }}$. Ohne eine solide konzeptionelle Planung wollte er sie jedoch nicht veröffentlichen:

Ich werde aber diese Bücher nicht herausbringen, bevor ich nicht einen wirklichen aussichtsvollen Gesamtanfang sehe, der beileibe nicht der Beginn eines systematischen Gesamtwerkes zu sein braucht, aber buchhändlerisch und kaufmännisch die Basis für einen Verlag bilden kann. [...]

Wenn ich in der nächsten Zeit keine Aussicht sehe, eine Verlagstätigkeit beginnen zu können, müsste ich mich entschließen, die Werke an andere Verleger zu geben. Das würde mir freilich leid tun, weil ich glaube, dass mein Plan eine Durchführung wohl lohnen würde; ich würde mich auch bemühen, mich kaufmännisch mit der Sache so intensiv zu beschäftigen, dass sie ein neuartiger Versuch für das jüdische Buch sein könnte. ${ }^{93}$

Ganz seinen wirtschaftlichen Prämissen folgend, wollte Schocken die Gründung eines eigenen Verlages nur in Betracht ziehen, wenn das Unterfangen auch kaufmännisch vertretbar war, was nichts Anderes bedeuten kann, als dass der Verlag kein Verlustgeschäft darstellen sollte. Es ist gut möglich, dass Salman Schocken dabei auch an den wirtschaftlich geplagten Jüdischen Verlag dachte, der von Beginn an nur Verluste schrieb, was sich negativ auf die Beziehung zwischen Gründern und Besitzern auswirkte und schließlich zum Auseinanderbrechen der Verlegergruppe führte. ${ }^{94}$

Schocken fiel als Kaufhausbesitzer als innovativer und sozial denkender Patron auf, blieb aber gleichzeitig immer kaufmännischen Grundsätzen verpflichtet. Genauso verhielt er sich bei der Gründung seines Verlages. Erfahrungen im Verlegen von Büchern hatte er während seiner Tätigkeit als Vorsitzender des Kulturausschusses der ZVfD sammeln können, gleichzeitig wurde ihm in diesem Gremium bewusst, dass gute Ideen und Pläne nicht automatisch auch Erfolg garantieren. Vergleicht man die von ihm im Dezember 1916 formulierten Forderungen, was ein derartiger Ausschuss zu leisten hätte, mit der Zahl an tatsächlich publizierten Büchern, wird eine große Diskrepanz deutlich. Im Jahr 1929 verfügte Schocken jedoch über genügend Erfahrungen sowie über

92 Salman Schocken an Martin Buber, 16.07.1929. NLI, Buber Archiv, Ms. Var. 350/705.

93 Ebd.

94 Vgl. Schenker: Der jüdische Verlag 1902-1938, S. 6-74, 89-117. 
persönliche Kontakte zu Wissenschaftlern und Autoren, die Interesse an einer Zusammenarbeit hatten. Es darf zudem nicht außer Acht gelassen werden, dass in diesem Jahr sein Wirtschaftskonzern nach der Überwindung sämtlicher wirtschaftlicher Krisen der Nachkriegszeit gefestigt dastand und sich auf Expansionskurs befand. ${ }^{95}$ Zusammenfassend kann man die wirtschaftliche Situation Ende 1929 so beschreiben: Die Inflation war gestoppt, das Land befand sich in wirtschaftlichem Aufschwung und der Schocken-Konzern im Wachstum. Setzt man dies in Bezug zu Schockens persönlicher Situation - ein ausgedehntes Netzwerk innerhalb der jüdischen und besonders der zionistische Kreise in Deutschland, persönliche Beziehungen zu Autoren und Wissenschaftlern, erste Erfahrungen als Verleger im Rahmen seines Engagements für Der Jude und für den Kulturausschuss - und bedenkt man, dass auf dem Gebiet der Verlage die einzige Konkurrenz, der Jüdische Verlag, durch finanzielle Nöte sowie durch die enge Anbindung an die offiziellen Organe der ZVfD geschwächt war, scheint die Situation für die Gründung eines eigenen Verlages nahezu ideal.

Der Konzern sollte dann auch den Rahmen für den neu zu gründenden Verlag schaffen. Nach einer Aktennotiz von Siegfried Moses plante Schocken, den Verlag als Abteilung entweder der Schocken Kommandit-Gesellschaft auf Aktien oder des Zwickauer Stammhauses I. Schocken Söhne anzugliedern. ${ }^{96}$

Während Moses als Schockens Rechtsberater die firmenrechtlichen Möglichkeiten ausarbeitete, waren Bubers Vorschläge für die inhaltliche Konzeption und die Beschaffung von Manuskripten wichtig. Nachdem der erste Vorschlag, „durch Vorauszahlung an Autoren eine Literatur zu schaffen ${ }^{\text {“97 }}$, von Schocken abgelehnt wurde, legte Buber im August 1929 einen ausgearbeiteten Plan vor, der hier in voller Länge wiedergegeben wird:

Ein neuer Verlag hat die Möglichkeit der Manuskriptzufuhr:

1. Einlauf - d.h. Autoren, die Kenntnis davon erlangen, dass es auf ihrem Produktionsgebiete ein neues Verlagsunternehmen gibt, bieten ihm ihre Werke an, zumeist fertig vorliegend, zuweilen aber auch im Werden begriffene und zu

95 Vgl. Fuchs: Ein Konzern aus Sachsen, S. 127-186.

96 Vgl. Dahm: Das jüdische Buch im Dritten Reich, S. 287.

97 Martin Buber an Salman Schocken, 16.08.1929. SchA, Verlag, 312 (Buber 1914-1929). 
fördernde. Zu dieser Abteilung gehören auch Fälle, wo Autoren auf Veranlassung des Verlags selber ihm ein Angebot machen, der Verlag hat ihnen eben von seiner Existenz und seinen Interessen für ihr Produktionsgebiet Kenntnis gegeben. - Diese Möglichkeit kommt bei dem Verlagsplan, um den es sich handelt, kaum in Betracht; Autoren die "von selber“ die Bücher schreiben, die der geplante Verlag brauchen würde, werden wohl zu den besonderen Ausnahmen gehören. Wohl aber wird es solche geben, die dem Verlag anbieten werden, unter gewissen Bedingungen ein geeignetes Buch zu schreiben. Diese werde ich unter 3) mitbehandeln.

2. Neudrucke - Diese für mehrere große Verlage sehr wichtige Abteilung scheidet hier so gut wie ganz aus. Die hier in Betracht kommenden Neudrucke liegen entweder bereits vor, oder der Interessentenkreis ist zu klein.

3. Bestellung von Manuskripten bei berufenen Autoren - Dies muss hier naturgemäß die Hauptzufuhr bedenken. Nun ist aber diese „Bestellung“ durchaus nicht mit „Vorwegzahlung“ identisch. Vielmehr gibt es drei verschiedene Modalitäten:

a) die Honorierung (ganz oder ratenweise) vor Ablieferung des Manuskripts

b) die Honorierung (ganz oder partiell) bei Ablieferung des Manuskriptes, oder bei Erscheinen des Buches usw.

c) die Honorierung nach Maßgabe des Absatzes, also die Beteiligung des Autors am Risiko

Hiervon halte ich a) für keine gesunde Grundlage für einen neuen Verlag und nur in einzelnen Fällen von großer Wichtigkeit für empfehlenswert: bei Anwendung von c) wird es im Allgemeinen nicht gelingen, für die zu erteilenden Aufträge Autoren zu finden; b) ist der gegebene Modus. [...]

Selbstverständlich wird bei 3) die Auswahl der Autoren in besonderer Weise verantwortungsvoll. Ich begreife es daher vollkommen, dass Sie befürchten, bei großangelegten Sammelwerken könnten Lückenbüßer entstehen. Um dieser Befürchtung Rechnung zu tragen, will ich in meinen nachfolgenden Vorschlägen von solchen Sammelwerken ganz absehen und mich auf Bücher beschränken, bei denen von Anfang an eine weitgehende Sicherung möglich ist, d. h., die eben nicht eher 
unternommen werden, bis der oder die Autoren oder Übersetzer da sind und sich bereit erklärt haben, die Arbeit zu machen.

Ich begnüge mich zunächst damit, Ihnen für die Abteilung „Übersetzungen“ einige Vorschläge zu machen, und zwar nur solche, die ich bereits in der nächsten Zeit für ausführbar halte. Für die Abteilung „Originalwerke“ könnte ich erst nach Fühlungnahme mit einigen Autoren praktische Vorschläge machen.

Für die Abteilung der Übersetzungswerke denke ich vor allem an eine Klassikerreihe (es braucht nicht äußerlich als Serie gekennzeichnet sein, aber Format, Schrift und Einband - außer der Farbe - sollen gleich sein, wie z. B. bei den Tempelklassikern), also Übertragungen der repräsentativen Bücher aus dem Hebräischen, Griechischen und Arabischen. [...]

Bei dieser Gelegenheit mache ich Sie darauf aufmerksam, dass Louis Ginzbergs "Legends of the Jews“, die als Volksbuch vor Gorions „Sagen der Juden“ den Vorzug hatte, große zusammenhängende, sehr sorgfältig komponierte Erzählungen zu bieten [hat], das deutsche Manuskript liegt, wie mir Ginzberg auf Anfrage mitgeteilt hat, bei ihm und könnte ohne weiteres gedruckt werden.

Des weiteren empfehle ich, eine Reihe von Bänden über die großen Tanaim herauszugeben, in denen das einschlägige talmudische und misrachische Material nach Personen geordnet wäre. Jedes Bändchen hätte zu enthalten: 1. eine Lebensgeschichte, möglichst im Wortlaut der Texte, unter entsprechender Einbeziehung auch des Legendären; 2. eine nach Gegenständen geordnete Auswahl der Aussprüche. Die einzelnen Gestalten müssten, was sie bei Bacher eben gar nicht tun, in lebendiger Anschaulichkeit hervortreten. Auch hier könnte vielleicht an eine gleichzeitige hebräische Publikation gedacht werden.

Schließlich wäre an einiges folkloristisch Bedeutsame zu denken, z. B. an Schatzkes' „Vorpessach“ u. m. Man sollte auch versuchen, An-skis Nachlass zu verwerten.

Außerhalb der Übersetzungsabteilung, aber in sie eingreifend, schwebt mir ein Palästinabuch in der Art von Reisingers "Griechenland“ vor, also eine Auswahl der schönsten Stücke aus den Reisebeschreibungen alle Zeiten und Völker in einem handlichen, evtl. gut illustrierten Band. Daran könnte sich, schon wieder völlig in die Übersetzungsabteilung fallend, eine Auswahl von autobiographischen Darstellungen, Briefen, Berichten usw. aus der Geschichte des Jischard anschließen, von den chassidischen Unternehmungen bis auf unsere Zeit, ebenfalls in einen Band, also nur das Wertvollste und Wichtigste. 
Ich habe nur solche Bücher genannt, für die man meiner Überzeugung nach die geeigneten Übersetzer und Herausgeber schon jetzt finden kann (bis auf den KabbalaBand, dessen Zustandekommen, wie gesagt, von Scholems Mitarbeit abhängt).

$\mathrm{Zu}$ ergänzenden Mitteilungen über die einzelnen vorgeschlagenen Werke bin ich gern bereit.

Herzlich Grüßend Ihr

Martin Buber

Die Übersetzung des Makkabäerbandes und des Jüdischen Kriegs würde gewiss Karl Wolfskehl gern übernehmen, der gut griechisch kann. Für die Übersetzung von Philo denke ich an Diesendruck, der ein trefflicher Gräzist ist und ein vorzügliches Deutsch schreibt. Für Nr. 1 kommt Hugo Bergmann in Betracht. ${ }^{98}$

Schocken reagierte auf diese lange Ausführung Bubers nicht, sodass jener im Februar 1930 nachfragte, ob Schocken die Pläne weiterverfolge, da er inzwischen der Meinung sei, „dass ein jüdisches Publikationsunternehmen, d. h. ein für die deutschsprechenden Juden bestimmtes, ohne Einfügung in einen größeren Zusammenhang eine zu schmale ideelle und geschäftliche Basis hat." ${ }^{\text {“99 }}$ Schocken trat daraufhin kurzzeitig in Verhandlung mit dem Jüdischen Verlag, gab diese dann jedoch aus wirtschaftlichen Überlegungen auf, da der Vorschlag Siegmund Kaznelsons, der inzwischen die Leitung des Jüdischen Verlages innehatte, für Schocken nicht akzeptabel war. Kaznelson schlug nämlich vor, das Schocken die Herstellungskosten sowie die Autorenhonorare übernehme, während der Jüdische Verlag Produktion und Vertrieb der Bücher verantworte. Der Ertrag würde hälftig zwischen den Vertragspartnern geteilt. Aufgrund Kaznelsons Kalkulationen hätte Schocken erst beim Verkauf von 3.000 Exemplaren eines Buches Gewinn erzielt. Eine derart hohe Auflage war für Bücher jüdischer Autorinnen und Autoren zu dieser Zeit jedoch illusorisch. ${ }^{100}$ Die Ausstiegsklausel war zudem derart zu Ungunsten Schockens, dass dieser von

98 Martin Buber an Salman Schocken, 16.08.1929. SchA, Verlag, 312 (Buber 1914-1929).

99 Martin Buber an Salman Schocken, 10.02.1930. NLI, Buber Archiv, Ms. Var. 350/705I. 100 Vgl. Dahm: Das jüdische Buch im Dritten Reich, S. 289-290; Schenker: Der jüdische Verlag 1902-1938, S. 358-359. 
einer Zusammenarbeit absah. Laut Dahm ging es dem Jüdischen Verlag vor allem darum, mit dem Schocken-Konzern ein Geschäft ohne großes Risiko zu machen. ${ }^{101}$

Den letzten Anstoß zur Verlagsgründung gab schließlich Lambert Schneiders Mitteilung an Schocken im Jahr 1929, dass Schneiders eigene Mittel die Weiterführung seines Bibelübersetzungsprojektes „Verdeutschung der Schrift“ nicht mehr erlaubten. Lambert Schneider gründete erst 25-jährig einen eigenen Ver$\operatorname{lag}^{102}$ und initiierte mit der Neuübersetzung der hebräischen Bibel durch Martin Buber und Franz Rosenzweig ein Projekt von enormer Größe ${ }^{103}$ für einen noch unerfahrenen Verleger. Es war Schneiders Wunsch, das Alte Testament möglichst wortnah und frei von christlichen Einflüssen in die deutsche Sprache zu übertragen. ${ }^{104}$ Schocken gewährte Lambert Schneider, als dieser 1929 in Schwierigkeiten geriet, ein Darlehen und übernahm 1931, als dessen Verlag die Finanzierung nicht mehr garantieren konnte, das Bibel-Projekt schließlich ganz. Nach mehreren Gesprächen zwischen Schneider und Schocken, denen Verhandlungen mit Siegfried Moses folgten, unterbreitete Schocken Schneider das Angebot, sowohl die Bibelübersetzung wie auch die Judaika aus dem Lambert Schneider Verlag in den von ihm geplanten Verlag zu übernehmen, wenn Schneider die Leitung dieses Verlages übernehmen würde. ${ }^{105}$

Damit hatte Schocken für seinen eigenen Verlag eine Basis gelegt, die eine sofortige Produktion von Büchern erlaubte. Mit der Übernahme der Bibelübersetzung kam zudem ein prestigeträchtiges Projekt in den zukünftigen Verlag. Dass mit Martin Buber als Übersetzer der Bibel - Franz Rosenzeig war 1929 gestorben - ein ihm vertrauter Autor in den Verlag kam, mit dem er bereits in engem professionellem und persönlichem Kontakt stand, mag die Entscheidung erleichtert haben. Neben dem bereits bestehenden Vertrag mit Agnon, der Übernahme zweier Projekte aus dem Lambert Schneider-Verlag und Schockens

101 Vgl. Dahm: Das jüdische Buch im Dritten Reich, S. 449.

102 Eine Verlagsgeschichte des Lambert Schneider Verlages sowie eine Biographie seines Gründers stehen bis heute aus.

103 Die Arbeit kam erst 1962 zum endgültigen Abschluss.

104 Vgl. Dahm: Das jüdische Buch im Dritten Reich, S. 293.

105 Vgl. ebd., S. 291-292 sowie die Darstellung der Ereignisse aus Schockens Perspektive: Salman Schocken an Theodor Schocken, 10.12.1945. SchA, Verlag, 303, und aus Schneiders Blickwinkel: Lambert Schneider: Rechenschaft über vierzig Jahre Verlagsarbeit 1925-1965. Ein Almanach. Heidelberg: Lambert Schneider 1965, S. 19-21. 
verlegerischen Erfahrungen kam ein weiterer, die Verlagspläne positiv beeinflussender Faktor dazu: Schocken gründete im Jahr 1929 das Institut für die Erforschung der hebräischen Dichtung, das unter der Leitung von Heinrich Brody ${ }^{106}$ und der Mitarbeit von Jefim Schirmann ${ }^{107}$ und Menachem Zulay ${ }^{108}$ im Jahr 1930 seine Arbeit in Berlin aufnahm. ${ }^{109}$

Das Institut hatte unter anderem zum Ziel:

1. die gedruckten und handschriftlichen Quellen für die hebräische Poesie in möglichst erschöpfender Weise verzeichnen und sammeln;

2. wissenschaftlich fundierte zuverlässige Editionen hebräischer Dichterwerke veranstalten und Forschungen über hebräische Poesie durchführen und veröffentlichen. ${ }^{110}$

Obwohl das Forschungsinstitut auf einer privaten Initiative Schockens beruhte und es eigenständig wie strukturell unverbunden mit dem Verlag war, existierte

106 Brody galt schon damals als führender Experte im Bereich der mittelalterlichen jüdischen Poesie; seine wissenschaftlichen Publikationen sind bis heute Standardwerke auf dem Gebiet. Vgl. Ittai Jospeh Tamari: Das Volk der Bücher. Eine Bücherreise durch sechs Jahrhunderte jüdischen Lebens. München: Oldenbourg 2012, S. 147-148; Brody, Heinrich (R. Salomonsohn, Chaim Brody). In: Handbuch österreichischer Autorinnen und Autoren jüdischer Herkunft 18. bis 20. Jabrbundert, hrsg. v. Österreichische Nationalbibliothek Wien. Oldenburg: de Gruyter Saur 2002, S. 173-174.

107 Schirmann wurde 1937 als Gastdozent an die Hebräische Universität in Jerusalem berufen, wo er ab 1952 die Professur für mittelalterliche hebräische Poesie innehatte. Für einen kursorischen Einblick in seinen wissenschaftlichen Werdegang vgl. Isaac E. Barzilay: Hayyim (Jefim) Schirmann (1904-1981). In: Proceedings of the American Academy for Jewish Reserearch 49 (1982), S.xxv-xxxi.

108 Zulay wurde 1925 als Hebräischlehrer für Schockens Kinder eingestellt. Später arbeitete er im Schocken-Institut über frühe Piyutim, vgl. Jehuda Ratzaby: Zulay Menahem. In: Encyclopaedia Judaica. 2. Aufl., hrsg. v. Michael Berenbaum / Fred Skolnik. Detroit: Macmillan Reference 2007, S. 683.

109 Vgl. Materialzusammenstellung betreffend Gründung des Forschungsinstituts, Typoskript. SchA, Katalog und Salman Schocken: Über das Forschungsinstitut für Hebräische Dichtung. Vorwort zur ersten Veröffentlichung. In: Moritz Spitzer (Hrsg.): Almanach des Schocken Verlags auf das Jahr 5697. Berlin: Schocken 1936/37, S. 175-176. Zum Forschungsinstitut: Peter S. Lehnhardt: Das Forschungsinstitut für hebräische Dichtung und sein Beitrag zur Kenntnis der hebräischen Dichtung des Mittelalters. In: Schreuder / Weber (Hrsg.): Der Schocken-Verlag/Berlin, S. 299-320.

110 Schocken: Über das Forschungsinstitut für Hebräische Dichtung. 
eine enge Verbindung zwischen den beiden Unternehmungen. Einerseits entstanden durch die Forschungsarbeiten der am Institut tätigen Wissenschaftler Manuskripte, auf die der Verlag angewiesen war, andererseits schaffte der Verlag Publikationsmöglichkeiten für Bücher, die sonst kaum einen Verlag gefunden hätten.

\subsubsection{Das Verlagsprogramm}

Das Echo auf die Verlagsgründung im Jahre 1931 war äußerst positiv. So schickte u.a. Robert Weltsch Ende Oktober dieses Jahres folgendes Glückwunschschreiben an Schocken:

Ich hatte nicht die Gelegenheit, Sie zu der Eröffnung des Schocken-Verlages zu beglückwünschen. Hoffentlich wird dieser Verlag unsere arme jüdische Literatur um eine Reihe wertvoller Erscheinungen bereichern und kann so ein großes kulturelles Werk vollbringen. Ich bin überzeugt, dass es Ihnen an Projekten aller Art nicht mangelt. [...] [Man] wird Sie wahrscheinlich mit Vorschlägen für Publikationen aller Art überhäufen. ${ }^{11}$

Im Gründungsjahr trumpfte der Verlag mit einem qualitativ und quantitativ bemerkenswerten Programm auf, 10 Titel mit insgesamt 23 Bänden brachte der junge Verlag auf den Markt. ${ }^{112}$ Im Dezember 1932 veröffentlichte er erstmals seine Programmatik:

1. In der deutschsprachigen Abteilung soll das Jahrhunderte alte Kulturgut des Judentums und des gesamtsemitischen Kulturkreises in mustergültigen Übersetzungen und Ausgaben bereitgestellt werden. Die Bibelübersetzung von Buber und Rosenzweig ist das zentrale Kernstück dieser Abteilung und das Jüdische Lesebuch von Glatzer-Strauß ist unser erster Versuch, eine große Anzahl sorgfältig ausgewählter Stellen aus Midrasch und Talmud, aus dem Sohar und der mittelalterlichen jüdisch-philosophischen und poetischen Literatur, kabbalistische und chassidische Texte usw., einem größeren Publikum zugänglich zu machen.

111 Robert Weltsch an Salman Schocken, 21.10.1931. NLI, Buber Archiv, Ms. Var. 350/880164a.

112 Vgl. die Bibliographie des Schocken Verlags bei Dahm, hier 1931: Dahm: Das jüdische Buch im Dritten Reich, S. 476-477. 
2. In der hebräischen Abteilung erscheinen in engster Zusammenarbeit mit dem „Forschungsinstitut für hebräische Dichtung“ in Berlin Standardausgaben klassischer hebräischer Poesie des Mittelalters. Ferner sollen moderne hebräische Dichtungen [...] veröffentlicht werden. Die gesammelten Werke von S.J. Agnon bilden den Auftakt für diese Abteilung. ${ }^{113}$

1932 wurde zudem das Kernteam des Schocken Verlages um Moritz Spitzer als Lektor ergänzt. Spitzer, Doktor der Indologie, der schon als Jugendlicher unter dem Einfluss von Martin Buber zionistisch aktiv wurde, war ab 1930 als Hebräisch- und Religionslehrer für die Kinder des Ehepaars Schocken angestellt. 1928 gründete er die Jungzionistischen Blätter, eine Jugendbeilage der Jüdischen Rundschau und kurz darauf wurde er Leiter der Schule der jüdischen Jugend, einer Berliner Abendschule. Zu Beginn seiner Anstellung im Schocken Verlag assistierte er Buber in Heppenheim als wissenschaftlicher Sekretär bei der Bibelübersetzung. Erst 1934 zog Spitzer nach Berlin, um hauptberuflich im Verlag zu arbeiten. ${ }^{114}$

Das zweite Jahr nach der Gründung verlief weitgehend ruhig - die Bibliographie des Schocken Verlages weist für 1932 nur sieben Buchpublikationen aus, sechs davon waren Schriften Bubers, die aus anderen Verlagen übernommen wurden. ${ }^{115} 1933$ hingegen, im Jahr der nationalsozialistischen Machtübernahme, expandierte der Schocken Verlag. Im Mai 1933 wurde über den Ausbau des Verlages beraten und im Herbst 1933 der erste Almanach veröffentlicht. Ebenfalls 1933 erschienen die ersten Ausgaben der Schocken-Bücherei, kleine Bände, die der Bücherei des Insel Verlags nachempfunden waren. Im Mai 1933, in dem Monat also, in dem in vielen deutschen Städten im Zuge der, Aktion wider den undeutschen Geist' Bücher verbrannt wurden, planten Schocken und seine Verlagsmitarbeiter den systematischen Ausbau des Verlages.

113 Anhang zu einem Brief des Verlags an Dr. Wolf vom 14.12.1932, Gemeindezeitung der israelitischen Gemeinde Württembergs zur Publikation. SchA, Verlag, 331/51.

114 Vgl. Dahm: Das jüdische Buch im Dritten Reich, S. 307.

115 Vgl. Moritz Spitzer: Bio-Bibliographie des Schocken Verlages. Typoskript, 25.06.1957. SchA, Verlag, 30. 
Nach der Machtergreifung der Nationalsozialisten wurde der Verlag zu einer wichtigen Stütze des deutschen Judentums. ${ }^{116}$ Saskia Schreuder weist darauf hin, dass, nachdem die Nationalsozialisten den Antisemitismus zur Staatsdoktrin erhoben, das Bedürfnis innerhalb der jüdischen Bevölkerung Deutschlands nach „Orientierung und Stellungnahme, Solidarität und [...] praktischer Hilfe angesichts der massiven Angriffe durch den Staat [... $]^{\text {“117 }}$ wuchs und dies zur Intensivierung des öffentlichen jüdischen Lebens führte. Eine intensivierte Auseinandersetzung mit der jüdischen Vergangenheit und Kultur, aber auch mit dem jüdischen Glauben und Denken ließ die jüdische Buchproduktion anwachsen. Die Machtergreifung hatte ein sofortiges sprunghaftes Anwachsen der jüdischen Verlagstätigkeit zur Folge. Die Publikationen verdoppelten sich von $130 \mathrm{im} \mathrm{Jahr} 1930$ auf 247 im Jahr 1933, resp. 255 im Jahr 1934 und 260 im Jahr 1935. In den Jahren 1936 und 1937 gingen sie auf den Stand von vor 1933 zurück und 1939, nach der staatlich verfügten Schließung des Verlages im Jahr zuvor, kamen nur mehr einzelne Titel heraus, bis die Produktion schließlich gänzlich eingestellt werden musste. ${ }^{118}$

Der Schocken Verlag verfolgte ähnlich wie die übrigen jüdischen Verlagshäuser die Strategie, durch kulturelle Produktion den jüdischen Lesern eine Stütze in der schwierigen politischen Situation zu sein. Trotz der von Joseph Goebbels 1934 verfügten systematischen Ausgrenzung aus dem allgemeinen Literaturbetrieb durch den Ausschluss aus der Reichsschrifttumskammer, ließ man jüdische Autorinnen und Autoren bis Juli 1937 weitgehend unbehelligt in Verlagen mit jüdischen Programmen publizieren. Dadurch blieb die jüdische Verlagslandschaft nicht nur bestehen, sondern vergrößerte sich sogar in den ersten Jahren des NS-Regimes. Laut Schreuder wurde die jüdische literarische Szene

116 Vgl. auch Stefanie Mahrer: Schreiben aus den Katakomben. Bücher als Widerstand. Der Schocken Verlag Berlin in den Jahren 1933 bis 1938. In: Julius H. Schoeps / Dieter Bingen / Gideon Botsch (Hrsg.): Jüdischer Widerstand in Europa (1933-1945). Formen und Facetten. Berlin: de Gruyter 2016, S.222-239.

117 Saskia Schreuder: Würde im Widerspruch. Jüdische Erzählliteratur im nationalsozialistischen Deutschland 1933-1938. Tübingen: Niemeyer 2002, S. 5.

118 Vgl. Henry Wassermann: Bibliographie des Jüdischen Schrifttums in Deutschland 1933-1943. München: Saur 1989, S. xiv-xv. 
in qualitativer wie quantitativer Hinsicht vom [...] Schocken Verlag dominiert, der nach der nationalsozialistischen Machtübernahme prompt auf die neue Situation reagierte, indem er sein bis dahin eher auf einen kleinen, ausgesuchten Adressatenkreis ausgerichtetes Programm zum einen ausweitete und zum anderen popularisierte. ${ }^{119}$

Mit der Einführung von zwei populären Serien, dem Almanach und der Bücherei des Schocken Verlages, kam der Verlag dem Bedürfnis der Leser nach günstigen und im Umfang kleinen Bändchen entgegen.

Der erste Almanach, der zu Rosch ha-Schana 5694 (Herbst 1933) erschien, wurde unter dem Lektorat von Moritz Spitzer fast improvisatorisch aus bestehenden Manuskripten zusammengefügt. Der Erfolg des ersten Almanachs führte nicht nur zu einer zweiten Auflage, sondern auch zur Entstehung einer neuen Reihe innerhalb des Verlagsprogramms. Die günstigen Bände der Schocken-Bibliothek, herausgegeben von Moritz Spitzer, hatten meist einen Umfang von hundert Seiten und folgende Bestimmung:

Die Bücherei des Schocken Verlages will in allmählichem Aufbau aus dem fast unübersehbaren und häufig unzugänglichen jüdischen Schrifttum aller Länder und Zeiten in sorgfältiger Auswahl dasjenige bieten, was den suchenden Leser unserer Tage unmittelbar anzusprechen vermag. $[\ldots]^{120}$

Die Bibliographie des Verlagsprogrammes ${ }^{121}$ zeigt, dass einerseits eigene Projekte verfolgt wurden, andererseits Bestände von anderen Verlagen übernommen wurden. Der Aufbau des Verlages, der nach dem ursprünglichen Plan Schockens langsam hätte stattfinden sollen, beschleunigte sich nach 1933 drastisch. War der Verlag vor 1933 „ein intellektuell anspruchsvoller jüdischer Kulturverlag “ ${ }^{\text {122 }}$, änderte dieser vor allem mit dem Büchereiprogramm seine Ausrichtung in Richtung der Bedürfnisse einer breiteren Leserschaft.

Neben den jährlich zu Rosch ha-Schana erscheinenden Almanachen und der Bücherei-Reihe publizierte der Verlag folgende Sachgruppen: Die Jüdischen

119 Schreuder: Würde im Widerspruch, S. 8.

120 Prospekt der Schocken-Bibliothek.

121 Vgl. für eine detaillierte Darstellung des Programmes nach Sachgruppen geordnet Dahm: Das jüdische Buch im Dritten Reich, S. 321-366.

122 Ebd., S. 323. 
Lesehefte, eine Reihe kleiner und sehr günstiger Veröffentlichungen für Schulen und für Bildungsstätten für Erwachsene, die unter Mitwirkung der Reichsvertretung der deutschen Juden, resp. ab 1936 im Auftrag der Reichsvertretung, ${ }^{123}$ hergestellt wurden. Außerhalb dieser Reihen veröffentlichte der Verlag 80 weitere Titel, wissenschaftliche wie literarische, darunter viele Bücher, die aus anderen Verlagen wie dem Akademie Verlag übernommen wurden. ${ }^{124}$ Der Hebräische Verlag, wie die Produktionsgruppe genannt wurde, unterteilte sich in die Untergruppen klassische hebräische Dichtung, moderne hebräische Dichtung und Manuldrucke, Reproduktionen von Standardausgaben religiöser Gebrauchsliteratur. ${ }^{125}$

Werke nichtjüdischer Autoren wurden nur in Ausnahmen gedruckt, wenn diese von thematischer Relevanz waren. Dazu gehörten Ferdinand Gregorovius Das Ghetto und die Juden in Rom (Band 4, 1935), Von der Frankfurter Juden Vergangenheit (Sitten und Bräuche) (Band 12, 1934), dies ein Auszug aus Johann Jakob Schudts Werk Jüdische Merkwürdigkeiten (1714), Adalbert Stifters Abdias (Band 31, 1935), Johann Gottfried Herders Jüdische Dichtungen und Fabeln (Band 60, 1936), Annette von Droste-Hülshoffs Die Judenbuche (Band 68, 1936), des Weiteren ein Auszug aus Mommsens Römischer Geschichte. Judaea und die Juden (Band 70, 1936), sowie das Lesebuch Das siebenfache Licht (1936), zusammengestellt und herausgegeben von Emanuel bin Gorion. Bis auf Die Judenbuche wurde keines der eben erwähnten Bücher von den Nationalsozialisten beanstandet. Die Judenbuche wurde am 24. April 1937 verboten, aber nicht, wie Lambert Schneider festhielt, beschlagnahmt. ${ }^{126}$ Laut einem internen Schreiben der Gestapo hatte der Schocken Verlag sofort nach dem Erhalt des Verbotsschreibens der Reichsschrifttumskammer die Auslieferung des Buches gestoppt. Zu diesem Zeitpunkt befanden sich noch 300 Exemplare beim Verlag und bei der Buchbinderei Knaur \& Denck in Leipzig weitere 3.000 Rohdrucke. ${ }^{127}$ Der Verlag versuchte nach erlangter Genehmigung, die Restbestände des

123 Schocken war mit dieser Kooperation nicht einverstanden, beugte sich der Situation jedoch, vgl. ebd., S. 330 .

124 Vgl. ebd., S. 336-339.

125 Ebd., S. 331-336.

126 Vgl. Schneider: Salman Schocken, S. 200.

127 Vgl. Geheime Staatspolizei, Staatspolizeistelle Berlin an Geheime Staatspolizei, Geheimes Staatspolizeiamt, 10.05.1937. Bundesarchiv Berlin (fortan BArch), R 58/1023. 


\section{BÜCHEREI DES SCHOCKEN VERTAGS}

\section{Die Bücherei des Schocken Verlags will in allmäh-}

lichem Aufbau aus dem fast unübersehbaren und häufig unzugänglichen jüdischen Schrifttum aller Länder und Zeiten in sorgfältiger Auswahl dasjenige darbieten, was den suchenden Leser unserer Tage unmittelbar anzusprechen vermag. Die alte hebräische Literatur, deren Lebendigkeit sich gerade in kritischen Zeiten bewährt, soll durch sinnvolle Auszüge und angemessene Übertragungen, sowie durch zweisprachige Ausgaben dem heutigen Leser erschlossen werden. Aus dem zeitgenössischen jüdischen Schrifttum werden dichterische und erörternde Arbeiten aufgenommen, die in gedrängter Form Gültiges mitzuteilen haben. Verschollene oder nicht gebührend bekannte Werke der jüngeren Vergangenheit werden in Neudrucken herausgegeben. Hinzu kommen in wachsendem Maß Bücher belchrenden Inhalts.

1

Die Tröstung Israels. Aus Jeschajahu, Kapitel 40 bis 55. Hebräisch mit der Verdeutschung von Martin Buber und Franz Rosenzweig. I Diese sechzehn Kapitel des Jesaja-Buchs haben im jüdischen Bewußtsein, in Exegese und Liturgie seit je ihren Ort als das Trostbuch Israels gehabt. "Was diese Übersetzung für den Juden leistet, ist hier besonders intensiv zu fühlen. Das ist so stark, daß auch der Unwissende der Täuschung erliegen mag, das Urwort unmittelbar zu vernehmen.»(Efraim Frisch)

\section{2} Jehuda Halevi: Zionslieder. Hebräisch, mit der Verdeutschung von Franz Rosenzweig und seinen Anmerkungen. / Von den Dichtungen des unbestritten größten hebräischen Dichters sind in diese Auswahl 21 aufgenommen, die von Israel und Zion handeln. "Bei einer schlechthin vorbildlichen Treue und Genauigkeit gegenüber dem Original ist die enorme Musik des Dichters, die Größe und Tiefe seiner Inbrunst, das Pathos seiner mächtigen Sprache ungewöhnlich im Deutschen verwirklicht.

\section{3} Joseph und seine Brüder. Ein altjüdischer Roman. Herausgegeben von Micha Josef bin Gorion./ Die vorliegende Fassung folgt im wesentlichen dem Sefer Hajaschar (Buch der Redlichen), einem hebräischen Volksbuch des Mittelalters, in welchem so vieles, was in nachbiblischer Zeit frommer Glaube, Phantasie und rückgewandte Sehnsucht an den großen Gestalten der Vorzeit weiter gedichtet, geträumt und gedeutet hat, zusammenströmt. Die Erzählung ist von großer Einfachheit und Schönheit.

\section{Martin Buber: 100 Chassidische Geschichten. Die Reihe führt von Gott über Dienst und Weg, Sünde und Umkehr, Einfalt und Demut, Menschen- und Kreaturenliebe, Lehren und Lernen, Leid der Person und der Gemeinschaft hin zur Erlösung. "Es ist eine Theologie, die mitten in der Welt wohnt, spannungslos und selbstverständlich, als in dem einzigen ihr zukommenden Haus. Wie sich aus dem natürlichen Le- ben das geistig Bedeutungsvolle auslöst, ist demütig und köstlich zuglaich.}

In Pape gebunderi M $1.25 /$ Doppelnummer M 2.50

Abb. 6: Prospekt der Bücherei des Schocken Verlags, erste Seite, Typographie Malte Max Müller, 1935. 


\section{BÜCHEREI DES SCHOCKEN VERTAGS}

5 S. J.Agnon: In der Gemeinschaft der Frommen.

Sechs Erzählungen aus dem Hebräischen. I In den Agnonschen Geschichten entfaltet sich dichterisch die Gemütswelt des Chassidismus. Die Grenze vom Gewöhnlichen zum Wunderbaren ist in ihnen durch die milde Fülle eines gläubig erfahrenen Alltags überbrückt. »Solcher Alltag mag in der Wirklichkeit schwinden, der Dichter Agnon läßt seine innere Vollständigkeit und Erfülltheit noch einmal lebendig werden." (Efraim Frisch)

6 Leo Baeck: Die Pharisäer. Ein Kapitel jüdischer Geschichte. / Hier liegt endlich von berufener jüdischer Seite eine gemeinverständliche, klare Darstellung jener umstrittensten Erscheinung der jüdischen Geschichte vor, die nicht nur im Hinblick auf die alte religionsgeschichtliche Auseinandersetzung und die aus ihr sich ergebende Tagespolemik von Bedeutung ist, sondern darüber hinaus für das geistige Wesen auch des modernen Judentums als bestimmender Faktor gewertet werden muß.

\section{Aron David Bernstein: Vögele der Maggid.}

Eine Novelle. / Um die von innerem. Glanz erfüllte Geschichte zweier liebender Mädchen und ihrer Umgebung baut sich in der Novelle das Leben einer jüdischen Gemeinde vor hundert Jahren im deutschen Osten auf. Mit bezaubernder Anmut ist dem Dichter diese Schilderung gelungen. Im Gegensatz zu den späteren Auflagen geht diese Veröffentlichung auf die erste ungleich echtere und lebensnähere Fassung mit ihrem »Judendeutsch« zurück.

8 Das Haus Israel. Aus den Schriften von David Koigen. Herausgegeben und mit einem Nachwort versehen von Ernst Hoffmann. Der russisch-jüdische Philosoph Koigen, der von 1919 bis 1921 an der Universität in Kiew lehrte und dann nach Deutschland flüchtete, wo er 1933 starb, ist hier mit einer Auswahl aus seinen Schriften vertreten. Er sucht eine aus der geschichtlichen Wirklichkeit geschöpfte Antwort auf die Frage, die das Dasein des Judentums Juden und Nichtjuden auf Schritt und Tritt aufgibt.

9

Das Leben des Flavius Josephus. Aus seinen eigenen Aufzeichnungen zusammengestellt und übersetzt von Emanuel bin Gorion. I Aus den Schriften des Josephus hat der Herausgeber eine Lebensgeschichte gehoben, die zugleich ein Bild von der Zeit vor dem Untergang des jüdischen Staatswesens vermittelt. "Wie immer auch dieser jüdische Julius Cäsar als Charakter in der Geschichte fortlebt, diese seine Kriegsschilderung sollte unserer Jugend in größtem Ausmaß zugängig gemacht werden.»

Sprichwörter und Redensarten deutsch-jüdischerVorzeit. Aufgezeichnet und nach Wort und Sinn erklärt von Abraham Tendlau. / Zu jedem Sprichwort gibt Tendlau eine kleine Wort- und Sinnerklärung, wobei er auch auf die Etymologie, auf die Verwandtschaft mit ähnlichen Sprichwörtern anderer Völker usw. eingeht und die Zusammenhänge mit dem jüdischen Schrifttum erörtert. Diese Erläuterungen geben einen einzigartigen Einblick in jüdische Überlieferung und volkstümlicheDenkweise.

In Pappegebunden M $1.25 /$ Doppelnummer M 2.50 
Buches an einen ausländischen Verlag zu verkaufen. ${ }^{128}$ Da kein Käufer gefunden werden konnte, wurden die Bestände Mitte Juli 1938 vernichtet. ${ }^{129}$

Bis zur Einführung der Vorzensur Ende Juli 1937 konnte der Schocken Verlag relativ ungehindert publizieren. Insgesamt brachte er es von der Gründung im Jahr 1931 bis zu seiner Zwangsschließung Ende 1938 auf 249 Titel (ohne unveränderte Neuauflagen), zwei Drittel davon in den Jahren 1934 bis $1937 .{ }^{130}$ Der Schocken Verlag konnte auch nach August 1937 einigermaßen ungehindert sein Programm weiterverfolgen. Als jüdischer Verlag, der er schon vor dem Ausschluss aus der Reichsschriftkammer war, produzierte er weiterhin Bücher für, zumindest offiziell, ein jüdisches Publikum.

\subsubsection{Zwangsschließung Ende 1938}

Im Laufe des Jahres 1938 wurde es auch für den Schocken Verlag deutlich schwieriger, weiterzuarbeiten. Die Einführung der Zensur, die immer gewalttätigeren Übergriffe auf Juden und Jüdinnen, die erschwerten Reisebedingungen für die Verlagsmitarbeitenden und die forcierten Zwangsenteignungen von jüdischen Betrieben führten schließlich zur Zwangsschließung des Verlages. Zwar glaubte im Juli 1938 Moritz Spitzer, der Lektor des Schocken Verlags, noch daran, zu Pessach 1939 den hundertsten Band der Schocken-Bücherei als Abschluss zu publizieren. Jedoch liefen gleichzeitig intensive Vorbereitungen zur Rettung des Buchlagers ins Ausland.

Im Juli 1938 traf sich Theodor Schocken mit Spitzer in London. In Theodors Brief an seinen Vater vom 14. Juli 1938 ging es darum, wie der Schocken Verlag weiterbestehen könnte:

Durch die Vorgänge in den letzten Wochen, die das ganze Bild der jüdischen Existenz in Deutschland völlig verändert haben, glaubt Dr. Spitzer auch eine Änderung in diesem Programm für richtig zu halten. Er schlägt vor, dass die hebräische und wissenschaftliche Produktion, die ja vom Vertrieb in Deutschland im wesentlichen unabhängig ist, weiter fortgesetzt wird, soweit dafür Mittel bei der Abwicklungsstelle zur Verfügung stehen.

128 Vgl. Geheime Staatspolizei, Staatspolizeistelle Berlin an Geheime Staatspolizei, Geheimes Staatspolizeiamt, 23.12.1937. BArch, R 58/1023.

129 Vgl. Geheime Staatspolizei, Staatspolizeistelle Berlin an Geheime Staatspolizei, Geheimes Staatspolizeiamt, 06.08.1938. BArch, R 58/1023.

130 Vgl. Dahm: Das jüdische Buch im Dritten Reich, S. 308. 
Die Bücherei möchte Dr. Spitzer langsam weiterführen, sodass etwa zu Pessach nächsten Jahres der Band 100 erscheint, den Dr. Spitzer jetzt im Gegensatz zu seinen früheren Auffassungen als Abschlussband der Bücherei betrachtet.

Dr. Spitzer glaubt, dass als Folge der jetzigen Vorgänge der Käuferkreis für unsere Bücher in ganz kurzer Zeit zusammenschrumpfen wird, und dass der deutsche Markt also keine genügende Basis für eine weitere Produktion bietet. Er hat auch den Eindruck, dass das Interesse der Juden an der Lektüre von Büchern jüdischen Inhalts erheblich vermindert ist, und er glaubt, dass - ganz im Gegensatz zu der Lage im Jahre 1933 - es keine Stütze mehr für das deutsche Judentum bedeutet, wenn man jüdische Bücher noch herausbringe. [...] Er hat [...] aus Gesprächen mit Buchhändlern gehört, dass das Interesse an jüdischen Büchern unserer Art fast erlahmt sei.

Die Menschen wollen, wenn sie schon ein Buch in die Hand nehmen, heute irgendeine leichte Lektüre haben, die sie von den Problemen des Tages ablenkt. Die Jugend, die in den Schulen mit jüdischen Dingen überfüttert würde, wehre sich zum Teil schon gegen das Lesen von jüdischen Büchern. [... $]^{131}$

Es wird deutlich, dass Spitzer im Sommer 1938 von einem stark verminderten Interesse an jüdischen Büchern ausging. Spitzer war zudem wegen der offenen Drohungen Hitlerdeutschlands gegen sein Heimatland Tschechoslowakei um seine eigene Sicherheit besorgt. ${ }^{132}$ Auch zeigte die Évian-Konferenz, dass sich kein Staat dazu entschließen wollte, der bedrohten jüdischen Bevölkerung Deutschlands substantielle Hilfe in Form von Einwanderungsbewilligungen oder Asyl zu gewähren. ${ }^{133}$ Der Abbruch der Münchner Synagoge auf Anordnung Hitlers Anfang Juni 1938 und die Inhaftierung von insgesamt 1.500 ,vorbestraften' Juden und ,asozialen' Nichtjuden in Konzentrationslagern waren nur zwei Ereignisse, die deutlich machten, dass es für Juden und Jüdinnen in Hitlerdeutschland keine Zukunft mehr gab. Theodor kommentierte die Einschätzung Spitzers mit folgenden Worten: „So weit Spitzers Meinung, ich teile sie nicht ganz, wenn ich auch verstehe, dass Spitzer nach den Erlebnissen und

131 Theodor Schocken an Salman Schocken, 14.07.1938. SchA, Verlag, 331/41.

132 Vgl. dazu genauer Kap. 9.1.

133 Zur Asylpolitik in den 1930er und 1940er Jahren vgl. u. a. Frank Caestecker / Bob Moore (Hrsg.): Refugees From Nazi Germany and the Liberal European States. New York: Berghahn 2010; Susanne Heim: International Refugee Policy and Jewish Immigration Under the Shadow of National Socialism. In: Ebd., S. 17-47; Insa Meinen: Verfolgt von Land zu Land. Jüdische Flüchtlinge in Westeuropa 1938-1944. Paderborn: Schöningh 2013. 
Erfahrungen der letzten Wochen heute die jüdische Situation in Deutschland so negativ sieht. ${ }^{\text {134 }}$

Moritz Spitzer beklagte sich später, dass Schocken, Buber sowie Lambert Schneider die Gefahr ignoriert hätten; sie hätten den Verlag einfach in Deutschland weiterführen wollen. Für Spitzer hingegen war 1938 klar, dass die Probleme der unter immer stärkeren Repressionen leidenden Juden nicht mit Büchern behoben werden konnten. Nach den gewalttätigen Ausschreitungen in der Reichspogromnacht schien die Auflösung des Verlages ihm kaum mehr aufhaltbar. ${ }^{135}$ Schocken hingegen versuchte um jeden Preis, die Aufgabe des Verlages zu verhindern, selbst nach den Pogromen in der Nacht vom 8. auf den 9. November 1938 wollte er von einer Liquidation nichts wissen. ${ }^{136}$ Der durch die Nationalsozialisten angeordneten Zwangsliquidation Ende Dezember 1938 konnte sich dann aber auch Salman Schocken nicht mehr widersetzen.

\subsection{Das Buch im Netzwerk}

\subsubsection{Das Netzwerk der Beziehungen}

Peter de Mendelssohn bezeichnete die Geschichte eines Verlages als „die Geschichte einer eng verflochtenen Gemeinschaft von Schaffenden, die auf kleinen Raum zusammenwirken und deren Wirken in die Fremde auszustrahlen vermag. ${ }^{\text {"137 }}$ Die Räumlichkeiten des Schocken Verlages an der Jerusalemer Straße in Berlin, eine Adresse nahe dem Gendarmenmarkt in unmittelbarer Nähe zum Mossehaus ${ }^{138}$, dem Sitz des vom deutsch-jüdischen Verleger Rudolf Mosse gegründeten Mosse-Verlages, lagen mitten in dem damaligen Zeitungsviertel der Hauptstadt. In diesem Viertel in der südlichen Friedrichstadt hatten

134 Theodor Schocken an Salman Schocken, 14.07.1938. SchA, Verlag, 331/41.

135 Vgl. Dahm: Das jüdische Buch im Dritten Reich, S. 445-462.

136 Vgl. Ebd., S. 449.

137 Peter de Mendelssohn: S. Fischer und sein Verlag. Frankfurt am Main: S. Fischer 1959, S. 1332 .

138 Das sogenannte Mossehaus wurde von den Architekten Wilhelm Cremer und Richard Wolffenstein entworfen und befindet sich an der Ecke Jerusalemer/Schützenstraße. Das Haus wurde während der Novemberrevolution im Jahr 1919 stark beschädigt. Der Nachfolger Rudolf Mosses beauftragte den Architekten Erich Mendelsohn mit der Neugestaltung. Vgl. Ita Heinze-Greenberg: Erich Mendelsohn. ,Bauen ist Glückseligkeit'. Berlin: Hentrich \& Hentrich 2011, S.35. 
über 500 Druckereien, Verlagshäuser und Betriebe des grafischen Gewerbes ihren Sitz. ${ }^{139}$ Dass Salman Schocken diese Adresse im Zentrum der Berliner Buchproduktion als Verlagssitz wählte, war wohl kein Zufall. Es soll hier aber weniger um die Beziehungen des Verlages in diesem Quartier gehen, sondern vielmehr um das Beziehungsnetz des Schocken Verlages in der deutschjüdischen Kultur. Der Verlag und seine Mitarbeitenden waren gewichtige Akteure in diesem Netzwerk. Es wird im Folgenden den Akteuren wie auch den Verbindungslinien dieses Netzwerkes nachgegangen.

Salman Schocken war, bis er 1935 seinen Sohn Theodor als Teilhaber in den Verlag holte, alleiniger Besitzer. Da er aber kaum präsent war, lagen die Geschäfte in der Hand der Belegschaft. Lambert Schneider, der bis Frühling 1938 die Funktion des Verlagsleiters innehatte, war zuständig für Autorenkorrespondenz, Werbung, Herstellung und sämtliche administrativen Angelegenheiten. Lucy Knopf unterstützte ihn als Sekretärin ab Juni 1932. Moritz Spitzer war ab Mai 1932 freier Redakteur und Lektor, und wechselte Ende 1934 hauptberuflich in den Verlag. Er war zuständig für das gesamte Lektorat, die Lektoratskorrespondenz sowie für die beiden erfolgreichsten Serien Almanach und Bücherei. Ab Frühjahr 1938 war er Geschäftsführer des nunmehr vom Schocken-Konzern unabhängigen Verlages. ${ }^{140}$ Dora Landauer und Frau Loewenstein-Rosenthal waren für sein Sekretariat verantwortlich. Ebenfalls zu den festen Verlagsmitarbeitenden gehörten Hedwig Hünecke, die ab Ende 1943 als Vertriebsleiterin arbeitete, Lucie Birnbaum, Schockens Büroleiterin in Berlin, die die Verbindung zwischen Schocken und dem Verlag darstellte, sowie Fritz Picard, freier Verlagsvertreter, Ernst Cohn, der ab 1934 für Kalkulationen, Verträge und die Kontrolle der äußeren Herstellung verantwortlich war, sowie Frau Steinhoff, der die allgemeinen Schreibarbeiten sowie die Rezensionskontrolle oblagen. Darüber hinaus war Martin Buber als freier Lektor eng mit dem Verlag verbunden.

Salman Schocken hatte im Verlag keinen eigenen Arbeitsplatz, aber den brauchte er auch nicht, da er nur ganz selten persönlich in Berlin anwesend war. Nach seiner Emigration nach Jerusalem Ende des Jahres 1933 verbrachte er bis 1936 alljährlich zwar weiterhin viele Monate in Deutschland und ab 1936

139 Zum Zeitungsviertel vgl. Unda Hörner: Orte jüdischen Lebens in Berlin. Literarische Spaziergänge durch die Mitte. Berlin: Insel 2010, S. 17-42.

140 Vgl. Dahm: Das jüdische Buch im Dritten Reich, S.311-316. 
in verschiedenen europäischen Städten; ${ }^{141}$ er leitete den Verlag jedoch durch Korrespondenz und Berichte aus der Ferne. Das Tagesgeschäft oblag Spitzer und Schneider und deren Mitarbeiterinnen, was aber nicht bedeutete, dass Schocken keinen Einfluss ausübte. Die Verlagskorrespondenz sowie weitere Akten des Verlages im Schocken Archiv ${ }^{142}$ geben Aufschluss darüber, dass er zu jeglichen Fragen konsultiert werden wollte und dass er, was die Auswahl der Autor*innen, die Ausrichtung des Verlagsprogramms, sowie die Gestaltung der einzelnen Bände bis hin zur Auswahl des Papiers anbelangte, nicht nur bestens informiert war, sondern aktiv mitbestimmte. Auch sind Druckfahnen überliefert, in denen Schocken als Lektor Korrekturen anbrachte.

Neben den festen Mitarbeitenden gehörten auch die Autoren zum engen Beziehungsgeflecht des Verlags. Einige von ihnen standen in sehr engem Verhältnis zum Verlag, darunter natürlich Martin Buber, einer der ersten und wichtigsten Verlagsautoren, aber auch S.J. Agnon, Gershom Scholem und Ernst Simon, um nur einige Wenige zu nennen. Die Autoren waren nicht nur dem Verlag, sondern genauso seinem Besitzer Salman Schocken verbunden und das auf verschiedenen Ebenen. Buber und Agnon pflegten ein freundschaftliches Verhältnis mit Schocken, daneben waren sie finanziell von ihrem Verleger abhängig. Schocken und Scholem verband das gemeinsame Interesse an traditionellen jüdischen Texten und raren Druckwerken, Simon und Buber das Interesse an jüdischer Bildung. Ganz anders wiederum war die Verbindung zwischen Karl Wolfskehl und Schocken geformt. Schocken erwarb die Bibliothek des Dichters und ermöglichte diesem damit die Flucht aus dem nationalsozialistischen Deutschland. ${ }^{143}$ Menachem Zulay, um ein letztes Beispiel zu nennen, war als Leiter des Forschungsinstituts für mittelalterliche jüdische Dichtung auch gleichzeitig einer der regelmäßigen Verlagsautoren.

Die weite Ausdehnung dieses Netzwerkes ließe sich unendlich weiter rekonstruieren, denn es sind, so de Mendelssohn, „unzählige Strähnen inneren und

141 Vgl. Kap. 9.1.

142 Schocken verlangte, dass Durchschläge von Briefen, Kopien von Verträgen und ähnlichen Dokumenten kontinuierlich zur Kontrolle und Archivierung an sein Sekretariat in Jerusalem geschickt wurden. Vgl. Richtlinien für die Korrespondenz zwischen Herrn Schocken und Konzern und Verlag, 26.01.1936. SchA, Verlag, 331/47.

143 Vgl. Tomke Hinrichs: Fluchthilfe. Der Ankauf der Bibliothek von Karl Wolfskehl durch Salman Schocken. In: Medaon - Magazin für jüdisches Leben in der Forschung und Bildung 13 (2013), S. 1-4; Caroline Jessen: Der Sammler Karl Wolfskehl. Berlin: Jüdischer Verlag 2018, S. $188-191$. 
äußeren menschlichen Geschicks in den Teppich der Verlagsgeschichte einzuweben ${ }^{\text {"144 }}$. Eine erste Analyse von Schockens Gesamtkorrespondenz zeigt, dass die wenigen persönlichen Beziehungen, die er pflegte, durch sein Interesse an Büchern und Literatur entstanden. Zudem standen persönlicher Kontakt und Korrespondenz nie für sich allein, sie verliefen vielmehr gleichzeitig und eng verflochten mit der geschäftlichen Verbindung.

Eine dieser Beziehungen soll hier nun im Detail beleuchtet werden, nämlich jene zwischen Martin Buber und Salman Schocken. Die Wahl Bubers als Beispiel hat mehrere Gründe: Die Verbindung von Schocken zu Buber geht auf die Anfänge von Schockens zionistisch motiviertem Interesse an jüdischen Büchern zurück, es verbanden die beiden zudem viele unterschiedliche Projekte, die alle mit Büchern in Zusammenhang standen. Nicht zuletzt hat die Wahl einen pragmatischen Grund: Die Korrespondenz ist fast lückenlos überliefert, einerseits im Schocken Archiv, andererseits im Buber Archiv der Nationalbibliothek in Jerusalem.

\subsubsection{Bücher und Geld -}

\section{die Beziehung zwischen Martin Buber und Salman Schocken}

Die erste Kontaktaufnahme zwischen Schocken und Buber wurde bekanntlich durch Schockens Lektüre von Bubers Rabbi Nachman initiiert. Dass gerade ein Buch Anlass für den Anfang der Beziehung gab, ist paradigmatisch für das Verhältnis zwischen diesen unterschiedlichen Männern; die Freundschaft war im Wesentlichen durch ihr Interesse an Büchern und Texten bestimmt.

Eines der ersten Projekte, das sie zusammenbrachte, war die Sammlung von Büchern für jüdisch-russische Gefangene während des Ersten Weltkrieges. Viele Juden russischer Herkunft konnten oder wollten nach Kriegsbeginn nicht aus Deutschland ausreisen und wurden in der Folge als Angehörige einer feindlichen Kriegspartei in kleineren deutschen Provinzstädten, u. a. in Zwickau, interniert. Schocken zeigte ein besonderes Interesse an den ,jüdischen Gefangenen $^{\text {“145 }}$, wie er sie nannte. Einerseits kämpfte er auf mehreren Ebenen für die Zulassung der russisch-jüdischen Kinder an Schulen, andererseits initiierte er

144 Mendelssohn: S. Fischer und sein Verlag, S. 1333.

145 Vgl. u. a. Salman Schocken an S. J. Czaczkes, 22.02.1916. NLI, Agnon Archiv, Arc. 4. 1270; Martin Buber an Salman Schocken, 23.01.1917, 15.03.1917 und 16.04.1917. NLI, Buber Archiv, Ms. Var. 350/705I; Salman Schocken an Martin Buber, 18.04.1917. NLI, Buber Archiv, Ms. Var. 350/705. 
eine „Maßnahme zur Beschaffung von Lesestoff“"146 . Martin Buber war Teil dieser Aktion, indem er auf Bitte von Schocken Listen von Büchern erstellte, die er als geeigneten Lesestoff für die Internierten erachtete. ${ }^{147}$ Die Korrespondenz impliziert, dass Schocken als Auftraggeber fungierte und Buber für die etwas mühseligere Organisation verantwortlich war. „Ich bitte Sie“, schrieb Schocken am 18. April 1917 an Buber, „mir die genaue [sic] Versandbestimmungen zu verschaffen. "148 Auch übernahm Schocken einen Teil der Verhandlungen mit den Verlagen um günstige Konditionen ${ }^{149}$ und zeigte sich für das Einwerben von Spendengeldern verantwortlich, wobei Buber ihm dabei beratend zur Seite stand. ${ }^{150}$

Die Bücherspenden für internierte russische Juden waren eine Privataktion Schockens, der angetrieben von der Überzeugung, Erziehungsarbeit durch die Verbreitung von geeignetem Lesestoff leisten zu müssen, über den Zeitraum von ungefähr zwei Jahren sehr systematisch Bücher erwarb und diese in die Lager schicken ließ. Dieses Projekt für die jüdische Literatur brachte Buber und Schocken auf einer Ebene zusammen, die man als halbprivat bezeichnen kann. Die Auswahl der Bücher, deren Beschaffung und Verschickung führte zu einem Kontakt zwischen ihnen, der parallel zu den gemeinsamen Arbeiten im Kulturausschuss verlief. Das Zusammenspiel zwischen Schocken, dem Kaufmann, und Buber, dem Akademiker, zeichnet sich in dieser Zusammenarbeit bereits ab: in diesem Fall als Kooperation im Besorgen von Büchern, in Hinweisen auf mögliche Autoren bzw. das Empfehlen von Literatur. Diese Art des Austauschs war paradigmatisch für die Beziehung zwischen Schocken und Buber. Es wird deutlich, wie wichtig das Buch in dem Verhältnis der beiden Männer war.

Bis zur Verlagsgründung im Jahr 1931 blieben die gemeinsame Arbeit für den Kulturausschuss und das geteilte Interesse an der Verbreitung jüdischen Schriftgutes die zentralen Kontaktpunkte zwischen Martin Buber und Salman

146 M[iriam] Nussbaum: Chronologische Darstellung der jüdischen und zionistischen Tätigkeiten des Herrn Salman Schockens. SchA, Katalog zu 5: Jüdisches und Zionistisches.

147 Vgl. Martin Buber an Salman Schocken, 15.03.1917. NLI, Buber Archiv, Ms. Var. 350/705I.

148 Salman Schocken an Martin Buber, 18.04.1917. NLI, Buber Archiv, Ms. Var 350/705.

149 Vgl. Salman Schocken an Martin Buber, 31.05.1917. NLI, Buber Archiv, Ms. Var $350 / 705$.

150 Vgl. Martin Buber an Salman Schocken, 23.01.1917. NLI, Buber Archiv, Ms. Var. $350 / 705 \mathrm{I}$. 
Schocken. Darüber hinaus begann Schocken in den 1920er Jahren damit, seine private Bibliothek systematisch aufzubauen, Martin Buber und auch S.J. Agnon unterstützten ihn mit Wissen und Kontakten. So schreibt Schocken Ende Juni 1921 an Buber: „Auf Ihren Brief vom 18. Juni teile ich Ihnen mit, dass ich bereit bin, die mir empfohlene Handschrift zu erwerben und ich bitte Sie, an Herrn Bloch einen Kaufauftrag zu senden. ${ }^{\text {"151 }}$ Es handelte sich dabei um eine Handschrift des Buches des Rabbi Eisik von Kalew, die ursprünglich Buber angeboten wurde, für diesen aber zu teuer war. ${ }^{152}$ Ähnlich diesem Fall vermittelte Buber regelmäßig Bücher an Schocken.

Die Episode macht aber auch das Gefälle zwischen den beiden deutlich. Dass sich Schocken eine wichtige Handschrift leisten konnte, die Buber angeboten wurde, ist bezeichnend für die Beziehung. Ab 1923 vergrößerte sich Bubers finanzielle Abhängigkeit von Schocken. Im Oktober 1923 bat dieser seinen Freund ein für seine Arbeit wichtiges, aber für ihn viel zu teures Nachschlagwerk zu erwerben, ${ }^{153}$ was Schocken nur wenige Tage nach Erhalt von Bubers Schreiben auch tat. ${ }^{154}$ Nur wenige Monate darauf sah sich Buber gezwungen, Schocken um ein regelmäßiges Darlehen zu bitten. Der Zerfall der Währung brachte ihn in finanzielle Nöte.

Meine wirtschaftliche Lage, die seit der rückläufigen Bewegung auf dem Büchermarkt, also seit einem Jahr nicht günstig war, hat sich in den letzten Wochen so kompliziert, dass ich damit rechnen muss, in den Monaten Februar und März im Wesentlichen auf mein Gehalt vom Jüdischen Verlag - das für Dezember 210 Mark betrug - angewiesen zu sein. [...] [U]m über die schwierigste Zeit hinüberkommen zu können, habe ich daran gedacht ein Darlehen aufzunehmen, das mindestens 500 Mark betragen müsste [...]. Könnte ich es von Ihnen erhalten? [...] Meine Arbeitsfähigkeit hängt gegenwärtig in hohem Masse davon ab, ob ich die drückendsten Wirtschaftssorgen loswerde. ${ }^{155}$

151 Salman Schocken an Martin Buber, 28.06.1921. NLI, Buber Archiv, Ms Var 350/705.

152 Vgl. Martin Buber an Salman Schocken, 18.06.1921. NLI, Buber Archiv, Ms Var 350/705I.

153 Vgl. Martin Buber an Salman Schocken, 19.10.1923. NLI, Buber Archiv, Ms Var 350/705I.

154 Vgl. Salman Schocken an Martin Buber, 23.10.1923. NLI, Buber Archiv, Ms Var $350 / 705$.

155 Martin Buber an Salman Schocken, 05.01.1924. NLI, Buber Archiv, Ms Var 350/705I. 
Schocken zeigte sich ohne Zögern und ohne „besondere[...] Versicherung ${ }^{\text {«156 }}$ dazu bereit, Buber auszuhelfen. Auch die Rückzahlung wollte er erst später besprechen. ${ }^{157} \mathrm{Ab}$ diesem Zeitpunkt war Buber finanziell von Schocken abhängig, denn das als kurzzeitige Nothilfe gedachte Darlehen wurde mehrmals verlängert, darüber hinaus finanzierte Schocken einige Buch- und Forschungsprojekte Bubers auch nach dessen Berufung an die Universität Frankfurt im Herbst 1930.

Schocken finanzierte Buber, damit dieser ohne größere finanzielle Sorgen seiner philosophischen und schriftstellerischen Arbeit nachgehen konnte. Dabei waren Bücher ein zentrales verbindendes Element. Dies wurde nochmals verstärkt, als Schocken das von Lambert Schneider in seinem Verlag angesiedelte Übersetzungsprojekt der Bibel übernahm. Der junge Lambert Schneider setzte sich das ambitionierte Ziel, eine neue, eng am hebräischen Originaltext gehaltene Übersetzung des Pentateuchs zu publizieren. Martin Buber und Franz Rosenzweig wurden mit der Übersetzungsarbeit beauftragt, die nach dem Tod Franz Rosenzweigs nur noch langsam vorankam. Auf Anraten Leo Baecks wandte sich Schneider an Schocken, der gerade dabei war, seinen Verlag zu gründen. Nach einigem Überlegen übernahm Schocken mit der Schocken Liga 1930 das Bibelprojekt von Lambert Schneider. Im Zuge der Expansion des Schocken Verlages im Frühsommer 1933 kamen auch die übrigen BuberWerke vom Schneider Verlag zu Schocken. ${ }^{158}$ Einen Tag nach der offiziellen Übernahme legte Lambert Schneider im Namen des Schocken Verlages Buber einen Vertragsentwurf ${ }^{159}$ vor, kurz darauf kam es dann zum Vertragsabschluss. ${ }^{160}$ Buber verpflichtete sich damit vertraglich, alle Buchmanuskripte zuerst dem Schocken Verlag anzubieten. Als Honorar wurden ihm 15 Prozent vom Ladenpreis der billigsten gebundenen Ausgabe zugesprochen. Diese Klausel sollte solange Gültigkeit haben, wie Martin Buber Honorarvorschuss bezog. Sobald

156 Salman Schocken an Martin Buber, 20.01.1924. NLI, Buber Archiv, Ms Var 350/705.

157 Vgl. ebd.

158 Vgl. Honorarzahlungen an Professor Buber, verf. von Lambert Schneider, 12.06.1933. NLI, Buber Archiv, Ms Var 350/705.

159 Vgl. Vertragsentwurf und Brief, Lambert Schneider an Martin Buber, 16.06.1933. NLI, Buber Archiv, Ms Var 350/705.

160 Der gültige Vertrag ist nicht datiert, die Ablageordnung innerhalb der Archivs lässt aber darauf schließen, dass der Vertrag noch im selben Monat, also im Juni 1933, unterzeichnet wurde. 
der Honorarvorschuss abgedeckt wäre, stand es Buber laut dem üblichen Generalvertrag frei, seine Manuskripte in einem höher bietenden Verlag zu publizieren. Dieser Fall konnte jedoch kaum je eintreten, betrug der Honorarvorschuss bis zur Unterzeichnung des Vertrages bereits etwas mehr als 28.000 Reichsmark. Neben vielen Detailfragen wurde auch ein genauer Arbeitsplan für die Bibelübersetzung im Vertrag vermerkt. Dieser Plan war jedoch derart ambitioniert, dass er nicht eingehalten werden konnte: Buber hätte innerhalb von drei Jahren acht Bände zur Druckreife bringen müssen. ${ }^{161}$

Fünfzehn Monate darauf schloss der Verlag einen weiteren Vertrag mit Martin Buber ab, in dem dieser als fester Lektor und Verlagsberater bis Ende des Jahres 1936 verpflichtet wurde. ${ }^{162}$ Die damit geschaffene vertragliche Bindung zwischen Buber als Autor wie Lektor und Schocken als Verleger scheint die Beziehung verändert zu haben. Die persönlichen Briefe wurden nun seltener, auch wenn Buber Schocken im Mai 1934 nochmals um Hilfe bat, als sein Sohn mit Zertifikat nach Palästina auswandern wollte, um dort in der Landwirtschaft zu arbeiten. Er musste für Reise- und Ausrüstungskosten aufkommen, da sein Sohn über kein eigenes Auskommen verfügte. Daher bat er Schocken um ein Darlehen von 600 RM. ${ }^{163}$ Es wird aus einem späteren Brief jedoch deutlich, dass Buber zunehmend zögerte, Schocken um finanzielle Hilfe zu bitten. Schocken sei für ihn „nie der reiche Mann gewesen“, sondern „immer ein Mensch, der mich angeht, dessen Existenz mir wichtig ist, der zum Bau meines Lebens gehört. “164 Indem Schocken nun sein Verleger sei, habe sich an dieser „inneren Beziehung“ nichts geändert, jedoch habe sich bei Buber „ein natürliches, legitimes Gefühl der Leistungsverpflichtung“ eingestellt. ${ }^{165}$ Die Beziehung nahm ab diesem Zeitpunkt verstärkt einen professionellen Charakter an, auch wenn sie weiterhin durch das gemeinsame Interesse am Buch geprägt war. Der Schocken Verlag brachte nicht weniger als 30 unabhängige Publikationen von Buber heraus, dazu kamen die Neu- und Sonderausgaben der Schrift, zwei

161 Vgl. Vertrag zwischen Herrn Professor Buber und dem Schocken Verlag, o. D. NLI, Buber Archiv, Ms Var 350/705.

162 Vgl. Abkommen zwischen Schocken Aktiengesellschaft und Martin Buber, 28.09.1934. NLI, Buber Archiv, Ms Var 350/705.

163 Vgl. Martin Buber an Salman Schocken, 16.05.1934. NLI, Buber Archiv, Ms Var 350/705I.

164 Martin Buber an Salman Schocken, 03.10.1934. NLI, Buber Archiv, Ms Var 350/705I.

165 Ebd. 
Privatausgaben sowie die Beiträge in den ab 1933 jährlich zum jüdischen Neujahrsfest erscheinenden Verlags-Almanachen. ${ }^{166}$ Insbesondere in der Anfangszeit des Verlages und im Expansionsjahr 1933 griffen Lambert Schneider und Salman Schocken auf bereits fertiggestellte Manuskripte Bubers zurück, so erschienen in den ersten drei Jahren 18 Werke Bubers im Schocken Verlag. Aber auch in den Folgejahren war Buber der meistverlegte Autor im Verlag, sodass Schocken im März 1936 in einem Telefongespräch mit Schneider und Spitzer seine Besorgnis ausrückte, dass im Programm „zu viel von Buber ${ }^{\text {“167 }}$ vorkomme. Buber versorgte nicht nur durch seine kontinuierliche Schaffenskraft den Verlag mit Manuskripten, sondern prägte auch die Ausrichtung und die Außenwirkung des Verlages ganz deutlich.

Eine einzelne Beziehung ist kein Netzwerk, sie ist in diesem Fall aber Beispiel, wie Verknüpfungen zwischen zwei Menschen auf unterschiedlichen Ebenen und in verschiedenen Kontexten beschrieben werden können. Die Beziehung zwischen Schocken und Buber, die geprägt war durch persönliche Freundschaft, die Zusammenarbeit in zionistischen Gremien sowie privaten Initiativen und schließlich durch den Verlag, fand im Interesse am jüdischen Buch eine Gemeinsamkeit. In anderen Bereichen gingen die beiden unterschiedliche Wege: So konnte sich Schocken später z. B. nie für Bubers Engagement für einen jüdisch-arabischen Dialog erwärmen. Buber selbst war durch seine langjährige zionistische Arbeit und durch das Renommee in Kreis der zionistischen Geistesschaffenden weiter vernetzt, was Schocken mitunter die Türe zu weiteren Kreisen eröffnete, so z. B. zur Hebräischen Universität in Jerusalem. ${ }^{168}$ Das Netzwerk deutsch-jüdischer Intellektueller, das in den 1910er Jahren durch gemeinsame zionistische Initiativen entstand und das in den folgenden Jahren kontinuierlich anwuchs, fand in den 1930ern im Schocken Verlag eine Plattform. Der Verlag ermöglichte die Publikation von Büchern, die in dieser Form in Deutschland und womöglich auch nirgendwo sonst in diesem Umfang veröffentlicht hätten werden können. Dass in Deutschland publiziert wurde, bedeutete jedoch nicht, dass die einzelnen Akteure noch in Deutschland

166 Vgl. die bibliographische Dokumentation bei Dahm: Das jüdische Buch im Dritten Reich, S. 474-500.

167 Notiz über ein Telefongespräch zwischen Herrn Salman Schocken und den Herren Dr. Schneider und Dr. Spitzer, 26.03.1936. SchA, Verlag 331/12.

168 Vgl. Kap. 8. 
lebten. Schocken selber hatte seinen Hauptwohnsitz ab Januar 1934 in Jerusalem, Gershom Scholem lebte seit 1923 und Ernst Simon ab 1928 in Palästina. Es handelte sich in den 1930er Jahren also um ein hochmobiles, auf mehreren Ebenen verbundenes, deutschsprachiges, aber transnationales Netzwerk. Wichtige verbindende Faktoren waren sicherlich die deutsche Sprache, der Zionismus, ein großes Interesse an jüdischer Kultur und Tradition sowie der Wunsch, dem eine Sprache zu geben. Darüber hinaus gab es persönliche Freundschaften. Der Schocken Verlag war folglich nur einer der Verknüpfungspunkte, er war jedoch zentral. Zu diesem Zeitpunkt war angesichts der nationalsozialistischen Politik der Verdrängung und Vertreibung der jüdischen Bevölkerung der Schocken Verlag eine der wenigen Inseln, auf denen jüdische Kultur einigermaßen ungehindert gepflegt und verbreitet werden konnte. Das jüdische Buch nahm in den Jahren 1933 bis Ende 1938 eine immens wichtige Rolle in der Selbstbehauptung des deutschen Judentums im In- und Ausland an.

\subsubsection{Druck und Typographie - Zusammenarbeit über große Distanzen}

Salman Schocken legte höchsten Wert auf die äußere Erscheinung der in seinem Verlag verlegten Werke. ${ }^{169}$ Mit Spitzer hatte er einen Mitarbeiter, der diesen Anspruch teilte. Dabei wurden auch bei den günstigen Sparten des Verlages wie der Schocken-Bibliothek keine Abstriche gemacht. Insbesondere die zweisprachigen Ausgaben stellten die Verlagsmitarbeitenden und die Drucker vor große Schwierigkeiten, aber ebenso vor die Möglichkeit, in neue Richtungen zu denken und zu experimentieren. ${ }^{170}$ Dies war vor allem der Fall, weil den Büchereibändchen trotz ihrer einheitlichen äußeren Gestaltung kein typographisches Konzept zugrunde lag, da sich Satz und Inhalt des Buches komplementär ergänzen sollten. Dementsprechend variierten auch die Satzbreite und die Lettern trotz der einheitlichen Größe von $11 \times 19 \mathrm{~cm}$ der Büchereibändchen.

169 Die Autorin ist dieser Thematik in einem bereits erschienenen Artikel im Detail nachgegangen. Die hier folgenden Ausführungen zur Ästhetik und Druckgeschichte der SchockenBücher basieren zum Teil auf dieser Publikation, vgl. Mahrer: Tradition and Modernity. Zur Buchgestaltung im Schocken Verlag. Vgl. auch Heinz-Hermann Hoppe: Zur Buchgestaltung des Schocken Verlages. In: Schreuder / Weber (Hrsg.): Der Schocken-Verlag/Berlin, S.321-326.

170 Vgl. Ittai Jospeh Tamari: Hebräische Typographie des Schocken Verlags. In: Schreuder / Weber (Hrsg.): Der Schocken-Verlag/Berlin, S.327-346. 
So wurden z. B. Ludwig Strauss' Botschaft und Martin Bubers Buch über den Baal-Schem-Tow in altmodischen Typen - Letzteres in holländischen Lettern von 1670 - gedruckt, während Heines Rabbi von Bacherach eine moderne Erscheinung hatte und mit schwarz-weißen Illustrationen bebildert war. Sehr speziell nahm sich der Band Joseph und seine Brüder aus, dessen Text nicht mit dem Buchdeckel verbunden, sondern in einer Art Broschüre eingelegt war, während farbige Illustrationen eines unbekannten russischen Künstlers lose in einem im hinteren Buchdeckel festgeklebten Umschlag steckten. Die Pessach Haggada schließlich war ein Meisterstück eines bilingualen typographischen Designs. Die hebräischen und lateinischen Typen ergänzten sich trotz der stilistischen Unterschiede und der gegensätzlichen Leserichtung zu einem fließenden und zusammenhängenden Textbild.

Obwohl diese Bändchen in kürzester Zeit produziert werden mussten - Schocken sah einen Erscheinungsrhythmus von zwei Ausgaben pro Monat vor -, ${ }^{171}$ wachte er genau über die Gestaltung. Für Spitzer und Schneider, die für die Kommunikation mit den Autor*innen, den Behörden und mit den Druckern zuständig waren, bedeutete dies einen enormen Aufwand, vor allem für Spitzer, der zusätzlich mit Lektorat, Übersetzungen aus dem Hebräischen und teilweise mit der Gestaltung betraut war. Bei der Betrachtung der Verlagsbibliographie ist zu erkennen, was diese beiden Mitarbeiter geleistet haben. Die Bibliographie verdeutlicht aber auch, dass es bis 1938 möglich war, jüdische Bücher von hoher Qualität zu produzieren. Dies wäre ohne die enge Zusammenarbeit mit nichtjüdischen Druckern und Typographen so nicht möglich gewesen. ${ }^{172}$

Gedruckt wurde bis zur Zwangsschließung des Verlages fast ausschließlich in Deutschland. Die Verlagsgeschichte ist damit auch ein Beispiel dafür, dass professionelle Kontakte zwischen Juden und Nichtjuden weiterhin möglich waren. Die Bücher, die im Schocken Verlag in den Jahren 1933 bis 1938 verlegt wurden, waren, so soll hier argumentiert werden, ein Kommunikationsmittel; sie bauten Brücken über den Graben, den die Nationalsozialisten zwischen Juden und Nichtjuden geschaffen haben. Die wenigen Akten zur Druckgeschichte,

171 Vgl. Schneider: Salman Schocken, S. 197.

172 Die Ausführungen zur Zusammenarbeit zwischen dem jüdischen Verlagshaus und den nichtjüdischen Druckern und Typographen basiert auf dem Artikel: Mahrer: Texts and Objects. 
die heute noch existieren, geben Einblick in die enge Zusammenarbeit zwischen den Angestellten der Druckereien und des Verlages.

Der Schocken Verlag arbeitete hauptsächlich mit den in Leipzig ansässigen Druckereien Haag-Drugulin und Poeschel \& Trepte sowie Oswald Schmid zusammen. Diese Druckereien arbeiteten auch nach der Machtergreifung der Nationalsozialisten weiterhin mit Schocken zusammen und zwar nicht nur für die Produktion der deutschsprachigen Bücher. Neben den deutschen Reihen, von denen einzelne Ausgaben zweisprachig waren, verlegte der Schocken Verlag hebräischsprachige Bücher, die sich in erster Linie an ein akademisches Publikum richteten. Diese Ausgaben wurden fast ausschließlich von Haag-Drugulin gesetzt und produziert, da diese Druckerei über eine spezielle Abteilung für fremdsprachigen Druck verfügte. ${ }^{173}$ Lambert Schneider erinnerte sich daran, dass Ernst Kellner, der Inhaber von Haag-Drugulin, stolz darauf war, dass seine Druckerei im Stande war, schöne hebräische Drucke herzustellen. Kellner zeigte sich auch glücklich darüber, dass seine Druckerei gemeinsam mit dem Schocken Verlag neue Dinge ausprobierte. ${ }^{174}$

Die bilingualen Ausgaben in lateinischer und hebräischer Schrift stellten die Typographen und Setzer vor die größte Herausforderung. Während in der hebräischen Reihe des Verlages die Bücher komplett, einschließlich der Seitenzahlen, hebräisch gesetzt wurden, war der Mischsatz höchst komplex. Die Komplexität nötigte die Verlags- und Druckereimitarbeiter aber auch, innovativ zu denken und an Lösungen zu experimentieren. Wie Ittai J. Tamari festhält, bietet der Mischsatz eine Reihe von gestalterischen Möglichkeiten: So wurde bei den zweisprachigen Ausgaben versucht, bei der Auswahl der Lettern den Inhalt zu reflektieren. ${ }^{175}$ Die weiter unten detaillierter besprochene Ausgabe der 23 Psalmen in der Übersetzung von Martin Buber wurde hingegen so gesetzt, dass der hebräische Text visuell gegenüber der deutschen Übersetzung hervortrat. ${ }^{176}$ Tamari hält fest, dass die typographische Qualität der Reihe stark variierte. Ist bei einigen Ausgaben eine bewusste Auseinandersetzung mit den Schwierigkeiten des Mischsatzes sichtbar, wirkten andere wenig durchdacht. ${ }^{177}$

173 Vgl. Schneider: Salman Schocken, S. 202.

174 Vgl. ebd., S.201-202.

175 Vgl. Tamari: Hebräische Typographie des Schocken Verlags, S. 327.

176 Vgl. ebd., S. 338.

177 Vgl. ebd., S.339. 
Für besonders komplexe Projekte wurde Max Malte Müller ${ }^{178}$ eingestellt, der zu einem großen Teil für die bewunderte Typographie des Schocken Verlages verantwortlich war. Müller, ein religiöser Sozialist und Freund von Gustav Landauer, für den er Der Sozialist setzte und verlegte, eine ursprünglich sozialistische später anarchistische Zeitschrift, war ein enorm talentierter und gut geschulter Typograph. Nach dem Ersten Weltkrieg arbeitete er für Jakob Hegner in Hellerau, Dresden und nach Hegners Bankrott für den Verlag Heinrich Mercy Sohn in Prag, wo Schocken unter anderem den fünften und sechsten Band seiner Kafka-Ausgabe drucken ließ. ${ }^{179}$

Die Zusammenarbeit mit den Druckern und besonders die Problematik des zweisprachigen Druckes waren wiederkehrende Themen bei Verlagssitzungen. Die Lösungen, die während der Jahre in Betracht gezogen wurden, waren nicht nur zahlreich, sondern auch kreativ. Eine Idee war die Einrichtung einer eigenen Druckerei für hebräische Ausgaben in Deutschland. Müller wurde im Jahr 1935 beauftragt, Informationen zu sammeln und ein Exposé auszuarbeiten, ${ }^{180}$ der Plan wurde wegen der zu hohen Kosten verworfen. Ebenfalls nie zur Umsetzung gelangte die Überlegung, alle Druckaufträge nach Polen zu vergeben. Dort existierte eine lange Tradition hebräischer Typographie, entsprechend wurde auch der größte Teil der Druckereien in Palästina von polnischen Fachkräften geführt. ${ }^{181}$

Eine letzte Idee, die Schocken lange verfolgte, war der Plan, sämtliche hebräische Ausgaben in Palästina drucken zu lassen oder dort eine eigene Druckerei zu gründen. ${ }^{182}$ Müller sollte in Palästina die Bedingungen für eine eigene

$178 \mathrm{Zu}$ Max Malte Müller sind nur wenige biographische Bruchstücke bekannt, am meisten weiß man über seine Freundschaft mit Gustav Landauer. Dank Lambert Schneiders Memoiren wissen wir auch, dass er, nachdem er den Stellungsbefehl für die Wehrmacht erhielt, diesem nicht folgte und sich das Leben nahm. Er konnte, so Schneider, das Leben in Hitlerdeutschland nicht ertragen. Vgl. Schneider: Rechenschaft über vierzig Jahre Verlagsarbeit 1925-1965, S. 51-55.

179 Vgl. Dahm: Das jüdische Buch im Dritten Reich, S. 352.

180 Vgl. die Korrespondenz in SchA, Privates, 851/822; Grundlegende Bearbeitung für eine Druckerei von Herrn M. Müller, 1936. Ebd.

181 Vgl. Philipp Messner: Von der Form der Sprache. Hebräische Renaissance und typographischer Diskurs in Deutschland zur Zeit der Weimarer Republik. In: Karin Bürger / Ines Sonder / Ursula Wallmeier (Hrsg.): Soncino-Gesellschaft der Freunde des jüdischen Buches. Ein Beitrag zur Kulturgeschichte. Berlin: de Gruyter 2014, S. 42-74.

182 Für den Plan von 1935 vgl. SchA, Privates, 851/822 und für den Plan von 1938: Pläne Druckerei Palästina. SchA, Verlag 351/821. 
Druckerei klären und einen betriebswirtschaftlichen wie organisatorischen Plan entwerfen. Als technischer Leiter für die Druckerei war Henri Friedländer vorgesehen. Friedländer hatte eine Lehre im graphischen Handwerk in zwei Druckereien absolviert, widmete sich anschließend - neben seiner Arbeit - dem Selbststudium und besuchte schließlich die Leipziger Akademie für Schrift, unter anderem unter Max Malte Müller bei Jakob Hegner in Hellerau. Später war er in der Hausdruckerei von Klingspor und schließlich bei Ernst Kellner in der Offizin Haag-Drugulin angestellt. Die 1930er Jahre verbrachte er auf der Flucht vor den Nationalsozialisten in Holland, wo er sein enormes Wissen in Druckfragen und Schriftgestaltung noch weiter vertiefte und junge Typographen ausbildete. Nach dem Krieg und dem Holocaust, den er im Versteck in Holland überlebte, emigrierte er nach Palästina, wo er die erste Ausbildungsstätte für Schriftgestaltung und Typographie aufbaute. ${ }^{183}$ Der Plan, dass Henri Friedländer Schockens Druckerei in Palästina vorstehen sollte, wurde wie viele andere Pläne nie umgesetzt. Es lässt sich heute nicht mehr nachvollziehen, ob der Schocken Verlag Friedländer in dieser Frage überhaupt kontaktierte.

Die Pläne, den Druck von Büchern ins Ausland zu verlagern, machen aber deutlich, dass im Schocken Verlag nach Lösungen außerhalb Deutschlands gesucht wurde. Die politische Situation und der zunehmende Druck auf die jüdische Bevölkerung und auf jüdische Betriebe waren ein wichtiger Grund dafür. Schockens kontinuierliche Suche nach neuen Wegen, den Druck mit hebräischen Schriftzeichen zu verbessern, spielten dabei sicherlich eine Rolle.

Trotz der schwierigen Umstände druckte Schocken also weiterhin fast ausschließlich in Deutschland. Ein Teil der Bücher wurde von Moritz Spitzer gestaltet, andere von Max Malte Müller, der größte Teil in den bereits benannten Druckereien entworfen und gesetzt. Die gemeinsame Arbeit an den Büchern des Schocken Verlages brachte Juden und Nichtjuden zusammen. Zusammen schufen die Beteiligten eine Insel der professionellen Zusammenarbeit, die auch die Nationalsozialisten nicht zerstören konnten. Der Schocken Verlag war kein Einzelfall, auch in anderen Wirtschaftsfeldern blieben Kooperationen zwischen sogenannten Ariern und Juden während der 1930er Jahren bestehen. Jedoch kann festgehalten werden, dass das Buch ein wichtiger Akteur im Kommunikationskreislauf war. Mit der Zwangsschließung der

183 Für die vollständigen biographischen Angaben vgl. Gerrit Willem Ovink: Die Gesinnung des Typographen. Laudatio anlässlich der Verleihung des Gutenberg-Preises 1971 der Stadt Mainz am 21. Juni 1971 an Henri Friedlaender. Mainz: Gutenberg-Gesellschaft 1973. 
letzten jüdischen Verlagshäuser in Deutschland kam auch der Druck hebräischer Bücher in Deutschland zu einem Ende. In den 1930er Jahren hingegen wurden im nationalsozialistischen Deutschland eine ganze Reihe aus typographischer Sicht qualitativ hochwertiger Texte in Hebräisch und in Mischdruck gedruckt und publiziert.

\subsection{Text - das Buch als Widerstand}

\subsubsection{Das Autodafé der Bücher - eine Einleitung}

Im Herbst 1933, ein knappes halbes Jahr nach der ersten Bücherverbrennung unter Führung des Nationalsozialistischen Deutschen Studentenbundes auf dem Berliner Opernplatz, die bald in 21 anderen deutschen Universitätsstädten nachgeahmt wurde, begann der Schocken Verlag zu expandieren. Salman Schocken verneinte zwar später, dass die Expansion eine Reaktion auf die nationalsozialistische Literaturpolitik und die sogenannte ,Aktion wider den undeutschen Geist' darstellte, ${ }^{184}$ man kommt aber kaum umhin, den massiven Ausbau des Verlagsprogramms in diesem Kontext zu sehen. Ein mikroskopischer Blick auf die Tage unmittelbar nach der symbolträchtigen Bücherverbrennung in Berlin unterstützt diese These.

Der 10. Mai war als Höhepunkt der studentischen ,Aktion wider den undeutschen Geist' geplant. Das neugegründete Hauptamt für Presse und Propaganda der Deutschen Studentenschaft wollte sich mit einer, Gesamtaktion', die für den Zeitraum vom 12. April bis zum 10. Mai 1933 anberaumt war, der Öffentlichkeit vorstellen. Am 8. April informierte ein Rundschreiben, dass es bei dieser Aktion um die „öffentliche Verbrennung jüdischen zersetzenden Schrifttums durch die Studentenschaft der Hochschulen aus Anlass der schamlosen Hetze des Weltjudentums gegen Deutschland“185 gehen sollte. Die Studenten waren aufgerufen, in ihren eigenen Bibliotheken die, jüdische Zersetzungsliteratur auszusondern, um die öffentlichen Bibliotheken davon zu ,befreien'. Als eigentlicher Schlussakt waren die öffentlichkeitswirksamen Verbrennungen geplant.

184 Vgl. M[iriam] Nussbaum: Zu: LBIYB 1,1, 1956. Aufsatz E. Simon: The New Midrash, S.92-98, 09.04.1958. SchA, Verlag, 303. Vgl. dazu auch Anm. 230.

185 Aus dem Rundschreiben „Nr. 2 betr. erste Massnahmen des Propagandaamtes“, hier zit. n. der Quellensammlung zur Bücherverbrennung von Gerhard Sauder (Hrsg.): Die Bücherverbrennung. Zum 10. Mai 1933. München: Hanser 1983, S. 74-76. 
Die Symbolik der brennenden Bücher erinnert an die mittelalterlichen Scheiterhaufen, auf denen in zahlreichen europäischen Städten Juden und Jüdinnen verbrannt wurden. Auch Joseph Goebbels, Gauleiter Berlins und Reichspropagandaleiter der NSDAP, muss sich dieser machtvollen Bildsprache bewusst gewesen sein: Trotz strömendem Regen hielt er eine Rede bei der Bücherverbrennung am Opernplatz. ${ }^{186}$ „Dann am späten Abend Rede am Opernplatz. Vor dem Scheiterhaufen der von den Studenten entbrannten Schmutz- und Schundbücher. Ich bin in bester Form. Riesenauflauf." ${ }^{\text {"187 }}$

Obwohl Goebbels die Aktion sichtlich guthieß und ihr durch seine Rede staatliche Legitimation gab, wurde die Aktion von der Studentenschaft organisiert, und nicht, wie auch Jan-Pieter Barbian und Volker Dahm vermerken, von staatlicher Seite. ${ }^{188}$ Dennoch lässt die Rhetorik Goebbels keinen Zweifel daran, dass er die Aktion der Studentenschaft ideologisch unterstützte. Über den Deutschlandsender wurde die sogenannte ,Feuerrede', in der er das nächtliche Flammenspektakel als Reinigungsritual feierte, im ganzen Reich verbreitet.

Das Zeitalter eines überspitzten jüdischen Intellektualismus ist zu Ende gegangen, und die deutsche Revolution hat dem deutschen Wesen wieder die Gasse freigemacht. [...] In den letzten vierzehn Jahren [...] füllten sich die Bibliotheken mit Schund und Schmutz jüdischer Asphaltliteraten. [...] Deshalb tut ihr gut daran, in dieser mitternächtlichen Stunde den Ungeist der Vergangenheit den Flammen anzuvertrauen. Hier sinkt die geistige Grundlage der Novemberpolitik zu Boden. [...] Das Alte liegt in den Flammen, das Neue wird aus der Flamme unseres eigenen Herzens wieder emporsteigen. ${ }^{189}$

186 Zur Rede vgl. Gerhard Sauder: Der Germanist Goebbels als Redner bei der Berliner Büchervebrennung. In: Horst Denkler / Eberhard Lämmert (Hrsg.): ,Das war ein Vorspiel nur.... Berliner Colloquium zur Literaturpolitik im ,Dritten Reich'. Berlin: Akademie der Künste 1985, S. 56-81.

187 Tagebucheintrag vom 11.05.1933. In: Elke Fröhlich (Hrsg.): Die Tagebücher von Joseph Goebbels. Sämtliche Fragmente. Teil I: Aufzeichnungen, 1924-1941, Bd. 2: 01.01.193131.12.1936. München: Saur 1987, S.419.

188 Vgl. Jan-Pieter Barbian: Literaturpolitik im, Dritten Reich'. Institutionen, Kompetenzen, Betätigungsfelder. Überarb. u. akt. Aufl. München: dtv 1995, S. 139-140; Volker Dahm: Anfänge und Ideologie der Reichskulturkammer. Die ,Berufsgemeinschaft' als Instrument kulturpolitischer Steuerung und sozialer Reglementierung. In: Vierteljahreszeitschrift für Zeitgeschichte 34,1 (1986), S. 53-84, hier S. 58.

189 Die Rede wurde abgedruckt im Völkischen Beobachter, 12.05.1933. 
Golo Mann, der als Augenzeuge zugegen war, schilderte die Rede als „schwach “190. Goebbels forderte in ihrem neunten Abschnitt die Studentenschaft nachdrücklich dazu auf, „hinter das Reich und hinter seine neuen Autoritäten zu treten. ${ }^{“ 191}$ Ansonsten habe sich das Reichsministerium für Volksaufklärung und Propaganda "merkwürdig zurückgehalten “192, konstatiert Dahm, obwohl die Aussonderung unerwünschter Literatur von staatlicher Seite als wichtige Maßnahme im Zuge der, völkischen Wiedergeburt' des deutschen Volkes betrachtet wurde. Bereits am 5. April leitete Hans Hinkel ${ }^{193}$, der nach der Machtergreifung Reichsorganisationsleiter des Kampfbundes für deutsche Kultur und dritter Geschäftsführer der Reichskulturkammer wurde, und damit im Vorstand der beiden zentralen kulturpolitischen Institutionen des nationalsozialistischen Deutschlands war, einen Abend unter dem Motto „Buch und Geist“, bei dem es um die Durchsetzung der nationalen Revolution auf literarischem und buchhändlerischem Gebiet ging. ${ }^{194}$ Dass es sich bei der ,Aktion' um mehr als eine studentische Initiative handelte, wird nicht nur durch die Beteiligung von Goebbels und Hinkel, sondern auch durch das Ausmaß der ,Säuberungen ' ersichtlich. Im vorläufigen Bericht der Berliner Polizei vom 20. Mai kann man nachlesen, dass „in Berlin die politische Polizei schätzungsweise etwa 10.000 Zentner Bücher und Zeitschriften beschlagnahmt und in die Ställe der ehemaligen berittenen

190 Golo Mann in einem undatierten Gespräch mit Pierre Bertaux, Gottfried BermannFischer und Brigitte Bermann-Fischer. Pierre Bertaux: Die Bücherverbrennung in Berlin am 10. Mai 1933. In: Hermann Haarmann / Walter Huder / Klaus Siebenhaar (Hrsg.): ,Das war ein Vorspiel nur.... Bücherverbrennung Deutschland 1933. Voraussetzungen und Folgen. Ausstellungskatalog Akademie der Künste. Berlin: Medusa 1983, S. 228-231, hier S. 230.

191 Zit. n. Sauder: Der Germanist Goebbels als Redner bei der Berliner Büchervebrennung, S. 70 .

192 Dahm: Anfänge und Ideologie der Reichskulturkammer, S. 58.

193 Hinkel war ein überzeugter Nationalsozialist der ersten Stunde. Er war frühes NSDAPMitglied und nahm 1923 am Hitlerputsch teil. Vor der Machtergreifung war er u. a. Redakteur des Völkischen Beobachters. 1931 trat er der SS bei. Ab Juli 1933 überwachte er in seiner Funktion als Staatskommissar und ,Reichskulturwalter' den Kulturbund Deutscher Juden. Ab 1935 war er im Reichsministerium für Volksaufklärung und Propaganda als Sonderbeauftragter für ,Kulturpersonalien' zuständig, seine Funktion war besser bekannt unter dem Namen „Sonderreferat Hinkel, Judenfragen“. Für weitere Details zur Biographie und Funktion Hinkels vgl. Alan E. Steinweis: Hans Hinkel and German Jewry, 1933-1941. In: LBIYB 38,1 (1993), S. 209-219.

194 Vgl. Sauder: Die Bücherverbrennung, S. 105. 
Schutzpolizei geschafft [hat]. ${ }^{\text {195 }}$ Damit war die ,Aktion wider den undeutschen Geist' zwar von der Studentenschaft geplant und durchgeführt, staatliche Stellen jedoch auf unterschiedlichsten Ebenen daran beteiligt. So wurde die Polizei bei der Beschlagnahmung von Büchern eingesetzt, denn „viele Büchereien [haben] ihre Bücher in Schlupfwinkel[] [geschafft], um sie dem Zugriff der Polizei zu entziehen. ${ }^{\text {"196 }}$ Die Aktion war damit keine freiwillige ,Säuberung von Privat- und Leihbibliotheken. Es handelte sich dabei vielmehr um eine Zwangsaktion gegen unerwünschte Literatur und Schriftsteller*innen, die von höchster Stelle abgesegnet und auch durch staatliche Kräfte durchgesetzt wurde.

Bereits im April 1933 begann zusätzlich der Ausschuss zur Neuordnung der Berliner Stadt- und Volksbüchereien mit der Indizierung von unerwünschtem Schriftgut. In den Akten der Reichsschrifttumskammer ${ }^{197}$ finden sich ,schwarze Listen', auf deren Grundlage die öffentlichen Büchereien gesäubert werden sollten. Sie wurden unter dem Vorsitz von Wolfgang Herrmann ${ }^{198}$ erstellt, um, so seine eigenen Worte, „die Verbrennung der marxistischen und jüdischen Bücher einzuleiten. “199 Herrmann schickte die umfassende Liste für ,Schöne Literatur' am 1. Mai an das Amt für Presse und Propaganda der Deutschen Studentenschaft. Er schrieb weiterhin, dass

195 Völkischer Beobachter, 21./22.05.1933, zit. n. ebd., S. 107.

196 Ebd.

197 Vgl. u. a. Dahm: Anfänge und Ideologie der Reichskulturkammer.

198 Herrmann arbeitete nach seiner Promotion im Jahr 1928 als Bibliothekar, zunächst als Volontär in der Volksbibliothek Breslau, anschließend als wissenschaftlicher Hilfsarbeiter in der Volksbibliothek Stettin. Er trat 1933 der NSAP bei, am 1. Mai desselben Jahres wurde er als Abteilungsleiter der Zentralstelle für das deutsche Bibliothekswesen berufen, muss diese Funktion jedoch schon einige Tage vorher aufgenommen haben. Ein knappes Jahr später wurde er zum Bibliothekar in Königsberg ernannt. Es drohte ihm 1936 ein Parteiausschuss, da er u. a. in einer Schrift von 1932 die Führungsqualitäten Adolf Hitlers anzweifelte. Das Verfahren zog sich über zwei Jahre hin und wurde erst auf eine Verfügung Hitlers Ende April 1937 eingestellt. Über seinen Tod gibt es widersprüchliche Angaben; laut Schliebs fiel er 1944, Sauder hingegen gibt an, dass er 1945 auf der Flucht gestorben sei. Vgl. Siegfried Schliebs: Verboten, verbrannt, verfolgt .... In: Haarmann / Huder / Siebenhaar (Hrsg.): ,Das war ein Vorspiel nur..., S. 442-444; Sauder: Die Bücherverbrennung, S. 111.

199 BArch NS 36 (Oberstes Parteigericht der NSDAP), zit. n. Hildegard Brenner: Die Kunstpolitik des Nationalsozialismus. Reinbek: Rowohlt 1963, S. 44. 
die Liste für Ihre Aktion gegen die Leihbüchereien etc. von Nutzen sein [würde]. Ich würde Ihnen eine Vervielfältigung vorschlagen, damit jedem Ihrer ,Stoßtrupps eine Liste zur Verfügung steht. Wann wir von der Volksbücherei aus noch Listen für die Gebiete der Philosophie, Sexualwissenschaft etc. anfertigen können, weiß ich im Augenblick noch nicht anzugeben. Die Liste für Geschichte geht Ihnen morgen zu. [...] Der Ausschuss zur Neuordnung der Berliner Volks- und Stadtbücherei [...] hat dem Bürgermeister Hafemann Mitteilung gemacht, dass wir Hand in Hand mit der studentischen Aktion arbeiten wollen. ${ }^{200}$

Die ,Aktion“ wurde damit von verschiedenen offiziellen Stellen tatkräftig unterstützt. Mit dem hervorgehobenen „wir“verdeutlichte Herrmann auch, dass er ab diesem Zeitpunkt eine tragende Rolle für sich und seinen Ausschuss forderte.

Die nach Sparten geordneten ,schwarzen Listen' umfassten keineswegs nur Publikationen jüdischer Autoren und Autorinnen. Vielmehr wurden von verschiedenen Bibliothekaren, Buchhändlern, Autoren und Kampfbund-Mitgliedern, ${ }^{201}$ die als Autoritäten im Aufspüren von ,zersetzender' Literatur betrachtet wurden, Bücher zur Indizierung vorgeschlagen. Bis zum Autodafé am 11. Mai bestand jedoch nur die Liste ,Schöne Literatur. Auf ihrer Grundlage wurden Buchhändler und Bibliothekare, die nicht kooperierten, dazu gezwungen, die gelisteten Bücher auszuliefern, obwohl die Liste zu diesem Zeitpunkt noch nicht amtlich war. Vielmehr handelte es sich um „eine Vorarbeit ohne amtliche Bestätigung. “ ${ }^{202}$ Ganz allgemein herrschte eine unklare Rechtslage und, wie Dietrich Aigner es in seiner Studie zur Indizierung von Schriftgut im National-

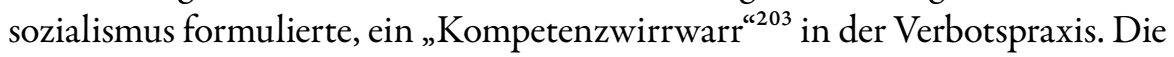
Polizeibehörden hatten daher einen relativ großen Spielraum in der Beschlagnahmung von Büchern und Druckschriften. Erst 1935 wird eine von der Reichsschriftumskammer zusammengestellte Liste verbreitet, die intern bereits

200 Dr. Wolfang Herrmann an Herr Leistritz, Deutsche Studentenschaft, Amt für Presse und Propaganda, 01.05.1933, zit. n. der Quellensammlung von Sauder: Die Bücherverbrennung, S. 115-116 (Herv. i. Orig.).

201 Vgl. ebd., S. 117.

202 Verband Deutscher Volksbibliothekare: Zum Umbau des deutschen Volksbüchereiwesens. In: Bücherei und Bildungspflege 13 (1933), S. 169-170, hier S. 169.

203 Dietrich Aigner: Die Indizierung, schädlichen und unerwünschten Schrifttumes' im Dritten Reich. Sonderdruck aus dem Archiv für Geschichte des Buchwesens. Bd. XI, Lieferung 3-5. Frankfurt am Main: Buchhändler-Vereinigung 1971, Sp. 953. 
ein Jahr von der Gestapo verwendet wurde. ${ }^{204}$ Trotz des unstrukturierten Vorgehens verbrannten am 10. Mai Zehntausende Bücher. Die Verbrennung war das Resultat von minutiöser Vorarbeit der Studentenschaft, von Wissenschaftlern und Bibliothekaren. Wie George L. Mosse schmerzlich, aber dennoch treffend feststellte, „verbrannten die Bildungsbürger ihre eigenen Bücher. ${ }^{\text {“205 }}$

Völlig gegenläufig zur Utopie einer ,rassisch reinen' deutschen Kultur stieg die jüdische Buchproduktion in den Jahren 1933 bis 1936 sprunghaft an. Das war möglich, weil zu Beginn der NS-Herrschaft jüdische Autoren, Verleger und Buchhändler noch keinem Arbeitsverbot unterlagen. Bei der Gründung der Reichskulturkammer und der Reichsschrifttumskammer sah man davon ab, einen ,Arierparagraphen' einzuführen, jedoch wurde nur knapp einem Viertel der insgesamt ungefähr 2.000 Antragsgesuche, nichtarischer ${ }^{`}$ Autoren und Autorinnen auf Mitgliedschaft im Reichsverband deutscher Schriftsteller stattgegeben. Diese zunächst recht liberale Kulturpolitik wurde nach einem Erlass von Joseph Goebbels im Frühjahr 1934 bereits wieder unterbunden. Fortan wurden Juden systematisch aus dem Kulturbetrieb ausgeschlossen. Anders als bei anderen Berufsgruppen hatte dies kaum Auswirkungen auf die Volkswirtschaft. Trotz des Ausschlusses aus dem Fachverband konnten jüdische Schriftsteller weiter publizieren, wenn sie dies in einem Verlag mit dezidiert jüdischem Programm taten. ${ }^{206}$

\subsubsection{Expansion:}

\section{Die Reaktion auf die Bücherverbrennung im Schocken Verlag}

Es ist nicht mehr rekonstruieren, ob es eine Reaktion Schockens auf diese Ereignisse gab. Hingegen existieren drei Briefe aus dem Verlag aus den Tagen unmittelbar nach der Bücherverbrennung. Das erste Schreiben war an Agnon gerichtet: Am 13. Mai schrieb Lambert Schneider an Agnon und bat ihn, alles deutsche Übersetzungsmaterial an den Verlag zu schicken. Zudem sei der Verlag an Agnons neuster Erzählung interessiert. Gustav Schocken, der nach seinem Abitur eine Palästinareise unternahm, bevor er in Heidelberg sein Studium aufnehmen wollte, ${ }^{207}$ besuchte Agnon im April in Jerusalem. Im Anschluss

204 Vgl. ebd., Sp. 945.

205 George L. Mosse: Die Bildungsbürger verbrennen ihre eigenen Bücher. In: Denkler / Lämmert (Hrsg.): ,Das war ein Vorspiel nur...', S.35-50, hier S.35.

206 Vgl. Schreuder: Würde im Widerspruch, S.7-8.

207 Vgl. Salman Schocken an S.J. Agnon, 08.03.1933. NLI, Agnon Archiv, Arc 41270. 
informierte er Schneider, dass Agnon eine neue Erzählung fertig habe, die eventuell in einer palästinensischen Zeitschrift zum Vorabdruck kommen könnte. Nach Rücksprache mit Schocken kamen beide zum Schluss, dass ein Vorabdruck nicht wünschenswert sei, zumal, und dies ist das wirklich Interessante an diesem Brief, der Schocken Verlag plane, im September einen Almanach zu bringen, in dem man sich eine kurze Erzählung Agnons wünsche. ${ }^{208}$ Auch das zweite Schreiben bezog sich auf den geplanten Almanach: Im Juni 1933 schrieb Moritz Spitzer an Gershom Scholem und lud ihn ein, einen Beitrag für den Verlagsalmanach zu verfassen. In diesem Brief wies Spitzer Scholem darauf hin, dass der Beitrag zumindest andeutungsweise etwas „Anzügliches“209 zur gegenwärtigen Situation enthalten solle. Der Verlag plante also, in seinen Publikationen Bezug auf die politischen Ereignisse zu nehmen.

Die ,Aktion wider den undeutschen Geist' wurde vom Verlag durchaus als Bedrohung aufgefasst, ans Aufhören dachte man aber nicht. Im dritten Brief aus dem Frühjahr 1933 schrieb Schneider am 23. Mai an Gershom Scholem, dass „im verlag alle pläne zurückgestellt werden [mussten], solange es nicht sicher war, dass der verlag in seiner jetzigen form weiter arbeiten könne. ${ }^{\text {“210 }} \mathrm{Er}$ fährt dann aber positiver fort: „,inzwischen haben sich die verhältnisse zwar noch nicht ganz geklärt, aber es ist immerhin anzunehmen, dass wir unsere arbeit in dem bisherigen sinn durchführen können. “211 Darüber hinaus machte Schneider Scholem die verbindliche Zusage zur Zusammenarbeit. Höflich, aber mit einem gewissen Druck bat er ihn, dem Verlag mitzuteilen, in welchen Abständen Scholem die einzelnen Werke ${ }^{212}$ fertigzustellen gedenke. ${ }^{213}$

208 Vgl. Lambert Schneider an S.J. Agnon, 13.05.1933. NLI, Agnon Archiv, Arc 41270.

209 Moritz Spitzer an Gershom Scholem, 06.06.1933, zit. n. Noam Zadoff: Gershom Scholem. From Berlin to Jerusalem and Back. An Intellectual Biography. Waltham, MA: Brandeis UP 2018, S. 31.

210 Lambert Schneider an Gershom Scholem, 23.05.1933. NLI, Scholem Archiv, Arc. 4 1599, 012341, Bd. 1 .

211 Ebd.

212 In einem Gespräch zwischen Salman Schocken und Gershom Scholem wurde die Publikation eines fünfbändigen Werkes zur Kabbala von Scholem durch den Schocken Verlag geplant. Vgl. Lambert Schneider an Gershom Scholem, 21.01.1933; Gershom Scholem an Lambert Schneider, 06.04.1933. NLI, Scholem Archiv, Arc. 4 1599, 01 2341, Bd. 1.

213 Vgl. Lambert Schneider an Gershom Scholem, 23.05.1933. NLI, Scholem Archiv, Arc. 4 1599, 01 2341, Bd. 1. 
Die Aufforderung an Agnon, die neue Erzählung zu schicken, die Einladung an Scholem, in einem Text Bezug auf die aktuelle Situation zu nehmen und die Anfrage an Scholem, in welchem Zeitrahmen er die Bände seiner KabbalaStudien fertigzustellen gedenke, lässt darauf schließen, dass der Schocken Verlag weiter in die Zukunft plante. Spätestens aber die Übernahme von Bubers Werk in den Verlag im Juni 1933 musste bedeuten, dass die anfängliche Verunsicherung überwunden war. Der Schocken Verlag reagierte also nicht mit Resignation, sondern mit verstärktem Engagement und Expansion auf die Verdrängung der Juden aus dem deutschen Kulturleben. In ähnlicher Weise reagierten auch jüdische Künstler: Aus den staatlichen Kulturbetrieben im Zuge des Gesetzes zur Wiederherstellung des Berufsbeamtentums vom 7. April 1933 entlassen, gründeten sie den Kulturbund deutscher Juden ${ }^{214}$ im Juli 1933 als Selbsthilfeorganisation. ${ }^{215}$

Anders als der Kulturbund, der aus einer Notlage heraus entstand und damit ein ,Ausgrenzungsprodukt' war, agierte der Schocken Verlag freier. Der Kulturbund, der die wichtige Funktion hatte, arbeitslosen Künstler*innen eine Plattform zu bieten, wurde später dem Reichsministerium für Volksaufklärung und Propaganda unterstellt und kam dadurch auch unter die Kontrolle der Gestapo. Durch die relative Freiheit des Schocken Verlages konnte er sich, anders als eben der Kulturbund, zu einer kritischen, humanistischen und gar widerständigen Stimme im gleichgeschalteten Deutschland entwickeln.

Allein die Expansion des Verlages, also die gesteigerte Produktion und Publikation von Büchern jüdischer Autoren und Autorinnen, muss als widerständig bezeichnet werden. Zu einem Zeitpunkt, zu dem jüdisches Kulturgut als ,undeutscher Schmutz' beschimpft und aus der deutschen Öffentlichkeit verbannt wurde, beschlossen Schocken und seine Führungskräfte die Vergrößerung des Verlagsprogramms durch zwei neue Reihen, die enorm erfolgreiche Schocken-Bibliothek, die der Insel Bücherei nachempfunden wurde, sowie den jährlich erscheinenden Schocken Almanach. Bücher zu drucken und auf den Markt zu bringen, rückt Texte, Meinungen und Traditionen in die öffentliche

214 Die Gestapo erlaubte zwar die Institution, erzwang aber einen Namenswechsel zu Jüdischer Kulturbund, die Verknüpfung von „deutsch“ und „jüdisch“ wurde verboten.

215 Zum Kulturbund vgl. Akademie der Künste (Hrsg.): Geschlossene Vorstellung. Der Jüdische Kulturbund in Deutschland, 1933-1941. Berlin: Hentrich 1992; Eike Geisel / Henryk M. Broder (Hrsg.): Premiere und Pogrom. Der Jüdische Kulturbund 1933-1941. Texte und Bilder. Berlin: Siedler 1992. 
Wahrnehmung. Auf die Verbrennung von Büchern wurde mit Neuproduktion reagiert.

Mit Blick auf die theoretischen Ausführungen zu Beginn dieses Kapitels, die darauf abheben, dass dem Text selbst, also seiner inhaltlichen Seite, eine zentrale Bedeutung zukommt (was von der Buchwissenschaft oft vernachlässigt wird), ist die obengenannte These zu ergänzen: Zwar war bereits die Produktion von jüdischen Büchern in den Jahren 1933 bis 1938 ein widerständiger Akt gegen die Entrechtung, in viel stärkerem Masse waren es jedoch die Texte. Spätestens seit dem Paradigmenwechsel des Cultural Turn ${ }^{216}$ fand eine verstärkte interdisziplinäre Zusammenarbeit zwischen Literatur- und Geschichtswissenschaft statt. Katja Stopka identifiziert als Schnittstelle der zwei Disziplinen, die gleichermaßen textwissenschaftlich arbeiten, die „Erforschung von Geschichtsnarrativen in sozial- und kulturhistorischen Kontexten ${ }^{\text {"217. }}$. Texte sind immer ein Produkt ihrer Zeit, sie sind eingebettet in ihr soziokulturelles Umfeld und nur aus diesem heraus zu verstehen. Die Beziehung zwischen Text und Kontext ist jedoch wechselseitig: Texte entstehen in einer bestimmten Wirklichkeit und greifen gleichzeitig in sie ein. ${ }^{218}$ Damit werden Texte zu Akteuren der Geschichte. Ähnlich argumentiert auch Peter D. McDonald, wenn er Schreiben als Teil der Sozialgeschichte begreift. ${ }^{219}$ Damit werden sowohl der Text als kulturelles Produkt wie auch die Herstellung des Textes zu Akteuren und Quellen der Geschichtswissenschaft. Der Begriff der ,Textherstellung' anstelle des Schreibbegriffes ist gewählt, da hier argumentiert werden soll, dass nicht nur das Verfassen eines Textes, sondern auch das Auswählen und Kompilieren von Texten mit klarer oder unklarer Autorenschaft als wichtiger Gegenstand der Geschichtswissenschaft verstanden werden muss. Gerade in Zeiten zunehmend totalitärer Herrschaft, so wird in den folgenden Ausführungen deutlich werden, ist es durch den Rückgriff auf tradierte Texte möglich, Kritik am System zu üben.

216 Zum Cultural Turn vgl. u. a. Doris Bachmann-Medick: Cultural Turns. Neuorientierung in den Kulturwissenschaften. Hamburg: Rowohlt 2006, S. 124-126; Georg G. Iggers: Geschichtswissenschaft im 20. Jahrhundert. Ein kritischer Überblick im internationalen Zusammenhang. Berlin: Vandenhoeck \& Ruprecht 2007.

217 Katja Stopka: Zeitgeschichte, Literatur und Literaturwissenschaft. In: DocupediaZeitgeschichte (2010), S. 1-17, hier S.3.

218 Vgl. ebd.

219 Vgl. McDonald: British Literary Culture and Publishing Practice 1880-1914, S. 12. 


\subsection{3 „Der jüdische Mensch von heute“ - Trost und Ermutigung für die Verfolgten}

In den Veröffentlichungen in den Jahren 1933 bis 1938 zeigt sich eine offene und kritische Auseinandersetzung mit dem Unrecht, das der jüdischen Bevölkerung Deutschlands nach der Machtergreifung Hitlers angetan wurde.

Moritz Spitzer erinnerte sich in den 1960er Jahren in einem Interview mit Dov Kulka an den Sommer 1933

Ich fühlte mich zuversichtlich, den Veränderungen jener Tage entgegenzutreten. Wir waren am Leben -vorerst - und mussten die Tage irgendwie verbringen. Die Frage war: wie? In Verzweiflung und Verderb, oder auf der Suche nach der Bedeutung dessen, was uns wiederfuhr. Mit anderen Worten: Können wir ihnen [der jüdischen Bevölkerung Deutschlands] helfen, ihre jüdische Identität zu verstehen und zu akzeptieren, indem wir ihnen die Mittel gaben, die helfen und erklären, sich dieses Schicksals zu eigen zu machen und es wertzuschätzen. ${ }^{220}$

Das verdeutlichen vor allem die im Herbst 1933 gegründeten Reihen Bücherei und Almanach. Der von Moritz Spitzer redigierte Almanach auf das Jahr 5694, der zum jüdischen Jahreswechsel im Herbst 1933 erschien, eröffnet mit einem kurzen Text Bubers, den er im April 1933 verfasste.

Der jüdische Mensch von heute ist der innerlich ausgesetzteste Mensch unserer Welt. Die Spannungen des Zeitalters haben sich diesen Punkt ersehen, um an ihm ihre Kraft zu messen. Sie wollen erfahren, ob der Mensch ihnen noch zu widerstehen vermag, und erproben sich am Juden. Wird er standhalten? Wird er in Stücke gehen? Sie wollen durch sein Schicksal erfahren, was um den Menschen ist. Sie machen Versuche mit dem Juden, sie versuchen ihn. Besteht ers? ... Etwas ist geschehen. Statt des einen Wesens, an dem die Spannungen des Zeitalters sich auslassen wollten, sind zwei zu schauen, - ein zerfallendes und ein bezwingliches. Eins, das Licht ausgibt wie ein phosphoreszierender Sumpf, und eins, das Licht ausgibt wie der Orion. Aber dieses steht für jenes ein. Dieses sagt von jenem: Das bin ich. Es streckt sich über es

220 Dov Kulka: Interview mit Moshe Spitzer. Transcript. Project: The Reaction of German Jewry to Nazi Persecution. 1933-1939. Departement of Oral Documentation, Institute for Contemporary Jewry, Hebrew University of Jersualem [1964] [Hebr.] (Übers. S. M.). 
hin, es deckt es, es duldet, was zu dulden ist. Und wenn eure Probe bestanden sein wird, Spannungen des Zeitalters, werden nicht mehr zwei da sein, sondern einer, der Überwinder. $^{221}$

Dem Text Bubers geht kein Vorwort voran. Dem Impressum und dem Inhaltsverzeichnis folgt unmittelbar der hier in seiner ganzen Länge zitierte Text. Obwohl Buber darauf verzichten muss, die Schuldigen beim Namen zu nennen, ist der Text mehr als deutlich. Einerseits versucht er, Kraft und Mut zu spenden, um den „Spannungen des Zeitalters“ zu widerstehen. Er spricht aber auch eine Warnung aus, indem er auf das Wesen der nationalsozialistischen Bewegung verweist, das er als "phosphoreszierende[n] Sumpf “ umschreibt. Wie die Sirenen, die Odysseus mit ihrem schönen Gesang zu verführen suchten, um ihn dem Verderben auszuliefern, strahlt der Sumpf ein verführerisches Licht aus, das die Massen anlocken soll, um sie dann ebenfalls ins Verderben zu führen. Der Text richtet sich demnach nicht nur an die Juden Deutschlands, sondern gleichermaßen an nichtjüdische Leser. Während den Juden Mut und Trost zugesprochen wird, warnt Buber alle anderen. Trotz seiner offensichtlichen Doppeldeutigkeit wurde der Text von den nationalsozialistischen Behörden weder beanstandet noch verboten. Ähnlich deutlich wurde Buber in nur zwei weiteren eigenen Texten: in dem kurzen Almanach-Text Erkenntnis tut not (1935/36) und ein Jahr zuvor in einem Bändchen der Bücherei-Reihe mit dem Titel Zwiesprache (1934). Beide Publikationen sind einer genaueren Betrachtung wert. Zwiesprache war eine Neuausgabe des Essays Ich und Du, der 1923 in der von Martin Buber, Joseph Wittig und Viktor von Weizsäcker herausgegebenen Kreatur erschien. ${ }^{222}$ Diese bedeutendste Kulturzeitschrift der Weimarer Republik erschien vierteljährlich und wurde von 1926 bis 1930 im Lambert Schneider Verlag herausgebracht. Sie legte den Fokus auf den Dialog zwischen Judentum und Christentum auf Grundlage wechselseitiger Toleranz und absoluter Gleichrangigkeit. Im Jahr 1934 einen Text mit einer derartigen Provenienz

221 Martin Buber: Der jüdische Mensch von heute. In: Moritz Spitzer (Hrsg.): Almanach des Schocken Verlags auf das Jahr 5694. Berlin: Schocken 1933/34, S. 5. Der Text wurde im Schocken Verlag ein weiteres Mal im Jahr 1936 in einer Sammlung von Reden und Aufsätzen publiziert, wiederum wurde er den anderen Texten vorangestellt. Die Datierung auf April 1933 entstammt dieser Publikation: Martin Buber: Die Stunde und die Erkenntnis. Reden und Aufsätze 1933-1935. Berlin: Schocken 1936.

222 Martin Buber: Ich und Du. In: Die Kreatur 3,2 (1929), S. 201-222. 
als Einzelpublikation in der populärsten Reihe des Schocken Verlages auf den Markt zu bringen, darf als offener Affront gegen die nationalsozialistischen Machthaber gelten. Buber beließ es jedoch nicht beim ursprünglichen Text, der einen gleichberechtigten Dialog zwischen Juden und Christen forderte und die tiefe Verbundenheit zwischen Glaubenden der zwei Religionen feststellte. Buber lotete diese Verbindungen auf verschiedenen Ebenen aus. In der Ausgabe von 1934 ergänzte er seinen Text mit einer Analyse der Gegenwart.

Die Männer des Kollektivums blicken mit überlegner Gebärde auf die „Sentimentalität" der nächstvergangenen Generation, des Geschlechts jener "Jugendbewegung" nieder. Damals befasste man sich weitläufig und tiefsinnig mit der Problematik aller Lebensbeziehungen, man intendierte „Gemeinschaft" und problematisierte sie zugleich, man kreiste in Kreisen und kam nicht vom Fleck. Jetzt aber wird kommandiert und marschiert, denn jetzt gibt es die „Sache“. Man ist aus den Irrgängen der Subjektivität auf die zielgerichtete Straße des Objektivismus gelangt. Doch wie dort eine Pseudo-Subjektivität, da es an der elementaren Kraft des Subjektseins fehlte, so besteht hier ein Pseudo-Objektivismus, da man nicht einer Welt, sondern einer weltlosen Parteiung eingefügt ist. Wie dort alle Loblieder auf die Freiheit ins Leere gesungen wurden, weil man nur die Freimachung von den Bindungen, nicht aber die Befreiung zur Verantwortung kannte, so sind auch hier die edelsten Hymnen auf die Autorität ein Missverstand, weil sie faktisch nur die erredete, erschriene Scheinautorität stärken, hinter der sich eine in die mächtigen Faltenwürfe der Haltung gewandte Haltlosigkeit birgt, die echte Autorität aber, die jene Hymnen feiern, die des echten Charismatikers in seiner steten Verantwortung zum Herrn der Charis, dem politischen Raum der Gegenwart unbekannt geblieben ist. ${ }^{223}$

Mit diesen wenigen Zeilen riskieren Buber und der Verlag viel: So deutlich wurden die nationalsozialistischen Autoritäten in keiner anderen Publikation des Schocken Verlages angegriffen. Buber lässt es nicht dabei, die Fehlerhaftigkeit der Ideologie und die Fehlleitung der mitmarschierenden Massen anzuprangern. Er macht vielmehr einen weiteren, gefährlichen Schritt, indem er die Autorität als „erschriene“, „erredete“ und scheinbare bezeichnet. Es stellt sich die Frage, an wen sich die Worte richteten. Anders als in dem vorangehend zitierten Text sind hier keine Worte des Trostes zu finden. Natürlich spielt

223 Martin Buber: Zwiesprache. Berlin: Schocken 1934, S.64-65. 
der Text im Kontext des ursprünglichen Publikationsortes auf die Möglichkeit eines gleichberechtigten Miteinanders zwischen Juden und Christen an. Aber eben nicht dieser neue Textteil. Das kann als ein Hinweis darauf gesehen werden, dass sich dieser an ein nichtjüdisches Publikum wandte. Aus den Erinnerungen Lambert Schneiders wissen wir, dass die Publikationen des Schocken Verlages auch viele nichtjüdische Leserinnen und Leser hatten. Zwar durften ,arische' Buchhandlungen jüdische Publikationen nicht in ihrem Sortiment führen; einige verkauften sie jedoch illegal. Zudem waren jüdische Buchhandlungen frei zugänglich und das gesamte Sortiment konnte direkt beim Verlag auf dem Postweg bestellt werden. ${ }^{224}$

Der Schocken Verlag konnte unbehelligt publizieren, weil er sich, schon bevor er im Sommer 1937 gezwungen wurde, die Bezeichnung zu tragen, als jüdischer Verlag verstand. Schneider erinnerte sich später, dass der Versuch der Nationalsozialisten, den Verlag, in ein Ghetto zu sperren', ihm ermöglichte, relativ frei zu agieren. ${ }^{225}$ Anders als die nationalsozialistischen Machthaber annahmen, sprach der Verlag auch ein nichtjüdisches Publikum an. Der im Herbst $1935 \mathrm{im}$ Almanach auf das Jahr 5696 erschienene Text Erkenntnis tut not von Buber verdeutlicht dies ebenso wie die deutliche Kritik am Regime vonseiten des Autors.

In diesem kurzen Essay widmet er sich den Notwendigkeiten, die sich einem Menschen stellen, dessen Existenz und Identität unverschuldet wie grundsätzlich in Frage gestellt wurden. Dabei geht er auf die Möglichkeit des Dialoges ein und konstatiert: „[E]s gibt den Raum nicht mehr, in dem wir zu dem anderen sprechen und von ihm vernommen werden können. Es gibt den Dialog nicht mehr. ${ }^{\text {226 }}$ Um dann nur wenige Zeilen weiter unten fortzufahren: „Der Raum ist taub geworden. Und doch auch wieder nicht. Denn was wir im ertaubten Raum der Öffentlichkeit zu uns selber, nur noch zu uns selber sagen, kann ja doch von jedem Beliebigen, dem es gar nicht zugedacht war, gehört werden. Wohl, so werde es gehört. ${ }^{\text {"227 }}$ Im Herbst 1935 hatte sich, so die naheliegende

224 Vgl. Schneider: Rechenschaft über vierzig Jahre Verlagsarbeit 1925-1965, S. 42.

225 Vgl. ebd., S.41.

226 Martin Buber: Erkenntnis tut not. In: Moritz Spitzer (Hrsg.): Almanach des Schocken Verlags auf das Jahr 5696. Berlin: Schocken 1935/36, S. 11-14, hier S. 13.

227 Ebd. 
Interpretation, nun auch für Buber der „Raum“, der den Gedankenaustausch zwischen Juden und Nichtjuden ermöglichte, geschlossen.

Das Jahr 1935 war geprägt von den bis dahin schwersten antisemitischen Ausschreitungen. Auch der Staatsterror gegen Juden nahm eine neue Dimension an. Im März des Jahres verbot der Präsident der Reichsschrifttumskammer jüdischen Autorinnen und Autoren jegliche schriftstellerische und literarische Tätigkeit in Deutschland. Anlässlich des ,Parteitages der Freiheit' am 15. September wurden die sogenannten Nürnberger Gesetze eingeführt, genau zwei Wochen vor Rosch ha-Schana, das im Jahr 1935 am 28. September gefeiert wurde. Da der Almanach alljährlich zum jüdischen Neujahrsfest erschien, musste die redaktionelle Arbeit um den 15. September herum abgeschlossen worden sein. Wann genau Buber seinen Text fertigstellte, ist aus den überlieferten Akten nicht mehr zu eruieren; er entstand aber eindeutig unter dem Eindruck des sich verschärfenden Antisemitismus des Jahres 1935. Zu diesem Zeitpunkt war mit den Nürnberger Gesetzen der Dialog zum Verstummen gebracht, aber wie Buber selbst in dieser Situation noch feststellte, konnte jeder dem Selbstgespräch zuhören, der nur hören wollte. Dieses Selbstgespräch war im Schocken Verlag derart deutlich und kampfeslustig, dass es auch außerhalb der aufgezwungenen Grenzen des jüdischen Raumes gehört werden musste.

\subsubsection{Das innerjüdische Selbstgespräch}

Das innerjüdische Selbstgespräch über den zunehmenden Antisemitismus in Deutschland begann nicht erst 1935. Bereits 1933 finden sich erste Spuren davon. Es sind dies in erster Linie von Buber ausgewählte und übersetzte biblische Texte, die angesichts der politischen Ereignisse eine neue Bedeutung erhielten. Darüber hinaus handelte es sich um weitere, oft religiöse Texte der jüdischen Tradition, die in ihrer Auswahl Bezug zur Gegenwart nahmen. Lambert Schneider erinnert sich in Rechenschaft, einem Almanach zum vierzigjährigen Bestehen seines Verlages - der, durchsetzt mit Lebenserinnerungen, weit mehr war als ein Almanach - an ein Gespräch mit Buber im Jahr 1934. Buber habe geäußert, dass sie lernen müssten, „in den Katakomben zu leben“228. Dies habe er folgendermaßen erläutert: „[f]ür uns Schriftsteller kommt es darauf an, so klug zu schreiben, dass die derzeit Mächtigen nicht gleich unseren Widerstand sehen und uns beim Wickel nehmen können, so klug zu schreiben, 
dass uns viele Menschen gelesen haben, ehe man uns zur Verantwortung ziehen kann. ${ }^{\text {"229 }}$ Buber spielt hier auf die - inzwischen vonseiten der historischen Forschung widerlegte - Annahme an, dass Katakomben der christlichen Minderheit im Römischen Reich als geheime Treffpunkte dienten: In den unterirdischen Stollen wurden ihre Toten nach christlichen Bräuchen bestattet, aber auch Gottesdienste und Treffen abgehalten. Dergestalt müssten jüdische Schriftsteller und Schriftstellerinnen Katakomben finden, um zu schreiben, um trotz Verfolgung und Ausgrenzung aus dem Verborgenen das Eigene weiterbestehen lassen. Buber will gehört werden, und das nicht nur von den Eigenen. Zwar spricht er 1935 vom jüdischen Selbstgespräch, da der Raum für Dialog verschlossen sei; er rechnet jedoch mit Zuhörern. Das Gesagte sollte auch ,nach oben' dringen. Das Gespräch in den Katakomben sollte aber vor allem den Verfolgten und Entrechteten die Möglichkeit bieten, so frei und in der Aussage so deutlich wie möglich zu sprechen, und im Weiterbestehen und Kampf Hoffnung zu schöpfen. Die im Schocken Verlag publizierten Texte Bubers aus jener Zeit sind Zeugnis davon, wie gut ihm dies gelang.

Als ,Versteck' dienten vor allem biblische sowie andere religiöse Texte. Der erste Band der Schocken-Bibliothek im Herbst 1933 erschien unter dem Titel Die Tröstung Israels. Die zweisprachige Ausgabe der Kapitel 40 bis 55 aus Jeschajahu enthielt den hebräischen Originaltext sowie die deutsche Übersetzung von Martin Buber und Franz Rosenzweig. Dass für den ersten Band auf einen Auszug aus Bubers Übersetzungsprojekt zurückgegriffen wurde, war nicht nur dem Umstand geschuldet, dass der Verlag mit nur sehr wenig Vorbereitungszeit die Schocken-Bibliothek und den Verlagsalmanach lancierte. Gleichermaßen wollten Schocken, Schneider, Spitzer und Buber ein Zeichen setzen. Zwar sind die Unterlagen im Schocken Archiv nicht überliefert, es kann aber davon ausgegangen werden, dass die Wahl des ersten Bandes nicht willkürlich getroffen wurde, nicht zuletzt, weil die ersten fünf Bändchen der ersten Reihe gleichzeitig in den Verkauf kamen. ${ }^{230}$ Neben dem erwähnten Band eins, der den Verfolgten Tröstung versprach, waren dies Jehuda Halevis Zionslieder (Band zwei), Joseph und seine Brüder herausgegeben von Micha Josef bin Gorion (Band drei), Hundert Chassidische Geschichten nochmals von Buber (Band vier) und Agnons In

229 Schneider: Rechenschaft über vierzig Jabre Verlagsarbeit 1925-1965, S. 38.

230 Vgl. Dahm: Das jüdische Buch im Dritten Reich, S. 327. 
der Gemeinschaft der Frommen (Band fünf). Der Auftaktband war eben keine dieser vier Publikationen, sondern Die Tröstung Israels.

„Tröstet tröstet mein Volk, / spricht euer Gott ${ }^{\text {“231 }}$, mit dieser ersten Zeile eröffnet der Schocken Verlag seine Bücherei-Reihe. Im Herbst 1933 brauchte die jüdische Bevölkerung Deutschlands, die sich der deutschen Kultur, Gesellschaft und Geschichte zugehörig fühlte, eines: Trost.

Du aber,

Jissrael, mein Knecht,

Jaakob, den ich wählte,

Same Abrahams, meines Liebenden!

du den ich erfasste von den Rändern der Erde her,

von ihren Achseln her habe dich ich gerufen

und sprach zu dir:

Mein Knecht bist du!

Gewählt habe ich dich einst

und habe dich nie verworfen, -

fürchte dich nimmer,

denn ich bin bei dir,

starre nimmer umher,

denn ich bin dein Gott,

ich stärke dich

ich helfe dir auch,

ich halte dich auch

mit der Rechten meiner Wahrhaftigkeit. ${ }^{232}$

Die Bücherei des Schocken Verlages richtete sich vor allem an ein Lesepublikum, das mit der jüdischen Tradition und deren Texten nicht vertraut war. ${ }^{233}$ So heißt es im Prospekt, der ab 1935 allen Ausgaben beigefügt war:

231 Jes. 40,1. Martin Buber: Die Tröstung Israels mit der Verdeutschung von Martin Buber und Franz Rosenzweig. Bücherei des Schocken Verlages, Bd. 1. Berlin: Schocken 1933, S. 4.

232 Jes. 41,8-10. Ebd., S. 8.

233 Vgl. auch Davidowicz: Rückführung zum Judentum. 
Tröstet tröstet mein Volk, spricht euer Gott,

zu Herzen redet Jerusalem

und rufet ihr zu,

$\mathrm{da} \beta$ vollendet ist ihr Scharwerk,

daß abgegnadet ist ihre Schuld,

daß gedoppelt von SEINER Hand sie empfängt

für all ihre Sündenbußen.

Stimme eines Rufers:

„In der Wüste bahnt

SEINEN Weg,

ebnet in der Steppe

eine Straße für unseren Gott!

alles Tal soll sich heben,

aller Berg und Hügel sollen sich niedern,

das Höckrige werde zur Ebne

und die Grate zum Gesenk!

Offenbaren will sich

SEINE Erscheinung,

alles Fleisch vereint wirds sehen.

$\mathrm{Ja}$, geredet hats SEIN Mund."

Stimme eines Sprechers:

„Rufe!“"

Es spricht zurück:

"Was soll ich rufen!

alles Fleisch ist Gras,

all seine Holdheit der Feldblume gleich!

Verdorrt ist das Gras,

verwelkt ist die Blume,

da Sein Braus sie angeweht hat!"6

- Gewiß,

Gras ist das Volk,

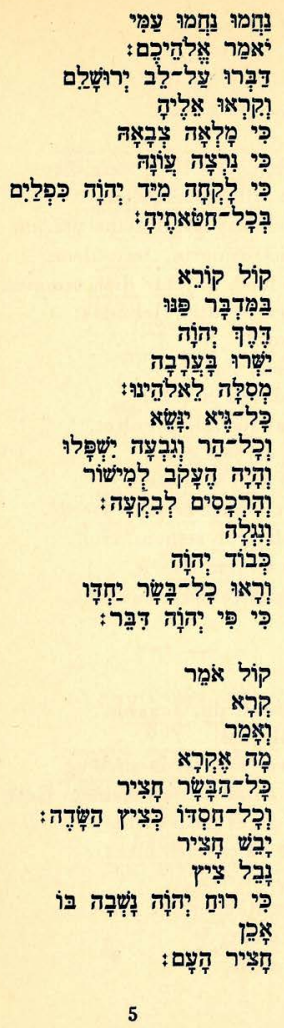

Abb. 7: Die Tröstung Israels in der Verdeutschung von Martin Buber und Franz Rosenzweig. Bücherei des Schocken Verlags, Bd. 1. Berlin: Schocken 1933, S.4-5.

Die Bücherei des Schocken Verlages will in allmählichem Aufbau aus dem fast unübersehbaren und häufig unzugänglichen jüdischen Schrifttum aller Länder und Zeiten in sorgfältiger Auswahl dasjenige darbieten, was den suchenden Leser unserer Tage unmittelbar anzusprechen vermag. ${ }^{234}$

Religiöse Texte, immer in Übersetzung und oft mit Kommentaren und Einleitungen versehen, zu publizieren, folgte diesem Anspruch. Darüber hinaus waren die Texte eine geschickt gewählte Tarnung, um tröstende wie kritische

234 Der Büchereiprospekt wurde ab Band 23 allen Ausgaben der Bücherei beigefügt. 
Worte drucken zu können. Letztere, zuweilen in einem durchaus kämpferischeren Ton, finden sich vor allem in den späteren Publikationen des Verlages.

Ein etwas außergewöhnliches Beispiel dafür ist der Band 51 der Bücherei-Reihe aus dem Jahr 1936. Er enthält 23 Klage- und Dankpsalmen, die von Buber nicht nur eingeleitet und übersetzt, sondern auch neu angeordnet wurden. In der Einleitung stellt Buber einen direkten Bezug zwischen dem biblischen Text und der Gegenwart der Leser her.

[...] Der Aufschrei dessen, der das Wir der Gemeinde spricht und der nur sie, nicht seine Sonderexistenz im Sinn hat, [ist] so unmittelbar der eines gepeinigten und hoffenden Menschenherzens, dass man das Historische eben doch als ein Biographisches erfährt und immer neu merkt, wie auch das Volk nicht anders Leib gewinnen kann als in der Person. ${ }^{235}$

Daher seien die Psalmen auch „lebensgeschichtlich “236 angeordnet. Durch diese neue Anordnung entsteht ein neuer Text, beginnend mit dem ,Ruf aus Tiefen', der ein Zwiegespräch zwischen Mensch und Gott zum Gegenstand macht. Buber stellte nicht ein Verlangen nach dem ,Aufhören der Not', sondern ,nach der lebenden Gottheit' in den Vordergrund. Die Frage, ,warum hast du mich vergessen?', und nicht, ,warum muss ich leiden?', zieht sich durch den Text. Die kaum noch zu ertragende Qual treibt den Menschen zu der Klage: ,wie lange noch?', darauf folgt aber Einsicht und schließlich Unterwerfung unter den göttlichen Plan. Die Hoffnung auf Befreiung und Erlösung erwacht und zum Schluss des Textes triumphiert der zu Beginn noch Schwache. ${ }^{237}$

\subsubsection{Der neue Midrasch}

Es ließen sich zahlreiche weitere Beispiele dafür anführen, wie offen und deutlich der Schocken Verlag Kritik übte und diese gleichermaßen vor der nationalsozialistischen Kontrolle tarnen konnte. Ernst Simon war wohl der Erste, der die Publikationen als , geistigen Widerstand ${ }^{\text {238 }}$ gegen den Nationalsozialismus

235 Martin Buber: Aus den Tiefen Rufe ich dich. 23 Psalmen in der Urschrift mit der Verdeutschung von Martin Buber. Bücherei des Schocken Verlages, Bd. 51. Berlin: Schocken 1936, S. 6. 236 Ebd., S.7

237 Die Zusammenfassung folgt dem Vorwort Bubers, vgl. ebd., S.7-8.

238 Vgl. Ernst Simon: Jewish Adult Education in Nazi Germany as Spiritual Resistance. In: LBIYB 1,1 (1956), S.68-104. 
bezeichnete. Simon, ein langjähriger Autor des Verlages, prägte für diese versteckt-offene Kritik am Regime den Begriff des ,neuen Midrasch ${ }^{239}$. „Midrasch ist ursprünglich die Bezeichnung für jegliche Art der Bibelauslegung “240, schreibt Max Dienemann ${ }^{241}$ in seiner Einleitung zu Midraschim der Klage und des Zuspruchs, das selbst ein Beispiel für solchen ,geistigen Widerstand' des Schocken Verlages ist. Eine klare Definition ist jedoch kaum möglich, so Stemberger. ${ }^{242}$ Auch Roger Le Déaut zufolge lässt sich Midrasch nicht definieren, sondern nur beschreiben. ${ }^{243}$ Gary G. Porton ordnet Midrasch ein als

a type of literature, oral or written, which stands in direct relationship to a fixed, canonical text, considered to be the authoritative and the revealed word of God by the midrashist and his audience, and in which this canonical text is explicitly cited or clearly alluded to. ${ }^{244}$

239 Vgl. Simon: Jewish Adult Education in Nazi Germany as Spiritual Resistance, S.93-98. Der Aufsatz wurde erstmals publiziert im ersten Band des $L B I Y B$. Auf Deutsch erschien er drei Jahre später als eigenständiges Kapitel in Simons Werk Aufbau im Untergang. Jüdische Erwachsenenbildung im nationalsozialistischen Deutschland als geistiger Widerstand. Tübingen: Mohr 1959, S. 76-91. Salman Schocken war mit Simons Darstellung nicht einverstanden, er wollte die Verlagsgründung nicht im Zusammenhang mit der nationalsozialistischen Machtergreifung verstanden wissen. Schockens Replik auf Simon wurde von Miriam Nussbaum verfasst, wie es scheint, wurde dieser Text jedoch nie veröffentlicht. Vgl. M[iriam] Nussbaum: Zu LBIYB 1,1, 1956. Aufsatz Prof. E. Simon „The Jewish Midrash“. SchA, Verlag, 303.

240 Max Dienemann: Midraschim der Klage und des Zuspruchs. Bücherei des Schocken Verlages, Bd.36. Berlin: Schocken 1935, S.6.

241 Der Publizist und Philologe Max Dienemann (1875-1939) war einer der führenden liberalen Rabbiner Deutschlands. Er ordinierte Regina Jonas im Jahr 1935 zur ersten Rabbinerin Deutschlands und stand gemeinsam mit Leo Baeck dem Allgemeinen Rabbinerverband vor. Während der nationalsozialistischen Herrschaft wurde er zweimal in ein Konzentrationslager deportiert, 1933 ins KZ Osthofen und im November 1938 nach Buchenwald. Nach seiner erneuten Freilassung flüchtete er im März 1939 mit seiner Familie nach Palästina. Er starb kurze Zeit später, im April 1939, in Tel Aviv. Vgl. Frank Surall: Dienemann Max. Rabbiner und jüdischer Theologie. In: Biographisch-Bibliographisches Kirchenlexikon, Bd.XXXI, hrsg. v. Friedrich-Wilhelm Bautz / Traugott Bautz. Nordhausen: Bautz 2010, Sp. 354-365.

242 Vgl. Günter Stemberger: Einleitung in Talmud und Midrasch. 8. neubearb. Aufl. München: Beck 1992, S. 233.

243 Vgl. Roger Le Déaut: A propos d'une définition du midrash. In: Biblica 50,3 (1969), S.395-413, hier S. 401.

244 Gary G. Porton: Defining Midrash. In: Jacob Neusner (Hrsg.): The Study of Ancient Judaism. New York: Ktav 1981, S. 55-92, hier S.62. 
Dienemann stellt in seiner Midrasch-Definition den Bezug zur jeweiligen Gegenwart ins Zentrum. Er unterstreicht dabei besonders die „lebendige Geschichtsauffassung $^{\text {“245 }}$ : Im Midrasch sei der Begriff der Geschichte „aufgehoben“246.

Denn Geschichte heisst, dass etwas ,geschehen' ist, also nicht mehr ist, dass Menschen gewesen sind, die nicht mehr sind, man erfährt von ihnen, man lernt, wer sie waren, aber sie waren. Und im Midrasch leben alle gleichzeitig, kein Geschlecht ist abgetreten und nicht mehr wirksam, kein Geschlecht ist so vergangen, dass es nicht mehr gegenwärtig sein könnte. ${ }^{247}$

Auch Stemberger verweist auf diesen Aspekt: „Wesentlich bleibt jedoch immer das Bewusstsein, dass die Bibel relevant bleibt, das Wort Gottes an den Menschen von heute ist. “248

Dienemann stellte im Bücherei-Band nicht einen einzelnen Midrasch-Text vor, sondern eine Sammlung von Stücken, „die um Trauer und Niederbruch der Einzelnen und der Gesamtheit kreisen. ${ }^{249}$ In den letzten Zeilen der Einleitung stellt Dienemann einen Gegenwartsbezug her. Die Einführung in die „Welt des Midrasch“, das vordergründige Ziel des Büchleins, habe einen praktischen Zweck, denn es wolle den

heutigen Juden, die aus dem Entferntsein und Abgewandtsein zurückkehren und Nähe suchen, dazu verhelfen, dass sie einen Tag wie etwa den Tischa beaw, den groBen Tag der jüdischen Trauer, in einer Form begehen, bei der sie teilhaben an der Trauer und der Tröstung, an Klage und Zuspruch. ${ }^{250}$

Dienemann wählte kurze, aber umso deutlichere Textstellen aus, die den verfolgten Juden Mut zusprechen sollten. Eröffnet wird die Sammlung mit einem einseitigen Text, der mit „Die Wendung“ überschrieben wurde. Er beinhaltet einen kurzen Ausschnitt aus dem Midrasch Echa Rabbati (EkhR), der

245 Dienemann: Midraschim der Klage und des Zuspruchs, S.9.

246 Ebd.

247 Ebd., S.9-10 (Herv. i. Orig.).

248 Stemberger: Einleitung in Talmud und Midrasch, S. 236.

249 Dienemann: Midraschim der Klage und des Zuspruchs, S. 14.

250 Ebd. 
haggadischen Auslegung der Klagelieder. ${ }^{251}$ Ausgangspunkt ist Vers 1.2 aus dem Klagelied: „Zion hat keinen Tröster“, „en la menachem “252 im hebräischen Original. Daraufhin sagte Rabbi Lewi, so der Midrasch: „Wo immer das Wort en, man hat nicht, steht, da wendet es sich und es wird. ${ }^{253}$ Als Beispiele werden die Schwangerschaften von Sara und Hannah angefügt, die trotz Unfruchtbarkeit ein Kind gebaren: „denn Gott bedachte Sara“ (Gen. 21.1). „So auch hier. Du denkst: Zion hat in Ewigkeit keinen Tröster - doch er kommt, denn so ists verheißen (Jes. 51.13).“254 Der kurze Text verspricht eine Wendung zum Guten, dies wird verstärkt durch den Titel, der von Dienemann stammt.

Dienemann bietet seinen Leserinnen und Lesern wenig Kontext zu diesem Midrasch, der entsprechend der fünf Kapitel der Klagelieder in fünf Paraschiot gegliedert ist, die den biblischen Text Vers für Vers auslegen. Der Midrasch enthält neben Wort- und Sacherklärungen zahlreiche Gleichnisse und Erzählungen. Die Klagelieder wurden vor allem am neunten $A v$, dem Tag der Zerstörung des Tempels in Jerusalem durch die Römer im Jahr 70 u. Z. gelesen. Daher enthält der EkhR zahlreiche Erzählungen über die Zerstörung Jerusalems im Jahr 70 u. Z., aber eben auch über andere Notzeiten unter Trajan und Hadrian. Daneben stehen Erzählungen, in denen die Überlegenheit der Bewohner Jerusalems gegenüber jenen Athens dargestellt wird. ${ }^{255}$ Den mit rabbinischen Texten vertrauten Lesern erschloss sich dieser Kontext und damit weitere Inhaltsund Bedeutungsebenen. Für die mit der jüdischen Tradition weniger vertrauten Leser, an die sich die Bücherei explizit richtete, stand der Ausschnitt, wie er von Dienemann gewählt wurde, zwar für sich alleine, war damit aber keinesfalls isoliert: Durch die Einleitungsworte wurde ein direkter Bezug zwischen ihrer Gegenwart und den großen Katastrophen in der jüdischen Geschichte hergestellt.

251 Für eine deutsche Übersetzung vgl. August Wünsche: Der Midrasch Echa Rabbati. Das ist die Haggadaische Auslegung der Klagelieder. Zum ersten Male ins Deutsche übertragen. Leipzig: Schulze 1881. Dienemann folgt jedoch nicht dieser Übersetzung; da keine weiteren Übersetzungen existieren, muss davon ausgegangen werden, dass er den Text selbst ins Deutsche übertrug.

252 Dienemann: Midraschim der Klage und des Zuspruchs, S. 15.

253 Ebd.

254 Ebd.

255 Vgl. Stemberger: Einleitung in Talmud und Midrasch, S. 316. 
Die Verbindung zwischen dem aktuellen und den vergangenen Leiden ist der Midrasch, der - wie in dem oben zitierten Satz aus dem Vers 1.2 - die Umkehr des Unglücks verspricht: „wendet es sich und wird“. Das Wort Gottes, wie es in der Bibel tradiert wird, behält damit, entsprechend der Lehrmeinung, seine Relevanz für die Gegenwart. Wie Sara von ihrer Unfruchtbarkeit erlöst wurde, wird das deutsche Judentum von seinen Qualen erlöst werden. So verliert ein Text, der in der ersten Hälfte des fünften Jahrhunderts entstanden ist, 1500 Jahre später nichts von seiner Aktualität. ${ }^{256}$

Ernst Simon greift diesen Aktualitätsbezug auf, bezieht ihn jedoch nicht ausschließlich auf den Text, sondern gleichermaßen auf das Konzept. Er sieht den Midrasch als Textsorte, als Selbstgespräch einer Minderheit:

Eine verfolgte Minorität schaffte sich im Midrasch schon zur Zeit seiner Entstehung eine Binnensprache für ihre Auseinandersetzung mit der Außenwelt, die der Gegner selten, der Volks- und Glaubensgenosse fast immer verstand. ${ }^{257}$

Damit ist das „innerjüdische Selbstgespräch“, wie Buber es nennt, als Midrasch zu verstehen. Eine genaue Lektüre der in Frage kommenden Texte unterstützt Simons Interpretation. Der Gegenwartsbezug vieler Manuskripte, die im Schocken Verlag publiziert wurden, ist frappant. Dieser wird teilweise von den Autoren oder Herausgebern - im Fall von Dienemann in Kommentaren und Einleitungen - ausformuliert, oft bleibt es aber dem Leser überlassen, diesen herzustellen.

Auch Buber spielt in der bereits angesprochenen Publikation ${ }^{258}$ auf die Gegenwärtigkeit an. Er stellt den Text, den er durch seine Auswahl und Anordnung der 23 Psalmen erst schafft, als das Suchen nach dem Zwiegespräch zwischen Mensch und Gott dar. In Simons Lesart kommt dem Text eine andere Bedeutung zu: Er wird zur Kampfesschrift. Ende der 1950er Jahre, also fast 25 Jahre nach Erscheinen des Buber-Textes, kommentiert Simon Passagen daraus, indem er sich als Erzähler einbringt.

256 Zur Datierung vgl. ebd., S.316-317.

257 Simon: Aufbau im Untergang, S.76-77.

258 Buber: Aus den Tiefen Rufe ich dich. 
„Das Leben deiner Gebeugten,

nimmer vergiss es in die Dauer! $(74,19)$

Blick auf den Bund! (74,20)

...

Steh auf, Gott!

streite deinen Streit!

gedenke deiner Verhöhnung

durch den Schändlichen all den Tag!“ $(74,22)$

Ja, Gott wird rächen ...

„Fürchten müssen sich alle Menschen“ $(64,10)$

und retten:

„Du aber, DU, wirst ihrer lachen, wirst all der Weltstämme spotten.“ $(59,9)$

Er wird erkennen, weshalb Israel leidet:

„Denn deinetwegen trage ich Hohn,

hüllt Beschimpfung mein Antlitz ein“, $(69,8)$

wird seines Volkes Gebet erhören:

„Reiße mich aus dem Schlamm, dass ich nimmer versinke, entrissen sei ich meinen Hassern, den Wassertiefen!“ $(69,15)$

Deshalb darf man ihn preisen:

„Preisen sollen ihn Himmel und Erde, die Meere und allwas sich drin regt! $(69,35)$

Denn Gott wird Zion befreien, 
aufbauen die Städte Jehudas,

dass man dort siedelt und sie ererbt!" $(69,36)$

Und wer ihn leugnet:

„Der Schändliche spricht in seinem Herzen:

,Da gibts keinen Gott!

Verderbt, greulich ward ihre Sitte,

keiner ist mehr, der Gutes tut." $(14,1)$

dem wird die Antwort:

„König ist Er

der Weltzeit und Ewigkeit!“ $(10,16)$

Dieser Ewigkeit gegenüber sind die Herrscher des Tages im vergänglichen Schein, auch und gerade dann, wenn der Psalmist sie in ihrer ganzen trägen und feisten Gegenwart voraussagt, die besonders für einen von ihnen fast porträtähnlich zutraf:

„Feist ist ihr Wanst, $(73,4)$

in der Menschenpein sind sie nie,

mitsamt den Leuten werden sie nicht geplagt. $(73,5)$

Drum ist Hoffart ihr Nackengeschmeid,

hängt Unbill als Kragen ihnen um. $(73,6)$

Aus dem Fett dringt ihr Auge hervor,

drüber ziehn die Malerein des Herzens.“ (73,7)

Gott aber

„prüft Herzen und Nieren,

ein wahrhaftiger Gott!“ $(7,10)$

Und denen, die sein Volk ducken $(94,5)$

„Die Witwe, den Gastsassen[ $\left.{ }^{259}\right]$ würgen,

die Waisen morden ..." $(94,6)$

259 Das sind Fremde. 
weil sie meinen:

„Nicht sieht es Er!“

und:

„Nicht merkt es Jaakobs Gott!“ (94,7)

wird gesagt:

„Selig der Mann,

den du in Zucht nimmst...." $(94,12)$

Wenn einst David und sein Volk rufen werden (4,2), wird Gott antworten; wird das Gebet der Umkehr, das immer wiederkehrende, erhören.

„Gott, Umscharter $\left[{ }^{260}\right]$,

lass uns wiederkehren!

lichte dein Antlitz

und wir sind befreit!“ $(80,8 ; 20)$

Die Frage:

„Ist für die Dauer dahin seine Huld?“ $(77,9)$

wird, in allem verzweifelten Ernst, zu einer fast rhetorischen, Gott wird sein Antlitz nicht immer vor dem stöhnenden Menschen verbergen, wird dessen Seele

„vor der Lügenlippe,

vor der trügrischen Zunge“ (120,2)

retten, diese Seele, die gleich einem befreiten Vogel dem Fänger entschlüpfte (124,7).

260 Das ist der Gott der Heerscharen. 
Die Heimkehrer Zions werden wie Träumende sein $(126,1)$, mit Lachen in ihrem Munde, mit Jubel in ihrem Gesang $(126,2)$ mit Harfe und Leier das neue Morgenrot grüßend $(57,9) \cdot{ }^{261}$

Simon wird den Text bereits im Jahr des Erscheinens gelesen haben, gehörte er doch als Autor, Lektor, Rezensent und Freund Bubers zum engeren Kreis des Verlages. Seine Bearbeitung der von Buber ausgewählten und zusammengestellten Psalmen fügt dessen Text eine weitere Ebene hinzu. Seine Kommentierung Ende der 1950er Jahre ermöglicht uns, mit den Augen eines Betroffenen zu lesen.

\subsubsection{Die ,Ghettoexistenz' als Schutz gegen die Behörden?}

Die kritischen Stimmen, die im Schocken Verlag ein Sprachrohr fanden, wurden in den ,Katakomben' gehört. Warum der Verlag trotz solcher Publikationen bis in den Spätsommer 1938 weitgehend unbehelligt publizieren konnte, scheint auf einer Verknüpfung verschiedener Ursachen zu beruhen. Die zuständigen Beamten waren weder ungebildet noch begriffsstutzig, und die Publikationen wurden durchaus zur Kenntnis genommen. Dies ist einem Brief zu entnehmen, in dem Lambert Schneider Schocken von einem Gespräch zwischen Moritz Spitzer vom Schocken Verlag und Erich Kochanowski und zwei weiteren Mitarbeitern des ,Sonderreferats Hinkel, Judenfragen ' berichtet. Demzufolge wurde, so Schneider, die Arbeit des Verlages vom Sonderreferat mit Respekt betrachtet. Das Gespräch fand auf Wunsch der Verlagsarbeiter statt, die darum aufgrund der Entwicklungen vom Sommer 1937 ersuchten.

Am 30. Juli 1937 wurden neue Einschränkungen für jüdische Buchhändler und Verleger erlassen, was bedeutete, dass sie aus der Reichsschrifttumskammer ausgeschlossen wurden. ${ }^{262}$ Der Schocken Verlag erhielt ein auf den 31. Juli 1937 datiertes Schreiben, in welchem ihm explizit und widerruflich genehmigt wurde, die Firma als ,Jüdischen Buchverlag' weiterzuführen. Salman Schocken zeigte sich besorgt über diese Entwicklungen und wollte die Lage in einem persönlichen Gespräch klären. Da er selbst zu diesem Zeitpunkt Deutschland seit etwas mehr als einem Jahr mied und Lambert Schneider als ,Arier das nunmehr offiziell als jüdischer Verlag gebrandmarkte Unternehmen nicht

261 Simon: Aufbau im Untergang, S. 81-84.

262 Vgl. Erstes Rundschreiben an die zum jüdischen Buchhandel gehörenden Personen und Unternehmen, Schreiben Hans Hinkel vom 30.07.1937. SchA, Verlag, 331/91. 
vertreten durfte, fiel die Wahl auf Moritz Spitzer. Diesem wurde ein Gespräch gewährt. Laut Schneider ging es über drei Stunden und verlief sehr erfolgreich. Zwar gefiel Hinkel nicht, dass der Schocken Verlag als Aktiengesellschaft des Schocken-Konzerns geführt wurde, und er drängte zu einer Ausgliederung, jedoch erreichte Spitzer, dass auf Zensur der Manuskripte weiterhin verzichtet wurde. Man scheint im Sonderreferat gewillt gewesen zu sein, die Geschäfte des Schocken Verlages nicht übermäßig zu erschweren. Schneider zufolge war vonseiten des Sonderreferats die Erklärung dafür, dass man der Arbeit, wie bereits erwähnt, Respekt entgegenbrachte. Dabei mutet es fast ironisch an, dass gerade Bubers „Arbeiten und Person sehr hoch geachtet“ wurden und „dass gegen keines seiner Bücher Bedenken bestehe. ${ }^{\text {“263 }}$ Es scheint, als ob das innerjüdische Selbstgespräch gerade von der Behörde, von der man erwarten müsste, dass sie besonders genau hinschaut und -hört, nicht vernommen wurde. Damit glückte dem Schocken Verlag ein Meisterstück. Über fünf Jahre hinweg, 1933 bis 1938, publizierte er tröstende, kritische und widerständige Texte vor den Augen der Nationalsozialisten.

Der obengenannte Respekt vor einzelnen Autoren oder der Arbeit des Verlages mag eine Rolle dabei gespielt haben, dass dies möglich war. Über andere und weitere Gründe lässt sich nur spekulieren. Es ist davon auszugehen, dass die zuständigen Stellen bei der Reichsschrifttumskammer es als ausreichend ansahen, den Verlag aus entscheidenden Institutionen und Prozessen des Buchmarktes auszuschließen.

Damit hat die dergestalt geschaffene ,Ghettoexistenz' den Schocken Verlag, aber auch andere Verlage, die sich auf ein rein jüdisches Programm spezialisierten, weitgehend von Zensur verschont. Das betraf ebenfalls den Jüdischen Verlag, die Jüdische Rundschau, den Hebräischen Verlag Menorah und die Verlage J. Kauffmann und M. Lehrberger. ${ }^{264}$ Solange Schocken davon absah, nichtjüdische Literatur zu verlegen, konnte er einigermaßen ungehindert arbeiten, und war damit freier in der Auswahl seines Programmes als , arische 'Verlage. Barbian verdeutlichte in einer Studie, dass Autoren und Verlegern im nationalsozialistischen Deutschland der 1930er Jahre enge Grenzen gesetzt waren. Durch brutale Einschüchterung und Festnahmen wurde versucht,

263 Lambert Schneider an Salman Schocken, 22.08.1937. SchA, Verlag, 331/42.

264 Vgl. Dahm: Das jüdische Buch im Dritten Reich, S. 74. 
abweichendes Verhalten zu unterbinden. ${ }^{265}$ Nicht nationalsozialistische Verleger, so Barbian, waren einem besonders hohem Druck ausgesetzt.

Sie hatten sowohl auf die politische Zensur der staatlichen Behörden [...] zu reagieren, als auch die wirtschaftliche Existenzfähigkeit ihrer Unternehmen mit einem Programm zu sichern, das den Machthabern keine Angriffsfläche bieten durfte, und das Lesepublikum zufriedenstellen musste. ${ }^{266}$

Selbstzensur, politische Zurückhaltung und Ausschluss von unerwünschten Autoren gehörten zu den Strategien, Repressionen zu vermeiden. Von den Autoren leistete nur eine verschwindend kleine Minderheit Widerstand oder äußerte offen Protest. ${ }^{267}$

Schocken scheint von diesen Entwicklungen kaum betroffen gewesen zu sein: Er konnte problemlos jüdische Autoren verlegen und seine Verkaufszahlen steigern. Die Anfangsperiode der NS-Herrschaft fiel sogar mit dem Ausbau des Verlages zusammen. Unter den Augen der antimodernistischen und antisemitischen Behörden verlegte er Bücher mit eindeutig kritischem Inhalt. Die textliche Ebene der religiösen Schriften verdeckte dabei die Intentionen der Texte, die erst durch den Gegenwartsbezug deutlich wurde.

Schocken war nicht der einzige Verleger, der während der ersten sechs Jahre des NS-Regimes mit Publikationen direkt auf die Situation der deutschen Juden Bezug nahm. Saskia Schreuder widmet sich in ihrem 2002 erschienenen Buch Würde im Widerspruch der literarischen Verarbeitung der historischen Erfahrung durch unmittelbar Betroffene. Ihr zufolge hob sich der Schocken Verlag von den übrigen jüdischen Verlagshäusern der Zeit ab. ${ }^{268}$ Mit Ausnahme von Alfred Mombert verlegte er keine Prosa von noch in Deutschland lebenden Autoren, da es nach Ansicht von Spitzer „an wirklich guter Belletristik“269 fehlte.

265 Vgl. Jan-Pieter Barbian: Literaturpolitik im NS-Staat. Von der, Gleichschaltung'bis zum Ruin. Überarb. Ausg. Frankfurt am Main: Fischer 2010, S.405-406.

266 Ebd., S. 409.

267 Vgl. ebd., S. 405.

268 Vgl. Schreuder: Würde im Widerspruch, S. 8-9.

269 Moritz Spitzer an Kurt Blumenfeld, 29.12.1933. SchA, Verlag, 332/18. 
Im Spätsommer 1938 wurde dann auch der Schocken Verlag Opfer der nationalsozialistischen Zensur. Dies lässt sich durch zwei Briefe von Spitzer rekonstruieren. In einem Brief an Scholem bedauert Spitzer, dass Scholem in der AlmanachAusgabe 1938/39 nicht vertreten sein werde, wobei er glaubte, dass „durch verhältnismäßig leichte Änderungen“ der Aufsatz „zu wenden“ sei und erscheinen könne. ${ }^{270}$ Spitzers Formulierungen sind von Zurückhaltung geprägt:

Mit dem diesjährigen Almanach habe ich überhaupt großes Pech. Mehr als ein Viertel der Texte, und darunter keineswegs die schlechtesten Beiträge, sind mir gestrichen worden. Aus dem Rest muss ich nun notdürftig etwas zusammenflicken, nur damit der Almanach erscheinen kann. Dass ich das nicht freudig tue, können Sie sich leicht denken. ${ }^{271}$

Scholems Reaktion auf diesen Brief ist nicht überliefert. Sein Beitrag fehlt jedoch im Almanach, sodass wir davon ausgehen müssen, dass er sich gegen den Eingriff der Zensurbehörden stellte und konsequenterweise auf die Publikation seines Beitrages verzichtete. Dass es sich nicht um redaktionelle Wünsche von Schocken, sondern tatsächlich um Eingriffe der Nationalsozialisten handelte, wird in einem Brief Spitzers an Ernst Simon klar, den er zwei Tage nach dem Brief an Scholem verfasste. So schreibt er:

[I]ch muss Ihnen in aller Eile von einem Unfall Bericht erstatten: von Ihrem Almanachbeitrag ist nur der kleine Abschnitt über Zunz zum Druck freigegeben worden. Dieses Schicksal hat leider mehr als ein Viertel des gesamten für den Almanach vorgesehenen Textumfangs betroffen, und ganz besonders die historischen Beiträge. Natürlich ist die Komposition des Almanachs damit zerschlagen, und was nun doch herauskommt - nachdem ich in der ersten Regung auf die Herausgabe verzichten wollte - ist ein arg zusammengeflickter Torso. Wie für den ganzen Almanach bestand auch für Ihren Beitrag die Frage, ob man ihn so bruchstückhaft drucken solle. Ich habe mich dazu aus rein opportunistischen Gründe entschlossen, weil - wie Sie sehen werden - er die Brücke zwischen zwei anderen Beiträge bildet (Heine und Luzatto $[s i c]$ ), die sonst hätten wegfallen müssen, was ich mir bei dem

270 Moritz Spitzer an Gershom Scholem, 07.09.1938. NLI, Scholem Archiv, Arc. 4 1599, 01 2341, Bd. 1 .

271 Ebd. 
verringerten Umfang des Textes nicht gestatten konnte. [...] Ich versuchte, Sie und mich zu salvieren, indem ich den Titel folgendermaßen änderte: ,Eine Bemerkung über Leopold Zunz. Bruchstücke einer Arbeit über die westjüdische Aufklärung im 19. Jahrhundert'. ${ }^{272}$

Im September 1938 trat damit ein, was der Schocken Verlag lange zu verhindern wusste: Die Freiheit zu publizieren, solange man sich auf jüdische Autorinnen und Autoren beschränkte, wurde beschnitten. Ganze Texte wurden zensiert, sodass nur noch Bruchstücke der Originalbeiträge übrigblieben. Aber selbst in dieser Situation versuchte Moritz Spitzer die Würde des Verlages und die der Autoren zu wahren, indem er einerseits daran festhielt, die Ausgabe dennoch zu produzieren, und indem er - bspw. bereits im Titel von Simons Beitrag - auf die Eingriffe hinwies. Spitzer gelang es, trotz der massiven Eingriffe diese letzte Ausgabe des Schocken Almanachs zu publizieren. Der gekürzte Beitrag von Simon erschien unter dem Titel, den Spitzer in seinem Brief vorgeschlagen hatte. ${ }^{273}$

Auch wenn es Moritz Spitzer nochmals gelang, den Almanach herauszubringen, schätzte er die politische Situation realistisch ein. Anders Schocken, der glaubte, auch im kommenden Jahr mit der Verlagsarbeit fortfahren zu können, gab sich Spitzer dieser Illusion nicht hin. Im Schlusssatz des oben zitierten Briefes an Simon schreibt er, dass es hoffentlich nicht mehr lange dauern werde, bis man sich „in Jerusalem sehen könne. “274 Tatsächlich ließ Spitzer sich ein halbes Jahr später in Jerusalem nieder. ${ }^{275}$

Bis zur Verbreitung des Fernsehers in Privathaushalten war das schriftliche Wort das diskursbestimmende Massenmedium. Günstige Volksausgaben, wie die der Schocken-Bibliothek, waren für einen Großteil der Bevölkerung erschwinglich. Dass die Nationalsozialisten bereits im Frühjahr 1933 versuchten, die Verbreitung von aus ihrer Sicht ideologisch unerwünschtem Schriftgut zu unterbinden, verdeutlicht nochmals, wie einflussreich Bücher und andere

272 Moritz Spitzer an Ernst Simon, 09.09.1938. NLI, Ernst Simon Archiv, Arc. 4 1751/3008. 273 Ernst Simon: Eine Bemerkung über Leopold Zunz. Bruchstück einer Arbeit über die westjüdische Aufklärung im 19. Jahrhundert. In: Moritz Spitzer (Hrsg.): Almanach des Schocken Verlags auf das Jahr 5699. Berlin: Schocken 1938/1939, S.65-68.

274 Ebd.

275 Vgl. Zur Frage der Tätigkeit des Herrn Dr. Spitzer, 21.07.1939. SchA, Verlag, 331/43. 
Schriftzeugnisse waren. Die Bedeutung der Publikationen des Schocken Verlages für das deutsche Judentum sollte daher nicht unterschätzt werden. Die Verlagsmitarbeitenden riskierten für die Juden Deutschlands viel, denn man konnte nicht wissen, ob man nicht plötzlich einer willkürlichen Aktion zum Opfer fiel. Auch in anderer Hinsicht nahmen Schockens Mitarbeiterinnen und Mitarbeiter einiges in Kauf. So beklagte sich Moritz Spitzer mehrmals, dass das von Schocken vorgegebene Arbeitstempo kaum einzuhalten sei, ${ }^{276}$ er sprach aber auch von einem „Auftrag der Öffentlichkeit ${ }^{4277}$, der darin bestehe, den deutschen Juden Lesematerial zur Verfügung zur stellen.

Mit jüdischen Publikationen in deutscher Sprache ist es heute so, dass man sie schnell herstellen muss; denn wer weiß, wie lange sie noch Leser finden, und die Leser, die heute da sind, die warten sehr darauf, wirklich nahrhaft jüdische Bücher in die Hand zu bekommen. ${ }^{278}$

Schocken, Schneider und Spitzer sahen die Bücherei als Medium, um den deutschen Juden Zugang zur jüdischen Tradition zu verschaffen und ihnen damit eine Stütze in den Jahren der Entrechtung und Diskriminierung zu sein. ${ }^{279}$ In zahlreichen zeitgenössischen Rezensionen findet sich der Anspruch des Schocken Verlages bestätigt, von jüdischer Seite eine offene und kritische Auseinandersetzung mit der nationalsozialistischen Judenpolitik zu führen. Ernst Simon schreibt am 12. November 1933 in der Jüdischen Rundschau:

Das Jahr 1933 wird zum Jahr der großen Heimholung. Es ist das Jahr der Gründung ${ }^{280}$ des Schocken-Verlages. Seine Leistung und Haltung sind ein Teil der Antwort, die das Judentum Deutschlands auf dieses Schicksalsjahr und die ihm folgenden Ereignisse gegeben hat. ${ }^{281}$

276 Vgl. Moritz Spitzer an Ernst Simon, 26.03.1936. NLI, Ernst Simon Archiv, Arc. 4 1751/3008.

277 Ebd.

278 Moritz Spitzer an S.J. Agnon, 14.10.1935. NLI, Agnon Archiv, Arc 41270.

279 Vgl. Programm der Bücherei vom Herbst 1934. Vgl. auch Weber: ,Halt und Richte', S. 39.

280 Simon verwechselte hier wohl das Gründungsjahr mit dem Expansionsjahr.

281 Ernst Simon: Der Schocken Verlag. In: Jüdische Rundschau, 12.11.1937, S. 9. 
Eine systematische Auswertung aller zeitgenössischen Zeitschriften und Zeitungen hinsichtlich der Besprechungen des Verlagsprogrammes steht noch aus. ${ }^{282}$ Die kursorische Durchsicht verdeutlicht jedoch, dass viele Rezensenten die Absichten des Schocken Verlages verstanden und aufgenommen haben. Der jüdische literarische Kommunikationsraum der 1930er Jahre war geprägt von dem Versuch, der Unterdrückung und dem Ausschluss entgegenzuwirken. ${ }^{283}$ Moritz Goldstein, der 1912 die Kunstwart-Debatte ${ }^{284}$ auslöste, forderte 1933 in der Jüdischen Rundschau, ,weiterzumachen'. Dabei ging es allerdings nicht um die deutsch-jüdische Symbiose, aber um die Teilhabe am europäischen Projekt.

Weitermachen.

Wenn wir auch erleben, dass die staatsbürgerliche Gleichberechtigung der Juden zurückgenommen wird: die welthistorische Tatsache ihres Eintritts in die europäische Kulturgemeinschaft lässt sich nicht zurücknehmen. Die Juden sind mündig geworden. Sie haben sich dem Strom der europäischen Geistesleben geöffnet, der Strom hat sie mit sich fortgetragen. Europäische Kultur und Zivilisation, seit jeher eine Gesamtleistung vieler konkurrierender Nationen, hat seit 100 Jahren auch die Mitleistung der Juden in sich aufgenommen, die Anteile lassen sich nicht mehr scheiden.

[...]

Ein Jahrhundert lang haben wir die Teilnahme am europäischen Geist als ein bequemes Recht genossen. Jetzt sind wir in eine Lage geraten, wo Heroismus dazu gehört, um weiter teilzunehmen. Es hängt von uns ab, von unserer Zähigkeit, von unserer Empfänglichkeit, von unserer seelischen Kraft, von unserer Zuversicht, von unserem Schwung und unserer Leidenschaft, ob wir daran teilnehmen können.

282 Saskia Schreuder hat in ihrem Beitrag „Inmitten aller Not und aller Angriffe“. Der Schocken-Verlag im Spiegel der jüdischen Kritik einen Teil der zeitgenössischen Kritiken aufgearbeitet, dies jedoch nicht abschließend. Vgl. Schreuder: ,Inmitten aller Not und aller Angriffé.

283 Die folgenden Darlegungen stützen sich, wenn nicht anders angegeben, auf Schreuder: Würde im Widerspruch.

284 Goldstein löste mit seinem Essay „Deutsch-jüdischer Parnass“ eine heftige Debatte über die Integration der deutschen Juden aus. Vgl. Moritz Goldstein: Deutsch-jüdischer Parnass. In: Kunstwart 25,11 (1912), S.281-294. 
Wir werden weiter daran teilnehmen. Mag das, was man uns aufzwingt, als Ghetto gemeint sein: der Geist wird darin herrschen. Darauf allein kommt es an. Alles andere ist äußerlich. ${ }^{285}$

Im Israelitischen Familienblatt wurde als Reaktion auf die Bücherverbrennungen vom Mai 1933 von den zeitgenössischen Autoren und Autorinnen hingegen eine, literarische Neuorientierung' verlangt:

[...] [E]s ist so, dass wir, so wie wir sind, Funktionen für Deutschland übernehmen können, die andere nicht zu bieten imstande sind, dass unser geistiger und sozialer Status, unsere Geschichte, unsere Tradition uns innerhalb des deutschen Kulturkreises bestimmte Rollen gewachsen sein lassen, ja - dass sie uns diese zwingend zuweisen. [...] Bis zum Scheiterhaufen von Berlin hielt sich der jüdische Autor für einen Schriftsteller schlechthin, was er sagte, ging durch die Sonde der Kunst, nicht durch die seiner speziellen menschlich-moralischen Möglichkeiten.

Nun muss er, ehe er zur Feder greift, aus urjüdischen Büchern, aus unverbrennbarem jüdischen Traditionsgut gelernt haben, wes Kind er ist.

Erst dann wird er wissen, was zu sagen $i h m$, gerade ihm, auferlegt wurde. ${ }^{286}$

Auch Robert Weltsch forderte in derJüdischen Rundschau zwei Tage nach der Bücherverbrennung eine Rückbesinnung auf Jüdisches.

Aber für uns Juden ist gerade die Symbolik des Vorgangs bedeutungsvoll. Sie ist ein Fanal, das uns zur Besinnung aufruft.

Jude, besinne dich auf dich selbst -

das ist für uns in Flammenschrift auf den Himmel geschrieben. ${ }^{287}$

Die jüdische Literatur soll in Rückbesinnung auf das Eigene Trost spenden und Sinn stiften. Eigene Erfahrungen von Ausgrenzung und Verfolgung sollten literarisch aufgearbeitet werden und die Bewältigung des Unheils dargestellt.

285 Moritz Goldstein: Kulturghetto? In: Jüdische Rundschau, 28.01.1933, S. 373.

286 Literarische Neuorientierung. Jüdische Schreiber und Leser in der Zeitenwende. In: Israelitisches Familienblatt für Groß-Berlin, 02.06.1933, S. 13 (Herv. i. Orig.).

287 Robert Weltsch: Fanal und Besinnung. In: Jüdische Rundschau, 12.05.1933, S. 187, 190 (Herv. i. Orig.). 
Gerson Stern schrieb noch 1938 im Israelitischen Familienblatt, das in der von Leid geprägten jüdischen Geschichte immer auch die Überwindung eingeschrieben sei. ${ }^{288}$ Der anfängliche Optimismus über die neuerwachte jüdische Literatur schwand jedoch bereits 1936 und wich einer äußerst kritischen Betrachtung der zeitgenössischen Belletristik. Einerseits wurde das ästhetische Niveau bemängelt, andererseits ein Nachlassen des Interesses bei der Leserschaft. ${ }^{289}$ Von der harschen Kritik wurden die Publikationen des Schocken Verlages explizit ausgenommen.

Was Itta Schedletzky für die jüdische Exilliteratur feststellt - dass diese während der 1930er Jahre keine grundsätzlich „neue[n] Fragestellungen und For-

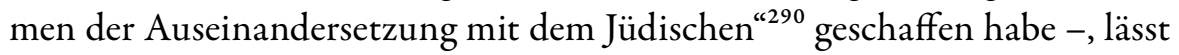
sich, so Schreuder, auch auf die jüdische Literatur in Deutschland beziehen. ${ }^{291}$ Die literarische Verarbeitung der Situation resultierte, so auch die Kritik der Zeitgenossen, in ,Konjunkturschriftstellerei“.

Schnell ein wenig Dubnow, ein wenig Graetz oder gar Kastein gefällig [...], in flotten Reimen dargeboten. [...] Nein, so geht es nicht. [...] [B]losse Verse sind noch keine Gedichte. Kunst kommt von Können, nicht von Wollen. Dieser banale Satz darf gerade in unserer Lage nicht vergessen werden, weil das ein immer tieferes Herabsinken zur Folge hätte [...]. Aber wir brauchen Heilung unserer seelischen Not; sie kann nur kommen aus echten Kunstwerken in einer einmaligen unmittelbaren Form, denn nur sie bewegt uns. ${ }^{292}$

Der Schocken Verlag verzichtete darauf, zeitgenössische Romane von noch in Deutschland lebenden Autoren und Lyrikern zu verlegen. Mit Werken von Samuel Joseph Agnon, die aus dem Hebräischen ins Deutsche übertragen wurden, oder mit Karl Wolfskehls Die Stimme spricht wurden jedoch zeitgenössische Autoren ins Programm aufgenommen. Den Verlegern im Schocken Verlag

288 Vgl. Gerson Stern: Jüdischer Roman in Deutschland. In: Israelitisches Familienblatt, 28.04.1938, S. 28.

289 Vgl. Schreuder: Würde im Widerspruch, S. 47-48.

290 Itta Schedletzky: Existenz und Tradition. Zur Bestimmung des ,Jüdischen' in der deutschsprachigen Literatur. In: Dies. / Hans Otto Horch (Hrsg.): Deutsch-jüdische Exil und Emigrationsliteratur im 20. Jahrhundert. Tübingen: Niemeyer 1993, S. 3-14, hier S.3-4.

291 Vgl. Schreuder: Würde im Widerspruch, S. 20, Anm. 3.

292 Jakob Picard: Unsere Dichtung in diesen Tagen. In: Jüdische Rundschau, 22.11.1935, S.6. 
gelang es, so war sich die damalige Kritik einig, Werke, welche die aktuellen Erfahrungen in komplexer Weise reflektierten und dabei einem ästhetischen Anspruch genügten, auf den Markt zu bringen. Die Gedichte des im italienischen Exil verfassten Gedichtzyklus von Wolfskehl z. B. transportierten,

ein emphatisches, religiöses Bekenntnis zum Judentum und stehen zugleich, was Form, Motive, Metrum und die Typographie der zweiten Ausgabe (1936) [...] anbelangt, in der Tradition einer produktiv rezipierten - insbesondere Georgschen Lyrik. $^{293}$

Aber insbesondere der Rückgriff auf historische Stoffe aus der jüdischen Vergangenheit und Tradition, also die zeitliche Verfremdung der Realität, ermöglichte die Bewältigung der eigenen Situation. Dabei handelte es sich jedoch nicht, wie in vielen anderen Fällen, um ein Ausweichen auf historische Stoffe in der zeitgenössischen Literatur zwecks „psychologischer Selbstabschirmung “294, sondern um eine bewusste Selbstvergewisserung in der eigenen Vergangenheit. Das Beispiel des Schocken Verlages verdeutlicht damit, dass es mit viel Geschick auch in den 1930er Jahren möglich war, kritische, aussagestarke und teilweise kämpferische Publikationen auf den Markt zu bringen. Die Bücher wurden damit zu wichtigen Akteuren; sie waren mehr als Träger von Inhalt, sie wurden zu Agenten der Auflehnung und des Widerstands.

\subsection{Fazit}

Ein buchwissenschaftlicher Zugang zur Sozial- und Kulturgeschichte sowie zu einer netzwerkorientierten Biographieschreibung ermöglicht eine Vielzahl von Erkenntnissen. Dazu zählen Einblicke in die Prozesshaftigkeit und die Prozesse der Diskursbildung. Darntons Kommunikationskreislauf verdeutlicht die Rolle der Bücher. Bücher sind weit mehr als kulturelle Artefakte, vielmehr nehmen sie Bezug wie Einfluss auf die Gegenwart und wirken diskursbildend in die Zukunft. Die Buchpolitik der Nationalsozialisten, die mit allen Mitteln versuchte, Schriften, die ihrer Ideologie zuwiderliefen, zu verbieten und

293 Schreuder: Würde im Widerspruch, S. 46. Zu den Ausgaben und der Typographie des Bändchens vgl. SchA, Verlag, 332/148.

294 Ebd., S. 45. 
zu vernichten, verdeutlicht, welche Wirkungsmacht Büchern beigemessen wird. Das Beispiel des Schocken Verlages zeigt ebenfalls, dass es möglich war, sich einen Handlungsspielraum zu erkämpfen. Hier war es gerade der Rückzug auf die über zweitausendjährige jüdische Texttradition, die die nötige Freiheit ermöglichte. Die bewusste Kontextualisierung der Texte machte sie zum einen zeitlos, zum anderen äußerst aktuell, indem die Lebenswelt der jüdischen Leserinnen und Leser direkt angesprochen wurde. Autoren und Verleger arbeiteten eng zusammen, um Leserinnen und Lesern, die zunehmende Entrechtung und Verfolgung erleben mussten, einen Rückhalt zu geben. Wie bedeutend die Publikationen des Schocken Verlages waren, zeigt sich auch darin, dass die Bände bis heute in israelischen Antiquariaten und bei Wohnungsräumungen zu finden sind. Zahlreiche deutsche Juden und Jüdinnen, die auf der Flucht vor der Verfolgung durch die Nationalsozialisten Deutschland verließen und sich im Mandatsgebiet Palästina niederließen, nahmen ihre Bibliotheken oder Teile davon mit. ${ }^{295}$

Der Fokus auf den Inhalt und dessen Rezeption sollte nicht dazu führen, zu übersehen, dass die Bücher des Schocken Verlages auch ästhetisch höchsten buchkünstlerischen Ansprüchen genügten. Die Gestaltung eines jeden einzelnen Bandes wurde dem Inhalt angepasst, so variieren nicht nur die Typographie, sondern auch der Satzspiegel und die Wahl des Papiers. Ohne eine enge Zusammenarbeit mit Typographen und Druckern wäre dies nicht möglich gewesen. Obwohl hier wegen fehlenden Akten nur kursorisch auf den Produktionskreislauf eingegangen werden konnte, zeigte sich deutlich, dass der Schocken Verlag durch die Maßnahmen der Nationalsozialisten nicht sofort isoliert wurde. Vielmehr existierte auch nach 1933 zunächst weiterhin eine konstruktive Zusammenarbeit mit Druckereien und mit den Typographen, die für den Verlag arbeiteten und mit ihm drucktechnisch schwierige Aufgaben lösten.

Der Fokus auf das Buch - unter Einbezug der Autoren, Verleger, Leser, Drucker und unter Berücksichtigung der Wirkmächtigkeit des Textes im Kontext der jeweiligen politischen und gesellschaftlichen Realität - ermöglicht ein differenziertes Bild auf die Geschichte, in diesem Fall auf die jüdische Minderheit in der ersten Hälfte der NS-Diktatur. Sie lässt aber auch Rückschlüsse auf die nationalsozialistischen Machthaber zu, die trotz Verboten, Ausschlüssen und Einschüchterungen gegenüber Texten zu einem gewissen Grad wehrlos waren.

295 Zur Bedeutung von Bibliotheken im Exil vgl. Kap. 7.3.3. 
Hier scheint sich Miltons Überlegung zu bestätigen, dass Bücher ein Dasein unabhängig von ihrem Verfasser und damit eine eigenständige Existenz führen, die über die Materialität des Textes hinausgeht. ${ }^{296}$

Schwenken wir nun zum zweiten übergeordneten Thema des Kapitels: der Frage nach der Relevanz des Buches für Schockens Biographie und für seine Position im Netzwerk der deutsch-jüdischen Intellektuellen und Zionisten. Schockens persönliche Verbindung zu zahlreichen Akteuren des deutschen Kulturzionismus sowie zu Intellektuellen entstand über das gemeinsame Interesse an Büchern und an der jüdischen Texttradition. Die Idee, dass die für Zionisten problematische Assimilation großer Teile der deutschen Juden und Jüdinnen durch Zugänglichmachen dieser Texttradition überwunden werden könnte, trieb ihn und zahlreiche andere an. Die verborgenen Schätze des Judentums sollten ausgegraben werden und der jüdischen Bevölkerung, die sich der Tradition entfremdet hatte, wieder Zugang zur eigenen Religion und Kultur eröffnen. Die Bücheraktion für die russischen Kriegsgefangenen, die Gründung des Kulturausschusses der ZVfD, die Unterstützung und Zusammenarbeit mit S.J. Agnon, das Engagement für die Zeitschrift Der Jude, die Übernahme der Buber-Rosenzweig-Bibelübersetzung und schließlich die Gründung des Schocken Verlages sind Resultate dieses Wunsches.

Schockens Vermögen, seine wirtschaftliche Expertise und die Möglichkeit, jederzeit auf den Stab qualifizierter Mitarbeiterinnen und Mitarbeiter seines Konzerns zurückgreifen zu können, gestatteten ihm diese kulturellen Betätigungen. Wäre er jedoch nicht Teil eines funktionierenden Netzwerkes gewesen, wären diese Anstrengungen ohne große Wirkung verblieben. Um seine Ideen verwirklichen zu können, musste Schocken in der kulturzionistischen Hierarchie weit genug aufsteigen. Seine Beziehungen zu Exponenten innerhalb dieses sozialen Mikrokosmos stattete ihn mit hinreichend sozialem Kapital aus, um darin bald eine wichtige Position einzunehmen. Die Verbindung von sozialem mit wirtschaftlichem Kapital ermöglichte ihm schlussendlich eine zentrale Stellung in diesem Netzwerk. Während persönliche Beziehungen zu Martin Buber wie auch zu anderen Leitfiguren als Türöffner für weitere soziale Kontakte fungierten, erlaubten es seine finanziellen Mittel, Ideen schnell umzusetzen. Im eng geflochtenen Beziehungsnetz der deutsch-jüdischen Geistesarbeiter wurde der Kaufmann Salman Schocken zu einer wichtigen Figur. Als dieses

296 Vgl. Milton: Areopagitica, S.5. 
Netzwerk durch die Vertreibungspolitik der Nationalsozialisten zunehmend transnational wurde und sich - im Laufe der 1930er Jahre - das geographische Zentrum der deutsch-jüdischen Kultur nach Jerusalem verschob, hatte das starke Auswirkungen auf die Rolle Schockens. Es gelang ihm, einen großen Teil seines Vermögens und Besitzes zu retten und sich in Jerusalem zu etablieren. Er übernahm die Tageszeitung Haaretz, die sein Sohn zu einem der Leitmedien der jüdischen Zivilgesellschaft in Palästina ausbaute, gründete einen weiteren Verlag und fand eine neue Aufgabe als administrativer Leiter der Universität. Damit war er zeitweise eine der zentralen Figuren im Kreis der deutschen Exilanten in Palästina - obwohl Schocken selbst glaubte, dass seine gesellschaftliche Position nicht mit der in Deutschland zu vergleichen wäre. Ob dies zutrifft, ist auch Thema im zweiten Teil dieser Untersuchung. 



\section{TeIL II \\ JERUSALEM (1933-1940)}




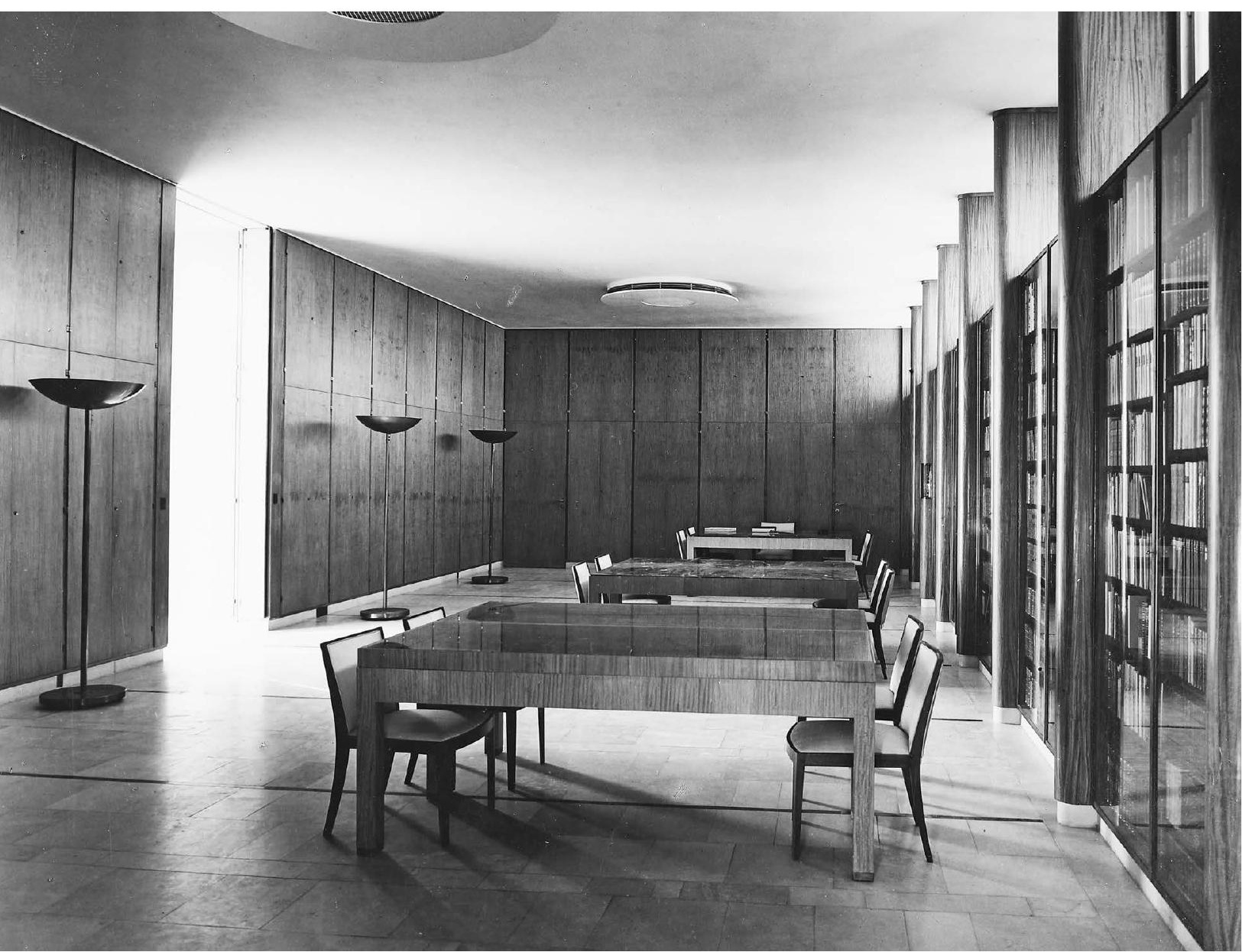

Abb. 8: Alfred Bernheim: Lesesaal der Schocken Bibliothek, 1937. 


\section{6 \\ Jerusalem als Zufluchtsort \\ Einleitende Überlegungen}

Zwischen 250.000 bis 300.000 Juden und Jüdinnen verließen während der nationalsozialistischen Herrschaft Deutschland. ${ }^{1}$ Davon gelangten bis Ende 1938 zwischen 39.600 und 44.000 nach Palästina. ${ }^{2}$ Viele dieser deutschen Immigrant* innen waren keine überzeugten Zionisten; sie verließen Deutschland aufgrund der zunehmenden Gefahr, die vom nationalsozialistischen Regime ausging. Die Migration von deutschen Juden und Jüdinnen ins britische Mandatsgebiet Palästina, die Ankunft in der neuen Heimat, die Integration in die jüdische Gesellschaft Palästinas, aber auch die Erinnerungen der Migrantinnen und Migranten fanden Niederschlag in zahlreichen wissenschaftlichen Publikationen, ${ }^{3}$

1 Die genaue Zahl lässt sich wegen fehlender zeitgenössischer Erhebungen nicht eruieren. Vgl. Werner Rosenstock: Exodus 1933-1939. A Survey of Jewish Emigration From Germany. In: LBIYB 1,1 (1956), S.373-390, hier S.373-374.

2 Die erstgenannte Zahl entspricht den Angaben der Jewish Agency, die zweitgenannte ist eine Schätzung von Albert J. Phiebig. Vgl. Albert Phiebig: Statistische Tabellen. In: Spitzer (Hrsg.): Almanach des Schocken Verlags auf das Jahr 5696, S. 137-153. Die Angabe der Jewish Agency wurde hier dem Artikel von Werner Rosenstock entnommen, vgl. Rosenstock: Exodus 1933-1939, S. 376.

3 Um nur einige unter vielen zu nennen: Eva Beling: Die gesellschaftliche Eingliederung der deutschen Einwanderer in Israel. Eine soziologische Untersuchung der Einwanderung aus Deutschland zwischen 1933 und 1945. Frankfurt am Main: EVA 1967; Moshe Zimmermann / Yotam Hotam (Hrsg.): Zweimal Heimat. Die Jeckes zwischen Mitteleuropa und Nahost. Frankfurt am Main: beerenverlag 2005; Tel Aviver Jahrbuch für deutsche Geschichte 41 (2013): Deutsche(s) in Palästina und Israel. Alltag, Kultur, Politik, hrsg. v. José Brunner; Christian Kraft: 
in literarischen Werken, ${ }^{4}$ in Gedichten, Filmen und in aufgezeichneten Lebenserinnerungen. ${ }^{5}$ In der Geschichte dieser fünften Alija spielt die Reaktion der schon länger ansässigen Jüdinnen und Juden auf die Neueinwanderer, die eben oft nicht aus zionistischer Überzeugung, sondern auf der Flucht vor den Übergriffen der Nationalsozialisten den Weg ins Heilige Land fanden, eine große Rolle.

„Kommen Sie aus Deutschland oder aus Überzeugung?“ - diese bissige Redewendung zeigt bereits deutlich, dass ihre Ankunft im jüdischen Palästina konfliktgeladen war. Lange Zeit war die Literatur geprägt von einseitigen Stereotypen: Die deutschen, oft bürgerlich sozialisierten Einwanderer fanden sich nur schlecht in der Jischuv-Gesellschaft zurecht, die weder durch deutsche noch durch bürgerliche Umgangsformen und Kultur geprägt war, sondern durch den tatkräftigen Aufbau des Landes. Die Landarbeiter, die den Boden Eretz Israels beackerten und fruchtbar machten, genossen höchste gesellschaftliche Anerkennung. Aber gerade dazu waren die an deutschen Gymnasien und Universitäten geschulten deutschen Juden kaum in der Lage, so lautete eines der zahlreichen Vorurteile. Probleme mit der hebräischen Sprache und dem heißen Klima, den lockeren Umgangsformen und dem ungewohnten Essen ${ }^{6}$, fehlender Nutzen der akademischen Bildung im neuen Kontext und das angebliche Unvermögen, sich von alten Gepflogenheiten zu lösen und den neuen Umständen zu stellen, gehörten ebenfalls ins Bild der sogenannten, Jeckes ${ }^{7}$.

Aschkenas in Jerusalem. Die religiösen Institutionen der Einwanderer aus Deutschland im Jerusalemer Stadtviertel Rechavia (1933-2004). Transfer und Transformation. Göttingen: Vandenhoeck \& Ruprecht 2014.

4 Vgl. u. a. Alice Schwarz-Gardos (Hrsg.): Heimat ist anderswo. Deutsche Schriftsteller in Israel. Erzählungen und Gedichte. Freiburg i. Br.: Herder 1983. Vgl. auch den 1971 posthum erschienenen Roman Schira von S.J. Agnon, der den Mikrokosmos der deutschsprachigen Wissenschaftler in Jerusalem beschreibt. S.J. Agnon: Schira, aus d. Hebr. v. Tuvia Rübner. Frankfurt am Main: Jüdischer Verlag 1998.

5 Gideon Greif / Colin McPherson / Laurence Weinbaum (Hrsg.): Die Jeckes. Deutsche Juden aus Israel erzählen. Mit einem Geleitwort von Dan Diner. Köln: Böhlau 2000; Joachim Schlör: Endlich im Gelobten Land? Deutsche Juden unterwegs in eine neue Heimat. Berlin: Aufbau 2003.

6 Vgl. Viola Rautenberg-Alianov: Schlagsahne oder Shemen-Öl? In: Tel Aviver Jahrbuch für deutsche Geschichte 41 (2013): Deutsche(s) in Palästina und Israel. Alltag, Kultur, Politik, S. 82-96.

7 Der Ursprung des Begriffes Jecke ist unklar. Populär ist die Erklärung, dass der Begriff von der Jacke herrührt, die die deutschen Juden kaum ablegten, sondern selbst in der brütenden Hitze des nahöstlichen Sommers stets korrekt in Hemd und Jackett gekleidet waren. Vgl. 
Die deutschen Juden, die, wie es Moshe Zimmermann und Yotam Hotam formulieren, „das Paradebeispiel des assimilierten Judentums ${ }^{\text {“8 }}$ waren, wurden von der Gesellschaft in Palästina nach der Emigration als nicht assimilierbar angesehen. Nicht selten überlappen sich in diesen Stereotypen Selbst- und Fremdwahrnehmung. Der Schriftsteller Herbert Friedenthal, der nach seiner erzwungenen Emigration nach England den anglisierten Namen Freeden annahm, beschreibt in einem kurzen Text, der den Titel Requiem für die Jekken trägt, seine eigenen Landsleute.

Die Jekkes kamen zum großen Teil mit Berufen, die sich für das Land nicht eigneten, ihren ganzen Ballast europäischer Kultur im Koffer. Sie kannten Goethe und Lessing und waren mit der Musik Beethovens und Mozarts aufgewachsen, aber in der Auslegung der heiligen Schrift waren sie nicht so bewandert, von jüdischer Geschichte wussten sie weniger als vom Dreißigjährigen Krieg, und obwohl manche von ihnen Latein oder Griechisch in der Schule gelernt hatten - zum Hebräischen hat es nie gereicht. ${ }^{9}$

Die Fremdheit am neuen Ort wurde für viele zu einem Trauma. ${ }^{10}$ Die aus der deutschen Kultur und Gesellschaft Verstoßenen trafen auch am neuen Ort auf Ablehnung. Das verheißene Land der Zionisten zeigte sich den Verfolgten und Entrechteten gegenüber weder großzügig noch warmherzig. Die ersten Jahre der Niederlassung waren für viele durch Erfahrungen von Zurückweisung und Spott gekennzeichnet. Die deutsche Sprache und Literatur und der Habitus der Jeckes verloren vor dem Hintergrund der nationalsozialistischen Rassenpolitik und Kriegstreiberei den hohen kulturellen Status und waren im Jischuv als Teil des verhassten Deutschtums schlecht angesehen. Die deutsch-jüdischen Exilanten wurden damit nicht nur ihrer Heimat beraubt; auch ein positiver Bezug auf die eigene Sprache und Kultur wurde schwierig.

Gisela Dachs (Hrsg.): Die Jeckes. Frankfurt am Main: Jüdischer Verlag 2005, S. 7. Für eine differenzierte Auseinandersetzung mit solchen Zuschreibungen vgl. auch Dan Diner: Jeckes. In: Zimmermann / Hotam (Hrsg.): Zweimal Heimat, S. 100-103.

8 Moshe Zimmermann / Yotam Hotam: Vorwort. In: Dies. (Hrsg.): Zweimal Heimat, S. 10-13, hier S. 10 .

9 Herbert Freeden: Requiem für die Jekken. In: Schwarz-Gardos (Hrsg.): Heimat ist anderswo, S. 18-30, hier S. 20.

10 Vgl. Michael Dak: Israelis aus Not. In: Zimmermann / Hotam (Hrsg.): Zweimal Heimat, S. 125-131. 
Die deutschen Immigranten waren jedoch keine homogene Gruppe. Viele litten durchaus unter den Umständen ihrer Emigration und dem schwierigen Start im Land, aber es gab auch jene, die sich bereits in Deutschland auf ihre Einwanderung vorbereitetet hatten und sich als Teil des zionistischen Aufbauprojektes verstanden. So erwarben vor allem junge Zionisten und Zionistinnen in Umschulungsinstitutionen Wissen für den landwirtschaftlichen Aufbau Palästinas. Ihnen gelang es in der Regel deutlich besser, sich mit den neuen Umständen - dem Klima, der Sprache und der dürftigen Infrastruktur - zu arrangieren. Das galt ebenfalls für die Gruppe der zionistisch orientierten Wissenschaftler, Autoren und Künstler, die zwar auch nicht freiwillig nach Palästina übersiedelten, jedoch auf ein bereits bestehendes Netzwerk zurückgreifen konnten. Als Verleger und Mäzen gehörte Salman Schocken zu dieser Gruppe, die sich größtenteils im Jerusalemer Stadtteil Rechavia niederließ.

Der zweite Teil dieser Untersuchung legt den Fokus auf die Zeit, die Schocken im Mandatsgebiet Palästina verbrachte. Er verließ im Dezember 1933 gemeinsam mit seiner Frau Lili sowie den drei jüngeren Kindern, Eva, Gideon und Mischa, Deutschland und schiffte nach einer längeren Reise durch die Schweiz in Italien nach Palästina ein. ${ }^{11}$ Die Emigration wurde kurzfristig geplant, aber geschah nicht fluchtartig; es galt, sich bedeckt zu halten, um die Nationalsozialisten nicht auf sich aufmerksam zu machen. $\mathrm{Zu}$ viel hatte der reiche Kaufmann zu verlieren: Neben seiner Warenhauskette mit den angegliederten Betrieben und dem Verlag besaß er mehrere luxuriöse Privatimmobilien sowie Bankkonten, eine Kunstsammlung und eine äußerst wertvolle Privatbibliothek. Schocken ließ den Besitz nicht einfach zurück: Er vertraute ihn zum einen der Obhut seines zweitältesten Sohnes Theodor an, der sich als Teilhaber der Firma in Deutschland um die Geschäfte seines Vaters kümmerte. Zum anderen konnte Schocken auf seine leitenden Mitarbeiter sowie die Verwaltung seines Konzerns zählen, die auch in Abwesenheit des Patrons den Betrieb straff weiterführten. Nicht zuletzt bedeutete für Schocken die Emigration nach Palästina keinen endgültigen Abschied von Europa, denn er verbrachte bis zum Beginn des Krieges mehrere Monate pro Jahr dort. Bis Mitte September 1935 traf er seine Direktoren und Verlagsleiter in Deutschland, später fanden die Treffen in Zürich, Amsterdam und London statt.

11 In dieser Einleitung, die die wichtigsten Punkte des Teil II umreißt, wird auf die Angabe von Referenzen verzichtet, da sämtliche Themen in den folgenden Kapiteln mit Quellennennung besprochen werden. 
In den sechs Jahren, in denen Jerusalem sein offizieller Hauptwohnsitz war, führte Schocken ein Leben in zwei Welten. Einerseits baute er sich in Jerusalem seinen Lebensmittelpunkt auf, andererseits verbrachte er mindestens die Hälfte jedes Jahres in Europa. Der Bau der Privatvilla und des Bibliotheksgebäudes an der Smolenskin-Straße, resp. der Balfour-Straße auf der Grenze zwischen den Stadtvierteln Rechavia und Talbieh war sicherlich zentral für den Aufbau seiner Existenz in Jerusalem. Bibliothek wie Privathaus, beide entworfen von Erich Mendelsohn, wurden zu zentralen Treffpunkten der deutsch-jüdischen Akademiker. Auch führende Zionisten, die Universitätsleitung und Vertreter der britischen Mandatsmacht fanden regelmäßigen den Weg zu den zahlreichen Veranstaltungen in den beiden Schocken-Häusern. Die Gebäude waren damit keine reinen Privatgebäude; sie stehen einerseits für das Weiterbestehen der deutsch-jüdischen Kultur in Palästina, andererseits für Schockens Engagement beim Aufbau des Landes.

Schocken übernahm 1935 nach der Absetzung von Judah Leon Magnes als Kanzler der Hebräischen Universität deren Leitung, wenn auch unter anderem Titel. Nur wenige Monate später, im Dezember 1935, erwarb er die Tageszeitung Haaretz und baute sie zu der führenden linksliberalen Zeitung des Landes aus. Zwei Jahre darauf gründete er seinen zweiten Verlag, den Hotza'at Schocken in Tel Aviv, der von seinem Sohn Gershom geleitet wurde. Salman Schocken verfolgte in Palästina also ähnliche Strategien wie in Deutschland: Förderung von Literatur sowie Mitsprache und Mitarbeit bei der wissenschaftlichen, publizistischen und kulturellen Gestaltung des Landes.

Zeitgleich mit dem Aufbau des jüdischen Palästinas entwickelte sich die Lage für die Juden und Jüdinnen in Deutschland zum Unerträglichen. Die nationalsozialistische Judenpolitik bedrohte ihre Existenz und viele versuchten, Deutschland zu verlassen. Obwohl es Organisationen gab, die bei der Ausreise behilflich waren, so z. B. das Palästinaamt, mussten viele abgewiesen werden. Private Hilfe wurde daher im Verlauf der 1930er Jahre immer wichtiger. Salman Schocken, der über beträchtliche Mittel und über ein gutes Netzwerk verfügte, wurde fast täglich um Unterstützung gebeten. Zahlreiche Menschen überlebten den Nationalsozialismus nur dank der finanziellen und logistischen Hilfe, die ihnen von Schocken zugedacht wurde, viele wurden von ihm aber auch abgewiesen.

Der Aufbau des familiären Mittelpunktes in Jerusalem, die transnationale Existenz zwischen Palästina und Europa, Salman Schockens Rolle beim Aufbau des 
Landes, seine Häuser als Zentren der deutsch-jüdischen Intellektuellen und die Hilfen für Emigrationswillige und Emigranten bilden die Eckpunkte dieses zweiten Teils, der sechs Jahre umfasst. Aus biographischer Perspektive interessiert dabei, welche Strategien Schocken verfolgte, um mit der schwierigen Exilsituation umzugehen. Es wird deutlich werden, dass trotz des Reichtums, den er größtenteils retten konnte, und trotz seiner gesellschaftlichen Position auch für Schocken das Exil eine traumatische Erfahrung war. Im Vergleich zu vielen Emigranten und Flüchtlingen, die neben ihrem Besitz auch Familienmitglieder und Freunde verloren, scheint Schockens Emigration erfolgreich verlaufen zu sein. Ein genaues Lesen der Quellen legt jedoch nahe, das vollständige Gelingen des Ankommens im jüdischen Palästina in Zweifel zu ziehen.

Neben den klar biographisch orientierten Themen stehen zwei weitere Aspekte im Zentrum: Zum einen ist es die Frage nach dem im ersten Teil beschriebenen Netzwerk der deutsch-jüdischen Intellektuellen, das sich im Umkreis des Berliner Schocken Verlages bildete. Dieses Netzwerk wurde im Laufe der 1930 er Jahre erzwungenermaßen mobil und transnational. Es bewegte sich zwischen Jerusalem, Berlin, Zürich, Amsterdam und London. Eng damit verbunden ist schließlich die Frage nach der Neukonstituierung des deutsch-jüdischen Kulturraumes jenseits von nationalstaatlichen Grenzen. Neue Zentren deutsch-jüdischen Geisteslebens entstanden im Zuge der nationalsozialistischen Ausgrenzungs- und Verfolgungspolitik, das bedeutendste in Jerusalem. Diese Kontinuität und die Neukonstituierung eines deutsch-jüdischen Lebens in Palästina sollte (biographische) Brüche und Scheitern nicht ignorieren. In diesem Zusammenhang gilt es, die Konflikte zwischen den deutsch-jüdischen Intellektuellen und den Zionisten mit realpolitischen Ansprüchen, also auch der zionistischen Führung im vorstaatlichen Israel, zu betrachten. Das Gleiche gilt für die Konfrontation mit der Kultur der Jischuv-Gesellschaft, deren Mitglieder ganz andere Vorstellungen und Bedürfnisse hatten als die ,Jeckes Rechavias.

Obwohl sich dieser Teil in die Literatur der ,Jeckesforschung eingliedert, soll keine weitere Studie zu den Jeckes entstehen. Vielmehr ist es das Ziel, einen differenzierten Blick auf Schocken, seine persönlichen Strategien und auf seine Rolle im Aufbau der deutsch-jüdischen Kultur in Palästina zu werfen. 


\section{7 \\ Das Haus mit Rosengarten und die Bibliothek der geretteten Bücher \\ Schockens deutsche Enklave in Jerusalem}

\subsection{Deutsche Kultur in Palästina: Rechavia und seine Bewohner - eine Einleitung}

Rechavia, ein in den 1920ern und 1930ern erbautes jüdisches Stadtviertel, wurde in den 1930er Jahren zur Heimat vieler deutscher Juden und Jüdinnen, die auf der Flucht vor der nationalsozialistischen Verfolgung nach Palästina einwanderten. Gebaut wurde das Viertel auf Land, das die Palästinensische Landentwicklung, ein Organ der Jewish Agency, ab 1921 hauptsächlich aus dem Besitz der griechisch-orthodoxen Kirche aufkaufen konnte. ${ }^{1}$ Geplant wurde der Stadtteil von dem deutschen Architekten Richard Kauffmann. Er entwarf ihn nach Vorbildern der modernen Gartenstadt aus England, den Niederlanden und Deutschland. ${ }^{2}$ Wie die restliche Neustadt, die in den 1920 er und 1930er Jahren entstand, wurde auch Rechavia im Internationalen Stil errichtet. Funktionalismus, Asymmetrie, schmucklose Fassaden und moderne Baustoffe sowie der Einbezug von einheimischen Motiven sind die Kennzeichen dieses architektonischen Stils, den die jüdischen Architekten aus Europa mitbrachten. ${ }^{3}$ Deren jüdische Hauptvertreter war neben Richard

1 Vgl. Kraft: Aschkenas in Jerusalem, S. 15.

2 Zur Planung des modernen Jerusalems unter der britischen Mandatsmacht vgl. David Kroyanker: Die Architektur Jerusalems. 3000 Jahre Heilige Stadt. Mit einer Einleitung von Teddy Kollek. Stuttgart: Kolhammer 1994.

3 Vgl. ebd., S. 145. 
Kauffmann Erich Mendelsohn, der für Schocken in Deutschland und später in Jerusalem baute.

Bis heute ist Rechavia mit seinen schönen alten Baumbeständen eines der grünsten und begehrtesten Wohnviertel der Stadt. In einem Prospekt der Hachscharat ha-Jischuv, der 1930 zur Förderung des Verkaufs von Bauland in Rechavia gedruckt wurde, wird es folgendermaßen beschrieben:

Das Wohnviertel Rechavia liegt an der Hauptstraße des neuen Jerusalems. Es ist Teil der Stadt selbst, liegt in der Nähe des Bahnhofs und des Einkaufzentrums. [...] Rechavia ist eine Gartenstadt. Von jedem Grundstück werden zwei Drittel für Gemüseund Blumengärten, für Anpflanzungen und freien Luftzug abgenommen. Zwischen den Häusern gibt es einen ordentlichen Abstand. Hier und da entdeckt man wundervolle Ausblicke auf die Berge Jerusalems und Moavs. Der besondere Vorzug Rechavias liegt darin, dass es eine Gartenstadt in der Nähe des Stadtzentrums ist. Sie zieht weite Kreise an, die durch ihre Geschäfte mit der Stadt verbunden sind und in einem Viertel mit Gärten und viel frischer Luft wohnen wollen. ${ }^{4}$

Mehr als durch die Gärten wurde das Quartier jedoch durch seine Bewohnerinnen und Bewohner geprägt. ${ }^{5}$ Dies waren zunächst vornehmlich deutsche Einwanderer, die im Zuge der fünften Alija während der 1930er Jahre immigrierten. In den ersten zwanzig Jahren seines Bestehens war Rechavias Einwohnerschaft relativ homogen. Sie setzte sich aus Erwerbstätigen in freien Berufen sowie Beamten zusammen und war größtenteils säkular und liberal. Gebildete Vertreter des Regierungs- und Verwaltungsapparates sowie des Kultur- und Erziehungsestablishments wohnten ebenso dort wie zionistische Führer des Jischuv. ${ }^{6}$ Ein hoher Bildungsgrad sowie gewisser Wohlstand zeichnete die Familien Rechavias aus. Durch den hohen Grad an nationaler und kultureller Homogenität konnten gewohnte Lebensweisen und Habitus am neuen Ort fortbestehen. Dies beinhaltete neben der Beibehaltung des Deutschen

4 Zit. n. David Kroyanker: Rechavia. In: Zimmermann / Hotam (Hrsg.): Zweimal Heimat, S. 260-266, hier S.260-261.

5 Ein schönes, aber keinesfalls beschönigendes Bild des Lebens der deutschen Bewohner*innen Rehavias zeichnet Thomas Sparr in seinem Band Grunewald im Orient. Das deutschjüdische Jerusalem. Berlin: Berenberg 2018.

6 Vgl. Kroyanker: Rechavia, S. 261. 
als Umgangssprache auch die Errichtung sowohl von Kaffeehäusern nach mitteleuropäischem Vorbild als auch von Bibliotheken. Ebenso wurden in der privaten Sphäre deutsche Gepflogenheiten kultiviert: Die Möbel und Bücher waren als Auswanderungsgepäck mitgebracht worden, die Haushalte wurden, wenn es die Mittel erlaubten, nach bürgerlichen Standards geführt. Die früheren Einwanderer, die das Land mit Muskelkraft aufgebaut und urbar gemacht hatten, schauten oft spöttisch auf diese angeblich elitäre Jerusalemer Gesellschaft. Dabei darf aber nicht vergessen werden, dass sich die Bewohner Rechavias um den Aufbau der Universität, des Banken- und Versicherungswesens, der öffentlichen Verwaltung, der Armee, Medizin und Kultur des Landes verdient machten und damit ebenfalls zum Aufbau des Landes beitrugen. ${ }^{7}$

In diesem Quartier in unmittelbarer Nachbarschaft zu seinen Verlagsautoren, wie Gershom Scholem und Ernst Simon, zu zionistischen Weggefährten wie Menachem Ussischkin und Kurt Blumenfeld und zu vielen weiteren Bekannten und Freunden, ließ sich Salman Schocken mit seiner Familie nieder. Nach der Ankunft in Jerusalem im Winter 1934 bezog die Familie zuerst eine Mietwohnung an der Rambam-Straße. Nur zwei Häuser davon entfernt wurde in einer Wohnung, die ebenfalls gemietet wurde, Schockens Jerusalemer Sekretariat eingerichtet. Bereits kurz nach dem Eintreffen in Jerusalem beauftragte Schocken Mendelsohn mit den ersten Entwürfen für eine Privatvilla und eine Bibliothek, die 1937 bezogen wurden.

Im folgenden Kapitel soll es nun um diese beiden Gebäude gehen, die weit mehr waren als das Privathaus und die Bibliothek eines reichen deutschen Kaufmannes, der sich Extravaganzen und Luxus leisten konnte. Es ist unbestritten, dass beide Häuser einen Luxus verkörperten, der bis dahin in Jerusalem nicht bekannt war. Die Privatvilla verfügte über die neusten technischen Errungenschaften Europas sowie einen Swimmingpool im Garten, etwas Unerhörtes in der Trockenheit Palästinas, die Bibliothek über eine Klimaanlage und einen Vortragsaal, der mit Zitronenholzfurnier ausgekleidet war. Die Bauphase, welche die Freundschaft zwischen Bauherr und Architekt zuweilen arg strapazierte, wird ebenso thematisiert wie die technischen Einrichtungen und die Möblierung der Häuser. Die im Schocken Archiv erhaltenen Akten zu den Häusern geben Einblick in die Problematik des Bauens in den 1930er Jahren in Jerusalem. Sie zeigen aber auch, wie es Schocken gelang, einen Teil seines

7 Vgl. ebd., S. 264. 
Vermögens und fast seinen ganzen mobilen Besitz aus Deutschland zu retten. Bei den beiden Gebäuden handelt es sich zudem um architektonische Meisterstücke Mendelsohns, die längst zu schützenswertem Kulturgut hätten erhoben werden sollen. ${ }^{8}$

Neben den eigentlichen Gebäuden steht auch die Bibliothek, also Schockens private Sammlung, die sich aus ungefähr 60.000 hebräischen und 15.000 deutschen Büchern zusammensetzte, im Zentrum der Betrachtung. Sowohl die deutschsprachige als auch die hebräischsprachige Sammlung bestand in erster Linie aus Raritäten: äußerst wertvolle Erstausgaben, Autographen und Manuskripte. Mit der Rettung seiner Sammlung bewahrte Schocken eine der wertvollsten Privatbibliotheken seiner Zeit vor der fast sicheren Zerstörung in Deutschland. Hier soll der Fokus auf deren Bedeutung und Rettung gelegt werden. Als Quellen dienen dabei die Bestände der reichhaltigen Sammlung im Schocken Archiv, die die Rettungsaktion fast lückenlos erschließbar macht. Während die Rettung der Bestände noch kaum Beachtung fand, ${ }^{9}$ wurde die Bedeutung der Sammlung bereits in einigen Aufsätzen aufgearbeitet, diese dienen hier als Grundlage für die Ausführungen.

In einem dritten und letzten Punkt wird es um die Bedeutung und Funktion der beiden Häuser Schockens für die deutsch-jüdische Bevölkerung Jerusalems gehen. Es steht dabei die Frage im Zentrum, ob sie als Orte der Kontinuität im Sinne eines Weiterbestehens der in Deutschland entwickelten und gepflegten Kultur zu verstehen sind, oder ob es sich um Orte der Neuinterpretation von Bekanntem und dessen Weiterentwicklung im Exil handelt. Und schließlich soll an dieser Stelle auch die Bedeutung der beiden Häuser für Schockens

8 Die ehemalige Villa Schocken steht seit längerer Zeit leer und verwildert zusehends. Es gab Pläne, sie aufzustocken und damit Wohnraum im Luxussegment zu bauen, ebenfalls stand ein Abriss zur Debatte. Dagegen protestierte eine Gruppe von Historikern, Architekten und weiteren Interessierten. Das Gebäude steht seit 2009 unter Denkmalschutz, aber derzeit ist nicht klar, was mit dem Mendelsohn-Bau geschieht. Zur Debatte vgl. Carsten Krohn: Hoffnung für die Schocken-Villa. In Israel wird der Umgang mit Erich Mendelsohns Bauten neu diskutiert. In: NZZ, 15.03.2013, S. 50; Keshet Rosenblum: Mendelsohn Building Spurs Monumental Dilemma. In: Haaretz, 19.12.2012. https://www.haaretz.com/.premium-wherethere-s-a-villa-there-s-a-way-1.5275518 (Zugriff am 10.02.2020).

9 Die Ausnahme bildet ein Artikel der Autorin, der jedoch weniger ins Detail geht, als die folgenden Ausführungen das tun werden. Mahrer: ,Much More Than Just Another Private Collection". 


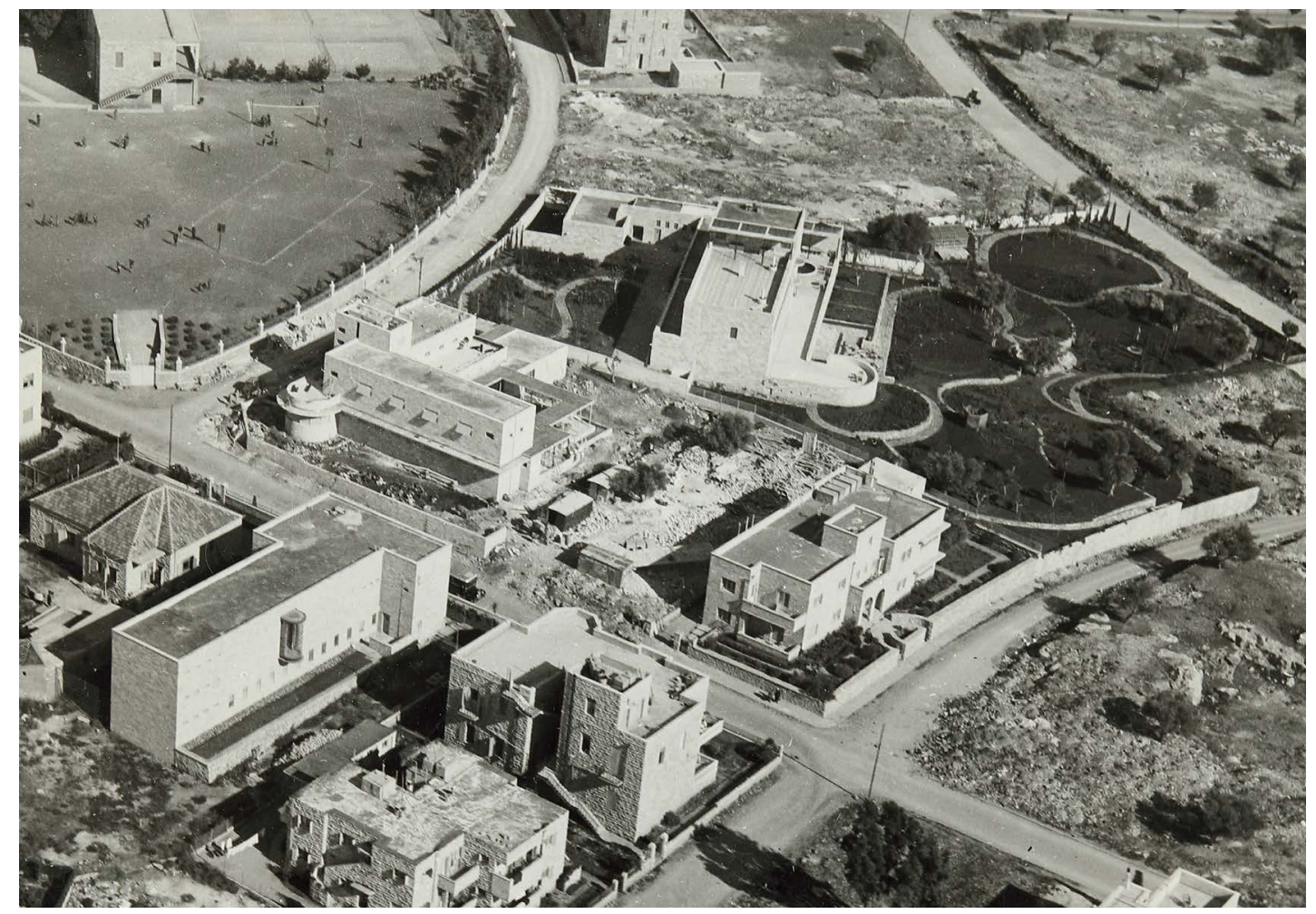

Abb. 9: Luftaufnahme der Villa Schocken und der Schocken-Bibliothek, 1937.

Biographie mit Blick auf seine Positionierung im kulturellen und politischen Gefüge Jerusalems untersucht werden.

\subsection{Zwei deutsch-palästinensische Häuser in Rechavia}

Die Luftaufnahme aus dem Jahr 1936 (siehe Abb. 9) macht deutlich, welch herausragende Arbeit der Architekt Erich Mendelsohn für seinen Bauherren Salman Schocken unter schwierigen Umständen leistete. Das Privathaus im hinteren Teil des Bildes fällt nicht nur durch seine Größe und durch die klaren Linien auf, sondern auch durch den parkähnlichen Garten, der sich terrassenförmig gegen Osten ausbreitete. Der Bibliotheksbau ist etwas schlichter, aber ebenfalls groß. Auch die Bibliothek verfügte über einen hier nicht in seiner ganzen Größe sichtbaren Garten, der sich in Richtung Westen bis an die GazaStraße erstreckte. Beide Gebäude wurden fast ausschließlich mit Materialien erbaut, die dafür eigens aus Deutschland nach Palästina importiert worden 
waren. Auch die Pflanzen in den beiden Gärten stammten zum größten Teil aus Europa.

Errichtet wurden die zwei Gebäude auf Grundstücken, die im Frühjahr des Jahres 1934 vom orthodoxen Patriarchat Jerusalem ${ }^{10}$ und von Privatleuten erworben wurden. ${ }^{11}$ Moses Smoira als Anwalt Schockens ${ }^{12}$ führte die Kaufverhandlungen und schloss die Geschäfte ab. Da Salman Schocken aus geschäftlichen Gründen von April bis September in Deutschland und in der Schweiz war, stand Smoira wegen der Landkäufe in ständigem Kontakt mit Lili Schocken. Am 11. September desselben Jahres, noch bevor Salman Schocken von seinem langen Europaaufenthalt nach Jerusalem zurückkehrte, reichte Erich Mendelsohn die ersten Pläne für das Haus und die Bibliothek ein. ${ }^{13}$ In diesen war der Bau des Bibliotheksgebäudes noch direkt neben dem Privathaus vorgesehen. ${ }^{14}$ Bis zum Baubeginn am 5. Juli 1935 verstrichen noch einige Monate, die für die Ausarbeitung der Pläne, Verhandlungen mit deutschen und britischen Stellen sowie mit zionistischen Organisationen, der Verpflichtung von Bauunternehmen und Handwerkern und dem Einkauf wie der Spedition der Baumaterialen von Deutschland nach Palästina benötigt wurden.

Die gesamten Verträge, die Korrespondenz und Arbeitsberichte, die mit dem Bau der Häuser zusammenhingen, wurden minutiös vom Sekretariat in Jerusalem gesammelt und archiviert. So stehen heute 35 Boxen mit Akten zur Verfügung, die ermöglichen, den Bau von Villa und Bibliothek bis ins kleinste Detail zu rekonstruieren. Dieses Material wurde für die vorliegende Arbeit erstmals systematisch gesichtet und ausgewertet. Das Resultat ist ein selten detaillierter Einblick in die Baupraxis vermögender deutscher Exilanten in Palästina, aber

10 Vgl. Deed of Sale, Land Registry Office of Jerusalem, 02.04.1934. SchA, Privates, 823, Bd. 33 .

11 Abrechnungen über Landkäufe, Moses Smoira an Lili Schocken, div. Daten von April bis Juni 1935. SchA, Privates, 823, Bd. 33.

12 Dr. Moses Smoira (1888-1961) promovierte in Königsberg in Jurisprudenz. Bevor er 1922 nach Palästina auswanderte und dort 1923 als Anwalt zugelassen wurde, war er Leiter einer hebräischen Sprachschule in Berlin. Er wurde 1930 Präsident der jüdischen Anwaltskammer in Palästina und nach der Staatsgründung bis 1954 Präsident des Obersten Gerichtshofes Israels. Schocken konsultierte Smoira in Jerusalem, wenn er rechtliche Fragen zu prüfen hatte.

13 Vgl. Erste Skizze, Moses Mendelsohn an Salman Schocken, 11.09.1934. SchA, Privates, 823, Bd. 30 .

14 Vgl. Baubüro Heinze an Lili Schocken, 24.10.1934. SchA, Privates, 823, Bd. 30. 
zeigt auch, wie Vermögen und Besitz aus dem nationalsozialistischen Deutschland gerettet werden konnten. Darüber hinaus lassen sich durch das Material die Schwierigkeiten deutscher Einwanderer nachvollziehen, sich in der neuen Lebenssituation zurechtzufinden, und ihre Versuche, diese zu ändern.

\subsubsection{Erich Mendelsohns Entwürfe und Schockens Ideen - eine Freundschaft wird auf die Probe gestellt}

Nachdem die Schockenbibliothek am 26. Dezember 1936 mit einem Abend zum Gedenken an Franz Rosenzweig eröffnet wurde, ${ }^{15}$ stand die zweite offizielle Veranstaltung am 15. März 1937 im Zeichen von Erich Mendelsohns 50. Geburtstag. In einer längeren Ansprache erinnerte Schocken sich nicht nur an das erste Treffen mit dem Architekten, sondern auch an ihre persönliche Beziehung.

Ich bin mit Erich Mendelsohn zum ersten Mal bekannt geworden - es ist vielleicht ein Zufall - im Zeichen Palästinas. Ich habe kein gutes Jahresgedächtnis, ich glaube, es war 1918 oder 1919, $\left[{ }^{16}\right]$ da wurde mir erzählt, ich müsste mir bei Paul Cassirer eine Ausstellung eines palästinensischen Plastikers ansehen.

Ich ging durch die Räume von Cassirer, sah dort schöne Figuren und habe nur mit einem Seitenblick die Wände betrachtet und fand dort Zeichnungen - Namen unbekannt-, die mich fesselten. Ich sah nicht mehr die runden Plastiken von A., sondern die Phantasien eines jungen Architekten, Erich Mendelsohn. [...]

Es vergingen Jahre, bis Erich Mendelsohn in unsern Kreis kam. Es charakterisiert in gewissem Sinne meine verflossene Berufsarbeit in Deutschland, dass ich die Möglichkeit hatte, acht Jahre lang gemeinsam mit Erich Mendelsohn in Deutschland zu bauen, und im Jahre 1933, als ich nach langer Abwesenheit in das zerbrochene Deutschland zurückkam, ${ }^{17}$ hätte ich nicht geglaubt, dass ich ihm hier in Jerusalem

15 Vgl. dazu genauer Kap. 7.4.2.

16 Die Ausstellung Erich Mendelsohn. Architekturen in Eisen und Beton wurde im Herbst 1919 gezeigt. Vgl. Regina Stephan: ,Denken von Tag zu Tag, wo Geschichte große Kurven schlägt und Hunderttausende unbefriedigt lässt.' Frühe expressionistische Bauten in Luckenwalde, Berlin und Gleiwitz. In: Dies. (Hrsg.): Erich Mendelsohn. Architekt 1887-1953. Gebaute Welten. Arbeiten für Europa, Palästina und Amerika. Ostfildern-Ruit: Hatje 1998, S. 44-63, hier S. 46.

17 Salman Schocken verbrachte aus gesundheitlichen Gründen die ersten vier Monate des Jahres 1933 in der Schweiz. 
in einem von Mendelsohn gebauten Hause begegnen würde, und so ist dieser Abend, den ich zum ersten Mal in einem geselligen Kreise in diesem Hause verbringe, für mich eine besondere Feier. [...]

Wieviele Menschen trifft man in seinem Leben, bei denen man den Eindruck hat: das ist ein Kerl, der seiner Aufgabe gewachsen ist; das ist jemand, der wirklich nur seiner Aufgabe lebt und sie ernst nimmt und bereit ist, dafür einen hohen Preis zu zahlen. Man kann sie an den Fingern abzählen, wenn man 60 ist.

Ich glaube, dass es zum Ernst der menschlichen Beurteilung gehört, dass man alles bejaht. Das Erlebnis ursprünglicher Persönlichkeiten zu haben, dazu gehört in erster Linie Kampf. Ich kenne keinen Menschen, mit dem ich so viel gekämpft hatte, wie mit Erich Mendelsohn seit dem Jahre 1925.

Der Beruf des Architekten ist an und für sich schon eine Unmöglichkeit und muss Kampf mit der Person des Architekten, sicher aber mit seiner Umgebung erzeugen, denn hier soll ein frei schaffender Künstler, der in die Dimensionen hineinträumt, mit Stein und Eisen etwas verwirklichen, was in der Regel alltäglichen Zwecken, rechnerisch korrekt hingesetzt, dient.

Wo gibt es in unserer banalen Welt einen Bauherrn, der bereit ist, $1 / 2 \%$ mehr zu zahlen, als die billigste Rechnung gerade noch hergibt?

Wenn nun zu diesem Künstler als Architekten ein Mensch kommt, der - ich möchte fast sagen - seinen „Gottesdienst“ darin sieht, Wirtschaft ernst zu nehmen, und der glaubt, dass es in diesem Lande für die Generation, in der wir stehen, keinen wichtigeren Schritt zu machen gibt als den, Wirtschaft ernst zu nehmen, so werden Sie verstehen, wie schwer es ist, die Brücke zu schaffen zwischen dem im Raum traumhaft schaffenden Architekten und dem pfennigfuchsenden Warenhaus-Kalkulator. [... $]^{18}$

Zwar zeigt Schocken in dieser Ansprache eine gewisse Selbstironie, dennoch wird deutlich, dass trotz seiner Wertschätzung des Architekten die persönliche Beziehung zwischen Künstler und Kaufmann nicht frei von Spannungen war. Konflikte über Kosten- und Terminfragen trübten die Freundschaft während der ganzen Bauphase und darüber hinaus. ${ }^{19}$

18 Rede des Herrn Salman Schocken beim Empfang für Erich Mendelsohn am 15.03.1937 in der Schocken-Bibliothek. Typoskript. SchA, Privates, 842/22.

$19 \mathrm{Zu}$ Erich Mendelsohn in Jerusalem sowie zu seiner Beziehung zu Salman Schocken vgl. auch Adina Hoffmann: Till We Have Built Jerusalem. Architects of a New City. New York: Farrar, Straus \& Giroux 2016. 


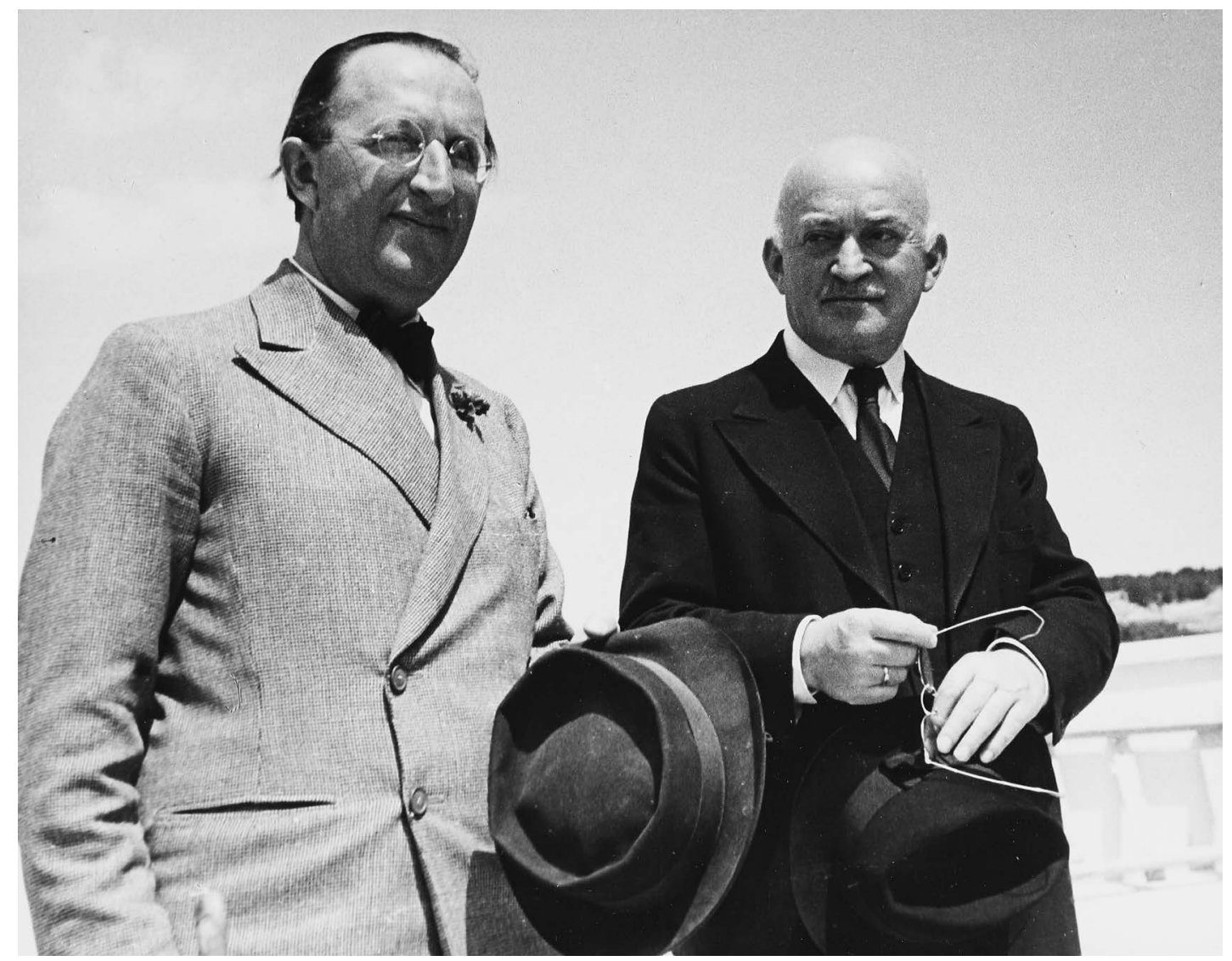

Abb. 10: Erich Mendelsohn (links) und Salman Schocken anlässlich der Eröffnung des Hadassah-Krankenhauses, 1939.

Salman Schocken war als Auftraggeber schwierig. Er wollte in kleinste Detailfragen einbezogen werden und forderte Mitsprache in allen Belangen. Mendelsohn seinerseits war ein international bekannter Architekt, der auf seinen künstlerischen Freiheiten beharrte und sich keine Vorschriften machen lassen wollte. Erschwerend kam dazu, dass Schocken bei der erzwungenen Emigration seinen Besitz retten konnte und seine Geschäfte in Deutschland weiterliefen. Mendelsohn, der ebenfalls 1933 mit Frau und Tochter aus Berlin flüchtete, ließ nicht nur sein Haus mit allem Besitz zurück, sondern verlor auch sein Berliner Architekturbüro, das eines der größten seiner Zeit war. Wie Briefe an seine Frau Louise Mendelsohn zeigen, kränkte ihn der Ausschluss aus seinem Beruf sehr. So schrieb er ihr im Februar 1933: „Die erste Auswirkung [...] zeigt sich in meiner Nichtaufforderung für den Wettbewerb um das 
neue Reichsbankgebäude. Unter dreißig deutschen Architekten. Dazu gehöre ich also nicht." ${ }^{\text {20 }}$

Durch den beruflichen Ausschluss, die Angst vor Bespitzelung und wegen der Enttäuschung über die plötzlichen Sympathien langjähriger Bekannte und Freunde für das Naziregime, fühlten sich die Mendelsohns äußerst isoliert. ${ }^{21}$ Nach einem längeren Aufenthalt in den Niederlanden und in England kamen er und seine Frau im Jahr 1934 nach Jerusalem. Mendelsohn ließ sich dort nicht vollständig nieder, vielmehr pendelte er bis 1939 zwischen London und Jerusalem, in beiden Städten gründete er ein Architekturbüro. ${ }^{22}$ In Jerusalem bewohnte das Ehepaar in Rechavia eine Windmühle, die keinerlei Komfort bot. Zwar zeichnet Louise Mendelsohn in ihren bislang unveröffentlichten Memoiren ein romantisches Bild des einfachen und ursprünglichen Lebens in der Mühle, das ganz im Gegensatz zu ihrem geselligen Leben in ihrer Berliner Villa stand, es wird jedoch auch deutlich, wie prekär ihr Leben im Exil war. Die Bauaufträge, die Schocken ihm als Privatmann sowie als Vertreter der Hebräischen Universität verschaffte, waren daher für Mendelsohn wichtig. Dass Schocken trotz ständiger Kontrollen und vieler Auseinandersetzungen mit der Arbeit Mendelsohns durchaus zufrieden war, zeigte sich in den zahlreichen Aufträgen in Deutschland und in Palästina. Mendelsohn transferierte nicht einfach seinen Baustil aus Europa in die Levante, sondern suchte nach einer Formsprache, die der neuen Umgebung entsprach. Mendelsohn bereiste Palästina bereits im Jahr 1923 geschäftlich. Obwohl er keines der zu diesem Zeitpunkt geplanten Projekte dort umsetzen konnte, ${ }^{23}$ zeigte er sich geradezu euphorisch über das Land. In einem Vortrag von 1925 reflektierte er diese Reise und das zionistische Projekt:

20 Erich an Louise Mendelsohn, 11.02.1933, zit. n. Erich Mendelsohn: Briefe eines Architekten, hrsg. v. Oskar Beyer. München: Prestel 1961, S. 94.

21 Vgl. Louise Mendelsohn: My Life in a Changing World. Unveröffentlichtes Typoskript. Museum of Modern Art, Manhattan, Special Collection, M36 M361m, S. 105. Mein Dank geht an Adina Hoffmann, dafür, dass sie mir die Memoiren zur Verfügung gestellt hat.

22 Vgl. Ita Heinze-Greenberg/Regina Stephan (Hrsg.): Erich Mendelsohn. Gedankenwelten. Unbekannte Texte zu Architektur, Kulturgeschichte und Politik. Ostfildern-Ruit: Hatje Cantz 2000, S. 59.

23 Vgl. Heinze-Greenberg: Erich Mendelsohn, S. 57. 
Wir verbinden als Sprösslinge des orientalischen Judenvolkes einen mehr oder weniger wesentlichen Teil unseres Daseins mit dem Boden Palästinas. [...] Kein Jude, der sich über seine Empfindungen klar zu werden vermag, bereist Palästina ohne tragische Berührung mit der eigenen Vergangenheit, ohne demütige Hoffnung auf seine Wiedergeburt. ${ }^{24}$

Er verstand die zionistische Wiederbesiedlung Palästinas jedoch nicht als chauvinistische Kolonisation im Stil der imperialistischen Projekte des 19. Jahrhunderts, sondern vertrat einen dialogbereiten Zionismus, der ein binationales, gleichberechtigtes Miteinander von Arabern und Juden zum Ziel hatte. ${ }^{25}$ Die Offenheit für das Land und die Kultur waren auch bestimmend für seinen architektonischen Stil in Palästina. Er übernahm, so Ita Heinze-Greenberg, „Elemente aus der lokalen arabischen Bautradition: geschlossene Wände, auf Schlitze reduzierte, stehende Fenster, Pergolen, Dachgärten, Innenhöfe, Jerusalemer Kalksandstein. ${ }^{\text {"26 }}$

Die Synthese von östlicher und westlicher Bautradition, die seine Entwürfe und sein Bauen prägten, war damit auch ein politisches Glaubensbekenntnis. ${ }^{27}$ Schocken hingegen lag nicht viel am jüdisch-arabischen Dialog. Zwar zeigte er sich mit Mendelsohns Idee, orientalische und westliche Bautraditionen zu vereinen, einverstanden, jedoch vertrat er einen deutlich nationalistischeren Zionismus als Mendelsohn. So bestand Schocken darauf, dass nur Bau- und Transportfirmen in Betracht gezogen wurden, die ausschließlich jüdische Arbeiter beschäftigten. Er zog sogar kurz in Betracht, einen jüdischen Steinbruch zu schaffen, da im Jahr 1935 alle Steinbrüche von arabischen Firmen geführt wurden; er wurde jedoch darauf hingewiesen, dass zu diesem Zeitpunkt selbst sakrale und staatliche Gebäude mit Steinen aus arabischen Steinbrüchen gebaut wurden. ${ }^{28}$ Da keine weiteren Akten zu dieser Frage vorhanden sind, können wir

24 Erich Mendelsohn: Palästina als künstlerisches Erlebnis, Vortrag von 1925, zit. n. ebd. Der Vortrag wurde in Auszügen von Ita Heinze-Greenberg und Regina Stephan veröffentlicht: Heinze-Greenberg/ Stephan (Hrsg.): Erich Mendelsohn. Gedankenwelten, S. 136-139.

25 Vgl. Erich Mendelsohn: Palestine and the World of Tomorrow. Jerusalem: Jerusalem Press 1940, S. 13.

26 Heinze-Greenberg: Erich Mendelsohn, S. 64.

27 Vgl. Ita Heinze-Greenberg: ,Ich bin ein freier Bauer.' In: Stephan (Hrsg.): Erich Mendelsohn. Architekt 1887-1953, S. 244.

28 Vgl. Firma Albina, Dounié \& Katinke an Salman Schocken, 26.05.1935. SchA, Privates, 823, Bd. 16. 
davon ausgehen, dass Schocken keinen Steinbruch eröffnete und den Sandstein für seine Villa von einem arabischen Produzenten bezog.

Dass Schocken so auf Firmen mit jüdischen Arbeitern bestand, kann mehrere Gründe gehabt haben. Ein möglicher Erklärungsansatz ist, dass er durch die Beschäftigung von jüdischen Arbeitern diesen eine Verdienstmöglichkeit bieten, also im Sinne des Zionismus den Aufbau einer jüdischen Arbeiterschicht fördern wollte. Eine andere, weniger positive Erklärung könnte sein, dass er keine Araber bei sich beschäftigen wollte, sei dies aus Angst vor Anschlägen oder aus schlichtem Desinteresse an einer Zusammenarbeit zwischen Juden und Arabern in Palästina. Anders als ein großer Teil seines Bekanntenkreises zeigte Schocken nie Sympathien für Brit Schalom. Dieser Verband, zu Deutsch ,der Friedensbund', wurde 1925 von einer Gruppe Intellektueller gegründet, die sich für die jüdisch-arabische Verständigung in Palästina einsetzten und ein gerechtes Zusammenleben in einem zukünftigen binationalen Staat anstrebten. ${ }^{29}$ Dennoch vereinten die Villa Schocken und die Bibliothek lokale Bautraditionen und europäische Standards. Beide Bauten sind aus Jerusalemer Sandstein gebaut, weisen kleine Fenster auf, verfügen über Flachdächer, die Villa über einen Dachgarten, und waren, so wie es Kauffmanns Plan von der Gartenstadt Rechavia vorsah, von großen Gärten umgeben. Die Böden waren aus Marmor, nicht wie in Deutschland üblich aus Holz. Im Kontrast zu diesen lokalen Bautraditionen stehen der Swimmingpool im Garten, die versenkbaren Fenster im Wohnzimmer, aber auch die technischen Gerätschaften und die bürgerlichen Möbel, die alle aus Deutschland importiert wurden.

Wie unsicher Mendelsohn hinsichtlich der Reaktion der Schockens auf seine Entwürfe war, zeigt ein Brief vom Dezember 1934 an seine Frau:

Heute Schockenvillaplan fertig gestellt. [...] Guter Plan, ohne zu wissen wie Beide [sic] Sch. reagieren werden. Heute Bibliothekplan entworfen mit Vorlesungsraum u. Forschungsinstitut für jüd. Dichtung. Der Bauplatz ist unsinnig aber der Plan hat Witz

29 Vgl. zu Brit Schalom u. a. Dietmar Wiechemann: Traum vom Frieden. Das bi-nationale Konzept des Brith-Schalom zur Lösung des jüdisch-arabischen Konfliktes in der Zeit von 1925-1933. Schwalbach a. T.: Wochenschau 1998; Shalom Ratzabi: Between Zionism and Judaism. The Radical Circle in Brith Shalom 1925-1933. Leiden / Boston / Köln: Brill 2002; Walter Laqueur: Der Weg zum Staat Israel. Geschichte des Zionismus, aus d. Engl. v. Heinrich Jelinek. Wien: Europa 1975, S.268-272. 
und Palladio. Muss bis morgen Abend fertig sein, um beide Pläne mit Sch. ernstlich zu diskutieren. ${ }^{30}$

Schocken zeigte sich mit diesen Plänen jedoch noch nicht zufrieden und Mendelsohn musste sie in den folgenden Monaten noch mehrere Male überarbeiten. Schocken wollte das Haus verkleinern, nicht nur, damit es günstiger im Bau würde, sondern auch, „um aus dem üblichen bürgerlichen Rahmen nicht herauszufallen. “31

Die ständigen Änderungswünsche müssen für den renommierten Architekten ärgerlich gewesen sein, zumal er Ende Dezember 1934 davon ausging, dass die Planung abgeschlossen sei. Am 15. Dezember berichtete er seiner Frau:

Liebstes, ich komme eben von Schocken. Liege bereits im Bett, Dir nur kurz zu berichten, dass beide Schock. von den neuen Plänen sehr beglückt sind. Das Haus soll nur verkleinert werden nicht durch Wegnahme irgend eines Teiles, sondern nur durch gleichmäßige Reduktion der Masse. Damit wird der Organismus nicht angetastet. ${ }^{32}$

Und zwei Wochen später genehmigte Schocken alle Pläne, er verhielt sich dabei laut Mendelsohn „sehr beglückt und freundschaftlich “33. Da aber der Baubeginn wegen der Schwierigkeit, Baumaterial in Deutschland zu beschaffen, was mit zahlreichen organisatorischen und rechtlichen Problemen verbunden

30 Erich an Louise Mendelsohn, 07.12.1934. In: Digitales Erich Mendelsohn-Archiv (EMA), Brief 1099. http://ema.smb.museum/1099 (Zugriff am 26.05.2015). Das EMA ist das Resultat einer Kooperation des Getty Research Institute, Los Angeles mit der Kunstbibliothek, Staatliche Museen zu Berlin. Im Zentrum steht der Jahrzehnte währende Briefwechsel zwischen den Eheleuten Mendelsohn, der bislang getrennt archiviert war. Louises Nachlass liegt seit 1988 im Getty Research Institute, Erichs gelangte 1975 in den Besitz der Kunstbibliothek Berlin. In der Datenbank wurden die Briefe erstmals zusammengefügt. Etwas über 2.700 Briefe stehen nun in digitalisierter und teilweise transkribierter Form öffentlich zur Verfügung.

31 Tagesbericht für Herrn Baumeister Heinze, Besprechung Salman Schocken, Herr Mendelsohn, Herr Schreiner, Herr Heinze, 10.04.1935. SchA, Privates, 823, Bd. 1.

32 Erich an Louise Mendelsohn, 15.12.1934. In: EMA, Brief 1104. http://ema.smb. museum/1104 (Zugriff am 26.05.2015).

33 Erich an Louise Mendelsohn, 27.12.1934. In: EMA, Brief 1109. http://ema.smb. museum/1109 (Zugriff am 26.05.2015). 
war, zu diesem Zeitpunkt noch nicht feststand, konnten die Pläne immer wieder aufs Neue hinterfragt werden. Sie wurden bis zum tatsächlichen Baubeginn im Juli 1935 auf Anordnung Salman und Lili Schockens immer wieder geändert. So wünschte Schocken im April 1935, über die im Dezember geplante Verkleinerung des Hauses durch eine "gleichmäßige Reduktion der Masse“ hinaus, das Haus zudem durch die Wegnahme von Räumen und Balkonen zu verkleinern. $^{34}$

Aber auch als mit dem Bau endlich begonnen werden konnte, zeigten sich Schockens als schwierige Bauherren. So wollten Salman oder Lili bei allen wichtigen Besprechungen anwesend sein. Noch schwieriger für Mendelsohn war, dass Schocken ihm den extra aus Deutschland für den Bau der zwei Häuser angereisten Baumeister Willy Heinze an die Seite stellte. Heinze, ein Angestellter des Baubüros im Schocken-Konzern, übernahm in Jerusalem die Rolle des Baumeisters. Er war zuständig für den Verkehr mit den Export- und Einkaufsbüros in Deutschland, die eigens für den Bau der zwei Häuser innerhalb des Konzernes in Zwickau eingerichtet wurden. Zudem führte er die Verhandlungen mit palästinensischen Firmen und kontrollierte die Arbeit Mendelsohns und dessen Büro. Dass angesichts der Komplexität der Logistik, die der Einkauf von Baumaterial und Geräten in Deutschland mit sich brachte, ein Experte aus Deutschland eingestellt wurde, scheint durchaus nachvollziehbar. Die Berichte, die Heinze täglich auf dafür eigens erstellten Formularen verfassen musste und die von Schocken persönlich eingesehen wurden, sind Zeugnis der Komplexität der Baugeschichte. Sie zeugen aber auch vom Kontrollbedürfnis Schockens und von dessen großem Misstrauen gegenüber Ämtern und Mitarbeitenden, was Mendelsohn durchaus einschloss. Am 4. Februar 1936 trug Schocken Heinze auf, nachzuprüfen „inwieweit [...] von Mendelsohn Formen und Konstruktionen gewählt worden sind, die eine Verteuerung der Herstellung bedeuten [...].“35 Zudem sollte „die Qualität der bisherigen Bau-Ausführungen“ überprüft werden und eine „Termin-Kontrolle über die Arbeitsweise im Bureau Mendelsohn“ durchgeführt. ${ }^{36}$ Denn Schocken hatte den Verdacht, „dass dort andauernd Arbeiten vernachlässigt werden und diese Verschiebung dann auf andere

34 Tagesbericht für Herrn Baumeister Heinze, Besprechung Salman Schocken, Herr Mendelsohn, Herr Schreiner, Herr Heinze, 10.04.1935. SchA, Privates, 823, Bd. 1.

35 Auftrag für Herrn Baumeister Heinze, 04.02.1936. SchA, Privates, 823, Bd. 21.

36 Ebd. 
Stellen geschoben wird. “37 Eine Antwort von Heinze darauf ist leider nicht überliefert. Sehr deutlich zeigt sich hier die Ambivalenz der Beziehung von Schocken zu Mendelsohn. Auf der einen Seite unterstellte Schocken seinem Architekten, Arbeiten zu verzögern und den Bau unnötig zu verteuern, auf der anderen Seite lobte er ihn öffentlich ausgiebig und verschaffte ihm prestigeträchtige Aufträge wie den Bau des Hadassah-Universitätskrankenhauses auf dem Skopusberg. ${ }^{38}$ Nur drei Tage, bevor Schocken Heinze den Auftrag zur Kontrolle von Mendelsohns Arbeiten an der Villa und der Bibliothek gab, pries er diesen im Hadassah-Baukomitee:

Hadassah ist perfekt u. alle sind zufrieden. Green ist aus dem Comitee [sic] ausgebootet, Schocken an seiner Stelle. Er hat sich reizend benommen u. ist wirklich mein Bewunderer. Hat zu Golub gesagt, M. können Sie nicht bezahlen u. wenn er die 4\% annimmt ist es ein Geschenk fürs Judentum. ${ }^{39}$

Schocken war ein widersprüchlicher Mensch, was sich in seiner Beziehung zu Mendelsohn bestätigt. Neben seiner aufrichtigen Bewunderung für die Architektur Erich Mendelsohns kam auch in diesem Verhältnis das ständige Misstrauen zum Tragen, das er den Menschen gegenüber hegte, die für ihn arbeiteten. Schockens Angst, finanziell ausgenutzt zu werden, und sein damit verbundener Kontrollwahn belasteten die Beziehung zu vielen Menschen in seinem Umfeld. Dass der reiche Mann äußerst bestrebt war, die Baukosten so niedrig wie möglich zu halten, vereinfachte das Arbeitsverhältnis zu Mendelsohn nicht. Die Zurückhaltung bei Ausgaben war jedoch nicht nur der Tatsache geschuldet, dass Schocken „ein pfennigfuchsender Warenhaus-Kalkulator “40 war. Sie lag auch darin begründet, dass er durch die erzwungene Auswanderung einen Teil des Vermögens verloren hatte, und einen Teil der blockierten Vermögenswerte nur durch den zeitaufwändigen und höchst komplexen Export von Material und Maschinen aus Deutschland zu retten vermochte. Trotz aller

37 Ebd.

38 Vgl. zum Hadassah-Bau: Ita Heinze-Greenberg: Erich Mendelsohn. Bauten und Projekte in Palästina (1934-1941). München: Scaneg 1986, S. 166-235.

39 Erich an Louise Mendelsohn, 01.02.1936. In: EMA, Brief 1147. http://ema.smb. museum/1147 (Zugriff am 26.05.2015).

40 Rede des Herrn Salman Schocken beim Empfang für Erich Mendelsohn am 15.03.1937 in der Schocken-Bibliothek. Typoskript. SchA, Privates, 842/22. 
Schwierigkeiten konnten schließlich beide Gebäude fertiggestellt werden. Bei den abschließenden Einrichtungsfragen zeigte sich, dass auch Mendelsohn seine Ideen durchzusetzen wusste. In einem Brief an seine Frau schrieb der Architekt im Juli 1936:

Schocken, eben zurück, reist mit Frau u. Kindern [...] für 2 Monate nach England. Er ist aber guter Laune - war gestern Tag über auf seinen Bauten u. Abends (CurfewPass) bis nach Mitternacht bei ihm. Ist von Bauten sehr befriedigt $u$. hat mehr oder weniger alles bestellt. Möblierung des Hauses teils alt teils neu - aber immer mit meiner Genehmigung. Komme ihm möglichst weit entgegen, ohne Grundsätzliches aufzugeben. [...] Bepflanzung nach meinen Angaben. Bibl-Saal nach meinen Entwürfen - Tische u. Stühle. ${ }^{41}$

Was die Inneneinrichtung anging, war Mendelsohn streng mit den neuen Hausbesitzern. Er verfolgte das Ziel, seine Architektur durch entsprechende Möblierung perfekt zu inszenieren und vergaß dabei, dass sich im Haus eine Familie wohlfühlen sollte. Während Salman Schocken den Vorgaben seines Architekten anscheinend ohne große Bedenken folgen wollte, lehnte sich Lili Schocken teilweise vehement gegen die ihr kühl und unpersönlich wirkende Innenarchitektur und -einrichtung auf. ${ }^{42}$ Mendelsohn konnte sich bei Nichtbeachtung seiner Vorgaben durchaus wenig zimperlich verhalten. Anlässlich eines Besuches bei Schocken am 8. Mai 1938, bei dem er die Villa im bewohnten Zustand besichtigte, störten ihn Gegenstände, die Lili Schocken zur Dekorationszwecken aufstellte: „Ich zerbrach - natürlich wirst Du sagen - dabei eine der vielen Meißen Nippes u. fand das ganz in Ordnung. ${ }^{\text {“43 }}$

41 Erich an Louise Mendelsohn, 09.07.1936. In: EMA, Brief 1155. http://ema.smb.museum/ 1155 (Zugriff am 26.05.2015).

42 Vgl. Kap. 7.2.2.

43 Erich an Louise Mendelsohn, 08.05.1938. In: EMA, Brief 1222. http://ema.smb.museum/ 1222 (Zugriff am 26.05.2015). 


\subsubsection{Veilchen und Teppiche - die Auseinandersetzungen zwischen Hausfrau und Architekt}

Der aus dem deutschen Haushalt stammende, von Mendelsohn verabscheute ,Nippes', hatte für Lili Schocken eine Bedeutung, die von dem Architekten nicht verstanden wurde. Erich Mendelsohn und seine Frau verließen Deutschland in großer Hast und ließen fast ihren gesamten Besitz zurück. Zwar erschwerte die Mittellosigkeit einen Neustart im Exil, sie wurde von Louise Mendelsohn aber auch als Befreiung empfunden.

It is hard to describe my feelings on leaving our cherished and beloved house. I can only say that I was not at all unhappy to leave everything behind. An entire period of our lives had come to an end; a new one would start, unburdened by possessions, relying only on ourselves. ${ }^{44}$

Lili und Salman Schockens Neustart war dem diametral entgegengesetzt: Die Listen im Schocken Archiv zeugen davon, dass der gesamte Berliner Haushalt bis zum letzten Stück verpackt und nach Jerusalem verschickt wurde. Neben den wertvollen Möbeln, dem Porzellan und Tafelsilber wurden auch die Hauben für Hausmädchen, Seifenschalen, Fußabstreicher, Saftflaschen, Weckgläser, Kanalreinigungswellen, Eimer etc. aufgelistet, verpackt und schließlich als sogenannter Lift nach Palästina verschifft. ${ }^{45}$ Dass Schocken den gesamten Hausrat mit ins Exil nahm, hatte mehrere Gründe. Einerseits konnten viele dieser Dinge in Palästina nicht erworben werden, andererseits wäre es finanziell gesehen unsinnig gewesen, Hausrat zurückzulassen, um ihn dann neu zu kaufen. $\mathrm{Zu}$ diesen beiden praktischen Gründen kommt ein dritter hinzu, der psychologischer Natur ist.

Doerte Bischoff und Joachim Schlör machen in ihrem Einleitungstext zu dem Band Dinge des Exils deutlich, dass mit den Gegenständen, die von den Emigranten mitgenommen oder zurückgelassen wurden, Erinnerungen an „verlorene Heimaten, an das Herausgerissensein und Unterwegssein, aber auch an das Ankommen " ${ }^{\text {"46 }}$ verknüpft sind. Insbesondere, aber nicht nur in der

44 Mendelsohn: My Life in a Changing World, S. 107.

45 Vgl. Inventurlisten, 04.01.1934. SchA, Privates, 822.

46 Doerte Bischoff/Joachim Schlör: Dinge des Exils. Zur Einleitung. In: Exilforschung. Ein internationales Jahrbuch 31 (2013): Dinge des Exils, S.9-20, hier S. 10. 
lebensweltlich orientierten Geschichtsschreibung, die den Fokus auf das individuelle Erleben von Geschichte legt, hat der in der europäischen Ethnologie übliche Blick auf Sachkultur und Gegenstände gerade für die Erfahrung von Vertreibung, Flucht und Exil großen Wert. ${ }^{47}$ Während sich die europäische Ethnologie traditionell in erster Linie mit Dingen beschäftigt, die ,vor Ort' blieben, eröffnen neuere Studien Fragen nach der Bedeutung von Dingen, wenn das Zuhause verlassen werden muss oder zerstört wurde. ${ }^{48}$ Flüchtlinge müssen in der Regel abwägen, was mitgenommen werden kann und was zurückgelassen werden muss. Nutzen und Kosten stehen sentimentalen Überlegungen gegenüber; nicht alles kann mitgenommen werden, vieles wäre am neuen Ort gar nur Ballast.

Die deutschen Juden, die vor 1938 nach Palästina migrierten, nahmen, wenn sie es sich leisten konnten, neben ihren Bibliotheken auch den größten Teil des Haushaltes mit ins Exil. Dahinter standen emotionale wie praktische Gründe. Die ,Migration der Dinge ist immanenter Teil des kulturellen Transfers, der in der Situation einer (erzwungenen) Auswanderung hilft, kulturelle Brüche zu überbrücken. Lili Schocken litt genauso wie weniger wohlhabende Emigranten an dem Verlust der Heimat. Ihr Beharren auf den ihr bekannten ,Nippes', auf Teppiche und Veilchen waren Teil der Strategie, ihre Wohnkultur in der Fremde fortzusetzen. Der Begriff der Kultur wird hier im Sinne von Edward Burnett Tylor verstanden, der sie definiert als „that complex whole which includes knowledge, belief, art, morals, law, custom, and any other capabilities and habits acquired by man as a member of society ${ }^{\text {“49. }}$.

Lili Schockens Einrichtungs- und Dekorationsvorstellungen entsprachen jenen der bürgerlichen Hausfrauen Deutschlands. Die Villa in Berliner Stadtteil Zehlendorf stammte aus der Gründerzeit und verkörperte in ihrer Architektur und Einrichtung der Geschmack des deutschen Bürgertums. ${ }^{50}$ Die moderne, im Internationalen Stil erbaute Villa in Rechavia mit ihrem hohen technischen

47 Beispiele dafür sind u. a. das Projekt „People and Things on the Move: Migration and Material Culture“ am Neubauer Collegium for Culture and Society an der University of Chicago oder aber die Spezialausgabe „Migrant Worlds, Material Culture“ der Zeitschrift Mobilities: Paul Basu / Simon Coleman: Introduction. Migrant Worlds, Material Cultures. In: Mobilities 3,3 (2008), S.313-330.

48 Vgl. Bischoff/Schlör: Dinge des Exils, S. 11.

49 Edward Burnett Tylor: Primitive Culture. London: Murray 1871.

50 Vgl. Pläne und Beschreibungen in SchA, Privates, 822. 
Standard, den geraden Linien und dem kalten Stein kontrastierte damit. Lili Schocken stellte sich ihr neues Heim eher wie eine gelungene Fusion ihres Zehlendorfers Hauses und Mendelsohns deutschem Wohnsitz vor. ${ }^{51}$ Mendelsohn stellte sich jedoch gegen die Vorstellungen seiner Bauherrin. Wie Ita Heinze-Greenberg es formuliert, wollte Mendelsohn „kein eingeigeltes Heim für Exilanten [...], sondern eine Wohnung für in Jerusalem Angekommene “52 bauen. Damit schrieb er sich in das zionistische Narrativ ein, das die jüdischen Immigranten in Palästina als Heimgekommene, als dem Exil Entronnene verstand. Dem stand jedoch das persönliche Empfinden vieler Juden und Jüdinnen entgegen, die Deutschland ausschließlich wegen Hitler verließen und sich mangels besserer Alternativen in Palästina niederließen. ${ }^{53}$

Während sich Salman Schocken, der sich bereits in Deutschland neuen Bauformen gegenüber aufgeschlossen zeigte, für die Fusion von arabischer Bautradition und westlicher Architektur begeisterte, konnte sich Lili Schocken für die von dem Architekten entworfene Einrichtung ihres neuen Heims nicht erwärmen. Mendelsohn beharrte jedoch auf seinen Plänen, die unter anderem die Auswahl der Teppiche und der Farben der Wände festlegten, aber auch andere direkte Anweisungen enthielten. So liest man in einem Besprechungsprotokoll, dass „mit Rücksicht auf die zarten Farben des Cezanne [...] keine zu bunten Blumen ins Arbeitszimmer gestellt werden [sollten]. ${ }^{{ }^{54}}$ Im Esszimmer hingegen dürften „auf dem Mahagonitisch keine roten, sondern gelbe und weiße Blumen“ stehen, zudem wollte Mendelsohn keine Stühle an der Wand sehen, daher seien „nach den Mahlzeiten [...] alle Stühle wieder an den Tisch zu setzen. “55

51 Vgl. Erich an Louise Mendelsohn, 18.12.1934. In: EMA, Brief 1150. http://ema.smb. museum/1105 (Zugriff am 27.05.2015).

52 Ita Heinze-Greenberg: „Palästina verpflichtet!!!“. Der Jerusalemer Emigrantenkreis um Else Lasker-Schüler, Salman Schocken, Erich Mendelsohn. In: Burcu Dogramaci / Karin Wimmer (Hrsg.): Netzwerke des Exils. Künstlerische Verflechtung, Austausch und Patronage nach 1933. Berlin: Gebr. Mann 2011, S.31-49, hier S. 34.

53 Vgl. auch Donna Robinson Divine: Exiled in the Homeland. Zionism and the Return to Mandate Palestine. Austin: U of Texas P 2009; dies.: Exiled in the Homeland. In: Shofar. An Interdisciplinary Journal of Jewish Studies 21,2 (2003), S.66-81.

54 Besprechungsprotokoll der Herren Schocken, Mendelsohn, Heinze und Littmann, 30.05.1937. SchA, Privates, 823, Bd. 1.

55 Ebd. 
Nach dem Einzug widersetze sich Lili Schocken mithilfe von ,Nippes', Veilchen u. Ä. den Vorgaben des Architekten. Schon in Berlin züchtete sie ZimmerAlpenveilchen und auch in Jerusalem stellte sie an allen möglichen Orten Töpfchen mit ihren Lieblingspflanzen auf, um das neue Haus etwas wohnlicher und vertrauter zu gestalten. ${ }^{56}$ Das Haus behielt aber - nach Ansicht seiner Bewohnerinnen und Bewohner - trotz dieser Bemühungen eine kühle Atmosphäre. ${ }^{57}$ Ganz anders ging Louise Mendelsohn mit ihrem neuen Zuhause in Jerusalem um. Die Windmühle in Rechavia bot zwar keinen Komfort, sie wurde für die Mendelsohns aber zum neuen Heim. Ohne Möbel und Besitz in Jerusalem angekommen, kaufte Louise auf dem arabischen Schuk in Jerusalem lokale Artefakte, Möbel und Teppiche und richtete damit die Windmühle ein. Aus ihren verschriftlichen Erinnerungen wird deutlich, dass sie sich von dem Angebot geradezu verzaubern ließ.

I never knew where to turn first. There was the copper street, the silver street, over there the high-piled silks from Damascus; there were streets where only glass from Hebron was sold; another turn brought exciting scents of spices. ${ }^{58}$

Solche Beschreibungen der lokalen arabischen Kultur finden sich selten in den Erinnerungen der deutschen Juden und Jüdinnen. Schilderungen von Versuchen, europäische Kultur und im Besonderen deutsche Gemütlichkeit nach Palästina zu transferieren, sind hingegen in zahlreichen Erzählungen zu finden. Sie legen Zeugnis ab über den biographischen Bruch, der die Emigration aus Deutschland bedeutete. Die vertrauten Möbel und Einrichtungsgegenstände vermochten diesen Bruch nur bedingt zur überbrücken, denn die vertrauten Gegenstände waren gleichzeitig eine ständige Erinnerung an die verlorene Heimat. ${ }^{59}$

56 Die Informationen stammen aus einem Interview, das Ita Heinze-Greenberg im Mai 1980 mit Louise Mendelsohn führte. Vgl. Heinze-Greenberg: „Palästina verpflichtet!!!“, S. 34.

57 Vgl. Gespräch der Autorin mit Dvora Schocken am 13.11.2013.

58 Mendelsohn: My Life in a Changing World, S. 132.

59 Vgl. auch Stefanie Mahrer: The Uncanny of the Schocken Villa. Interior Design and Objects of Exile. In: Yfaat Weiss / Caroline Jessen / Anna Kawałko / Elisabeth Gallas (Hrsg.): Contested German Jewish Cultural Property After 1945. The Sacred and the Profane. Göttingen: Vandenhoeck \& Ruprecht 2019, S. 185-193. 


\subsubsection{Die wirtschaftlichen Überlegungen hinter dem Luxus}

Beide Gebäude der Familie Schocken, die Villa wie die Bibliothek, fügten sich optisch in die sie umgebende Landschaft ein. Erst bei näherer Betrachtung erschloss sich dem Betrachter die eigentliche Besonderheit der Häuser: Sie waren zu über 90 Prozent aus Materialien erbaut, die aus Deutschland kamen. Die im Schocken Archiv in über dreißig Ordner überlieferten Bauakten zeigen, welche Baumaterialien und Gerätschaften aus Deutschland eigens für den Bau importiert wurden. Die Liste importierter Waren ist äußerst lang - und einfacher ist es, die Materialien zu nennen, die vor Ort bezogen wurden: Das waren der Sandstein für die Außenfassade, ${ }^{60}$ der Marmor für die Böden, ${ }^{61}$ Mesusot $^{62}$ und wahrscheinlich auch der Sand, ${ }^{63}$ der zum Mischen des Betons nötig war. Der mit Abstand größte Teil der benötigten Materialien, und dazu gehören schwer zu transportierende und sperrige Materialien wie Fensterglas, Holzfurnier und Linoleum ebenso wie Kleinstartikel wie Türzargen, Gardinenschienen und Lichtschalter, wurden über die Exportabteilung des Zwickauer Zentralbüros bestellt, per Schiffsfracht nach Haifa verschickt und vom dortigen Hafen auf Lastwagen nach Jerusalem transportiert.

Hinter der Entscheidung, für den Bau fast ausschließlich Importmaterial zu verwenden, standen mehrere Überlegungen. Als Erstes muss beachtet werden, dass zahlreiche Produkte in Palästina zu dieser Zeit nicht oder nur in schlechter Qualität aufzufinden waren. Dies wurde auch dem Jerusalemer Arbeiterrat (Mo'atzat Póalei Jeruschalajim) gegenüber als Argument für die Importe angebracht. Der jüdischen Arbeiterschaft im britischen Mandatsgebiet waren Importe von diesem Umfang ein Dorn im Auge. Die Wirtschaft befand sich in den 1930er Jahren im Aufbau und der Import von Baumaterial und Gegenständen, die auch in Palästina hätten bezogen resp. hergestellt werden können, rief bei der jüdischen Arbeiterschaft, die dringend auf Aufträge angewiesen

60 Vgl. Firma Albina, Dounié \& Katinke an Salman Schocken, 26.05.1935. SchA, Privates, 823 , Bd. 16.

61 Der Marmor wurde von der Firma Sela in Beth Zafafa bezogen. Vgl. diverse Briefe 1937. SchA, Privates, 823, Bd. 30.

62 Vgl. Bestellung Mesusot, 15.10.1936. SchA, Privates, 823, Bd. 30.

63 Der Zement wurde nachweislich in Deutschland eingekauft und nach Palästina verschifft (vgl. u. a. Sekretariat Schocken an Herrn Schwabe, Exportabteilung, 17.10.1935. SchA, Privates, 823, Bd. 15), zum Einkauf von Sand sind hingegen keinerlei Akten überliefert. 
war, Unmut hervor. Deshalb wurde anscheinend im Jahr 1935 ein Brief an den Arbeiterrat verfasst. Der Brief selbst ist zwar nicht überliefert, jedoch eine Notiz aus dem Sekretariat, der zu entnehmen ist, dass ein Schreiben auf Hebräisch an den Mo'atzat Póalei Jeruschalajim geschickt wurde. In diesem wurde darauf hingewiesen, dass Schocken "Selbsttransferent " ${ }^{\text {“64 }}$ sei und sich als solcher beim privaten Import im Allgemeinen auf Materialien beschränke, bei denen im Lande keine angemessene Qualität zu finden sei. Als kurzer Nachsatz findet sich der Hinweis „evtl. persönlich sprechen“, was bedeuten muss, dass man sich im Sekretariat auf "weiteren Protest der organisierten Arbeiterschaft“ einstellte. ${ }^{65}$ Am 11. Juli desselben Jahres traf auch ein Schreiben des Industriellen-Verbandes in Jerusalem bei der Palestine Building Syndicate Ltd. ein, einer Baufirma aus Jaffa mit Büro in Jerusalem, die kurze Zeit später einen Zuschlag für Bauarbeiten von Schocken erhielt. In dem Brief wurde verlangt, dass im Vertrag zwischen dem Palestine Building Syndicate Ltd. und Salman Schocken ein Passus eingebaut werden müsse, dass alle Baubestandteile, die in Palästina hergestellt werden könnten, nicht aus dem Ausland bezogen werden dürften. In diesem Fall ging es explizit um Eisenarbeiten, man habe vernommen, dass Schocken „im Begriff“66 sei, diese aus dem Ausland zu beziehen. Dass der Verband rechtlich nicht dagegen vorgehen konnte, zeigt die Drohung, dass, „falls Herr Schocken verschiedene Bestandteile aus dem Ausland bezieht, die man hier erhalten kann, er nicht einen einzigen Schlosser finden wird, der an seinem Bau irgendeine Arbeit verrichten wird. ${ }^{\text {67 }}$

Die Baufirma Palestine Building Syndicate Ltd. erhielt noch im Juli 1935 den Zuschlag für sämtliche Bau- und Putzerarbeiten für die Privatvilla. ${ }^{68}$ Welche Argumente ausschlaggebend für die Auftragsvergabe waren, lässt sich nicht mehr eruieren. Die Tatsache, dass die Verhandlungspartner Einwanderer aus Deutschland waren und die Firma Erfahrung mit Bauvorhaben vorzuweisen hatte, die ebenfalls mit Importware aus Deutschland arbeiteten, beeinflusste

64 Verweis auf Brief, 06.01.1935. SchA, Privates, 823, Bd. 16.

65 Ebd.

66 Übersetzung des Schreibens des Industriellen-Verbandes Jerusalem, 11.07.1935. SchA, Privates, 823 , Bd. 30 .

67 Ebd.

68 Vgl. Baubüro an Salman Schocken, 25.07.1935. SchA, Privates, 823, Bd.29. 
die Entscheidung sicherlich positiv. ${ }^{69}$ Die Firma hatte nicht nur Erfahrung mit deutschen Bauherren, sondern auch mit den Regulierungen und Vorgaben, was den Import von deutschen Baumaterialien anbelangte. ${ }^{70}$ Sie antwortete auf die Drohung des Industriellen-Verbandes, dass die Verträge mit Schocken bereits unterzeichnet seien und der gewünschte Zusatz daher nicht mehr eingefügt werden könne. ${ }^{71}$ Während der langen Bauzeit kam es dennoch zu keiner Arbeitsniederlegung durch Arbeiter. Vielleicht ist dies im Zusammenhang damit zu sehen, dass Schocken großen Wert darauf legte, nur organisierte jüdische Arbeiter auf seinen Baustellen zu beschäftigen. ${ }^{72}$ Die Anstellung der Arbeiter, mit Ausnahme von Tischlern und anderen Fachkräften, die für die Inneneinrichtung eingestellt wurden, wurde von den Baufirmen, also dem Palestine Building Syndicate Ltd. für die Privatvilla und dem Misrad Kablani ${ }^{73}$ für die Bibliothek, übernommen.

Während der gesamten Bauphase gab es jedoch immer wieder Probleme mit der Histadrut ${ }^{74}$, der ständig neue, mit der Baustelle nicht vertraute Arbeiter schickte, ${ }^{75}$ Schockens Ansicht nach überzogene Forderungen stellte, nachträglich versuchte, Preise zu erhöhen, und bei Nichterfüllung seiner Forderungen

69 Vgl. Protokoll der Besprechung des Herrn Schocken mit den Herren Haberland und Dr. Feuerstein von dem Palestine Building Syndicate Ltd., 15.04.1935. SchA, Privates, 823, Bd.29.

70 Den Import und die damit verbundenen Verhandlungen mit zionistischen und deutschen Stellen wurden dann aber nicht von der Baufirma, sondern von Schockens eigenen Anwälten und Angestellten geführt.

71 Vgl. Palestine Building Syndicate Ltd. an Manufacturers Association of Palestine, 17.05.1935. Sch A, Privates, 823, Bd. 30.

72 Vgl. Protokoll, 17.05.1935. SchA, Privates, 823, Bd. 1.

73 Vgl. Baubüro an Salman Schocken, 25.07.1935. SchA, Privates, 823, Bd.29.

74 Der Allgemeine Verband der Arbeiter Israels (Ha-Histadrut ha-klalit Ha-Owdim be-Eretz Israel) wurde 1920 vom späteren ersten Ministerpräsidenten des Staates Israel, David Ben Gurion, gegründet. Der mächtige Dachverband der Gewerkschaften war zionistischsozialistisch organsiert und weit über gewerkschaftliche Aufgaben hinaus gesellschaftlich wichtig. Auf ihn gingen die Gründungen des größten Krankenversicherers (Kupat Cholim), einer Bank (Bank Hapoalim), von Sportvereinen, Erholungsheimen u. v. m. zurück. Vgl. zur Geschichte der Histadrut Manuela Maschke: Die israelische Arbeiterorganisation Histadrut. Vom Staat im Staate zur unabhängigen Gewerkschaft. Frankfurt am Main: Haag + Herchen 2003.

75 Vgl. u. a. Baubüro Schocken (Heinze) an Erich Mendelsohn, 03.08.1936. SchA, Privates, 823, Box 30. 
die Arbeiter von den Baustellen abzog. ${ }^{76}$ In der Folge erwog Schocken, auf organsierte Arbeiter zu verzichten und „nur mit jüdischen Arbeitern - gleichviel ob organisiert oder nicht - zu arbeiten. ${ }^{\text {"77 }}$ Die Auseinandersetzung zwischen Schocken und dem Histadrut rührte daher, dass der Arbeiterverband von Schocken Preise verlangte, die 10 bis 15 Prozent über dem Durchschnitt lagen. Man begründete diese Preispolitik damit, dass Schocken, „,bessere Arbeit als gewöhnlich verlange[n] würde. ${ }^{\text {"78 }}$

Schocken, der aus Deutschland eine hohe Qualität bei Material und Arbeit gewohnt war, verlangte Vergleichbares in Palästina. Da die meisten Arbeiter ungelernt waren, konnten sie kaum leisten, was der Bauherr verlangte. Noch schwerwiegender war jedoch die Macht der Gewerkschaft, die Schocken zu Verhandlungen zwang, die er so nicht zu führen gewohnt war. Es ist naheliegend, dass der Histadrut Schocken als vermögend genug ansah, um höhere Preise zu fordern, zumal er neben seinen Privatbauten auch für die Bauprojekte der Hebräischen Universität auf dem Skopusberg verantwortlich war. ${ }^{79}$ In dieser Funktion verschaffte er Erich Mendelsohn den Auftrag, das HadassahKrankenhaus auf dem Skopusberg zu entwerfen. Schocken setzte auch bei diesem Projekt auf seinen vertrauten Mitarbeiter Willy Heinze als Baumeister. Es war Heinze, der in einem Briefentwurf vermutete, dass der Histadrut bei den Privatbauten Schockens die Preise zu erhöhen versuchte, um bei den Verhandlungen der öffentlichen Aufträge ebenfalls höhere Preise verlangen zu können. ${ }^{80}$ Denn während es Schocken als Privatmann freigestanden hätte, nichtorganisierte Arbeiter einzustellen, hatte er bei Bauprojekten der Universität diese Wahl nicht. Laut überlieferten Akten ließ Schocken den Konflikt mit dem Histadrut nicht eskalieren; er bestand auf die üblichen Preise, verzichtete aber darauf, unorganisierte Arbeiter für die Bau- und Gartenarbeiten einzustellen. Hingegen wurden bei den Tischlern, Malern sowie den Strom- und

76 Vgl. Nicht gesendeter Brief von Heinze an Salman Schocken, 03.08.1936. SchA, Privates, 823, Box 30.

77 Ebd.

78 Aktennotiz betr. Wohnhaus, gez. Kempinski (Büro Mendelsohn), 28.07.1936. SchA, Privates, 823 , Box 34 .

79 Vgl. die Akten in SchA, Universität, 042/1-6.

80 Vgl. Nicht gesendeter Brief von Heinze an Salman Schocken, 03.08.1936. SchA, Privates, 823, Box 30. 
Wasserinstallateuren - also bei jenen Arbeiten, die nicht durch Verträge mit den Baubüros Misrad Kablani und Palestine Building Syndicate Ltd. geregelt waren und bei denen fachkundige Handwerker wichtig waren -, nur Kleinstfirmen mit deutschen Handwerkern berücksichtigt. ${ }^{81}$

Damit wurden die groben Arbeiten von organisierten jüdischen Arbeitern und die technisch schwierigeren von eingewanderten deutschen Fachkräften ausgeführt. Wirtschaftliche Gründe spielten hierbei ebenso eine Rolle wie bei dem Import von ca. 90 Prozent der Baumaterialien aus Deutschland. Auch wenn Schocken als offizielle Begründung die mindere Qualität und das Fehlen der Waren auf dem palästinensischen Markt anführte, spielte ein zweiter Grund eine mutmaßlich gewichtigere Rolle. Bei der Auswanderung aus Deutschland wurde Schockens Vermögen, wie bei allen jüdischen Auswanderern und Flüchtlingen, von den nationalsozialistischen Behörden blockiert. Schocken gelang es zwar, große Teile seines Vermögens im Ausland in Sicherheit zu bringen - er hatte wohl bereits vor der Machtergreifung Konten im europäischen Ausland -, dennoch wurden große Teile seines Besitzes in Deutschland eingefroren. ${ }^{82}$ Es gab für deutsche Juden in den 1930er Jahren nur sehr beschränkte Möglichkeiten, das eigene Vermögen zu retten. Eine dieser Möglichkeiten war der Export von Gütern. Möglich machte dies ein Abkommen zwischen der Zionistischen Vereinigung für Deutschland und dem Reichswirtschaftsministerium.

Das unter dem Namen ,Ha'avara ${ }^{\text {(83 }}$ bekannte Abkommen regelte den Transfer von Waren und Vermögen aus Deutschland nach Palästina. Das bis heute umstrittene Abkommen ermöglichte es zahlreichen Auswanderungswilligen, zumindest Teile ihres Besitzes von Deutschland nach Palästina zu transferieren. ${ }^{84}$

81 Vgl. Div. Verträge. Sch A, Privates, 823, Box 9.

82 Die Akten, die über das Vermögen (Bargeld, Bankkonten, Immobilien, Aktien und Obligationen) Auskunft geben könnten, sind aus Datenschutzgründen nicht einsehbar. Einige wenige Schriftstücke in anderen Beständen lassen aber den Schluss zu, dass Konten in der Schweiz und in Großbritannien bestanden. Darüber hinaus ist auch bekannt, dass die Familie Bankschließfächer bei mehreren Schweizer Banken besaß.

83 Hebräisch für "Transfer“.

84 Das Abkommen und die Kontroversen, die es auslöste, sind Thema einiger wissenschaftlichen Arbeiten. Dazu gehören die Darstellungen von Werner Feilchenfeld, des langjährigen Vorsitzenden der Trust and Transfer Office Haavara Ltd., die damit gleichzeitig auch als Zeitdokument zu gelten haben: Werner Feilchenfeld / Dolf Michaelis / Ludwig 
Obwohl zionistische Körperschaften die Migration nach Palästina unterstützten, konnten längst nicht alle die Reise antreten. Die britische Mandatsmacht beschränkte trotz ihrer ursprünglich prozionistischen Haltung, wie sie unter anderem in der Balfour-Deklaration von 1917 zum Ausdruck kam, die Einwanderung von Juden und Jüdinnen. ${ }^{85}$ Bis 1936 stand Palästina den jüdischen

Pinner (Hrsg.): Haavara-Transfer nach Palästina und Einwanderung deutscher Juden 1933-1939. Tübingen: Mohr Siebeck 1972; ders.: Fünf Jahre deutsche Palästinawanderung und Haavara-Transfer, 1933-1938. Tel-Aviv: Trust and Transfer Office „Haavara“ 1938. Die beiden ausführlichsten und zuverlässigsten Auseinandersetzungen sind bis heute nur in Hebräisch erhältlich: Yoav Gelber: המדיניות הציונית והסכם ההעברה [Zionistische Grundsätze und das Ha'avara-Abkommen]. In: Yalkut Moreshet 1,XVII (1974), S. 97-152; ders.: המדיניות הציונית והסכם ההעברה [Zionistische Grundsätze und das Ha'avara-Abkommen]. In: Yalkut Moreshet 2,XVIII (1974), S.23-100; David Yisraeli: הריך הגרמני וארץ ישראל [Das deutsche ,Reich' und Eretz Israel]. Ramat Gan: Bar Ilan UP 1974. Von der letztgenannten Arbeit ist eine frühere, deutlich kürzere Version in Englisch erschienen: David Yisraeli: The Third Reich and the Transfer Agreement. In: Journal of Contemporary History 6,2 (1971), S. 129-148. Die Arbeit von Edwin Black hat nach dem ersten Erscheinen 1984 viel Aufmerksamkeit erhalten und liegt inzwischen in der dritten Auflage vor. Leider ist sie von zahlreichen Ungenauigkeiten geprägt und die Interpretation der Ereignisse ist mehr sensationsheischend als quellenbasiert. Edwin Black: The Transfer Agreement. The Dramatic Story of the Pact Between the Third Reich and Jewish Palestine. Überarb. Aufl. New York: Carroll \& Graf 2001. In deutscher Sprache liegt eine kurze, aber sehr präzise und gut verständliche Darlegung von Knaupe und Wurzel vor: Henk Knaupe / Ulrich G. Wurzel: Die Jewish Agency und die IG Farben. Das Haavara-Abkommen und die wirtschaftliche Entwicklung Palästinas. Berlin: Klaus-Schwarz 1994. Sowohl Bauer wie auch Ben Elissar widmen dem Ha'avaraAbkommen jeweils ein Kapitel ihrer allgemeineren Darstellungen der Verhandlungen und Abkommen zwischen zionistischen Organisationen und nationalsozialistischem Deutschland: Yehuda Bauer: Jews for Sale? Nazi-Jewish Negotiations, 1933-1945. New Haven: Yale UP 1994, S. 5-29; Eliahu Ben Elissar: La diplomatie du IIIème Reich et les juifs (1933-1939). Paris: Julliard 1969, S. 85-94. Neben diesen allgemein gehaltenen Darstellungen bietet Barkai eine konzise Darlegung der deutschen Interessen am Abkommen: Avraham Barkai: German Interests in the Haavara-Transfer Agreement 1933-1939. In: LBIYB 35,1 (1990), S. 245-266. Yfaat Weiss' Aufsatz hingegen thematisiert die zeitgenössischen Kontroversen, die das Abkommen in Deutschland und in Polen auslöste: Yfaat Weiss: The Transfer Agreement and the Boycott Movement. A Jewish Dilemma on the Eve of the Holocaust. In: Yad Vashem Studies 26 (1998), S. 129-171.

85 Die Geschichte Palästinas und des Jischuv während der britischen Mandatsmacht ist Thema unzähliger historischer, soziologischer und politikwissenschaftlicher Arbeiten und Abhandlungen. An dieser Stelle sei daher nur auf die kürzlich erschienene, klar strukturierte Überblicksdarstellung von Anita Shapira sowie die darin enthaltene thematisch gegliederte Bibliographie verwiesen: Anita Shapira: Israel. A History. Waltham, MA: Brandeis UP 2012, S.65-152. 
Einwanderern weitgehend offen. 1936, als Reaktion auf blutige Aufstände der arabischen Bevölkerung gegen die wachsende jüdische Bevölkerung und auf einen sechsmonatigen landesweiten Streik der arabischen Arbeiter, wurde die Immigration erstmals beschränkt und 1939 auf einem sehr tiefen Level eingefroren. Um nach Palästina einzuwandern, mussten Zertifikate vorgewiesen werden, von diesen stand nur das Zertifikat A 1, das sogenannte Kapitalistenzertifikat, unbegrenzt zur Verfügung. Um dieses zu erhalten, mussten 1.000 Palästina-Pfund $(£ \mathrm{P})$ als ,Vorzeigegeld ' nachgewiesen werden. Das Palästinensische Pfund entsprach dem Pfund Sterling, was bedeutete, dass 1933 die Summe von knapp 14.000 Reichsmark (siehe Diagramm, S. 228) für ein solches Zertifikat aufgebracht werden mussten. ${ }^{86}$ Zwar vergaben die Briten auch Einwanderungszertifikate für Vertreter der freien und religiösen Berufe, für Handwerker, Rentner und Schüler. Die Statistiken (siehe Tabelle 1) verdeutlichen aber, dass die britische Mandatsregierung in erster Linie an kapitalkräftigen Einwanderern interessiert war und sich durch den Kapitalfluss eine wirtschaftliche Entwicklung ihres Mandatsgebietes erhoffte. Die vergleichbar hohe Zahl an Arbeiterzertifikaten erklärt sich dadurch, dass deren Vergabe von der Zahl der Kapitalistenzertifikate abhängig war. Dadurch gelangten in den 1930er Jahren in erster Linie finanzkräftige Einwanderer und gut ausgebildete Arbeiter von Deutschland nach Palästina. ${ }^{87}$

Bis 1938 war es das erklärte Interesse der Nationalsozialisten, so viele Juden wie möglich zur Emigration zu bewegen. Um die Immigration nach Palästina zu ermöglichen, musste also gewährleistet werden, dass finanzkräftige Ausreisewillige die nötigen Mittel für das sogenannte Vorzeigegeld nach Palästina transferieren konnten. Darüber hinaus konnte die Emigration nur forciert werden, wenn Privatbesitz, also Möbel, Schmuck, Kunst sowie Vermögenswerte aus Deutschland ausgeführt werden konnten. Das galt für die potentiellen Erwerber von ,Kapitalistenzertifikaten` wie für weniger finanzkräftige Auswanderer. Problematisch dabei war jedoch, dass die deutsche Reichsbank

86 Ein Vergleich der Kaufkraft Mitte der 1930er Jahre mit der im Jahr 2006 ergibt ein Verhältnis 1 RM (1935) zu ca. 3.60 Euro (Januar 2006). Damit entsprächen die 14.000 RM ,Vorzeigegeld' ungefähr 50.400 Euro im Jahr 2006. Die Berechnung stützt sich auf Angaben der Deutschen Bundesbank, zit. n. Folker Schmerbach: Das, Gemeinschaftslager Hanns Kerrl'für Referendare in Jüterbog 1933-1945. Tübingen: Mohr Siebeck 2008, S. 165, Anm. 74.

87 Vgl. Knaupe / Wurzel: Die Jewish Agency und die IG Farben, S. 11. 


\begin{tabular}{|l|l|r|r|r|r|r|r|}
\hline \multicolumn{2}{|l|}{ Kategorie } & $\mathbf{1 9 3 3}$ & $\mathbf{1 9 3 4}$ & $\mathbf{1 9 3 5}$ & $\mathbf{1 9 3 6}$ & $\mathbf{1 9 3 7}$ & Total \\
\hline A I & Kapitalisten & 2.982 & 3.128 & 2.666 & 2.790 & 1.368 & $\mathbf{1 2 . 9 3 4}$ \\
\hline A II & Freie Berufe & 6 & 10 & 14 & 0 & 0 & $\mathbf{3 0}$ \\
\hline A III & Handwerker & 29 & 76 & 231 & 127 & 11 & $\mathbf{4 7 4}$ \\
\hline A IV & Rentner & 15 & 20 & 24 & 51 & 27 & $\mathbf{1 3 7}$ \\
\hline A V & Seltene Berufe & 22 & 0 & 3 & 0 & 0 & $\mathbf{2 5}$ \\
\hline B II & Religiöse Berufe & 7 & 37 & 32 & 18 & 4 & $\mathbf{9 8}$ \\
\hline B III & Schüler & 89 & 386 & 337 & 662 & 263 & $\mathbf{1 . 7 3 7}$ \\
\hline C & Arbeiter & 3.129 & 4.082 & 2.871 & 2.605 & 980 & $\mathbf{1 3 . 6 6 7}$ \\
\hline D & Angehörige & 524 & 758 & 1.269 & 1.643 & 627 & $\mathbf{4 . 8 2 1}$ \\
\hline Total & & 6.803 & 8.497 & 7.447 & 7.896 & 3.280 & 33.923 \\
\hline
\end{tabular}

Tabelle 1: Einwanderer aus Deutschland nach Palästina nach Zertifikatskategorien $(1933-1937)^{88}$

wegen deutschem Devisenmangel nur bereit war, die erforderlichen $1.000 £ \mathrm{P}$ in Devisen umzutauschen.

Hierbei trafen unterschiedliche Interessen aufeinander: Die Briten erleichterten es vor allem jüdischen Immigranten, die ein relativ großes Vermögen vorweisen konnten, nach Palästina einzureisen. Die zionistischen Verbände versuchten die Migration von Juden nach Palästina um jeden Preis zu fördern, um den Jischuv demographisch zu stärken. Die deutsche Regierung wiederum sah die Emigration der deutsch-jüdischen Bevölkerung, zumindest bis Ende 1938, als möglichen Weg zur Lösung der sogenannten Judenfrage. Die deutsche Reichsbank hingegen verfolgte finanzpolitische Interessen und beschränkte die Auszahlung von Devisen bis 1935 massiv, danach stellte sie dies gänzlich ein. Das Reichswirtschaftsministerium war wiederum daran interessiert, das deutsche Exportgeschäft zu stärken und den 1933 von jüdischen Organisationen ausgerufenen

88 Angaben übernommen von: Phiebig: Statistische Tabellen. In: Spitzer (Hrsg.): Almanach des Schocken Verlags auf das Jahr 5699, S. 148. 
Boykott deutscher Waren zu unterlaufen. ${ }^{89}$ Und schließlich war da die ganz persönliche und individuelle Not der Emigranten und Flüchtlinge, die versuchten, ihr Leben und ihre Habe in Sicherheit zu bringen.

Sowohl die Zionisten wie auch die offiziellen deutschen Stellen versuchten, die Probleme der jeweils anderen Seite zu berücksichtigen, wobei das ungleiche Kräfteverhältnis eindeutig von deutscher Seite beherrscht wurde. Dem Ha'avaraAbkommen, das den Interessen der deutschen Regierung und der zionistischen Organisationen entsprach, lag ein privates Abkommen zwischen der Hanotea Ltd., einer jüdischen Zitrus-Pflanzungsgesellschaft in Netanya, und dem Reichswirtschaftsministerium zugrunde. Das Hanotea-Abkommen, ein eigentlicher Vorläufer des Ha'avara-Abkommens, sah vor, dass Auswanderer durch Zahlung auf ein Sperrkonto der Hanotea Privatvermögen bis zu 40.000 RM für den Aufbau einer neuen Existenz in Palästina einzahlen konnten. ${ }^{90}$ Die Hanotea verpflichtete sich, den Auswanderern ein Haus oder eine Zitruspflanzung im Gegenwert der Einzahlung zur Verfügung zu stellen. In Deutschland, wo das Sperrkonto mit den Auswandererguthaben lag, erwarb die Gesellschaft Waren für den eigenen Bedarf und exportierte diese nach Palästina. ${ }^{91}$ Das Interesse auf Seiten von Auswanderungswilligen war derart groß, dass der ursprünglich genehmigte Betrag von einer Million Reichsmark bald ausgeschöpft war. Am 18. Juli 1933 erteilte das Reichswirtschaftsministerium die Genehmigung, weitere drei Millionen Reichsmark in dieser Weise zu transferieren. Nach Ansicht offizieller jüdischer Stellen überstieg dieses zweite Abkommen die Kapazitäten einer Privatgesellschaft. Nur einen Tag nach der Bewilligung der weiteren drei Millionen schaltete sich die ZVfD ein, vertreten durch Georg Landauer und Sigmund Hoofien, den Direktor der Anglo-Palestine Bank ${ }^{92}$. An einem Treffen zwischen Landauer, Sam Cohen für die Hanotea, sowie Vertretern der Reichsbank und des Auswärtigen Amtes sollte über Zukunft des Abkommens verhandelt werden. Laut Landauer brachten die deutschen Behörden nach eigenen Angaben dem Auswanderungsinteresse der deutschen Juden großes Verständnis

89 Die unterschiedlichen und sich oft diametral entgegenstehenden Interessen deutscher Verwaltungs- und Regierungsstellen sind gut aufgearbeitet bei Barkai: German Interests in the Haavara-Transfer Agreement 1933-1939.

90 Das Gesamtvolumen der Zahlungen wurde auf eine Million Reichsmark beschränkt.

91 Vgl. Feilchenfeld / Michaelis / Pinner: Haavara-Transfer nach Palästina und Einwanderung deutscher Juden 1933-1939, S. 24.

92 Die Anglo-Palestine Bank, bis 1934 Anglo-Palestine Company, wurde 1902 aufgrund von Beschlüssen auf dem 1. und 2. Zionistenkongress gegründet. 
entgegen, ${ }^{93}$ was angesichts der Verdrängungs- und Einschüchterungspolitik der Nationalsozialisten nur als zynisch beschrieben werden kann.

Auf der Sitzung wurde die Überführung des privaten Abkommens zwischen der Hanotea und dem Deutschen Reich in einen offiziellen Vertrag zwischen der zionistischen Organisation und Deutschland beschlossen. Zur Implementierung des Ha'avara-Abkommens gründete die ZVfD die PalästinaTreuhandstelle zur Beratung deutscher Juden GmbH, bekannt unter dem Akronym ,Paltreu'. Gesellschafter der Paltreu waren die deutsch-jüdischen Bankhäuser M. M. Warburg \& Co und A. E. Wassermann und die von der Anglo-Palestine Bank errichtete palästinensische Treuhandstelle Trust and Transfer Office Haavara Ltd. Der hebräische Begriff für Transfer ,Ha'avara' bezeichnete hernach alle Vorgänge dieser Unterstützung der Auswanderung deutscher Juden. ${ }^{94}$

Vereinfacht lässt sich der Transfer folgendermaßen beschreiben: Auswanderungswillige Juden und Jüdinnen bezahlten ihr liquidiertes Vermögen auf die Konten der Paltreu bei Wassermann und Warburg ein. Das Kapital wurde dann zur Bezahlung von deutschen Exportwaren in Palästina und in einem begrenzten Maß auch in anderen Ländern verwendet. Für die Mittel, die den deutschen Firmen dadurch zuflossen, wurde der Begriff,Ha'avara-Mark'verwendet. Die Haavara Ltd. in Palästina erhielt gleichzeitig das Monopol für die Einfuhr von deutschen Waren in den jüdischen Wirtschaftssektor in Palästina. Die Importeure in Palästina bezahlten die Rechnungsbeträge auf ein Konto der Bank der Templergesellschaft in Jaffa ein. Nach ihrer Einreise konnten die deutschjüdischen Immigranten über das Kapital, das sie in Deutschland einbezahlt hatten, verfügen. Damit konnten sie die für das Kapitalistenzertifikat nötigen $1.000 £$ P vorweisen. ${ }^{95}$

Zwischen 1933 und 1938 konnten dank des Abkommens ungefähr 45.000 Juden und Jüdinnen, davon ungefähr ein Drittel ,Kapitalisten', aus Deutschland auswandern. ${ }^{96}$ Während dieser Zeit änderten die deutschen Partner die

93 Vgl. Dolf Michaelis: Die wirtschaftliche und politische Entwicklung der Auswanderungsund Transferfrage im nationalsozialistischen Deutschland. In: Feilchenfeld / Michaelis / Pinner (Hrsg.): Haavara-Transfer nach Palästina und Einwanderung deutscher Juden 1933-1939, S. 15-33, hier S.24-25.

94 Vgl. ebd., S.25-27.

95 Vgl. Knaupe / Wurzel: Die Jewish Agency und die IG Farben, S. 13-14.

96 Vgl. Feilchenfeld: Fünf Jahre deutsche Palästinawanderung und Haavara-Transfer, 1933-1938, S. 21. 
Bestimmungen des Abkommens mehrmals. Standen in den ersten Jahren wirtschaftliche Überlegungen - Stärkung des deutschen Exportes, Bekämpfung des weltweiten Boykottes deutscher Waren durch jüdische Organisationen - im Zentrum, ${ }^{97}$ richteten sich ab Herbst 1935 die Bestrebungen vor allem darauf, die Emigration deutscher Juden mit aller Kraft zu forcieren. ${ }^{98}$

Insgesamt wurden von 1933 bis Ende 193894 Millionen RM Auswanderervermögen transferiert. Dazu gehörten neben dem Vorzeigegeld für Kapitalisten $(1.000 £ \mathrm{P})$ das Vorzeigegeld für Einwanderer mit Spezialvisa für freie Berufe, Handwerker etc. $(250 £ \mathrm{P})$, regelmäßige Beiträge oder Sonderspenden für den zionistischen Fonds, die Jugend-Alija und andere Institutionen. Weiterhin wurden Ersparnisse transferiert, die über den Betrag des Vorzeigegeldes hinausgingen (max. 50.000 RM), diese wurden von den deutschen Behörden auf Antrag für zusätzliche Transferprojekte Projekte wie Eigen-, Emissions- und Bautransfer freigegeben. Transferiert wurden auch öffentlich-rechtliche oder private Pensionen, Schulgeld für Kinder und junge Erwachsene, deren Eltern in Deutschland blieben, während sie auf palästinensischen Schulen und Hochschulen ausgebildet wurden, aber auch die Aufenthaltskosten für deutschjüdische Touristen in Palästina. ${ }^{99}$

Das Transferabkommen darf nicht darüber hinwegtäuschen, dass die Auswanderung aus Deutschland für die große Mehrheit der deutsch-jüdischen Palästinaeinwanderer aus Angst und Not gewählt wurde und große Teile ihres Auswanderervermögens durch gesetzliche Sonderauflagen von deutscher Seite konfisziert wurden. Das geschah durch verschiedene Instrumente: Neben der Reichsfluchtsteuer, die alle Emigranten zu entrichten hatten, und dem Einfrieren von Vermögen, das nicht im Rahmen der Ha'avara transferiert werden konnte, zählten dazu auch Spezialbestimmungen für den Export von Waren durch das Ha'avara-Abkommen.

Die Sonderbestimmungen für den Warenexport im Rahmen des HaavaraAbkommens schlossen diese Transaktionen von den sonst üblichen ,PreisAusgleichsbonifikation' aus, da sich die deutschen Stellen geweigert hatten, die sonst übliche Exportprämie für deutsche Waren auszubezahlen. Dazu war die Bezahlung in ,Ha'avara-Mark' nur möglich, wenn die Höhe des Preises ,frei

97 Vgl. Barkai: German Interests in the Haavara-Transfer Agreement 1933-1939, S. 246-247. 98 Vgl. ebd., S.248-249, 257.

99 Vgl. Feilchenfeld: Fünf Jahre deutsche Palästinawanderung und Haavara-Transfer, 1933-1938. 
deutsche Grenze ${ }^{\text {(100 }}$ beglichen wurde. ${ }^{101}$ Im Welthandelsverkehr kamen auch damals üblicherweise CIF-Preise ${ }^{102}$ zur Anwendung, und nicht die von den Nationalsozialisten für den Ha'avara-Export vorgesehenen FOB-Preise, die für den Käufer der Ware, in diesem Fall also die Paltreu, ungünstig waren, da sie die Transport- und Versicherungskosten selber zu tragen hatte. Diese beiden diskriminierenden Sonderkonditionen verteuerten die Exportware auf dem Weltmarkt. Dazu kam, dass die Paltreu nur begrenzte Geschäftsmöglichkeiten besaß, sodass viele Auswanderer bereit waren, auf einen Teil ihres Vermögens zu verzichten, wenn dadurch die Ausreise beschleunigt wurde. ${ }^{103}$

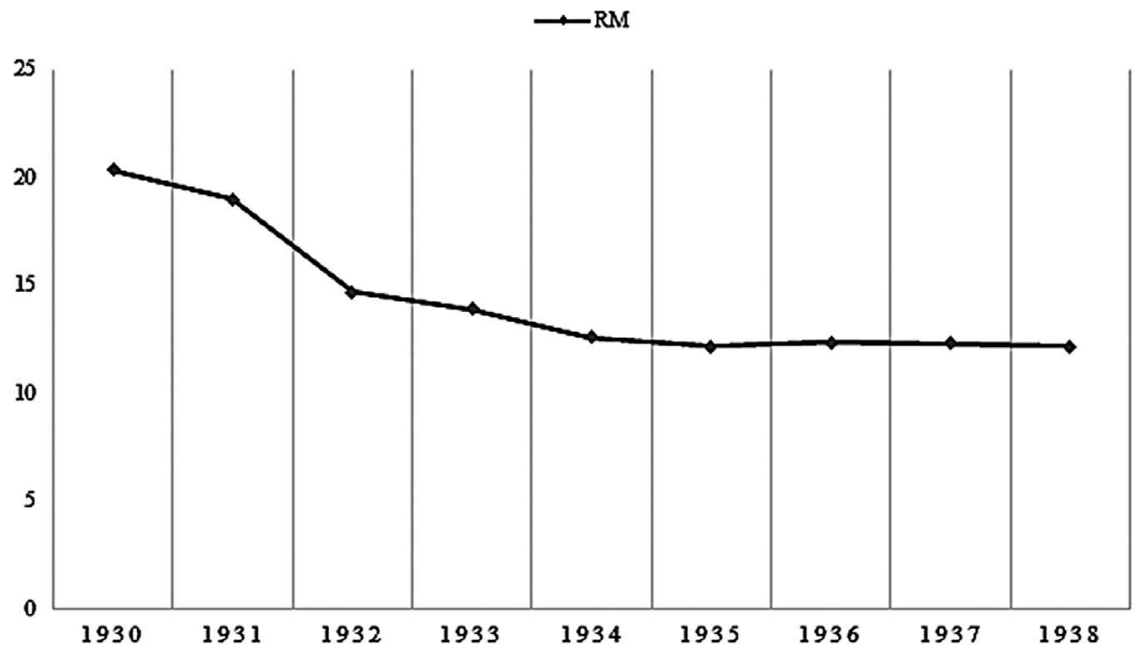

Diagramm: Entwicklung des Devisenkurses des Palästinensischen Pfunds im Verhältnis zur Reichsmark, Stand der Berliner Banken ${ }^{104}$

100 Das entspricht den internationalen FOB-Preisen (Free on Board).

101 Vgl. Knaupe / Wurzel: Die Jewish Agency und die IG Farben, S. 18-19.

102 CIF ist das Akronym von Cost, Insurance, Freight.

103 Vgl. Knaupe / Wurzel: Die Jewish Agency und die IG Farben, S. 19.

104 Reinhard Hübner: Arabisches Wirtschaftsleben. Heidelberg/ Berlin: Vowinckel 1943, S. 122; vgl. Heinze an Salman Schocken, 01.09.1936. SchA, Privates, 823, Box 30. 
Für Salman Schocken war das Ha'avara-Abkommen von höchster Relevanz. Er äußerte sich zwar wiederholt sehr kritisch darüber, für die Rettung seines Vermögens war das Abkommen jedoch immens wichtig. Sein Privatvermögen überstieg deutlich die 50.000 RM, die auf Antrag über die Ha'avara transferiert werden konnten. Wie Schocken sein Privatvermögen und nach dem Verkauf des Konzerns im Jahr 1938 den Erlös daraus aus Deutschland rettete, ist aus den zugänglichen Akten nicht zu eruieren. Für die Rettung des Vermögens spielte die Ha'avara jedoch eine große Rolle: Er finanzierte den größten Teil seiner zwei Bauprojekte mit Ha'avara-Vermögen, indem er als Selbsttransferent Baumaterial aus Deutschland einführte.

Für den Bautransfer erließ die Ha'avara spezielle Bedingungen. ${ }^{105}$ Denen zufolge galt „die Verwendung von Reichsmarkguthaben jüdischer Auswanderer aus Deutschland [...] bei der Haavara zum Ankauf von Baumaterial " ${ }^{106}$ als Bautransfer. Zugelassen waren unter anderem Bauvorhaben, die der Transferent selbst als Bauherr durchführen ließ, so bspw. für die Schaffung eines Eigenheimes. ${ }^{107}$ Die Genehmigung musste schriftlich bei der Haavara eingeholt werden und erfolgte nach Beratungen der Bautransfer-Kommission. Die Ha'avara erhob für ihren Aufwand Transferspesen von 5 Prozent, eine Provision für den Transferberater von 2,5 Prozent sowie eine Durchschnittsbonifikation zum Preisausgleich von 37,5 Prozent. ${ }^{108}$ Vom ursprünglich bei der Paltreu einbezahlten Reichsmarkbetrag wurden alleine von der Ha'avara 45 Prozent abgezogen, dazu kamen die ungünstigen FOB-Preise, bei denen der Transferent die Versicherungsund Transportkosten zu tragen hatte. Unter diesen Umständen verlor ein Bautransferent 1937 mindestens die Hälfte seines einbezahlten Kapitals.

Salman Schocken importierte bereits vor 1937 das Material für seine Bauprojekte und konnte teilweise bessere Konditionen aushandeln. Dennoch musste auch er große Verluste in Kauf nehmen. Die im Schocken Archiv zugänglichen Akten verdeutlichen ebenfalls, dass Schocken und seine Mitarbeiter während der ganzen Bauphase mit Vertretern der Ha'avara und den deutschen Stellen in Verhandlung standen, um möglichst gute Bedingungen auszuhandeln.

105 Vgl. „Haavara“ Misrad Neemanut: Bedingungen für den Bautransfer der, Haavara' Ltd. Tel Aviv: typ. B. Ortner 1937.

106 Ebd., S. 1.

107 Vgl. ebd.

108 Vgl. ebd., S.3-4. 
Erste Abklärungen von Heinze, die Schocken im April 1934 einforderte, gingen noch davon aus, dass Salman Schocken das gesamte nach Palästina zu importierende Baumaterial in freier Mark bezahlen könne. Diese Regelung kam zu diesem Zeitpunkt in Frage, da Schocken noch die deutsche Staatsbürgerschaft besaß. Wäre er bereits Auslandsdeutscher gewesen, hätte er 60 Prozent in Sperrmark und 40 Prozent in Devisen aufbringen müssen. Für Heinze war der Transfer im Rahmen des Ha'avara-Abkommens die schlechteste Option, „da nach denjetzigen [sic] Gepflogenheiten damit zu rechnen ist, dass jetzt schon in Deutschland eingezahlte Gelder erst nach etwa einem Jahr hier verfügbar sein könnten. ${ }^{\text {"109 }}$ Die Ha'avara hatte tatsächlich das Problem, dass einbezahlte Gelder wegen zu geringen deutschen Exporten nach Palästina nur mit großer Verspätung ausbezahlt werden konnten.

Der erste Antrag an die Devisenstelle in Leipzig datiert auf den 8. Mai 1935 und beinhaltet neben der Information, dass Schocken für seine Bauprojekte in Palästina plant, Baumaterial im Wert 130.000 bis 150.000 RM aus Deutschland zu importieren, die Anfrage, „ob damit gerechnet werden kann, dass Herrn Salmann [sic] Schocken genehmigt werden wird, diese Baustoffe zu Lasten seines gesperrten Kontos [...] zu beziehen. “110 In einem persönlichen Gespräch zwischen Schockens Rechtsvertreter und Karl Engelke von der Devisenstelle wurde aber deutlich, dass man auf deutscher Seite nicht gewillt war, den gesamten Betrag in Mark freizugeben, und dass Schocken nicht damit rechnen dürfe, mehr als 50 Prozent in Sperrmark zu bezahlen. ${ }^{11}$ Trotz dieses negativen Bescheides traten im Juni desselben Jahres Heinze und Gustav Schocken in Verhandlungen mit der Ha'avara, um erste Abklärungen vorzunehmen, in welcher Form Schocken der Import von deutschen Baumaterialen im Wert von 150.000 bis 200.000 RM - ein deutlich höherer Wert als er noch einen Monat zuvor angegeben wurde -, gewährt werden könne. Herr David von der Ha'avara teilte ihnen mit, dass der Transfer bewilligt würde, wenn Schocken die Genehmigung vom Reichswirtschaftsministerium erhalte, die Kosten in Reichsmark zu begleichen. Da die Háavara das Monopol auf die Einfuhr von deutschen Waren in den jüdischen Sektor Palästinas besaß, müsse mit zusätzlichen Kosten

109 Bericht Heinze an Salman Schocken, 19.04.1935. SchA, Privates, 823, Box 30.

110 Siegfried Moses an Präsidenten des Landesfinanzamtes, Devisenstelle, 08.05.1935. SchA, Privates, 823, Box 14 .

111 Vgl. Bericht für Herrn Schocken, 09.05.1935. SchA, Privates, 823, Box 14. 
von 9 Prozent des Einfuhrwertes für die Ha'avara und ein Prozent für die Paltreu gerechnet werden. Die von der Ha'avara üblichen 15 Prozent Bonifikation würden bei Selbsttransferenten auf 5 Prozent reduziert. ${ }^{112}$ Dieses Angebot der Ha'avara war für Schocken sehr günstig, wobei in den Verhandlungen der negative Bericht des Reichswirtschaftsministeriums komplett ausgeblendet wurde. Möglicherweise müssen diese ersten Verhandlungen als Sondierung der Lage verstanden werden, auf die später aufgebaut werden sollte. Dass eine komplette Bezahlung des zu exportierenden Baumaterials mit Reichsmark nicht möglich sein würde, war ab Mitte Mai 1935 klar. Siegfried Moses gelang es aber, beim Landesfinanzamt Leipzig die Bewilligung einzuholen, dass Schocken bis zu 50 Prozent der Rechnungsbeträge von seinem Auswanderersperrkonto bezahlen durfte, solange der Auslandskostenanteil der Rohstoffe nicht mehr als 20 Prozent betrug. Der Restbetrag musste gleichzeitig entweder in Devisen oder freien Reichsmark beglichen werden. ${ }^{113}$

Die ökonomische Lage in Deutschland beeinflusste diese Entscheidung sicherlich zugunsten Schockens. Deutschland hatte weiterhin große Probleme, den Export anzukurbeln und die durch schlechte Exportzahlen tiefen Devisenbestände aufzustocken. Daher richtete sich die Wirtschaftspolitik dieser Jahre darauf, den Export zu fördern, um so an die dringend benötigten Devisen zu gelangen. Das Landesfinanzamt Leipzig muss sich bewusst gewesen sein, dass Schocken als Auswanderer die nötigen 50 Prozent der Kosten nicht in freien Reichsmark aufbringen konnte, oder wenn, dann nur mit sehr hohen Verlusten, da Deutschland sämtliche Konten von jüdischen Auswanderern sperrte und die Gelder nur mit sehr hohen Abzügen freigab. Insofern rechnete man im Reichswirtschaftsministerium damit, dass Schocken 50 Prozent der anfallenden Kosten in Devisen begleichen würde. Problematisch war jedoch, dass die Frachtspesen nicht mit Sperrmark beglichen werden durften, sondern zu 100 Prozent in Devisen zu zahlen waren. ${ }^{14}$

112 Vgl. Besprechungsprotokoll, David, Heinze und Gustav Schocken, 26.06.1935. SchA, Privates, 823, Box 14 .

113 Vgl. Präsident des Landesfinanzamtes Leipzig, Devisenstelle, Abt. IV, 9 Wkl/Gr. an Siegfried Moses, 26.07.1935 [Abschrift vom 04.06.1937]. SchA, Privates, 823, Box 14.

114 Vgl. Telegramm Sekretariat Jerusalem an Salman Schocken, 10.03.1936. SchA, Privates, 823, Box 2; Bericht für Herr Schocken von Romann, Sekretariat Jerusalem, 13.03.1936. SchA, Privates, 823, Box 14. 
Da keine Dokumente überliefert sind, die anderes vermuten lassen, hatte diese Abmachung zwischen Schocken und dem Reichswirtschaftsministerium, die außerhalb des Ha'avara-Abkommens abgeschlossen wurde, ${ }^{115}$ wohl bis Ende der Bauzeit Gültigkeit. Diese Sondervereinbarung erlaubte Schocken, zumindest einen Teil seines Sperrguthabens zu liquidieren und für den Kauf von Baumaterial aufzuwenden. Er bezog jedoch auch über das offizielle Ha'avara-Abkommen Material für seine beiden Bauprojekte. Aus den Akten wird ersichtlich, dass Schockens Angestellte in Jerusalem in ständigen Verhandlungen mit Vertretern der Ha'avara standen. In der Regel optierte Schocken für die Abwicklung des Importes durch die Ha'avara, wenn für ihn lohnende Bonifikationen gewährt wurden. ${ }^{116}$ Dies lässt vermuten, auch wenn es im Detail in den Akten nicht belegt ist, dass für einen Großteil der Waren mit der Ha'avara verhandelt wurde - je nach Entscheid wurden die Geschäfte über das Sonderabkommen mit dem Reichswirtschaftsministerium oder über die Ha'avara abgeschlossen. Klar ist jedoch, dass bei Schocken keine fixen Bonifikationen berechnet wurden, sondern dass jede Warengruppe einzeln verhandelt werden konnte. Wobei man sich in Jerusalem erhoffte, dass ein Mittelwert für die Bonifikationen ausgehandelt werden könne mit dem Ziel, „die Gesamtbonifikation etwas höher zu stellen. ${ }^{\text {“17 }}$ Die Ha' avara ihrerseits zeigte sich sehr interessiert an Geschäften mit Schocken und bot in einem Schreiben vom 26. April 1936 eine geschäftliche Partnerschaft an: Man informierte, dass es für ihn nicht teurer sei, den Export über die Ha'avara abzurechnen als im Rahmen des deutschen Sonderabkommens - wobei die Ha avara Schocken bei den Bonifikationen nicht weiter entgegenkommen könne. ${ }^{118}$

Dass bei diesen komplexen Abläufen mit zahlreichen involvierten Stellen, und den Abklärungen, die zwischen Jerusalem und Zwickau kommuniziert werden mussten, Fehler passierten, ist nicht verwunderlich. So ist bspw. ein Fall belegt,

115 Vgl. Notiz für Theodor Schocken, Turnowsky und Heinze von Salman Schocken, 25.05.1937. SchA, Privates, 823, Box 14; Zentrale Zwickau, Abteilung Export an Romann, Sekretariat Jerusalem, 30.12.1936. SchA, Privates, 823, Box 14.

116 Vgl. Bericht für Herrn Schocken von Romann, Sekretariat Jerusalem, 13.03.1936. SchA, Privates, 823, Box 14.

117 Schwabe, Sekretariat Jerusalem an Heinze, 23.04.1936. SchA, Privates, 823, Box 14.

118 Vgl. Central Office for Transfer, Commercial Department of Haavara Ltd. an Salman Schocken, 26.04.1936. SchA, Privates, 823, Box 14. 
bei dem die Bewilligung der Devisenstelle vorlag, Waren im Rahmen des Sonderabkommens zu exportieren; die Rechnung wurde schließlich aber mit HaavaraMark bezahlt. In der Zwickauer Exportabteilung war man besorgt, dass solche Fehler schwerwiegende Konsequenzen haben könnten, im schlimmsten Falle die Sistierung des Abkommens. ${ }^{119}$ Dies macht auch deutlich, dass man sich in Zwickau der prekären Situation bewusst war, dass solche Abkommen ohne weitere Vorwarnung von deutscher Seite für nichtig erklärt werden könnten. Für die Mitarbeitenden des Zwickauer Baubüros schien die Gefahr, die von den nationalsozialistischen Behörden ausging, sehr viel fassbarer gewesen zu sein als für die Mitarbeitenden des Jerusalemer Sekretariates und Baubüros. In Jerusalem war man sich offensichtlich auch nicht darüber bewusst, wie aufreibend die Verhandlungen mit den deutschen Behörden waren und unter welchem Druck sich die Schocken-Mitarbeitenden in Deutschland befanden. Denn auch wenn mit dem Sonderabkommen eine Regelung für den Export gegeben war, mussten sämtliche Rechnungen, die zu bezahlen waren, einzeln von der Devisenstelle bewilligt werden. Dies geschah quartalsweise, wobei der Devisenstelle eine Sammelrechnung mit detaillierter Auflistung vorgelegt werden musste. Zwar wurden sämtliche Zahlungen bewilligt, jedoch setzte die Devisenstelle für die Begleichung eine Frist. Nach Ablauf dieser Fristen verfiel die Bewilligung und konnte auch kein zweites Mal eingeholt werden. Vor diesem Hintergrund ist es sehr verständlich, dass sich Zwickau über die verzögerte Bearbeitung der Zahlungsfreigaben in Jerusalem beschwerte. ${ }^{120}$ Ein weiterer Grund, warum Zwickau auf schnelle Erledigung der Zahlungsabwicklung drängte, lag darin, dass der Zahlungsprozess kompliziert und damit zeitintensiv war. Die Akten geben einen guten Einblick in diesen langwierigen Prozess: Nachdem von der Devisenstelle die Freigabe von Sperrmark für die Hälfte des Rechnungsbetrages gewährt worden war, musste mit der Ha'avara verhandelt werden, damit ein Scheck der Anglo-Palestine Bank in Pfund Sterling ausgestellt wurde, der per Luftpost nach Zwickau gesandt und dort entweder als Devisencheck oder

119 Vgl. Zentrale Zwickau, Abteilung Export an Baubüro Schocken Jerusalem, 28.08.1936. SchA, Privates, 823, Box 14.

$120 \mathrm{Vgl}$. Zentrale Zwickau, Abteilung Export an Romann, Sekretariat Schocken Jerusalem, 30.12.1936; Telegramm Zentrale Zwickau, Abteilung Export an Heinze, Baubüro Jerusalem, 14.01.1937. SchA, Privates, 823, Box 14. 
umgewechselt in Reichsmark zur Bezahlung der zweiten Hälfte des Rechnungsbetrages eingesetzt werden konnte. ${ }^{121}$

Zwar wurde das Abkommen zwischen Schocken und dem Reichswirtschaftsministerium nie offiziell gekündigt, es wird jedoch aus den Akten deutlich, dass ab 1938 vermehrt mit Schwierigkeiten gerechnet wurde. Die Devisenstelle bewilligte weiterhin die Transaktionen, verdeutlichte aber auch, dass in Zukunft kein Anrecht darauf bestehe, dass die "Zahlung 50 : 50 von der Devisenstelle genehmigt wird. “122 Gleichzeitig wurde auch der Transfer über das Haavara-Abkommen eingeschränkt. Zahlreiche Materialien durften nicht mehr exportiert werden. Innerhalb der nationalsozialistischen Behörden und Regierungsstellen setzten sich verstärkt jene Stimmen durch, die den Besitz der jüdischen Auswanderer und Flüchtlinge annektieren wollten. Im Frühsommer 1938 herrschte in Zwickau zunehmend eine gewisse Hektik. ${ }^{123}$ Das war einerseits darauf zurückzuführen, dass der Konzern verkauft wurde und damit der Export für den Privatmann Schocken eingestellt werden musste. Andererseits wurde deutlich, dass das Ha'avara-Abkommen nicht mehr lange Bestand haben würde.

In den Jahren 1935 bis 1938 gelang es Schocken also dank der Verhandlungen seiner Mitarbeitenden und dank seines gesellschaftlichen Status sowie dem dazugehörigen Netzwerk, zu dem auch ranghohe Offizielle der Ha'avara zählten, fast das gesamte Baumaterial für seine beiden Bauprojekte von Deutschland nach Palästina zu importieren. Sonderregelungen in Deutschland wie in Palästina ermöglichten dies. Die Summe, die er für Material, Export und Arbeitsstunden aufzuwenden hatte, lässt sich heute nicht mehr eruieren. Verbrieft ist, dass Schocken wohl mehr als die eigentlich für Einzelpersonen vorgesehenen 50.000 RM über die das Ha'avara-Abkommen transferierte. Sicher ist zudem, dass er trotz Sondergenehmigungen bedeutende Teile seines Vermögens durch die für Juden geltenden diskriminierenden Steuern und nachteiligen Geschäfts- und Bezahlungsmodalitäten verlor. Dennoch gelang es ihm wie kaum jemand anderem, Vermögenswerte und Besitz zu retten.

121 Vgl. SchA, Privates, 823, Box 2, Box 14, Box 30.

122 Ernst Jacobson an [Ernst] Romann, 31.05.1938. SchA, Privates, 823, Box 14.

123 Vgl. diverse Schreiben des Exportbüros an das Sekretariat Jerusalem mit dem Hinweis, dass alte Ausstände dringend bezahlt werden müssten, da die Möglichkeit mit sogenannten Ha'avara-Mark zu bezahlen, schwinde, Juni-August 1938. SchA, Privates, 823, Box 14. 


\subsubsection{Swimmingpool und Garten - Luxus in der trockenen Landschaft}

Adon!

[...] Ich freute mich gestern so in Ihrem Garten tausendschön und ich hätte es Ihnen gerne mündlich gesagt, aber ich wollte Sie nicht wieder stören. Ließ aber bestellen Ihnen, Adon, Dank! Ihr äußerst freundlicher Gärtner, Adon Spiro zeigte mir alle Bäume und Blumen und wurde nicht ungeduldig mir zu antworten, mir zu erklären. Ich sah die ehemaligen Riesen - die Philister und den aller höchsten Goliath der Bäume. Und die prachtvollen Cypressen, vor dem Rasen plötzlich eine kleine Gesellschaft - im Gespräch. ${ }^{124}$

Die Dichterin Else Lasker-Schüler, die ab Frühjahr 1939 unfreiwillig in Jerusalem lebte, da die Schweiz ihr das Visum zur Wiedereinreise verweigerte, ${ }^{125}$ war nicht die einzige Bewunderin des Gartens. Im Mai 1946 erschien in der Palestine Tribune ein Artikel von Ada Rosenberg über Privatgärten in Jerusalem. ${ }^{126}$ Der Garten der Schockens wurde darin ausführlich beschrieben. Rosenberg geht in ihrem Artikel insbesondere auf die Einheit, die Architektur und Garten bilden, ein.

The close collaboration, in planning both house and garden, as an entity and the application of English landscape principles by using natural scenery are at once apparent. The garden really enlarges the house and carries it on into nature, in which it forms a couple of single rooms, habitable, as demanded by Lord Bacon, father of English landscape gardening. [... $]^{127}$

124 Else Lasker-Schüler an Salman Schocken, 26.07.1940. In: Lasker-Schüler: ,Was soll ich bier?', S. 68.

125 Zur Bedeutung Palästinas für Else Lasker-Schüler vgl. Alfred Bodenheimer: Die auferlegte Heimat. Else Lasker-Schülers Emigration in Palästina. Tübingen: Niemeyer 1995. Zu ihrem Gesamtwerk: Sigrid Bauschinger: Else Lasker-Schüler. Ihr Werk und ibre Zeit. Heidelberg: Stiehm 1980. Zu ihrer Biographie: Sigrid Bauschinger: Else Lasker-Schüler. Biographie. Göttingen: Wallstein 2004, zum Jerusalemer Exil insb. S. 411-447. Zur Beziehung zwischen Salman Schocken und der Dichterin vgl. Kap. 9.3.1.

126 Ada Rosenberg: Jerusalem's Private Gardens. In: The Palestine Tribune, 23.05.1946, S. 11-12.

127 Ebd., S. 11. 
Die Einheit von Garten und Architektur geht sicherlich darauf zurück, dass Erich Mendelsohn bei der Gestaltung des Gartens wie bei der Auswahl der Bäume, Büsche und Blumen mitwirkte. Zwar oblag die Gesamtplanung den englischen Gartenarchitekten Jellicoe and Parkeiens, Mendelsohn behielt sich aber vor, Änderungen in den Plänen vornehmen zu können. Geoffrey Jellicoe war einer der bekanntesten und renommiertesten Landschaftsarchitekten seiner Zeit. Der Brite war Mitbegründer des Landscape Institute und Verfasser zahlreicher Studien. Die Zusammenarbeit kam mutmaßlich durch die Vermittlung von Erich Mendelsohn zustande, der mit seinem Londoner Büro in gutem Kontakt zur englischen Architekturszene stand. Zudem legte Mendelsohn größten Wert auf eine einheitliche, sich ergänzende Formsprache zwischen Bau und Garten. ${ }^{128}$ Trotz seines Ruhmes war Jellicoe aber nur die zweite Wahl Schockens. Schocken wollte nämlich ursprünglich den deutschen Landschaftsarchitekten Heinrich Wiepking-Jürgensmann, der bereits Schockens Garten im Berliner Zehlendorf geplant hatte, ${ }^{129}$ verpflichten. Wiepking-Jürgensmann lehnte den Auftrag mit Verweis auf seine Mitgliedschaft in der Reichskulturkammer und seine Professur an der Technischen Hochschule Berlin ab. Er war in diesen Funktionen für die Ausbildung von Gartenplanern zur Zeit des Nationalsozialismus zuständig. Wie einem Bericht Heinzes an Schocken zu entnehmen ist, zeigte sich Wiepking jedoch bereit, die Pläne Mendelsohns zu kommentieren und Verbesserungsvorschläge zu unterbreiten. Er scheint die Pläne genau studiert zu haben; seine Kritik fiel sehr detailliert aus. ${ }^{130}$ Schocken scheute sich nicht, bekennende Nationalsozialisten für seine Projekte anzufragen. Für ihn zählten auch noch im Jahr 1937 persönliche Beziehungen mehr als Parteizugehörigkeit. Diese Offenheit war jedoch einseitig; Wiepking fürchtete wohl um seine Position. So entstand der Garten also weitgehend ohne Mitarbeit des deutschen Professors.

Wie zuvor die Baumaterialien, wurde der größte Teil der Pflanzen aus Deutschland, aber auch aus Holland und später aus Italien importiert. Nicht nur kleinere Gewächse führte man aus Europa ein, sondern auch ganze Bäume, wie ein

128 Vgl. u. a. Erich Mendelsohn an Lili Schocken, 06.03.1935. SchA, Privates, 823, Box 34.

129 Vgl. Gesprächsprotokoll Salman Schocken und Gärtner Admoni, 15.10.1936. SchA, Privates, 823 , Box 25 .

130 Vgl. Bericht Willy Heinze über Gespräch zwischen Prof. Wiepking und Herrn Lempke, 22.03.1937. SchA, Privates, 823, Box 30. 
Brief Schockens an das Agricultural Department zeigt. ${ }^{131}$ Während Gemüsesetzlinge und Beerenstauden für den Bibliotheksgarten vornehmlich aus Deutschland bezogen wurden, stammten die Tulpenzwiebeln aus Holland. War schon der Import von Baustoffen nicht immer einfach, kam bei den Pflanzenlieferungen erschwerend dazu, dass für sämtliche Sendungen Gesundheitsatteste mitgeschickt werden mussten. Wenn dies einmal nicht geschah, wurden die Pflanzen am Hafen zurückbehalten, bis die Papiere eintrafen. ${ }^{132}$ Bis zum April 1939 wurden die Pflanzen, wenn möglich, aus Deutschland bezogen, erst ab Ende April fand ein Umdenken statt. Am 30. April 1939 schreibt Schocken persönlich an die Firma N. V.H. Homan \& Co., dass er bis zu diesem Zeitpunkt den Bedarf für seine „große Gartenanlage "133 durch seine Firma in Deutschland gedeckt habe, sich nun aber nach Alternativen umschaue. Ob er mit der Firma ins Geschäft kam, ist nicht überliefert.

In Jerusalem plante Schocken mit seinem Architekten und dem Gartenbauer eine parkähnliche Anlage, die sich über mehrere Terrassen und eine Gesamtfläche von fünf Duram, also einen halben Hektar erstreckte. Rosen kletterten an den Hausmauern empor, immergrüne Büsche aus Süditalien, blühende Sukkulenten, wilde Blumen und Tulpen waren so angeordnet, dass der Betrachter das Gefühl hatte, eine natürliche Umgebung um sich zu haben. ${ }^{134}$ Mehrere Ruh- und Sitzplätze luden zum Verweilen ein und der Pool auf der großen Terrasse bot die Möglichkeit zur Erfrischung im heißen und staubigen Sommer Jerusalems.

Nicht nur der Entwurf, sondern auch die Erhaltung und Pflege des Gartens wurden minutiös geplant. Ein Gärtner, der sich nur um die zwei Gärten zu sorgen hatte, wurde fest eingestellt. Darüber hinaus ließ Schocken eine Kartei anlegen, in der sämtliche Pflanzen systematisch erfasst wurden. Schocken sah seinen Garten auch als eine Art Versuchslabor, in dem die Anpassungsfähigkeit mitteleuropäischer Pflanzen an die klimatischen Bedingungen der Levante beobachtet werden konnte.

131 Vgl. Briefentwurf Salman Schocken an Director of the Agricultural Department of the British Government, Jerusalem, 04.04.1937. SchA, Privates, 823, Box 25.

132 Vgl. Salman Schocken an Director of the Department of Agriculture \& Fisheries, Jerusalem, 03.02.1938. SchA, Privates, 823, Box 16.

133 Salman Schocken an N. V.H. Homan \& Co., Holland, 30.04.1939. SchA, Privates, 823, Box 32.

134 Vgl. die Beschreibung in: Rosenberg: Jerusalem's Private Gardens. 


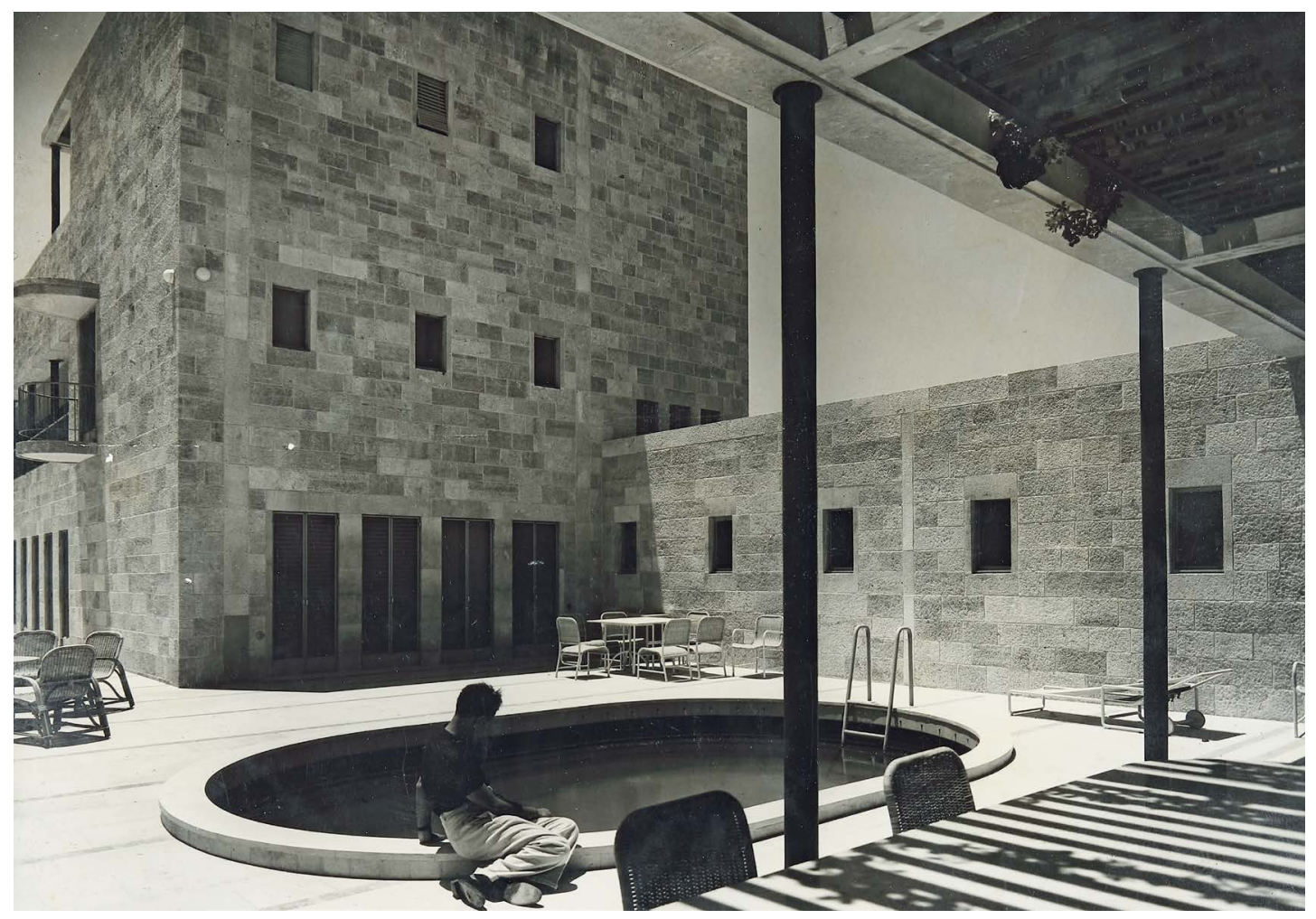

Abb. 11: Swimmingpool der Villa Schocken, 1937.

Es stellt sich jedoch die Frage, wie man den Gegensatz zwischen der Realität in Deutschland und den schon fast paradiesischen Plänen in Jerusalem bewerten soll: Aus heutiger Sicht mutet es angesichts der Entwicklungen in Deutschland - die Lage für die dort lebenden Juden und Jüdinnen verschlechterte sich ab November 1938 noch einmal drastisch - erstaunlich bis schockierend an, dass man sich in Jerusalem mit der farblichen Anordnung von Blumen, der Bestellung von Rosen, Tulpen und anderen Pflanzen auseinandersetzte. In der Tat sollte in Palästina eine neue Welt geschaffen werden, während der des deutschen Judentums der Untergang drohte. Der Aufbau einer jüdischen Heimstätte fern von Europa erfolgte zeitgleich mit der Vernichtung einer jahrhundertelangen Existenz in Europa. Während jedoch der Aufbau einer jüdischen Zivilgesellschaft, der technischen Erschließung des Landes, der Aufbau eines Gesundheits- und Bildungswesen für die jüdische Bevölkerung Palästinas als Dienst am Judentum verstanden und daher der Aufbau auch als Teil eines Rettungsversuches gedeutet werden kann, ist die Planung eines Gartens, der auf 


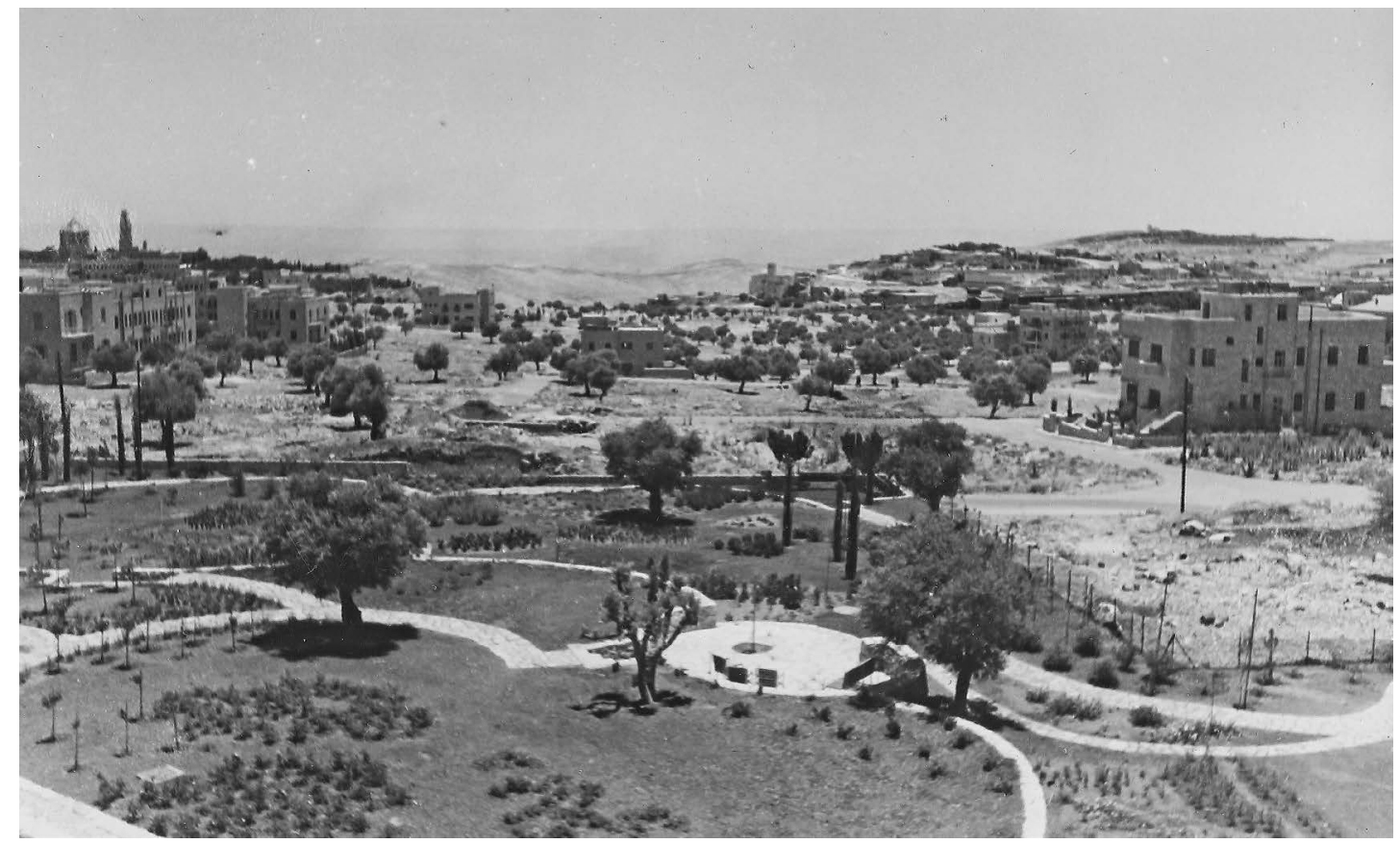

Abb. 12: Teilansicht des Gartens, 1937.

den ersten Blick nur das ästhetische Empfinden einer wohlhabenden Familie befriedigen sollte, schwieriger einzuordnen.

Anders als beim Einkauf von Baumaterial und Einrichtungsgegenständen ging es bei der Beschaffung der Pflanzen auch nicht um die Rettung von Vermögen. Und während der Gemüse- und Obstgarten der Bibliothek im Kontext der teilweise schwierigen Versorgungslage verstanden werden kann, hatte der Garten der Villa tatsächlich nur ästhetischen Wert. So müssen wir den Garten wohl als Versuch verstehen, den biographischen Bruch zu kitten, der ausgelöst wurde durch die erzwungene Migration. Obwohl die Schockens zu den reichsten Immigranten zählten, war auch für sie die Emigration ein schmerzhafter Prozess. Der kunstvoll geplante Garten in seiner ganzen Schönheit kann als Gegengewicht zur Unplanbarkeit einer Emigration gelesen werden und auch als Gegengewicht zu der unsicheren Lage in einem Land, das weder eine eigenstaatliche Sicherheit für die jüdische Bevölkerung noch eine mit Europa vergleichbare Infrastruktur bot. Schwimmbad und eine parkähnliche Anlage, die intensiver Bewässerung bedurfte, waren ein unerhörter Luxus in der Trockenheit Palästinas, aber sie waren auch Rückzugsort für eine durch die erzwungene Emigration verunsicherte Familie. Die Villa wie der Garten waren damit 
Orte der Sicherheit und Planbarkeit in der Unsicherheit und Unfertigkeit des palästinensischen Exils.

\subsection{Deutsche und hebräische Bücher vereint unter einem Dach - die Schocken-Bibliothek in Jerusalem}

Die Schocken-Bibliothek an der Balfour-Straße liegt nur gerade hundert Meter von der Privatvilla entfernt und ist ebenso modern wie das Wohnhaus. Auch sie ist größtenteils aus Baumaterialien gefertigt, die aus Deutschland importiert wurden. Sie beherbergte nach ihrer Fertigstellung im Dezember 1936 Hunderte von Manuskripten, eine einzigartige Sammlung von Inkunabeln ${ }^{135}$, also frühe Wiegedrucke, die vor 1500 mit beweglichen Lettern gedruckt wurden und in Format, Typographie und Illustration dem Erscheinungsbild mittelalterlichen Handschriften ähnlich waren. Zudem umfasste sie über 60.000 hebräische Bücher, viele davon Erstausgaben und seltene Sammelstücke und ca. 15.000 ebenso wertvolle wie seltene deutsche Bücher ${ }^{136}$, darunter die wohl wichtigste Goethe-Sammlung ihrer Zeit. Damit war die Privatbibliothek um einiges gröBer als die bekannte Bibliothek des Jüdisch-Theologischen Seminars in Breslau, deren Basis die Bibliothek des bibliophilen Leon Vita Saravan (1771-1851) war. Die Saravan-Bibliothek umfasste 30.000 Bücher, ca. 400 Manuskripte und 5 Inkunabeln. Sie wurde von der Gestapo konfisziert und in der Folge

135 Anlässlich der Eröffnung des neuen Gebäudes im Jahr 1931 übergab Schocken der National- und Universitätsbibliothek Jerusalem 64 Inkunabeln als Leihgabe, 1938 wandelte er sie in eine Schenkung um. Vgl. Schaeper: S'ridei Schocken, S. 628; Schocken: Salman Schocken, S. 242; Abraham Yaari: Schocken-Sammlung hebräischer Inkunablen der Jüdischen National- und Universitätsbibliothek. In: Mitteilungsblätter der Hebräischen Universität Jerusalem 4 (1938), S.39-41. Schocken sammelte weiter Inkunabeln, sodass er 1939 bereits wieder 30 Exemplare besaß, davon waren 6 auf Pergament gedruckt. Vgl. Lachmann: Die Bibliothek Salmann Schocken. Unveröffentlichtes Typoskript, 1934. SchA, Privates, 871/9.

136 Die Sammlung deutscher Bücher wurde nach dem Tod Salman Schockens auf mehreren Auktionen verkauft. Da eine Bibliographie der Bestände fehlt, muss auf die Auktionskataloge zurückgegriffen werden, um einen Überblick über die Sammlung zu erhalten. Dabei muss man davon ausgehen, dass die Kataloge die einstige Sammlung nicht vollständig abbilden, da einige Werke außerhalb dieser Auktionen verkauft wurden. Ernst Hausedewell / Ernst Nolte: Die Bibliotheken Salman Schocken und Karl Wolfskehl. Auktion Dr. Ernst Hausedewell \& Ernst Nolte, Antiquariat und Aktionshaus. 2 Teile. Hamburg: Hausedewell \& Nolte 1975-1976. 
auseinandergerissen. ${ }^{137}$ Sie war auch größer als die Bibliothek der jüdischen Gemeinde Berlins, die 1933 um die 60.000 Bände umfasste. ${ }^{138}$ Schockens Bibliothek wurde nicht zerstört, sondern gerettet, indem ihr Besitzer sie als Auswanderer als Privateigentum nach Palästina verschiffen ließ. Das folgende Teilkapitel beleuchtet die Sammlung, Rettung und Bedeutung dieser Bibliothek.

\subsubsection{Sammlungen}

Aus dem Wunsche des Juden, in seinem Hause je ein wohlerhaltenes Exemplar der Grundbücher der jüdischen Tradition und Literatur zu haben, entstand nach und nach eine Sammlung, die zweitweise ihren Schwerpunkt auf Erstausgaben, seltene Drucke, frühe Drucke und Inkunabeln legte.

Die Geschichte des jüdischen Volkes in seinen Büchern, aber auch an seinen Büchern zu verfolgen, war dann lange Zeit der Leitgedanke des Sammlers, besonders da, wo er eigene Wege gehen konnte. So verfolgte er die Wanderung vom Westen nach dem Osten, die Wanderung der Typen und Druckstöcke aus Spanien nach Nordafrika, Italien nach der Türkei; die Wanderung der Drucker aus Westdeutschland über Italien nach dem Orient; aus Mitteleuropa auf manchen Umwegen nach dem polnischen Osten.

Den Wunsch nach dem alten jüdischen Buche hatte ursprünglich Zunz geweckt. Mit Zunz hatten Dukes und Luzatto [sic] das Interesse für die hebräische Dichtung hervorgerufen. Dann war ich unter die Führung von Steinschneider getreten, hatte hebräische Bücher des Buches wegen gesammelt, restauriert, aus einzelnen Resten zusammengestellt, unbekannte Bücher aus den alten jüdischen Wohnländern herangeschafft. ${ }^{139}$

137 Vgl. Samuel Löwinger / Bernard D. Weinryb: Catalogue of the Hebrew Manuscripts in the Library of the Jüdisch-Theologisches Seminar in Breslau. Wiesbaden: Harrassowitz 1965. Das Jüdisch-Theologische Seminar wurde 1938 von den Nationalsozialisten geschlossen und eine große Zahl seiner Studenten nach Buchenwald deportiert. Die Gestapo konfiszierte die Sammlung und riss sie auseinander, Teile davon wurden in den 1980er Jahren in der tschechischen Nationalbibliothek gefunden und 2004 nach Breslau zurückgegeben. Vgl. Anna Holzer-Kawałko: The Dual Dynamics of Postwar Cultural Restoration: On the Salvage and Destruction of the Breslau Rabbinical Library. In: Weiss / Jessen / Kawałko / Gallas (Hrsg.): Contested German Jewish Cultural Property After 1945, S. 92-102; dies.: From Breslau to Wrocław: Transfer of the Saraval Collection to Poland and the Restitution of Jewish Cultural Property After WWII. In: Naharaim 9,1-2 (2015), S.48-72.

138 Vgl. Ein Gang durch die Bibliothek der Berliner Gemeinde. In: Berliner israelitisches Familienblatt, 19.10.1933, S.9.

139 Lachmann: Die Bibliothek Salmann Schocken. SchA, Privates, 871/9. 
So beschrieb Salman Schocken die Entwicklung seines Sammelinteresses. Mit dem Verweis auf Leopold Zunz (1794-1886), einem der Begründer der, Wissenschaft des Judentums', also jener Bewegung des frühen 19. Jahrhunderts, die das Judentum aus einer wissenschaftlichen Perspektive zu beleuchten trachtete, gibt er seiner Sammlung eine Funktion und Legitimation. Er macht damit deutlich, dass er seine Bibliothek nicht nur als Büchersammlung eines reichen Kaufmannes verstanden wissen wollte, der sich lediglich für das Sammeln und die Ästhetik des Buches interessierte. Die Bibliothek sollte vielmehr dazu dienen, das Judentum auf Grundlage seiner Quellen zu erforschen, und damit auch den Ansprüchen einer modernen Wissenschaft genügen. Dass dies nicht nur leere Worte waren, zeigt sich in Schockens Initiative, ein Forschungsinstitut für hebräische Dichtung des Mittelalters einzurichten. Für das Mittelalter, das verdeutlicht Peter Lehnhardt, war die Engführung von jüdischer Kultur auf die rabbinisch-talmudische Tradition nicht mehr haltbar. Das literarische Erbe dieser Epoche, das sich in Handschriften und frühen Drucken überliefert fand, war reichhaltig und ausdrucksstark. In Anbetracht dieser Kultur ließ sich wissenschaftlich eine neue, nicht talmudische und nicht halachische Definition von Judentum und jüdischer Tradition entwickeln. ${ }^{140}$ Das von Schocken 1930 gegründete Forschungsinstitut für hebräische Dichtung des Mittelalters geht auf diesen Anspruch zurück. Die Gründung des Schocken-Instituts erfolgte im Jahr 1930 in Berlin. Mit der Emigration Schockens zog auch das Institut nach Jerusalem. Zunächst arbeiteten die Wissenschaftler noch in Räumen einer Privatwohnung, bevor sie Ende 1936 Räumlichkeiten im Bibliotheksgebäude bezogen. ${ }^{141}$

In dem eingangs zitierten Ausschnitt verweist Schocken neben Zunz auch auf den Orientalisten und Bibliographen Moritz Steinschneider (1816-1907). Damit erschließt sich eine zweite Motivation hinter seiner Bibliothek: Die Sammlung von Büchern des Buches wegen. Steinschneider, der 1848 den Auftrag erhielt, einen Katalog der hebräischen Druckschriften der Bibliotheca Bodleiana in Oxford zu erstellen, galt als, Vater der hebräischen Bibliographie‘ und

140 Vgl. Lehnhardt: Das Forschungsinstitut für hebräische Dichtung und sein Beitrag zur Kenntnis der hebräischen Dichtung des Mittelalters, S.302-303.

141 Zur Geschichte des Forschungsinstitutes vgl. ebd. Zu den Publikationen bis Ende 1938 vgl. die Bibliographie des Schocken Verlages. In: Dahm: Das jüdische Buch im Dritten Reich, S. 476-501. 
katalogisierte nach seinem ersten Werk zahlreiche weitere hebräische Sammlungen in Europa. ${ }^{142}$ Steinschneiders bibliographische Arbeit verfolgte ähnlich wie Zunz' Literaturgeschichte ${ }^{143}$, die auf der Aufarbeitung von $500 \mathrm{Hand}$ schriften beruhte, das Ziel, die literarische Tradition des Judentums systematisch zu erschließen und damit der wissenschaftlichen Forschung zugänglich zu machen. Das Systematisieren, das bei Steinschneider noch stärker bestimmend ist als bei Zunz, lag auch Schockens Sammlung zugrunde. Schocken, den man ohne Zweifel als systematisch denkenden und handelnden Menschen begreifen kann, fand bei Steinschneider damit leicht Anknüpfungspunkte. Wenn seine Sammlung auch eindeutig das Bedürfnis des Kaufmannes nach schönen und wertvollen Gegenstände befriedigte, war sie weit mehr als die private Büchersammlung eines reichen deutschen Juden. Es würde zu weit führen, die Sammlung Schockens bis ins letzte Detail aufzulisten, jedoch sollen anhand einiger Angaben die Breite und die Systematik der Bibliothek dargestellt werden. ${ }^{144}$ Schocken sagte selbst über seine Bibliothek, dass sie eine „Sammlung wertvoller Bücher", aber auch „eine Sammlung schöner Bücher" sei. ${ }^{145}$

Schocken begann schon als Lehrling mit dem Aufbau einer kleinen Bibliothek, die zu dieser Zeit aus finanziellen Gründen aus günstigen Ausgaben (Reclam, Meyers Volksbücherei) bestand. Diese Bücher gingen bei einem Umzug verloren. Erhalten blieben jedoch einige Bücher, die aus dem Familienbesitz stammten,

142 Vgl. Günter Stemberger: Steinschneider Moritz. In: Österreichisches Biographisches Lexikon 1815-1950, Bd. 13. Wien: Österreichische Akademie der Wissenschaften 2007-2010, S. 198-199.

143 Vgl. Lehnhardt: Das Forschungsinstitut für hebräische Dichtung und sein Beitrag zur Kenntnis der hebräischen Dichtung des Mittelalters, S.316, Anm. 5.

144 Zur Schocken-Bibliothek gibt es bis heute keine abschließende Bibliographie. Einen guten Überblick über die wichtigsten Exemplare und die wertvollsten Bestände geben folgende Aufsätze und Auktionskataloge: Schaeper: Goldadern wertvollen jüdischen Lebens; dies.: The History of the Book Collection of Salman Schocken; dies.: Bibliophilie als kultureller Auftrag; dies.: S'ridei Schocken; Heinrich A. Mertens: Die Schocken-Bibliothek in Jerusalem. In: Börsenblatt für den deutschen Buchhandel 13,61 (1957), S. 1047-1049; Hausedewell / Nolte: Die Bibliotheken Salman Schocken und Karl Wolfskebl; Kestenbaum \& Co. (Hrsg.): Catalogue of Important Hebrew Printed Books From the Library of the Late Salman Schocken (1877-1959). To Be Offered for Sale by Auction on Tuesday, $2^{\text {nd }}$ June, 2003. New York: Kestenbaum 2003; Sotheby's: Important Hebrew Books From the Library of the Late Salman Schocken. Catalogue of Auction Held in London on Monday, $6^{\text {th }}$ December, 1993. London: Sotheby's 1993.

145 Lachmann: Die Bibliothek Salmann Schocken. SchA, Privates, 871/9 (Herv i. Orig.). 
sie waren Bestandteil der Jerusalemer Bibliothek. ${ }^{146}$ In den 1920er Jahren, als Schocken als Warenhausbesitzer bereits über die nötigen Mittel verfügte, sich wertvolle Drucke und Handschriften zu leisten, begann er seine Sammlung systematisch mit Ankäufen auf Auktionen und mit dem Erwerb von Privatbibliotheken aufzubauen. ${ }^{147} \mathrm{Zu}$ Beginn kaufte er vor allem hebräische Dichtung, bald aber schon hebräische Bücher aller Art in Erstausgaben, die vor dem Ende des 17. Jahrhunderts gedruckt wurden. Vor allem die Frühzeit des hebräischen Buchdrucks weckte sein Interesse. Zeitgleich begann er auch hebräische Handschriften auf dem Gebiet der Kabbala und der hebräischen Sakraldichtung zu sammeln. Mit hohen Vorauszahlungen sicherte er sich Vorkaufsrechte für Funde der Wiener Buchhändler David Fränkel und Lipa Schwager, zwei Chassidim, die in den zwanziger Jahren Italien, die Türkei, Syrien, den Jemen, Palästina und Tunesien bereisten, um wertvolle und seltene Handschriften und Drucke aufzustöbern. 1928 erwarb er eine Handschrift, die Tausende unbekannte hebräische Gedichte von mittelalterlichen jüdischen Poeten Spaniens enthielt, und die bis dahin unbekannt war. Der Fund der unter dem Namen „Schocken Manuskript 37“ bekannten Sammelhandschrift galt unter Kennern als Sensation.

Die wachsende Sammlung Schockens legte schließlich eine Spezialisierung nahe: Neben Frühdrucken und Inkunabeln gehörten hebräische Sakral- und Profandichtung, Gebetsbücher, Haggadot, hebräische Grammatiken und Wörterbücher, Kabbalistica, Mussar, frühe jiddische Literatur, Karaitica und hebräische Periodika zu den Sammelinteressen Schockens. ${ }^{148}$ Eine Spezialisierung, die also immer noch sehr breit angelegt war.

Schocken zählte beim Aufbau seiner hebräischen Sammlung auf die fachkundige Beratung zahlreicher Personen aus seinem Umfeld. Agnon war einer der ersten Berater Schockens beim Kauf von seltenen Büchern. Die SchockenAgnon-Korrespondenz zeigt, wie sehr sich Schocken auf seinen Autor und Freund Agnon verließ. Der erste Hinweis auf eine Vermittlertätigkeit Agnons findet sich bereits im April 1916. ${ }^{149}$ Im Gegenzug versorgte Schocken ihn in Form

146 Zur Geschichte der Schocken-Bibliothek. Älteste in der Bibliothek vorhandene Bücher aus meinem Besitz. Typoskript, 04.12.1949. SchA, Privates, 870.

147 Die folgende Darstellung stützt sich, wenn nicht anders angegeben, auf die Ausführungen von Schaeper: Bibliophilie als kultureller Auftrag.

148 Vgl. ebd., S.348.

149 Vgl. Salman Schocken an S. J. Agnon, 11.04.1916. NLI, Agnon Archiv, Arc. 41270. 
von Leseempfehlungen und Büchersendungen mit deutscher Literatur, sowie, vor allem während des Ersten Weltkrieges, auch mit Gegenständen des täglichen Bedarfes. ${ }^{150}$ Es war auch Agnon, der Schocken darauf aufmerksam machte, dass sein Schwager, der Bibliophile Moses Marx, seine Privatbibliothek zu verkaufen gedenke. ${ }^{151}$ Unklar ist, ob Agnon auch den Kontakt zwischen Marx und Schocken herstellte, oder ob sich die zwei Büchersammler bereits vorher in der Soncino-Gesellschaft der Freunde des jüdischen Buches kennengelernt hatten. ${ }^{152}$ Marx gehörte dem Vorstand der Soncino-Gesellschaft an, bei der Schocken ebenfalls Mitglied war. Einiges spricht dafür, dass sich die beiden Männer bereits vor 1924 persönlich kannten, der letztgenannte Brief von Agnon lässt jedoch das Gegenteil vermuten. Die Soncino-Gesellschaft wurde 1924 gegründet, es ist also möglich, dass diese Ereignisse ungefähr zeitgleich stattfanden. Als Buchhändler war Marx Schocken definitiv bereits vor 1924 bekannt. ${ }^{153}$ Außer Agnon beriet eine Anzahl an Fachleuten Schocken beim Ankauf seiner Bücher. Dazu zählten neben dem bereits erwähnten Moses Marx, der im Laufe der Zeit ein wichtiger Berater in Fragen hebräischer Bücher sowie hebräischer Typographie wurde, Menachem Zulay, dem späteren Assistenten Chaim Brodys im Forschungsinstitut für jüdische Dichtung, Aron Freimann, Isaia Sonne und Arthur Spanier. ${ }^{154}$ In den dreißiger Jahren berieten ihn zudem seine leitenden Verlagsmitarbeitenden Lambert Schneider und Moritz Spitzer, die vor Ort auch oft die Verhandlungen mit potenziellen Verkäufern führten. Schließlich muss auch die Arbeit von Abraham Meir Habermann erwähnt werden. Habermann, der als junger Chassid 1923 eine Anstellung als Lehrer der Schule der israelitischen Religionsgemeinde Zwickau fand, war von 1928 bis 1967 hauptberuflich als Bibliothekar für den Aufbau und die Betreuung der hebräischen

150 Vgl. u. a. Fischer, Sekretariat Schocken an S.J. Agnon, 03.10.1916; Salman Schocken an S.J. Agnon, 20.07.1916. NLI, Agnon Archiv, Arc. 41270.

151 Vgl. Salman Schocken an S.J. Agnon, 31.03.1924; S. J. Agnon an Salman Schocken, 08.05.1924. NLI, Agnon Archov, Arc. 41270.

152 Vgl. Silke Schaeper: Bibliophilie als kultureller Auftrag. In: Schreuder / Weber (Hrsg.): Der Schocken-Verlag/Berlin, S. 347-360, hier S. 348.

153 Vgl. Salman Schocken an Martin Buber, 23.10.1923. NLI, Buber Archiv, Ms. Var. $350 / 705$.

154 Namensliste nach Silke Schaeper: Bibliophilie als kultureller Auftrag. In: Schreuder / Weber (Hrsg.): Der Schocken-Verlag/Berlin, S.347-360, hier S. 348. 
Abteilung der Schocken-Bibliothek tätig. ${ }^{155}$ Um diese kümmerte er sich schon in Zwickau als Teilzeitkurator. ${ }^{156}$

Schockens Bibliothek war also das Resultat des Engagements einer Vielzahl von Experten, die dem Kaufmann beratend zur Seite standen. Ein Netzwerk von Wissenschaftlern, Bibliophilen und Händlern machte ihn auf interessante Drucke und Manuskripte aufmerksam. Sein Sekretariat in der Zwickauer Konzernzentrale erledigte die Korrespondenz mit Buchhändlern, Verlagen und Antiquaren. Nur die besten Buchbinder und -restauratoren wurden für die sachkundige Reinigung, Ausbesserung und Neubindung herangezogen. Als Käufer blieb er, wie Silke Schaeper ausführt, im Hintergrund. Auf Auktionen sowie teilweise auch bei Händlern ließ er sich von Kommissären vertreten; er verhinderte damit auch, dass sein Name die Preise übermäßig in die Höhe trieb. Und schließlich zog er professionelle Bibliothekare zu Rate, die ihn über Methoden der Bibliotheksverwaltung informierten. ${ }^{157}$ Schocken ließ professionelle Karteien und Zettelkataloge anlegen, um seine Sammlung systematisch zu erfassen. ${ }^{158}$ Schockens Bibliophilen-Netzwerk, wie es aus Mangel eines besseren Begriffes genannt werden soll, überschnitt sich also teilweise mit dem Netzwerk seines Verlages. Agnon, Marx, Schneider, Spitzer sowie Buber, der Schocken seltener als Agnon, aber dennoch regelmäßig auf seltene Bücher hinwies, und Gershom Scholem waren Teil seines Verlags- wie auch Bibliophilen-Netzwerkes. Das Buch war wiederum ein wichtiger Akteur in diesem zwischenmenschlichen Beziehungsnetz. Schocken als reicher Kaufmann konnte sich eine der exklusivsten Büchersammlungen leisten, die bis dahin teilweise unbekannte, teilweise weit verstreute hebräische Frühdrucke und Manuskripte systematisch vereinte. Diese Sammlung kam Wissenschaftlerinnen und Wissenschaftlern zugute, die mit den Beständen arbeiten konnten. Zwar stand der Zugang insbesondere zur Handschriftensammlung nur wenigen Auserwählten offen, ${ }^{159}$

155 Vgl. Diamant: Zur Chronik der Juden in Zwickau, S. 40. Vgl. auch die Korrespondenz Habermanns die Bibliothek betreffend, u. a. in SchA, Privates, 844/2, Bd. 5; 871/52; 871/53; $871 / 73$. Habermann war auch maßgeblich an der Verschickung und Rettung der SchockenBibliothek beteiligt. Vgl. Kap. 7.3.2.

156 Vgl. Poppel: Salman Schocken and the Schocken Verlag, S. 28.

157 Vgl. Schaeper: Goldadern wertvollen jüdischen Lebens, S. 126.

158 Diese Karteien werden sich bei der Rettungsaktion als unschätzbar wichtig erweisen.

159 Vgl. Schaeper: Goldadern wertvollen jüdischen Lebens S. 129; dies.: Bibliophilie als kultureller Auftrag, S. 350 . 
dennoch profitierte die Fachwelt von der Privatbibliothek. Nach der Verschiffung der Bibliothek nach Jerusalem stand sie Forschenden der Hebräischen Universität, insbesondere den Mitarbeitenden der beiden Schocken-Institute, dem Forschungsinstitut für hebräische Dichtung, geleitet von Chaim Brody, und dem Forschungsinstitut für jüdische Mystik unter Leitung von Gershom Scholem, zur Verfügung. Schocken wollte, wie er sagte, „keine tote Anhäufung von Büchern, die nur unter dem Gesichtspunkt der Sammlung zusammenbracht ist und erhalten wird. ${ }^{1160}$

Neben der hebräischen Sammlung, der der Wunsch nach einer systematischen Erschließung der frühen jüdischen Literatur zugrunde lag, bestand die Schocken-Bibliothek aus einer kleineren, aber nicht weniger exklusiven deutschen Sammlung. Die deutsche Bibliothek entsprach zu weiten Teilen dem Lesegeschmack seines Besitzers, wobei auch diese Sammlung in erster Linie wertvolle Erstausgaben, Autographen, Manuskripte und seltene Drucke umfasste. Die Sammlung an Goethe-Erstdrucken, die Jean-Paul-Sammlung und kostbare Hölderlin-Drucke waren wichtiger Teil der als reine Privatbibliothek konzipierten deutschen Sammlung. ${ }^{161}$ Aber auch Autographen von Novalis, Heine, Stifter und Fontane gehörten zu den Kostbarkeiten der Bibliothek. 1937 erwarb Schocken zudem die ungefähr 8.000 Bände umfassende Bibliothek aus dem Besitz Karl Wolfskehl, bestehend aus Büchern und Autographen. ${ }^{162}$ Der Schriftsteller und Übersetzer war einer der Mitbegründer der

160 Zweiter Entwurf für ein Exposé betreffend das Bibliotheksgebäude in Jerusalem-Talbieh, 02.06.1942. SchA, Privates, 871/9.

161 Zur deutschen Sammlung vgl. die Auktionskataloge: Hausedewell / Nolte: Die Bibliotheken Salman Schocken und Karl Wolfskehl.

162 Laut Eberhard Köstler umfasste die gesamte Bibliothek Wolfskehls 30.000 Bände. Inwiefern diese Angabe stimmig ist, kann an dieser Stelle nicht überprüft werden. Schocken erwarb jedoch rund 12.000 Bände. Vgl. Eberhard Köstler: Bücher Bücher Bücher Bücher. Aus der Blütezeit der Münchner Bibliophilie. In: Imprimatur. Ein Jabrbuch für Bücherfreunde XXII (2009), S. 259-286, hier S. 264. Seit 2017 rekonstruiert die Bibliothek des Literaturarchivs Marbach (DLA) in Kooperation mit dem Lehrstuhl für Jüdische Geschichte und Kultur der Ludwig-Maximilians-Universität München und dem Schocken Institute for Jewish Research in Jerusalem die Wolfskehl-Bibliothek. Der Buchbestand wird als „Virtuelle Bibliothek Kiechlinsbergen" in Kallias, dem OPAC des DLA, nachgewiesen und rund 12.000 Bände umfassen. Bücher aus Wolfskehls Besitz, deren Standorte heute bekannt sind, werden mit Provenienzen erschlossen. Vgl. Virtuelle Rekonstruktion der Bibliothek Wolfskehl in Kiechlinsbergen, 1937. In: Deutsches Literaturarchiv Marbach. https://www.dla-marbach. de/bibliothek/projekte/die-bibliotheken-von-karl-wolfskehl/virtuelle-rekonstruktion-derbibliothek-wolfskehl-in-kiechlinsbergen-1937/ (Zugriff am 17.02.2020). 
Gesellschaft der Münchner Bibliophilen, ${ }^{163}$ er selbst sammelte insbesondere Werke des Barock und der Romantik.

Mit dem Kauf der Bibliothek ermöglichte Schocken dem Schriftsteller die Emigration aus Deutschland. Wolfskehl, der 1933 in die Schweiz und von dort aus ein Jahr später nach Italien flüchtete, stand 1936 mit Schocken wegen eines neuen Publikationsprojektes in Kontakt. ${ }^{164}$ Das Projekt wurde zwar nicht umgesetzt, dafür kam es zu einem Gespräch über den Kauf der Wolfskehl-Sammlung. Wolfskehl stimmte dem im Oktober 1936 zu. Nach langen Verhandlungen kamen sie im Mai 1937 zu der Übereinkunft, dass Wolfskehl 20.000 RM sowie rückwirkend ab dem 1. Oktober 1936 eine monatliche Leibrente von 20 britischen Pfund erhalten solle. Die Formalitäten in Deutschland - die Bibliothek befand sich zum Zeitpunkt des Verkaufes in Wolfskehls ehemaligen Wohnort Kiechlinsbergen am Kaiserstuhl -, wurden von Siegfried Moses, Theodor Schocken und Elise Pelz abgewickelt. ${ }^{165}$ Der Verkauf verdeutlicht, wie verzweifelt Wolfskehl gewesen sein muss. Ohne den Erlös aus dem Verkauf und die lebenslängliche Leibrente hätte der Dichter sein Überleben im Exil nicht sichern können, zumal er 1938, nach dem Besuch Mussolinis in Deutschland, aus Italien nach Neuseeland flüchtete. ${ }^{166}$ Zwar wähnte Wolfskehl seine Bücher bei Schocken in „guten Händen “167, dennoch muss die Trennung von der Sammlung ein schmerzhafter Akt gewesen sein. Mit dem Verkauf seiner Sammlung sorgte der Dichter aber nicht nur für die eigene Rettung, sondern auch für die seiner Bücher. Wie die hebräische und deutsche Sammlung von Schocken wurden auch die Wolfskehl-Bestände nach Jerusalem verschifft. Dort gliederte man sie nicht in die Gesamtbibliothek ein, sondern stellte sie gesondert auf. $^{168}$

163 Vgl. Köstler: Bücher Bücher Bücher Bücher, S. 264, 278-282.

164 Vgl. Briefwechsel Karl Wolfskehl - Salman Schocken. SchA, Verlag, 332/148. Bereits 1934 war Wolfskehls Gedichtband Die Stimme spricht als siebzehnter Band der SchockenBibliothek erschienen, vgl. die Korrespondenz zwischen dem Verlag und dem Dichter in: SchA, Verlag, 332/148.

165 Vgl. Hinrichs: Fluchthilfe, S. 2-3.

166 Vgl. Köstler: Bücher Bücher Bücher Bücher, S. 264.

167 Hinrichs: Fluchthilfe, S.2.

168 Vgl. Notiz für Herrn Habermann, Fräulein Birnbaum und Frau Swet von Salman Schocken, 02.05.1938. SchA, Privates, 871/53. 
Auf den folgenden Seiten wird die Versendung der Schocken-Bibliothek von Deutschland nach Palästina - eine der größten Rettungsaktionen einer jüdischen Bibliothek in den 1930er Jahren - beleuchtet.

\subsubsection{Rettung}

Am ersten Dezember 1935 wurden im Hafen von Haifa 164 Holzkisten entladen. Die Frachtpapiere wiesen den Inhalt dieser Kisten als „alte und gebrauchte Bücher ${ }^{\text {"169 }}$ aus. Tatsächlich erreichte an diesem grauen und regnerischen $\mathrm{Tag}^{170}$ nach einmonatiger Reise die Schocken-Bibliothek Palästina. Die Bücher der Sendung waren einzeln in weiches Papier eingeschlagen und wurden in eigens dafür angefertigten Holzkisten, die zum Schutz gegen Wasser mit Ölpapier ausgekleidet waren, transportiert. Elise Pelz ${ }^{171}$, die unter anderem für den Transport verantwortlich war, wollte nicht das Risiko eingehen, dass die wertvolle Fracht auf dem langen Transportweg Schaden nehmen könnte. Zahlreiche Bücher waren bereits vor diesem Großtransport in einzelnen Sendungen von Berlin, Zwickau und anderen Orten nach Palästina verschickt worden. Die wertvollsten Stücke sowie Schockens Kunstsammlung lagerten in der Schweiz in Banksafes und wurden erst später verschifft. ${ }^{172}$ Die hebräischen und deutschen Bücher, die Wolfskehl-Bibliothek sowie die Kunstsammlung fanden jedoch in dem Mendelsohn-Bau an der Balfour-Straße 6 in Jerusalem ein neues Heim.

Mit dem Entschluss, seine Bibliothek nach Jerusalem zu transferieren, rettete Schocken die wertvolle Sammlung vor der Zerstreuung, wenn nicht sogar der Zerstörung in Deutschland. ${ }^{173}$ Ernst Fischer widmet sich in einem Artikel den Folgen, die die Emigration jüdischer Büchersammler aus Deutschland für die Sammlungen hatte. Er hält dabei fest, dass ein großer Teil der teilweise sehr

169 Exportvaluta-Erklärung, 12.10.1935. SchA, Privates, 871/52; vgl. Hans Romann an Ernst Cohn und Elise Pelz, 01.12.1935. SchA, Privates, 871/52.

170 Vgl. Express Service Haifa an Schocken Office, Jerusalem, 26.12.1935. SchA, Privates, $871 / 52$

171 Elise Pelz war Mitarbeiterin in der Schocken-Konzernzentrale in Zwickau.

172 Vgl. Bibliothek und Sammlung, Verwaltung, SchA, Privates, 871/72.

173 Die Rettungsaktion wurde erstmals von der Verfasserin aufgearbeitet und kann im Detail im folgenden Artikel nachgelesen werden: Mahrer: ,Much More than Just Another Private Collection: 
wertvollen Privatbibliotheken zerstört wurde. ${ }^{174}$ Zwar gab es zu keiner Zeit ein generelles Ausfuhrverbot für Bücher - Fischer führt dies auf die Kulturfeindlichkeit der Nationalsozialisten zurück -, dennoch überstanden nur wenige Sammlungen die nationalsozialistische Epoche. Die Gründe dafür sind zahlreich. Das größte Hindernis, die Bücher im Ausland in Sicherheit zu bringen, waren wohl die Kosten, die mit ihrem Transport verbunden waren. Diese zwangen die Sammler oftmals, ihre Bibliotheken nur in Teilen ins Exil mitzunehmen oder sie ganz aufzugeben. ${ }^{175}$ Viele waren wie Wolfskehl gezwungen, ihre Sammlungen zu verkaufen, um die Ausreise oder die Flucht zu finanzieren. Bis heute ist nicht aufgearbeitet worden, was mit jenen Beständen geschah, die in Antiquariate gelangten. Inzwischen etwas besser erforscht ist das Schicksal der Bücher, die den Nationalsozialisten in die Hände fielen. Es handelte sich dabei einerseits um mehrere Tausend Bücher, die zur persönlichen Bereicherung von NS-Funktionären geraubt wurden. Andererseits fielen, insbesondere nach November 1938, als die Ausreise für deutsche Jüdinnen und Juden durch räuberische Zwangsabgaben zunehmend erschwert wurde und die Verhaftungen zahlreicher wurden, vermehrt Büchersammlungen in die Hände der Behörden.

Die Gestapo ließ die Buchbestände meist versteigern; die Berliner GestapoLeitstelle wich jedoch von dieser Praxis ab und ließ alle angelieferten Bücher einstampfen. ${ }^{176}$ Auf diese Weise wurden unzählbare Bücher von unschätzbarem Wert einfach vernichtet. Andere Stellen sammelten Bücher systematisch, so z. B. das Frankfurter Institut zur Erforschung der Judenfrage. Das 1941 eröffnete Institut führte Hunderttausende Bücher mit dem Ziel zusammen, nach der sogenannten Endlösung Material zur Erforschung der vernichteten Rasse zur Verfügung zu haben. ${ }^{177}$ Das Institut, eine offizielle Einrichtung der NSDAP, raubte mithilfe des Einsatzstabes Reichsleiter Rosenberg ganz dezidiert Hebraika und Judaika. ${ }^{178}$ Dass der Raub von jüdischem Kulturgut geplant

174 Vgl. Ernst Fischer: Zerstörung einer Buchkultur. Die Emigration jüdischer Büchersammler aus Deutschland. In: Imprimatur. Ein Jahrbuch für Bücherfreunde XVII (2002), S. 176-195.

175 Ebd., S. 181.

176 Vgl. ebd., S. 183-184.

177 Vgl. ebd., S. 183.

178 Vgl. u. a. Dov Schidorsky: Das Schicksal jüdischer Bibliotheken im Dritten Reich. In: Peter Vodosek / Manfred Komorowsky (Hrsg.): Bibliotheken während des Nationalsozialismus. Wiesbaden: Harrassowitz 1992, S. 189-222. 
wie systematisch vonstattenging, hat auch Elisabeth Gallas in ihrer Dissertation nachgewiesen. ${ }^{179}$

Dov Schidorski schätzt, dass europaweit ungefähr vier Millionen Bände Judaika und Hebraika während der Kriegsjahre Schaden nahmen und dass davon die Hälfte komplett zerstört wurde. ${ }^{180}$ Da diese Schätzungen Privatbibliotheken, die in der Regel wenig erfasst sind, nicht einschließen, muss Markus Kilchhoff zufolge von wesentlich höheren Zahlen ausgegangen werden. ${ }^{181}$

Aber auch Privatbibliotheken, die ins Ausland gebracht wurden, blieben oft nicht vor Zerstörung bewahrt. Enge Platzverhältnisse im Exil, Mehrfachmigrationen und Veräußerung der Sammlung zur Sicherung des Lebensunterhaltes sind zentrale Gründe für die Auflösung zahlreicher Sammlungen. ${ }^{182}$ Es wurden dennoch einige Privatbibliotheken erfolgreich ins Ausland transferiert und dort weiter vergrößert. Dazu zählt unter anderen die Kulturwissenschaftliche Bibliothek Warburg. Sie wurde Ende 1933 von Hamburg nach London verschifft und dort zum Grundstock des Warburg Institute. ${ }^{183}$ Nicht zu vergessen sind natürlich auch zahlreiche Privatbibliotheken von Nicht-Sammlern, die mit dem übrigen Auswanderungsgepäck mit ins Exil genommen wurden. Diese oft einem bürgerlichen Bildungskanon verpflichteten Familienbibliotheken, die in ihrem Umfang stark variierten, hatten für die Emigranten weniger als Sammlung, sondern vielmehr als identitätsstiftende Objekte große Bedeutung. Sie waren Teil der Familiengeschichte und „bekräftigten“, so Caroline Jessen, „die Kontinuität der Biographie ihrer Besitzer über die Bruchstelle der Emigration hinweg “"184. Solche Privatbibliotheken fand man zuhauf in Quartieren wie Rechavia, wo

179 Vgl. Elisabeth Gallas: Das Leichenhaus der Bücher. Kulturrestitution und jüdisches Geschichtsdenken nach 1945. Göttingen: Vandenhoeck \& Ruprecht 2013, S.30-36.

180 Vgl. Schidorsky: Das Schicksal jüdischer Bibliotheken im Dritten Reich, S. 189-222. Schidorskys Schätzungen beruhen auf folgenden Ausführungen: The Commission on European Jewish Cultural Reconstruction: Tentative List of Jewish Cultural Treasures in Axis-Occupied Countries. In: Jewish Social Studies 8,1 Supplement (1946), S. 1-103.

181 Vgl. Markus Kirchhoff: Looted Texts. Restituting Jewish Libraries. In: Dan Diner / Gotthart Wunberg (Hrsg.): Restitution and Memory. Material Restoration in Europe. New York / Oxford: Berghahn 2007, S. 161-188, hier S. 165.

182 Vgl. Fischer: Zerstörung einer Buchkultur, S. 8-10.

183 Vgl. ebd., S. 10.

184 Caroline Jessen: Das problematische Bild der geretteten Kultur. In: Tel Aviver Jahrbuch für deutsche Geschichte 41 (2013): Deutsche(s) in Palästina und Israel. Alltag, Kultur, Politik, S. 179-194, hier S. 179. 
sich die deutschen Einwanderer niederließen. S. J. Agnon beschreibt die Liebe der deutschen Emigranten zu ihren Büchern sehr anschaulich in seinem posthum erschienenen Roman Schira.

Salman Schockens Sammlung gehörte jedoch nicht in diese Kategorie, sondern war, wie weiter oben deutlich wurde, eine der wohl bedeutendsten Privatbibliotheken seiner Zeit. Vom Umfang her nur etwas kleiner als die eben erwähnte Bibliothek Warburg, gehörte sie zu den wohl größten Privatsammlungen, die vor den Nationalsozialisten in Sicherheit gebracht wurden. Anders als die Sammlung des Kunsthistorikers Aby Warburg, der vier Jahre vor der Machtergreifung der Nationalsozialisten verstarb, enthielt Schockens Bibliothek zum größten Teil Judaika und Hebraika. Man kann im Anbetracht des Sammel- oder vielmehr Raubinteresses des Einsatzstabes Reichsleiter Alfred Rosenberg davon ausgehen, dass Schockens Bibliothek, wäre sie in die Hände der Nationalsozialisten gefallen, ein ähnliches Schicksal ged roht hätte wie vielen wertvollen Gemeinde- und Institutionsbibliotheken. Die Sammelsystematik wäre durch die persönliche Bereicherung und durch die Eingliederung in die Bibliothek des Instituts zur Erforschung der Judenfrage komplett zerstört worden.

Vor diesem Hintergrund wird deutlich, dass die Verschiffung der SchockenBibliothek als außergewöhnliche Rettung von jüdischem Kulturgut verstanden werden muss. Nach heutigem Wissensstand wurde zu keiner Zeit während des Nationalsozialismus eine vergleichbar große Menge an wertvollen und seltenen jüdischen Büchern und Manuskripten aus Deutschland ins Ausland geschafft. Ermöglicht wurde dies durch die professionelle Arbeit der Sekretariate und Bibliothekare Schockens, durch die Unterstützung des Verwaltungsund Rechtsapparates des Schocken-Konzerns und die finanziellen Mittel Schockens.

Vier Personen waren hauptsächlich für den Versand der Bibliothek zuständig: In Zwickau waren dies Schockens Privatsekretär Dr. Ernst Cohn sowie Elise Pelz, Mitarbeiterin im Zentralbüro des Konzerns, in Jerusalem war Abraham Meir Habermann, Schockens Bibliothekar, zuständig für die Abwicklung von Einfuhr- und Zollformalitäten, sowie die Einrichtung der Bibliothek im Gebäude. Die vierte Person war Salman Schocken selbst, der wie üblich über sämtliche Schritte informiert werden wollte und direkt in Entscheidungen eingriff. Daneben hatten Theodor Schocken, der bis 1938 in Deutschland lebte, 
sowie Siegfried Moses, der Schocken weiterhin als Rechtsberater zur Seite stand, ${ }^{185}$ einen - wenn auch kleineren - Anteil.

Das größte Problem für Cohn und Pelz war die Zerstreuung der Bücher - die Schocken-Bibliothek sollte in Jerusalem erstmals unter einem Dach vereint werden. Der größte Teil der Bücher befand sich in Schockens Berliner Villa in Zehlendorf, mehrere Kisten lagerten in Zwickau, andere in Marienbad, wohin Schocken jährlich zur Kur fuhr, und schließlich wurden einige besonders wertvolle Stücke in der Schweiz in Banksafes aufbewahrt. Die von Habermann noch in Deutschland angefertigte Kartei der Bibliotheksbestände, die von Pelz nach der Emigration Habermanns weitergeführt wurde, bewies sich in dieser Situation als unerlässlich. Durch sie verloren die Angestellten zu keiner Zeit den Überblick über die Bestände und deren jeweiligen Lagerungsgort.

Die Versendung von Büchern nach Jerusalem erfolgte ungefähr zu dem Zeitpunkt, als die Familie aus Deutschland abreiste. Am 26. Oktober 1933 wurden die ersten zwölf Kisten mit Büchern nach Jerusalem geschickt. ${ }^{186}$ Während der Inhalt dieser Kisten nicht bekannt ist, wissen wir genau, welche Bücher mit der zweiten Sendung, die auch einige Möbelstücke und Schreibmaschinen enthielt, Anfang November verschickt wurden. In dieser Sendung befand sich unter anderem das äußerst wertvolle Manuskript des Machsor Korfu. ${ }^{187}$ Während eines Jahres wurde eine große Anzahl von Kisten von Deutschland nach Palästina verschickt. Diese noch unkoordinierten Aktionen fanden im Oktober 1934 ein Ende, als Salman Schocken Regeln für zukünftige Sendungen erließ: Die Bücher sollten in den Frachtpapieren immer als „alt und gebraucht “188 ausgewiesen werden, um Einfuhrzölle in Palästina zu vermeiden; täglich sollte nicht mehr als eine Box versendet und die Frachtspesen sollten immer in Sperrmark beglichen werden.

Gleichzeitig wurden die ersten vorbereitenden Schritte für die Versendung der Gesamtbibliothek unternommen. Am 17. Oktober 1933 traf sich Ernst Cohn mit Ernst Hoffmann ${ }^{189}$, einem jungen Mann, der in Deutschland für die Bibliothek

185 Moses führte die Verhandlungen mit der Devisenstelle wegen der blockierten Konten, zudem verhandelte er mit den Versicherungen, um die wertvolle Fracht zu versichern.

186 Vgl. SchA, Privates, 871/52.

187 Vgl. Firma Caro und Jellinek an Chaim Brody, 02.11.1933. SchA, Privates, 871/52.

188 Elise Pelz an Ernst Cohn, 10. u. 15.10.1934. SchA, Privates, 871/52.

189 Bis anhin gibt es keinerlei biographische Arbeiten zum Leben Hoffmanns, sein Nachlass wird jedoch zurzeit im Leo Baeck Archiv in Jerusalem erschlossen. 
der Hebräischen Universität Bücher er- und Spenden einwarb und beides nach Jerusalem sandte. Schocken war zu dieser Zeit bereits zum administrativen Vorsitzenden der Universität gewählt worden und unter anderem mit dem Aufbau der Bibliothek betraut. ${ }^{190}$ Cohn wollte im Gespräch mit Hoffman, der im Verschicken von Büchern von Deutschland nach Palästina erfahren war, klären, welche Boxen für Büchertransporte am besten geeignet wären. Ebenso waren Preise für Versicherungen und Transport sowie Transportrouten Thema des Gesprächs. ${ }^{191}$

Während die Vorbereitungen für den großen Transport liefen, wurden fortwährend kleinere Sendungen verschickt. Es scheint fast, als sollten mit den Einzelsendungen Erfahrungen für den Großtransport gesammelt werden. Es taten sich dabei laufend neue Probleme auf: Während der Export aus Deutschland weiterhin kein Problem darstellte, verzögerten die sich oft ändernden Einfuhrbestimmungen in Palästina die Auslösung der Pakete im Hafen. Für Schocken hatte das zur Folge, für die Lagerung am Hafen bezahlen zu müssen. ${ }^{192}$ Der Import von Waren, die schon vor der Ausreise dem Empfänger gehörten, waren bis Mai 1935 unter der Bedingung von Einfuhrzöllen befreit, dass anstelle einer Rechnung detaillierte Listen mit dem Inhalt der Sendung in zweifacher Ausführung per Luftpost an das Zollamt verschickt wurden. ${ }^{193}$ Wiederum zeigte sich die detaillierte Kartei Habermanns für die Rettung der Bibliothek von größter Bedeutung. Ab Mai 1935 verlangte die britische Verwaltungsmacht jedoch ein detailliertes Rechnungsformular, das nicht nur den Inhalt auflistete, sondern zusätzlich von der deutschen Handelskammer abgestempelt worden war. ${ }^{194}$ Dass die Transporte ungestört weitergingen, lässt darauf schließen, dass die deutschen Behörden diese Formulare ohne große Einwände mit den nötigen Beglaubigungen versahen.

In der Zwischenzeit verpackten Mitarbeiter von Transportfirmen unter genauer Kontrolle von Elise Pelz die Bestände. ${ }^{195}$ Ende August waren sämtliche Bücher

190 Vgl. die Korrespondenz in SchA, Universität, 061/1.

191 Vgl. Gesprächsprotokoll, 17.10.1934. SchA, Privates, 871/52.

192 Vgl. Romann an Cohn, 09. u. 30.05.1935. SchA, Privates, 871/52.

193 Vgl. Richtlinien für den Versand nach Palästina, 09.05.1935. SchA, Privates, 871/52.

194 Vgl. Sekretariat Schocken, Jerusalem an Ernst Cohn, 30.05.1935. SchA, Privates, 871/52. 195 Vgl. Siegfried Moses an den Präsidenten des Landesfinanzamtes, Leipzig, 08.12.1934; Bericht, 03.04.1935: Bestellung Kisten, 17.08.1935. SchA, Privates, 871/52. 
und Manuskripte verpackt, sodass im September Angebote von Transportfirmen und Versicherungsgesellschaften eingeholt werden konnten. Schocken war an einer schnellen Abwicklung der Ausfuhr interessiert, da er fürchtete, dass ein Krieg - er meinte wohl den Krieg zwischen Italien und seiner Kolonie im heutigen Äthiopien -, Versicherungssummen verteuern und möglicherweise den Seeweg ab Italien versperren würde. ${ }^{196}$ Tatsächlich bewahrheiteten sich Schockens Befürchtungen und mit Beginn des Abessinienkrieges am 3. Oktober 1935 konnten die Bücher nicht über die kürzere und daher günstigere Route von Triest nach Haifa verschifft, sondern mussten von Hamburg aus versendet werden. ${ }^{197}$ So wurden die 164 Seekisten mit der Schocken-Bibliothek auf den Dampfer Isenloh verfrachtet und nach Haifa verschifft. Weder der Export noch der Import verursachten Probleme, nur der starke Regen in Haifa verunmöglichte den sofortigen Weitertransport nach Jerusalem. Aus Angst, die wertvollen Bücher würden auf dem letzten Stück ihrer Reise Schaden nehmen, wurden sie vorsichtshalber im Hafen eingelagert und später auf Lastwagen nach Jerusalem transportiert. ${ }^{198}$

Im folgenden Jahr wurden schließlich die Bücher und Manuskripte, die zusammen mit Gemälden von Picasso, Monet, Chagall und Renoir in Schweizer Banksafes lagerten, von der Schweiz aus versendet. ${ }^{199}$ Eine weitere Ladung Bücher, hauptsächlich die von Lili Schocken und der Kinder, wurde zusammen mit den Möbeln aus Zehlendorf verschickt. ${ }^{200}$ Die letzten Kisten erreichten Jerusalem im Juni $1939 .{ }^{201}$ Die letzten Sendungen enthielten größtenteils Neuerwerbungen, darunter die Wolfskehl-Bibliothek, die Schocken kurz zuvor erworben hatte. Die Emigration führte bei Schocken nicht dazu, dass er seine Sammlertätigkeit aufgab. Vielmehr suchte er weiterhin in Deutschland und

196 Vgl. Salman Schocken an Ernst Cohn, 21.09.1935. SchA, Privates, 871/52.

197 Vgl. Telefonprotokoll, Gespräch zwischen Schwabe und Ernst Cohn, 10.10.1935. SchA, Privates, $871 / 52$.

198 Vgl. „Invoice“, Express Service an Salman Schocken, 16.12.1935. SchA, Privates, 871/52. 199 Vgl. Bibliothek und Verwaltung, SchA, 871/72. Einige wenige Manuskripte und Bücher wurden in der Schweiz belassen und erst nach dem Krieg exportiert. Vgl. Notiz an Salman Schocken, 29.12.1940. SchA, Privates, 871/79.

200 Vgl. Diverse Briefe und Listen, September und Oktober 1936. SchA, Privates, 871/52; Abteilung Export, Zwickau an Willy Heinze, 22.10.1936. Sch A, Privates, 823.

201 Vgl. Liste Büchertransport, 08.10.1936. SchA, Privates, 871/52. 
anderen europäischen Ländern, vor allem aber in Palästina nach Büchern und Manuskripten und erwarb jene, die ihn interessierten. ${ }^{202}$

Der Transport der Schocken-Bibliothek nach Palästina galt nach dem Ende des Krieges, nachdem das Ausmaß der Zerstörung jüdischen Lebens in Europa deutlich wurde, als einmalige Rettungsaktion jüdischen Kulturgutes. Wenn man sich mit den Akten zum Transport beschäftigt - wie es auf den vorhergehenden Seiten geschehen ist -, zeigt sich, dass diese eher als planvolle und gut organisierte Aktion verstanden werden muss, denn als „klandestine Rettungsaktion “203, wie es auf der Webseite der Schocken-Bibliothek heißt. Perfekt durchgeführt von Schockens Mitarbeitern und Mitarbeiterinnen in Berlin, Zwickau und Jerusalem ist der Buchtransport ein weiterer Beweis für die Effizienz seines Verwaltungssystemes. Wie beim Bau der Villa und der Bibliothek konnte Schocken auch bei der Verschiffung seiner wertvollen Bibliothek auf seine loyalen Mitarbeitenden und die Verwaltungseinheiten seines Konzernes zählen.

Nachdem die Kisten zunächst in den Räumlichkeiten des Schocken-Sekretariates in Jerusalem bis zur Fertigstellung des Bibliotheksgebäudes zwischengelagert worden waren, fanden die Bücher Ende 1936 ihren vorgesehenen Standort in den ebenfalls aus Deutschland importierten Regalen der neuen Bibliothek. Damit wurden erstmals die zerstreuten Bestände der Sammlung unter einem Dach vereint. Die Bibliothek, die am 26. Dezember 1936 mit einem Abend zum Gedenken an den 1929 verstorbenen Franz Rosenzweig eröffnet wurde, war jedoch weit mehr als eine Büchersammlung: Sie wurde zu einem kulturellen Zentrum Jerusalems.

\subsubsection{Funktion und Bedeutung der Bibliothek für Besitzer und Besucher - Abschlussbetrachtung}

Die Schocken-Bibliothek nahm mehrere, teils sehr unterschiedliche Funktionen ein, die hier, das Kapitel abschließend, dargelegt und diskutiert werden sollen. Dafür müssen wir uns jedoch zuerst überlegen, was wir unter einer Bibliothek verstehen.

Als erste Definition soll aufgrund ihrer Klarheit die von Achim Hölter dienen, der schreibt:

202 Vgl. u. a. eine Buchbestellung in Zürich: Quittung, 18.05.1938. SchA, Privates, 871/52. 203 About the Library. In: The JTS-Schocken Institute for Jewish Research, o. D. https://www. schocken-jts.org.il/english/library/ (Zugriff am 26.02.2018). 
Eine Bibliothek ist eine Sammlung von Büchern (worunter hier alle sammelwürdigen Informationsträger verstanden werden), deren Existenz sich in Raum und Zeit erstreckt, besessen, verwaltet, bewahrt wird von bestimmten Personen, und deren Geschichte sich, sofern es sich im eine öffentliche Sammlung handelt, in der Regel einsinnig abspielt, d.h. einen Anfang, aber kein Ende zu haben scheint. Die Existenz einer Bibliothek hängt prinzipiell nur von den sie konstituierenden Büchern ab, praktisch ist sie gebunden an Räumlichkeiten, die in Gebäuden in bestimmten Städten beheimatet sind mit der Folge einer meist eindeutigen Besetzung. Eine Bibliothek ist also ein Bücher-Raum mit Geschichte, Atmosphäre, Charakter, geprägt von Architekten, Kustoden, Benutzern. Eine Bibliothek besteht aus derlei individuellen Elementen, zu denen nicht zuletzt die spezielle Zusammensetzung der Sammlung zählt, und aus Standardkomponenten, die zu praktisch jeder Bibliothek gehören, ohne dieser an sich ein Gesicht zu verleihen: Katalog, Magazin, Informationsstelle u.v. m., also aus dem, was die Bibliotheksgeschichte und dem, was die ,bibliothéconomie' beschreibt. ${ }^{204}$

Für Hölter hat eine Bibliothek in erster Linie eine bewahrende Funktion; sie ist ein Ort der unendlichen Sammelmöglichkeit. Kirsten Dickhaut verweist in der Einleitung ihrer kulturgeschichtlichen Studie zu Bibliotheken in der französischen Literatur jedoch darauf, dass der Topos der Bibliothek als Ort des Bewahrens nicht auf einem natürlichen Charakteristikum beruhe. Vielmehr sei er aus einem historischen Entwicklungsprozess hervorgegangen und wurde als „konstruierter Idealzustand “205 zur Norm erhoben. Auch wenn die Kritik Dickhauts für eine vertiefte Auseinandersetzung mit dem multikonzeptuellen Ort der Bibliothek ihre Berechtigung hat, bietet für die vorliegende Studie die Definition Hölschers eine gute Arbeitsgrundlage. Zwar stellt Hölscher die Funktion der Bibliothek als Sammelspeicher in den Vordergrund, verweist jedoch ebenfalls auf die Relevanz der Räumlichkeiten, des geographischen Standortes sowie der Leser und Benutzer der Sammlungen. Damit ist die Bibliothek mehr als ein verwalteter Bücherspeicher: Sie wird zu einem Raum mit eigener Geschichte und Atmosphäre, und mit spezifischem Charakter.

204 Achim Hölter: Kritische Marginalie. Zum Motiv der Bibliothek in der Literatur. In: Arcadia. Zeitschrift für Vergleichende Literaturwissenschaft 28,1 (1993), S.65-72, hier S. 67. 205 Kirsten Dieckhaut: Verkehrte Bücherwelten. Eine kulturgeschichtliche Studie über deformierte Bibliotheken in der französischen Literatur. München: Fink 2004, S. 42. 
Die Bibliothek wird in der kulturwissenschaftlichen Literatur darüber hinaus oft als Gedächtnisspeicher, als "geordnete Form “206 des kulturellen Gedächtnisses verstanden. Dieses Verständnis der Bibliothek, bei dem die Speicherfunktion und zudem der Inhalt betont und die räumliche Dimension außer Acht gelassen wird, ist für die vorliegende Untersuchung relevant, greift jedoch für ein tieferes Verstehen der Funktion der Schocken-Bibliothek zu kurz. Eine Bibliothek, so soll deutlich werden, ist mehr als die Materialisierung des kulturellen Gedächtnisses an einem spezifischen Ort, sie ist mehr als bloße Sammlung. Sie ist Gedächtnisort, ${ }^{207}$ sie ist Bewahrungsort materiell und immateriell wertvoller Bücher und sie ist - angelehnt an Jean-Paul Sartre - ein Ort, an dem der Makrokosmos im Mikrokosmos gespiegelt wird. ${ }^{208}$ Ähnlich argumentiert der französische Literaturwissenschaftler Émilien Carrassus, wenn er die Bibliothek als weltumfassenden Ort beschreibt:

La bibliothèque prétend, en effet, à enfermer le monde dans ses rayonnages. Elle constitue un univers isolé, coupé du monde extérieur, mais en même temps, en ce lieu clos et apparemment paisible, ce monde extérieur se vient refléter, un monde extérieur, un monde extérieur spiritualisé, aseptisé, purifié, semble-t-il, des souillures temporelles, mais cependant vivace. ${ }^{209}$

In den folgenden abschließenden Betrachtungen zur Schocken-Bibliothek soll der Frage nachgegangen werden, welche Funktionen der Bibliothek für den Besitzer und für die anderen deutschen Exilanten in Jerusalem zukamen. Dabei wird deutlich werden, dass sie mehr war als ein Speicherort für Bücher und mehr als eine Materialisierung des kulturellen Gedächtnisses des deutschen Judentums. Anknüpfend an Raumtheorien wird die Bibliothek als spezifischer Kultur- und Identitätsraum verstanden, der unterschiedliche Funktionen übernehmen kann.

206 Dieckhaut: Verkehrte Bücherwelten, S. 14.

207 Vgl. Pierre Nora: Entre Mémoire et Histoire. In: Ders.: Les Lieux de Mémoire, Bd. 1: La République. Paris: Gallimard 1984, S. XVII-XLII.

208 Vgl. Jean-Paul Sartre: Les mots. Paris: Gallimard 1964, S. 37.

209 Émilien Carassus: Bibliothèque-Fiction. In: Littératures. Études de littérature moderne. Annales publiées par la Faculté des lettres de Toulouse 11 (1984), S.97-105, hier S. 99. 
The Schocken library located in the City of Jerusalem plays an important part in the great movement of the Jewish renaissance and symbolizes by its being transferred from the Golah to Palestine the idea of "The children shall come home to their own border". ${ }^{210}$

Mit diesem Zitat aus Jeremia 31,17 schließt ein nicht publizierter Artikel über die Schocken-Bibliothek. Es fehlen Angaben zum Verfasser und zur Entstehungszeit, die jedoch aus dem Archivkontext auf 1937 geschätzt werden kann. Schocken nahm in der Regel persönlich Einfluss auf solche Artikel, sodass man auch in diesem Fall davon ausgehen kann, dass er dem Verfasser Stichworte und Hinweise zur Verfügung stellte.

Im Kontext der Schocken-Bibliothek nimmt der Vers, in dem jüdische Bücher als in der Diaspora zerstreute ,Kinder Israels' bezeichnet werden, eine doppelte Bedeutung an. Es sind einerseits Worte des Trostes in dem Sinne, dass die Bücher aus dem Feindesland, vor dem Hitler-Regime gerettet wurden, andererseits nimmt der biblische Vers eine zionistische Bedeutung an: Die jüdischen Bücher, die Repräsentation der jüdischen Vergangenheit und Zukunft, ,kehren heim' ins verheißene Land.

Die Bücher, die in der Galut geschrieben wie gedruckt, und in Deutschland als Sammlung zusammengefügt wurden, stehen für die vorstaatliche jüdische Existenz. Sie wurden von einem Ort zum anderen geschickt, reisten mit ihren Besitzern und wurden über Grenzen hinweg verkauft. Die Bücher repräsentieren die geographisch und historisch bedingt heterogenen jüdischen Kulturen und spiegeln die jüdische Existenz als Minorität wider.

Schocken stellt nun den Transport der Bibliothek von Deutschland ins britische Mandatsgebiet Palästina, nach Eretz Israel, als Heimkehr innerhalb des zionistischen Narrativ dar. Eretz Israel, das Land Israel, ist nicht länger ein abstrakter Sehnsuchtsort. Es wird zu einem weltlichen Ort, an dem die Wanderung der Juden nach ihrer Vertreibung aus Jerusalem, nach der Zerstörung des Zweiten Tempels durch die römischen Truppen im Jahr 70 u. Z. ein Ende finden soll. Jerusalem soll dabei zum kulturellen und politischen Zentrum des Judentums werden. Gemäß dem säkularen zionistischen Narrativ versteht Schocken das ,neue Jerusalem' als kulturellen Mittelpunkt, aus dem die jüdische Renaissance hervorgehen soll. Daher baut er auch in Jerusalem und nicht in der

210 The Schocken Library Jerusalem, unveröff. Typoskript, o. D. SchA, Privates, 871/9. 
modernen jüdischen Stadt Tel Aviv einen säkularen Tempel für seine Bücher. Bücher, so wurde bereits weiter oben deutlich, waren für Schocken die Quelle der jüdischen Wiedergeburt, eine Zukunft konnte nur durch das Studium dieser Quellen entstehen. Die Einrichtung der Schocken-Bibliothek in Jerusalem war daher für ihn in zionistischer Lesart ein Heimkommen der jüdischen Kultur. Das Gebäude und die Sammlung wurden zu einem distinkten jüdischen Ort in der Stadt Jerusalem.

Die Bibliothek war gleichzeitig ein deutscher Ort, und dies nicht nur in einem materiellen Sinn. Das Fundament, auf dem sie stand, war sowohl im eigentlichen wie auch im übertragenen Sinne deutsch. Der Zement, das Eisen, die Regale, die Schrauben, Lichtschalter und Türklinken waren deutsche Produkte; aber ebenfalls die Sammlungen waren deutsch, sie wurden in Deutschland aufgebaut, katalogisiert und erweitert. Auch als Institution muss man die Bibliothek bis zur Ausreise ihres Besitzers als dezidiert deutschen Ort bezeichnen. Leseabende und Vorträge fanden in deutscher Sprache statt und man hielt sich an die kulturellen und sozialen Normen der deutsch-jüdischen Bourgeoisie. Sogar der Wein, der im Anschluss an die Vorträge ausgeschenkt wurde, stammte aus Deutschland. ${ }^{211}$

Der Lese- wie auch der Büchersaal wurden zu einem Heim für die fünfte Alija. Damit wurde der zionistische mit dem deutschen Raum kontrastiert. Dies ist im Kontext der 1930er Jahre zu verstehen, in denen der Rückverweis auf die deutsche Kultur und Sprache Hand in Hand mit dem Aufbau eines zionistischjüdischen Gemeinwesens ging. Die Schaffung eines deutschen Raumes, der gleichzeitig zionistisch verstanden wurde, ist nicht widersprüchlich, da beide Selbstverständnisse für den Besitzer wie auch für Benutzer und Gäste kulturund identitätsstiftend waren.

Nach 1945, als die Verbrechen der Nationalsozialisten am jüdischen Volk in aller Grausamkeit bekannt wurden, erhielt die Schocken-Bibliothek eine dritte Funktion: Sie wurde zu einem Erinnerungsort.

[Les lieux de mémoire sont] simples et ambigus, naturels et artificiels, immédiatement offerts à l'expérience la plus sensible et, en même temps, relevant de l'élaboration la

211 Vgl. Kosten eines Empfanges von 50 Personen, Aufstellung von Dr. Hans Romann, 06.03.1938. SchA, Privates, 842/23. 
plus abstraite. Ils sont lieux, en effet, dans les trois sens du mot, matériel, symbolique et fonctionnel, mais simultanément, à de degrés seulement divers. ${ }^{212}$

Die Schocken-Bibliothek bestand aus Büchern, die für die lange und vielfältige Geschichte und Kultur der Juden Europas stand - eine Geschichte, die die Nationalsozialisten auszulöschen versuchten. Indem Schocken seine Bücher nach Palästina verschiffte, rettete er sie vor der Zerstörung. Nur aus einer Post-Holocaust-Perspektive wird deutlich, wie weitreichend diese Entscheidung war. In einem materiellen Sinn stehen die Bücher also für eine Kultur, die durch die Zerstörung ihrer Artefakte und durch den Massenmord an den europäischen Jüdinnen und Juden fast ausgelöscht wurde. Nur durch rechtzeitige Emigration und Flucht und durch die Rettung von Kulturgut konnten Spuren davon überdauern. Auf einer symbolischen Ebene repräsentieren die Bücher, die Schocken mitnahm, die Kultur, die Existenz eines europäischen Judentums, die jüdische Wissenschaft über die Jahrhunderte hinweg und eine oftmals schwierige Koexistenz zwischen jüdischer Minderheit und christlicher Mehrheit vor der Schoa.

Heute, mehr als sechzig Jahre nach dem Holocaust und nach der Gründung des Staates Israel, dient die Bibliothek, oder das, was von ihr übriggeblieben ist, als Erinnerungsort für die Kultur und Geschichte der Einwanderer der fünften Alija, für Formen und Strategien des Ankommens von vor allem deutschjüdischen Exilanten in Jerusalem vor der Staatsgründung.

Die deutsch-jüdischen Büchersammlungen, die im Gepäck der meist unfreiwilligen Einwanderer ins Mandatsgebiet Palästina mitgebracht wurden, standen für deren verlorene Heimat. Sie schufen aus der Perspektive der Eigentümer eine Kontinuität über die Brüche der Migration hinweg. Heute ist diese Kultur fast gänzlich verschwunden; sie lebt nur noch in den Erzählungen ihrer letzten Träger fort. Fast alle Buchsammlungen sind aufgelöst und stehen in Antiquariaten zum Verkauf. Auch die Schocken-Bibliothek wurde von dieser Entwicklung nicht verschont. Während der hebräische Bestand bis heute - zwar nicht komplett, jedoch in großen Teilen - erhalten ist, wurde der deutsche Teil nach dem Tod Schockens von der Familie in mehreren Auktionen zum Verkauf

212 Nora: Entre Mémoire et Histoire, S. XXXIV. 
angeboten. ${ }^{213}$ Die deutschen Bücher hatten im jungen Staat Israel ihre Bedeutung verloren.

Die Schocken-Bibliothek kann nur in ihrer Gesamtheit verstanden werden: Indem Architektur, Baugeschichte, Sammlung, Besitzer und Leser als Gesamtbild gesehen werden, wird deutlich, was dieser Ort für die Zeitgenossen bedeutet haben muss, welche Erwartungen und Erinnerungen sich mit ihm verknüpften. In ihrem äußeren Erscheinungsbild fügte sich die Bibliothek in die karge und trockene Landschaft Palästinas ein und war gleichzeitig integraler Teil der Gartenstadt Rechavia. Ihr Architekt verstand es, die unterschiedlichen Bautraditionen miteinander zu verbinden und gleichzeitig ein Haus zu bauen, das seinem Zweck entsprach: Die Unterbringung einer der bedeutendsten privaten Bibliotheken ihrer Zeit. Die Wahl der Baumaterialien ermöglichte es dem Bauherrn nicht nur dafür zu sorgen, dass das Gebäude seinen hohen Anforderungen an Qualität entsprach, sondern auch, Teile seines in Deutschland blockierten Vermögens zu liquidieren und damit zu retten.

Die hebräische und die deutsche Sammlung standen für zwei Kulturen, die eng miteinander verbunden waren und durch die Machtergreifung der Nationalsozialisten auseinandergerissen wurden. In Jerusalem, unter einem Dach zusammengefasst, symbolisierten sie die zwei Funktionen der Bibliothek: Sie war gleichermaßen ein Ort des Heimkommens wie ein Ort des Exils. Damit steht sie für die Heimkehr des jüdischen Volkes im zionistischen Sinne sowie für die Vertreibung der deutschen Juden aus Europa und wird damit einerseits zu einem dynamischen Ort der Forschung und gleichzeitig zu einem Erinnerungsort für eine verlorene und zerstörte Kultur Europas.

213 Hausedewell / Nolte: Die Bibliotheken Salman Schocken und Karl Wolfskehl; Christie, Manson \& Woods International Inc. (Hrsg.): Important Hebrew Manuscripts From the Salman Schocken Collection. New York: Christie's 2005; Sotheby's: Important Hebrew Books From the Library of the Late Salman Schocken; Kestenbaum \& Co.: Catalogue of Important Hebrew Printed Books From the Library of the Late Salman Schocken (1877-1959). Mitte der 1950er Jahre unternahm Edgar Salin, Professor für Volskwirtschaft an der Universität Basel und Freund Wolfskehls den Versuch, die Bibliothek des Dichters nach München oder Stuttgart zu vermitteln. Zunächst zeigte sich Schocken interessiert an dem Angebot, dachte er doch, die Bibliothek sollte in die Schweiz verkauft werden. Als es ihm deutlich wurde, dass der Verkauf nach Deutschland ginge, sah er nach einigem Zögern von den Plänen ab. Vgl. Edgar Salin an Salman Schocken 11.11.1947-12.03.1956. UB Basel, NL 144 (Nachlass Edgar Salin), Fb 2512-2517; Salman Schocken an Edgar Salin 10.12.1947-25.05.1956. UB Basel, NL 144, Fa 8524-8538a; Jessen: Der Sammler Karl Wolfskehl, S. 285-287. 


\subsection{Vortragsreihen und Kaffee und Kuchen - das bürgerliche Leben in den zwei Häusern}

Beide Gebäude, die Bibliothek und die Villa, standen Besuchern und Gästen offen. Während in der Bibliothek größere Veranstaltungen, wie Leseabende, Vortragsreihen und selten sogar Konzerte stattfanden, war die Villa Austragungsort kleinerer und auf den ersten Blick privater Zusammenkünfte. Regelmäßig luden Salman und Lili Schocken bei sich zuhause zu Kaffee und Kuchen, der traditionellen deutschen Mahlzeit zwischen Mittag- und Abendessen ein und etwas weniger regelmäßig zum Abendessen. Während die Veranstaltungen in der Bibliothek ganz eindeutig öffentlichen Charakter hatten, auch wenn die Gästelisten begrenzt waren, fällt es schwer, die Einladungen in die Villa zu klassifizieren. Auf den ersten Blick scheinen sie privater Natur gewesen zu sein, eine genauere Auseinandersetzung verdeutlicht jedoch, dass es sich auch bei diesen scheinbar privaten Essenseinladungen um semi-offizielle Veranstaltungen handelte.

Das vorliegende Kapitel, das letzte des siebten Kapitels, wird die Veranstaltungen in der Bibliothek und in der Villa beleuchten. Das Leben in den zwei Gebäuden war ebenso deutsch wie bürgerlich geprägt. Welche Funktion kam den Veranstaltungen zu: Sollten sie eine Kontinuität über den Bruch der gezwungenen Emigration schaffen, im Sinne eines linearen Weiterbestehens der zurückgelassenen Kultur im Exil? Oder waren es Orte der Neuinterpretation und der Weiterentwicklung des Bekannten? Schließlich muss mit Blick auf die Biographie Schockens der Frage nachgegangen werden, welche Funktion die Häuser für Schockens Rolle in Palästina und in Jerusalem besaßen.

\subsubsection{Veranstaltungen in der Villa}

Die Villa Schocken wurde etwas vor der Bibliothek fertigstellt. Wann genau die Familie ihr neues Heim bezog, kann aus den Akten nicht mehr genau rekonstruiert werden, es muss jedoch im Laufe des Jahres 1936 gewesen sein. Das Haus war in zwei Bereiche unterteilt. Die oberen Stockwerke waren der Familie vorbehalten, dort befanden sich die Schlaf- und Wohnzimmer von Lili und Salman Schocken, je mit einem Badezimmer, sowie die Zimmer der Kinder. Ebenfalls im privaten Bereich lagen das Gästezimmer, der Wirtschaftsflügel und die Personalzimmer. Besprechungsprotokolle zeigen, dass die Privaträumlichkeiten dem Luxus der unteren öffentlichen Räume in nichts nachstanden. Die Möbel wurden entweder aus dem Zehlendorfer Haushalt übernommen, 
nachdem sie, wenn nötig, in London restauriert worden waren, oder sie wurden nach den Entwürfen Mendelsohns extra angefertigt. Auf dem Dach wurde für die Familie eine Sportanlage aufgebaut. ${ }^{214}$

Die unteren Räume, also Empfangs-, Wohn- und Esszimmer dienten zwar auch der Familie, hatten darüber hinaus aber eindeutig repräsentative Funktion. Dvora Schocken erinnerte sich daran, dass das Esszimmer für die Familie viel zu groß und daher sehr ungemütlich war. ${ }^{215}$ Auch wenn man sich die Bilder dieser Räume anschaut wird deutlich, dass sie nicht für eine vierköpfige Familie - zu dieser Zeit lebten nur noch die zwei jüngeren Söhne Gideon und Micha bei den Eltern -, sondern für den Empfang größerer Gruppen entworfen wurden.

Die Inneneinrichtung für diese Räumlichkeiten lag fast komplett in Erich Mendelsohns Hand. Bis auf wenige Ausnahmen gehen die Möbel auf seine Entwürfe zurück. ${ }^{216}$ Es war auch Mendelsohn, der die Auswahl der Bilder für die unteren Räume traf:

In der Halle wird der van Gogh eingebaut, aber ohne Beleuchtung. Im Esszimmer, zwischen Tür und Büffet wird das Renoir Blumenstück eingebaut. Alles andere bleibt im Rahmen und kann nach Angaben von Mendelsohn von Ihnen verwendet werden, wie Sie es für richtig halten. ${ }^{217}$

Dass Lili Schocken mit den Einrichtungswünschen Mendelsohns nicht immer glücklich war, da sie sich ein gemütlicheres und mehr auf die Bedürfnisse der Familie ausgerichtetes Heim gewünscht hätte, wurde weiter oben bereits ausgeführt. Architektur und Einrichtung lassen aber darauf schließen, dass die Räumlichkeiten im unteren Stockwerk weniger für die Familie gedacht waren, vielmehr sollten sie als Kulisse für die zahlreichen privaten, semi-privaten und öffentlichen Veranstaltungen dienen, die hier stattfanden.

214 Vgl. Besichtigungsprotokoll, Salman Schocken und Willy Heinze, 10.02.1937. SchA, Privates, 823, Box 30; Bestellungsauftrag Willy Heinze an Exportabteilung, 24.06.1937. SchA, Privates, 823, Box 10.

215 Vgl. Gespräch der Autorin mit Dvora Schocken am 13.11.2013.

216 Vgl. zu der Möblierung in Mendelsohns Privathaus in Deutschland: Erich Mendelsohn / Bruno Zevi: Neues Haus, neue Welt [1932]. Berlin: Gebr. Mann 1997.

217 Willy Heinze an Salman Schocken, 26.08.1936. SchA, Privates, 823, Box 30. 


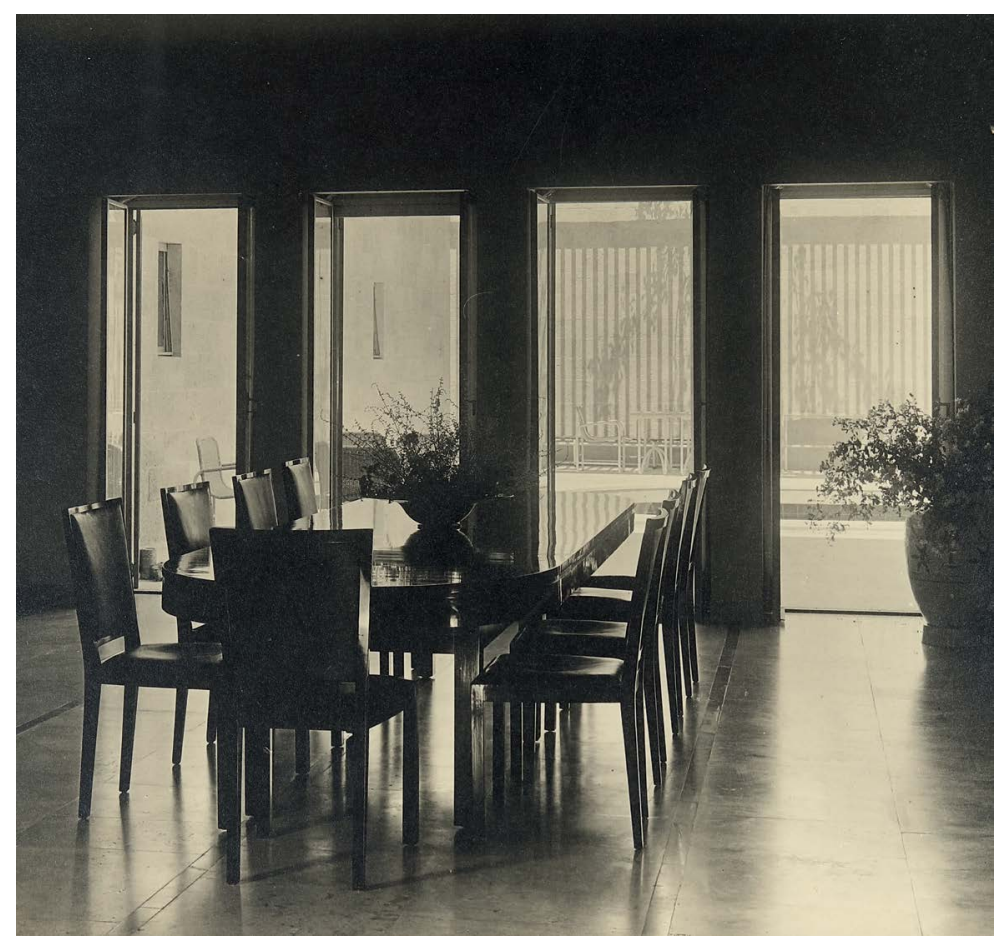

Abb. 13: Alfred Bernheim: Esszimmer mit Blick auf die Terrasse und den Swimmingpool. Möblierung von Erich Mendelsobn, 1937.

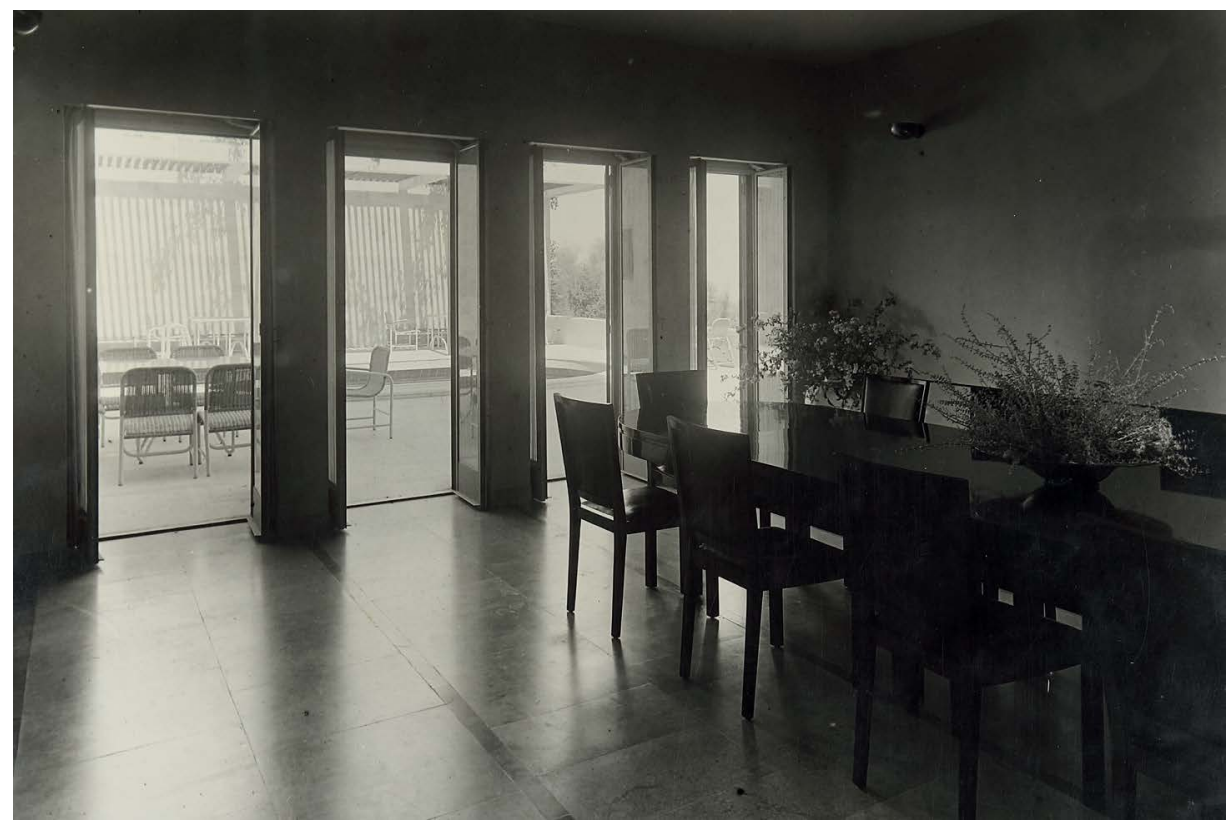

Abb. 14: Alfred Bernheim: Esszimmer mit Blick auf die Terrasse und den Swimmingpool. Möblierung von Erich Mendelsobn, 1937. 


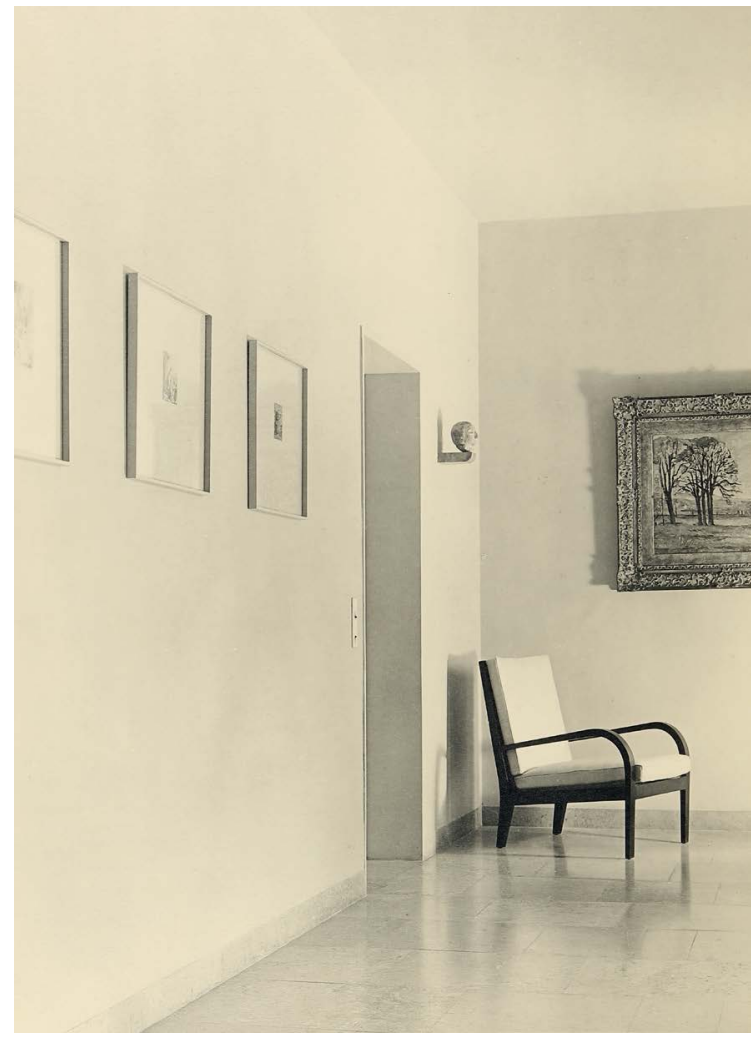

Abb. 15

Alfred Bernheim:

Empfangshalle mit Sessel von Erich Mendelsohn, 1937.

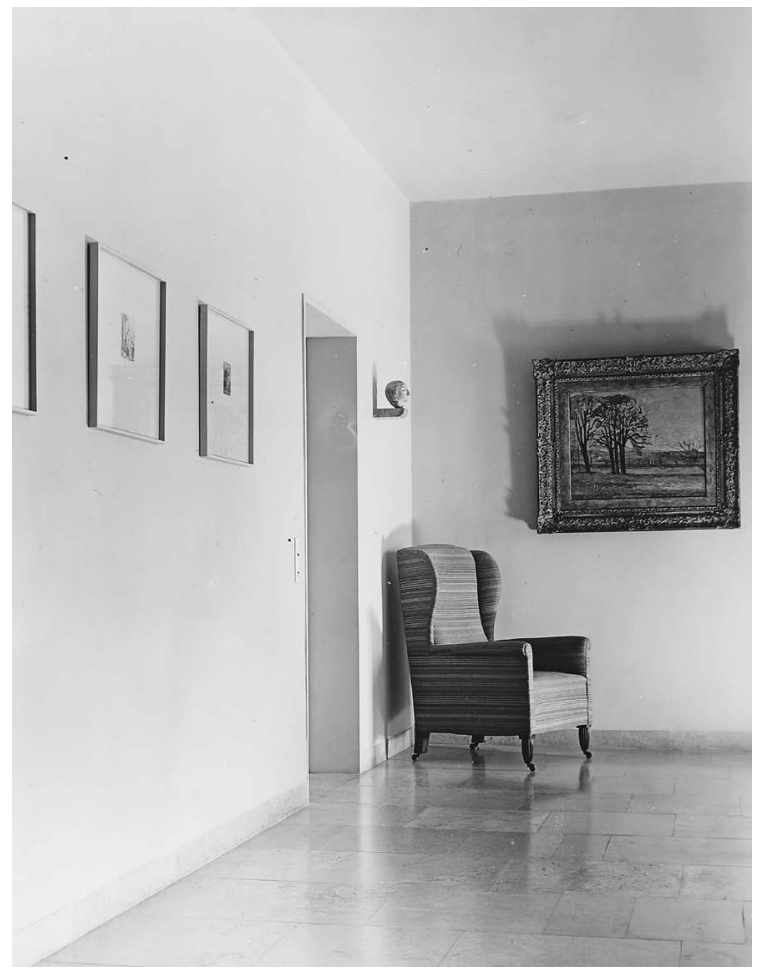

Abb. 16

Alfred Bernheim:

Empfangshalle mit Sessel aus dem Berliner Haushalt, 1937. 


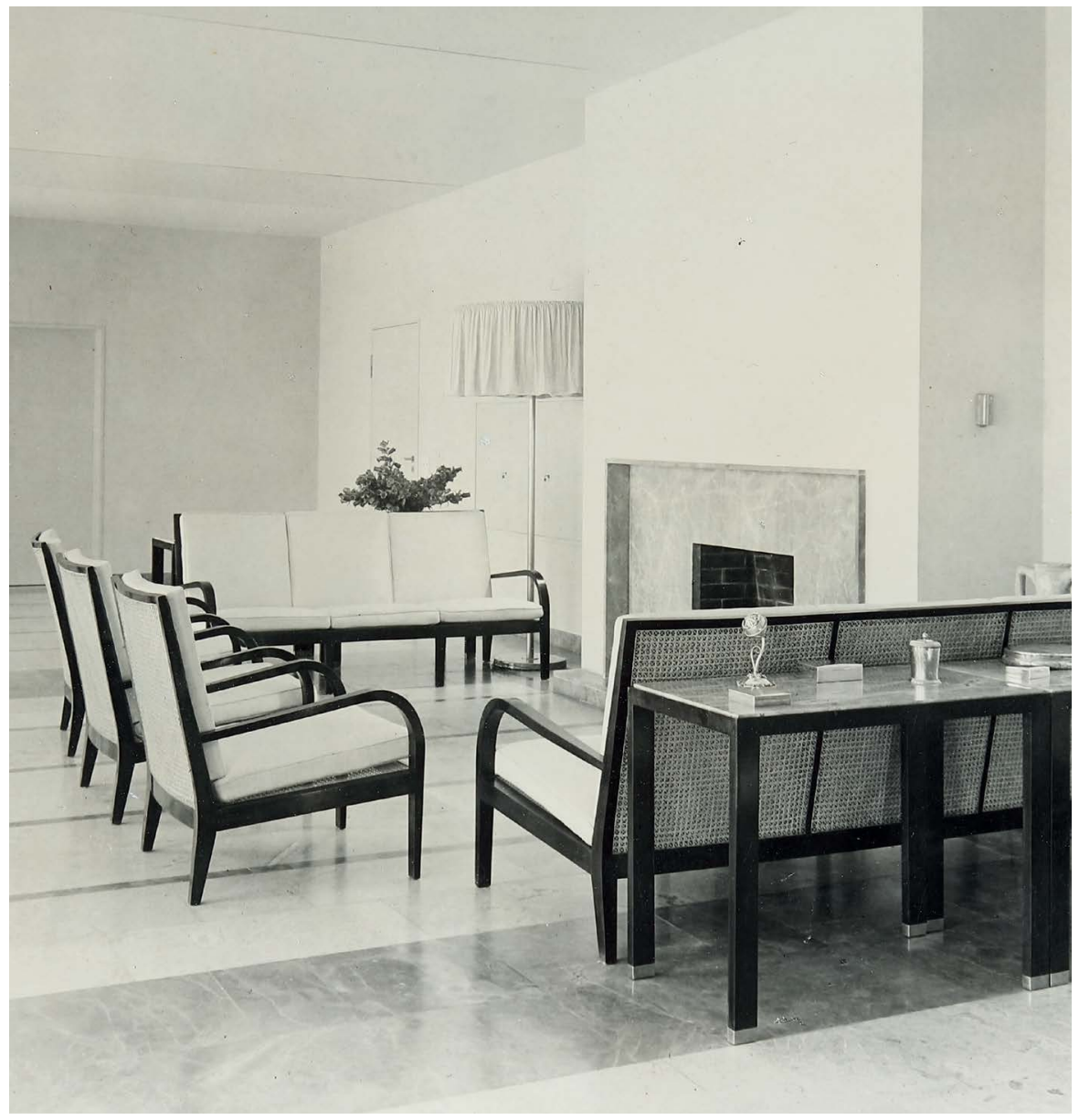

Abb. 17: Alfred Bernheim: Sitzecke vor Kamin. Möblierung von Erich Mendelsohn, 1937.

Salman Schocken ließ über sämtliche Veranstaltungen genau Buch führen, sodass zahlreiche Akten vorliegen, in denen die Empfänge im Privathaus dokumentiert sind. In den Monaten, in denen Schocken in Jerusalem war, ${ }^{218}$ fanden in der Regel drei bis vier Veranstaltungen wöchentlich im Privathaus statt. Dies waren Treffen zum Tee mit alten Bekannten wie dem Ehepaar Buber, Einladungen zu Kaffee und Kuchen in einem etwas größeren Kreis, aber auch große Dinners mit der Universitätsleitung und Professoren, mit zionistischen Persönlichkeiten und Repräsentanten der britischen Mandatsmacht. Ebenso fanden Konzerte und private Feiern wie die Hochzeit von Gustav Schocken statt. 
Über die Eingeladenen und Abwesenden wurde ebenso Buch geführt wie über die Kosten der Empfänge. Dank der Einladungslisten, auf denen entschuldigtes und nicht-entschuldigtes Fernbleiben von Gästen minutiös vermerkt wurde, gewinnt man ein recht präzises Bild des gesellschaftlichen Umfeldes der Schockens. ${ }^{219}$ Diesbezüglich ebenfalls interessant sind die Adressbücher, die in unterschiedliche Kategorien eingeteilt waren. ${ }^{220}$ Der Bekanntenkreis Schockens wurde eingeteilt in A: Gesellschaftlicher Kreis; D: Deutscher Kreis; E: Allgemeine zionistische Persönlichkeiten; L: Literatur; U: Universität; W: Wissenschaft. Jede dieser sechs Gruppierungen wurde nochmals in drei Stufen, nämlich I bis III klassifiziert. Diese Klassifizierung weist auf den Wichtigkeitsgrad der jeweiligen Personen hin. Dabei ist es oft der Fall, dass eine Person in mehrere Listen aufgenommen wurde: So tauchte z. B. der heute kaum mehr bekannte Dr. Bernhard Joseph ${ }^{221}$ im ,Gesellschaftlichen Kreis' auf, wo er auf Stufe II eingeordnet wurde, und ebenso als zionistischer Akteur, wo er mit der Stufe I als Persönlichkeit ersten Ranges aufgeführt war.

Dass die Veranstaltungen im Stile des gehobenen Bürgertums abgehalten wurden, lässt sich aus der Kostenaufstellung für die Empfänge erschließen. Diese Aufstellungen geben nicht nur Auskunft darüber, dass den Gastgeber ein Sommeranlass bedeutend teurer zu stehen kam als eine vergleichbare Veranstaltung im Winter - die Kühlung des Hauses war viel kostspieliger als das Heizen, zudem mussten mehr Getränke angeboten werden -, sondern auch, was den Gästen angeboten wurde. Neben Tee, Limonade, Soda, Likör und Wein, im Sommer weißer und im Winter roter, wurden Sandwiches, Kuchen, kleines Gebäck sowie Pralinen gereicht, darüber hinaus, wie in solchen Kreisen üblich,

219 Vgl. Empfänge im Wohnhaus, SchA, Privates, 842/3; Einladungen zu Tee-Nachmittagen, SchA, Privates, 842/1; Hochzeit Gustav und Shulamit Schocken, SchA, Privates, 842/2.

$220 \mathrm{Vgl}$. Einladungslisten nach Kategorien, SchA, Privates, 842/211.

221 Bernhard Joseph (1899-1980), der sich später Dov Yosef nannte, wurde 1936 Rechtsberater der Jewish Agency und stellvertretender Direktor der politischen Abteilung. Während des Zweiten Weltkrieges koordinierte er für die Jewish Agency die Mobilisierung Freiwilliger für die britische Armee. 1948, noch vor der Staatsgründung, war er Mitglied eines Komitees, das die Gründung eines Verwaltungsapparates vorbereitete, gleichzeitig amtete er als Militärgouverneur von Jerusalem. 1949 wurde er für die Mapai in die Knesset gewählt und hatte in der Regierung Ben Gurion mehrere Ministerposten inne, u. a. war er kurze Zeit Justizminister. Vgl. Dov (Bernard) Yosef. In: The Knesset, o. D. http://www.knesset.gov.il/mk/eng/mk_ eng.asp?mk_individual_id_t=188 (Zugriff am 20.07.2015). 
Zigarren und Zigaretten. Das Personal, das für die Bedienung eingestellt wurde, musste zudem mit Schürzen und Jacken ausgestattet werden. ${ }^{22}$ Eine vergleichbare Aufstellung für ein Dinner fehlt leider, sodass wir keine Informationen haben, was zu diesen Anlässen serviert wurde. Die explizit an Einwanderinnen aus Mitteleuropa gerichteten, von der WIZO (Women's International Zionist Organization) herausgegebenen Kochbücher können jedoch als Anhaltspunkte dienen. ${ }^{223}$ Die Autorin dieser Kochbücher rief die Hausfrauen dazu auf, auf die „gesunde Palästina Küche ${ }^{\text {“224 }}$ umzusteigen, das heißt, lokalen Produkten den Vorrang zu geben. Auf fettige Fleischgerichte sollte verzichtet werden, Butter sollte durch Olivenöl und Kartoffeln durch Bulgur ersetzt werden. Leichte Kost, basierend auf lokalem Gemüse und Obst, sollte dafür den Speiseplan bestimmen. ${ }^{225}$ Hinter den Aufforderungen, kulinarische ,Galut-Traditionen' aufzugeben, stand sowohl die zionistische Überlegung, dass der Import von Nahrungsmitteln die lokalen Produzenten schwäche, wie auch die Tatsache, dass viele Einwandererfamilien, die in Deutschland dem mittleren Bürgertum angehörten, sich in Palästina in einer ökonomisch prekären Situation wiederfanden. Sie konnten sich die teuren Importprodukte kaum leisten und mussten zudem auf die Hilfe von Personal verzichten. ${ }^{226}$

Lili Schocken musste in ihrem Haushalt weder auf die Hilfe von Personal noch auf die technischen Einrichtungen Europas verzichten. Es kann davon ausgegangen werden, dass sie sich auch finanziell nicht einschränken musste. Die Tatsache, dass deutsche Hausfrauen mit einem bedeutend kleineren Budget durch Kochbücher explizit zum Umdenken in der Speisegestaltung aufgerufen werden mussten, kann Beweis genug sein, dass im Schocken'schen Haushalt weiterhin deutsche Kost serviert wurde. So wurde bei den Dinnerpartys wohl eher Braten als die von der WIZO propagierten Auberginenfrikadellen serviert. Lili Schocken stand auch in Jerusalem einem bürgerlichen Haushalt vor, in dem

222 Vgl. Hans Romann: Kosten eines Empfanges von 50 Personen, 06.03.1938. SchA, Privates, $842 / 23$.

223 Vgl. Rautenberg-Alianov: Schlagsahne oder Shemen-Öl?

224 Erna Meyer: Wie kocht man in Erez-Israel?, hrsg. im Auftrag der Women's International Zionist Organization (WIZO), dreisprachig Hebräisch, Deutsch, Englisch. Tel Aviv: Histadrut Naschim Zioniot 1936, S.7.

225 Vgl. ebd.

226 Vgl. Rautenberg-Alianov: Schlagsahne oder Shemen-Öl?, S. 83, 88. 
eine Köchin für das Essen, Zimmermädchen in Häubchen und Schürzen für die Reinigung, ein Pförtner mit Ehefrau für den Wachdienst sowie technische Reparaturen und ein Gärtner für die Pflege der parkähnlichen Anlage zuständig waren. Dieses Setting war ideal für die zahlreichen Einladungen: Das Haus und der Garten boten genug Platz, Gesellschaften von über fünfzig Personen zu bewirten, das deutsche Personal sorgte für perfekten Service, sodass sich die Gastgeber nur um ihre Gäste kümmern mussten.

Wenn man die Gästelisten etwas genauer betrachtet, wird schnell deutlich, dass nur ein verschwindend kleiner Teil der Veranstaltungen tatsächlich privater Natur war. Dazu gehörten die wenigen Nachmittage, an denen nur Martin Buber und dessen Frau geladen waren. Fast alle anderen Veranstaltungen wurden zu Ehren wichtiger Persönlichkeiten abgehalten, wie z. B. ein Empfang zu Ehren des Direktors der American Friends of the the Hebrew University, Samuel B. Finkel, am 23. Oktober 1937, oder ein Empfang für Agnon am 13. August $1938 .{ }^{227}$ Aber auch Nachmittags- und Abendeinladungen ohne besonderen Grund hatten offiziellen Charakter. Geladen waren neben einem festen Kreis von Universitätsprofessoren meist auch hochrangige Vertreter des Jischuv sowie weitere Persönlichkeiten des öffentlichen Lebens und der Kultur. Es versammelte sich also nicht nur ein Kreis deutschsprachiger Intellektueller, die bereits in Deutschland zum Kreis um Schocken und seinen Verlag gehörten, sondern vermehrt auch wichtige Persönlichkeiten des Jischuv, seien dies Politiker, Wissenschaftler oder Funktionäre.

Schließlich dürfen die wirklichen Großanlässe wie die Eröffnung des HadassahKrankenhauses, der Universitätsklinik auf dem Skopusberg, nicht vergessen werden. Salman Schocken hatte als Chairman of the executive council of the Hebrew University jahrelang für die Einrichtung der Universitätsklinik Gelder eingeworben und Grundstücke erworben. Zudem war er stark in die Planung involviert. Das Eröffnungsfest richtete er am 16. Mai 1939 in seinem Privathaus aus. ${ }^{228} \mathrm{Zu}$ diesem Anlass versammelten sich sämtliche Vertreter der Präfakultät, der Präsident der Universität, das Exekutivkomitee, Dekane, Vertreter der ,Freunde der Universität', Vertreter des Hadassah-Krankenhauses, führende Mediziner, die Architekten, Mitarbeitende der Klinik und Pressevertreter in

227 Vgl. Empfänge im Wohnhaus. SchA, Privates, 843/3.

228 Vgl. ebd; Eröffnung Hadassah, Rede Salman Schocken. SchA, Universität, 029. 
der Villa. Schocken selber hielt eine längere Ansprache in Hebräisch, ${ }^{229}$ die er in englischer Übersetzung verteilen ließ.

Der bedeutendste Teil der Veranstaltungen im Privathaus stand im Zusammenhang mit der Hebräischen Universität. Universitätsprofessoren und -leitung, wichtige internationale Gäste wie der bereits erwähnte Samuel B. Finkel, aber auch andere potentielle Großspender für die Universität fanden sich an Samstagnachmittagen zu Kaffee und Kuchen oder zu größeren Dinners ein. Dass Schocken für derlei offizielle Universitätsveranstaltungen sein Heim öffnete, hatte wohl mehrere Gründe. In Jerusalem gab es zu dieser Zeit es nur wenige Restaurants, die den Ansprüchen solcher Anlässe genüge getan hätten. In seinem Haus konnte Schocken hingegen davon ausgehen, dass Ambiente, Essen und Service zu seiner Zufriedenheit ausfallen würden. Zudem litt die Universität, wie die Akten zeigen, chronisch unter finanziellen Problemen. ${ }^{230}$ Die Ausrichtung von größeren Empfängen hätte für die Institution weitere Ausgaben bedeutet, die sie möglicherweise nicht hätte aufbringen können. Schocken, der für das Budget verantwortlich war, wusste um diese Situation. Durch die Ausrichtung der Veranstaltung in seinem Privathaus entlastete er die Universität zumindest ein wenig. Ein weiterer wichtiger Grund, der für Wahl des Privathauses als Austragungsort offizieller Empfänge spricht, war die vermeintliche Privatheit des Anlasses. Insbesondere wenn es um die Kontaktpflege mit möglichen Sponsoren oder mit Direktoren der internationalen Freundeskreise der Universität ging, konnte es vorteilhaft sein, wenn in privater Atmosphäre empfangen wurde. Die Beziehung der Universitätsleitung mit den Freundeskreisen war in den 1930er Jahren meist angespannt: Die Universität war auf die Mittel, die diese philanthropischen Vereinigungen in ihren jeweiligen Ländern aufbrachten, angewiesen und versuchten sich diese vertraglich zu sichern. Das forsche Auftreten der Universität führte nicht selten zu Verstimmungen auf Seiten der Gönner, die sich teilweise zu Zahlungen genötigt fühlten, die sie nicht aufbringen konnten. Dahingehend war es sicherlich strategisch geschickt, solche Veranstaltungen in einem privateren Rahmen abzuhalten.

229 Die Rede wurde zuerst auf Deutsch verfasst, dann ins Hebräische übertragen und für Schockens Vortrag mit der nötigen Punktierung versehen. Vgl. Eröffnung Hadassah. SchA, Universität, 029.

230 Die finanzielle Lage war ständiges Thema von Sitzungen und Besprechungen. Die Dokumentation dazu findet sich in folgenden Aktenbeständen: SchA, Universität, 052/4; 023/2; 031/5; 011; 021/1; 021/32; 016/16; 024/1; 071/1;071/32; 072/3;072/22;072/32;072/41. 
Für Salman Schocken selbst hatten die Veranstaltungen gesellschaftlich große Bedeutung. In Deutschland war er als Kaufmann und Verleger hoch angesehen und stand im Zentrum eines kulturzionistischen Kreises. Dementsprechend wurde er zudem in zentrale zionistische Gremien gewählt, war regelmäBiger Teilnehmer und Redner bei zionistischen Weltkongressen und persönlich bekannt mit den wichtigsten Vertretern des politischen wie des kulturellen Zionismus. Nach der Emigration nach Palästina wurde seine politische Position durch die Wahl an die Spitze des Exekutivkomitees der Hebräischen Universität weiterhin gestärkt. Durch die Veranstaltungen in seinem Privathaus wurde diese Position über die Grenzen der Universität hinweg sichtbar. Es gelang ihm problemlos, die wichtigsten Persönlichkeiten zu privaten, semi-privaten und öffentlichen Treffen zu empfangen.

Bei Schocken traf sich ungefähr über vier Jahre hinweg - also zwischen der Fertigstellung der Villa und der Emigration Lili und Salman Schockens in die USA - regelmäßig die Elite Jerusalems. Das Setting war bürgerlich und unterschied sich wohl nur bedingt von jenem in Deutschland. Dennoch war die Villa Schocken kein Ort der Kontinuität. Schocken versuchte nicht, seine deutsche Existenz zu kopieren und nach Jerusalem zu transferieren. Vielmehr diente das bürgerliche Ambiente als Kulisse für seine palästinensische Existenz. Er versuchte, sich in seiner neuen Heimat zu positionieren, ohne jedoch seine deutschen Kreise zu vernachlässigen. Auf Basis des sozialen Kapitals, das er in Deutschland erworben hatte, baute er seine Existenz in Palästina auf.

\subsubsection{Die Bibliothek als Arbeits- und Versammlungsort}

Die Schocken-Bibliothek wurde am 26. Dezember 1936 mit einer Feier zum Gedenken an Franz Rosenzweig eröffnet. Etwas mehr als hundert geladene Gäste versammelten sich im Büchersaal im ersten Stock zu dieser Veranstaltung, an der u. a. Gershom Scholem und Ernst Simon vortrugen. Der Abend muss sehr kontrovers abgelaufen sein, da Scholem und Simon in ihren Ausführungen sich diametral gegenüberstehende Positionen einnahmen. Schocken war mit dem inhaltlichen Aufbau daher nicht zufrieden. ${ }^{231}$ Die Feier bildete den Auftakt zu zahlreichen Vorträgen und Diskussionsabenden, die in der Bibliothek stattfanden. In den Jahren bis zur Abreise Schockens nach New York fanden

231 Vgl. Schocken: Beobachtungen aus der ersten Bibliotheks-Veranstaltung. SchA, Privates, $842 / 212$. 
zahlreiche Einzelvorträge, sogenannte Bibliotheksabende, ${ }^{232}$ viele davon in deutscher Sprache, sowie eine von Gershom Scholem organisierte hebräischsprachige Vortragsreihe $\operatorname{statt}^{233}$.

Schocken wünschte sich die Bibliothek als öffentlichen Raum für die Gelehrten, Schriftstellerinnen und Schriftsteller Jerusalems. Zwar war es nur ein kleiner Kreis, eine Elite, die sich hier regelmäßig versammelte, um Vorträgen und Diskussionen beizuwohnen, dennoch war es ein lebendiger Ort. Im Vergleich mit den repräsentativen Nachmittagsveranstaltungen und Dinners in der Privatvilla scheinen die Bibliotheksabende in sehr viel kleineren und daher intimeren Runden stattgefunden zu haben. Das an sich öffentlichere Gebäude konstituierte dadurch einen sehr viel privateren Raum als die Privatvilla.

In der Bibliothek fand sich ein Kreis zusammen, der jenem des Schocken Verlages sehr viel näherstand als jener, der sich im Privathaus versammelte. Buber, Scholem, Simon, Agnon und viele andere waren Schocken seit Jahren, wenn nicht gar Jahrzehnten, als Lektoren, Berater und Autoren eng verbunden. In Jerusalem fanden sie sich bei Schocken wieder vereint. Einige der regelmäßigen Besucher der Bibliothek verließen Deutschland vor der Machtergreifung der Nationalsozialisten, der größte Teil ließ sich aber im Laufe der 1930er Jahre aufgrund der nationalsozialistischen Judenpolitik in Jerusalem nieder. Die Schocken-Bibliothek wurde für die Emigranten zu einem Arbeits- und Versammlungsort, sie stand für das Weiterbestehen von wissenschaftlichem Austausch, Forschungs- und Publikationstätigkeit. Denn neben dem nicht zugänglichen Büchermagazin im Lese- und Büchersaal wurden auch die Räumlichkeiten des Forschungsinstituts für hebräische Dichtung im MendelsohnGebäude untergebracht. Unter der Leitung von Heinrich Brody und der Mitarbeit von Chaim Jefim Schirmann sowie Menachem Zulay waren die Ziele des Instituts:

1. die gedruckten und handschriftlichen Quellen für hebräische Poesie in möglichst erschöpfender Weise verzeichnen und versammeln;

2. wissenschaftlich fundierte zuverlässige Editionen hebräischer Dichterwerke veranstalten und Forschungen über hebräische Poesie durchführen und veröffentlichen;

232 Vgl. Abende in der Bibliothek. SchA, Privates, 842/23.

233 Vgl. Messiboth Madaioth. SchA, Privates, 842/25. 
3. durch öffentliche Vorlesungen und Übungen alle Interessierten in die Kenntnis der hebräischen Dichtung einführen, sie mit ihrer Geschichte, ihrer Sprache, ihren Formen und der Art und der Methode ihrer Interpretation vertraut machen;

4. Forscher in ihren Arbeiten durch Überlassung handschriftlichen Materials fördern, gegebenenfalls sie mit Aufträgen für die Bearbeitung und Herausgabe von hebräischen Dichtwerken oder Forschungen über die hebräische Poesie betrauen. ${ }^{234}$

Neben den eigentlichen Forschungsarbeiten war das Institut auch damit beauftragt, alle wichtigen Bibliothekskataloge nach Handschriften zu durchsuchen, diese zu sichten und für das Institut fotografisch reproduzieren zu lassen. Jefim Schirmann reiste somit im Auftrag Schockens zu den wichtigsten Bibliotheken Europas, um die Quellen, wie es im ersten Punkt zu den Institutszielen vermerkt wurde, möglichst vollständig zu versammeln.

Zulay, der sich in seiner Arbeit auf die Erforschung der frühen synagogalen Poesie der byzantinischen Epoche und auf die Bearbeitung der HandschriftenFragmente der Kairoer Geniza spezialisierte, führte wenige Originale sowie zahlreiche Kopien der Fragmente im Schocken-Institut zusammen. Sein Verdienst war ihre Katalogisierung, die es ihm und den nachfolgenden Forschergenerationen erlaubte, sich einen systematischen Überblick über die Fragmente zu verschaffen. ${ }^{235}$

Wie Lehnhardt feststellt, wurde die Kartothek zu einem der wichtigsten Hilfsmittel zur Lokalisierung der Werke der hebräischen Dichtung. Zudem ermöglichten die fotografischen Reproduktionen die Herstellung zahlreicher Editionen. Beides waren neue Techniken, die nur durch die großzügige finanzielle Unterstützung Salman Schockens möglich waren. Die Offenheit Schockens für technische Neuerungen ermöglichte dem Schocken-Institut, die selbstgesteckten oben aufgeführten Ziele zu erreichen. ${ }^{236}$ Systematik und Vollständigkeit waren, wie die vorliegende Untersuchung zeigen konnte, zentrale Anliegen

234 Heinrich Brody: Aus den Berichten des Institutsleiters Heinrich Brody. In: Spitzer (Hrsg.): Almanach des Schocken Verlags auf das Jahr 5697, S. 176-181, hier S. 177.

235 Vgl. Lehnhardt: Das Forschungsinstitut für hebräische Dichtung und sein Beitrag zur Kenntnis der hebräischen Dichtung des Mittelalters.

236 Vgl. ebd., S.312-313. 
Schockens. Dass er daher die großen finanziellen Investitionen, die eine systematische Sammlung und Erschließung von Handschriften mit sich bringt, nicht scheute, scheint nicht weiter zu verwundern.

Die Kartothek und Fotosammlung des Jerusalemer Schocken-Instituts wurden zur Grundlage der zahlreichen Publikationen der Institutsmitarbeitenden, die größtenteils im Berliner Schocken Verlag erschienen. ${ }^{237}$ Damit war das Institut ein Bindeglied zwischen Schockens Engagement in Palästina und seiner verlegerischen Tätigkeit in Berlin. Die Bibliothek wurde somit auch zu einem Ort im Exil, an dem die deutsche Identität Schockens weiterbestand.

Die Tätigkeiten der Institutsmitarbeiter in den Räumlichkeiten und mit den Beständen der Bibliothek verdeutlichen aber auch, dass die Bibliothek ein dynamischer Raum war. Zwar bot sie den deutsch-jüdischen Wissenschaftlern Jerusalems ein Heim im Exil und war Rahmen für Zusammenkünfte, sie wurde aber nicht zu einem Museum für eine verlorene Kultur. Es stimmt, dass Bekanntes an den neuen Ort mitgebracht wurde, dass sich das Netzwerk um den Schocken Verlag auch in Jerusalem wieder zusammenfand und dass gewisse habituelle Strukturen transferiert wurden; jedoch handelte es sich nicht um lineares Weiterbestehen. Forschungsarbeit bedeutet Weiterentwicklung: Neue Themenfelder werden erschlossen und stets werden im Forschungsprozess weiterführende Fragen generiert. Sowohl Institut wie auch Vortragsreihen sind in diesem Sinne als beweglich und dynamisch zu verstehen. Aufbauend auf den Büchern, die aus Deutschland mitgebracht wurden, und auf die akademischen Traditionen aus Deutschland wurde in Jerusalem weitergearbeitet. Die Bibliothek war damit kein Ort des Stillstandes, aber auch keiner, der sich einer wichtigen Funktion entledigte: Raum der Kontinuitäten für deutsche Emigranten zu sein. Vielmehr baute man auf bestehende Traditionen auf, verschloss sich aber den neuen Herausforderungen gegenüber nicht und arbeitete an einem dynamischen Weiterbestehen.

Die Bibliothek ist damit Beleg dafür, dass die stereotypen Jecke-Bilder überdacht werden müssen. Dass Netzwerke im Exil weiterbestehen, um Emigrantinnen und Emigranten besonders in der schwierigen Anfangszeit Halt zu

237 Vgl. die Bibliographie des Verlages in Dahm: Das jüdische Buch im Dritten Reich; Lehnhardt: Das Forschungsinstitut für hebräische Dichtung und sein Beitrag zur Kenntnis der hebräischen Dichtung des Mittelalters, S.305-306. 
geben, ist nicht außergewöhnlich. ${ }^{238}$ Weltbilder und Habitus mit dem Verlassen der Heimat nicht einfach abzulegen, ist ebenfalls normal. Mikrohistorische Betrachtungen zeigen jedoch, dass diese Entwicklungen sehr viel differenzierter ablaufen, als ein Makroblick es zu erfassen vermag. Auf den ersten Blick scheinen die Villa wie auch die Bibliothek Schockens Orte des Stillstandes und der Reproduktion der zurückgelassenen Kultur zu sein. Dass eine solche Interpretation zu kurz greift, sollte im voranstehenden Kapitel deutlich geworden sein.

238 Vgl. u. a. Charles Tilly: Transplanted Networks. In: Virginia Yans-McLaughlin (Hrsg.): Immigration Reconsidered. History, Sociology, and Politics. New York / Oxford: Oxford UP 1990, S.79-95. 


\section{8 \\ Salman Schocken in Jerusalem und sein Beitrag zum Aufbau der jüdischen Zivilgesellschaft}

Nach genauer Prüfung ordnete Salman Schocken die wirtschaftlichen Möglichkeiten Palästinas für sich als begrenzt ein. Untätig war er jedoch nicht. Obwohl er in Deutschland einem Kaufhauskonzern vorstand und einen Verlag leitete, weshalb er einen großen Teil seiner Zeit in Deutschland und im übrigen Europa verbrachte, war er ab 1935 in Palästina in drei Bereichen tätig: Er ließ sich in den Vorstand des Exekutivkomitees der Hebräischen Universität Jerusalem wählen, er erwarb die bislang unrentable Tageszeitung Haaretz und er gründetet einen weiteren Verlag, den Hotza'at Schocken. Sein Hauptbeschäftigungsfeld war jedoch die Universität, da die Zeitung und der Verlag de facto von seinem Sohn Gershom (Gustav) geführt wurden.

Im folgenden Kapitel wird es um Schockens Engagement im vorstaatlichen Israel, genauer um seinen Beitrag zum Aufbau der jüdischen Zivilgesellschaft gehen. Schockens Arbeit für die Universität ist bislang von der Geschichtswissenschaft vernachlässigt worden, obwohl er der Institution fünf Jahre vorstand. Daher muss als Erstes sein Wirken aus den Quellen aufgearbeitet werden. Grundlage dafür sind die Akten im Schocken Archiv. Diese sind ausführlicher als die im Universitätsarchiv, da Schockens Privatsekretariat dafür sorgte, dass sämtliche Unterlagen wie Korrespondenz, Protokolle, Notizen sowie Pressematerial und andere Drucksachen im Privatarchiv abgelegt wurden. Neben einer allgemeinen Darstellung von Schockens Rolle und Aufgaben, die auch die Geschichte der Universität in diesen schwierigen Jahren nachzeichnet, soll sein Einfluss auf die Entwicklung der Universität rekonstruiert werden. 
Im zweiten und dritten Teil dieses Kapitels stehen der Verlag und die Zeitung im Fokus. Da die Quellenlage hierzu dürftig ist, fallen diese Ausführungen kurz aus. Das Zeitungsarchiv der frühen Jahre ist nach Informationen der Familie und der Firmenarchivarin nicht überliefert. Auch das Verlagsarchiv ist weitgehend nicht zugänglich, da es nicht erschlossen ist. Die Erschließung dieser Bestände ist für eine zukünftige Bearbeitung der frühen Geschichte des Verlages von zentraler Bedeutung, kann aber nicht Aufgabe der vorliegenden Untersuchung sein. Basierend auf den wenigen Quellen, die im Schocken Archiv zugänglich sind, können lediglich einige Aspekte der Zeitungs- und Verlagsgeschichte dargestellt werden.

Die zentrale Frage der drei Unterkapitel ist der Einfluss der deutschen Immigranten auf das kulturelle, publizistische und wissenschaftliche Leben des Jischuv. Im letzten Jahrzehnt hat sich die Forschung vermehrt mit dieser Frage auseinandergesetzt. Anhand von einigen kürzeren und wenigen längeren Einzelstudien löste man sich vom bestehenden Bild der Jeckes, oder hinterfragte es zumindest kritisch. Dazu gehören die u. a. die Untersuchungen von Naama Sheffi, ${ }^{1}$ sowie im Besonderen die Arbeiten im Sammelband Zweimal Heimat, herausgegeben von Moshe Zimmermann und Yotam Hotam. ${ }^{2}$ Hier befassen sich zwanzig Artikel mit der Thematik der , migrierenden Kultur. Während einige der Autor*innen nach dem Beitrag der Jeckes zur Jischuv-Kultur fragen, legen andere den Schwerpunkt darauf, wie die Identität nach der erzwungenen Migration gesichert wird.

Im folgenden Teil dieser Untersuchung werde ich argumentieren, dass sich diese beiden Aspekte nicht voneinander lösen lassen. Die Mitnahme von Kultur und das Festhalten an Traditionen sind Strategien der Kontingenzbewältigung. Aus diesem Festhalten an Strukturen und kulturellem Inhalt kann aber, so die hier vertretene These, Neues entstehen. Wandel und Tradition sind demnach nicht als Gegensatzpaare zu verstehen. Bisherige Traditionen mögen in der Phase der Ankunft an einem neuen Ort verstärkt gelebt und verteidigt werden, weil sie in der Fremde Sicherheit spenden und damit einem Identitätsverlust vorbeugen. In alte wie neue Kommunikationsräume eingebunden zu sein, die

1 Naama Sheffi: The Hebrew Absorption of German Literature in the Yishuv. In: Efraim Karsh (Hrsg.): The First Hundred Years. London: Cass 2000, S. 158-171.

2 Zimmermann/Hotam: Zweimal Heimat. 
Wahrnehmung wirtschaftlicher Möglichkeiten, eigene Integrationsbemühungen und möglicherweise Assimilationsdruck, die Konfrontation mit divergierenden Wertesystemen, oder anders formuliert, die Auseinandersetzung mit lebensweltlichen Strukturen, die sich von denen des Herkunftsortes unterscheiden, spiegeln sich in kulturellen Veränderungen in der Einwanderungsgesellschaft. Der lebensweltliche Zugang kann dabei als Analysewerkzeug dienen, wenn es darum geht, Kontinuitätsherstellung aufzudecken. Ausgehend von Habermas' These, dass Brüchen in der Sinnkonstruktion durch ,kulturelle Reproduktion' vorgebeugt wird, können Strategien der Kontinuitätsherstellung am neuen Ort aufgedeckt werden. Die Konfrontation mit Brüchen kann, wie er anfügt, zum Sinnverlust führen, sie kann aber auch kreative Kräfte im Sinne einer beabsichtigten Neugestaltung von Bisherigem freisetzen. Emigration ermöglicht, gerade weil sie sich krisenhaft gestaltet, Innovationen und kann wissenschaftliche wie gesellschaftliche Leistungen hervorbringen, die, so Dan Diner, „unter Bedingungen von Stetigkeit und Kontinuität der Lebensentwürfe kaum zu erwarten gewesen wären “3 .

3 Dan Diner: Einleitung. In: Ders. (Hrsg.): Historische Migrationsforschung. Gerlingen: Bleicher 1998, S. 1 -4, hier. S. 3. 


\subsection{Hebräische Universität}

\subsubsection{Eine kurze Geschichte der Gründungszeit der Universität}

Es mag auf den ersten Blick wohl paradox scheinen, dass wir in einem Lande mit einer so spärlichen Bevölkerung, einem Lande, dem noch die elementarsten Dinge wie Pflüge, Landstraßen und Häfen fehlen, schon ein Zentrum geistigen Schaffens aufzubauen beginnen. Der Kenner der jüdischen Seele aber wird das nicht als Paradoxie empfinden. Gewiss harren noch große politische und soziale Probleme ihrer Lösung in diesem Lande. Wir Juden aber wissen, dass nur in dem Masse, wie dem Geiste die Möglichkeit freister Entwicklung geboten wird, nur in dem Masse, wie wir uns einen Mittelpunkt für die Entfaltung jüdischen Geisteslebens erschaffen, uns auch die Möglichkeit der Durchführung unserer materiellen Ziele gewährleistet ist. ${ }^{4}$

Ende Juli 1918, also etwas mehr als ein halbes Jahr nachdem die Briten als Mandatsmacht mit der Balfour-Deklaration ${ }^{5}$ die Absicht erklärten, in Palästina eine ,nationale Heimstätte für das jüdische Volk zu errichten, wurde auf dem Skopusberg im Norden der Stadt der Grundstein für die erste jüdische Universität gelegt.

Die Idee einer jüdischen Hochschule geht auf eine Forderung der Demokratischen Fraktion ${ }^{6}$ beim 5. Zionistenkongress 1901 in Basel zurück. Als Vertreter der Kulturkommission regten Buber und Weizmann unter anderem die Gründung einer Nationalbibliothek und einer jüdischen Hochschule an. Der Kongress ging darauf ein und beauftragte das Aktionskomitee, die Forderung nach

4 Aus der Rede von Chaim Weizmann anlässlich der Grundsteinlegung der hebräischen Universität auf dem Skopusberg am 24. Juli 1918. In: Zionist Organization / University Committee (Hrsg.): Die Hebräische Universität in Jerusalem anlässlich der Eröffnung am siebenten Nissan 5685, ersten April 1925. Berlin: Marx 1925, S. 12-13.

5 Zur Balfour-Deklaration vgl. u. a. Shapira: Israel, S. 70-75.

6 Vgl. weiter oben Kap. 5.1.1. 
einer jüdischen Hochschule einem gründlichen Studium zu unterziehen. ${ }^{7}$ Es sollten Jahre vergehen, bis es tatsächlich zur Gründung einer Universität kommen sollte.

1913 wurde auf Beschluss des 11. Zionistenkongresses ein vorbereitendes Komitee für die Gründung einer hebräischen Universität in Jerusalem eingesetzt. Das Komitee, dem unter anderen Chaim Weizmann angehörte, arbeitete einen Plan für die Einrichtung eines naturwissenschaftlichen Instituts aus, es gelang ihm zudem, Mittel für einen ersten Landkauf auf dem Skopusberg einzuwerben. Nachdem durch den Beginn des Ersten Weltkrieges die Vorbereitungen vorerst unterbrochen werden mussten, konnte im Juli 1918 schließlich der Grundstein gelegt werden. ${ }^{8}$ In den Jahren bis zur offiziellen Eröffnung der Universität am 1. April 1925 wurden einige naturwissenschaftliche Institute eröffnet und 1924 der Beschluss gefasst, ein Institut für judaistische und orientalische Studien zu gründen. ${ }^{9}$ Durch die Übernahme der 1892 von der Jerusalemer Loge des BnaiBrit-Ordens gegründeten Bibliothek durch die Zionistische Organisation und die Einstellung von Hugo Bergmann als Direktor im Frühjahr 1920 wurde zudem die Grundlage für die zukünftige National- und Universitätsbibliothek gelegt. $^{10}$

Die Gründung der Universität in Palästina war eine höchst politische Sache. Zum einen lässt sich in den Anfangsjahren der Machtkampf zwischen der Zionistischen Weltorganisation, die in London ihr Zentrum hatte und deren Vorsteher Chaim Weizmann war, und dem Jerusalemer Komitee ablesen. Letzterem gehörten Judah Magnes, der spätere Kanzler der Universität, Menachem Ussischkin, Israel Klausner, David Yellin, Achad Ha'am und Chaim Nachman Bialik an: Sie plädierten für eine stärke Stellung des Jischuv. ${ }^{11}$ Zum anderen war die Gründung der Universität in Jerusalem ein Meilenstein in der Etablierung

7 Martin Buber, Berthold Feiwel und Chaim Weizmann publizierten nur ein Jahr nach dem Auftrag durch den Kongress eine Schrift zur Errichtung einer jüdischen Hochschule: Martin Buber / Berthold Feiwel / Chaim Weizmann: Das Projekt einer jüdischen Hochschule. Berlin: Jüdischer Verlag 1902.

$8 \mathrm{Vgl}$. Die Hebräische Universität in Jerusalem anlässlich der Eröffnung am siebenten Nissan 5656/ersten April 1925.

9 Vgl. ebd., S. 12-13.

10 Vgl. ebd., S. 14.

11 Vgl. Arthur A. Goren: The View From Scopus. Judah L. Magnes and the Early Years of the Hebrew University. In: Modern Jewish Studies 45,2 (1996), S.203-224, hier S. 210. 
eines jüdischen Gemeinwesens in Palästina. Die Unterstützung, die das Projekt durch die Briten erhielt, war für Chaim Weizmann ein großer Erfolg. An der Eröffnungszeremonie im April 1925, die im dafür eigens errichteten Amphitheater stattfand und über die Weizmann präsidierte, nahmen Diplomaten aus neun verschiedenen Staaten, der Hochkommissar Sir Herbert Samuel, Lord Allenby sowie Vertreter von 62 Universitäten und zionistische Führungspersönlichkeiten teil. Der größte Triumph für Weizmann war, dass Lord Balfour die Eröffnungsrede hielt. Die Teilnahme Balfours war für die Zionisten ein Zeichen, dass sich Großbritannien an seine Zusage hielt, in Palästina eine jüdische Heimstätte zu unterstützen. ${ }^{12}$

Die Gründungsjahre der Universität waren spannungsgeladen, da grundlegende Fragen geklärt werden mussten. Vor allem, ob sich die Universität als reine Forschungsstätte oder als Lehr- und Forschungsinstitution etablieren sollte, war in der Gründergeneration umstritten. Während Vladimir Ze'ev Jabotinsky sich für die zweite Option, also die Einrichtung einer Lehr- und Forschungsstätte einsetzte, forderten Achad Ha'am und Weizmann eine reine Forschungsinstitution. ${ }^{13}$ Weizmanns und Ha'ams Konzeption der Universität setzte sich vor ihrer Gründung durch, dies nicht zuletzt, weil die zwei hauptsächlichen Förderer der Universität, der deutsche Nobelpreisträger Paul Ehrlich und der französische Baron Edmond de Rothschild, eine reine Forschungsstätte bevorzugten. ${ }^{14}$ Noch vor der eigentlichen Gründung im April 1925 wurden Forschungsinstitute für Chemie und Mikrobiologie sowie das Institut für Jüdische Studien eingerichtet. ${ }^{15}$

Das Institut für Jüdische Studien ging auf die Initiative von drei unabhängigen Komitees in London, Paris und Jerusalem zurück. Im Juli 1924 trafen sich die Vertreter der drei Ausschüsse in London, darunter Chaim Weizmann und Judah Magnes, wo sie sich dazu entschlossen, ein Institut für judaistische und orientalische Studien zu gründen. Die Forschungsgebiete dieser ersten geisteswissenschaftlichen Abteilung umfassten jüdische Religion, das Hebräische

12 Vgl. Goren: The View From Scopus, S. 204-205.

13 Vgl. Yaacov Iram: Higher Education in Transition. The Case of Israel. A Comparative Study. In: Higher Education 9 (1980), S. 81-95, hier S. 84.

14 Vgl. David N. Myers: A New Scholarly Colony in Jerusalem. The Early History of Jewish Studies. In: Judaism 45,2 (1996), S. 142-159, hier S. 147; Goren: The View From Scopus, S. 205 .

15 Vgl. Iram: Higher Education in Transition, S. 85. 
und ihm verwandte Sprachen, jüdische Literatur, Geschichte, Philosophie und Kulturgeschichte, jüdisches Recht und die Erforschung Palästinas. ${ }^{16}$ Die Gründung des Institutes war der erste große Erfolg von Magnes, der sich damit gegen Weizmann durchsetzen konnte, der in erster Linie die Naturwissenschaften fördern wollte. ${ }^{17}$

Judah Leon Magnes (1877-1948), der in den USA und in Deutschland seine Ausbildung erhalten hatte, war Reformrabbiner, Pädagoge, Pazifist und Zionist. 1922 ließ er sich in Jerusalem nieder. ${ }^{18}$ Noch im selben Jahr wurde er Mitglied des Jerusalemer Komitees der Hebräischen Universität, das nicht nur eine Loslösung der Universität von der zionistischen Politik, sondern auch die Gründung einer geisteswissenschaftlichen Fakultät forderte. Beide Ansinnen standen jenen von Weizmann diametral gegenüber. Darüber hinaus schlug der Ausschuss eine klare Trennung von Kompetenzen zwischen Jerusalem und London vor: Das Jerusalemer Komitee beanspruchte die Exekutivgewalt, während London das Fundraising übernehmen sollte. London konnte sich mit diesen Plänen nicht einverstanden erklären. ${ }^{19}$ Dennoch gelang es Magnes in den Jahren 1922 bis 1925, seinen Einfluss kontinuierlich auszubauen. Sein größter Triumph war Felix Warburgs ${ }^{20}$ Spende von 100.000 \$ für die Gründung des Institutes für Jüdische Studien.

Zwar sah Warburg davon ab, seine Spende von seinen ursprünglichen Forderungen abhängig zu machen - dass Magnes als Verwalter der Kontribution eingesetzt werden und eine führende Rolle in der Universität besetzen solle -, dennoch war klar, dass Magnes Warburgs Interessen vertrat und nur er Zugang zu ihm und anderen großzügigen Spendern aus den USA hatte. ${ }^{21}$ Warburg zeigte sich zudem mit Magnes einig, dass die Verwaltung der Universität vor

16 Vgl. Die hebräische Universität in Jerusalem anlässlich der Eröffnung am siebenten Nissan 5656/ersten April 1925.

17 Vgl. Goren: The View From Scopus, S. 208.

$18 \mathrm{Zu}$ seiner Biographie vgl. Daniel P. Kotzin: Judah L. Magnes. An American Nonconformist. New York: Syracuse UP 2010.

19 Vgl. Goren: The View From Scopus.

20 Felix Moritz Warburg (1871-1937) war ein deutsch-amerikanischer Bankier und Mäzen. Er wanderte 1894 in die Vereinigten Staaten aus, wo er Frieda Schiff, die Tochter seines Seniorpartners heiratete. Warburg war führendes Mitglied des Joint, ab 1925 Mitglied des Board of Governor der Hebräischen Universität sowie in zahlreichen weiteren Aufsichtsgremien.

21 Goren: The View From Scopus, S. 203-224. 
Ort anwesend sein solle und sprach sich somit deutlich gegen die Londoner Gruppe um Weizmann aus.

Der Konflikt zwischen Jerusalem und London spielte sich auf mehreren Ebenen ab: Einerseits war man sich über die Ausrichtung der Universität nicht einig. Weizmann bevorzugte zu Beginn eine rein naturwissenschaftlich orientierte Universität, während Magnes als Förderer der geisteswissenschaftlichen Disziplinen auftrat. Aber auch politisch konnte man sich nicht einigen. Weizmann sah die Universität als Aufgabe der Zionistischen Weltorganisation und verstand sie als einen Teil der Bemühungen, in Palästina eine jüdische Zivilgesellschaft aufzubauen. Magnes hingegen lehnte die Verbindung zwischen dem politischen Zionismus und den Geschicken der Universität kategorisch ab. Er wollte eine von sämtlichen politischen Belangen unabhängige Forschungsund Lehrinstitution aufbauen. Schließlich zweifelte London öffentlich an den Fähigkeiten der Jerusalemer Komiteemitglieder. Weizmann zögerte ebenso wenig wie Albert Einstein, zu erklären, dass in Jerusalem die intellektuelle Sphäre fehle. Magnes und seinen Mitstreitern fehle es an akademischen und beruflichen Qualifikationen, die sie für den Aufbau und die Leitung der Universität qualifiziere. ${ }^{22}$

Im Frühjahr und Sommer 1925 versuchte London mit allen Mitteln zu verhindern, dass die Leitung der Universität gänzlich an Jerusalem ging. Einstein warnte vor einer ,Bauernuniversität' und Weizmann erklärte, dass nur die zionistische Führung in der Lage sei, das Vertrauern von Sponsoren und die Unterstützung von führenden Wissenschaftlern zu gewinnen. ${ }^{23}$ Magnes' amerikanische Fürsprecher entgegneten, dass es der Universität schade, wenn sie weiterhin ein Anhang der Zionistischen Weltorganisation sei, da dadurch Spenden von Nichtzionisten verloren gingen. Und Magnes warf schließlich ein, dass er bereit sei, Weizmann als Präsident zu akzeptieren, wenn dieser das Präsidium der Zionistischen Weltorganisation aufgäbe, seinen Wohnsitz nach Jerusalem verlege und sich einzig dem Dienst an der Universität verschreibe.

Als im September 1925 der Verwaltungsrat der Universität in München tagte, sprach sich Magnes daher gegen den Vorsitz Weizmanns in diesem Gremium

22 Vgl. David N. Myers: Re-Inventing the Jewish Past. European Jewish Intellectuals and the Zionist Return to History. New York: Oxford UP 1995, S. 55-56; Goren: The View From Scopus, S. 213.

23 Goren: The View From Scopus, S. 213. 
aus. In einem Versuch, einen Kompromiss zwischen den verhärteten Fronten zu finden, wählte der Verwaltungsrat Weizmann und Einstein als Co-Präsidenten, Magnes als Kanzler und Bentwich als Vizekanzler der Universität. Diese Lösung vermochte den Konflikt jedoch nicht zu lösen, da man sich über die Befugnisse der Posten nicht einigen konnte. Erst die Sitzung des Verwaltungsrates im folgenden Jahr schaffte etwas mehr Klarheit. Weizmann wurde als Präsident gewählt, Einstein übernahm den Vorsitz des akademischen Rates und Magnes wurde als Kanzler bestätigt. ${ }^{24}$

Magnes hatte dieses Amt bis 1935 inne, als Salman Schocken zwar nicht als Kanzler, jedoch als Vorsitzender der Exekutive gewählt wurde, und damit faktisch Magnes Position einnahm. Der Konflikt zwischen Weizmann und Magnes spielte bei der Entscheidung von 1935, Magnes den Rücktritt nahezulegen, keine unwichtige Rolle. Seit der Eskalation von 1925 herrschte zwischen den beiden Männern Misstrauen und es bestanden Aversionen. Zwar gelang es ihnen, diese persönlichen Probleme zeitweilig beiseitezulegen, um gemeinsam für die Universität einzustehen, ${ }^{25}$ jedoch konnte Magnes nicht auf die Loyalität Weizmanns zählen, als Konflikte zwischen Magnes' amerikanischem Führungsstil und den mehrheitlich zentraleuropäischen Akademikern ausbrachen. ${ }^{26}$ Als Magnes sich Ende 1920er Jahre zudem vermehrt dahingehend äußerte, dass der Jischuv eine gemeinsame Lösung mit der arabischen Bevölkerung suchen müsse und er eine gleichberechtigte Koexistenz befürwortete, wollte Weizmann ihn ganz offiziell entmachten. Weizmann konnte nicht tolerieren, dass Magnes die Universität als Plattform für seine politischen Ansichten nutzte. So erklärte Magnes bspw. in seiner Ansprache zur Eröffnung des akademischen Jahres 1929, wenn in Palästina eine Gruppe eine andere dominiere, sei das zionistische Projekt gescheitert. „If the only way of establishing the Jewish National Home is upon the bayonets of some Empire, our whole enterprise is not worth while. ${ }^{\text {" } 27}$ Die Rede wurde weithin wahrgenommen und löste im Jischuv einen Sturm von Entrüstung aus. Selbst US-amerikanische Kreise, die sich zu Magnes' loyal verhielten, kamen nicht umhin, ihn darauf hinzuweisen, dass er sich als Kanzler

24 Vgl. ebd., S.215-216.

25 Vgl. ebd., S. 216.

26 Vgl. Joseph Ben-David: Universities in Israel. Dilemmas of Growth, Diversifiction and Administration. In: Studies in Higher Education 11,2 (1986), S. 105-130, hier S. 109.

27 Goren: The View From Scopus, S. 219. 
der hebräischen Universität eine derart offene Unterstützung für die Rechte der arabischen Bevölkerung nicht erlauben dürfe. ${ }^{28}$

Nach 1929 wurde es für Magnes immer schwieriger, seine Position zu verteidigen. Die Weltwirtschaftskrise, arabische Aufstände und die Schwierigkeiten, renommierte Wissenschaftler für die junge Universität zu gewinnen, erschwerten die Situation für ihn. Seine Führungsqualitäten wurden zunehmend in Frage gestellt und 1933 schließlich ein Ausschuss eingesetzt, das Survey Committee, der die Universität und ihre Verwaltung einer genauen Untersuchung unterziehen sollte. Magnes und seine Führungsqualitäten standen dabei im Zentrum der Aufmerksamkeit. Der Schlussreport ergab eine klare Absage an seinen „diktatorischen Führungsstil “29.

Vor diesem Hintergrund sah sich Magnes gezwungen, bei der Kuratoriumssitzung in Luzern im September 1935 von seinem Amt zurückzutreten. Er wurde, da seine Verbindungen zu den amerikanischen Geldgebern weiterhin als wichtig eingestuft wurden, zum Präsidenten der Universität ernannt. Der Posten war ein reines Ehrenamt ohne jegliche exekutiven Befugnisse. Chaim Weizmann, sein langjähriger Gegenspieler, wurde Vorsitzender des Kuratoriums und Salman Schocken Vorsitzender der Exekutive mit besonderen Rechten. ${ }^{30}$ Damit war Schocken in die wichtigste Verwaltungsposition der Hebräischen Universität gewählt. Er leitete ihre Geschicke während eines halben Jahrzehntes. Bei Salman Schockens Antritt zählte die Universität 450 Studierende und 90 Wissenschaftlerinnen und Wissenschaftler. Seine Amtszeit war einerseits geprägt durch die nationalsozialistische Judenverfolgung, andererseits durch die schwierige Aufgabe, Gelder für die Universität einzuwerben. Schocken ging diese Probleme auf seine Weise an: Er war in erster Linie Kaufmann, der mit einem System von Zentralisierung und Kontrolle mit seinem Konzern sehr erfolgreich war. Diese Strategien versuchte er auch bei seiner Arbeit für die Universität anzuwenden, was bei vielen auf Widerstand stieß.

28 Vgl. Goren: The View From Scopus, S. 219.

29 Myers: A New Scholarly Colony in Jerusalem, S. 153.

$30 \mathrm{Vgl}$. Minutes of the $9^{\text {th }}$ Meeting of the Board of Governors of the Hebrew University, Lucerne, 08. u. 09.09.1935. SchA, Universität, 011/2. 


\subsubsection{Professionalisierung und Zentralisierung in schwieriger Zeit: Die Entwicklung der Universität während Salman Schockens Amtsjahren}

Salman Schocken wurde 1934, ohne dass er davon zuvor in Kenntnis gesetzt wurde, ${ }^{31}$ vom Kuratorium der Hebräischen Universität zum Schatzmeister berufen $^{32}$ - das Amt entsprach seinen Fähigkeiten bestens. In dieser Funktion war er verantwortlich für das Jahresbudget der Universität. Es war seine Aufgabe, dafür zu sorgen, dass die Abteilungen ihr jeweiliges Budget nicht überzogen, was ihm die Macht gab, Gelder nicht zu bewilligen. Das Budget musste er jährlich dem Kuratorium zur Prüfung vorlegen. Zudem oblag ihm die Verwaltung des Vermögens, der Immobilien und des Landbesitzes der Universität. ${ }^{33}$ Wer Schocken für diesen Posten nominierte, ist heute nicht mehr zu eruieren, und damit ebenso wenig die Gründe, warum er für die Aufgabe gewählt wurde. Schocken befürchtete zu Beginn seiner offiziellen Tätigkeit für die Universität, dort einfach als ,reicher Mann' zu gelten, der im Notfall die Institution finanziell unterstützen würde. Buber, dem ein Brief des Kaufmanns an Lambert Schneider vorlag, in dem Schocken diese Befürchtungen zum Ausdruck brachte, versuchte ihn zu besänftigen: Die Universität sei nicht an seinem Vermögen, sondern vielmehr an seiner Reputation und seinen Verbindungen gelegen. Man erhoffe sich, so Buber, dass der Name Schocken bei potentiellen Gönnern Vertrauen erwecken würde. ${ }^{34}$ Es kann aber auch davon ausgegangen werden, dass Weizmann als Präsident der Universität, der Schocken seit Langem kannte, in ihm in erster Linie den fähigen Ökonomen sah, dem er die schwierige Aufgabe zutraute, die finanziellen Geschicke der Universität zu leiten.

Schocken war bekannt für seine strenge Finanzpolitik: Sämtliche Ausgaben ließ er minutiös prüfen. Sein Konzern, der ohne jegliche Kredite auskam, aber auch seine Arbeit in den Wirtschaftsabteilungen der Jewish Agency war weitum bekannt. Als es zu Beginn der 1930er Jahre darum ging, Magnes als Kanzler zu entmachten, lastete die bereits erwähnte Untersuchungskommission, bestehend aus Sir Philip Hartog und Dr. Redcliffe N. Salaman, diesem auch an, in

31 Vgl. Salman Schocken an Judah L. Magnes, 28.12.1934. SchA, Universität, 013/19.

$32 \mathrm{Vgl}$. Minutes of the $8^{\text {th }}$ Meeting of the Board of Governors of the Hebrew University, Zürich, 13.-16.08.1934, S. 12. SchA, Universität, 011/1.

33 Vgl. ebd., S. 10.

34 Vgl. Martin Buber an Salman Schocken, 03.10.1934. NLI, Buber Archiv, Ms. Var. 350/705I. 
wirtschaftlichen Fragen nicht kompetent gehandelt zu haben. Die Universität war während Magnes' Amtszeit größtenteils abhängig von privaten amerikanischen Spendern, die in einer persönlichen Verbindung zum Kanzler standen. Auch für Schocken war die Gewinnung von Mitteln für die Universität keine leicht zu bewältigende Aufgabe: Die jüdische Gemeinschaft war in den 1930er Jahren durch die Machtergreifung Hitlers und die Vertreibung der jüdischen Bevölkerung sehr gefordert. Es war schwierig, Gelder für akademische Arbeit einzuwerben, obwohl sich die Hebräische Universität nicht einfach in den sprichwörtlichen Elfenbeinturm zurückzog, sondern einem Teil der aus den deutschen Universitäten entlassenen jüdischen Wissenschaftler*innen die Möglichkeit bot, ihre Karrieren fortzusetzen. Der Ruf an die Jerusalemer Universität konnte Leben retten, da mit der Einstellung die britischen Behörden ein Visum für die Einreise nach Palästina ausstellten.

In den folgenden Absätzen sollen die eben erwähnten Themen genauer beleuchtet werden. Die Entwicklung, die die Universität in den 1930er Jahren nahm, geht zu weiten Teilen auf Salman Schocken zurück, der an ihrer Reorganisation und Vergrößerung arbeitete; er baute eine professionelle, im Sprachgebrauch der Zeit sogenannten Propagandaabteilung auf, diversifizierte die Finanzierung der Institution und wirkte an der Rettung deutscher Wissenschaftler und Wissenschaftlerinnen mit.

Wie aus der überlieferten Korrespondenz der beiden deutlich wird, konsultierte Weizmann Schocken bereits in der ersten Hälfte des Jahres 1935 - also bevor Schocken zum Vorsitzenden der Exekutive gewählt wurde -, mit Fragen, die nicht in Schockens Kompetenz als Schatzmeister fielen. Es ging hauptsächlich um den Ausbau der Universität, insbesondere die Einrichtung einer naturwissenschaftlichen Fakultät, um Fragen, für die eigentlich der Kanzler, also Magnes, zuständig gewesen wäre. ${ }^{35}$

Interessant in dieser Hinsicht ist auch, dass Schocken bereits im Juni 1935, also drei Monate vor seiner Wahl zum Vorstand der Exekutive, weitreichende Pläne für die Universität schmiedete. In einem Entwurf eines Briefes an Weizmann listete er die für ihn zentralsten und dringendsten Punkte auf: Die Klärung der Leitung der Universität, das heißt, die Absetzung Magnes' und die

35 Vgl. Protokoll Telefongespräch, Salman Schocken - Chaim Weizmann, 06.03.1935; Chaim Weizmann an Salman Schocken, 24.04.1935. SchA, Universität, 011/7. 
Neustrukturierung der Leitungsfunktionen durch die Abschaffung des Kanzleramtes und die Einrichtung einer reiner Ehrenpräsidentschaft, die finanzielle Sicherung der Institution, die Regelung der Assistentenordnung sowie die Klärung der Beziehung der Universität zum landwirtschaftlichen Institut in Rechovot. ${ }^{36}$ In der Kuratoriumssitzung in Luzern im September 1935 wurden, nachdem Schocken in die Funktion des Exekutivvorstandes gewählt wurde, diese Punkte besprochen. Es kam zu einer Neuorganisation der Leitungsfunktionen, eine Kommission zur Regelung der Assistierendenordnung wurde einberufen und die Beziehung zum College für Agrikultur in Rechovot wurde geklärt. $^{37}$

Es zeigte sich schon vor und besonders während Schockens Amtszeit, dass er seine Aufgaben in der Universität ernst nahm. Er beschränkte sich nicht darauf, lediglich seinen Namen als Garantie für finanzielle Sicherheit einzusetzen, sondern strebte Veränderungen und Umstrukturierungen an. Als Besitzer einer Warenhauskette und Kaufmann stand er in Deutschland einem Unternehmen mit mehreren Tausend Mitarbeitenden vor, suchte Wege, den Einzelhandel weiterzuentwickeln, neue Produktions- und Distributionsmöglichkeiten zu finden und die Verwaltung zu zentralisieren. Er zog sich nicht aus dem von ihm entworfenen Verwaltungssystem zurück, sondern hielt auch mit wachsendem Erfolg die Zügel fest in der Hand. Ähnliches scheint ihm auch für seine neue Rolle in der Universität vorgeschwebt zu haben. Die Akten zeigen, dass er an zahlreichen Sitzungen teilnahm, viele Besprechungen abhielt und über sämtliche Belange, die ihm wichtig und zentral schienen, Korrespondenz führte. Sein privates Sekretariat war damit beauftragt, ihn bei Abwesenheit über Entwicklungen und Probleme auf dem Laufenden zu halten.

Nach einem Jahr im Amt erstattete Schocken der Kuratoriumssitzung im August 1936 in Zürich erstmals Bericht. Um sich in seiner neuen Aufgabe

36 Vgl. Briefentwurf Salman Schocken an Chaim Weizmann, 09.06.1935. SchA, Universität, 011/7. Der Entwurf stammte von Gustav (Gershom) Schocken, der zu dieser Zeit seinen Vater bei dessen Aufgaben für die Universität unterstützte. Es gibt keinerlei Hinweise, dass er eine offizielle Funktion in der Universitätsverwaltung hatte, es finden sich in den Akten jedoch einige Entwürfe, Notizen, Übersetzungen und Zusammenfassungen von längeren Dokumenten, die mit Gustav Schocken signiert sind. In Rechovot befand sich der Wohnort Weizmanns sowie das landwirtschaftliche Institut, das der Universität angegliedert werden sollte.

$37 \mathrm{Vgl}$. Minutes of the $9^{\text {th }}$ Meeting of the Board of Governors, Luzern, 08.09.1935. SchA, Universität, 011/2. 
orientieren zu können, ließ er noch im Herbst 1935 eine „umfassende Bestandsaufnahme ${ }^{\text {“38 }}$ der Hebräischen Universität aufstellen. „Ich halte“, so Schocken auf der Sitzung,

die Schaffung einer Gesamtdarstellung der Hebräischen Universität, einer Art Nachschlagebuch, für unerlässlich, aus dem mühelos und systematisch festgestellt werden kann, was auf dem Skopus vorhanden ist. Dann wird auch manche falsche Vorstellung schwinden. ${ }^{39}$

Hier zeigen sich deutliche Parallelen von Schockens Führungsverständnis in Konzern und Universität: Stets basierte es auf systematischer Fehlererkennung und zentralen Lösungsansätzen. Anders als in seinem Konzern hatte Schocken als gewählter Leiter der Universität jedoch, trotz weitreichender Befugnisse seines Amtes, keine absolute Entscheidungsmacht. Er konnte Kritik üben, Verbesserungsvorschläge ausarbeiten und Ideen entwickeln - die endgültigen Entscheidungen mussten jedoch in Gremien und Versammlungen getroffen werden.

In den ersten beiden Jahren seiner Amtszeit wurde Schockens Arbeitszeit für die Universität hauptsächlich für finanzielle Belange in Anspruch genommen: Einerseits versuchte er, das Budget auszugleichen, andererseits, vor allem durch Fundraising, neue Mittel für die ständig wachsende Institution aufzubringen. Die Frage der Finanzierbarkeit stand auch bei der Einstellung deutscher Wissenschaftlerinnen und Wissenschaftler im Raum, die im Zuge des Gesetzes zur Wiederherstellung des Berufsbeamtentums vom 7. April 1933 entlassen wurden. In einem undatierten, aller Wahrscheinlichkeit nach in der ersten Hälfte des Jahres $1935^{40}$ verfassten „Statement" verdeutlicht die Universitätsleitung, dass die Jerusalemer Universität gegenüber den vertriebenen deutsch-jüdischen Wissenschaftlern - anders als alle anderen Universitäten inner- und außerhalb Europas - eine ,moralische Verantwortung' wahrnehme. Es wird aber auch deutlich, dass die Universität nur Wissenschaftler berufen will und kann, die in die Struktur der Institution passen.

38 Die Tagung des Kuratoriums der Hebräischen Universität, Auszüge aus Salman Schockens Bericht. SchA, Universität, 011/3.

39 Ebd.

40 Im Dokument werden die von der Leitung der Universität bewilligten Berufungen aus den Jahren 1933 und 1934 aufgelistet. 
That consideration has made it imperative, in selecting the appointees, to take into account also the needs of the University. For obviously only in the case of scholars holding posts that fit into the permanent structure of the University could there be justification for, and hope of, an eventual permanent appointment, funds permitting. For the same reason, it was desirable to make the appointments for a longer period than is usual elsewhere, and yet, it was obviously necessary to spread the funds at our disposal over as many appointments as possible. It has, therefore, been decided to adopt a three years plan for the time being, but at the same time to make every effort immediately to secure funds for carrying on that plan for at least two more years, after which time it may be hoped to incorporate the German refugee scholars into the regular framework of the University. ${ }^{41}$

Die Finanzierung von Stellen für die deutschen „refugee scholars“, wie die deutsch-jüdischen Wissenschaftler in den Akten oft genannt wurden, war prekär. Der englische Begriff, der kaum ins Deutsche übertragen werden kann, macht deutlich, dass es sich bei dieser Gruppe um Assistenten, wissenschaftliche Mitarbeiter und Professoren handelte, die nicht nur ihre akademische Laufbahn, sondern auch ihr Leben in Gefahr sahen. Die Finanzierung von weiteren Stellen bedeutete damit nicht nur, dass die Betroffenen ihre Karrieren und ihre Forschung weiterführen konnten, sondern auch einen Ausweg aus der bedrohlichen Situation in Deutschland.

Verschiedene Organisationen, wie die in Zürich und in London ansässige Notgemeinschaft deutscher Wissenschaftler im Ausland, ${ }^{42}$ versuchten, vertriebenen Wissenschaftlerinnen und Wissenschaftlern zu helfen. Die Hebräische Universität war ihrerseits bestrebt, so vielen wie möglich in Jerusalem eine Perspektive zu bieten. Das größte Problem dabei war, dass die Universität zu dieser Zeit kaum die Kosten des regulären Betriebes zu decken vermochte. Die betreffenden Akten verdeutlichen das große Engagement von Schocken und

41 Statement on the German refugee scholar's appointment at the Hebrew University [1935]. SchA, Universität, 052/4.

42 Zur „Notgemeinschaft“ vgl. u. a. Philip Schwartz / Helge Peukert: Notgemeinschaft. Zur Emigration deutscher Wissenschaftler nach 1933 in die Türkei. Marburg: Metropolis 1995; Gerald Kreft: Zürich und die Notgemeinschaft Deutscher Wissenschaftler im Ausland. In: Schriftenreihe der Deutschen Gesellschaft für Geschichte der Nervenheilkunde 18 (2012), S. 101-129. Im Schocken Archiv sind zudem Veröffentlichungen der Gemeinschaft zu finden (SchA, Universität, 052/4). 
Senator, zusätzliche Gelder und Spenden für die deutschen Professoren einzuwerben. Einerseits hoffte man auf private Geldgeber, andererseits auf Organisationen wie das Council for German Jewry, eine britische Organisation, die 1936 gegründet wurde, um deutschen Juden und Jüdinnen bei der Ausreise oder Flucht aus Deutschland behilflich zu sein. ${ }^{43}$

Schocken persönlich schrieb am 13. Juli 1936 an Sir Herbert Samuel, den ersten Hochkommissar des Britischen Mandatsgebietes in Palästina (1920-1925), Mitglied des House of Common und Vorsitzender der Liberal Party in England (bis 1935), und bat darum, die Universität bei der Gewinnung von Mitteln für deutsche Wissenschaftler zu unterstützen, und in ihrem Namen Gelder beim Council for German Jewry zu beantragen. Samuel hatte sich bereits in der Vergangenheit für die Sache eingesetzt, und Schocken hoffte, dass sich durch seine Vermittlung das Council eher bereit erklären würde, die Finanzierung der Stellen zu übernehmen. ${ }^{44}$ Dem Schreiben ging eine längere Auseinandersetzung mit deutschen Professoren voraus, die zu diesem Zeitpunkt bereits länger als drei Jahre an der Universität lehrten und forschten, und trotz anderweitigem Entscheid des Wa'ad ha-po'el, des Exekutivkomitees, ${ }^{45}$ nicht ins reguläre Budget der Universität überführt wurden, und damit finanziell und hierarchisch unter den übrigen Professoren standen. ${ }^{46}$ Das Council machte den Antragstellern keine große Hoffnung, da es selbst mit einem engen Budget arbeiten musste. Es gelang Schocken jedoch, das Gremium von der Not der Universität zu überzeugen: Das Council versprach am 10. Dezember einen Betrag über 2.200 £P für

43 Zur Fluchthilfe für akademische Emigranten vgl. Greg Burgess: The League of Nations and the Refugees From Nazi Germany. James G. McDonald and Hitler's Victims. London: Bloomsbury Academic 2016; Isabella Löhr: Solidarity and the Academic Community. The Support Networks for Refugee Scholars in the 1930s. In: Journal of Modern European History 12,2 (2014): Ideas, Practices and Histories of Humanitarianism, S. 231-246; Doron Niederland: The Emigration of Jewish Academics and Professionals in the First Years of Nazi Rule. In: LBIYB 33,1 (1988), S. 285-300.

44 Vgl. Salman Schocken an Sir Herbert Samuel, 13.02.1936. SchA, Universität, 052/2.

$45 \mathrm{Vgl}$. Antrag der Doktoren Alexander, Lewy, Wolfsohn und Polotsky sowie den Professoren Koebner und Wertheimer auf „Normalisierung“ ihres Status, das heißt auf Entfristung ihrer Stellen, an Salman Schocken als Vorsitzenden des Wa'ad ha-po'el; Dr. Lewy an Salman Schocken, 08.02.1936. SchA, Universität, 053/4; Entscheid des Wa'ad ha-po'el, die deutschen Professoren nach dreijähriger Amtszeit ins reguläre Budget zu übernehmen. Notiz für Herrn Schocken, 06.04.1936. SchA, Universität, 052/4.

46 Vgl. Briefe Koebner, Alexander und Wolfsohn an Salman Schocken, April und Mai 1936. SchA, Universität, 052/4. 
die deutschen Wissenschaftler ${ }^{47}$ sowie zusätzliche $3.000 £ \mathrm{P}$ für das Bureau for the Settlement of German Jews. Diese durften nur für Neuberufungen, nicht aber für schon bestehende Stellen eingesetzt werden. ${ }^{48}$

Da im Sommer 1936 ein positiver Entscheid des Council for German Jewry nicht absehbar war, wandte sich Schocken an Chaim Weizmann, der in London bestens vernetzt war, und bat ihn, bei Sir Philip Hartog in dieser Sache vorzusprechen. ${ }^{49}$ Hartog, ein Chemiker, war zu dieser Zeit Mitglied des Professional Committee des Council for German Jewry und Vorsitzender der British Friends of the Hebrew University, also ein wichtiger Akteur in diesem Netzwerk. Tatsächlich gelang es Hartog, die britischen Freunde der Universität zu überzeugen, $5.000 £$ P für die deutschen Wissenschaftler, die bereits an der Universität arbeiteten, zu spenden. ${ }^{50} \mathrm{Ob}$ die persönliche Beziehung zwischen Weizmann und Hartog oder Schockens Ruf als strenger Finanzfachmann den Ausschlag für das erfolgreiche Fundraising gaben, kann aus den Quellen nicht eruiert werden. Man kann aber davon ausgehen, dass die zahlreichen Vernetzungspunkte der Akteure den Ausgang positiv beeinflusst haben. Weizmanns Wohnsitz und hauptsächlicher Arbeitsort lag weiterhin in London und er war mit den führenden Protagonisten der Organisationen und Kommissionen bekannt und vernetzt. Salman Schocken stand seinerseits in enger Beziehung zu Weizmann und war zudem selbst oft in London zugegen.

Dennoch gelang es in den folgenden Jahren der Universitätsleitung nicht mehr, Spendengelder in dieser Höhe einzuwerben. Der Druck auf sämtliche Hilfsorganisationen wuchs durch die Entwicklungen in Deutschland. Immer mehr deutsche Jüdinnen und Juden verließen das Land und waren auf die Unterstützung von gemeinnützigen Organisationen angewiesen. 1937 erhielt die Universität noch $2.200 £ \mathrm{P}^{51}$ und im Jahr 1938 nurmehr $500 £ \mathrm{P}^{52}$ vom Council for German Jewry. Das Council war sich der schwierigen Lage der Universität bewusst, operierte jedoch selbst zunehmend mit begrenzten Mitteln und konnte daher

47 Vgl. Sekretariat des Council for German Jewry (M. Stephany) an Salman Schocken, 10.12.1936. SchA, Universität, 052/4.

48 Vgl. Norman Bentwich an Salman Schocken, 29.12.1936. SchA, Universität, 052/4.

49 Vgl. Salman Schocken an Chaim Weizmann, 13.07.1936. SchA, Universität, 052/4.

50 Vgl. Philip Hartog an Salman Schocken, 15.09.1936. SchA, Universität, 052/4.

51 Vgl. Notiz für Herrn Schocken, 06.01.1937. SchA, Universität, 052/4.

52 Vgl. Sekretariat des Council for German Jewry an Mr. Shneerson, 07.02.1938. SchA, Universität, 052/4. 
keine größeren Summen mehr spenden. Privatspenden, wie jene der Rockefeller Foundation für die Stelle von Dr. Jacob H. Polotsky für das Lehrjahr 1936/37 ${ }^{53}$ wurden zwar dankbar angenommen, vermochten die Lage aber nicht zu entspannen. Salman Schocken selber finanzierte aus seinen Privatmittel ${ }^{54}$ den Lehrstuhl Martin Bubers ${ }^{55}$ sowie die Stellen der wissenschaftlichen Mitarbeiter am Institut für die Erforschung der hebräischen Dichtung, das zwar von Schocken gegründet und finanziert wurde ${ }^{56}$ und in seiner Bibliothek untergebracht war, jedoch als Institut der Universität angegliedert war.

Die Berufung Bubers an die Hebräische Universität hat eine lange Vorgeschichte. Obwohl er zu den Ersten gehörte, die eine Universität in Jerusalem planten, ${ }^{57}$ war er beim realen Aufbau der Universität kaum involviert. 1927, als Magnes im Rahmen einer Professorensitzung die Gründung eines religionswissenschaftlichen Instituts besprach und dabei Buber als möglichen Kandidaten für den Lehrstuhl ins Gespräch brachte, wurden von der Professorenschaft Zweifel am „streng wissenschaftlichen Charakter von Bubers Lehre“ geäußert. ${ }^{58}$ Der Ruf kam nicht. Genau zwei Jahre später machte ihm Magnes, „in aller Form den Antrag [...], als ,akademisches Oberhaupt (auf Deutsch: lebenslanger Rektor)

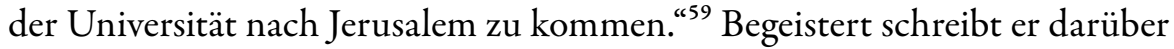
seiner Frau und meinte, nur noch die "Situation ${ }^{460}$, wohl das Finanzielle, mit Salman Schocken klären zu müssen. Magnes gelang es jedoch nicht, den Senat von der Wahl zu überzeugen. Auch ein dritter Anlauf, Buber an die Universität zu holen, scheiterte. 1934 sollte er auf Vorschlag von Gershom Scholem und Hugo Bergmann als Lehrstuhlinhaber für die hebräische Bibel oder für Jüdische Studien berufen werden. Die Fakultät stimmte der Wahl zu, diesmal war

53 Vgl. Paris Office Comptroller, The Rockefeller Foundation an Mr. M. Shneerson, 12.03.1937. SchA, Universität, 052/4.

54 Die Abrechnung lief über den Schocken-Konzern, da Schockens Privatkonten gesperrt waren.

55 Vgl. I. Schocken Söhne an Werner Senator, 20.01.1938. SchA, Universität, 031/4.

56 Vgl. Treasurer's office an M. Shneerson, 27.03.1938. SchA, Universität, 031/4.

57 Vgl. Kap. 8.1.1.

58 Vgl. Hugo Bergmann an Martin Buber, 31.08.1937. In: Buber: Briefwechsel aus sieben Jahrzehnten, Bd.2, S. 288-289.

59 Martin Buber an Franz Rosenzweig, 15.08.1929. In: Ebd., S. 338.

60 Vgl. Martin Buber an Paula Buber, o. D. [wohl 15.08.1929]. In: Ebd., S.338-339. 
es das Kuratorium, dass den Ruf verhinderte. ${ }^{61}$ Im September 1935 schließlich kam auf Schockens Insistieren eine Mehrheit im Kuratorium für eine Berufung Bubers zustande. Wie er seiner Frau schrieb, habe man sich in der Sitzung auf die Personalie, nicht aber aufs Fach einigen können. ${ }^{62}$ Zur Diskussion standen der theoretisch-pädagogische sowie der religionswissenschaftliche Lehrstuhl, für beide wurde er nicht gewählt. Schließlich einigte man sich auf eine Professur für Soziologie. ${ }^{63}$ Er trat die Stelle schließlich im Jahr 1938 an.

Die Finanzierung der deutschen refugee scholars, wie auch die hier nicht weiter erörterten Stipendien für jüdische Studierende aus Deutschland, machten nur einen Teil des finanziellen Problems der Universität aus. Mit wenigen Ausnahmen handelte es sich dabei um befristete Stellen, die unabhängig vom Globalbudget der Universität liefen. Dass dies auf Seiten der Wissenschaftler zu Unsicherheit und Frustration führte, wurde bereits deutlich. Die Schwierigkeit, ab Mitte der 1930er Jahre Gelder zu akquirieren, die eine längerfristige Planung ermöglicht hätten, darf jedoch nicht außer Acht gelassen werden. Den Universitätsmitgliedern und der Leitung lag viel daran, vertriebenen und verfolgten Akademikern zu helfen, dennoch verstand man dies nur als Teil des Auftrages. Der Aufbau der Institution, die Verbreiterung des Forschungs- und Lehrangebotes, die Gewinnung von führenden Fachwissenschaftlerinnen und -wissenschaftlern wurde trotz der Situation in Deutschland nicht vernachlässigt. Auch wenn zahlreiche Mitglieder des Verwaltungsapparates selbst aus Deutschland stammten, verstanden sie die Hochschule nicht als Exiluniversität, sondern als Teil des wachsenden jüdischen Gemeinwesens in Palästina. Sie hatte in erster Linie dessen Zielen zu dienen. Zudem hatten das kontinuierliche Wachstum und die Diversifizierung Folgen für den finanziellen Bedarf der Universität. Salman Schocken setzte daher einen großen Teil seiner Arbeitszeit, seiner Kompetenzen sowie seiner Reputation für die Gewinnung weiterer Mittel ein. Während Magnes' Amtszeit als Kanzler war die Hebräische Universität in hohem Masse von amerikanischen Großspendern abhängig. Um sie finanziell breiter abzustützen und sie aus der Abhängigkeit von Einzelpersonen zu lösen,

61 Vgl. Paul R. Mendes-Flohr: Martin Buber. A Life of Faith and Dissent. New Haven / London: Yale UP 2019, S. 204-205.

62 Vgl. Martin Buber an Paula Buber, 10.09.1935. In: Buber: Briefwechsel aus sieben Jahrzehnten, Bd.2, S. 571-572.

63 Vgl. Martin Buber an Gershom Scholem, 10.10.1935. In: Ebd., S. 574. 
versuchte Schocken, die Einwerbung von Mitteln zu diversifizieren. Dabei war nicht das Ziel, sich komplett von den amerikanischen Gönnern zu lösen, was einer der Gründe war, warum man Magnes den Ehrenposten des Präsidenten anbot. ${ }^{64}$ Schocken schwebte eine Finanzierung der Universität durch Stiftungen und Fonds vor, die es erlaubten, deren Fortbestand auch in ungünstigen Zeiten zu sichern. ${ }^{65}$ Dieses zu Beginn seiner Arbeit für die Universität formulierte Ziel wird Schocken nicht erreichen, zu gravierend war die Situation in Europa. Beträge, die von verschiedenen Organisationen zugesagt worden waren, konnten bereits 1936 nicht mehr aufgebracht werden, zudem gab es vermehrt Probleme mit dem Devisentransfer. Schocken sah sich gezwungen, sich verstärkt um Geldgeber außerhalb Kontinentaleuropas zu bemühen. Die Hoffnungen richteten sich vor allem auf Großbritannien, die USA und Südafrika. ${ }^{66}$ Schocken wollte vermeiden, dass die Finanzierung von rein persönlichen Verbindungen abhängig war, und initiierte daher eine „systematische Bestandsaufnahme der Hebräischen Universität ${ }^{\text {“67 }}$. Aus dem gesammelten Material „über alles an [der] Anstalt bestehende" sollte eine Veröffentlichung entstehen, die „den Freunden und Mitarbeitern in allen Ländern [...] berichten wird, was die Hebräische Universität heute ist. ${ }^{\text {"68 }}$ Schocken versprach sich von dieser Publikation, potentiellen Stiftern im Ausland die Entwicklung und das Potential der Universität näherzubringen. ${ }^{69}$ Schocken griff dabei auf ihm bekannte Methoden zurück. Auch die Geschäfte seines Konzernes wurden kontinuierlich statistisch erfasst und die dabei gewonnenen Daten einerseits für interne Planungen verwendet, andererseits in vereinfachter Form publiziert, um Zulieferern, Kunden und interessierten Wirtschaftsverbänden den Konzern und seine Arbeitspraxis vorzustellen. Die 1935 erfolgte Gründung der sogenannten Propaganda-Kommission der Universität, der Hugo Bergmann vorstand, ${ }^{70}$

64 Magnes war in amerikanischen, dem Zionismus positiv geneigten Kreisen höchst angesehen, er blieb das auch nach seiner Absetzung. Vgl. Samuel B. Finkel: American Jews and the Hebrew University. In: American Jewish Yearbook 39 (1938), S. 193-201.

65 Vgl. Rede des Herrn Salman Schocken am 11.11.1935. SchA, Universität, 029.

66 Vgl. Rede des Vorsitzenden der Executive der Hebräischen Universität, Herrn Schlomoh S. Schocken, zur Eröffnung des Lehrjahres 5697, 01.11.1936. SchA, Universität, 029.

67 Ebd.

68 Ebd.

69 Vgl. ebd.

70 Vgl. Protokoll der Besprechung der Propaganda-Kommission der Universität, 14.01.1935. SchA, Universität, 071/1. 
hatte die Aufgabe, durch Veröffentlichungen die Universität bekannt zu machen und neue Geldgeber zu akquirieren. ${ }^{71}$ Mehrere Dokumente nennen als die Hauptaufgabe der Abteilung, „einen Kreis wohlhabender Juden zu finden, die jährlich einen größeren Beitrag oder einmalig einen sehr hohen Beitrag ${ }^{672}$ zugunsten der Universität leisten wollten. Dazu sollten auch die Wissenschaftler hinzugezogen werden, die „mit dem jüdischen Bürgertum ${ }^{\text {“73 }}$ bekannt gemacht werden sollten. Es wird zwar bemerkt, dass die Wissenschaftler dieser Art von Arbeit gegenüber negativ eingestellt waren, da sie sich wie an anderen Universitäten der Forschung und Lehre widmen wollten. Ein Vergleich mit anderen Universitäten sei jedoch nicht zulässig, daher habe sich das wissenschaftliche Personal „zuerst der Sicherung und dem Aufbau der Universität ${ }^{\text {“74 }}$ zu widmen.

Eine nachhaltige Finanzierung der Universität ist auch Schocken nicht gelungen, eine Diversifizierung der Geldgeber jedoch schon: Der größte waren eindeutig die American Friends of the Hebrew University, eine Gruppe von Philanthropen, die jährlich hohe Summen für die Universität aufbrachten. Aber auch die südafrikanischen, britischen und Schweizer Freundeskreise trugen jährlich mit beträchtlichen Summen zum Aufbau und Bestand der Jerusalemer Hochschule bei. Daneben wurden in Deutschland durch das Aktionskomitee Sammelaktionen durchgeführt und Gelder über den Keren Hayesod ${ }^{75}$ nach Palästina transferiert. Nicht zu vergessen sind die zahlreichen Einzelspenden von Philanthropen weltweit, die Mittel zum allgemeinen Budget beitrugen oder spezifische Einrichtungen förderten.

Schocken versuchte auch die Jewish Agency sowie den Keren Hayesod stärker für die Universität zu begeistern. Das Verhältnis zwischen den Führungspersönlichkeiten des Jischuv und der Leitung der Hochschule, obwohl diese Teil des jüdischen Gemeinwesens war, blieb jedoch angespannt. Zwar war der

71 Für eine detaillierte Darstellung der Aufgaben der Abteilung vgl. Propagandaplan für die Universität [1935]. SchA, Universität, 071/1.

72 Vgl. Protokoll der Besprechung der Propaganda-Kommission der Universität, 14.01.1935. SchA, Universität, 071/1.

73 Ebd.

74 Ebd.

75 Der Keren Hayesod (hebräisch für „Gründungsfonds“) wurde 1920 in London gegründet. Zweck des Fonds war es, Gelder für den Aufbau eines jüdischen Heimatlandes in Palästina aufzubringen. 
Jischuv an der Ausbildung junger Juden und Jüdinnen interessiert, das Interesse beschränkte sich jedoch auf die praktischen Disziplinen wie Hygiene, Agrikultur, Pädagogik und Medizin. Die Universitätsleitung und ihre Wissenschaftlerinnen und Wissenschaftler verstanden sich als Teil des Jischuv, fühlten sich jedoch gleichermaßen der universitären Wissenschaftsgemeinschaft angehörig. Der Konflikt zwischen den Führungspersönlichkeiten des Jischuv und der Leitung der Universität macht deutlich, dass die Körperschaften durchaus eigene Interesse verfolgten und sich nicht einer einheitlichen (Finanz)-Politik unterordnen mochten.

Schockens Versuche, die Finanzierung neu aufzustellen und die Universität stärker in den Jischuv zu integrieren, standen in enger Verbindung mit seinem Ruf nach einer Reorganisation der Universität. Wie einleitend deutlich wurde, sparte er bereits vor seiner Wahl zum Vorsitzenden des Exekutivkomitees nicht mit Kritik an den bestehenden Zuständen. Es würde zu weit führen, sämtliche Initiativen Schockens hier im Detail zu beleuchten, die von ihm angestrebten und teilweise auch umgesetzten Veränderungen der Verwaltungsstruktur werden jedoch im Folgenden in groben Zügen aufgezeigt.

Schocken war von seinem Konzern eine zentralistische Führungs- und Verwaltungsstruktur gewohnt. An der Universität sah er sich mit dezentralen Einheiten - Fakultäten und Instituten - konfrontiert. Die akademische Selbstverwaltung, wie sie an deutschen Universitäten üblich war und welche die Lehrstuhlinhaber mit weitreichenden Kompetenzen ausstattete, war dem Kontrollmenschen Schocken suspekt. So berief er gegen den Widerstand der akademischen Mitarbeiter als Berater Otto Toeplitz, der in Deutschland seinen Lehrstuhl für Mathematik verloren hatte und aus Angst vor weiteren Repressionen dringend nach einer Auswanderungsmöglichkeit für sich und seine Frau suchte. ${ }^{76}$ Toeplitz wurde beauftragt, die Organisation der akademischen Arbeit der Universität zu prüfen,

1. mit dem Ziel einer größeren Planmäßigkeit des Aus- und Aufbaus der Universität und zur Ausarbeitung von Vorschlägen über eventuelle Umstellungen und

$76 \mathrm{Zu}$ Toeplitz' akademischer Karriere in Deutschland vgl. Walter Purkert: Otto Toeplitz (1881-1940). In: Birgit Bergmann / Moritz Epple (Hrsg.): Jüdische Mathematiker in der deutschsprachigen akademischen Kultur. Berlin / Heidelberg: Springer 2009, S. 103-109. 
Veränderungen in der Forschungs- und Lehrtätigkeit, und 2. mit dem Ziel einer Klärung der Probleme der akademischen Verfassung und Selbstverwaltung. ${ }^{77}$

Der Berufung Toeplitz' gingen zahlreiche Überlegungen Schockens voraus, die er in einer Ansprache anlässlich der Kuratoriumssitzung im September 1938 darlegte. Schocken wies darauf hin, dass sich seit 1933 das Budget der Universität von $50.000 £ \mathrm{P}$ auf $100.000 £ \mathrm{P}$ verdoppelte; zudem verfüge die Institution über ein Trustvermögen von $500.000 £ \mathrm{P}$. Genauso wichtig schien ihm der ,methodische' Bodenkauf auf dem Skopusberg mit dem Ergebnis von 250 Dunam zusammenhängendem Land im Besitz der Universität im Herbst 1938. Außerhalb dieses Geländes besaß die Universität einzelne Gebiete, die für den Hadassah-Bau sowie für zukünftige Wohnviertel verwendet werden sollten. Diese Darlegungen zu Sicherung und Aufbau der Universität unter seiner Leitung verdeutlichen, dass Schocken an nachhaltiger Stabilisierung und kontrolliertem Wachstum gelegen war. ${ }^{78}$ Dass er persönlich nur selten in Jerusalem anwesend war und daher auf engagierte Mitarbeit zahlreicher Experten angewiesen war, verschwieg er dabei nicht. Zudem thematisierte er die Probleme bei dem Verkauf seines Konzernes in Deutschland. Nun aber stehe er vor der Entscheidung, in welcher Form er sich der Universität und der Arbeit zu widmen habe. „Nach den erfolgreichen Bemühungen der letzten 10 Monate in Europa bin ich nun ein freier Privatmann, zum ersten Mal in meinem Leben. ${ }^{\text {"79 }}$ Diese Freiheit, wie er es nannte, setzte Kräfte und Zeit für die Universität frei. Diese wollte er für die Umstellung der Verwaltung nutzen, „damit nicht vorherrschend sei die Sitzung und kommissionsmäßige Beratung für Gebiete, in denen schnelles und verantwortliches Handeln besser am Platze ist. ${ }^{\text {“80 }}$ Auch die akademische Selbstverwaltung wollte er „in ähnlicher Weise “81 abändern. Ein Ansinnen, das von der Verwaltung geteilt, von den Akademikern jedoch bekämpft wurde.

77 Auftrag an Professor Töplitz, 15.07.1938. SchA, Universität, 023/2.

78 Zur vorstaatlichen Planungsgeschichte des Universitätscampus bis zur Gründung auf dem Skopusberg vgl. Diana Dolev: The Planning and Building of the Hebrew University, 1919-1948. Facing the Temple Mount. New York / London: Lexington 2016.

79 Ansprache des Herrn Schocken, Sitzungen des Kuratoriums, London, 07.-09.09.1938. SchA, Universität, 011.

80 Ebd.

81 Ebd. 
Es erstaunt nicht, dass Schocken als Praktiker und als Kaufmann mit der traditionellen Freiheit, die Akademiker an Hochschulen genossen, wenig anfangen konnte. Zwar unterstützte er als Privatmann die Arbeit von Autoren und Wissenschaftlern - wobei er auch in diesen Fällen, wie deutlich wurde, Resultate in Form von Manuskripten einforderte -, als Verwalter der Universität legte er jedoch Wert auf messbaren Nutzen. So begann Schocken - nachdem er durch den Verkauf seines Konzernes mehr Zeit hatte -, sich im Jahr 1939 intensiver mit den Geschicken der Universität auseinanderzusetzen. Dabei richtete er seine Aufmerksamkeit im Besonderen auf die Lehre. Gestützt auf Erhebungen von Toeplitz, die den Berufseinstieg der Universitätsabsolventen untersuchten, forderte er eine stärkere Gewichtung der praktischen Ausbildung an der Hochschule. Er kritisierte, dass der Fokus zu ausschließlich auf die Forschung gelegt würde, es gelte die Berufsausbildung der Studenten stärker in den Blick zu nehmen. ${ }^{82}$

Er war sich bewusst, dass die Dozenten den Eingriff in die traditionell garantierte Freiheit der Lehre nicht goutieren würden. Wiederholt, so auch bei einer Sitzung des Kuratoriums der Universität in Genf, wies er aber darauf hin, dass sich die Hebräische Universität in einer speziellen Situation befände: Erstens müsse sie sich den Bedürfnissen des Jischuv unterordnen, solange die Gesellschaft im Aufbau begriffen wäre. Zweitens seien durch die Situation in Deutschland den Absolventen die meisten Universitäten Europas als zukünftiger Arbeitsort verschlossen und es sei unmöglich, Absolventen in Jerusalem längerfristige Anstellungen in der Wissenschaft anzubieten. Und schließlich sei der größte Teil der Studentenschaft mittellos und könne nicht, wie früher üblich, auf die Unterstützung der Familie zählen, die für eine akademische Laufbahn nötig sei. Aus diesen Gründen gelte es, so Schocken, den jungen Studierenden eine gute und auf dem Arbeitsmarkt verwertbare Berufsausbildung zu garantieren. ${ }^{83}$ Schocken schwebte dabei das amerikanische Universitätsmodell vor und damit eine Mischform von freier Forschung und zielgerichteter Lehre. ${ }^{84}$

82 Vgl. Rede Salman Schocken, Sitzung des Kuratoriums der Universität in Genf, 13.08.1939. SchA, Universität, 011/5.

83 Vgl. ebd.

84 Vgl. zu den Universitätsmodellen Englands, Deutschlands und der USA: Iram: Higher Education in Transition, S.81-82. 
Viele seiner Pläne konnte Schocken nicht umsetzen, da die nötigen Mittel fehlten, aber auch, weil er sich gegen andere Gremien nicht durchsetzen konnte. Die Leitung einer Universität, so musste er feststellen, ließ sich nicht mit der eines Konzernes vergleichen. Zwar war er auch dabei auf die Mitarbeit seiner Direktoren und anderer leitender Angestellter angewiesen, als Besitzer konnte er jedoch die Struktur seines Konzernes bestimmen. In der Universität musste er auf verschiedene Gremien, Gruppierungen und deren Befindlichkeiten Rücksicht nehmen und politisch geschickt agieren. Zwar hielten sich die manifesten Konflikte - wie etwa der mit Magnes - in Grenzen, dennoch waren auch ihm Grenzen gesetzt.

Auch wenn Schocken relativ kurz als Leiter der Universität amtierte, erstaunt es, dass seine Rolle und die Erfolge seiner Arbeit in der Forschung bislang wenig Beachtung finden. In der vorliegenden Studie ist es nicht das Ziel, Schockens Arbeit für die Universität im Detail zu beleuchten, auch wenn dies - im Rahmen einer ausführlichen Geschichte der Universität - wünschenswert wäre. An dieser Stelle wird das Thema mit einem kurzen Blick auf das Vermächtnis Schockens abgeschlossen, bevor im nächsten Teilkapitel die Frage nach Schockens Motivation behandelt werden soll.

Schocken gelang es, so wurde bereits deutlich, die Finanzen der Universität während der Krisenjahre zu stabilisieren. Durch sein unermüdliches Lobbyieren, seine Reputation, die ihm half, Spender zu gewinnen, und durch seine internationale Vernetzung gelang es ihm, finanzielle Mittel für die Universität einzuwerben. So wuchs die Institution während seiner Amtszeit: Die Zahl der Mitarbeitenden, Lehrstühle und Studenten stieg beachtlich und es wurden neue Institute gegründet und renommierte Forscher an die Universität berufen. Ein weiteres Vermächtnis war der Bau von zahlreichen Gebäuden: Der HadassahBau, also die Universitätsklinik, ein gemeinsames Projekt der Hebräischen Universität und der Hadassah-Stiftung in den USA, konnte in seiner Amtszeit vollendet werden. Schocken war dabei nicht nur beim Kauf des Bodens, bei den Verhandlungen mit der Stiftung in den USA, sondern auch bei der Auswahl des Architekten involviert. Es gelang ihm, Erich Mendelsohn für das Projekt zu gewinnen, und ihn gegen Widerstände in der Universität durchzusetzen.

Es stellt sich abschließend die Frage, warum Schockens Rolle beim Aufbau der Universität heute so wenig wahrgenommen wird. Ein möglicher Erklärungsansatz ist das umstrittene Ende seiner Amtszeit: Schocken reiste im Jahr 1940 ein erstes Mal in die USA, um dort für die Universität weitere Gelder zu 
akquirieren. Er traf sich mit einflussreichen Persönlichkeiten der American Friends, des Joint Distribution Committee (Joint), den amerikanischen Mitgliedern des Boards, den Mitgliedern zionistischer Organisationen und weiterer prozionistischer Kreise. ${ }^{85}$ Dabei verfolgte er das Ziel, die Universität zu repräsentieren und die persönliche Bindung der Sponsoren an die Institution zu stärken. Letzteres wurde wichtig, da Magnes' Einfluss nachließ.

Dass Salman Schocken diese Reise im Auftrag der Universität antreten sollte, wurde damit begründet, dass er nicht nur als Vertreter der Universität, sondern auch als Kaufmann und Förderer der jüdischen Kultur wahrgenommen werde. Die Universitätsleitung versprach sich viel von seinem Renommee. ${ }^{86}$ In New York angekommen, machte sich Schocken umgehend daran, seinen Auftrag zu erfüllen. Er und seine Frau waren in Repräsentation und Networking geübt. Bald waren sie in die relevanten Kreise eingeführt und nahmen Teil an offiziellen Dinners. Auch hielt er Reden vor unterschiedlichen Gruppierungen, was seinem Besuch zusätzliches Gewicht verlieh. Wie geplant kehrte Schocken im Frühjahr 1940 von dieser ersten Reise zurück. Seine zweite USA-Reise Ende desselben Jahres sollte seinen Abschied von Jerusalem bedeuten: Zwar brach er auch zu diesem zweiten Aufenthalt im Namen der Universität auf, zurückkehren sollte er aber erst im Oktober 1945.

In diesen fünf Jahren betätigte er sich weiterhin als Fundraiser für die Hebräische Universität, aber mit dem Kriegseintritt der USA am 8. Dezember 1941 wurde es zunehmend schwierig, Gelder für die Hochschule zu akquirieren. Immer seltener trafen Briefe von ihm ein, und dies nicht nur, weil durch die Kriegshandlungen die Postwege langsamer wurden. Im Februar 1945 schrieb Weizmann an Schocken, dass die Universitätsleitung über sein Schweigen und wegen der langen Abwesenheit verunsichert und nicht erfreut sei. Von ihm als Vorstand des Exekutivkomitees würde in dieser schwierigen Zeit erwartet, dass er die Bürden mittrage; die Situation sei so nicht mehr tragbar. ${ }^{87}$ Schocken reichte daraufhin seine Demission ein, die am im Juli 1945 angenommen wurde. ${ }^{88}$

85 Eine Liste der Adressaten von Briefen, die Schocken und Senator vor Schockens Abreise an mögliche Gesprächspartner schickten, ist zu finden unter: SchA, Universität, 074/220.

86 Vgl. Werner Senator: Aufzeichnung der Reise nach Amerika, 29.05.1939. SchA, Universität, 074/220.

87 Vgl. Chaim Weizmann an Salman Schocken, 22.02.1945. SchA, Universität, 021/42.

88 Chaim Weizmann an Salman Schocken, 31.07.1945. SchA, Universität, 021/42. 
Man empfand es in Jerusalem so, dass Schocken die Universität in diesen Krisenjahren im Stich ließ. Dies wog schwerer als all seine Leistungen zuvor. Es scheint fast so, als ob damit sein Name aus dem Gedächtnis der Universität gelöscht wurde und so in Vergessenheit geriet. Sein Vermächtnis verblasste und er wurde zum unsichtbaren Verwalter der Universität der 1930er Jahre.

\subsection{Der Publizist:}

\section{Ein deutsches Programm in hebräischer Sprache}

Während der Name Schocken mit der Hebräischen Universität kaum mehr in Verbindung gebracht wird, ist er bis heute mit der israelischen Tageszeitung Haaretz eng verknüpft. Sie wird gegenwärtig in der dritten Generation von der Familie Schocken verlegt und ist die einzige noch bestehende linksliberale Tageszeitung in Israel. Haaretz wurde 1919 von mehrheitlich russischen Einwanderern gegründet. Unter den ersten Mitarbeitern finden sich bekannte Namen wie Ze'ev Jabotinsky und Achad Ha'am. Dennoch blieb die Zeitung relativ unbedeutend, bis sie im Jahr 1935 von Salman Schocken aufgekauft wurde. Schocken wollte das in Tel Aviv beheimatete Blatt zu einem modernen Medium umgestalten. So sollte die Zeitung eine Sabbat-Beilage erhalten, die von Moritz Zobel ${ }^{89}$ betreut werden sollte. Zobel verfügte als langjähriger Redaktor der Zeitschrift Die Welt, dem Zentralorgan der zionistischen Bewegung, über ausreichend Erfahrungen, arbeite jedoch, so Schocken, „für den Tagdienst [...] zu solid und zu langsam “90. Vorbild für diese Wochenendausgabe war die Frankfurter Zeitung.

Die weitreichenden Pläne Schockens für die Haaretz lassen sich dank einer mehrseitigen Gesprächsnotiz von Moritz Spitzer über eine Unterredung zwischen dem Verleger und ihm am 29. Oktober 1936 nachvollziehen, ${ }^{91}$ auch wenn Schocken in einem Brief an den Philosophen und Historiker Hans Kohn bemerkte, dass er die Absicht habe, „es dort eine Zeit lang beim Alten

89 Moritz Zobel (1876-1961) war Sekretär für hebräische Korrespondenz im Wiener Kongressbüro der zionistischen Exekutive und Übersetzer der hebräischen Beiträge für Die Welt, eine von Theodor Herzl gegründete und von 1897 bis 1914 existierende zionistische Wochenschrift. Im Schocken Verlag Berlin erschien Moritz Zobel: Das Jahr der Juden in Brauch und Liturgie. Bücherei des Schocken Verlages, Bd. 55/56. Berlin: Schocken 1936.

90 Gesprächsnotiz, Dr. Spitzer und Herrn Schocken, 29.10.1936. SchA, Verlag, 331/43.

91 Vgl. ebd. 
zu lassen und langsam im Aufbau der neuen Verlags-Organisation Änderungen vorzunehmen. ${ }^{\text {"92 }}$

Schocken entwickelte seine Ideen für die Haaretz überwiegend mit Blick auf deutsche Vorbilder. Es schwebte ihm eine dem Ideal des deutschen Bildungsbürgertums verpflichtete Zeitung vor. So merkt er in dem Gespräch mit Moritz Spitzer kritisch an, dass

in der palästinensischen Presse, mit Ausnahme der ,Palestine Post' der europäischen Literatur und den Ereignissen in der geistigen Welt grundsätzlich überhaupt keine Aufmerksamkeit zugewendet wird. Hinweise dieser Art haben mehr zufälligen Charakter. (Der,Davar 'verfolgt lediglich sozialistische und politische Literatur.) Bei der internationalen Zusammensetzung der palästinensischen Judenschaft scheint mir die Chance für ein gepflegtes, weltumfassendes Literaturblatt gegeben zu sein. ${ }^{93}$

Auch über wichtige Ereignisse in Natur- und Geisteswissenschaften müsse berichtet werden. Qualifizierte Autoren seien in Palästina genügend zu finden. Es wird - sehr trocken - festgestellt, dass ,deren Qualifikation in anderer

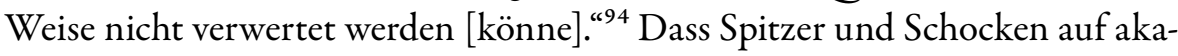
demisch gebildete Einwanderer aus Deutschland anspielten, lässt sich aufgrund der Ergänzung vermuten, dass die „meisten dieser Menschen [...] noch nicht imstande [seien], ihre Arbeiten Hebräisch abzufassen." ${ }^{\text {“9 }}$

In der Tat war es für deutsche Akademiker in Palästina außerordentlich schwierig, Arbeitsmöglichkeiten zu finden, die ihren Qualifikationen entsprachen. ${ }^{96}$ Schocken selbst hatte jungen, akademisch gebildeten Jüdinnen und Juden in Deutschland, die unter dem Druck der nationalsozialistischen Judenverfolgung eine Auswanderung nach Palästina in Erwägung zogen, wiederholt davon abgeraten. Er vertrat die Ansicht, dass, ohne reelle Chancen auf eine berufliche

92 Salman Schocken an Hans Kohn, 12.06.1936. SchA, Privates, 844/2, Bd.3.

93 Gesprächsnotiz, Dr. Spitzer und Herrn Schocken, 29.10.1936. SchA, Verlag, 331/43 (Herv. i. Orig.).

94 Ebd.

95 Ebd.

96 Vgl. Robert Jütte: Die Emigration der deutschsprachigen, Wissenschaft des Judentums.. Die Auswanderung jüdischer Historiker nach Palästina 1933-1945. Stuttgart: Steiner 1991. 
Eingliederung im Jischuv, von einer Emigration abgesehen werden sollte. ${ }^{97}$ Als Verleger verhielt er sich jedoch verantwortlich gegenüber jenen Einwanderern, die sich in Palästina wirtschaftlich nur schlecht über Wasser halten konnten.

Dass sich die Zeitung vorwiegend an ein deutsches Lesepublikum richten sollte, scheint auch dadurch naheliegend, dass er plante, eine "Sprachecke“ einzurichten, durch welche „in einem geschickten, aber dennoch seriös bleibenden Plauderton auf häufige Fehler hingewiesen wird und Anhaltspunkte für einen besonderen Gebrauch der Sprache“ gegeben werden. ${ }^{98}$ Schockens Neigung zum Pädagogischen schien auch bei der Restrukturierung des Haaretz durch.

Wie bereits bei der Einrichtung von Bücherabteilungen in seinen Warenhäusern, bei der zionistischen Arbeit und bei der Gründung seines Berliner Verlagshauses, lag Schocken auch in Palästina die Förderung der Lesekultur am Herzen. Neben der Idee, die Zeitung zu einem „gepflegte[n], weltumfassende[n] Literaturblatt“ zu machen, schwebte ihm eine Einrichtung eines „super-Abonnements auf populärwissenschaftliche und literarische Werke in wöchentlichen Bogenlieferungen (auf definitivem Buchpapier) als Abonnentenprämie“ vor. ${ }^{99}$ Literarische und populärwissenschaftliche Werke sollten als Fortsetzungen erscheinen und die Abonnenten nach Vollendung eines jeden Werkes Buchdeckel erhalten. ${ }^{100}$ Diese von den Lesern selbstgebundenen Bände sollten sich, so der Plan, in einer Serie zusammenfinden. Die Idee war nicht neu. Die tschechische Zeitung Lidové noviny gab auf diese Weise und mit Erfolg eine Serie an Fortsetzungswerken heraus. ${ }^{101}$

Die Einführung einer literarischen Serie erinnert stark an die Schocken-Bibliothek des Berliner Verlages. In der Tat können die literarischen Publikationen der Haaretz als Beginn des späteren hebräischsprachigen Schocken Verlages gelten. So zeigt die überlieferte Korrespondenz, dass zur Anfangszeit der Haaretz unter Salman Schockens Führung die Zeitung einen starken Fokus auf Literatur und Kultur legte. Erst mit der Übergabe der Leitung an seinen Sohn Gustav

97 Exemplarisch für diese Haltung steht das Schreiben Salman Schockens an Frau R. Frohknecht vom 02.01.1936, in dem er ganz deutlich sagt, dass ohne Erfahrungen in einem praktischen Beruf und ohne solide Sprachkenntnisse eine Immigration nach Palästina nicht sinnvoll sei und er daher diese nicht unterstützen könne. Vgl. SchA, Privates, 844, Bd. 2.

98 Ebd.

99 Gesprächsnotiz, Dr. Spitzer und Herrn Schocken, 29.10.1936. SchA, Verlag, 331/43.

100 Vgl. ebd.

101 Vgl. ebd. 
(Gershom) im Jahr 1939 verschiebt sich die inhaltliche Ausrichtung. Gustav, der in Heidelberg und an der London School of Economics studierte, übernahm 1939 die Leitung der Zeitung von seinem Vater. David Witzthum beschreibt die Veränderung in der Zeitungslandschaft Palästinas, die mit der Übernahme der Haaretz durch Gustav Schocken einherging, als „erste jeckische Wende “102: Die Zeitung entwickelte sich unter Gustavs Leitung ${ }^{103}$ zu einem „modernen, unparteilichen Kommunikationsmittel, das sich verpflichtete, seinen Lesern, wie in der Presse in Europa und den Vereinigten Staaten allgemein üblich, Nachrichtungen und Meinungen zu vermitteln. ${ }^{\text {104 }}$

Der Einfluss Salman Schockens auf die Zeitungslandschaft des vorstaatlichen Israels war wohl bedeutend kleiner als der seines Sohnes. Es darf jedoch nicht außer Acht gelassen werden, dass er mit dem Kauf der Zeitung und den ersten Änderungen in der Ausrichtung, die Entwicklung zu einem modernen, an europäischen Standards orientiertem Medium vorgab. Salman Schockens Prägung lässt sich insbesondere in der zentralen Position, die die Literatur in der Zeitung einnahm, ablesen. Ebenso ist sie in der ästhetischen Neugestaltung durch den von Franzisca Baruch entworfenen und bis heute nicht veränderten Zeitungskopf sichtbar. Anders als sein Sohn nahm er jedoch kaum Einfluss auf die Politik des Jischuv. Erst unter Gustav wurde die Zeitung zu jenem regierungskritischen Medium, das es bis heute geblieben ist. Für Salman Schocken stand die Verbreitung von literarischen, philosophischen und populärwissenschaftlichen Texten im Vordergrund.

Aus diesem Grund nimmt sich eine längere Episode um das Erscheinen der Jüdischen Weltrundschau (JWR) etwas seltsam heraus. ${ }^{105}$ Nachdem in

102 David Witzthum: Deutsche Presse in hebräischer Sprache. In: Zimmermann / Hotam (Hrsg.): Zweimal Heimat, S. 187-294, hier S. 289.

103 Witzthum datiert irrtümlicherweise die Übernahme der Leitung durch Gustav Schocken auf das Jahr 1937. Zwar drängte in jenem Jahr Walter Turnowsky, der frühere Sekretär des Keren Hayesod, Salman Schocken, die Leitung der Haaretz an seinen Sohn zu übergeben, dazu kam es laut den Akten jedoch erst 1939. Vgl. Walter Turnowsky an Salman Schocken, 09.05.1937. SchA, Privates, 844/2, Bd.7 (44).

104 Witzthum: Deutsche Presse in hebräischer Sprache, S. 289.

105 Der Streit zwischen Salman Schocken, resp. der Haaretz, und Kaznelson und Weltsch über die Jüdische Weltrundschau wurde erstmals in einer kürzeren Form geschildert in Stefanie Mahrer: Salman Schockens Lebensjahre in Palästina. In: Borrmann / Mölders / Wolfram (Hrsg.): Konsum und Gestalt. Leben und Werk von Salman Schocken und Erich Mendelsohn vor 1933 und im Exil, S. 103-122. 
Deutschland seit 1938 keine jüdische Presse mehr erscheinen durfte, brachten Robert Weltsch und Siegmund Kaznelson in Paris die JWR heraus. Sie war die Nachfolgerin der nunmehr verbotenen Jüdischen Rundschau und sollte deren Aufgabe übernehmen, Sprachrohr des deutschen Zionismus zu sein. Die Herausgeber formulieren dieses Selbstverständnis in der ersten Ausgabe folgendermaßen:

Nachdem das jüdische Zentrum in Deutschland verschwunden ist und von dort aus keine jüdische Zeitung die verbindende Funktion zwischen den deutschsprechenden Juden wieder aufnehmen kann, nimmt die ,Jüdische Welt-Rundschau diese Aufgabe an sich. ${ }^{106}$

Ziel war es, den deutschen Juden ein Gefühl des Zusammenhalts zu geben, über die Situation der in Deutschland Verbliebenden zu informieren und gleichzeitig das Selbstbewusstsein durch die zionistische Aufbauarbeit in Palästina zu stärken. Die Zeitung erschien in Paris, doch der Produktionssitz war in Jerusalem, was Salman Schocken energisch zu verhindern versuchte.

Nachdem er von Weltschs Plänen in Kenntnis gesetzt wurde, unternahm Schocken alles, um ihn davon abzubringen. Weltsch und Schocken waren zu diesem Zeitpunkt seit vielen Jahren durch die zionistische Arbeit eng verbunden. Ursprünglich stellte Schocken Weltsch, der nach der Zwangsschließung der Jüdischen Rundschau ohne Einkommen war, eine leitende Position bei der Haaretz in Aussicht. Doch Schocken zeigte sich in solchen Versprechen nicht immer zuverlässig, so auch bei Weltsch. Schlussendlich entschied sich Weltsch gemeinsam mit dem Verleger Kaznelson, eine deutschsprachige Zeitung für ein deutsches Lesepublikum außerhalb Deutschlands zu publizieren. In einem persönlichen Brief vom 26. Juni 1938 wandte er sich an Schocken:

Wenn ich zunächst an Palästina denke, so scheint mir, dass die Juden dort nichts so dringend brauchen wie eine Einwirkung, die ich mit einem nicht ganz präzisen Wort volkserzieherisch nennen möchte. [...] Dafür möchte ich mich einsetzen. Was nun die Publizistik betrifft, so sehe ich die Hauptschwierigkeit darin, dass die hebräische Presse faktisch nur einen kleinen Ausschnitt des Jischuv wirklich beeinflussen kann.

106 [Robert Weltsch/Siegmund Kaznelson:] An unsere Leser. In: Jüdische Weltrundschau, 10.03.1939, S. 1 . 
Die Mehrheit liest nicht Hebräisch, oder nicht fließend genug, scheut die Mühe oder hat keine Zeit dazu. Es ist daher in vorsichtiger Form schon der Gedanke aufgetaucht, die ,Jüd. Rundschau' so erscheinen zu lassen, dass sie in Palästina eine stärkere Wirkung haben könnte als bisher. ${ }^{107}$

Damit entsprachen Weltschs Überlegungen Schockens Einstellungen zur Erziehung der Massen in hohem Maße. Zudem muss sich Schocken durchaus bewusst gewesen sein, dass vielen deutschen Einwanderern - ob diese aus zionistischer Überzeugung oder aus anderen Gründen nach Palästina einwanderten -, die Lektüre einer hebräischen Zeitung schwerfiel.

Nachdem Schocken die Herausgabe der JWR nicht verhindern konnte, bekämpfte er sie nach dem Erscheinen mit allen Mitteln. Als Argument führte er an, dass die Publikation einer deutschsprachigen Wochenzeitung der zionistischen Ideologie widerspräche. Was als Unstimmigkeit begann, mündete in einer Hetzkampagne gegen Weltsch und Kaznelson. Sie wurden in öffentlichen Annoncen beschimpft, im jüdischen Palästina in der "Nazi-Sprache“ ${ }^{108} \mathrm{zu}$ publizieren; Kioske, die die Zeitung verkauften, wurden ebenso boykottiert wie Firmen und Geschäfte, die Werbung in der Zeitung platzierten.

Die Rolle Salman Schockens in diesem Streit wird in seinem Verlauf zunehmend unklar. Fakt ist, dass sich die Haaretz aktiv an der Bekämpfung der deutschsprachigen Jüdischen Weltrundschau beteiligte, und dass Schocken nicht alleinig für die harsche und teilweise diffamierende Reaktion auf die $J W R$ verantwortlich war. Es bildete sich vielmehr eine Gruppe, der Wa'ad tziburi ${ }^{109}$, welche allgemein die Verteidigung der hebräischen Sprache zum Ziel hatte. Die Befürworter der Jüdischen Weltrundschau kämpften mit vergleichbaren Mitteln gegen diese an: „Is it not curious that the youths who are persuaded to use brown-shirt methods of bullying and boycott in this case are not aware that they are serving as the commercial interest of Nazis and other people?" ${ }^{110}$

107 Robert Weltsch an Salman Schocken, 26.06.1938. SchA, Privates, 844/2, Bd. 8.

108 „Puzzle“: Published in Paris? / Edited in Jerusalem / Printed in Jerusalem / in the Nazi Language / Palestine-Jerusalem / What is it? / [Gespiegelt] The Judische [sic] Welt-Rundschau. In: Palestine Illustrated News, Jerusalem, o. D. SchA, Privates, 844/2, Bd. 8.

109 Hebräisch für öffentlicher Ausschuss, hier der Name für die Gruppierung.

110 Erich Cohen: German Papers in Palestine. Reader's Letters. In: Palestine Post, 20.04.1939, S.6. 
Auch Kurt Blumenfeld übte massive Kritik und warf seinem engen Bekannten Schocken und der Haaretz vor, dass es im Grunde gar nicht um die Verteidigung der hebräischen Sprache, sondern um den hart umkämpften Inseratemarkt gehe. ${ }^{111}$

Die Fronten des Sprachenstreites verliefen quer durch die deutsche Einwanderergemeinde und politische Zugehörigkeit. In einem zur Unterstützung gegründeten ,Freundeskreis' der $J W R$ befanden sich neben dem bereits genannten Blumenfeld u. a. Georg Landauer, Martin Buber, Siegfried Moses, Felix Rosenblüth, Arthur Ruppin, Werner Senator und das Ehepaar Ticho. ${ }^{112}$ Die Unterstützer betonten, dass

das Erlernen der Sprache einen inneren Willen voraus[setzt], der erweckt und zu dem erzogen werden muss. Erst die gefühlsmäßige Verbindung mit dem lebendigen, unser Schicksal bestimmenden Judentum kann für die ältere Generation den Ansporn bilden in ständiger Bemühung um die hebräische Sprache, ohne die in unserer Zeit Judentum nicht zu erfassen ist. Die J. W. R. ist in ihrem ganzen Geist nach eine Propaganda für das Hebräische. ${ }^{113}$

Zusammengefasst stritten sich zwei Gruppierungen darüber, wie die deutschen Einwanderer am besten im Jischuv aufgefangen, für die zionistischen Ziele begeistert und sprachlich ebenso wie kulturell integriert werden könnten. Von außen mutete dieser in großen Teilen innerdeutsche Streit wohl etwas grotesk an.

Ein Leserbriefschreiber der Palestine Post äußerte sich zum Umstand des Boykotts der deutschen Sprache durch alle palästinensischen Zeitungen und zum Fakt, dass die $J W R$ fortan in Paris gedruckt werden musste, da es in Palästina lebenden jüdischen Arbeitern untersagt wurde, für die Zeitung zu arbeiten:

It was all the more astonishing, therefore, that a May Day celebration could take place in Haifa under the patronage of the General Federation of Labour, at which Aba Hushi, Secretary of Haifa Council, spoke in German, and all performances were

111 Vgl. Kurt Blumenfeld an Salman Schocken, 22.03.1939. SchA, Privates, 844/2, Bd. 8 . 112 Vgl. für die ausführliche Liste: Freundeskreis der "Jüdischen Weltrundschau“, offener Brief, o. D. SchA, Privates, 844/2, Bd. 8 .

113 Ebd. 
likewise in this banned language. Still worse, the advertisements for this celebration were issued to the public in German. What is the reason for this inconsistency? Why is Mr. Weltsch not allowed to issue an impartial Zionist paper, chiefly addressed to German speaking Jews outside Palestine, while labour organizations may avail themselves of this ,odious' language? ${ }^{\text {114 }}$

In der Tat muss man sich fragen, warum sich Salman Schocken so vehement in die Diskussion einbrachte, die Verunglimpfung unterstützte und sich mit engen Freunden und Bekannten öffentlich zerstritt. Wenngleich sich die Wogen nach der Einstellung der Jüdischen Weltrundschau wieder glätteten und Robert Weltsch Ende 1945 mit Schocken sogar wegen einer Mitarbeit bei der Haaretz in Kontakt stand, hatte der Sprachenstreit tiefgehende und vielfältige Ursachen.

Zum Verständnis der Auseinandersetzung gilt es, Salman Schockens Interessen als Herausgeber der Haaretz zu betrachten. Der Inseratemarkt war angesichts einer noch recht schwachen Wirtschaft im vorstaatlichen Israel klein und daher stark umkämpft. Es ging aber um mehr als nur um wirtschaftliche Interessen. Der Konflikt begann zu einem Zeitpunkt, als den deutschen Juden in Palästina klarwurde, dass die Tore nach Europa nun endgültig verschlossen waren. War es bis Ende 1938 noch möglich, dorthin zu reisen, wurde dies im Laufe des Frühjahres 1939 immer schwieriger. So verbrachte auch Schocken zwar den Februar und März 1939 in Amsterdam und Paris, und den August und September in Genf und London, dies steht jedoch in keinem Vergleich zu den vorherigen Jahren, in denen er sich von Januar bis April und von September bis November in Europa aufhielt. Zudem waren zum Zeitpunkt des Streits alle jüdischen Firmen und Geschäfte in Deutschland arisiert: Schockens Warenhäuser waren zwangsverkauft und sein Verlag aufgelöst. Die aus diesen Entwicklungen resultierenden politischen und wirtschaftlichen Sorgen und Frustrationen betrafen alle aus Deutschland Eingewanderten; dies spielte in der Zuspitzung der Auseinandersetzung eine wohl nicht unwichtige Rolle.

Die Kontroverse um das Erscheinen der deutschsprachigen $J W R$ markiert auch das Ende von Schockens Wirken in der Haaretz. Im Oktober 1939 übergab er die Leitung offiziell an Gustav und zog sich selbst zurück. Auch wenn Haaretz in den Anfangsjahren unter Salman Schocken noch wenig Einfluss auf die

114 H. Herzberg: The 'No German' Campaign. To the Editor of the Palestine Post. Reader's Letters. In: Palestine Post, 09.05.1939, S.6. 
Politik des Jischuv ausübte, so stellte er mit seiner inhaltlichen und ästhetischen Modernisierung der Zeitung doch die Weichen. Durch seine Verbindungen konnte er in den deutschsprachigen Emigrantenkreisen bekannte Autoren wie Martin Buber und Gershom Scholem für Artikel gewinnen. Damit schuf er jedoch eher ein Kultur- und Literaturblatt als eine am politischen Geschehen interessierte Tageszeitung.

Witzthum folgert in seinem Artikel über die deutsche Presse in hebräischer Sprache, dass die Jeckes an ihrer Zugehörigkeit zur deutschen Kultur festhielten und deren Werte allen Widerständen zum Trotz weitergaben. Entsprechend leisteten sie zentrale Beiträge in Verwaltung, Justiz, Universität und Presse, jedoch nicht in der Politik. ${ }^{15}$ So auch Salman Schocken: Sein Einfluss in Palästina erstreckte sich auf die Felder der Ästhetik, der Kultur und der Verwaltung der Universität. Dies war in Schockens Fall nicht ,fehlenden Ellbogen geschuldet, die Witzthum den deutschen Immigranten kategorisch abspricht; ${ }^{116}$ diese Feststellung müsste ohnehin einer kritischen Analyse unterzogen werden, aber sicherlich trifft sie für Salman Schocken nicht zu. Vielmehr richtet sich sein Interesse schlichtweg auf andere Gegenstände: Verwaltung, Kultur und Ästhetik. So stellt die Haaretz unter Schocken sich eher als Vorläufer und Wegbereiter seines hebräischen Verlagshauses dar, denn als eine politische Zeitung. Eine stärkere Hinwendung zum Politischen vollzog Gustav, der zwar das Interesse seines Vaters an Literatur und Ästhetik teilte, ${ }^{117}$ aber die Rolle des Verlegers auch darin sah, die politischen Verhältnisse kritisch zu kommentieren. ${ }^{118}$ Die Idee hinter dem Jerusalemer Verlag ähnelt Schockens Überlegungen, als er das Berliner Haus gründete. Er wollte den Juden, die gezwungen waren, ihre Heimat zu verlassen und sich in Palästina niederzulassen, gute Bücher in Hebräisch anbieten, damit es zur ,Sprache der jüdischen Masse‘ werde. Dabei plante er Übersetzungen bestehender Texte, die Herausgabe neuer Werke von Autorinnen und Autoren, die in Deutschland nicht mehr publizieren konnten,

115 Vgl. Witzthum: Deutsche Presse in hebräischer Sprache, S. 292.

116 Vgl. ebd.

117 Gustav Schocken führte einerseits die enge Verbindung zu Salman Schockens Autoren über dessen Emigration und Tod hinaus fort, andererseits veröffentlichte er unter Pseudonymen eigene Gedichte.

118 Vgl. u. a. Peter B. Flint: Gershom G. Schocken, 78, Editor of Israeli Newspaper for 50 Years. In: The New York Times, 24.12.1990, S. 48. 
aber auch hebräischer Literatur von bereits ansässigen Autoren. ${ }^{119}$ Er wollte es jedoch vermeiden, einen ,Exilverlag zu gründen. Getreu Schockens pädagogischem Sendungsbewusstsein sah er den Auftrag seines Verlages darin, deutschen Exilanten zu helfen, Zugang zur neuen, hebräischen Kultur zu finden. In den ersten Jahren publizierte der Verlag jedoch größtenteils Übersetzungen von Büchern, die im deutschen Verlag erschienen waren. Lediglich die Arbeiten Agnons wurden in ihrer Originalsprache Hebräisch verlegt, aber auch Agnon war Verlagsautor des Berliner Hauses.

Aus unterschiedlichen Gründen war die Anzahl der publizierten Bücher in den Anfangsjahren eher gering. Neben praktischen Problemen wie der Knappheit von Druckpapier gestaltete sich auch das Akquirieren von Manuskripten schwierig; an Ideen fehlte es jedoch zu keiner Zeit. 1938 spielten Salman und Gershom Schocken mit der Idee, ein Programm namens hebräische Bücherei zu lancieren, womit man an die erfolgreichste Reihe der Berliner Schocken Verlages anknüpfen wollte. Gershom Schocken schickte im Mai 1938 eine Liste mit möglichen Titeln an Martin Buber. Interessant an der Zusammenstellung ist, dass es sich dabei ohne Ausnahme um Titel nichtjüdischer Autoren und Philosophen des europäischen Kanons handelte, die in hebräischer Übersetzung gebracht werden sollten. ${ }^{120}$ Jedoch wurden diese Pläne zunächst nicht verwirklicht. Später, unter der Leitung von Gershom Schocken und danach unter Racheli Edelman, wurde der Verlag in der Tat für seine Übersetzung wichtiger europäischer und US-amerikanischer Belletristik sowie von Klassikern der kontinentalen Philosophie bekannt.

Es ist auf Grundlage der vorliegenden Quellen kaum zu rekonstruieren, welchen Einfluss der Verlag unter Salman Schockens Leitung auf die Gesellschaft des Jischuv hatte. Auch in der Forschungsliteratur finden sich diesbezüglich nur allgemeine, wenig detaillierte Hinweise. ${ }^{121}$ Die Tatsache, dass die Bestände

119 Vgl. Gesprächsnotiz, Dr. Spitzer und Herrn Schocken, 29.10.1936. SchA, Verlag, 331/43. 120 Vgl. Gershom Schocken an Martin Buber, 15.05.1938. NLI, Buber Archiv, Ms. Var. $350 / 705$.

121 Vgl. Andreas Kilcher: Deutsche Sprachkultur in Palästina und Israel im 20. Jahrhundert. Historisch-politischer Kontext und literarische Kultur. In: Ders. / Eva Edelmann-Ohler (Hrsg.): Deutsche Sprachkultur in Palästina/Israel. Geschichte und Bibliographie. Berlin: de Gruyter 2016, S.9-63, hier S.38; Matthias Hambrock: Das ,jüdische Buch“ und seine Verlage im deutschsprachigen Raum. In: Handbuch der deutsch-jüdischen Literatur, hrsg. v. Hans Otto Horch. Berlin: de Gruyter 2015, S. 539-554, hier S. 551. 
des Verlages nicht zugänglich sind, erschwert die Bewertung zusätzlich. Vor diesem Hintergrund kann festgehalten werden, dass Salman Schocken mit der Gründung seines zweiten Verlages an Bekanntes anzuknüpfen versuchte, zugleich wollte er sein Programm erweitern. Der Verlag wie auch die Zeitung blühten jedoch erst unter der Leitung von Gershom Schocken auf, der anders als sein Vater Teil der Gesellschaft des Jischuv und später des jungen Staates Israel war. 



\section{9 \\ Zwischen zwei Realitäten}

\section{3 bis 1940}

Salman Schocken gehörte zu jener Minderheit deutscher Juden, der es gelang, nicht nur das Leben, sondern auch den größten Teil des Besitzes vor der nationalsozialistischen Verfolgung zu retten und weiterhin ein bürgerliches Leben zu führen. Wie im dritten Kapitel dargestellt, prosperierten seine Unternehmungen trotz seiner Emigration im Jahre 1933. Der Konzern blieb bis 1938 in seinem Besitz und der Verlag wuchs in den ersten Jahren der nationalsozialistischen Herrschaft. Schocken vergrößerte zudem seine Büchersammlungen mit gezielten Ankäufen; ${ }^{1}$ kompetente Mitarbeiterinnen und Mitarbeiter waren mit der Pflege der Immobilien betraut, und organisierten ebenso die Verschiffung der Möbel, der Bibliotheken und anderer Wertgegenstände. Sein Freundes- und Bekanntenkreis migrierte ebenfalls größtenteils nach Jerusalem, wo er - als erfolgreicher und wohlhabender Zionist - bald am Aufbau des Kultur- und Geisteslebens des Jischuv beteiligt war. Gleichzeitig wurde er von vielen Seiten um Hilfe für eine Emigration aus dem zunehmend judenfeindlichen Europa gebeten. Mitarbeitende, Verwandte, Bekannte der Familie, Künstler und Literaten, aber auch völlig unbekannte Personen erhofften sich von Salman Schocken finanzielle Unterstützung bei dem Versuch, Deutschland zu verlassen oder sie baten ihn um persönliche Einflussnahme und Referenzschreiben.

In dem folgenden letzten Kapitel, das sich mit Schockens Leben in Jerusalem beschäftigt, soll es um diesen biographisch schwierigen Balanceakt zwischen

1 Vgl. u. a. die Korrespondenz zwischen Schocken und seiner engen Mitarbeiterin Edith Michelsen in SchA, Privates, 844/2, Bd. 5. 
Alltag und Verfolgung gehen. Auf der einen Seite bemühte sich Schocken um Normalität: um Kontinuität im Geschäftlichen und um den Aufbau einer neuen Existenz in Jerusalem. Auf der anderen Seite zeigten zahlreiche Bittgesuche, der Kontakt mit verzweifelten Emigranten und die Nachrichten von Verfolgung und Boykott, dass es für Juden und Jüdinnen in Europa keine Normalität mehr gab. Dieses Nebeneinander von äußerst unterschiedlichen Realitäten führte dazu, so lautet die im Folgenden ausgeführte These, dass Salman Schocken ab 1934 ein Leben im Dazwischen führte: ein Leben auf zwei Kontinenten, ein Leben zwischen Normalität und Verfolgung, und ein Leben zwischen Erfolg und Scheitern. Diesen drei Themenkreisen wird in diesem Kapitel nachgegangen.

\subsection{Schocken in Palästina, Schocken in Europa - ein Leben auf zwei Kontinenten}

Von 1934 bis 1940 lebte Salman Schocken offiziell in Jerusalem. Während dieser Zeit ließ er eine Villa für seine Familie und eine Bibliothek für seine Bücher bauen, stand der Hebräischen Universität vor, übernahm eine Tageszeitung und gründete einen Verlag. Er war Gastgeber zahlreicher Veranstaltungen, förderte Künstler und Wissenschaftler im Land, war in Kontakt mit Politikern und Behörden, obwohl er selbst kaum vor Ort war. Die Auswertung der Akten "Reisen“2 im Schocken Archiv sowie die Erfassung der Orte, an denen Briefe Schockens versendet wurden, gibt recht genaue Auskunft über seine An- und Abwesenheit in Jerusalem.

1934, also im ersten Jahr seiner offiziellen Niederlassung in Jerusalem verbrachte Schocken vom 14. April an fünfeinhalb Monate, nämlich bis zum 30. September, in Europa. Während einer Woche hielt er sich in der Schweiz auf, wo er an Sitzungen der Hebräischen Universität teilnahm und sich um die Verwaltung seines Vermögens kümmerte. ${ }^{3}$ Zehn Tage war er zudem zur Kur im tschechischen Marienbad. ${ }^{4}$ Die restliche Zeit verbrachte er vornehmlich aus geschäftlichen Gründen in Berlin. Auch im darauffolgenden Jahr verlebte

2 SchA, Privates, 845/3.

3 Vgl. Aufenthalte des Herrn Schocken in Europa 1934/35. SchA, Privates, 835/5.

$4 \mathrm{Zu}$ Marienbad als Kurort für jüdische Gäste vgl. Miriam Triendl-Zadoff: Nächstes Jahr in Marienbad. Gegenwelten jüdischer Kulturen der Moderne. Göttingen: Vandenhoeck \& Ruprecht 2007. 
er fünf Monate in Europa, wo er wiederum größtenteils geschäftlich in Berlin weilte, aber auch einen Monat in Marienbad und in Donauwörth kurte und zu Sitzungen und Vermögensverwaltung in die Schweiz fuhr. 1936 verbrachte er fast sieben Monate in Europa, jedoch mied er Deutschland und hielt sich vornehmlich in Amsterdam, London, Zürich und Lugano auf. Zwar war ursprünglich ein Besuch in Deutschland zwecks Bücherbeschaffung für die Hebräische Universität vorgesehen, Schocken entschied sich jedoch aus unbekannten Gründen gegen die Reise. ${ }^{5}$ Erst nach Kriegsende wird er sich wieder in Deutschland aufhalten.

1937 reiste Schocken dreimal nach Europa, wo er knapp vier Monate geschäftlich und privat in Zürich, und vier weitere Monate in Amsterdam und Wien verbrachte. In Zürich wohnte er in der Regel im noblen Hotel Bellerive am Utoquai direkt am See. ${ }^{6}$ Über den Jahreswechsel 1937/38 stieg er im schweizerischen St. Moritz ab, um ab dem 14. Januar weitere drei Monate in Zürich zu arbeiten. Er kehrte erst Mitte April nach Jerusalem zurück, wo er bis Ende August blieb, bevor er sich ein weiteres Mal in Haifa einschiffte. Den September brachte er in London und Paris zu, von dort aus reiste er weiter er nach Zürich, wo er den Oktober verbrachte, um dann für einen weiteren Monat nach London zurückzukehren.

Gesundheitliche Probleme mit seinen Augen zwangen ihn im Februar 1939 mit dem Flugzeug nach Holland zu reisen, wo er sich einer Augenoperation zu unterziehen hatte. Nach einem einmonatigen Aufenthalt in Amsterdam und Utrecht reiste er im März nach Paris weiter, von wo er nach einem weiteren Monat die Rückreise nach Palästina antrat. Im August reiste er ein weiteres Mal nach Europa, um am Zionistenkongress in Genf teilzunehmen und im Anschluss für weitere Sitzungen nach London zu reisen. Den Oktober und November verbrachte Schocken in Jerusalem. Anfang Dezember fuhr er gemeinsam mit seiner Frau im Auftrag der Hebräischen Universität in die USA. Über Rom kehrten sie - ein letztes Mal - nach Palästina zurück.

Diese knappe Rekonstruktion von Schockens Reisen verdeutlicht, wie sehr er auch nach seiner Emigration nach Palästina in Europa verwurzelt blieb. Trotz der Restriktionen, denen Juden bei Reisen unterworfen waren, da zahlreiche europäische Staaten jüdischen Emigranten und Flüchtlingen die Einreise bzw.

5 Vgl. Bericht für Herrn Schocken, 05.02.1936. SchA, Privates, 835/5.

6 Das lässt sich den Absendeadressen diverser Briefe entnehmen. 
den Aufenthalt verweigerten, konnten Salman Schocken und seine Frau, die ihn auf einigen Reisen begleitete, mühelos reisen. Durch ihre palästinensischen Pässe wurden ihnen problemlos Visa ausgestellt. Für die Schweiz, die den Grenzübertritt von Juden besonders restriktiv handhabte, ${ }^{7}$ war für Inhaber palästinensischer Pässe noch nicht einmal ein Visum nötig. ${ }^{8}$ So lebte Salman Schocken in den Jahren 1934 bis 1939 auf zwei Kontinenten, und war privat wie geschäftlich mit beiden verbunden.

In den vorigen Kapiteln ging es in erster Linie um Schockens Leben in Palästina inklusive der Immobilien in Rechavia, die eine gefestigte Niederlassung in Jerusalem suggerierten, und um seinen Beitrag beim Aufbau des jüdischen Gemeinwesens. Schockens Existenz in Palästina war jedoch weit weniger gefestigt als vor diesem Hintergrund zu vermuten wäre. Mindestens die Hälfte jedes Jahres verbrachte er in Europa, nahm an Sitzungen teil, traf seine Mitarbeitenden, kaufte Bücher für seine Sammlungen und ließ sich ärztlich behandeln. Ermöglicht wurde diese Existenz durch ein gut eingespieltes Team von Mitarbeitenden, im Besonderen die mitreisenden Sekretäre und Sekretärinnen. Schocken war bei Weitem nicht der einzige jüdische Emigrant, der bis zu Beginn des Zweiten Weltkrieges regelmäßig nach Europa reiste. Führende Zionisten, aber auch Wissenschaftler und Geschäftsleute verbrachten Teile eines jeden Jahres aus beruflichen oder privaten Gründen in Europa.'

Sitzungen der Universität fanden in der Regel in der Schweiz oder in London statt, wo zahlreiche internationale Organisationen ihren Sitz hatten. Aber auch Sitzungen und Versammlungen der Zionistischen Weltorganisation sowie ihrer Gremien wurden in Europa abgehalten. Zahlreiche Mitarbeiter und Delegierte verließen zwar Deutschland, ließen sich jedoch in den angrenzenden europäischen Staaten in der Hoffnung nieder, dass sich die Lage in Deutschland bald normalisieren würde. Sitzungen in Palästina abzuhalten, war schon aus diesem Grund wenig sinnvoll. Dazu kam, dass für die Einreise nach Palästina ein Visum der britischen Mandatsmacht eingeholt werden musste und diese restriktive Kriterien für die Vergabe anwendete. Auch wenn Schocken mit seinen

7 Vgl. u. a. Michèle Fleury/Valérie Boillat: Die Schweiz und die Flüchtlinge zur Zeit des Nationalsozialismus. Zürich: Chronos 2001.

8 Vgl. Theodor Schocken an Herrn Bergner (Palestine \& Egypt Lloyd), 08.07.1937. SchA, Privates, $835 / 5$.

9 Dieses Phänomen wurde von der Forschung bislang noch nicht untersucht. 
mehrmonatigen Europaaufenthalten sicherlich ein extremes Beispiel ist, lässt sich an seiner Korrespondenz ablesen, wie mobil dieser Kreis von Personen war. Mit wenigen Ausnahmen scheint auch die Kommunikation problemlos funktioniert zu haben. Dank Telegrammen konnten Nachrichten selbst auf den Schiffspassagen gesendet und empfangen werden. Gerade diese an sich ruhige Zeit auf den Reiseschiffen wurde gerne für informelle Treffen verwendet.

Wie beliebt Reisen von Palästina nach Europa waren, zeigt eine kurze Klammerbemerkung von Salman Schocken in einem Brief an Karl Eskuchen vom Juni 1937: "Jetzt ist überhaupt die Reiserichtung nach Europa so stark en vogue, dass alle Schiffe bis Ende Juli ausverkauft sind, und man erörtert sogar die Tage einen Flug. ${ }^{\text {"10 }}$ Gerade die in Palästina heißen und staubigen Sommermonate wurden gerne im klimatisch angenehmeren Europa verbracht. Entsprechend fanden auch die Zionistenkongresse und die im Vorfeld oder Anschluss geplanten Gremiensitzungen meist in den Sommermonaten statt. Jedoch waren Schockens Reisen selten rein geschäftlicher und politischer Natur. So ließen er und seine Frau z. B. wichtige Operationen nicht in Palästina durchführen, sondern von Koryphäen in europäischen Kliniken. ${ }^{11}$

Europa und insbesondere die Schweiz waren zudem beliebte Ziele für Urlaubsreisen. Salman Schocken brachte jährlich mehrere Wochen im bei solventen Reisenden beliebten St. Moritz zu. ${ }^{12}$ Aber auch Gershom Scholem verbrachte noch im August 1938 einen Urlaub in der Schweiz. Das ist umso bemerkenswerter, als die Schweiz im August 1938 als Reaktion auf den sogenannten Anschluss Österreichs die Grenzen für Juden und Jüdinnen sperrte. Die Einführung des ,Judenstempels - die Markierung der Pässe jüdischer Inhaber wurde ebenfalls von schweizerischer Seite angeregt. ${ }^{13}$ Für jüdische Emigranten und Flüchtlinge war durch die Grenzschließung und die rassistische Markierung

10 Salman Schocken an Prof. Eskuchen, 24.06.1937. SchA, Privates, 844/2, Bd.2.

11 Vgl. Korrespondenz zwischen Salman Schocken und Prof. Eskuchen, April bis Juli 1937. SchA, Privates, 844/2, Bd.2, und Korrespondenz zwischen Dora Landauer, Lili Schocken und dem Sekretariat in Jerusalem, Februar und März 1939. SchA, Privates, 844/2, Bd. 4.

12 Vgl. Salman Schocken an S.J. Agnon, 13.01.1938. NLI, Agnon Archiv, Arc. 41270.

13 Vgl. Heinz Roschewski: Rothmund und die Juden. Eine historische Fallstudie des Antisemitismus in der schweizerischen Flüchtlingspolitik 1933-1957. Basel: Helbing \& Lichtenhahn 1997; Regula Lüdi: Dwindling Options. Seeking Asylum in Switzerland 1933-1939. In: Caestecker / Moore (Hrsg.): Refugees From Nazi Germany and the Liberal European States, S. 82-102; Fleury / Boillat: Die Schweiz und die Flüchtlinge zur Zeit des Nationalsozialismus. 
der Reisepapiere die Reise in die politisch neutrale Schweiz nur noch bei ausreichendem Vermögen möglich. Damit war ein wichtiges Flucht- und Durchgangsland für notleidende und verfolgte deutsche und österreichische Jüdinnen und Juden verschlossen. Salman Schocken, der 1938 noch recht frei reisen konnte, bekam die Restriktionen zunächst indirekt zu spüren.

Nachdem Schocken Deutschland nach 1936 nicht mehr betrat, wickelte er Geschäftliches in der Regel in Zürich ab. Dort logierte er jeweils in einer Suite und mietete zusätzliche Zimmer für Sekretäre, die ihn auf seinen Reisen begleiteten. Für Sitzungen mit den Direktoren des Schocken-Konzerns wurden diese jeweils für einige Tage nach Zürich bestellt. Ebenso fanden wichtige Besprechungen des Verlages dort statt. Die Schweizer Behörden scheinen dabei bis zum Spätsommer 1938 keine Probleme bereitet zu haben. Während Schocken weiterhin unbehelligt einreisen durfte, wurde Moritz Spitzer, der im Oktober zu Besprechungen mit Schocken in Zürich erwartet wurde, das Visum verweigert.

Spitzer und Schocken trafen sich Mitte September kurz in London und wollten zu ausführlichen Besprechungen im Oktober nochmals in Zürich zusammenkommen. Die Sitzung wurde anberaumt, weil es erstmals zu größeren Problemen durch Zensur kam. Ein Viertel der Almanachtexte der Ausgabe zu Rosch ha-Schana 1938 wurde von den nationalsozialistischen Behörden beanstandet und gestrichen. Schocken wünschte dies mit Spitzer zu besprechen, der zu dem Treffen jedoch nicht erscheinen konnte, da er kein Visum für die Schweiz mehr erhielt, oder, wie es Schocken in einem Brief an Scholem knapp bemerkte, „aus Passgründen nicht reisen durfte ${ }^{\text {"14 }}$. Der Herbst 1938 stellte nun auch für Schocken einen Einschnitt dar: Zwar durften er und seine Familie sich weiterhin frei bewegen, seine Mitarbeiter waren jedoch Einschränkungen unterworfen. Moritz Spitzer befand sich als tschechoslowakischer Jude im Herbst 1938 in einer beängstigenden Situation. Er befürchtete im Kontext der Sudetenkrise ${ }^{15}$, dass er ohne Vorwarnung interniert werden könnte. Der Konflikt zwischen Hitlerdeutschland und der Tschechoslowakei schwelte seit dem Jahr 1935, als die Autonomiebewegung der rund dreieinhalb Millionen Sudetendeutschen

14 Salman Schocken an Gershom Scholem, 31.10.1938. NLI, Scholem Archiv, Arc. 4 1599, 013050, Bd. 10.

15 Vgl. zur Sudetenkrise: Detlef Brandes: Die Sudetendeutschen im Krisenjahr 1938. München: Oldenbourg 2008. 
sich verstärkt nationalsozialistisch orientierte. Die Sudetendeutsche Partei unter der Führung Konrad Henleins ${ }^{16}$ wuchs durch Wahlen im Mai 1935 zur größten Partei der Tschechoslowakei an. Die Expansionsbestrebungen des nationalsozialistischen Deutschlands, die im März 1938 vorerst im ,Anschluss' Österreichs an das Deutsche Reich kulminierten, beunruhigte die europäischen Großmächte, die um die Sicherheit des Kontinentes fürchteten. Der ,Anschluss Österreichs führte zu großen Demonstrationen von Sudetendeutschen, die unter dem Motto ,Heim ins Reich!'standen. Die Tschechoslowakei verfügte am 21. Mai eine Teilmobilmachung, die von Frankreich und Großbritannien gebilligt wurde. Hitler sah sich dadurch veranlasst, mehrfach die ,Beseitigung der Tschechoslowakei zu fordern. Die sogenannte Sudetenkrise eskalierte am 12. September 1938, als Hitler vor dem Reichsparteitag die Prager Regierung als verbrecherisch bezeichnete und verkündete, dass er die, Unterdrückung der deutschen Volksgenossen' nicht länger hinnehmen werde. Die Rede löste im Sudetenland einen Aufstand auf, der zahlreiche Opfer forderte. Daraufhin brachte sich der britische Premierminister Arthur Neville Chamberlain ein, der ein persönliches Treffen mit Hitler forderte. Ein erstes Treffen zwischen Hitler und Chamberlain fand am 15. September statt; Hitler forderte hierbei die Angliederung des Sudetenlandes an das Deutsche Reich.

Europa stand vor einem Krieg. Am 29. September kam mit dem Münchner Abkommen in letzter Minute eine Übereinkunft zustande. ${ }^{17}$ Das von den Ministerpräsidenten Frankreichs, Édouard Daladier, Englands, Neville Chamberlain, und Italiens, Benito Mussolini, unterzeichnete Abkommen, verpflichtete die Tschechoslowakei, die bei dem Treffen nicht vertreten war, die Sudetengebiete am 1. Oktober 1938 an Deutschland abzutreten, im Gegenzug wurde die Autonomie des restlichen Staatsgebietes gewährleistet. Damit war die politische Krise vorerst gebannt.

Moritz Spitzer war von der Sudetenkrise doppelt betroffen. Einerseits verlor sein Pass an Wert, da er infolge der Krise in Europa als potentieller Flüchtling galt, der möglicherweise das Gastland nicht mehr verlassen wollte oder konnte.

$16 \mathrm{Zu}$ Konrad Henlein vgl. Ralf Gebel: ,Heim ins Reich!' Konrad Henlein und der Reichsgau Sudetenland (1938-1945). München: Oldenbourg 2000.

17 Zum Münchner Abkommen vgl. u. a. Jürgen Zarusky / Institut für Zeitgeschichte (Hrsg.): Das Münchener Abkommen von 1938 in europäischer Perspektive. München: Oldenbourg 2013; David Faber: Munich. The 1938 Appeasement Crisis. London: Pocket Books 2009. 
Andererseits war er nun der Willkür der deutschen Machthaber ungeschützt ausgeliefert. Entsprechend löste die Nachricht, dass es Chamberlain am 15. September nicht gelang, die Krise zu beruhigen, bei Moritz Spitzer Panik aus und bewog ihn zu einer überstürzten Ausreise nach Holland. Er schilderte Schocken, dass er Angst habe, als Tschechoslowake „selbst ohne Krieg oder Abbruch der diplomatischen Beziehungen [...] Opfer von Repressalien deutscher Stellen gegen irgendwelche Maßnahmen der tschechischen Regierung im eigenen Land zu werden. ${ }^{\text {"18 }}$ Bereits im Juni schrieb er an Schocken, die Verlagsarbeit in Deutschland würde kaum mehr lange fortgesetzt werden können, zumal der Käuferkreis für jüdische Bücher immer kleiner werde. ${ }^{19}$ Zur Bedrohung seiner persönlichen Sicherheit durch die Sudetenkrise kam damit die Unsicherheit über das Weiterbestehen der deutsch-jüdischen Kulturarbeit, mit der er seinen Lebensunterhalt bestritt. Daher wollte er, wie er Theodor Schocken anvertraute, Deutschland wenn möglich noch im Jahr 1938 verlassen. ${ }^{20}$ Die Kulmination der Sudetenkrise setzte ihn weiter unter Druck. In jenem Brief an Salman Schocken, in dem er ihn über die überhastete Flucht nach Amsterdam in Kenntnis setzte, brachte er auch seine Angst zum Ausdruck, dass

mein tschechischer Pass kein Pass mehr sein wird, und ich nirgendwo mehr eingelassen werde. Ich hatte jetzt schon die größten Schwierigkeiten, in Holland eingelassen zu werden. Ohne Igersheimer $\left[{ }^{21}\right]$, der mich abholte, wäre es nicht gelungen hereinzukommen. ${ }^{22}$

18 Moritz Spitzer an Salman Schocken, 16.09.1938. SchA, Verlag, 331/43.

19 Vgl. Moritz Spitzer an Salman Schocken, 17.06.1938. SchA, Verlag, 331/43. Darüber beriet sich Spitzer auch mit Theodor Schocken, der von diesem Gespräch in einem Brief an seinen Vater berichtete: Theodor Schocken an Salman Schocken, 14.07.1938. SchA, 331/43.

20 Vgl. Theodor Schocken an Salman Schocken, 14.07.1938. SchA, Verlag, 331/43.

21 Hermann Igersheimer, Cousin Max Horkheimers, war Buchhändler in Amsterdam, wohin er 1924 migrierte. Er verließ Holland 1941 und ließ sich in New York nieder. Vgl. Manfred R. Jacobson / Jacobson Evelyn M: Max Horkheimer. A Life in Letters. Selected Correspondence. Lincoln, NE: U of Nebraska P 2007, S. 84. Igersheimer war der Vertreter des Schocken Verlags-Vertriebes in Holland. Vgl. Salman Schocken an Gustav Schocken, 21.06.1938. SchA, Privates, 851/821.

22 Moritz Spitzer an Salman Schocken, 16.09.1938. SchA, Verlag, 331/43. 
Spitzer sollte mit seinen Befürchtungen Recht behalten. In einem weiteren Brief an Salman Schocken beschreibt er seine missliche Lage in Holland: ${ }^{23}$ Zehn Tage nach seiner Einreise war er verpflichtet, bei der Fremdenpolizei vorzusprechen. Die holländische Behörde versagte ihm aber sogar eine zeitlich befristete Aufenthaltsgenehmigung. Er beabsichtigte, in Den Haag nochmals einen Antrag zu stellen, glaubte aber nicht daran, dass er einen positiven Entscheid erhielte. Spitzer benötigte jedoch noch einige Tage im Land, um die Weiterreise zu organisieren.

Die Niederlande führten nach dem Ersten Weltkrieg während der wirtschaftlichen Depression Einreisebeschränkungen ein, um den eigenen Arbeitsmarkt zu schützen. Während die Visumspflicht für deutsche Staatsangehörige im Februar 1926 aufgelöst wurde, galt sie für Osteuropäer weiterhin. Dies sollte in erster Linie mittellose Hausierer und Straßenhändler von einer Immigration abhalten. Zum Zeitpunkt der Machtergreifung Hitlers waren die Grenzen für deutsche Juden damit weitgehend offen. Die Behörden verlangten zwar, dass alle Ausländer, die sich in den Niederlanden niederlassen wollten, sich innerhalb von einigen Tagen mit einer Adresse zu registrieren hatten. Dieser Beschluss wurde jedoch kaum durchgesetzt, sodass sich ausländische Staatsangehörige relativ frei und unbehelligt eine neue Existenz aufbauen konnten. Diese laxe Immigrationspolitik führte in der ersten Hälfte des Jahres 1933 zu einem sprunghaften Anstieg von Immigranten, in erster Linie Juden aus Deutschland, die ihre Heimat nach der Machtergreifung der Nationalsozialisten fluchtartig verließen. Um den eigenen Arbeitsmarkt zu schützen, erlieBen die Niederlande 1934 neue Immigrationsgesetze, die beinhalteten, dass bestimmte Berufsgruppen sich um Arbeitsbewilligungen bewerben mussten. Diese Einschränkungen wurden über die Jahre verschärft und hatten direkte Auswirkungen auf die Interpretation der niederländischen Immigrationsgesetze. Das 1937 ratifizierte Gesetz zur Regulierung von selbständigen Gründungen durch Ausländer legte eine Bewilligungspflicht für Unternehmen fest, die von fremden Staatsangehörigen gegründet wurden. Damit konnten Immigranten bei der Einreise nicht länger angeben, dass sie als qualifizierte

23 Zur holländischen Judenpolitik vor der Besetzung durch die Nationalsozialisten vgl. Bob Moore: Refugees From Nazi Germany in the Netherlands, 1933-1940. Dordrecht / Boston / Lancaster: Nijhoff 1986. Zu verschärften Restriktionen für jüdische Immigranten und Flüchtlinge im Jahr 1938 ist insb. das Kap. III/4 (S. 77-82) relevant. 
Händler selbständig ihrem Beruf nachgehen und sich damit finanzieren könnten. Diese Maßnahme reduzierte die Anzahl von deutschen Immigranten beträchtlich. Erschwerend kam hinzu, dass die holländischen Behörden einen Vermögensnachweis verlangten, ohne den Immigranten nicht länger einreisen durften. Da in der Zwischenzeit die nationalsozialistischen Behörden die sogenannte Reichsfluchtsteuer drastisch erhöhten, konnten zahlreiche jüdische Emigranten und Flüchtlinge nicht länger nachweisen, dass sie ihren Lebensunterhalt aus eigener Kraft bestreiten konnten. Schließlich gab es für Juden aus Deutschland nur noch drei Möglichkeiten, sich in die Niederlande abzusetzen: ein illegaler Grenzübertritt, was durchaus möglich war, da es für die Grenzschutzbehörden schwierig war, die lange und oft unübersichtliche Grenze ausreichend zu schützen. Zweitens war es für jene Emigranten möglich, denen es gelang, Teile ihres Vermögens außerhalb von Deutschland in Sicherheit zu bringen, das heißt, für jene kleine Oberschicht, die seit längerer Zeit ihr Geld auf Konten im Ausland anlegte und/oder weitere Vermögenswerte in Bankschließfächern aufbewahrte. Eine dritte und letzte Möglichkeit bestand für jene, die Verwandte oder Bekannte in Holland hatten, die Einladungen aussprechen konnten. Jedoch mussten sich die Eingeladenen nach einigen Tagen registrieren lassen und dabei bestand die Gefahr, des Landes verwiesen zu werden. ${ }^{24}$ Spitzer wurde im Sommer 1938 zwar dank der Einladung eines Bekannten trotz seines tschechoslowakischen Passes die Einreise gewährt, jedoch im Rahmen der gesetzlichen Vorschriften ein längerer Aufenthalt verwehrt. Er verfügte, soweit bekannt ist, über keine Vermögenswerte außerhalb Deutschlands und konnte daher nicht nachweisen, seinen Lebensunterhalt bestreiten zu können. Er plante zwar keineswegs, sich in den Niederlanden niederzulassen, für die Behörden war dies jedoch anscheinend kein Argument, ihm eine Aufenthaltsgenehmigung für wenigstens einige weitere Wochen zu genehmigen. Spitzer zog Großbritannien als ein mögliches Migrationsziel in Betracht, fürchtete aber, dass er ohne Einladung gar nicht erst einreisen dürfe. Palästina, das er seit Frühsommer des Jahres immer wieder als Ziel nannte, erwähnte er brieflich ein weiteres Mal. Die Einholung eines Zertifikates dauerte jedoch länger als die wenigen Tage, die ihm in Holland gewährt wurden. Angesichts dieser

$24 \mathrm{Vgl}$. zu diesen Ausführungen: Bob Moore: Jewish Refugees in the Netherlands 1933-1940. The Structure and Pattern of Immigration From Nazi Germany. In: LBIYB 29,1 (1984), S.73-101, hier S.75-77. 
schwierigen Situation drückte er Salman Schocken gegenüber die Hoffnung aus, dass sich die Situation in Deutschland beruhigen möge, sodass er nochmals nach Berlin zurückkehren könne, um „noch einiges den Verlag und die Abwicklung Betreffendes zu ordnen. ${ }^{\text {"25 }}$

Mit dem Münchner Abkommen beruhigte sich die Lage dann tatsächlich soweit, dass Spitzer es für sicher genug erachtete, nach Deutschland zurückzukehren, um seinen obengenannten Plan umzusetzen. Gleichzeitig verdeutlichte die Weigerung der Schweiz, Spitzer im September ein Visum auszustellen, dass Europa für ihn nicht mehr frei zu bereisen war. Die Mobilität, die bis zum Herbst 1938 für Schockens Mitarbeitende möglich war, hatte ein Ende gefunden. Die Grenzen wurden zunehmend undurchlässig und der Kreis jener, die weiterhin ungehindert reisen konnten, verkleinerte sich drastisch. Auch wenn diese Entwicklungen für Schockens eigene Reisetätigkeit vorerst keine Einschränkungen mit sich brachten, wird es ihm doch verdeutlicht haben, dass er seine transnationale Existenz nicht unendlich würde weiterführen können. Noch ignorierte er jedoch die politische Situation in Europa, wie seine wenig verständnisvolle Reaktion auf Moritz Spitzers Pläne, so schnell wie möglich aus Deutschland zu emigrieren, zeigte.

Für Schocken kam die Reisetätigkeit erst nach Beginn des Krieges zu einem Ende. Noch im Jahr 1939 hielt er sich knapp vier Monate in Europa auf. Anders als Spitzer wurde Schocken als Inhaber mehrerer Konten in der Schweiz und in Palästina anscheinend problemlos die nötige Aufenthaltsgenehmigung erteilt. Dieses Beispiel verdeutlicht nochmals, wie frei sich Schocken auch nach 1938 noch in Europa bewegen konnte. Als vermögendem Mann waren ihm Freiheiten vergönnt, die für den Großteil der europäischen Jüdinnen und Juden nicht mehr vorstellbar waren. Jedoch darf dabei nicht vergessen werden, dass auch er von den Nationalsozialisten beraubt wurde und seinen Lebensmittelpunkt Deutschland seit Jahren nicht mehr betreten konnte.

$\mathrm{Zu}$ seinem letzten Aufenthalt in Holland wurde Schocken von seiner Frau Lili sowie einer entfernteren Verwandten, Dora Landauer, begleitet. ${ }^{26}$ Auch Lili Schocken und die als Sekretärin mitreisende Landauer erhielten problemlos Aufenthaltsbewilligungen für Holland. Als vermögende Emigranten mit palästinensischen Visa wurden sie von den holländischen Behörden sehr viel

25 Moritz Spitzer an Salman Schocken, 26.09.1938. SchA, Verlag, 331/43.

26 Zu Dora Landauer vgl. Kap. 3.2, Anm.69. 
zuvorkommender behandelt als Spitzer, der sich in einer Notsituation befand. Schocken litt unter einer starken Einschränkung des Sichtfeldes und ließ sich in Utrecht von Professor Wave in der Ooglijderskliniek operieren. Der Eingriff verlief zufriedenstellend, sodass er bereits nach gut zwei Wochen nach Paris weiterreisen konnte. ${ }^{27}$ Ende März kehrte Schocken schließlich nach Jerusalem zurück, um im Mai die Eröffnung des Hadassah-Krankenhauses in Jerusalem, die von Lili und ihm in ihrer Privatresidenz ausgerichtet wurde, zu leiten.

Für den 21. Zionistenkongress, der vom 16. bis 25. August in Genf stattfand, reiste Schocken ein weiteres Mal nach Europa. Am 13. und 14. August, also einige Tage vor Beginn des Kongresses, fand im Parkhotel Carlton ${ }^{28}$ in Genf die jährliche Sitzung des Universitätskuratoriums statt, an der Schocken als administrativer Leiter der Universität teilnahm. In seiner Rede verwies Schocken auf die Erfolge der Universität im vorangegangenen Jahr - insbesondere auf die Eröffnung der Hadassah Medical School, die Grundsteinlegung des Rosenbloom Buildings ${ }^{29}$, auf Schenkungen an die Universität - sowie auf die fachliche Ausrichtung der Institute. Erwähnung fanden auch Überlegungen zur Schaffung eines Programmes, das es ausländischen Studenten ermöglichen sollte, die Universität während einiger Semester zu besuchen, „um sich eine jüdische und allgemeine Bildung zu holen. “30

Schocken blieb also auch noch im August 1939 bei seiner üblichen Rhetorik: Rückblick auf Erfolge, kritische Bemerkungen, Pläne für die Zukunft sowie Finanzberichte. Die Idee, ein Programm für Gaststudierende einzurichten,

27 Vgl. Dora Landauer an Lili Schocken, 07.03.1939. SchA, Privates, 844/2, Bd.4. Schocken litt jedoch weiterhin an einer Einschränkung seiner Sehkraft. Im Herbst 1958 ließ er sich ein weiteres Mal operieren. Diese zweite Operation verbesserte zu seiner großen Freude wieder seine Fähigkeit, zu lesen. Vgl. zwei Briefe von Salman Schocken an Gershom Scholem, 17.06.1958 und 04.03.1959. NLI, Scholem Archiv, Arc. 4 1599, 01 3050, Bd. 10.

28 Vgl. Salman Schocken an Chaim Weizmann, 06.08.1939. SchA, Universität, 011/7.

29 Das Rosenbloom Building, benannt nach der Rosenbloom-Familie aus Pittsburgh, sollte das Institut für Jüdische Studien beheimaten. Nach jahrelangen Auseinandersetzungen u. a. zwischen Universitätsleitung und Architekten wurde das Gebäude 20 Jahre nach Beginn der Planung eröffnet. Vgl. Dolev: The Planning and Building of the Hebrew University, 1919-1948, S.77-92; Diana Dolev / Haim Gordon: The Architectural Challenge of a Jewish Studies House at the Hebrew University. A Lost Opportunity. In: Shofar. An Interdisciplinary Journal of Jewish Studies 11,1 (1992), S. 1-11.

30 Rede Salmann Schocken, Sitzung des Kuratoriums der Universität in Genf, 13.08.1939. SchA, Universität, 011/5. 
mutet jedoch im August 1939 etwas realitätsblind an. Es erschließt sich nicht, wie er sich dies zu einer Zeit vorstellte, die gekennzeichnet war durch die Markierung der Reisepässe von Juden, durch Grenzschließungen in Europa und restriktive Ein reisebestimmungen in Palästina. Das Ausmaß der sich abzeichnenden Katastrophe für die europäischen Juden findet in Schockens Überlegungen kaum Eingang, obwohl er täglich auch in seinem persönlichen und beruflichen Umfeld damit konfrontiert wurde. Die Schwierigkeiten von Moritz Spitzer, der ab Herbst 1938 nicht mehr frei reisen konnte und in der Zwischenzeit nach Jerusalem emigrierte, ist nur ein Beispiel von vielen. ${ }^{31}$

In seiner einstündigen Rede wies Schocken jedoch nur in einer kurzen Nebenbemerkung auf das Schicksal der europäischen Juden hin, indem er feststellte, dass die polnischen Absolventen der Hebräischen Universität „bei uns im Land bleiben. ${ }^{* 32}$ Er fuhr fort:

[...] und da Sie ungefähr wissen, wie tragisch unsere allgemeinen jüdischen Umstände aussehen, werden Sie verstehen, wie schwer es wiederum ist, den akademischen Berufstätigen Platz zu schaffen in der Welt. Hier liegt eine Frage vor uns, die rechtzeitig beachtet werden muss. ${ }^{33}$

Für Schocken lag dieses „rechtzeitig“ weiterhin in der Zukunft. In den protokollierten und offiziell beglaubigten Beschlüssen des Kuratoriums wird dann tatsächlich die Einrichtung von Gastplätzen für ausländische Studierende aufgeführt. Auf die Lage in Europa, das kurz vor dem Beginn des Zweiten Weltkrieges stand, wird nicht weiter eingegangen. ${ }^{34}$

Nach den Sitzungen in Genf kehrte Schocken nach Palästina zurück, wo er gute zwei Wochen nach dem Überfall der deutschen Armee in Polen ankam. In einem Brief an Weizmann legte er seine Pläne für die nahe Zukunft dar: Er wolle einige Monate bleiben, um sich in dieser ,Notfallsituation' über die weiteren Entwicklungen der Universität Gedanken zu machen. Er beschäftigte

31 Vgl. dazu weiter unten.

32 Rede Salman Schocken, Sitzung des Kuratoriums der Universität in Genf, 13.08.1939. SchA, Universität, 011/5.

33 Ebd.

$34 \mathrm{Vgl}$. Resolutions Adopted at the $12^{\text {th }}$ Meeting of the Board of Governors of the Hebrew University, 12.-14.08.1939, Geneva. SchA, Universität, 011/5. 
sich hauptsächlich mit den Berufungen, die in Genf beschlossen wurden, und erwähnte dabei die angespannte finanzielle Situation, die die sofortige Einstellung von einigen Professoren verunmögliche. Der größte Teil dieses fünfseitigen Briefes befasst sich mit Schockens Ideen zu seiner geplanten Fundraising- und Propagandareise nach Amerika und den Problemen, die die Rückstufung von Magnes in Hinsicht auf mögliche Sponsoren verursachen könnte. Schocken erwähnt auch das Schicksal der jüdischen Wissenschaftler in Polen und dass es sehr schwierig sei, diesen Hilfe zukommen zu lassen. Zudem versuche man mit allen möglichen Mitteln, fünf- bis sechshundert Studierendenzertifikate für Studenten aus Europa zu erlangen, damit diese an der Hebräischen Universität in Sicherheit ihr Studium abschließen könnten. ${ }^{35}$

Der deutsche Angriff auf Polen und die kurz darauf erfolgte Kriegserklärung Frankreichs und Großbritanniens an das Deutsche Reich lösten auch bei Schocken eine Reaktion aus. Europa befand sich im Krieg, und die deutschen und polnischen Juden sahen sich in nicht abzuschätzender Gefahr. Für Schocken persönlich bedeutete dies, dass sein bisheriges Leben auf zwei Kontinenten zu einem Ende kam. Reisen nach Europa waren kaum mehr möglich. Sein Konzern war längst ,arisiert', der Verlag zwangsgeschlossen und auch Sitzungen und Besprechungen waren nicht länger möglich. Was die Universität anbelangte, war er jedoch im Großen und Ganzen optimistisch, wie er es in den Schlusszeilen seines Briefes an Weizmann ausdrückte.

The systematic work of organization we have done in the last years is bearing fruit in spite of the drawbacks which have occurred on account of those events in Europe over which we had no control whatsoever. But much carefully planned work is still necessary, particularly in the English speaking countries. I do not think that England and South-Africa are already fully exploited for the University. ${ }^{36}$

Dass aus Europa keinerlei Gelder mehr fließen würden, war Schocken bewusst, er war aber der Meinung, dass das von ihm aufgebaute System es erlaube, Unterstützung aus außereuropäischen Gebieten zu werben. Er selbst reiste Ende des Jahres gemeinsam mit seiner Frau ein erstes Mal in die USA, um sich dort mit Vertretern amerikanisch-jüdischer Organisationen und mit Geldgebern

35 Vgl. Salman Schocken an Chaim Weizmann, 06.10.1939. SchA, Universität, 011/17.

36 Ebd. 
zu treffen. Von dieser Reise kam er im April 1940 nochmals zurück nach Jerusalem, bevor er Ende des Jahres Palästina endgültig verließ und sich mit seiner Frau in New York niederließ, wo ihr Sohn Theodor und ihre Tochter Eva seit einiger Zeit lebten. Das Privathaus wurde verschlossen und 1943 unter den Schutz des amerikanischen Konsulates gestellt, das den Sternenbanner über der Villa und der Bibliothek hisste. ${ }^{37}$

Wie wichtig Europa als Referenzpunkt in Schockens Leben war, wird nochmals deutlich, als mit Beginn des Zweiten Weltkrieges Reisen dahin endgültig unmöglich wurden. Obwohl Schocken seit 1936 nicht mehr nach Deutschland fuhr, blieb er dem Land geschäftlich und durch persönliche Beziehungen eng verbunden. Nachdem aber sein Konzern ,arisiert' und der Schocken Verlag unter Zwang aufgelöst worden waren, ging der letzte Kontakt verloren. Das Wegbrechen dieser Verbindung muss schwerer gewogen haben als seine Auswanderung sechs Jahre zuvor. Mit dem Ende der Beziehungen nach Deutschland endete auch sein transnationaler Lebensstil.

So wie er sich bis zum Beginn des Zweiten Weltkrieges nie endgültig unternehmerisch und verlegerisch aus Deutschland zurückzog, sondern über seinen Mitarbeiterstab und sein Kommunikationssystem sowie durch seine eigene Anwesenheit verbunden blieb, so hielt er auch während seiner Abwesenheit von Palästina über dasselbe System den Kontakt. Ein Großteil seiner wichtigsten persönlichen und geschäftlichen Bekannten und Freunde führte ein ähnliches Leben zwischen Europa und Palästina, wenn auch nicht im selben Ausmaß wie Salman Schocken. Die Angaben, wer wann in welcher europäischen Stadt und in welchem Hotel erreicht werden könne, lassen mitunter vergessen, dass es sich bei den Schreibenden um Exilanten handelte, die Europa eigentlich verlassen hatten. Auch ohne moderne Kommunikationsmittel, dafür aber mit einer täglich mehrfachen Postzustellung, mit Telegrammen und mitreisenden Sekretären und Sekretärinnen sowie Ehefrauen, wurden wichtige Angelegenheiten ohne Aufschub erledigt. Nicht nur Schocken, sondern der ganze Kreis um ihn herum führte in den 1930er Jahren bis zum Beginn des Krieges ein transnationales Dasein. Verwurzelt in und verbunden mit Europa und Palästina verknüpften sie die beiden Räume durch ihre physische Anwesenheit. Dabei entstand in der Korrespondenz und in den Sitzungen ein transnationaler Raum, der nicht weniger real war als die zwei geographischen Räume.

37 Vgl. Gustav Schocken an Salman Schocken, 05.05.1943. SchA, Privates, 823, Box 35. 
Es ist bezeichnend, dass Salman Schocken mit seiner Frau Ende 1940 Jerusalem verließ und in die USA ging. Zwar kamen Lili und Salman 1945 tatsächlich nach einem langen Aufenthalt nach Jerusalem zurück, jedoch ließen sie sich dort nicht mehr nieder. 1949 verlor Schocken gar wegen ständiger Abwesenheit den Status als „resident“ ${ }^{38}$

Über die Gründe für Schockens abermalige Emigration, nun von Palästina nach Amerika, welche ihm gesellschaftlich schadete und wegen der sich langjährige Freunde von ihm abwandten, wurde viel spekuliert. Er selbst hat sich darüber, zumindest öffentlich, nie geäußert. Die schwierigen Lebensbedingungen in Palästina, einschließlich des Wetters, zählen zu den meistgenannten Gründen. Es scheint jedoch, dass vor allem der Abbruch sämtlicher Beziehungen nach Europa der Auslöser war.

Palästina und Jerusalem hatten für den Zionisten Schocken eine besondere Bedeutung, was er bereits in den 1920er Jahren deutlich machte. Der Aufbau eines jüdischen Gemeinwesens, der Erwerb von Land und eine kulturelle Erneuerung waren zentrale Anliegen, für die er seine Arbeit, seine Verbindungen und sein Vermögen einsetzte. Deutschland und die deutsche Kultur verloren dabei auch nicht an Bedeutung, als er sich persönlich zur Auswanderung gezwungen sah. Die Jahre von 1933 bis 1939 waren daher gekennzeichnet durch ein Dasein in den beiden geographischen Räumen. Dank guter Verkehrsverbindungen war es ihm möglich, in beiden zuhause zu sein. Palästina und Europa ergänzten sich in seinem Leben - er war Zionist in Europa und Deutscher in Palästina. Erst als seine Unternehmen zwangsveräußert worden waren, wurde ihm schmerzhaft bewusst, dass diese Existenz zu Ende war. Noch im November 1938, nachdem die Synagogen in Deutschland brannten und die Schließung sämtlicher jüdischer Geschäfte und Einrichtungen absehbar war, glaubte er daran, seinen Verlag weiterführen zu können. Moritz Spitzer, sein Verlagsleiter, bezeichnete ihn später als blind: Schocken hätte ebenso wie Lambert Schneider einfach immer nur weitermachen wollen. Für Spitzer hingegen war 1938 klar, dass die Probleme der unter immer stärkeren Repressionen leidenden Juden nicht mit Büchern behoben werden konnten. Nach den gewalttätigen Ausschreitungen in der Novemberpogromnacht schien die Auflösung kaum mehr aufzuhalten. Schocken selber versuchte um jeden Preis, die Aufgabe des Verlags zu verhindern; selbst nach den Novemberpogromen wollte er von

38 Siegfried Moses an Salman Schocken, 08.03.1949. SchA, Privates, 844/2, Bd. 1. 
einer Liquidation nichts wissen. ${ }^{39}$ Ende Dezember 1938 konnte er sich jedoch der durch die Nationalsozialisten angeordneten Zwangsliquidation nicht mehr widersetzen. Damit musste er sich eingestehen, dass es in Deutschland keine Perspektive für Jüdinnen und Juden mehr gab.

Mit dem Verlust Europas scheint Palästina für ihn ebenfalls keine Zukunft mehr geboten zu haben. Für sein ganz persönliches Dasein gehörten Palästina und Europa zusammen. Diese Verbindung wurde 1939 gekappt. Die Verdammung der deutschen Sprache, die im Streit um die Jüdische Weltrundschau hervortrat, kann als Wendepunkt gesehen werden. Deutschland, das ihm so nahestand, dessen Kultur und Literatur er bewunderte - Schockens Goethe-Sammlung war einzigartig -, zeigte ihm seine hässliche Fratze. Mit der Migration nach New York ließ Schocken nicht nur seine Häuser und Bibliothek zurück, sondern auch sein deutsches Leben. Zwar lebten in den USA viele deutsche Bekannte und Familienangehörige, dennoch bedeutete die Niederlassung in Amerika einen Bruch mit seinem bisherigen Leben. Die engsten Mitarbeiter und Freunde blieben in Palästina und mit dem Eintritt der USA in den Krieg brach die Verbindung zu ihnen fast gänzlich ab.

Aus migrationswissenschaftlicher Sicht besitzt dieses Phänomen keinen Seltenheitswert. Historische und sozialwissenschaftliche Forschungen haben vielmehr gezeigt, dass Migration selten als geographisch linearer und folglich abzuschließender Prozess zu interpretieren ist, sondern dass es regelmäßig zu Rück- oder Mehrfachmigration kommt. ${ }^{40}$ Begriffe und Zuordnungen wie ,Emigrant', ,Immigrant' oder ,Flüchtling' sind Ordnungskriterien, die mit der individuellen historischen Erfahrung des Subjekts nicht kongruent sein müssen. Die Fremdzuschreibungen reflektieren die „multiple Migrantenidentität “41 ebenso wenig wie transnationale Existenzen.

Aus behördlicher Perspektive war Salman Schocken ein deutscher Emigrant, der durch das Verlassen Deutschlands sämtliche staatsbürgerlichen Rechte, sofern er als Jude noch welche besaß, verwirkte. Für die britischen Behörden war er ein Immigrant, der dank seines Status als vermögender Jude das Recht genoss,

39 Vgl. Dahm: Das jüdische Buch im Dritten Reich, S. 449.

40 Vgl. Klaus J. Bade: Sozialhistorische Migrationsforschung. Göttingen: V\&R unipress 2004, S. 13-25.

41 Stephen Castles: The Age of Migration. International Population Movements in the Modern World. Basingstoke: Palgrave Macmillan 2009, S. 297 (Übers. S. M.). 
sich in ihrem Hoheitsgebiet niederzulassen und für den Jischuv war er ein Zionist, der durch den Prozess der Alija in die jüdische Heimat zurückkehrte. Die Betrachtung von Schockens Reisebewegungen verdeutlicht aber schnell, dass die Betrachtung der rechtlichen Ebene zu kurz fasst. Schocken ließ sich zwar in Jerusalem nieder, blieb aber Europa weiterhin aufs Engste verbunden.

\subsection{Weiterleben dank Schocken: \\ Finanzielle und organisatorische Unterstützung für die Flucht aus Deutschland}

Schockens Leben in den Jahren 1933 bis 1939 - das geprägt war von zahlreichen Reisen, der Fortführung seiner Geschäftstätigkeit in Deutschland, dem Aufbau des hebräischsprachigen Verlages in Palästina, dem Bau seines luxuriösen Privathauses und der Bibliothek - scheint bisweilen seltsam losgelöst vom historischen Kontext, als habe er in einer Blase gelebt und nicht wahrgenommen, was in Deutschland geschah. Es steht der Historikerin weder zu, darüber ein wertendes Urteil abzugeben, noch, eine psychologische Analyse dieses Verhaltens vorzunehmen. Es darf aber festgehalten werden, dass erzwungene Migration, um solch eine handelte es sich auch bei Schocken, unterschiedliche Reaktionen auslösen kann. Schocken, der sämtliche Aufgaben strategisch und systematisch zu lösen versuchte, verfolgte diesen Ansatz auch nach der Machtergreifung der Nationalsozialisten. Seine Korrespondenz sowie Interviews mit Zeitzeugen verdeutlichen jedoch, dass das Zwischenmenschliche unter dieser Lebenshaltung litt. Äußerungen des Mitgefühls sind in seinen Briefen auch dann nicht zu finden, wenn jemand ihm gegenüber eine existenzielle Bedrohung schildert, wie dies z. B. Moritz Spitzer tat, als er im Spätsommer 1938 aufgrund begründeter Angst vor Übergriffen nach Holland floh. Schocken verstand ebenso wenig, dass die Arbeit für den Verlag in Deutschland im Jahr 1938 kaum mehr möglich war und dass sich seine Angestellten in Sicherheit bringen wollten. Selbst als die Schweizer Behörden Spitzer die Einreise verweigerten, hielt Schocken an seiner Idee fest, den Verlag weiterzuführen.

Tatsächlich muss man sich fragen, wie es ihm gelungen ist, trotz täglich eintreffender Bittschreiben von in Deutschland verfolgten und entsprechend verängstigten Jüdinnen und Juden an seinen Geschäftsplänen festzuhalten und seinen Verpflichtungen in einer Weise nachzugehen, als ob die Verfolgung nicht existierte. Möglichweise stellte das pausenlose Organisieren, Aufbauen 
und Systematisieren einen Rückzug dar, war die Arbeitswelt für ihn ein psychologisch sicherer Ort. Im folgenden Unterkapitel soll es abschließend darum gehen, dass dieses vermeintliche Weiterbestehen der Normalität durchaus Risse hatte. Schocken unterstützte zahlreiche Menschen bei der Ausreise und bei dem Versuch, andernorts eine neue Existenz aufzubauen. Er tat dies bei engeren Bekannten direkt und verhältnismäßig unbürokratisch, in der Regel wurden Bittgesuche jedoch von einer eigens dafür eingerichteten Abteilung seines Konzerns systematisch geprüft.

Das Unterkapitel greift damit zwei bereits angesprochene Thematiken auf: Einerseits zeigt es nochmals, wie Salman Schocken versuchte, Probleme methodisch und damit in seinen Augen objektiv wie gerecht anzugehen. Andererseits wirft es einen Blick auf das Netzwerk der deutsch-jüdischen Emigranten in Palästina, indem es das Schicksal von wenigen ausgewählten Bekannten Schockens aufgreift, die vor allem dank seiner Unterstützung in Jerusalem Fuß fassen konnten.

\subsubsection{Individuelle Lösungen:}

\section{Die Hilfe für leitende und enge Mitarbeitende Schockens}

Ein Beispiel für die Hilfe, die Salman Schocken seinen leitenden Angestellten zukommen ließ, war der Fall von Dr. Robert Schiller und seiner Frau, die in die USA auszuwandern planten. Schiller war ein leitender Angestellter des Konzerns, der in der Geschäftsleitung mitarbeitete und zeichnungsberechtigt für eine Reihe von Konten war. ${ }^{42}$ Zudem kam ihm bei der Vorbereitung zum Verkauf des Konzerns wie bei der Abwicklung des eigentlichen Verkaufes eine wichtige Rolle zu. ${ }^{43}$ Schiller plante, nach dem Verkauf gemeinsam mit seiner Frau in die USA auszuwandern. Die finanziellen Auslandsreserven der Familie waren jedoch, wie er gegenüber Schocken festhielt, ,sehr bescheiden'. Nachdem die niederländischen Behörden seinen Antrag, seine in einer holländischen Bank liegenden 3.000 Gulden freizugeben, abgelehnt hatten, wandte er sich mit der Bitte an Salman Schocken, „ein Bankkonto in Höhe von etwa 10.000 \$ für [ihn] in USA zu eröffnen, und zwar zum Zweck der Erlangung des Visums. “" ${ }^{\text {"44 }}$ Darüber hinaus bat er im selben Schreiben um ein persönliches

42 Vgl. Robert Schiller an Salman Schocken, 25.04.1938. SchA, Privates, 844/2, Bd.7.

43 Ebd.

44 Robert Schiller an Salman Schocken, 25.03.1938. SchA, Privates, 844/2, Bd.7. 
Zeugnis über seine Tätigkeit und um Empfehlungen „an Firmen in USA“ und an „Dr. Kann für Marx \& Spencer ${ }^{\text {“45 }}$. Schocken sicherte ihm zu, dass er „gerne

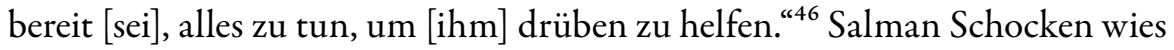
seinen Sohn Theodor an, bei der Chase National Bank of the City of New York, bei der Schocken Vermögen liegen hatte, ein Konto auf den Namen Schillers zu eröffnen und 10.000 US-\$ darauf zu transferieren. ${ }^{47}$ Der Betrag wurde kurze Zeit später auf ein anderes Konto transferiert: Nach der erfolgreichen Immigration Schillers zog Theodor 8.000 \$ vom Konto ab, die Hälfte davon verwendete er als Vorzeigegeld ${ }^{48}$ für Bullwachter, einen leitenden Angestellten des Schocken-Konzerns und später stellvertretender Leiter des Keren Hayesod und Leiter der Universitätsabteilung, ${ }^{49}$ und 2000 \$ für Vorzeigegelder für Graf in Amsterdam. ${ }^{50}$

Der Brief Theodors an seinen Vater gewährt Einblicke in Schockens Unterstützung: Mit einigen zehntausend \$ stellte er einer ganzen Reihe von ehemaligen Mitarbeitenden das nötige Vorzeigegeld für Visa für die USA zur Verfügung. Sobald das Visum gewährt worden war, wurde das Geld zu einem großen Teil wieder abgezogen, um es für die nächste Garantie auf ein neues Konto einzuzahlen. Der Brief zeigt aber auch, dass für den Fall, dass mehrere Garantiekonten gleichzeitig bestanden, auf das Privatvermögen der Familie zurückgegriffen wurde. So schreibt Theodor, dass er für das Garantiekonto von Bullwachter, neben den 4.000 \$ von Schillers Konto, 6.000 \$ vom Konto seiner Schwester Eva nehmen musste, da er keine Vollmacht über das „Chase-Konto "51 seines Vaters habe.

Schocken unterstützte Robert Schiller über die Bereitstellung des Garantiekontos hinaus. Er stellte ihm das gewünschte persönliche Referenzschreiben, es gelang ihm aber zu seinem Bedauern nicht, eine Stelle für ihn zu finden.

45 Robert Schiller an Salman Schocken, 25.03.1938. SchA, Privates, 844/2, Bd.7.

46 Salman Schocken an Robert Schiller, 03.04.1938. SchA, Privates, 844/2, Bd.7.

47 Vgl. u. a. Charles J. Spies, Assistant Manager, The Chase National Bank an Salman Schocken, 10.05.1938. SchA, Privates, 844/2, Bd.7.

48 Für zahlreiche Länder war ein Vorzeigegeld als Anfangskapital nötig, ohne das kein Visum ausgestellt wurde.

49 Vgl. M. Bullwachter an Salman Schocken, 28.06.1939; [Dr. A. Hantke] an Salman Schocken, 23.08.1939. SchA, Universität, 031/4.

50 Vgl. Theodor Schocken an Salman Schocken, 26.01.1939. SchA, Privates, 844/2, Bd. 7.

51 Ebd. 
Schocken bat daher Theodor, ,etwas für ihn zu tun.' Er nannte seinem Sohn eine Reihe von Personen und Betrieben, die möglicherweise eine passende Stelle für Schiller haben könnten. Er empfahl besonders, sich an Frau Reichmann-Fromm zu wenden, die sich in der Vermittlung von Arbeitsstellen wohl bewährt hatte. Schocken glaubte auch, dass sich Reichmann-Fromm möglicherweise um das Kind der Schillers kümmern könnte, bis die Eltern passende Stellen und eine Wohnung gefunden hätten. ${ }^{52}$ Theodor nahm sich der Familie Schiller an und holte diese auch vom Hafen ab. Während Hety Schiller am psychoanalytischen Institut der psychiatrischen Abteilung des Mount Sinai Hospitals in New York zugelassen wurde, gelang es ihrem Mann trotz der Empfehlungen und der Einführung von Theodor Schocken bei einer Reihe von Persönlichkeiten nicht, eine Stelle zu finden. ${ }^{53}$ Die Akten geben Einblick, dass Robert Schiller in den USA große Schwierigkeiten hatte, während es seiner Frau gelang, sich beruflich zu integrieren und weiterzuentwickeln. Nach ihrer Anstellung am Mount Sinai Hospital erhielt sie ein Fellowship der Social Workers of Cleveland, Ohio, das es ihr erlaubte, zwei Jahre an der Universität zu studieren. Zudem schreibt sie in einem Brief an Salman Schocken, dass ihr zugesagt wurde, dass sie im Anschluss an ihr Studium von Social Service übernommen werden würde, was „amerikanischer Staatsdienst mit Pensionsberechtigung “54 bedeutete. Großen Kummer bereitete ihr jedoch, dass sie ihre Tochter nicht mitnehmen könne und dass ihrem Mann weiterhin kein Glück beschert sei. ${ }^{55}$ Da Hety Schillers Stipendium für das Überleben der Familie kaum ausreichte, übernahm Salman Schocken die Kosten für die Unterbringung der Tochter bei einer deutschen Familie auf zwei Jahre. Er zeigte sich zudem bereit, Robert Schiller, den er als einen „ernsten, fleißigen, aber nach außen sehr lebensuntüchtigen Mitarbeiter ${ }^{\text {“56 }}$ bezeichnete, finanziell zu unterstützen. Er wolle nicht kleinlich sein, teilte er seinem Sohn mit, und Theodor solle entscheiden, welcher Betrag zur Unterstützung festgelegt werden solle. ${ }^{57}$ Der letzte Brief von Schocken an Hety Schiller ist datiert auf den 5. Juli 1939, Schocken bringt hierin die Hoffnung zum Ausdruck, dass er weiterhin über ihre Lebensverhältnisse informiert würde.

52 Vgl. Salman Schocken an Theodor Schocken, 16.11.1938. SchA, Privates, 844/2, Bd.7.

53 Vgl. Robert Schiller an Salman Schocken, [November 1938]. Privates, SchA, 844/2, Bd. 7.

54 Vgl. Hety Schiller an Salman Schocken, 26.01.1939. SchA, Privates, 844/2, Bd. 7.

55 Vgl. ebd.

56 Vgl. Salman Schocken an Theodor Schocken, 24.04.1939. SchA, Privates, 844/2, Bd.7.

57 Vgl. ebd. 
Wie sich das Leben der Familie Schiller weiterhin entwickelte, ist jedoch nicht überliefert.

Als zweites Beispiel soll hier jenes von Schockens langjähriger Sekretärin Edith Michelsen angefügt werden. Das Verhältnis zwischen Salman Schocken und seiner Sekretärin war freundschaftlich und eng. Sie war eine wichtige Kraft für ihn - zuständig für die Organisation seines Lebens zwischen den Kontinenten, unter anderem für den Versand seiner wertvollen Bibliothek. Wie Ernst Markowicz und Robert Schiller gehörte sie auch zu dem Arbeitskreis, der Bücher für die Bibliothek der Hebräischen Universität beschaffte, sowie zu dem ,Arbeitskreis Wolfskehlbibliothek ${ }^{58}{ }^{58}$ Daher zögerte er auch nicht, als Michelsen ihn 1937 um ein Darlehen für ihren Bruder Jost Michelsen, der an der Harvard University studierte, bat. Halbjährlich sollten ihm 300 \$ ausbezahlt werden. ${ }^{59}$ Im April 1938 bemühte sich Edith Michelsen schließlich um ein eigenes Ausreisezertifikat, nachdem sie jene für die Berliner Belegschaft organisiert hatte. ${ }^{60}$ Am 13. April 1938 erhielt sie vom englischen Konsulat die Nachricht, dass sie ihr Zertifikat in Empfang nehmen könne. Da es bis Ende September des Jahres gültig war, wollte sie den nächsten Europaaufenthalt Schockens abwarten, bevor sie abreiste. ${ }^{61}$ Da Schockens Europareise nicht absehbar war, entschloss sich Michelsen jedoch, früher als geplant abzureisen. Für ihre Dienste in Deutschland erhielt Edith Michelsen von Salman Schocken einen anscheinend hohen Betrag, der sich nicht mehr beziffern lässt: Die Akten, in denen die Höhe der Zahlung dokumentiert sind, sind unter den Dokumenten nicht mehr zu finden. Die Tatsache, dass Michelsen ihre „Bestürzung“ über eine „derartige Zuwendung" zum Ausdruck brachte, lässt jedoch darauf schließen, dass es sich um sehr viel Geld gehandelt haben muss. ${ }^{62}$ Nach ihrer Ankunft in Palästina arbeitet Edith Michelsen bis zur Abreise der Familie Schocken in die USA weiterhin für Schocken. Sie hatte ihr Büro in den Räumlichkeiten des Haaretz in Tel Aviv, schien aber weiterhin alle möglichen Aufgaben für Salman Schocken

58 Edith Michelsen übernahm wie viele andere Angestellte zahlreiche Aufgaben, die nicht unmittelbar dem Schocken-Konzern und dessen Unterabteilungen zuzuordnen sind.

59 Vgl. Salman Schocken an Edith Michelsen, 11.06.1937. SchA, Privates, 844/2, Bd. 5.

60 Vgl. Edith Michelsen an Salman Schocken, 11.04.1938. SchA, Privates, 844/2, Bd. 5.

61 Vgl. Edith Michelsen an Salman Schocken, 13.04.1938. SchA, Privates, 844/2, Bd. 5.

62 Edith Michelsen an Salman Schocken, 21.08.1938. SchA, Privates, 844/2, Bd. 5. 
zu übernehmen. ${ }^{63}$ Ihre Rolle sowohl in Deutschland wie dann auch in Palästina war wohl die einer persönlichen Assistentin. Das Vertrauensverhältnis zwischen ihnen hatte großen Anteil daran, dass Schocken sein Leben auf verschiedenen Kontinenten führen konnte. Er konnte sich auf ihre Loyalität, Genauigkeit und Beflissenheit zu jeder Zeit verlassen. Dies musste ihn veranlasst haben, ihr bei der Ausreise eine solche Gratifikation auszuzahlen. Wie der im Schocken Archiv hinterlassene Briefwechsel zeigt, blieben Michelsen und Schocken während vieler Jahre in schriftlichem Kontakt.

\subsubsection{Systematische Hilfe für die Angestellten des Konzerns}

Zum Zeitpunkt der nationalsozialistischen Machtergreifung befanden sich rund 250 jüdische Angestellte im Dienst des Schocken-Konzerns. Salman Schocken ahnte bereits im Spätwinter 1935, dass es für Juden in Deutschland keine Zukunft mehr gab. Dies steht im augenscheinlichen Gegensatz zu seinen Plänen mit dem Verlag, dem Beharren auf die Fortsetzung der Produktion und zu seiner Reaktion auf Moritz Spitzers Pläne von 1938, Deutschland so schnell wie möglich zu verlassen. Trotz dieser Haltung war sich Schocken der Gefahr bewusst, die das NS-Regime für Juden und Jüdinnen in Deutschland bedeuten konnte. Er nahm einen Besuch im Februar 1935 zum Anlass, den leitenden Angestellten des Konzerns seine Absicht mitzuteilen, dass er alles zu tun gedenke, den jüdischen Mitarbeiterinnen und Mitarbeitern zu einer „geordneten und planmäßigen Auswanderung ${ }^{\text {“64 }}$ zu verhelfen. Gleichzeitig legte er auch die Prinzipien dar, die für die Auswanderung der jüdischen Angestellten zur Anwendung kommen sollten: Ein von Schocken eingesetztes Komitee, dass sich aus Georg Spiro, einem Neffen Schockens, Bullwachter und Ernst Markowicz zusammensetzte, befasste sich mit der finanziellen Hilfe, der Planung der Auswanderung und individuellen anderen Problemen. Zu einem späteren Zeitpunkt stieß noch Robert Schiller zum Komitee, der sich um die Visabeschaffung sowie die Umwechslung von Sperrmark kümmerte.

Ernst Markowicz, einen promovierten Chemiker, wurde, nachdem er als Jude 1935 seine Stelle in einer chemischen Fabrik in Leipzig verloren hatte, ${ }^{65}$ von

63 Vgl. diverse Briefe, 1938 bis 1940. SchA, Privates, 844/2, Bd. 5.

64 Ansprache des Herrn Salmann Schocken vor den Geschäftsführern am Februar 1935 in Berlin. SchA, Konzern, 149/225.

65 Vgl. Ernst Markowicz an Salman Schocken, 20.09.1957. Leo Baeck Archive, Jerusalem (fortan LBAJ), JER 193II, Bd.6. 
Salman Schocken eingestellt. Er arbeitete als Chemiker in der wissenschaftlichen Warenprüfungsstelle in der Zentrale in Zwickau. ${ }^{66}$ Markowicz schilderte diese Aufgabe und jene des Komitees in einem Aufsatz über seine Tätigkeiten im Schocken-Konzern; den Text plante Gershom Schocken, zusammen mit weiteren Erinnerungen an seinen Vater und dessen Lebenswerk, zu veröffentlichen. ${ }^{67}$ Das Dokument gibt Einblick, wie systematisch Schocken die Auswanderungshilfe anging.

Die Unterstützung zur Auswanderung stand allen Angestellten unabhängig von ihrer Stellung im Konzern offen. Die Angestellten sollten auf die Notwendigkeit zur Auswanderung und „die Unabwendbarkeit des jüdischen Schicksals “68 aufmerksam gemacht werden. Die Entscheidung, ob sich jemand zur Auswanderung entschloss, lag jedoch alleinig bei den Arbeitnehmern. Vonseiten des Konzerns wurde kein Druck ausgeübt und wenn sich jemand zum Bleiben entschloss, wurde alles Mögliche unternommen, um dem Druck des NS-Regimes, die jüdischen Angestellten zu entlassen, entgegenzuwirken. Diejenigen, die sich zur Auswanderung entschlossen, wurden zunächst über mögliche Berufe im Exil beraten und die Firma half, einen "geeigneten Platz

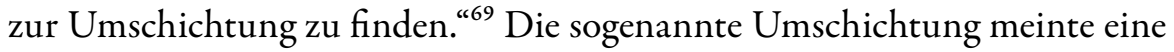
Weiter- oder Neuausbildung in einem Beruf, der eine bessere Integration in den Arbeitsmarkt des Exillandes versprach. In der Regel ging man davon aus, dass landwirtschaftliche und handwerkliche Berufe besser geeignet wären als kaufmännische, um sich im Exil eine neue berufliche Existenz aufzubauen. ${ }^{70}$

66 Vgl. Arbeitsvertrag zwischen Schocken Aktiengesellschaft Zwickau und Dr. Ernst Markowicz, 23.05.1935. LBAJ, JER 193II, Bd.6.

67 Vgl. Ernst Markowicz an Gershom Schocken, 01.06.1960. LBAJ, JER 193II, Bd.6. Die Veröffentlichung kam, soweit die Verfasserin informiert ist, nie zustande. Gründe dafür sind nicht bekannt. Der Aufsatz ist als Typoskript überliefert.

68 Ebd.

69 Ebd.

70 Die systematische Vorbereitung von (vor allem jungen) Jüdinnen und Juden auf eine Einwanderung nach Palästina wird als Hachschara bezeichnet. Auf landwirtschaftlichen Gütern, wie dem Gut Winkel, wurden die jungen Menschen durch Kurse in Land- und Hauswirtschaft, in Handwerk und Gärtnerei auf das Leben in Palästina vorbereitet. Vgl. Kurt Loewenstein: Die innerjüdische Reaktion auf die Krise der deutschen Demokratie. In: Werner E. Mosse (Hrsg.): Entscheidungsjahr 1932. Zur Judenfrage in der Endphase der Weimarer Republik. Tübingen: Mohr Siebeck 1966, S. 349-404, hier S. 389-399. 


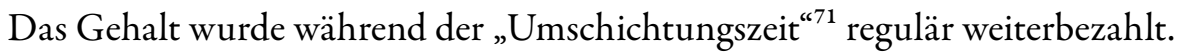
Auch die Reise ins Auswanderungsland wurde vom Schocken-Konzern bezahlt, ebenso die Beschaffung des Visums durch ihn erledigt. Jene Angestellten, die sich für eine Einwanderung nach Palästina entschlossen, wurden auf „Kosten der Firma, bezw. Herrn Schocken ${ }^{\text {“72 }}$ im Gut Winkel ${ }^{73}$ landwirtschaftlich ausgebildet und kulturell vorbereitet (Sprachkurse etc.). Es wurde festgehalten, dass niemand „durch Druck auf diesen Weg gebracht wird, jedoch insbesondere für junge und kräftige Menschen [rückte] diese Art der Umschichtung in den Vordergrund [...]. ${ }^{\text {“74 }}$ Während der Ausbildungszeit entweder auf dem Gut Winkel oder an einem anderen Ort wurde in Härtefällen eine finanzielle Unterstützung an die Eltern bezahlt, wenn dies zuvor von den Kindern übernommen wurde. Nach der erfolgten Auswanderung wurde jedem Angestellten ein Betrag von $50 £ \mathrm{P}$ ausbezahlt. Zudem erhielten sämtliche ausgewanderte Angestellte eine Abfindung, die anhand der Stellung im Betrieb sowie der geleisteten Dienstjahre berechnet wurde. ${ }^{75}$

Als Einwanderungsländer standen neben Palästina für die jüngeren Angestellten insbesondere Nord- und Südamerika im Fokus. Man versuchte, individuelle Lösungen zu finden und nach Möglichkeit ein Land zu wählen, in dem die Angestellten bereits über familiäre oder freundschaftliche Kontakte verfügten. Auf Wunsch Salman Schockens wurden seine persönlichen und beruflichen Kontakte mobilisiert, um den Angestellten nach der Auswanderung Hilfe zukommen zu lassen und ihnen Arbeitsplätze zu vermitteln. Die größte Herausforderung war jedoch, so erinnerte sich Markowicz, die Angestellten von der Notwendigkeit der Auswanderung zu überzeugen. Seine eigene Rolle im Auswanderungskomitee des Schocken-Konzerns war es, ihnen die ausweglose Situation für Jüdinnen und Juden in Deutschland zu verdeutlichen und sie davon zu überzeugen, ihre sichere Stellung bei Schocken aufzugeben und den Schritt in eine ungewisse Zukunft zu wagen. ${ }^{76}$

71 Ernst Markowicz an Gershom Schocken, 01.06.1960. LBAJ, JER 193II, Bd.6.

72 Ebd.

73 Zum brandenburgischen Gut Winkel vgl. Michaeli / Klönne: Gut Winkel.

74 Ernst Markowicz an Gershom Schocken, 01.06.1960. LBAJ, JER 193II, Bd.6.

75 Vgl. ebd.

76 Vgl. ebd. 
Während die leitenden Angestellten wie Schiller, Bullwachter, Georg Spiro und andere erst im Laufe des Jahres 1938 Deutschland verließen, ${ }^{77}$ Moritz Spitzer als Verlagsleiter sogar 1939, und für die Angestellten des Berliner Büros ebenfalls erst 1938 Auswanderungsmöglichkeiten organisiert wurden, ${ }^{78}$ emigrierten die übrigen auswanderungswilligen jüdischen Angestellten bereits bedeutend früher. Der größte Teil von ihnen, rund 200 der 250 jüdischen Mitarbeiterinnen und Mitarbeiter, machte Gebrauch von Schockens Auswanderungshilfe. Die überlieferte Korrespondenz im Schocken Archiv enthält zahlreiche Briefe von ehemaligen Angestellten, in denen Schocken gegenüber tiefste Dankbarkeit zum Ausdruck gebracht wird. Zahlreiche Verfasser*innen informierten ihren ehemaligen Patron auch über die privaten und beruflichen Entwicklungen in ihrem Leben im Ausland, einige hielten den Kontakt über Jahrzehnte aufrecht.

Ein Beispiel dafür war die Verkäuferin Selma Levi, die nach der Emigration aus Deutschland in der Handtaschenabteilung des New Yorker Haern's Department Stores tätig war. Sie berichtete Salman Schocken in unregelmäßigen Abständen von ihrem Leben in New York. Sie war dankbar für die Hilfe, die Schocken ihr zukommen ließ, und die Möglichkeit, gemeinsam mit ihrer Mutter und Schwester auszuwandern. Sie bemerkte aber auch, dass das Gehalt als Verkäuferin nur gerade zum Überleben reiche und dass - anders als bei Schocken - die Möglichkeit, „sich empor zu arbeiten “79, nur sehr gering sei. Sie bat daher Salman Schocken im August 1937, bei ihrem Arbeitgeber, Maurice Levin, ein gutes Wort für sie einzulegen. ${ }^{80}$ Ihr Brief wurde wegen Abwesenheit Schockens vom Sekretariat beantwortet, wo man ihr versicherte, dass sich Salman Schocken für sie einsetzen werde, falls er mit Maurice Levin bekannt sein sollte. ${ }^{81}$

Mit der systematischen Auswanderungshilfe für die jüdischen Angestellten seines Konzerns, übernahm er als Patron ein hohes Maß an Verantwortung für seine Mitarbeitenden. Es ist in Deutschland kein ähnlicher Fall bekannt, wo ein Firmeninhaber seine Angestellten derart umfassend in ihrer Auswanderung

77 Vgl. Theodor Schocken an Salman Schocken, 26.01.1939. SchA, Privates, 844/2, Bd. 7.

78 Vgl. Edith Michelsen an Salman Schocken, 11.04.1938. SchA, Privates, 844/2, Bd. 5.

79 Vgl. Selma Levi an Salman Schocken, 24.08.1937. SchA, Privates, 844/2, Bd. 4.

80 Ebd.

81 Vgl. Sekretariat Schocken an Selma Levi, 10.10.1937. SchA, Privates, 844/2, Bd.4. 
unterstützte. Rückblickend weiß man, dass er damit 200 Angestellten und darüber hinaus in vielen Fällen auch deren Familienangehörigen das Leben rettete. Die Weitsicht, bereits im Frühjahr 1935 mit der Planung der Auswanderung zu beginnen, hebt sich jedoch von Äußerungen, die aus anderen Kontexten überliefert sind, drastisch ab. So schreibt er im Dezember 1935 an seinen Jugendfreund und Sohn seines Lehrers, Isaak Herz - einer der wenigen Briefpartner, die er duzt -, dass er immer gefunden habe,

dass die Menschen, die etwa in deinem Beruf und Alter stehen, wie die Dinge nun einmal liegen, besser tun, sich auf die Verhältnisse dort [also in Deutschland, Anm. der Verf.] umzustellen, und wenn auch in reduziertem Masse, ihr Leben dort weiterzuführen. ${ }^{82}$

Diese harsche Absage auf eine Unterstützungsbitte eines Schulfreundes bedeutete aber nicht, dass Salman Schocken nicht bereit war, Verwandten und Bekannten zu helfen. Im selben Brief bot er nämlich an, dem Sohn von Isaak Herz einen Platz in der Jugend-Alija zu vermitteln.

\subsubsection{Unsystematisch, aber dennoch Prinzipien verpflichtet: Hilfe für Verwandte, Bekannte und Freunde bei der Auswanderung} Zahlreiche Menschen setzten in den 1930er Jahren ihre Hoffnung auf den gut vernetzten und wohlhabenden Kaufmann Salman Schocken. Während in den ersten zwei Jahren der NS-Herrschaft die Bittgesuche noch nicht zahlreich waren, stiegen sie 1935 sprunghaft an. Im Jahr 1938 erreichten sie ihren Höhepunkt. ${ }^{83}$ Die Auswertung der Antworten auf die unzähligen Briefe an Schocken und seine Familie lassen eine gewisse Systematik in der Hilfe ersichtlich werden. Angestellte des Konzerns sowie Familienangehörige von engen Mitarbeitenden konnten sich nicht nur auf finanzielle Hilfe, sondern auch auf Unterstützung bei Visumsanträgen und der Stellensuche verlassen. Schocken unternahm resp. veranlasste alles, was nötig war, um diesem Personenkreis eine möglichst problemlose Emigration zu ermöglichen.

82 Salman Schocken an Isaak Herz, 27.12.1935. SchA, Privates, 844/2, Bd. 3.

83 Diese Feststellungen beruhen nicht auf systematischen Auswertungen der Bittgesuche, sondern auf einfachen Beobachtungen solcher Schreiben in Schockens Privatkorrespondenz. Vgl. Sch A, Privates, 844/2, Bde. 1-8. 
Ebenfalls auf Schockens Unterstützung konnten jene Personen zählen, die privat oder geschäftlich eng mit ihm oder der Familie verbunden waren. Dazu gehörten Geschäftspartner, aber auch Ärzte und selbstverständlich seine Verlagsautoren sowie deren Familien. Zudem zeigte sich Salman Schocken oft bereit, Söhnen und Töchtern von Bekannten und Freunden eine Immigrationshilfe nach Palästina zu gewähren. Dazu gehörte nicht nur ein finanzieller Beitrag oder sogar die Übernahme sämtlicher Kosten für die Reise, sondern auch die Vermittlung von Plätzen in der Jugend-Alija oder in einem passenden Kibbutz. Fast gänzlich sah er jedoch von Unterstützung für Menschen seines Alters $\mathrm{ab}$, die ihr Glück in Palästina versuchen wollten. Seine Antworten konnten dabei äußerst harsch ausfallen. An seinen Jugendfreund Isaak Herz schrieb Schocken, dass er es als „ein menschliches und nationales Unglück [betrachte], dass die deutschen Juden ohne Unterschied in Palästina ihr einziges Refugium sehen. ${ }^{\text {(84 }}$

Der Grundsatz, älteren Auswanderungswilligen von einer Immigration nach Palästina abzuraten, zeigt sich auch in einem Brief von 1937 an Harris Wilson, einem Bekannten seines Bruders Hermann Schocken. In „aller Offenheit“, so schrieb Schocken, möchte er ihm seine „Standpunkte“ darlegen:

Palästina ist ein Land, das an die Gesundheit der Menschen sehr hohe Anforderungen stellt. Obwohl es sehr viel Sonne gibt, stellen sich auch dauernd Stürme ein, und die Übergänge sind ungewöhnlich schroff. [...] Außerdem ist zu bedenken, dass der Sommer lang und sehr heiß ist, der Winter dagegen kurz, mit heftigen Regengüssen und unangenehmen Stürmen. [...] Ferner aber - was ebenfalls ernst erwogen werden muss - ist hier durch die politische Not der Juden in Deutschland und in Polen eine soziale Not-Situation geschaffen, die an alle Hilfsinstanzen höchste Anforderungen stellt. Daraus ergibt sich, dass nur in den schwersten Fällen geholfen werden kann. ${ }^{85}$

An eine Bekannte der Familie, Frau Frohknecht aus Amsterdam, die sich für zwei ihr bekannte Menschen in Deutschland einsetzte, schrieb er zudem, dass es einen starken Zustrom von Akademikern, Verwaltungsbeamten und

84 Salman Schocken an Isaak Herz, 27.12.1935. SchA, Privates, 844/2, Bd. 3.

85 Briefentwurf Salman Schocken an Harris Wilson, 04.03.1937. SchA, Privates, 844/2, Bd. 8. Harris Wilson stammte nicht aus Deutschland und wollte aus persönlichen Gründen nach Palästina migrieren. 
kaufmännischen Angestellten aller Art gäbe. Entsprechend würden nur Menschen in „die Wirtschaft hineinkommen“, wenn sie vorher „die beiden Landessprachen: in erster Linie hebräisch, dann aber auch englisch beherrschen. ${ }^{\text {" } 86} \mathrm{Er}$ sehe davon ab, bei „erfolglosen Versuchen“ bei den Briten um Vergünstigungen bei der Zertifikatsvergabe, „die immer weiter eingeschränkt werden“, zu bitten und Protektion zu gewähren. ${ }^{87}$

Diesen Standpunkten blieb Salman Schocken fast immer treu. Schocken versuchte, seine Mittel gezielt einzusetzen. Aus einem Antwortschreiben an einen Herrn Bamberger aus Nürnberg, der bei Schocken um Hilfe bei der Auswanderung von Bekannten nach Palästina bat, wird ersichtlich, wie die private Unterstützung strukturiert wurde.

Der Etat, den Herrn Schocken für Hilfszwecke bestimmt hat, ist durch die Not der letzten Zeit in Fällen, die Herrn Schocken persönlich nahestehen und solchen, denen durch kleine Unterstützung wirklich produktiv geholfen werden konnte, völlig erschöpft, und es scheint uns nicht möglich, weitere Gesuche zu berücksichtigen. ${ }^{88}$

In einem zweiten Schreiben wurde zudem festgehalten, dass „vielfach Bestrebungen im Gange [seien], eine Reorganisation des Fürsorgewesens durchzusetzen, [...] die Verwirklichung der Pläne [würde leider] noch einige Zeit dauern. “89 Wie hoch Schockens finanzielle Hilfeleistungen in ihrer Gesamtheit ausfielen, lässt sich aus den Akten nicht eruieren. Dass es sich um einen erheblichen Betrag gehandelt haben muss, lassen jedoch die hohe Zahl der gewährten Hilfen sowie einige bekannte Beispiele vermuten. Um einen Einblick in die unterschiedlichen Hilfeleistungen Schockens zu geben, werden im Folgenden einige Fälle geschildert.

Als Erstes soll nochmals auf das Schicksal von Isaak Herz' Familie eingegangen werden. Während Salman Schocken davon absah, Isaak und seiner Frau Alina eine Emigration nach Palästina zu ermöglichen, zeigte er sich bereit, ihrem zwölfährigen Sohn Horst zu helfen. Er schrieb:

86 Salman Schocken an R. Frohknecht, 02.01.1936. SchA, Privates, 844/2, Bd.2.

87 Ebd.

88 Sekretariat Schocken an Bamberger, 01.10.1937. SchA, Privates, 844/2, Bd. 1.

89 Sekretariat Schocken an Bamberger, 22.11.1937. SchA, Privates, 844/2, Bd. 1. 
Nun schreibst Du von Deinem Sohn. Ich kann Dir dazu berichten, dass hier unzählige Kinder durch Jugend-Alijah und anderes sehr gut untergebracht wurden. Ich selber habe auf die gleiche Weise den Sohn meiner Nichte, Erna Arndtheim, veranlasst herzukommen, und ich möchte mich bereit erklären, wenn Ihr Euch entschließen könnt, den Jungen herzugeben, für ihn hier zu sorgen. Es ist mir ein lieber Gedanke, wenn ich an dem Enkel meines alten Lehrers Herz einen Dank abstatten kann, den ich mein ganzes Leben schuldig zu sein fühlte. [...] Ich kann mir [...] vorstellen, dass bei meinem Vorschlag alle Bedenken auszuschalten sind, es gibt hier viele Erziehungsheime auf dem Land, in denen die Kinder, in enger Verbindung mit dem Lande und einem tätigen Beruf, erzogen werden, und dann, nach menschlichen Ermessen, in eine gesicherte Lebensform hereinwachsen. Ich bitte Euch davon überzeugt zu sein, dass ich diesen Vorschlag sehr ernst meine. ${ }^{90}$

Herz antwortete auf das Angebot, dass er und seine Frau hofften, durch den Verkauf von Leinenkleidern sich in Palästina einen bescheidenen Unterhalt verdienen zu können, damit ihnen die Trennung von ihrem Kind erspart bliebe. „Ich brauche Dir ja nicht zu sagen“, schrieb Herz, „was es für uns, besonders für eine Mutter bedeutet, das Letzte ihr vom Schicksal gelassene herzugeben. Da es jedoch um die Zukunft unseres Kindes handelt, müssen wir uns eben auch damit abfinden und ins Unabänderliche fügen. ${ }^{\text {“91 }}$ Er dankte Schocken für das "hochherzige Angebot“ und zeigte sich überzeugt davon, dass ihr Sohn, wenn sich Schocken seiner annehme, zu „einem guten Juden und Menschen“ werde. ${ }^{92}$ Alina und Isaak Herz konnten nicht wissen, dass sie durch die Entscheidung, ihren zwölfjährigen Sohn Horst alleine nach Palästina reisen zu lassen, sein Leben retteten. Die Trauer um den Verlust und die Sorge um ihr einziges Kind fanden jedoch Ausdruck in mehreren Briefen, die Alina Herz an Schocken schickte. Sie sorgte sich, nachdem sie in Erfahrung gebracht hatte, dass Horst sich alleine in Jerusalem aufhielt und unter schlimmen Bedingungen in einer Baracke mit „arabischen Polizisten ${ }^{\text {“93 }}$ hauste. Schocken konnte die Mutter beschwichtigen, da er von einem jungen Bekannten, einem Herrn Littman, der Horst kenne, erfahren habe, dass alles in Ordnung sei, er ein eigenes Zimmer

90 Salman Schocken an Isaak Herz, 27.12.1935. SchA, Privates, 844/2, Bd. 3 .

91 Isaak Herz an Salman Schocken, 06.03.1936. SchA, Privates, 844/2, Bd.3.

92 Ebd.

93 Alina Herz an Salman Schocken, 24.01.1937. SchA, Privates, 844/2, Bd.3. 
in der Jehuda-Straße bewohne und „es keinerlei Anzeichen dafür [gäbe], dass

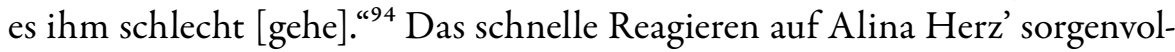
len Brief zeigt, dass Schocken die Sorgen und Nöte der Mutter ernst nahm. Ein anderer Fall war Salman Schockens Unterstützung für Eva Maly, eine Freundin der Familie. Schocken begann im Juli 1935, die junge Juristin zu unterstützen, nachdem diese nach Großbritannien übergesiedelt war, um eine Ausbildung im Hotelgewerbe zu absolvieren und die englische Sprache zu lernen. Sie entschloss sich zu einer Ausbildung am Wittingham College. Schocken regte ihre Pläne zur sogenannten Umschichtung an. Als sie in London keine Stelle fand, war er bereit, sie mit einem monatlichen Betrag von 12 Pfund, zahlbar von einem Konto auf einer nicht näher benannten Schweizer Bank, bis Ende Dezember 1935 zu unterstützen. ${ }^{95}$ Zudem kontaktierte Schocken Otto W. Schiff vom Jewish Refugee Comité in London und bat ihn, „diesen wertvollen jungen Menschen zu unterstützen. ${ }^{“ 96}$ Es fehle, so Schocken,

gerade in Palästina [...] an richtig geschulten Kräften, die im Hotel-Gewerbe das Niveau der Zimmerhaltung und Wäschehaltung sichern können. Wenn Fräulein Maly in London den richtigen Weg zu dieser Berufslaufbahn eröffnet wird, glaube [ich], dass sie in Palästina eine geeignete Position finden und gut ausfüllen [würde]. ${ }^{97}$

Bis im Frühjahr 1936 blieb Eva Maly in London, wo sie Englisch und Hebräisch lernte, ${ }^{98}$ und im Januar 1936 eine Volontariatsstelle „mit freier Station ${ }^{\text {“99 }}$ in einem Hotel fand. Daher wurde das monatliche Stipendium zwar verlängert, jedoch auf fünf Pfund monatlich reduziert. ${ }^{100}$ Nachdem sie mit Einwanderungszertifikat

94 Salman Schocken an Alina Herz, 10.02.1937. SchA, Privates, 844/2, Bd. 3 und Notiz für Herrn Schocken betr. Horst Herz, Littmann, 09.02.1937. SchA, Privates, 844/2, Bd.3.

$95 \mathrm{Vgl}$. Sekretariat Schocken an Salman Schocken mit roter handschriftlicher Zahlungsanweisung von Salman Schocken, 29.08.1935. SchA, 844/2, Bd. 5. Die Verwendung eines roten Bleistiftes war Salman Schocken vorbehalten. Dadurch war für alle ersichtlich, dass Anmerkungen, Korrekturen und Hervorstreichungen von Schocken angebracht wurden, ohne dass er zu signieren hatte. Vgl. Richtlinien für die Korrespondenz zwischen Herrn Schocken und dem Verlag, 26.01.1936. SchA, Verlag, 331/47.

96 Salman Schocken an Otto W. Schiff, 30.07.1935. SchA, Privates, 844/2, Bd. 5.

97 Ebd.

98 Vgl. Eva Maly an Salman Schocken, 12.11.1935. SchA, Privates, 844/2, Bd. 5.

99 Notiz für Dr. Kaufmann von Dr. Romann, 03.01.1936. SchA, Privates, 844/2, Bd. 5. 100 Vgl. Notiz Dr. Kaufmann, 10.01.1936. SchA, Privates, 844/2, Bd. 5. 
nach Palästina migrierte, unterstützte Schocken sie weiterhin, indem er zahlreiche Referenzschreiben für sie verfasste und sie möglichen Arbeitgebern vorstellte. ${ }^{101} \mathrm{Ob}$ Salman Schocken ihr bei der Einreise behilflich war und unter welcher Kategorie sie einreiste, ist nicht bekannt. Maly lebte vorerst im Moschav Nahalal westlich von Nazareth in der Jesreelebene, wo sie sich mit einem Herrn Marbach verheirate. Die Stellensuche gestaltete sich jedoch trotz ihres abgeschlossenen Studiums der Rechte, der Zweitausbildung im Hotelgewerbe und ihren Sprachkenntnissen als äußerst schwierig. Auf Vermittlung von Salman Schocken fand sie schließlich eine Anstellung als Stenotypistin bei einem Rechtsanwalt, die sie aber nicht lange behielt. ${ }^{102}$

Schocken engagierte sich auch mit kleineren, einmaligen Hilfeleistungen, wie jene für Dora Ury, die Tante eines Geschäftspartners. Er zeigte sich bereit, die Hälfte des nötigen Betrages für ein Kapitalistenzertifikat aufzubringen, wenn sein Geschäftspartner George Ury die andere Hälfte leisten würde. Ury war ein Händler aus Paris, mit dem der Schocken-Konzern geschäftlich verbunden war, und über den Schocken auch zahlreiche Pflanzen für seine Gärten, aber auch Stoffe wie Leder für Möbel und Vorhänge bezog. ${ }^{103}$ Die Hilfe für Dora Ury hob sich von den übrigen Fällen, in denen Schocken zu helfen bereit war, insofern ab, als er einwilligte, einer Dame die Emigration nach Palästina zu ermöglichen, die nicht seinen Anforderungen für eine Alija entsprach. Aus dem Briefwechsel lässt sich ablesen, dass die Tante Urys in Deutschland lebte, die Familie stammte ursprünglich aus Sachsen. Einerseits führte sicherlich die langjährige geschäftliche Verbindung zwischen Schocken und Ury dazu, dass Schocken sich verpflichtet fühlte, einer Verwandten eines geschätzten Kollegen zu helfen. Andererseits traf die Bitte im Jahr 1938 ein, als sich die nationalsozialistische Judenpolitik im Vergleich zu den früheren Jahren nochmals verschlimmerte. 1938 bemerkte auch Theodor Schocken, der als Mitglied der Geschäftsführung des Schocken-Konzerns und als Vertreter seines Vaters in Deutschland und später in den USA ebenfalls gut vernetzt und weitum bekannt war, dass die Hilfegesuche drastisch angestiegen seien. Er schrieb an seinen Vater:

101 Vgl. diverse Briefe Salman Schocken, 1936-1938. SchA, Privates, 844/2, Bd. 5.

102 Vgl. Eva Marbach an Lili Schocken, 03.03.1938. SchA, Privates, 844/2, Bd. 5.

103 Vgl. Briefwechsel Salman Schocken und George Ury, Mai bis Oktober 1938. SchA, Privates, $844 / 2$, Bd. 8 . 
Meine ganze freie Zeit hier ist ausgefüllt mit Korrespondenzen [...] mit Leuten, die hier Affidavits geben sollen. Mit einem Affidavit besteht eine gewisse Chance, die Menschen, die jetzt in Lagern in Deutschland sind, frei zu bekommen. ${ }^{104}$

Er fügt aber hinzu, dass,

[w]enn die amerikanische Einwanderungsquote nicht erhöht wird (und ich fürchte, Roosevelt fühlt sich nicht stark genug, um dafür energisch einzutreten), so haben diese Affidavits keinen Wert. Die Leute müssten in Deutschland Jahre und Jahre warten, bis sie drankommen. ${ }^{105}$

\subsubsection{Schockens Hilfe im Kontext}

1938 war ein Scheidepunkt in der Geschichte der Emigration von Juden und Jüdinnen aus Deutschland. Der Einmarsch deutscher Truppen in Österreich am 12. März und der einen Tag später erfolgte ,Anschluss' als ,Ostmark' an das Deutsche Reich, die kurz drauf erlassenen Grenzsperren in der Schweiz und Schweden sowie die Sudetenkrise im August und September spielten dabei eine zentrale Rolle. Für den Alltag der jüdischen Bevölkerung sehr viel einschneidender waren jedoch die unzählbaren antisemitischen Beschlüsse und Erlasse, die sich bedrohlich auf das Leben jedes Einzelnen auswirkten. Dazu zählten unter anderen das im Januar erlassene Gesetz zur Änderung von Familienund Vornamen (RGB1, I, 9), die Verordnung über die Anmeldung des Vermögens von Juden (RGB1, I, 415) im April, der im Juli erlassene ,Kennkartenzwang', der verfügte, dass Juden, die deutsche Staatsangehörige waren, sich bis Ende des Jahres bei der Polizeibehörde eine Kennkarte ausstellen lassen mussten (RGB1, I, 922), sowie im Oktober die Ungültigkeitserklärung der deutschen Reisepässe für Juden, die erst durch die Kennzeichnung mit einem eingestempelten "J“wieder Gültigkeit erlangten (RGB1, I, 1342). Das wichtigste Ereignis war jedoch die sogenannte Reichspogromnacht vom 9. auf den 10. November 1938. In der Pogromnacht, die euphemistisch als ,Kristallnacht in den allgemeinen Sprachgebrauch einging, und während der folgenden Tage, wurden Zehntausende verhaftet, darunter auch führende Persönlichkeiten der Reichsvertretung. Auf die Pogrome folgte die fast komplette Ausschaltung der

104 Theodor Schocken an Salman Schocken, 17.11.1938. SchA, Privates, 844/2, Bd.7. 105 Ebd. 
Juden aus dem deutschen Wirtschaftsleben und die Zerstörung der Organisationsstrukturen des deutschen Judentums. Die Emigrationszahlen spiegeln diese Ereignisse: Während in den ersten fünfeinhalb Jahren des Nationalsozialismus, also bis Mitte 1938, insgesamt ungefähr 150.000 Juden und Jüdinnen Deutschland verließen, emigrierten ab Mitte 1938 nochmals 100.000 bis $150.0000^{106}$ 1933 erfolgte die Emigration meist planlos als spontane Reaktion auf die Machtergreifung der Nationalsozialisten in die Nachbarstaaten. Ungefähr 72 bis 74 Prozent der Emigranten wanderten in europäische Staaten aus, knappe 19 Prozent nach Palästina und zwischen 7 bis 9 Prozent wählten Länder in Übersee als Destination (siehe Tabelle 2). Bereits im zweiten Jahr erfolgte die Emigration sehr viel geplanter. Nicht nur ging die Gesamtzahl der Emigranten von 37.000 auf 23.000 zurück, ${ }^{107}$ auch änderte sich die Aufteilung nach Migrationszielen: 1934 ließen sich 35 bis 40 Prozent in Palästina nieder, 37 Prozent in Europa und 23 bis 28 Prozent in Übersee. 1935 überstieg die Auswanderung nach Übersee erstmals jene nach Europa und 1936 überwog sie insgesamt (mit 33 bis 38 Prozent gegenüber 26 bis 31 Prozent nach Europa und 36 Prozent nach Palästina).

\begin{tabular}{|l|r|r|r|r|r|r|}
\hline & $\mathbf{1 9 3 3}$ & $\mathbf{1 9 3 4}$ & $\mathbf{1 9 3 5}$ & $\mathbf{1 9 3 6}$ & $\mathbf{1 9 3 7}$ & $\mathbf{1 9 3 8}^{108}$ \\
\hline Europa & $72-74 \%$ & $35-40 \%$ & $26-31 \%$ & $20-25 \%$ & $25 \%$ & $27,2 \%$ \\
\hline Palästina & $19 \%$ & $37 \%$ & $36 \%$ & $34 \%$ & $15 \%$ & $10,8 \%$ \\
\hline Übersee & $7-9 \%$ & $23-28 \%$ & $33-38 \%$ & $41-46 \%$ & $60 \%$ & $62,0 \%$ \\
\hline
\end{tabular}

Tabelle 2: Emigration von Jüdinnen und Juden aus Deutschland nach Migrationsziel $(1933-1938)^{109}$

106 Vgl. Rosenstock: Exodus 1933-1939, S.374.

107 Vgl. ebd., S.377.

108 Nur Januar bis Juni.

109 Angaben nach ebd., S.380-381 Die Zahlen sind insofern mit Vorsicht zu betrachten, als keine offiziellen Gesamtstatistiken vorliegen. Rosenstock bezog bei seinen Berechnungen die Jahresberichte des Zentralausschusses für Hilfe und Aufbau, der unter dem Dach der Reichsvertretung der deutschen Juden arbeitete, und die Statistiken der Emigrationsländer mit ein, sowie die Berichte der Meldestelle für Binnen- und Auswanderung des Preußischen Landesverbandes jüdischer Gemeinden, der nicht nur Angaben für Preußen, sondern für das ganze Gebiet Deutschlands erhob. Für das Jahr 1937 und die erste Hälfte 1938 liegen 
Diese Zahlen spiegeln sich in den Anträgen und Anfragen an Salman und Theodor Schocken, wovon auch der oben zitierte Brief des Sohnes an seinen Vater zeugt. Der Brief weist aber auch darauf hin, dass es zunehmend schwieriger wurde, jüdischen Flüchtlingen die Einreise in einen sicheren Staat zu ermöglichen. Die vom 6. bis zum 15. Juli im französischen Évian abgehaltene Konferenz zur Problematik der jüdischen Flüchtlinge, an der Delegierte von 32 Staaten sowie Repräsentanten von Flüchtlingsorganisationen teilnahmen, verlief ergebnislos, da sich - mit Ausnahme der Dominikanischen Republik kein Staat bereit erklärte, sein Kontingent für aus dem deutschen Machtbereich Geflüchtete zu erhöhen.

Die Konferenz wurde nach der Annexion Österreichs einberufen, die weitere 185.000 Juden und Jüdinnen unter die Herrschaft NS-Deutschlands brachte. $\mathrm{Zu}$ diesem Zeitpunkt wollte ein großer Teil der jüdischen Bevölkerung das NS-Herrschaftsgebiet verlassen, auch wenn dies mit dem Verlust des Besitzes und Vermögens einherging. In der Zwischenzeit hatten jedoch die europäischen Staaten die Aufnahme von jüdischen Emigranten und Flüchtlingen mit Kontingenten belegt. Auch die USA, die ab 1938 zu einem Hauptziel der Emigrationswilligen wurde, regelte seit 1924 die Immigration mit einer Obergrenze. Vor diesem Hintergrund rief Präsident Franklin D. Roosevelt, der unter politischem Druck stand, die Évian-Konferenz ein, die zum Ziel hatte, die Emigration von deutschen und österreichischen Juden zu regeln. Während der neuntägigen Konferenz am Genfer See drückten die Delegierten zwar ihr Mitgefühl für die verfolgten Juden aus, zeigten sich aber nicht bereit, ihre Kontingente für jüdische Emigranten und Flüchtlinge zu erhöhen. ${ }^{110}$ Die Staatenwelt versagte angesichts der drohenden Katastrophe, deren ganzes Ausmaß zu diesem Zeitpunkt noch nicht absehbar war; jedoch war im Sommer 1938 bereits offensichtlich, dass das deutsche und österreichische Judentum unter menschenverachtenden Repressionen litt.

Angesichts der restriktiven Einwanderungs- und Flüchtlingspolitik konnte auch die private Hilfe von Schocken wenig ausrichten. Zwar konnte mit der

erstmals genaue statistische Angaben vor. Vgl. dazu sowie auch zur kritischen Evaluation der drei Quellen: Werner Rosenstock: Exodus 1933-1939. A Survey of Jewish Emigration From Germany. In: LBIYB 1,1 (1956), S. 373-390, hier S. 374-377.

110 Zur Évian-Konferenz vgl. Michael R. Marrus: Evian. In: EJGK, Bd. 2, hrsg. v. Dan Diner. Stuttgart / Weimar: Metzler 2012, S.289-295. 
Bereitstellung von großen Summen auf Vorzeigekonten die Immigration von Familienangehörigen und engen Mitarbeitenden nach Palästina und in die USA auch 1938 noch ermöglicht werden - darüber hinaus reichten aber Affidavits und Referenzschreiben nicht mehr aus, da die Einreisekontingente bereits ausgeschöpft waren.

Es ist auf Grundlage der Akten kaum abzuschätzen, wie groß die Zahl der Menschen war, die mit Unterstützung Schockens rechtzeitig aus dem NSHerrschaftsgebiet emigrieren konnte. Während die Angestellten, die erfolgreich auswanderten, anhand der Angaben des Konzernes auf ungefähr 200 beziffert werden können, ist die Hilfe für Bekannte kaum messbar, da sie sich, wie deutlich geworden ist, auf verschiedenen Ebenen abspielte. Es kann aber festgehalten werden, dass die Unterstützung des Privatmannes Schocken, der mithilfe seines Vermögens, seiner Reputation und seines Netzwerkes Bekannten, Freunden und Geschäftspartnern die Emigration ermöglichte oder sie logistisch unterstützte, eine wichtige Ergänzung zu den durch offizielle jüdische Stellen assistierten Auswanderungen darstellte. In den Jahresberichten des Zentralausschusses wird zwischen vier Kategorien von assistierten Auswanderungsmöglichkeiten unterschieden. Der Hilfsverein der deutschen Juden unterstützte die Auswanderung nach Europa wie auch nach Übersee, die Emigration nach Palästina wurde assistiert durch das Palästina Amt, und die Repatriierung von osteuropäischen Juden in ihre Herkunfts- resp. Heimatländer wurde organisiert von der Hauptstelle für jüdische Wanderfürsorge. ${ }^{111}$ Der größte Teil der Auswanderungen erfolgte jedoch ohne offizielle Hilfe der jüdischen Organisationen. Es liegt in der Natur der Sache, dass die Anzahl an Menschen, die durch private Initiativen und Hilfeleistungen, wie jene von Salman Schocken, gerettet wurden, nicht mehr zu eruieren ist.

111 Vgl. Rosenstock: Exodus 1933-1939, S.374. 


\subsection{Angekommen und doch verloren. Die Unterstützung für mittellose Dichter*innen und Künstler*innen in Palästina}

Die Dichterin Else Lasker-Schüler lebte, nachdem ihr von den Schweizer Behörden ein Rückreisevisum in die Schweiz versagt wurde, vom Juli 1939 bis zu ihrem Tod im Januar 1945 in Jerusalem. ${ }^{112}$ Zwar zerrann "der exzentrischen Dichterin zeitlebens das Geld unter den Fingern "113, ihre Not in Jerusalem war jedoch nicht nur finanzieller Natur. Wie viele Exilschriftsteller*innen litt sie unter Armut, aber auch darunter, kaum mehr schreiben zu können. ${ }^{114}$ Anders als die bildende Kunst ist die Literatur auf Sprache angewiesen. Viele aus dem deutschsprachigen Raum nach Palästina emigrierte Dichter*innen und Schriftsteller*innen litten an der Unmöglichkeit, sich in der neuen Sprache zurechtzufinden. Nur wenigen gelang es, auch in Hebräisch zu schreiben, ${ }^{115}$ und Publikationsmöglichkeiten für deutsche Literatur gab es in Palästina kaum. Aber auch bildende Künstler*innen litten darunter, ihr kulturelles Umfeld und ihre Kunstwerke zurückgelassen zu haben. Dazu kam die große finanzielle Not, die zahlreiche Künstler und Künstlerinnen zwang, ihren Lebensunterhalt als Hilfsarbeiter zu verdingen. Andere versuchten, durch die Herstellung von Alltagsgegenständen oder Nahrungsmitteln etwas zu verdienen. ${ }^{116}$

Jerusalem wurde zum geographischen und kulturellen Zentrum der deutschsprachigen Kunstschaffenden. Zwar versuchten einige, sich in landwirtschaftlichen Siedlungen und den Küstenstädten Tel Aviv und Haifa niederzulassen,

112 Else Lasker-Schüler floh im April 1933 aus Berlin in die Schweiz. Sie bereiste 1934 und 1937 Palästina, da sie die Schweiz jeweils für mehrere Monate verlassen musste, damit ihr Visum erneuert wurde. Während ihres dritten Aufenthaltes im Jahr 1939 wurde ihr Visum von den Schweizer Behörden nicht mehr verlängert.

113 Sigrid Bauschinger / Helmut G. Hermann: Einleitung. In: Lasker-Schüler: ,Was soll ich bier?', S. 13-35, hier S. 13.

114 Zur Problematik der Sprache für Exilschriftsteller und -schriftstellerinnen vgl. u. a. Stephan Braese: Deutsche Sprache, jüdisches Exil - Optionen von ,Identität' nach 1933. In: Hans Otto Horch / Hanni Mittelmann / Karin Neuburger (Hrsg.): Exilerfahrung und Konstruktionen von Identität 1933 bis 1945. Berlin: de Gruyter 2013, S.7-16.

115 Vgl. u. a. Itta Schedletzky: Der Ort der Jeckes in der Literatur von Palästina / Israel. In: Zimmermann / Hotam (Hrsg.): Zweimal Heimat, S. 194-203, hier S. 200.

116 Die Typographin Franzisca Baruch stellte in ihrer Wohnung Marzipan her, um sich durch den Verkauf der deutschen Spezialität etwas dazuzuverdienen, vgl. Caroline Jessen: Franzisca Baruch’s Marzipan Biscuits From Jerusalem. In: Wardi (Hrsg.): New Types, S. 214-217. Weitere Beispiele finden sich in Gideon Ofrat: Berlin - Jerusalem. In: Zimmermann / Hotam (Hrsg.): Zweimal Heimat, S. 137-146, hier S. 139. 
die klimatisch angenehmeren Bedingungen und das intellektuelle Klima der Universitätsstadt Jerusalem wirkten jedoch als Magnet auf die aus Deutschland Emigrierten. Zwei Kultursalons, einer im Haus von Anna und Abraham Ticho und ein zweiter im Haus von Grete und Leopold Krakauer waren Treffpunkte der deutschsprachigen jüdischen Intellektuellen, Künstler*innen und Schriftsteller*innen. ${ }^{117}$ Gideon Ofrat bezeichnete die engen Beziehungen der aus Deutschland eingewanderten Künstlerinnen und Künstler, die sich in Emigrantencafés, Salons und Galerien trafen, als ein „kulturelles Miniatur-Ghetto “118. Laut Ofrat besteht auch kein Zweifel daran, dass die deutschen Einwanderer einen außergewöhnlichen Beitrag zur israelischen Kultur geleistet haben; dieser sei jedoch kaum in das kulturelle Gedächtnis Israels eingegangen. ${ }^{119}$ In der Gründung der Bezalel ha-chadasch, der Nachfolgeinstitution der 1929 geschlossenen Kunstschule Bezalel, manifestierte sich der deutsche Einfluss deutlich. Auf Initiative der deutschen Abteilung der Jewish Agency und von Persönlichkeiten wie Salman Schocken, Anna Ticho, Erich Mendelsohn und Herman Struck wurde die neue Bezalel-Schule 1937 gegründet. Die Institution sollte als eine Art „zionistisches Bauhaus “ ${ }^{120}$ wiedereröffnet werden mit einem Fokus darauf, Kunstschaffende in Gebrauchsgraphik, Metallkunst und Weben auszubilden mit ergänzendem Studium in Malerei, Zeichnung und Bildhauerkunst.

Salman Schocken bewegte sich in diesen Kreisen Jerusalems. Er war, wenn er nicht in Europa weilte, Gast im Kultursalon der Krakauers, wo auch Martin Buber, Samuel Joseph Agnon und der Dichter Abraham Sonne (später Avraham Ben Yitzhak) verkehrten. Zudem war er befreundet mit der Künstlerin Anna Ticho und deren Mann, arbeitete mit Erich Mendelsohn, aber auch mit der Typographin Franzisca Baruch. Und als Verleger war er ohnehin eng mit schriftstellerisch tätigen Exilanten verbunden. Dass er sich in Jerusalem gemeinsam mit einigen seiner Bekannten für die Wiedereröffnung der BezalelKunstschule als Lehrinstitution für Kunsthandwerk einsetzte, knüpft an seine

117 Vgl. Ofrat: Berlin - Jerusalem, S. 142.

118 Ebd., S. 144.

119 Laut Ofrat bewegten sich die deutschen Künstler*innen an der Peripherie der israelischen Kultur, während die vornehmlich aus Frankreich stammenden und avantgardistischen Künstler*innen, die sich in Tel Aviv niedergelassen hatten, in den großen Museen gezeigt und rezipiert wurden. Vgl. ebd., S. 145-146; Ziva Sternhell: Zwischen den Bergen Jerusalems und den Stränden Tel Avivs. In: Zimmermann / Hotam (Hrsg.): Zweimal Heimat, S. 147-152. 120 Ofrat: Berlin - Jerusalem, S. 144. 
frühen Ideen als Kaufmann an. 1931 verwies er in einem Vortrag anlässlich der Generalversammlung des Verbandes Deutscher Waren- und Kaufhäuser darauf, dass die Einzelhändler

[f]ür das Geschmacksniveau der Gebrauchsgegenstände in stärkerem Masse verantwortlich [sind], als sie es selbst wahrhaben wollen. Mancher Geschmacksgreuel wäre verschwunden, manches unsinnige Dessin nicht erst entstanden, wenn der Einzelhandel häufiger die Voraussetzungen für die Funktion der Auslese, die er ausüben soll, hätte: einen lebendigen Zusammenhang mit den kulturschöpferischen Elementen. [...] Wo das Kunstgewerbe die in dem verflossenen Jahrzehnt so beliebte Ebene der willkürlichen Formgestaltung und Dekoration verlässt und - häufig im Zusammenhang mit alten Kulturformen - gute, dem Zweck angepasste Geräte schafft und sich an das hält, was die Technik jetzt zu leisten vermag, kann das Warenhaus entscheidend dabei mitwirken, dass mustergültige Gebrauchswaren entstehen und in die Hände vieler Verbraucher kommen. ${ }^{121}$

Nicht nur die Qualität der Ware, sondern auch die Verbreitung des guten Geschmacks falle, so Schocken 1931, in den Aufgabenbereich des Händlers. Er sah den Kaufmann in der Pflicht, in enger Zusammenarbeit mit Kunstschaffenden für funktionale und gleichzeitig stilvolle Geräte zu sorgen. Im Rückverweis auf Vergangenes sollte eine Formsprache der Moderne entwickelt werden. ${ }^{122}$ Sechs Jahre später sah er diese Vision in der neuen Bezalel-Schule verwirklicht.

Schockens Hilfe für Kunstschaffende sowie Autorinnen und Autoren bestand vor allem darin, dass er ausgewählte Personen finanziell unterstützte. Darüber hinaus spendete er durchaus auch an Institutionen, die ihm unterstützungswürdig erschienen und die seiner Programmatik entsprachen. Schockens Programm, wie er es nannte, beinhaltete Wissenschaft, Literatur, Kunsthandwerk, bildende Kunst und Typographie. Außerhalb seines Programmes lagen Musik und Schauspiel. Hier zeigte er sich zwar bereit, sich an „allgemeinen Sammlungen ${ }^{\text {“123 }}$, wie er es nannte, zu beteiligen, aber nur mit kleineren Beträgen. Dass Schocken, bereits bevor er nach Palästina auswanderte, seine Unterstützung nur

121 Salman Schocken: Zwischen Produktion und Konsum. Berlin: Schocken 1931, S. 11.

122 Vgl. auch Mahrer: Tradition and Modernity.

123 Salman Schocken an Georg Landauer, 27.06.1937. SchA, Privates, 844/2, Bd.4. 
Institutionen und Personen zukommen ließ, die seinem Programm entsprachen, wird in einem Brief an das Habima-Theater vom Jahr 1929 deutlich. Er schrieb als Antwort auf ein Bittschreiben:

[...] Ich muss aber für mich das Recht in Anspruch nehmen, dass ich über die wirtschaftlichen und kulturellen jüdischen Aufgaben nach einem eigenen Programm arbeite und beitrage. Abweichend von der allgemeinen Oberschicht der Juden bewerte ich die ausgeübte Schauspielkunst als nationalen und kulturellen Faktor gering. ${ }^{124}$

Mit kleineren Spenden für jene Einrichtungen, die außerhalb seines Programmes lagen, und größeren Beträgen für Institutionen in seinem Interessensgebiet ermöglichte Schocken das Wachsen des deutsch-jüdischen Kulturschaffens in Palästina. Als Verleger der Haaretz und des Schocken Verlages Tel Aviv nahm er darüber hinaus direkten Einfluss auf die kulturelle Ausrichtung des Jischuv. Im Folgenden wird sein Engagement für in Not geratene Künstler und Autoren in Palästina beleuchtet.

\subsection{1 „Ihr dankerfüllter Prinz Jussuf“ - Schockens Hilfe für die Dichterin Else Lasker-Schüler}

„Ich kann mir wohl denken wie Sie den immer wieder aufs Neu erbittert [sic]. Immer diese Menschen, die irgend was haben möchten von Ihnen “125, schrieb Else Lasker-Schüler 1939 an Salman Schocken. Tatsächlich verbitterte es Schocken zunehmend, dass er von allen Seiten um Geld und Unterstützung angegangen wurde. Institutionen und Privatpersonen erhofften sich von dem

124 Salman Schocken an die Freunde der Habima, 18.01.1929. Tel Aviv University: Israeli Center for the Documentation of Performing Arts. Habima Administrative Archive, 82.1.8. Ich danke Jan Kühne herzlich für den Hinweis auf diesen Briefwechsel.

125 Else Lasker-Schüler an Salman Schocken, [27.07.1939]. SchA, Privates, 844/2, Bd. 4. Es handelt sich um eine im Sekretariat angefertigte Abschrift des handschriftlichen undatierten Briefes. Das Datum wurde anhand des Poststempels auf dem Umschlag im Sekretariat ergänzt. Sämtliche Originalbriefe liegen im Safe des Schocken Archivs unter Verschluss. Der Wortlaut der Abschrift entspricht jenem der im Lambert Schneider Verlag erschienenen Ausgabe der Lasker-Schüler-Schocken-Korrespondenz. Die Herausgeber arbeiteten mit Fotokopien, die sie mit den Originalen abgleichen konnten. Vgl. Lasker-Schüler: , Was soll ich hier?‘ 
Kaufmann, der als wohlhabender Mäzen bekannt war, Hilfe in ihrer Not. So auch Lasker-Schüler, die schon in Europa finanziell von anderen abhängig war. Lasker-Schüler kontaktierte Salman Schocken bereits 1935. Sie bat Martin Buber, bei Schocken ein gutes Wort für sie einzulegen, damit dieser die Restbestände ihrer Gesammelten Werke vom Jüdischen Kulturbund übernehme. Der Kulturbund zahlte keine Vergütungen und Lasker-Schüler lebte in der Angst, komplett zu verarmen. Schocken schlug das Angebot aus, was die Dichterin nicht davon abhielt, ihn im Herbst desselben Jahres direkt zu kontaktieren. Sie war zu diesem Zeitpunkt auf der Suche nach einem Verleger für ihr Buch Hebräerland, das sie nach ihrer ersten Palästinareise 1934 schrieb. Sie sandte die erste Hälfte des Manuskriptes an den Verlag; dieser sah sich aber nicht in der Lage, das Buch zu veröffentlichen. ${ }^{126}$ Die Devisenrestriktionen erlaubten es jüdischen Unternehmen kaum mehr, Devisen ins Ausland zu transferieren. Der Schocken Verlag wurde deswegen auch immer wieder von seinen Verlagsautoren angemahnt, die auf Honorare und Tantiemen warteten. ${ }^{127}$ Lasker-Schüler war jedoch persönlich wie finanziell durch die Ablehnung getroffen. Zwar wurde sie im Schweizer Exil von Mäzenen, wie z. B. Sylvain Guggenheim, unterstützt. Da ihre finanzielle Lage trotzdem problematisch war, versuchte sie diese durch Einnahmen von ihren Werken und Zeichnungen zu verbessern. ${ }^{128}$

Else Lasker-Schüler bemühte sich im Jahr 1937 erneut, Salman Schocken zu kontaktieren. Während ihrer zweiten Palästinareise schrieb sie mehrere Briefe an Judith Swet, Schockens Sekretärin in Jerusalem, aber auch 1937 kam es zu keinem Treffen zwischen der Dichterin und dem Kaufmann und Verleger. Erst 1939, auf ihrer dritten und unfreiwillig letzten Reise nach Jerusalem, kam es zu direktem Kontakt zwischen Lasker-Schüler und Schocken. In den Briefen an Schocken wird ihre Enttäuschung über das Land, das sie in ihrer Dichtung poetisch verklärte, deutlich; sie klagt über ihre schwierigen Lebensumstände

126 Vgl. ebd., S.24.

127 Vgl. u. a. Briefe Lambert Schneider an S.J. Agnon, 06.07.1933 u. 25.04.1934; S. J. Agnon an Lambert Schneider, 26.07.1936. NLI, Agnon Archiv, Arc. 4 1270. Briefe Lambert Schneider an Gershom Scholem, 30.05.1934 u. 08.08.1935. NLI, Scholem Archiv, Arc. 41599 01 2341; Moritz Spitzer an Ernst Simon, 11.06.1936. NLI, Ernst Simon Archiv, Arc. 4 1751/3008.

128 Vgl. Lasker-Schüler: ,Was soll ich hier?', S. 24. 
und die Tatsache, dass sie keine Publikationsmöglichkeit ${ }^{129}$ für ihre Werke findet. ${ }^{130}$ Scholem beschrieb Lasker-Schüler in einem Brief an Benjamin als „[e]ine Ruine, in der der Wahnsinn weniger haust als gespenstert. ${ }^{\text {“131 }}$

Ihre finanzielle Lage in Jerusalem war jedoch nicht so angespannt, wie sie es darstellte. Bodenheimer analysiert, dass sie in Palästina wirtschaftlich sogar besser abgesichert war als in der Schweiz und in Deutschland. Sie erhielt ab Oktober 1939 genau hälftig von der Jewish Agency und von Salman Schocken je fünf Pfund im Monat, was dem Gehalt eines verheirateten mittleren Beamten entsprach. Dazu kamen einmalige Zuschüsse von der Jewish Agency, von der Selbsthilfeorganisation der deutschen und österreichischen PalästinaEinwanderer und von Salman Schocken. ${ }^{132}$

Der Briefwechsel zwischen Schocken und Lasker-Schüler war einseitig. Von Salman Schocken sind nur vier Briefe an die Dichterin überliefert. Die Diskrepanz zwischen seinen knapp und emotionslos gehaltenen Schreiben und ihren klagenden und schmeichelnden, teilweise ins Phantastische reichenden Briefen, könnte nicht größer sein. Dennoch war Schocken bereit, der sich in Jerusalem verloren fühlenden Lasker-Schüler finanziell zu helfen. In einem ersten Brief vom Juli 1939, als Lasker-Schüler noch davon ausging, in die Schweiz

129 Die Gedichtsammlung Mein blaues Klavier, die 1943 von Moritz Spitzer in Jerusalem verlegt wurde, war das einzige Werk, das in Palästina / Israel zu ihren Lebzeiten veröffentlicht wurde. Vgl. Caroline Jessen: My Blue Piano. Else Lasker-Schüler's Last Poetry Volume, Jerusalem 1943. In: Wardi (Hrsg.): New Types, S. 167-171.

$130 \mathrm{Zu}$ Else Lasker-Schüler und ihrem Werk liegen zahlreiche Studien vor. Relevant sind für den Kontext der vorliegenden Arbeit insbesondere die Monographie von Alfred Bodenheimer zur Bedeutung Palästinas für Lasker-Schüler (Bodenheimer: Die auferlegte Heimat), des Weiteren Stefanie Leuenbergers Kapitel zu Lasker-Schüler in ihrer Studie zu literarischen Imaginationen Jerusalems zwischen 1848 und 1948 (Stefanie Leuenberger: Schrift-Raum Jerusalem. Identitätsdiskurse im Werk deutsch-jüdischer Autoren. Köln: Böhlau 2007, S. 104-144) sowie der Aufsatz von Doerte Bischoff zu den Begriffen Exil und Trauma im Werk von LaskerSchüler (Doerte Bischoff: Exile, Trauma and the Modern Jewish Experience. The Example of Else Lasker-Schüler. In: Bernhard Greiner (Hrsg.): Placeless Topographies. Jewish Perspectives on the Literature of Exile. Tübingen: Niemeyer 2003, S. 127-159). Darüber hinaus zu nennen ist die biographische Studie von Jakob Hessing: Else Lasker-Schüler. Biographie einer deutschjüdischen Dichterin. Karlsruhe: Loeper 1985.

131 Gershom Scholem an Walter Benjamin, 19.04.1934. In: Walter Benjamnin - Gershom Scholem. Briefwechsel 1933-1940, hrsg. v. Gershom Scholem. Frankfurt am Main: Suhrkamp 1980, S. 136.

132 Vgl. Bodenheimer: Die auferlegte Heimat, S. 102-103. 
zurückkehren zu können, zeigte er sich bereit, sie mit zehn Pfund für ihre Ausgaben in Palästina sowie weiteren zehn Pfund für ihre Reisespesen zu unterstützen. ${ }^{133}$ Zwischen diesem ersten und dem zweiten Brief Salman Schockens an Lasker-Schüler liegen nicht nur der Beginn des Krieges sondern auch der negative Visumsbescheid der Schweizer Behörden. Da Lasker-Schüler das Reisegeld bereits ausgegeben hatte, bot sie Salman Schocken an, ihm ein Plakat zu malen. „Ich kann das! Ha-Arez - groß und deutlich und außerordentlich. Wollen Sie, Adon?" ${ }^{134}$ Im selben Brief erwähnt sie auch, dass sie zwei ,heitere' Geschichten an die Haaretz gesandt hat. Schönberg, der bereits für sie übersetzte, sollte auch Die rote Katze und Der Versöhnungstag für sie ins Hebräische übertragen. ${ }^{135}$ Die Knappheit von Schockens Schreiben lassen keine Interpretation zu, warum er sich dem Schicksal der ihm als rationellem Menschen ganz fremd erscheinenden Dichterin annahm. Wir können daher nicht mehr als etwas erstaunt beobachten, wie er ihr Geld für Unternehmungen gab, die keine messbaren Ergebnisse bringen konnten, und ihr darüber hinaus seine wertvolle Zeit widmete. Im Dezember 1939 bedankte sich Lasker-Schüler für ein Treffen in der Bibliothek, bei dem Schocken ihr seine Heine-Sammlung zeigte.

Ich ging still durch den Mittag zurück. Es war so schön unsere Unterhaltung! Nun danke ich Ihnen, auch für alles noch mal, namentlich für die noble künstlerische Art, wie Sie mir helfen, Adon. [...] Aber Sie sind wirklich ein Mensch geblieben und ich bin froh, dass so liebe Menschen um Sie sind, Adon. ${ }^{136}$

Schocken hatte sie wohl, so muss dieser Brief interpretiert werden, erneut finanziell unterstützt. Die beiden so unterschiedlichen Persönlichkeiten waren

133 Vgl. Salman Schocken an Else Lasker-Schüler, 28.07.1939. NLI, Lasker-Schüler Archiv, Arc. Ms. Var. 501/5:265. Die Briefe Schockens an Lasker-Schüler sind als Kopie in der NLI vorhanden. Die Akte mit den Kopien der Lasker-Schüler-Briefe an Schocken im Schocken Archiv beinhalten nur die Schreiben der Dichterin, aber nicht jene Salman Schockens.

134 Else Lasker-Schüler an Salman Schocken, 21.09.1939. SchA, Privates, 844/2, Bd. 4.

135 Beide Texte sind erstmals 1932 in Lasker-Schülers Werk Konzert erschienen: Else LaskerSchüler: Konzert. Berlin: Rowohlt 1932. Die Herausgeber der Haaretz haben sie, aus mir nicht bekannten Gründen, 1939 jedoch nicht publiziert. Die rote Katze ist bis heute nicht auf Hebräisch erschienen, während Der Versöhnungstag 1980 in Übersetzung von Tuvia Rübner publiziert wurde, vgl. Else Lasker-Schüler: יום כיפור, aus d. Deutsch. v. Tuvia Rübner. In: Proza 35-37 (1980), S. 18-19.

136 Else Lasker-Schüler an Salman Schocken, 01.12.1939. SchA, Privates, 844/2, Bd. 4. 
sich darin ähnlich, dass sie den Alltag und das Leben in Jerusalem auf Dauer schlecht ertrugen. Lasker-Schüler schrieb am 6. Dezember 1939, kurz bevor Salman Schocken zu seiner ersten Amerika-Reise aufbrach, einen tief traurigen Brief:

„Die Dimdumim ${ }^{137}$ beginnt, die Dämmerung, die so traurig ist wie ich. Ich hab mir das Sein in Jerusalem so anders vorgestellt. Ich bin so tief enttäuscht. “138 Lasker-Schüler verklärte das Heilige Land in ihrer Dichtung so sehr, dass die Diskrepanz zwischen dem realen Dasein und der poetischen Imagination für sie kaum zu ertragen war. Palästina war für sie, so Bauschinger und Hermann in ihrem Vorwort zu den edierten Briefen, „das von Gott und den Menschen geliebte Land, in dem auch alle Menschen einander lieben; das Land, nach dem man sich immer sehnen muss." ${ }^{139}$

Will man von Palästina erzählen - geschmacklos, sich einen Plan zu konstruieren. Ganz Palästina ist eine Offenbarung! Palästina getreu zu schildern, ist man nur imstande, indem man das Hebräerland dem zweiten - offenbart. Man muss gerne vom Bibelland erzählen; wir kennen es ja alle schon von der kleinen Schulbibel her. Nicht wissenschaftlich, nicht ökonomisch; Palästina ist das Land des Gottesbuchs, Jerusalem - Gottes verschleierte Braut. Ich kam von der Wüste aus, reiste zur heiligen Hochzeit, eingeladen zur Feier, die immer Jerusalem umgibt. Immer ist Hochzeit unter dem Baldachin seines Himmels. Gott hat Jerusalem lieb. Er hat es in Sein Herz geschlossen. Er hat diese ewige Stadt der Städte erwählt. Jeder Gast, der in diese Stadt kommt, wechselt sein Kleid mit der Weihe des Gewands. Diese fromme Wandlung verpflichtet den Menschen, sich feierlich und artig zu benehmen, die andächtige Stimmung der auserlesenen, erhobenen Stadt nicht zu erschrecken. Ich muss sagen, ich habe nie ein überlautes Wort, nie einen schrillen Ton in Jerusalem vernommen, weder in seinen Straßen, noch in seinen Häusern und Palästen. Man hört darum deutlicher Gott atmen. Überwältigt von Seiner Nähe, beginnt der Mensch zu beben. Man muss sich an Gott gewöhnen. Und tut gut, sich zu reinigen, immer besser zu werden. Die Seele wird von tiefer Furcht ergriffen, beginnt zu brennen. Manchmal hätte ich mich gern vor Gott versteckt. ${ }^{140}$

137 Hebräisch für Dämmerung.

138 Else Lasker-Schüler an Salman Schocken, 06.12.1939. SchA, Privates, 844/2, Bd. 4.

139 Bauschinger / Hermann: Einleitung, S. 26.

140 Else Lasker-Schüler: Das Hebräerland. Zürich: Oprecht 1937, S. 9-10 (Herv. i. Orig.). 
Lasker-Schüler beschrieb in ihrem Werk „offensichtlich nicht ein historisches Palästina [...], sondern die Landschaft ihrer Dichtung. ${ }^{\text {“141 }}$ Die Realität war eine andere: Man war in der neuen jüdischen Hauptstadt mit sehr menschlichen Angelegenheiten beschäftigt. Das verklärte Sehnen nach der Ewigen Stadt wich dem täglichen Überlebenskampf und einem Alltag, der nicht mit LaskerSchülers früherer Existenz in Berlin oder in Zürich zu vergleichen war. So fuhr sie in ihrem Brief an Schocken fort:

Das Land blieb ja dasselbe: Urland, die Schöpfung; aber ich versinke in mir und werde hier vor Traurigkeit sterben. Und mein Kind wird immer vereinsamt auf dem Friedhof in Berlin ruhen. Man weiß ja nicht, wie alles ist, ich weiß nur, das Leben geht Hand in Hand mit dem Tod. Und logisch denken wollen ist gerade so unlogisch. Ich bin so tief enttäuscht. Wenn man sich auch manchmal unterhält mit einem Menschen, so bleibt kein Blutgewebe, das verbindet. Weg ist hier weg und fort, fort. Es ist keine Wärme hier, die wandert von Haus zu Haus, kein Haus verwandt mit dem anderen Haus. Ich - namentlich bin fremd unter auswendig gelernter Schätzung der Kleinbürgerlichkeit. Ich glaube, Sie wissen, dass Paulus, der mir gar nicht so gefällt, aber richtig sagt, ,aber die Traurigkeit erwirkt den Tod.'

Nun wollte ich Sie fragen, Adon, ob Sie mich, ob Sie und ihre liebreiche Gewerett, mich mitnehmen wollen? Ich bleibe dann Italien [sic], ob Gefahr oder nicht. Oder reise nach Berlin - da ich vor sieben Jahren Sichtvermerk bekam.

Ich habe doch nun so ein lieb Buch über Jerusalem geschrieben und bin immer fremder geworden. Im Herzensgrunde gewann ich keinen Menschen, der mir Trost sprechen würde alle mir eigentlich fremd. ${ }^{142}$

Die Vereinsamung ihres in Berlin begrabenen Kindes spiegelt ihre eigene Einsamkeit wider. Ihr einziger Sohn Paul starb nach einem Leiden von 22 Monaten im Dezember 1927 an Lungentuberkulose. Hessing macht deutlich, dass Paul nach dem Scheitern ihrer zweiten Ehe - der einzige Lichtpunkt in ihrem Leben und in ihrer Einsamkeit war; sein Tod „besiegelte ihre Hoffnungslosigkeit ${ }^{\text {"143 }}$. Im Hebräerland beschrieb sie noch "die heilende Wirkung, die Jerusalem auf

141 Hessing: Else Lasker-Schüler. Biographie einer deutsch-jüdischen Dichterin, S. 166-167.

142 Else Lasker-Schüler an Salman Schocken, 06.12.1939. SchA, Privates, 844/2, Bd. 4.

143 Hessing: Else Lasker-Schüler. Biographie einer deutsch-jüdischen Dichterin, S. 149-150. 
ihre Seele [hatte], das Erstarken ihrer schöpferischen Kräfte. “144 Davon ist weder in ihren Briefen an Schocken noch in denen an andere Korrespondenzpartner etwas zu spüren. Sie verspürte keine Wärme und keine Verbindung mehr, nicht zu den Menschen und nicht zu dem Ort. In dieser Verzweiflung wendet sie sich an Schocken.

Dieser, der so viele Briefe unbeantwortet ließ, antwortete umgehend auf die verzweifelten Worte Lasker-Schülers.

Ich habe Ihren Brief mit Interesse gelesen.

Ich kann mir Ihre schwierigen Umstände hier vorstellen. Ich kann mir vorstellen, dass Sie nach einer Periode optimistischer Wertung der Bedingungen dieses Landes jetzt eine gewisse Reaktion spüren, was ja jedem Besucher hier geschieht.

Wenn Sie, wie ich den Eindruck habe, erhoffen, durch eine kleine Reise durch das Land vielleicht das Land wieder von Neuem zu sehen, stelle ich Ihnen für diesen Zweck gern einen Sonderbetrag von LP 10.- zur Verfügung, den Sie in meinem Bureau beheben können. ${ }^{145}$

Der Brief liest sich im Kontrast zu Lasker-Schülers verzweifeltem Schreiben etwas unbeholfen in seiner trockenen Förmlichkeit. Dennoch geht Schocken auf die Nöte der Dichterin ein. Natürlich nimmt er sie nicht mit nach Italien, er hofft jedoch, sie mit einem Sonderbetrag zu einer Reise durch Palästina zu ermutigen und aufzumuntern. Ob er verstand, dass ihre Verzweiflung an der Realität viel tiefer gründete, lässt sich aus dem Brief nicht herauslesen, ist aber nicht unwahrscheinlich. Er selbst hielt es ebenfalls nie lange in Jerusalem aus, auch er war aus teilweise ähnlichen Gründen von Palästina enttäuscht.

Lasker-Schüler schuf im Hebräerland die Imagination einer Gemeinschaft. Das

Zusammensitzen im Rahmen einer religiösen Gemeinschaft wird an mehreren Stellen [...] als Möglichkeit angegeben, die Vereinzelung hinter sich zu lassen und sich zu Hause zu fühlen, in der Geworfenheit einer imaginären Kindheit. ${ }^{146}$

144 Hessing: Else Lasker-Schüler, S. 165.

145 Salman Schocken an Else Lasker-Schüler, 08.12.1939. NLI, Lasker-Schüler Archiv, Arc. Ms. Var 501/5:265.

146 Leuenberger: Schrift-Raum Jerusalem, S. 135. 
So beschreibt sie z. B. Besuche beim Oberrabbiner Kook, bei Hugo Bergmann, und bei Gershom Scholem.

Als sie 1939 an Schocken schrieb, versank sie in Verzweiflung über ihre Einsamkeit. Schocken seinerseits klagte zwar auch, aber nicht über gesellschaftliche Einsamkeit, sondern über seinen mangelnden Einfluss im Jischuv. Er vermisste es, so schrieb er an Bergmann, wie in Deutschland, um Rat gefragt zu werden. In Palästina seien alle immer nur an seinem Geld interessiert, nicht an seiner Expertise. Dass Schocken auf die Rolle des ,reichen Mannes' reduziert wurde, stimmt jedoch ebenso wenig wie Lasker-Schülers Selbstbild als gesellschaftlich vereinsamte Person. Schocken genoss bis zu seiner Abreise in den USA Ansehen und Einfluss durch seine Position in der Universität, durch seinen Verlag und seine Zeitung, aber auch als wichtige Persönlichkeit in den kulturellen Kreisen Jerusalems. Lasker-Schüler hatte sich in Jerusalem schließlich auch ein Netzwerk von Bekannten und Freunden geschaffen, das unter anderem Werner Kraft, Martin Buber, Schalom Ben-Chorin, S. J. Agnon, Uri Zwi Greenberg und Ernst Simon, in den sie sich im hohen Alter unglücklich verliebte, einschloss. Durch den von ihr 1942 gegründeten literarischen Zirkel Kraal, der sich ein- bis zweiwöchentlich zu Vorträgen zusammenfand, trug sie zudem zum kulturellen Leben der deutschen Juden in Jerusalem bei. ${ }^{147}$

Nach seiner Rückkehr von der ersten Amerika-Reise versicherte Schocken der Dichterin, dass er sie nicht vergessen habe, dass sie weiterhin auf seine Unterstützung zählen könne. Lasker-Schüler dankte ihm mehrfach überschwänglich. Sie schreibt von ihrer Arbeit und aus dem Briefen schimmert an einigen Stellen sogar Freude und Heiterkeit.

Ich danke Ihnen, dearest Adon Doktor, wieder Euch für das Budget, ich ess' und trinke mehr, kann wieder gehn und geh. Und spare wieder für eine Galiläajordanreise. Und finde wieder meine frühere Geste und meine Laune steigt, was Heiterkeit betrifft, aufs Beste! ${ }^{148}$

Gezeichnet war der Brief mit „Ihr dankerfüllter, Adon, armer Prinz Jussuf“.

147 Vgl. Bodenheimer: Die auferlegte Heimat, S. 103-104.

148 Else Lasker-Schüler an Salman Schocken, 30.09.1940. SchA, Privates, 844/2, Bd. 4. 


\subsubsection{Hilfe im Kleinen und im Großen}

Ein ganz anderer Fall war Schockens Unterstützungsangebot an Leopold Marx. Der schwäbische Schriftsteller, Dichter und Fabrikant war ein Freund Martin Bubers. Seine Söhne, Erich Jehoshua und Ephraim Marx, wanderten 1938 nach Palästina aus. Es war Buber, der Schocken im Dezember 1938 bat, die Emigration des aus dem Konzentrationslager Dachau entlassenen Dichters zu ermöglichen. Die Antwort fiel zunächst abschlägig aus. Schocken schrieb jedoch an Buber, das Schicksal Marx' sei ihm "sehr nahe gegangen“ und dass ihm daher „die ganz negative Beantwortung sehr schwer gefallen [sei] “. ${ }^{149}$ Er habe aber die Hoffnung,

dass vielleicht doch aus den internationalen Bemühungen jetzt ein Weg für Ausund Einwanderung der deutschen Juden gebahnt wird, und vielleicht ergeben sich dann Bedingungen für Herrn Marx, die hoffnungsreicher sind als jetzt bei dem Kapitalisten-Zertifikat. ${ }^{150}$

1939 wurde Marx in Stuttgart erneut von der Gestapo verhaftet, konnte aber dank der Hilfe des Stuttgarter Juristen Otto Hirsch ${ }^{151}$ und des Musikwissenschaftlers Karl Adler gemeinsam mit seiner Frau nach Palästina emigrieren. Sie ließen sich 1938 im von schwäbischen Immigranten gegründeten Moshav Shavei Zion ${ }^{152}$ an der Mittelmeerküste nieder, wo Marx zunächst als Gärtner einen bescheidenen Unterhalt verdiente. ${ }^{153}$

Nachdem Marx in Palästina angekommen war, bot Salman Schocken in einem persönlichen Gespräch an, den Schriftsteller mit einem Darlehen zu unterstützen.

149 Salman Schocken an Martin Buber, 03.01.1939. SchA, Privates, 844/2, Bd. 5 .

150 Ebd.

151 Otto Hirsch war als Repräsentant der deutschen Juden auf der internationalen Flüchtlingskonferenz in Évian. Er wurde im Juni 1941 im Konzentrationslager Mauthausen ermordet. Zu seinem Leben vgl. Paul Sauer: Für Recht und Menschenwürde. Lebensbild von Otto Hirsch (1885-1941). Gerlingen: Bleicher 1985.

152 Vgl. zur Geschichte des Moshav: Heinz Högerle / Träger- und Förderverein Ehemalige Synagoge Rexingen (Hrsg.): Ort der Zuflucht und Verheissung. Shavei Zion 1938-2008. Darmstadt: WBG Theiss 2008.

153 Die biographischen Angaben zu Marx sind entnommen aus: Werner P. Heyd: Marx, Leopold. In: Neue deutsche Biographie, Bd. 16, hrsg. v. Otto zu Stolberg-Wernigerode. Berlin: Maly-Melanchthon 1990, S. 347. 
Dieser lehnte das Angebot zunächst ab; es wäre ihm lieber, „einen Nebenverdienst aus [seinen] literarischen Arbeiten, für die [ihm] aber leider nur die Muttersprache zu Gebot steht ${ }^{\text {"154 }}$, zu erzielen. Schocken beschied ihm, dass er da nicht weiterhelfen könne, da sein Sohn Gustav sich um das Verlegerische kümmere. ${ }^{155}$ Er zeigte sich jedoch weiterhin bereit, das bereits versprochene bescheidene Darlehen an Marx zu leisten.

Hilfeleistungen wie jene für Marx gewährte Schocken vielfach - entweder durch direkte Zahlungen wie im eben angeführten Beispiel, oder durch den Ankauf von Kunstwerken, wie im Fall des bekannten Künstlers und späteren Leiters der Kunstschule Bezalel, Jakob Steinhardt, ${ }^{156}$ die Unterstützung des Schriftstellers Abraham Sonne ${ }^{157}$ oder durch Stipendien, wie jenes für eine junge Künstlerin, das durch Jakob Steinhardt vermittelt wurde. ${ }^{158}$

Salman Schocken war, auch wenn er es zeitweilig selber nicht so sah, ein bedeutender und einflussreicher Mann. Als wichtiger Mäzen förderte er im Kleinen wie im Großen und gestaltete für einige Jahre das Kulturleben Jerusalems mit. Er war Mitträger der neu eröffneten Kunstschule Bezalel, Mäzen der Dichterin Else Lasker-Schüler und unterstützte zahleiche bekannte und weniger bekannte Kulturschaffende. Darüber hinaus wirkte er durch die Bauaufträge als Privatmann und als Vertreter der Hebräischen Universität an Erich Mendelsohn auf die Architekturgeschichte Jerusalems ein. Seine Förderprojekte im Bereich der Wissenschaften waren ebenfalls Teil seines Mäzenatentums. Schocken trug mit ihnen dazu bei, dass einige Schriftsteller*innen, Wissenschaftler*innen und Künstler*innen in der schwierigen Exilsituation ihre Arbeit weiterführen konnten. Er half ihnen, anzukommen und wirtschaftlich zu überleben. Dass er dabei eine Auswahl traf und damit Menschen vor den Kopf stieß, war sein Recht als Privatmann. Er sah sich jedoch gezwungen, dieses Recht zu verteidigen, was ihn zunehmend verbitterte. Mit der Emigration in die USA entledigte er sich bis zu einem gewissen Grad dieses Problems.

154 Leopold Marx an Salman Schocken, 27.11.1939. SchA, Privates, 844/2, Bd. 5.

155 Vgl. Salman Schocken an Leopold Marx, 11.12.1939. SchA, Privates, 844/2, Bd. 5.

156 Vgl. die Korrespondenz zwischen Salman Schocken und Jakob Steinhardt. SchA, Privates, $844 / 2$, Bd. 7 .

157 Vgl. Salman Schocken an Julius Simon, 17.06.1940. SchA, Privates, 844/2, Bd. 6.

158 Vgl. Briefwechsel Jakob Steinhardt mit Salman Schocken. SchA, Privates, 844/2, Bd. 7. 
Seine großangelegten Unterstützungsprojekte, wie die Hilfe für Lasker-Schüler, aber auch die Finanzierung seiner beiden Forschungsinstitute waren von seiner Abreise nicht betroffen. 


\section{0 \\ Abreise ohne Abschied \\ Schlussbetrachtung und Überleitung zu Teil III}

Vielleicht hatte sich Schocken seine zweite Emigration, jene von Palästina in die USA, ähnlich vorgestellt, wie die von Deutschland nach Palästina, nämlich als eine Verschiebung des Lebensmittelpunktes, ohne die alte Heimat aufzugeben. Vielleicht ging er davon aus, dass er so, wie er ein Leben zwischen Europa und Palästina führen konnte, ein Leben zwischen Amerika und Palästina würde führen können. Zwar waren die Reise- und Kommunikationswege bedeutend länger als sie es zwischen Europa und Palästina waren, aber sie waren vorhanden. Zum Zeitpunkt seiner zweiten Reise in die USA war der Weg über den Atlantik offen, da die Vereinigten Staaten noch nicht in den Krieg eingetreten waren. Ungewiss ist, ob diese USA-Reise tatsächlich nur als Reise oder als Emigration gedacht war. Es gab keinen wirklichen Abschied, das Haus wurde vorerst nicht verschlossen und noch hatte er keinen seiner Söhne als seinen offiziellen Stellvertreter eingesetzt. Erst 1946, also nach Kriegsende, ernannte er Gustav Schocken zu seinem rechtmäßigen Vertreter in Palästina. ${ }^{1}$

Vor diesem Hintergrund wirkt die Auswanderung ungeplant. Es ist aber gleichermaßen möglich, dass Schocken der Kriegseintritt der USA und die damit verbundene Unmöglichkeit, nach Palästina zurückzukehren, entgegenkam. Dass er sich in Jerusalem mehr Einfluss erhoffte, wurde unter anderem mit Blick auf seine Funktion als Schatzmeister der Hebräischen Universität deutlich (siehe Kap. 8.1). In Deutschland sei er ,dabei' gewesen, er wurde um Rat

1 Vgl. Salman Schocken an Gustav Schocken, 24.07.1946. SchA, Privates, 823, Box 33. 
angefragt, seine Meinung zählte - so beschrieb es Schocken. In Palästina sei er ,nicht dabei', dort würde er nur als ,reicher Mann ' wahrgenommen. ${ }^{2}$ Dabei sieht Schocken lediglich die Rolle, die er in finanzieller Hinsicht spielte, die Tatsache, dass er mit seinem Geld viel ermöglichte, zahlreiche Institutionen mitbegründete oder unterstützte, als Mäzen in Erscheinung trat und mittellosen Schriftsteller*innen und Künstler*innen eine Existenz ermöglichte. Er wurde deshalb von vielen Menschen und Institutionen um finanzielle Hilfe, Spenden und Beiträge angegangen. Ohne Einfluss war er jedoch nicht. Nicht nur als Schatzmeister der Universität, auch als Privatperson genoss er hohes Ansehen. Sein Haus und seine Bibliothek waren wichtige Treffpunkte für gesellschaftliche Zusammenkünfte und intellektuellen Austausch. Seine Sammlung hatte in Palästina Seltenheitswert und wurde von Wissenschaftlern geschätzt und genutzt. Und nicht zuletzt nahm er als Verleger Einfluss auf das kulturelle und intellektuelle Geschehen im Jischuv. Im Gegensatz zu Schockens eigener Wahrnehmung ermöglicht die objektive Analyse seiner Rolle in Palästina die Schlussfolgerung, dass er durchaus über Geltung und Gestaltungsmöglichkeiten verfügte. Betrachtet man sein Werk während der sechs Jahre, in denen Salman Schocken seine offizielle Residenz in Jerusalem hatte, kann man schließen, dass er, ohne je ein politisches Amt bekleidet zu haben, großen Einfluss auf das kulturelle Leben, aber auch auf Institutionen des Jischuv ausübte. Warum er diesbezüglich zu einem anderen Schluss kam als die Historikerin, ist nicht zu rekonstruieren.

Man kommt aber nicht umhin, einen weiteren Aspekt in Betracht zu ziehen, wenn man verstehen will, warum Salman Schocken sein Leben in Jerusalem hinter sich ließ, nachdem er sich dort eine neue Existenz aufgebaut hatte. Der Beginn des Zweiten Weltkrieges schnitt ihn endgültig von Europa ab. Schockens Jerusalemer Jahre waren geprägt von seiner Existenz auf beiden Kontinenten. Trotz seiner Emigration blieb er Europa aufs Tiefste verbunden. Geschäftlich, kulturell und privat pflegte er enge Beziehungen zum alten Kontinent. Sukzessive brachen zwar wichtige Bezugspunkte in Europa weg, wobei der Verkauf des Konzerns August 1938 und die Zwangsschließung des Verlages im Dezember 1938 die Tiefpunkte dieser Entwicklung darstellten. Schocken reiste jedoch, zuletzt als Vertreter der Universität, bis zum Kriegsbeginn jedes Jahr für

2 Vgl. Schmuel Hugo Bergmann: Tagebücher und Briefe, Bd. 1: 1901-1948, hrsg. v. Miriam Sambursky. Königstein: Jüdischer Verlag 1985, S. 540. 
viele Monate nach Europa. Verwurzelt und gebunden in Europa und in Palästina verband er die beiden Räume durch seine Bewegung zwischen den Kontinenten. Dabei entstand aus dem Geflecht der Beziehungen und der Korrespondenz ein transnationaler Raum, dem in der Lebenswirklichkeit Schockens eine ebenso große Bedeutung zukam wie die beiden geographischen Räume. In seiner Existenz gehörten Palästina und Europa unverrückbar zusammen. Diese Verbindung wurde 1939 gekappt.

So markierte die abschiedslose Abreise nach New York nicht nur das Ende seines Jerusalemer Lebens, sondern auch den endgültigen Abschied von Europa. Dieser aufgezwungene Bruch mit seiner bisherigen Existenz bedeutete in letzter Konsequenz, dass auch sein Dasein in Palästina zu einem Ende kam. 



\section{TeIl III \\ New York}



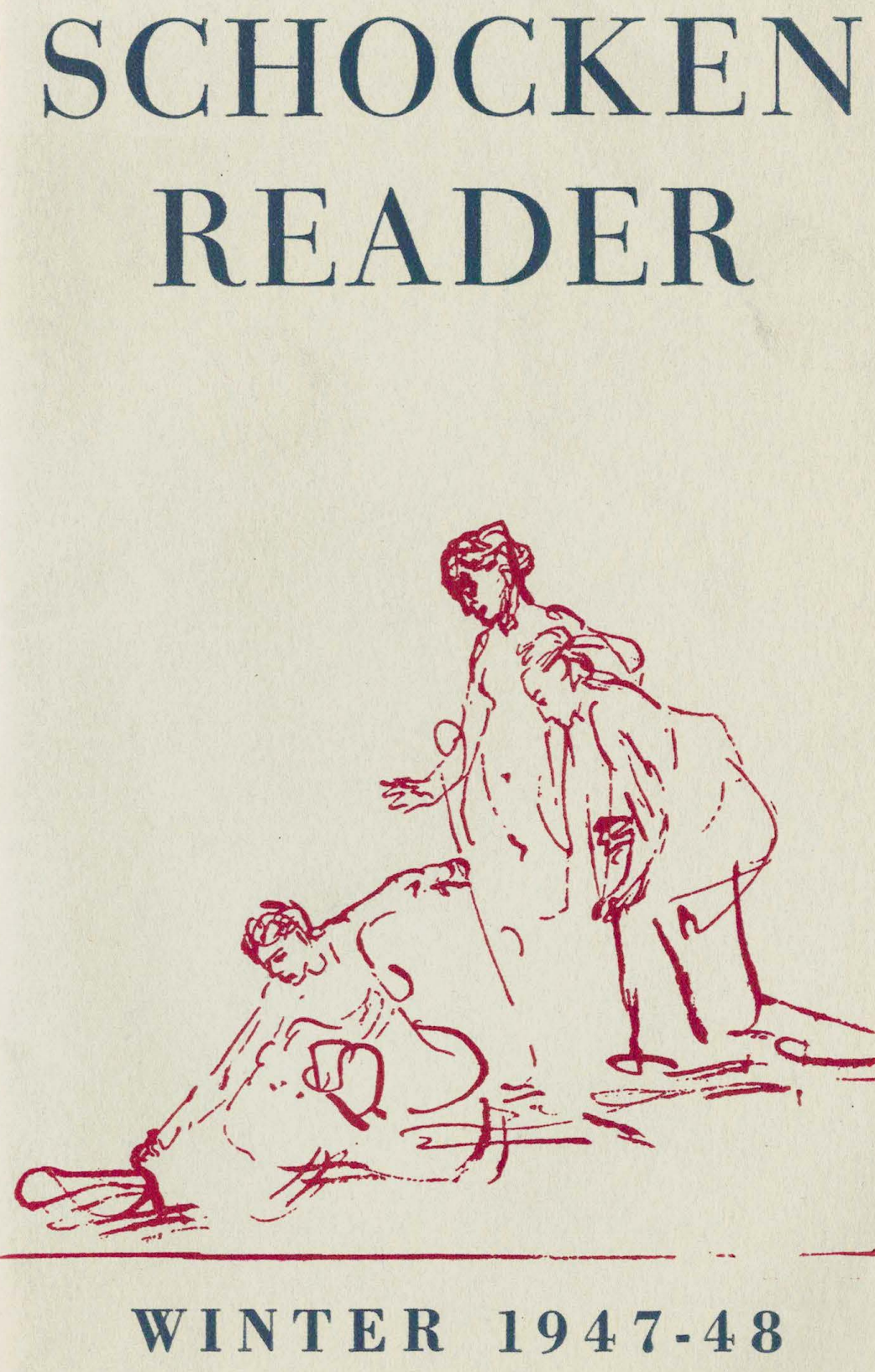

Abb. 18: Schocken Reader Winter 1947-48. New York: Schocken Publishing House. 


\section{1 \\ Reise und Ankunft \\ Erste Schritte in den USA}

\subsection{Palästina - Neuseeland - Amerika}

In einem Schreiben vom 5. Oktober 1940 drückte Schocken seine Zweifel hinsichtlich einer zweiten Amerika-Reise aus. Er schrieb an Werner Senator, dass ihm „der Entschluss, nach Amerika zu reisen, schwerer geworden [sei], als es [...] nach außen in Erscheinung getreten [sei]. ${ }^{11}$ Er sorge sich einerseits, dass ihm die Rückreise nicht mehr möglich sein würde, andererseits plage ihn die Ungewissheit, wie es mit der Hebräischen Universität während seiner Abwesenheit weitergehen würde. Dennoch trat er die Reise an und reiste über Neuseeland nach New York. Zuvor beauftragte er seinen Vertreter Senator, seine Grundsätze und Richtlinien weiterhin umzusetzen. ${ }^{2}$

Lili Schocken verließ zusammen mit ihrem jüngsten Sohn, Micha, Jerusalem bereits im Hochsommer. Anders als bei der ersten Amerika-Reise war ein Flug über Europa nicht mehr möglich. Lili wählte daher den Weg über Australien. Ein Brief von Betty Scholem an ihren Sohn Gershom erzählt vom Zusammentreffen der zwei Frauen. Lili Schocken, die sonst in den Quellen kaum zu Tage tritt und daher seltsam blass wirkt, verliert in den Schilderungen Betty Scholems jegliche Blässe und wird zu einer lebendigen Figur. Die Besuche von und bei Frau Schocken hinterließen bei der weltgewandten Betty Scholem großen Eindruck und spendeten ihr Trost. Sie litt im australischen Asyl unter

1 Salman Schocken an Werner Senator, 05.10.1940. SchA, Universität, 074/220.

2 Vgl. ebd. 
der Trennung von ihrem Sohn Gershom Scholem und unter dem ungewissen Schicksal von dessen Bruder Werner, der im Konzentrationslager Buchenwald interniert war. ${ }^{3}$

Betty lebte unter finanziell schwierigen Bedingungen in Sydney, wo auch ihre Söhne Erich und Reinhold Zuflucht fanden. Dass ihr Palästina-Zertifikat verfiel, weil sie zu krank war, die lange Reise von Australien dorthin anzutreten, schmerzte sie sehr. ${ }^{4}$ Der Besuch von Lili Schocken, die ihr vom Leben in Jerusalem und ihrem Sohn Gershom berichten konnte, munterte die alte Dame auf. Lili brachte Betty Fotos von Gershom und seiner zweiten Frau Fania mit und beruhigte sie, dass sie zu einem späteren Zeitpunkt sicherlich nach Jerusalem würde reisen können. Betty Scholem hatte zuvor gehofft, dass Lili ihr das ersehnte Zertifikat mitbringen würde, fand sich aber „trotz der Enttäuschung [...] schnell mit der Tatsache ab, dass während des Krieges an eine Übersiedlung nicht zu denken [ist].

Dass sie von Micha abgeholt wurde, bei Frau Schocken im Hotel zum Mittagessen eingeladen war und anschließend in Lilis Bett und ihrer seidenen chinesischen Jacke ein Mittagsschläfchen halten konnte, machte sie so froh, dass sie davon ausführlich an ihren Sohn berichtete. Sie traf noch zwei weitere Male mit Lili zusammen. Ein „Labsal“ sei diese für sie gewesen, „[diese] überaus reizende u. mütterlich fürsorgende Frau“6 . Auch Lili Schocken schildert die Begegnung mit Scholems Mutter als sehr freundschaftlich und erfreulich. Dementsprechend schwer fiel die Trennung den beiden Frauen.

Von Sydney aus reiste Lili mit der SS Mariposa, einem der schnellsten und luxuriösesten Pazifikdampfer der Zeit, weiter. Salman Schocken kam im Oktober mit dem Flugzeug von Tiberias aus ${ }^{7}$ über Australien und Neuseeland nach

3 Die Mutter wusste nicht, dass Werner Scholem zu diesem Zeitpunkt bereits tot war. Er wurde am 17. Juli 1940 im KZ Buchenwald erschossen. Zur Biographie Werner Scholems vgl. Miriam Zadoff: Der rote Hiob. Das Leben des Werner Scholem. München: Hanser 2014.

4 Betty Scholem an Gerhard [Gershom] Scholem, 12.06.1940. In: Itta Schedletzky / Thomas Sparr (Hrsg.): Betty Scholem - Gershom Scholem. Mutter und Sohn im Briefwechsel 1917-1946. München: Beck 1989, S. 487-488.

5 Lili Schocken an Gerhard [Gershom] und Fania Scholem, 22.08.1940. NLI, Scholem Archiv, Arc. 4 1599, 01 3050, Bd. 8.

6 Betty Scholem an Gerhard [Gershom] Scholem, 29.08.1940. In: Schedletzky/ Sparr (Hrsg.): Betty Scholem - Gershom Scholem, S. 489-490.

7 Vgl. Salman Schocken an S.J. Agnon, 05.10.1940. NLI, Agnon Archiv, Arc. 41270. 
Amerika. In Australien besuchte er, wie zuvor seine Frau, Betty Scholem, die sich sehr über den Besuch aus Jerusalem freute. ${ }^{8}$ Auch in Neuseeland machte er Halt und besuchte Karl Wolfskehl. Der Autor, auch er unglücklich und krank im fernen Exil, erinnerte in einem Brief an das nur wenige Stunden dauernde Treffen. Ob sich die beiden Männer über mögliche Publikationspläne unterhielten, ist nicht überliefert. Wolfskehl beschrieb nur seine Bewunderung für Schockens „eisklare, wirklich hüllenlose Schaukraft“9. Er sei ein Mann, „der sich nicht das mindeste [vormache], der sich in Gewalt [habe] und Umstände restlos [erkenne]. ${ }^{10}$ Es wird aus dem Brief nicht deutlich, in welcher Form sich Schockens „Schaukraft“ in dem Gespräch ausdrückte; Schockens Klarheit hinsichtlich der Umstände mag sich auf die weltpolitische Situation bezogen haben oder auf seine eigenen Möglichkeiten.

Wie klar sich Schocken darüber war, dass seine Reise nach Übersee wohl eine Reise ohne baldige Rückkehr nach Palästina sein würde, ist schwer zu rekonstruieren. Gegenüber Senator drückte er die Befürchtung aus, dass der Krieg eine Rückreise unmöglich machen würde, ähnlich äußerte sich auch Lili Schocken gegenüber Betty Scholem. In seinem Brief an Agnon kurz vor der Abreise schrieb er jedoch, dass er damit rechne, „Anfang Mai - wie im vorigen Jahr “11 wieder zurück zu sein. Der Eintritt der Vereinigten Staaten in den Zweiten Weltkrieg am 8. Dezember 1940 machte diese Pläne, hatte es sie denn tatsächlich gegeben, zunichte. Salman und Lili Schocken blieben bis nach Kriegsende in New York und besuchten Jerusalem erst wieder im Oktober 1945. ${ }^{12}$ Angekommen in New York begann Schocken schnell, sich mit Bekannten in Verbindung zu setzen und nahm seine Arbeit als Fundraiser für die Hebräische Universität auf.

8 Vgl. Betty Scholem an Gerhard [Gershom] und Fania Scholem, 10.11.1940. In: Schedletzky / Sparr (Hrsg.): Betty Scholem - Gershom Scholem, S. 493-494.

9 Karl Wolfskehl an Eugen Mayer, 25.10.1940. In: Cornelia Blasberg (Hrsg.): Karl Wolfskehls Briefwechsel aus Neuseeland 1938-1948. Mit einem Vorwort von Paul Hoffmann. Bd. 1. Darmstadt: Luchterhand 1988, S. 245.

10 Ebd.

11 Salman Schocken an S. J. Agnon, 05.10.1940. NLI, Agnon Archiv, Arc. 41270.

12 Vgl. Aufenthalte SS [Salman Schocken] in Israel ab 1945, 01.05.1959. SchA, Privates, 835 . 


\subsection{Im Auftrag der Universität: Die Schockens in der New Yorker Society}

Finanziell hatte Schocken vorgesorgt. Noch vor New York beauftragte er Erwin Lang, den Direktor des Zürcher Hauptsitzes der Schweizerischen Bankgesellschaft, ${ }^{13}$ eine ,große Transaktion ' vorzunehmen. Lang bestätigte die erfolgreiche Abwicklung der Transaktion auf privatem Briefpapier ohne jeglichen Hinweis auf seinen Arbeitgeber. Der Brief, der der einzige Beleg für die Abwicklung dieses Bankgeschäftes ist, macht weder deutlich, wie hoch der Betrag war, noch an welche Bank das Geld überwiesen wurde. Da der Betrag in mehr als einer Tranche überwiesen wurde und da auf die Nennung von Details in der Korrespondenz komplett verzichtet wurde, ist davon auszugehen, dass es sich um eine hohe Summe gehandelt hat. ${ }^{14}$ Somit starteten Lili und Salman Schocken finanziell abgesichert und zudem umgeben von drei ihrer Kinder in ihr amerikanisches Leben.

In New York angekommen ließen sie sich vorübergehend im Luxushotel Delmonico in Midtown Manhattan an der Ecke Park Avenue und $59^{\text {th }}$ Street nieder. Dass die Schockens vorerst keine eigene Wohnung in New York bezogen, mag als Hinweis verstanden werden, dass der Aufenthalt als Reise und nicht als Auswanderung gedacht war. Obwohl sich nicht leugnen lässt, dass eine Rückreise unwahrscheinlich war, kann man nicht von einem endgültigen Verlassen Palästinas sprechen. Das Leben im Zwischenraum, die Verbundenheit mit zwei Räumen, prägte das Dasein der Schockens seit ihrer Emigration aus Deutschland. Europa befand sich in einem Krieg, dessen Länge nicht abzuschätzen war. Vielleicht versuchte Salman Schocken, sich die USA als zweiten Raum neben Palästina zu erschließen. Theodor Schocken, der bis 1938 in Deutschland blieb und die Geschäfte des Vaters führte und diese schließlich abschloss, emigrierte Ende 1938 nicht nach Palästina, sondern wie zuvor schon seine Schwester Eva in die USA. Dadurch war das zweite Exil in den USA für Lili und Salman kein Ankommen in der Fremde. Es warteten zwei ihrer Kinder auf sie und da seit Schockens erster USA-Reise noch kein Jahr vergangen war, konnte er nahtlos an die entstandenen Kontakte anknüpfen.

13 Vgl. Marc Perrenoud: La place financière et les banques suisses à l'époque du nationalsocialisme. Les relations des grandes banques avec l'Allemagne (1931-1946). Zürich: Chronos 2002, S. 549.

14 Vgl. Erwin Lang an Salman Schocken, 17.05.1940. SchA, Privates, 844, Bd. 4. 
Für die erste Reise in die USA ließ sich Schocken von Werner Senator eine Liste mit wichtigen Persönlichkeiten, darunter Vertreter des Joint Distribution Committee (Joint), der American Friends of the Hebrew University, der Zionistischen Organisation, der Brandeis-Mack-Gruppe und der Hadassah Women's Zionist Organization of America, erstellen, die er zu kontaktieren beabsichtigte. ${ }^{15}$ Bevor er die Reise antrat, schrieb er an knapp 20 Personen, mit denen er persönliche Gespräche führen wollte. ${ }^{16}$ Darüber hinaus ließ sich Schocken von seinem Sekretariat eine Liste zusammenstellen, die sehr viel länger und ausführlicher als jene von Senator war. Zu jeder gelisteten Person finden sich Angaben zu deren Netzwerk und bisherigen finanziellen Zuwendungen, aber auch zu charakterlichen Eigenschaften. ${ }^{17}$ Diese Listen befinden sich im Schocken Archiv nicht nur in der Mappe zur ersten USA-Reise, sondern auch in der zur zweiten. Man darf also davon ausgehen, dass Schocken mit diesem Kreis an gut ausgebildeten, bestens vernetzten und gut situierten Personen als Erstes Kontakt aufnahm.

Schockens Auftrag war klar umrissen: Die Universität in Jerusalem war auf Gelder aus dem Ausland angewiesen, einerseits um den Betrieb aufrechtzuerhalten, andererseits, um diesen weiter ausbauen zu können. In Europa herrschte Krieg, von dort war keine Unterstützung zu erwarten, daher mussten Spenden vermehrt in den USA generiert werden. Die Universitätsleitung hatte auch während der Kriegszeit große Ambitionen: So sollten zahlreiche neue Institute gegründet werden, unter anderem eine medizinische Fakultät, um im Land selber Ärzte und Ärztinnen ausbilden zu können. Es galt darum, Neubauten, Geräte und Stellen zu finanzieren.

Seit der Gründung der Universität trugen amerikanische Geldgeber knapp 60 Prozent zum jährlichen Budget bei. ${ }^{18}$ Diese Hilfe wurde größtenteils von den American Friends of the Hebrew University geleistet. Die gemeinnützige Organisation wurde 1925 gegründet und zunächst von Felix M. Warburg präsidiert. Das Ziel der Friends, wie sie in der internen Korrespondenz oft abgekürzt

15 Werner Senator: Note to Mr. Schocken, 19.09.1939. SchA, Universität, 074/220.

$16 \mathrm{Vgl}$. Mr. Schocken has written short letters to the following, announcing his American visit, 15.11.1939. SchA, Universität, 074/220.

$17 \mathrm{Vgl}$. Notizen zu amerikanischen Persönlichkeiten, 03.12.1939. SchA, Universität, 074/220.

18 Vgl. Finkel: American Jews and the Hebrew University, S. 195. 
genannt wurden, war das Einwerben und die Verwaltung von Geldern, um die Universität in ihrer Entwicklung zu unterstützen. Darüber hinaus war es ihnen ein Anliegen, Informationen über die Tätigkeiten der Hochschule in den USA zu verbreiten, Kontakte zwischen der Hebräischen Universität und USamerikanischen und kanadischen Hochschulen zu vermitteln, Wissenschaftler und Studierende mit der Jerusalemer Universität zu affiliieren, sowie die Interessen der amerikanischen Juden im Verwaltungsrat zu vertreten. ${ }^{19}$ Die im Archiv abgelegte Korrespondenz mit den Friends sowie die Sekundärliteratur verdeutlichen, dass die Beziehung zwischen der Universität und den Vertretern der philanthropischen Gesellschaft nicht frei von Spannungen war.

Die Universität befand sich in ständigen finanziellen Nöten, sowohl wegen der Ausbaupläne als auch, wie es weiter oben dargelegt wurde, weil sie zahlreiche aus Europa geflüchtete Wissenschaftler und Studierende aufzunehmen versuchte. Die Forderungen der Universitätsleitung an die Friends wurden unter diesen Umständen nicht immer mit dem größten diplomatischen Geschick vorgetragen. Noch problematischer war, dass der neue Vorstand der Friends unter der Leitung von Samuel B. Finkel Entscheidungsbefugnisse über die Verwendung der Gelder einforderte. Schocken versuchte dies um jeden Preis zu verhindern, da er nicht zulassen wollte, dass außeruniversitäre Organisationen die Berechtigung erhielten, über Investitionen der Universität zu entscheiden. ${ }^{20}$ Dementsprechend war das Verhältnis zwischen der Universität und den Friends angespannt. Die finanzielle Abhängigkeit von den amerikanischen Philanthropen war derart groß, dass man sich in vielen Fragen beugen musste. Die Mitglieder der Friends waren bestens vernetzte, oft an den bekannten amerikanischen Universitäten ausgebildete Mitglieder der jüdisch-amerikanischen Oberschicht, die nicht nur eigene Mittel zu Verfügung stellten, sondern für die Universität auch als Verbindung zu weiteren philanthropischen Gesellschaften fungierten. Sie verhandelten mit Organisationen wie dem Joint oder der Hadassah, und setzten ihre guten Beziehungen für die Einwerbung von Legaten oder Einzelspenden vermögender Personen ein. Im Gegenzug forderten sie Mitspracherecht bei wichtigen Entscheidungen der Universität. ${ }^{21}$ Salman Schockens Aufenthalt in New York hatte den Zweck, die Zusammenarbeit zwischen der Universität

19 Vgl. Finkel: American Jews and the Hebrew University, S. 194-195.

20 Vgl. Salman Schocken an Samuel B. Finkel, 23.03.1937. SchA, Universität, 072/32.

21 Vgl. div. Korrespondenz in SchA, Universität, 072/3, 072/32, 078/3. 
und den Friends enger und persönlicher zu gestalten und die Interessen der Universität verstärkt einzubringen. Durch Schockens Teilnahme an Sitzungen, durch Reden bei Veranstaltungen und eine direkte Zusammenarbeit mit Finkel sollte über diesen persönlichen Kontakt das Einwerben von Geldern gefördert werden. Darüber hinaus versprach man sich wohl, dass Schockens guter Ruf weitere Organisationen und Privatpersonen zu Spenden anregen würde.

In den ersten zwei Jahren seines Aufenthaltes trat Salman Schocken regelmäßig als Redner auf Jahresversammlungen und Abendveranstaltungen auf. Bereits im Dezember 1940 hielt er seine erste Ansprache in Cleveland, in der er den Zuhörern nicht nur die Geschichte der Universität und ihrer Institutionen näherbrachte, sondern auch - durchaus etwas eitel - auf seine reichhaltige Erfahrung in der Leitung eines Großkonzerns in Deutschland verwies. Es lag ihm zugleich daran, die Wichtigkeit der Jerusalemer Universität für das Judentum und für die ganze Menschheit zu verdeutlichen. Als es darum ging, die Zuhörer von der Wichtigkeit von Spenden für die Universität zu überzeugen, unterließ er es auch nicht, auf die Gräuel in Europa hinzuweisen.

Ladies and Gentlemen: in every front a terrifying assault is being made today not only against the Jewish people but against the very citadel of the spiritual values and tradition of man. Not only the bodies of men lie bleeding. Wounds even sorer afflict their minds and souls. I have sought to present to you a picture of an institution and a cause of supreme value to us all, to you American Jews, to all man kind. Here as new citadel of the Jewish spirit which is at the same time one if the citadels of the human spirit itself. It must be strengthened; it must be made to withstand strain and siege. Who will dare to abandon it? Who can afford to see it enfeebled? Surely not you, Jews of America! Surely this university, this outpost of the eternal spirit, can count upon all your loyalty, your generosity, your veliantly $[s i c]$ sustaining friendship and support. ${ }^{22}$

In Schockens Rede wird die Hebräische Universität als Bollwerk des jüdischen und menschlichen Geistes stilisiert. Ob die Überhöhung Früchte trug, ist zu bezweifeln: Schockens Erfolg in New York war geringer als er hoffte und als er sich eingestehen wollte.

Während er in den Anfangsjahren zahlreiche Reden hielt, die inhaltlich kaum von der ersten in Cleveland abwichen, reduzierte sich im Laufe des Krieges deren

22 Salman Schocken: Cleveland, Typescript with notes, 26.12.1940. SchA, Reden Salman Schocken in Amerika, 074/223. 
Anzahl zunehmend. 1941 sprach er auf sechs Veranstaltungen, 1942 noch auf vier, 1943 trat er gar nicht öffentlich auf, ein Jahr später hielt er wieder zwei Reden. Dass er aber trotz vermindertem Engagement für die Universität, was in Jerusalem natürlich nicht unbemerkt blieb, in den USA zu bleiben gedachte, zeigte sich darin, dass er und Lili ihre Zimmer im Hotel Delmonico aufgaben. Sie zogen nach Stamford, Connecticut, das etwas mehr als eine Zugstunde nordöstlich von New York lag. Dort ließen sie sich an der Huntington Ridge Road, einer Straße, die außerhalb des Zentrums im Grünen lag und von großen Einfamilienhäusern gesäumt war, nieder. Schocken behielt in New York ein Büro, aber den größten Teil der Zeit verbrachte er mit seiner Frau weitab von der Hektik der Großstadt. Vielleicht sehnten sie sich nach einem ähnlichen Leben wie in Berlin, wo die Familienvilla auch außerhalb der Stadt im grünen Zehlendorf lag. Anders als in Berlin verlor Salman Schocken jedoch zunehmend an Einfluss. Die Tatsache, dass er Briefe monatelang unbeantwortet ließ, verstärkte diese Entwicklung.

Gershom Scholem, der ihm mehrmals schrieb, unter anderem, um ihn vom Tod Walter Benjamins zu unterrichten, ${ }^{23}$ war zunächst betrübt und dann verärgert, dass von Schocken keine Antwort kam. In einem Brief an Hannah Arendt äußerte er, dass es „gar keinen Sinn hat“ an Schocken zu schreiben, „er liest Briefe nicht ${ }^{\text {“24 }}$. Scholem, der ihm nicht nur aus privaten Gründen schrieb, sondern auch in seiner Funktion als Universitätsprofessor und Leiter des Institutes für jüdische Mystik, bat Schocken immer wieder, nach Jerusalem zurückzukehren. ${ }^{25}$ Aber Schocken blieb hartnäckig stumm und manövrierte sich damit ins Abseits. Das Schweigen Schockens hatte auch zur Folge, dass die Finanzierung von Scholems Forschungsinstitut nicht mehr gesichert war. Immer wieder bat er in Briefen und Telegrammen um diesbezügliche Nachricht. Schließlich schrieb er Schocken im Februar 1942, dass das Projekt wegen dessen Schweigen

23 Vgl. Gershom Scholem an Salman Schocken, 05.06.1941. NLI, Scholem Archiv, Arc. 4 1599, 01 3050, Bd. 10.

24 Gershom Scholem an Hannah Arendt, 21.12.1943. In: Marie L. Knott (Hrsg.): Hannah Arendt und Gershom Scholem. Der Briefwechsel. Frankfurt am Main: Jüdischer Verlag 2010, S. 44.

25 Vgl. Gershom Scholem an Salman Schocken, 09.10.1941. NLI, Scholem Archiv, Arc. 4 1599, 01 3050, Bd. 10. 
abgebrochen wurde. ${ }^{26}$ Erst im März 1943, nach über einem Jahr schrieb Schocken aus seinem Urlaub in Florida zurück.

I was always a happy reader: the same day with your letter, the second day of my stay here in Florida on a lonesome island for a vacation, arrived a copy of your book. I must congratulate you to this work. [...] For a whole year I hadn't heard anything about the work of the Institute [...]. I really think it would be useful that report dealing with essentials matters come regularly to me. $[. . .]^{27}$

Das Finanzierungsproblem von Scholems Forschungsinstitut scheint recht einfach gelöst worden zu sein. Im selben Brief informierte Schocken Scholem darüber, dass er als Reaktion auf Scholems Schreiben vom Februar sofort an seinen Sohn Gustav in Jerusalem schrieb, damit dieser die Sache in die Hand nehme. Gustav seinerseits schrieb am 26. April an Scholem, dass er interessiert daran sei, dass die Arbeit des Institutes wieder aufgenommen werde und einen Tag später schloss man eine Vereinbarung über das zukünftige Arbeitsprogramm des Instituts. ${ }^{28}$ In Palästina übernahm Gustav immer mehr die Aufgaben seines Vaters, auch wenn er erst 1946 als gesetzlicher Vertreter Salmans eingesetzt werden sollte. ${ }^{29}$ Dennoch hatte Schocken, zumindest offiziell, seine Rückkehrpläne noch nicht aufgegeben.

Anders als bei Scholems Forschungsinstitut ließen sich andere Probleme nicht mehr so leicht aus der Welt schaffen. Scholem war nicht der einzige, der monatelang auf ein Lebenszeichen Schockens hoffte. Schocken hielt sich gleichermaßen der Universitätsleitung gegenüber verschlossen. Er war sich durchaus bewusst, dass dies zu Unstimmigkeiten und Unmut führte, wie er Scholem gegenüber zugab:

26 Vgl. Gershom Scholem an Salman Schocken, 15.02.1942. NLI, Scholem Archiv, Arc. 4 1599, 013050 , Bd. 6 .

27 Salman Schocken an Gershom Scholem, 21.03.1942. NLI, Scholem Archiv, Arc. 4 1599, 013050, Bd. 10.

28 Vgl. Gustav Schocken an Gershom Scholem, 26.04.1942; Gustav Schocken an Gershom Scholem, 27.04.1942. NLI, Scholem Archiv, Arc. 4 1599, 01 3050, Bd. 2.

29 Vgl. Akte vom 27.07.1946. SchA, Privates, 823, Box 33. 
The distances, the duration of my absence and the necessary delay in communication are causing psychological difficulties. Thus, my relations to the University have gotten into a somewhat unsatisfactory state. [...] What our friends there [at the University] think is the right thing for me, would, in reality carry me away from my work. If Dr. Weizmann and the Board of Governors would take the same position, I would decide to leave. ${ }^{30}$

Was Schocken als „somewhat unsatisfactory state“ umschreibt, war bedeutend gravierender als er es sich eingestehen wollte. In Jerusalem wurden Stimmen laut, die entweder seine sofortige Rückkehr oder seine Absetzung forderten. Noch konnten ihm loyal gesinnte Personen, wie Werner Senator, das verhindern. Dass eine Rückkehr seine Arbeit in den USA vorzeitig abbrechen würde, stimmte nur sehr bedingt, denn dieser kam er weder engagiert noch besonders erfolgreich nach.

Zusätzlich zu den Schwierigkeiten mit der Universität hatte er in New York Unstimmigkeiten mit den Friends. Schocken hielt sich darüber derart bedeckt, dass man selbst in den Jerusalemer Universitätskreisen deren Gründe und Ausmaß nicht kannte. Scholem schrieb daher an seine Freundin Hannah Arendt, die ebenfalls in New York lebte, und fragte, welche „Unannehmlichkeiten [Schocken] mit unseren sogenannten Friends dort [hat]. Hier ist darüber Genaues nicht zu erfahren, und ich bin für Aufklärungen, die auch für uns wichtig sein könnten, dankbar. ${ }^{\text {“31 }}$ Arendt wusste keine Details, ihr zufolge beruhten die Schwierigkeiten ,auf den üblichen Konflikten zwischen ,refugees und Eingeborenen, die sich von ersteren nichts dreinreden lassen wollen. ${ }^{\text {“32 }}$ Was Arendt und Scholem in ihrer Korrespondenz ansprachen, war Schockens Versuch, die Finanzierung für den Aufbau einer medizinischen Fakultät zu sichern. Als Geldgeber wurde die Hadassah Women's Zionist Organization of America gewonnen, die 1912 von Henrietta Szold gegründet worden war. ${ }^{33}$

30 Salman Schocken an Gershom Scholem, 21.03.1942. NLI, Scholem Archiv, Arc. 4 1599, 013050 , Bd. 10.

31 Gershom Scholem an Hannah Arendt, 21.12.1943. In: Knott (Hrsg.): Hannah Arendt und Gershom Scholem, S. 45.

32 Hannah Arendt an Gershom Scholem, 20.05.1944. In: Ebd., S. 49.

33 Die Zionistin und Feministin Henrietta Szold wurde 1860 in Baltimore geboren. Sie war Erzieherin, Sozialarbeiterin, Autorin und Philanthropin und gründete die größte jüdische Organisation, die Hadassah, der sie selbst lange Zeit vorstand. Trotz ihrer zahlreichen Verdienste und ihrer außerordentlichen Stellung in Amerika und im Jischuv später in Israel war 
Hadassah eröffnete 1913 eine erste kleine Klinik in Jerusalem, die von zwei Schwestern geführt wurden. Das Ziel der Organisation war es, ein modernes, an amerikanischen Standards ausgerichtetes Gesundheitssystem im britischen Mandatsgebiet Palästina aufzubauen. Nachdem die kleine Klinik in Jerusalem während des Ersten Weltkrieges geschlossen werden musste, sandte die Hadassah im Jahr 1918 ein medizinisches Team von 45 Mitgliedern nach Palästina, um dort Spitäler und Kliniken zu eröffnen. Die Organisation gründete darüber hinaus eine Schwesternschule und eine Hygieneinstitution, das Ziel war die Ausrottung von infektiösen Krankheiten wie Malaria und Cholera. Die medizinische Versorgung durch die Hadassah war für alle Einwohnerinnen und Einwohner Palästinas zugänglich und stand damit dezidiert für eine pluralistische Gesellschaft ein, in der Juden und Araber friedlich nebeneinander leben sollten. Dies stand in keinem Widerspruch zu ihrer zionistischen Agenda, die die Gründung eines jüdischen Staates in Palästina zum Ziel hatte. In den USA widerstand Hadassah dem Druck von anderen zionistischen Organisationen, sich an landesweiten Spendenaktionen zu beteiligen; sie stand im Gegenteil für ihr Recht ein, unabhängig zu bleiben und so über Finanzierung und Lancierung ihrer Projekte frei entscheiden zu können. Der Ruf der finanziellen und organisatorischen Unabhängigkeit brachte ihr die Loyalität einer ständig wachsenden Zahl jüdischer US-Amerikanerinnen ein. 1939 wuchs die Organisation mit über 66.000 Mitgliedern zur größten zionistischen Organisation Amerikas heran. In den 1920er und 1930er Jahren baute Hadassah ihr Netzwerk an medizinischen Einrichtungen kontinuierlich aus, darunter waren zahlreiche Mutter-Kind-Kliniken. Neben der Förderung medizinischer Einrichtungen tat sich die Frauenorganisation in den 1930er Jahren vor allem auch in der Rettung jüdischer Kinder und Jugendlicher aus Nazi-Deutschland hervor, indem sie als einzige amerikanische Organisation die Jugend-Alija finanziell und logistisch unterstützte. Gleichzeitig arbeitete Hadassah gemeinsam mit der Hebräischen Universität an der Gründung einer Universitätsklinik auf dem Skopusberg. ${ }^{34}$

Szolds Leben und Werk nie Gegenstand einer größeren wissenschaftlichen Arbeit. Erschienen sind jedoch drei Biographien, die Einblick in das Leben und Wirken von Szold geben, unter diesen besonders zu empfehlen ist Rose Zeitlin: Henrietta Szold. Record of a Life. New York: Dial Press 1952.

34 Vgl. Erica Simmons: Hadassah. The Women's Zionist Organization of America. In: Encyclopaedia Judaica. 2. Aufl., hrsg. v. Michael Berenbaum / Fred Skolnik. Detroit: Macmillan Reference 2007, S. 185-188. 
1939 wurde - wie bereits in Kapitel 7.4. dargestellt - das von Erich Mendelsohn entworfene Rothschild-Hadassah-Universitätsspital eingeweiht.

Die Kosten für den weiteren Ausbau der Klinik, aber auch zur Deckung ihres Unterhaltes und der Gehälter waren hoch und mussten auch während der Kriegsjahre gesichert werden. Der Streit zwischen Salman Schocken und den American Friends of the Hebrew University brach wegen genau dieser Fragen aus. Schocken, der Wirtschaftsfachmann, der weit vorausplante und dem stark an der Respektierung seines Wissens lag, geriet mit Samuel B. Finkel und anderen Vertreter der Friends aneinander, weil er seine Ansichten nicht durchzusetzen wusste.

Hadassah war bereit, eine sehr große Summe, man sprach von drei bis vier Millionen Dollar, zu investieren, stellte jedoch die Forderung auf, dass die Friends sämtliche Gelder, die sie einwarben, ebenfalls für das Projekt zur Verfügung stellten. Zudem beanspruchten sie, die Hadassah Medical School unter gemeinsame Schirmherrschaft der Universität und der Hadassah Organization zu stellen. Beide Forderungen entsprachen nicht unbedingt den Vorstellungen der Universitätsleitung, konnten aber, so wurde in der Korrespondenz deutlich, akzeptiert werden. Schocken versuchte im Interesse der Universität, dies zu verhindern und argumentierte, dass die Universität in ihrer Entwicklung und Planung frei entscheiden können müsse. Wenn sich allerdings die Friends verpflichtet hätten, ihre Gelder für eine bestimmte Zeit nur für das Medical Center einzusetzen, hätten alle weiteren Entwicklungspläne auf Eis gelegt werden müssen. Der Unterhalt der bestehenden Strukturen wäre durch das Abkommen jedoch nicht gefährdet gewesen. ${ }^{35}$ Das Problem lag darin, dass Schockens Einwände langwierige Verhandlungen nach sich gezogen hätten und die Universität diese Zeit nicht hatte. Da Schocken weiterhin kaum nach Jerusalem schrieb, wusste man dort auch nicht, wie Schocken in New York verhandelte. Die Universität wollte nicht zuletzt deshalb den Rektor, Leon Roth, für die Verhandlungen nach New York schicken. Dieser sollte Schockens Aufgaben übernehmen. Man teilte Schocken mit, dass sein Einsatz in Jerusalem gebraucht würde und man daher einen Ersatz nach New York schicken wolle. ${ }^{36}$ Tatsächlich war

35 Vgl. Memorandum S[alman] Schocken an L[eon] Roth, 20.11.1944. SchA, Universität, $074 / 222$.

36 Vgl. Korrespondenz zwischen Werner Senator und Salman Schocken, November 1944. SchA, Universität, 074/22. 
es wohl eher so, dass die Universitätsleitung keine großen Hoffnungen mehr auf Salman Schocken setzte. Im Dezember kam es schließlich zu einem Abkommen zwischen der Universität, Hadassah und den Friends; das Abkommen schloss Roth hinter dem Rücken von Salman Schocken, worüber sich dieser in einem Brief an Werner Senator beschwerte. ${ }^{37}$

Gleichzeitig mit dem Memorandum, in dem Schocken das in seiner Sicht fehlgeleitete Abkommen kritisierte, schickte er einen von Senator langerwarteten Brief an diesen, in dem er sein langes Schweigen zu erklären versuchte. Anstelle einer Entschuldigung traf jedoch eine lange Liste von Vorwürfen in Jerusalem ein. Unter anderem beschuldigte Schocken die Universitätsleitung, Entscheidungen getroffen zu haben, ohne Rücksprache mit ihm gehalten zu haben und ihm wichtiges Material vorenthalten zu haben, das er für seine Verhandlungen gebraucht hätte. ${ }^{38}$ Dieses Schreiben ließ Senator etwas ratlos zurück. Seiner Antwort ist zu entnehmen, dass Schocken sämtliche Protokolle erhalten habe und jederzeit hätte eingreifen können. Schockens Einschätzungen zur Medical School seien sehr wohl zur Kenntnis genommen worden, wäre man aber seinen Ideen gefolgt, hätte sich die Sache weiter verzögert, was nicht im Interesse der Universität und des Jischuv gewesen wäre. Des Weiteren macht Senator deutlich, dass Schocken nicht verstanden habe, dass seine lange Abwesenheit seine Rolle und seinen Ruf an der Universität unwiderruflich verändert habe. ${ }^{39}$ Im April 1945, nur einen Monat später, forderte Senator ihn zur Demission auf, um einer Absetzung zuvorzukommen. Er teilte seine Einschätzung mit, dass eine Rückkehr die Gemüter inzwischen nicht mehr beruhigen würde, und äußerte sein Bedauern darüber. ${ }^{40}$ Bereits im Januar schrieb Chaim Weizmann, dass die Universitätsleitung durch die lange Abwesenheit beunruhigt sei und sich über das Schweigen ärgere. „In other words“, schrieb er, ,it is believed that the Executive Head of the University is not bearing his part of the burden in these critical times. ${ }^{“ 41}$ Am 17. Juli gab Schocken auf und reichte von London

37 Vgl. Memorandum Salman Schocken an Werner Senator, 06.12.1944. SchA, Universität, $074 / 22$.

38 Vgl. Salman Schocken an Werner Senator, 06.12.1945. SchA, Universität, 074/22.

39 Vgl. Werner Senator an Salman Schocken, 14.03.1945. SchA, Universität, 074/22.

40 Vgl. Werner Senator an Salman Schocken, 18.04.1945. SchA, Universität, 074/22.

41 Chaim Weizmann an Salman Schocken, 22.02.1944. SchA, Universität, 011/7. 
aus seine Demission ein, ${ }^{42}$ die der Vorstand an seiner Sitzung vom 30. Juli annahm. ${ }^{43}$ Damit kam nicht nur Schockens Engagement für die Universität zu einem Ende, sondern auch seine Arbeit für zionistische Körperschaften. 33 Jahre nachdem er sein erstes öffentliches Amt als Gründer und Vorsteher der lokalen Zweigstelle der Zionistischen Vereinigung für Deutschland in Zwickau annahm und fortan sein Wissen, sein Netzwerk und sein Vermögen für die Sache des Zionismus einbrachte, schied er 1945 wenig ruhmreich aus seiner letzten Funktion aus.

Die Frage, warum Schocken seine Stellung an der Universität und in Palästina derart ungeschickt gefährdete, kann nicht abschließend beantwortet werden. War er ausgebrannt vom jahrelangen Kampf für den Zionismus? Setzte ihm der Verlust der deutschen Heimat derart zu, dass er gleichsam gelähmt seine Aufgaben vernachlässigte? Oder war es Überheblichkeit, die ihm ein Gefühl von Unersetzbarkeit vermittelte und durch die er sich unverwundbar fühlte? Die Quellen geben keine Antworten darauf, man ist aber versucht, eine Kombination der hier genannten Gründe als Ursache für Schockens Passivität während der Kriegsjahre zu vermuten. Seinem Selbstverständnis nach war er weiterhin der Tat- und Erfolgsmensch, der er als Kaufmann und Verleger in Deutschland unbestritten war. Sein Talent und seine Expertise ließen ihn in die höchsten Ränge der deutschen Wirtschaft und des Zionismus aufsteigen. Seine Geschäftsmethode, erst nach einer aufwändigen Prüfung und Analyse der Sachlage Entscheidungen zu treffen, bewährte sich im Rahmen seines Konzernes. Das Tagesgeschäft delegierte er an fähige Mitarbeiter, die jedoch jede einzelne Entscheidung mit ihm abzustimmen hatten. Ähnlich wie er seinen Konzern und Verlag von Jerusalem aus steuerte, wollte er die Universität aus der Ferne leiten. Dass diese langwierigen Verfahren zur Entscheidungsfindung, im heutigen Sprachgebrauch micromanaging genannt, im Kontext der Hebräischen Universität von geringem Nutzen waren, sah er nicht. Er verstand sich als Stratege und Kontrollinstanz; schnelle Entscheidungen entsprachen dem nicht. In New York isolierte ihn diese Haltung - auch, da er immer weniger überhaupt zu einer Entscheidung kam. Überzeugt davon, dass seine Methode die richtige sei und davon, dass die Universitätsleitung ohne sein strategisches Denken nicht arbeiten könne, verkannte Schocken die Tatsache, dass er für die

42 Salman Schocken an Chaim Weizmann, 17.07.1945. SchA, Universität, 011/7.

43 Chaim Weizmann an Salman Schocken, 31.07.1945. SchA, Universität, 011/7. 
Universität zur Bürde wurde und überhörte die kritischen Stimmen von dort. Seine Ambitionen, die Universität aus der Ferne zu leiten, gerieten zunehmend als ,Marionettentheater' in die Kritik. Schocken sitze in New York, hieß es wiederholt, und versuche die Fäden seiner Marionetten in Jerusalem zu ziehen. ${ }^{44}$ Bei Schockens eigener Verkennung seiner Position - der Überschätzung seiner Macht und seiner Stellung - schwang sicherlich eine Spur Überheblichkeit mit. Dass dieser Mann, der für seine Analysefähigkeit weitum gelobt und bewundert wurde, nicht sah, wie sich die Tatsachen entwickelten, muss wohl tieferliegende Ursachen haben. Die bereits erwähnte Erschütterung, die die Entwicklungen in Deutschland bei Schocken auslöste, hat möglicherweise zu einer Erschöpfung geführt, aus der er nur schwer herauskam. Ohne Belege dafür kann dies aber nur eine Vermutung bleiben. Umso deutlicher sind die Konsequenzen seines Handelns oder vielmehr seiner Passivität: der erzwungene Rücktritt von seiner Position an der Universität und damit einhergehend der Bruch mit Palästina.

\subsection{Der unausgesprochene Entschluss, zu bleiben: Ein Fazit}

Schocken zeigte sich hinsichtlich der Angelegenheiten der Universität zwar passiv, dies hieß jedoch nicht, dass er in New York gänzlich taten- und ideenlos war. Zum einen nahm er weiterhin Anteil an den Entwicklungen des von ihm gegründeten Konzernes, über den er von Wilhelm Fonk, dem Verwaltungsratsvorsitzenden des Merkur-Konzerns nach Möglichkeit unterrichtet wurde. ${ }^{45}$ Zum anderen dachte er über die Gründung eines dritten Schocken Verlages nach: Bereits in den 1930er Jahren spielte er mit dem Gedanken, einen englischsprachigen Verlag zu gründen. 1936, als er sich noch mitten in den Vorbereitungen für den hebräischsprachigen Verlag befand, dachte er in einem Brief an Hans Kohn über die Möglichkeit eines Verlages für den englischsprachigen Markt nach. Er habe sich entschlossen, so Schocken, die „Ruppin Dankesschrift“ in drei Sprachen, also in „Deutsch, Hebräisch und eben auch English“ zu drucken, um zum „ersten Mal in englischsprechenden Ländern mit dem

44 Vgl. u. a. Werner Senator an Salman Schocken, 02.03.1944. SchA, Universität, 074/222. 45 Vgl. Stefanie Mahrer: Schocken und Merkur. Kontinuitäten des Unternehmens von der NS-Zeit bis in die Nachkriegszeit. In: Stefanie Fischer / Nathanael Riemer / Stefanie SchülerSpringorum (Hrsg.): Juden und Nicht-Juden nach der Schoah. Begegnungen in Deutschland. Berlin: de Gruyter 2019, S. 95-115. 
Verlagsnamen aufzutreten. ${ }^{446}$ Weitere Abklärungen fielen dann, so Schocken 1939 , ,recht wenig ermutigend ${ }^{\text {“47 }}$ aus, sodass die Pläne zunächst zurückgestellt wurden. Aber 1942, nun bereits in den USA wohnhaft und mit dem verlegerischen und kulturellen Angebot innerhalb der jüdischen Bevölkerung Amerikas vertraut, kam Schocken zu der Überzeugung, dass ein Bedarf für ein Verlagsprogramm, ähnlich jenem in Deutschland, vorhanden sei. ${ }^{48} \mathrm{Im}$ Jahr 1945 wurde dann der amerikanische Schocken Verlag in New York gegründet.

Nur ein Jahr später setzte Schocken in Jerusalem seinen Sohn Gershom, der in seiner privaten Korrespondenz mit seinem Vater weiterhin seinen deutschen Namen Gustav verwendete, als rechtmäßigen Vertreter für alle Geschäfte in Palästina ein. Gershom leitete seit Ende der 1930er Jahre und durch die Kriegszeit hindurch den Schocken Verlag in Jerusalem / Tel Aviv und die Zeitung Haaretz. Die Buchproduktion stagnierte zwar während des Krieges, da kaum qualitativ hochwertiges Papier zu finden war, es gelang ihm jedoch, die Zeitung weiter auszubauen und ihr seine Prägung zu verleihen. Mit der Übergabe im Mai 1946 an Gershom machte Schocken also nur offiziell, was längst Tatsache war. Der juristische Akt muss aber dennoch als Hinweis gelten, dass Salman Schocken nicht plante, nach Jerusalem zurückzukehren. Er verabschiedete sich damit endgültig von seinem Jerusalemer Leben. Durch die Gründung seines nun dritten Verlages in seiner Wahlheimat New York hatte er zudem eine Beschäftigung, die ihn forderte.

Seinen Entschluss, in den USA zu bleiben, hat er offiziell nie explizit ausgesprochen, zumindest ist dies in den vorliegenden Dokumenten nicht zu finden. Seine Taten verdeutlichten aber, dass eine Rückkehr nach Palästina ausgeschlossen war. Die Familienvilla wurde an das amerikanische Konsulat vermietet, das seit Mai 1943 dort seine Büros eingerichtet hatte. Das Verhältnis zu den Amerikanern war nicht immer einfach, sodass Schocken sich 1949 entschloss, nach einem Käufer für die Villa zu suchen. Nach langen und turbulenten Verkaufsverhandlungen mit den Amerikanern und der israelischen Regierung, die Interesse bekundete, die Villa als Sitz des Präsidenten zu erwerben, konnte die

46 Salman Schocken an Hans Kohn, 12.06.1936. SchA, Privates, 844/2, Bd.3.

47 Salman Schocken an Rabbiner Eugen Gaertner, 30.01.1939. SchA, Privates, 844/2, Bd. 2. 48 Vgl. Nahum Glatzer: Herrn Salman Schocken zum achtzigsten Geburtstag, „Schocken Books“, Typoskript [1957]. SchA, Verlag, 30. 
Immobilie erst zu Beginn der 1960er Jahre verkauft werden. Käuferin war die Akademie für Musik und Tanz. ${ }^{49}$

Wir befinden uns jedoch immer noch im Jahr 1945. Schockens Signale waren deutlich: Trotz eines ersten Besuchs in Jerusalem seit seiner Abreise im Herbst 1940, der zu den Hohen Feiertagen im Herbst 1945 stattfand, schien eine endgültige Rückkehr ausgeschlossen. Gershom hatte während der Abwesenheit des Vaters bewiesen, dass er im Stande war, dessen Geschäfte zu führen, ein neuer Verlag wurde in New York gegründet und das Familienheim war vermietet. Der Aufenthalt in Palästina erstreckte sich zwar über ganze sieben Monate, ${ }^{50}$ aber es blieb ein Besuch aufZeit. Sein Domizil war fortan Scarsdale im Bundesstaat New York, auch wenn er fast jedes Jahr für einige Monate nach Palästina resp. nach Israel reiste, um dort Familie und Bekannte zu treffen, sich mit seinen Büchern umgab und den einen oder anderen Vortrag hielt. Auch Europa stand auf dem jährlichen Reiseprogramm Schockens. Bis zum endgültigen Verkauf der Firma im Jahr 1953, deren westdeutschen Teile 1949 wiedererstattet wurden, ${ }^{51}$ war er einige Male in Deutschland, um sich vor Ort ein Bild von seinem Betrieb zu machen. Vor allem aber verbrachte er die Sommermonate in der Schweiz, wo er bereits vor dem Krieg viele Monate in Hotels weilte.

Wie nach dem offiziellen Verlassen Deutschlands im Dezember 1933 führte Schocken ein Leben, das durch ständiges Reisen geprägt war. Im Vergleich scheint sein Nachkriegsleben jedoch gesetzter. Von 1933 bis 1940 lebte er tatsächlich auf zwei Kontinenten: Seine zahlreichen Verpflichtungen in Europa und in Palästina im Auftrag der Universität, als Vertreter der zionistischen Bewegung, aber auch in seiner Position als Inhaber eines Verlages und eines Konzerns führten ihn von Ort zu Ort. Sein ganzes Umfeld war mobil und bewegte sich zwischen Europa und Palästina. Man schuf damit einen zionistisch geprägten deutsch-jüdischen Zwischenraum, der sich einerseits geographisch festmachen lässt, sich andererseits virtuell über die ständigen Briefkontakte aufspannte. Schockens Existenz nach 1945 scheint eine andere gewesen zu sein: Der Bruch mit Palästina, ausgelöst durch seine Abwesenheit und Passivität

49 Die Akten zu den Verkaufsverhandlungen mit dem israelischen Staat und dem amerikanischen Konsulat liegen im Schocken Archiv: SchA, 823, Box 35. Zum Verkauf in den 1960er Jahren vgl. Rosenblum: Mendelsohn Building Spurs Monumental Dilemma.

$50 \mathrm{Vgl}$. Aufenthalte in Israel nach 1945. SchA, Katalog 3/8/9.

51 Vgl. Fuchs: Ein Konzern aus Sachsen, S. 267-272. 
während der Kriegsjahre, manifestierte sich auch später in unterschiedlichen Momenten. Sein dortiges Netzwerk löste sich sukzessive auf, vor allem, weil er sich nur mehr halbherzig um Kontakte bemühte. In den Beziehungen zu früheren Weggefährten waren die Brüche zu tief; seine Aufenthalte in Israel und in Europa gestalteten sich als reine Besuche. Mit der Gründung des New Yorker Verlages versuchte Schocken an Vorheriges anzuknüpfen: Das Buch sollte ihn wieder in Kontakt mit seinen früheren Weggefährten bringen. Die Kontakte blieben jedoch, wie die Korrespondenz zeigt, im rein Geschäftlichen. 


\section{2 \\ Neuanfang mit Blick zurück}

Die Entscheidung, nach dem Krieg nicht nach Jerusalem zurückzukehren, sondern seinen Lebensmittelpunkt nach New York zu verlegen, kam einem Neuanfang gleich. Die Verbindungen nach Palästina gestalteten sich lose und Schocken verlor die Rolle, die er vorher im Netzwerk deutsch-jüdischer Intellektueller hatte. Zu gewissen Anlässen erinnerte man sich höflicherweise an Schocken; für den Aufbau des jüdischen Lebens nach der Schoa und ab 1948 des Staates Israel war er jedoch bedeutungslos. Nach Kriegsende war Salman Schocken knapp siebzig Jahre alt und hätte sich nach einem aktiven, vielleicht gar ruhelosen Leben, zur Ruhe setzen können. Tatenlosigkeit entsprach ihm jedoch nicht.

Es gab drei Bereiche, die ihn sein ganzes Erwachsenenleben beschäftigten und die ihn zu Höchstleistungen antrieben, und genau diesen wandte er sich nun, nach Ende des Krieges, wieder verstärkt zu: seinem Konzern, der hebräischen Typographie und jüdischen Büchern.

Er begann ungefähr drei Jahre nach dem Krieg, sich um Wiedergutmachung zu bemühen, und erhielt 1949 Teile seines 1938 zwangsverkauften WarenhausKonzerns zurück. Er war nun nicht mehr operativ tätig, aber brachte seine Expertise ein und stand de facto dem Betrieb bis zum endgültigen Verkauf im Jahr 1953 vor.

Bereits etwas früher, nämlich noch im Jahr des Kriegsendes, schaltete sich Salman Schocken in die Verhandlungen zwischen seinem Sohn Gustav und 
Franzisca Baruch ein, die seit 1943 damit befasst war, eine neue, moderne hebräische Drucktype zu entwerfen. Salman Schocken kritisierte seit seiner Zeit als Verleger in Deutschland, dass es kaum hebräische Typen gäbe, die den ästhetischen Ansprüchen eines klassisch-modernen Buchdruckes genügten. Frühere Pläne, eine neue Type entwickeln zu lassen, scheiterten, nun aber, im Jahre 1949, war die Arbeit weit gediehen und Baruch hatte bereits erste Entwürfe vorgelegt. ${ }^{1}$

Vielleicht das bedeutendste Nachkriegsprojekt Salman Schockens war die Gründung des US-amerikanischen Schocken Verlages, Schocken Books New York, ebenfalls im Jahr 1945. Nach langem Abwägen entschloss er sich, seine Visionen vom jüdischen Buch auch einem englischsprachigen Lesepublikum näherzubringen. Der Verlag nahm seine Arbeit noch 1945 auf und hat bis heute, inzwischen als Teil von Random House, Bestand.

Im folgenden Kapitel sollen diese drei Unternehmungen in unterschiedlicher Ausführlichkeit im Zentrum stehen. Bezeichnend für alle drei ist, dass Schocken damit an Vergangenes anknüpft. Er nimmt auf, was durch die Vertreibung und Vernichtung der europäischen Juden und durch den Krieg unterbrochen worden ist. Es wirkt, als wolle Schocken die Lücke zwischen 1939 und 1945 ausblenden. Dennoch bleibt sie präsent: Während Schockens Vorkriegsexistenz durch ein weitläufiges wie engmaschiges Netzwerk von Menschen mit unterschiedlichen Talenten und Aufgaben geprägt war, scheint er nach dem Krieg isoliert dazustehen. Zuvor waren seine unterschiedlichen Tätigkeiten aufs Engste miteinander verwoben: Der Verlag war Teil des Konzerns und konnte auf dessen finanzielle Rücklagen sowie die Verwaltungsstruktur zurückgreifen. Schockens Bemühungen um jüdische Bücher umfassten die Verbreitung von Texten, die Förderung von Autoren sowie ästhetische und drucktechnische Fragen. Er vermochte damit, eine große Anzahl von Autor*innen, Gestalter*innen, Intellektuellen, Lektor*innen sowie Setzern miteinander in Kontakt zu bringen, Schocken selbst stand dabei immer im Zentrum. Er schaffte durch seinen Verlag einen kulturellen Raum, in dem in den 1930er Jahren Widerstand geleistet wurde. Nach dem Krieg scheinen seine Unternehmungen losgelöst

1 Der Briefwechsel zwischen Gustav Schocken, Salman Schocken und Franzisca Baruch liegt im Archiv des Israel Museums, Jerusalem (IMJ). Der Bestand ist archivarisch noch nicht erschlossen, Archivsiglen fehlen. In der Folge wird auf Archiv und Briefdatum verwiesen. Ich danke Philip Messner und Ada Wardi, dass sie mir das Material zugänglich gemacht haben. 
voneinander. Das alte Netzwerk konnte nicht mehr wiederbelebt werden und Schocken schaffte es nicht, ein neues aufzubauen. Die Wiederaufnahme seiner Betätigungen wurde insofern weniger ein Anknüpfen an sein bisheriges Leben und Wirken, als vielmehr ein Neuanfang mit Blick zurück.

\subsection{Schocken Books New York}

Mit knapp 70 Jahren wurde Salman Schocken also ein drittes Mal Verleger und versuchte, in dieser Rolle an Vergangenes anzuknüpfen. Er war überzeugt, dass das US-amerikanische Judentum dem europäischen kulturell unterlegen war. Er sah hier große Lücken in der jüdischen Bildung und war überzeugt davon, dass man den amerikanischen Juden ihre kulturellen Wurzeln mit englischen Übersetzungen der wichtigsten jüdischen Texte näherbringen müsse. Die Parallelen zu seinen Ideen und Bemühungen in Deutschland sind nicht zu übersehen. In einer von Nahum N. Glatzer ${ }^{2}$ zum 80. Geburtstag Salman Schockens verfassten, aber nie publizierten Geschichte der Schocken Books, erinnerte sich der Verfasser an die Anfänge des Verlages. Schocken, so Glatzer, erwog seit 1943, einen englischsprachigen Verlag zu gründen. Er war davon überzeugt, dass der Bedarf an einem ähnlichen Publikationsprogramm wie er es in Deutschland vorlegte vorhanden war. Denn, so schrieb Glatzer,

[w]ith some notable exceptions, Jewish publishers in America did not want to take the risk of expanding the narrow limits of traditional publishing which centered around the synagogue, the rabbinical organizations, the schools and communal institutions. ${ }^{3}$

Was Glatzer hier besch reibt, spiegelt jedoch nicht die amerikanisch-jüdische Publikationslandschaft von 1943, sondern jene vor den 1880er Jahren. Nun ist der Text von Glatzer verfasst, dennoch muss man davon ausgehen, dass der Autor darin die Sicht Schockens wiedergibt, der ihn mit dem Verfassen der Geschichte beauftragt hat. Glatzer war sehr viel mehr als Schocken in die jüdisch-amerikanische Gesellschaft integriert - und entsprechend besser

2 Eine Kurzbiographie von Nahum N. Glatzer findet sich in Kap. 12.1.

3 Nahum N. Glatzer: Herrn Salman Schocken zum achtzigsten Geburtstag. Typoskript [1947]. SchA, Verlag, 30. 
informiert -, da er unterschiedliche Positionen in dezidiert amerikanischjüdischen Lehrinstitutionen innehatte. Zudem sind die überlieferten Gratulationsschriften und andere Abhandlungen zu Schockens Wirken als Huldigungen des Rezipienten verfasst. ${ }^{4}$

Was Schocken, der sich hauptsächlich in den Kreisen der deutschen Exilanten bewegte, übersah, waren die Entwicklungen innerhalb des amerikanischjüdischen Verlagswesens. Bis zur Wende zum 20. Jahrhundert war der kulturelle Output des sowohl ost- wie auch des westeuropäischen Judentums tatsächlich bedeutend größer als jener des US-amerikanischen. Die zwei großen religiösen Führungspersönlichkeiten des amerikanischen Judentums im 19. Jahrhundert Isaac Leeser, Vertreter der amerikanischen Orthodoxie, und der Reformer Isaac Mayer Wise - versuchten, durch die Publikation von Schriften ihren jeweiligen Anhängern ein kulturelles und religiöses Fundament zur Verfügung zu stellen. Denn es war in der Tat so, dass ein Großteil der amerikanischen Juden mit den traditionellen Texten kaum vertraut war. Zwar wurden auch im 19. Jahrhundert Bücher jüdischen Inhalts gedruckt, es handelte sich dabei aber größtenteils um institutionelle Dokumente, Predigten, Gebetsbücher und ähnliches. ${ }^{5}$ Leesers und Wises Bemühungen waren zwar wichtig für ihre eigenen Gemeinden, der eigentliche Wendepunkt war aber die Massenimmigrationen aus Osteuropa und dem Russischen Reich. Auf der Flucht vor wirtschaftlicher Misere, Hoffnungslosigkeit und Wellen von Pogromen, verließen zwischen 1881 und 1914 mehr als 2,5 Millionen Juden und Jüdinnen Osteuropa, ungefähr 2 Millionen ließen sich in den USA nieder. ${ }^{6}$ Robert Singermans Bibliographie, die die Judaica Americana in den Jahren 1850 bis 1900 erfasst, zeigt deutlich, wie ab den 1880er Jahren die Zahl der jüdischen Publikationen in den USA emporschnellte. Waren es in der Dekade zwischen 1870 und 1879 noch weniger

$4 \mathrm{Zu}$ den runden Geburtstagen Salman Schockens erschienen publizierte wie nicht publizierte Texte gegenwärtiger und ehemaliger Weggefährten. Unabhängig davon, wie gespannt das Verhältnis zwischen Autor und Empfänger war, waren die Schriften voll des Lobes. Zudem gaben sie kritiklos die Sicht Schockens auf die Dinge wieder.

5 Vgl. Jonathan D. Sarna: Jewish Culture Comes to America. In: Jewish Studies 42 (2003-2004), S. 45-57, hier S.45-47.

6 Vgl. Shmuel Ettinger: Drittes Buch. Vom 17. Jahrhundert bis zur Gegenwart. Die Neuzeit. In: Haim Hillel Ben Sasson (Hrsg.): Geschichte des jüdischen Volkes. Von den Anfängen bis zur Gegenwart. 5. erw. Ausg. München: Beck 2007, S. 887-1348, hier S. 1058-1060. 
als 700 Bücher, zählte man für die 1880er Jahre bereits 1.046 und für die 1890er Jahre 2.017 Publikationen. ${ }^{7}$ Der rasante Anstieg der jüdischen Bevölkerung der USA hatte direkten Einfluss auf die Publikationslandschaft des Landes. Unter den Emigranten befanden sich Autoren und Gelehrte, aber auch im Buchdruck ausgebildete Fachleute.

In der letzten Dekade des 19. Jahrhunderts wurden in den USA zahlreiche Projekte und Vereinigungen gegründet, die direkt mit der Produktion von Büchern zusammenhingen, die 1888 gegründete Jewish Publication Society (JPS) war darunter wohl die bedeutendste. Sie verlegte in der Folge bedeutende Werke amerikanisch-jüdischer Autor*innen und Wissenschaftler*innen. ${ }^{8}$ Michael Myers verdeutlicht, dass sich das amerikanische Judentum ab den letzten Dekaden des 19. Jahrhunderts kulturell vom europäischen emanzipierte, was, wenn auch zähneknirschend, in Europa anerkannt werden musste. ${ }^{9}$ Wie später Schocken in Deutschland gab es auch in den USA Verleger, die sich die Aufgabe stellten, Jüdinnen und Juden unterschiedlichster gesellschaftlicher und konfessioneller Zugehörigkeit durch Bücher zu einen und jüdische Bildung einer breiten Masse zugänglich zu machen. 1915 lancierte die JPS die Schiff Library of Jewish Classics. Geplant war, dass innerhalb der Serie 25 klassische jüdische Texte in einer wissenschaftlichen Edition und in englischer Übersetzung erscheinen sollten. Die Parallelen dieses Projektes zu der später entstandenen Berliner Schocken-Bibliothek sind nicht zu übersehen. Die Schiff Library scheiterte jedoch, da sich zu wenig Leser für die Serie zu begeistern wussten. Unter Kritikern galt sie als zu abgehoben für eine breite Leserschaft, so wurden lediglich neun der geplanten 25 Bände publiziert. ${ }^{10}$ Nur wenige Jahre später lancierte Bloch Publishing eine sehr viel populärer ausgerichtete Serie, die sämtliche

7 Vgl. Robert Singerman: Judaica Americana. A Bibliography of Publications to 1900. New York: Greenwood 1990.

8 Vgl. Sarna: Jewish Culture Comes to America, S. 48-49. Zur Geschichte der JPS vgl. Jonathan Sarna: JPS. The Americanization of Jewish Culture, 1888-1988. Philadelphia: Jewish Publication Society 1989.

9 Vgl. Michael A. Meyer: German-Jewish Identity in Nineteenth-Century America. In: Jacob Katz (Hrsg.): Toward Modernity: The European Jewish Model. New Brunswick: Routledge 1987, S. 247-267. Vgl. auch Sarna: Jewish Culture Comes to America, S. 49.

10 Vgl. Sarna: Jewish Culture Comes to America, S. 51-52; ders.: JPS, S. 120-130. 
jüdischen Texte in Übersetzung herausbrachte. Diese stieß auf größeres Interesse bei der Leserschaft. ${ }^{11}$

Während hebräischsprachige Bücher bis zum Beginn des Ersten Weltkrieges noch vornehmlich in Europa oder in Palästina gedruckt wurden, musste danach im Land nach Lösungen gesucht werden. Die USA waren von den beiden Druckzentren abgeschnitten; zudem wurden wichtige Druckpressen durch die Kriegshandlungen zerstört. Als Reaktion darauf entschied die JPS nach dem Krieg, eigene Druckereien einzurichten. Man erwarb in Europa zwei Monotypmaschinen ${ }^{12}$ und gewann mit Moses Alperovich, der vor dem Krieg in der renommierten Romm-Druckerei in Vilnius arbeitete, einen bestens ausgebildeten Fachmann als Leiter der Druckerei. ${ }^{13}$

Noch bevor das Ausmaß der Vernichtung des europäischen Judentums bekannt war, herrschte unter amerikanisch-jüdischen Wissenschaftlern und Intellektuellen die Meinung, dass das amerikanische Judentum das neue kulturelle Zentrum darstelle. Der Historiker Jacob Rader Marcus schrieb im Jahr 1941:

Almost everywhere Jewish books are being destroyed. Almost nowhere outside the United States are they being printed. The Jewish Publication Society is the only surviving literary medium of mass instruction west of Jerusalem. [...] Jewish culture and civilization and leadership are shifting rapidly to these shores. ${ }^{14}$

Das amerikanische Judentum bemühte sich nach der Auslöschung des jüdischen Lebens in Europa, das Fortbestehen der jüdischen Kultur zu sichern. Im Jahr 1942 wurde mit dem Jewish Book Council eine weitere Organisation gegründet, die sich des jüdischen Buches annahm. Das Book Council wollte als Antwort auf die Vernichtung des europäischen Judentums eine jüdische

11 Vgl. Charles A. Madison: Jewish Publishing in America. The Impact of Jewish Writing on American Culture. New York: Sanhedrin 1976, S. 76.

12 Zur Geschichte der Drucktechnik vgl. u. a. James Mosley: The Technologies of Print. In: Michael F. Suarez / Henry R. Woudhuysen (Hrsg.): The Book. A Global History. Oxford: Oxford UP 2013, S. 130-153.

13 Vgl. Sarna: Jewish Culture Comes to America, S. 52.

14 Jacob Rader Marcus: New Literary Responsibility. In: American Jewish Yearbook 43 (1941/42), S.784-791, hier S.789. 
Renaissance in Amerika auslösen und stellte dabei die Buchproduktion in den Mittelpunkt. ${ }^{15}$

Als Schocken also 1945 mit seinem New Yorker Verlag startete, schaute das US-amerikanische Judentum auf knapp sechzig Jahre Publikationsgeschichte zurück. Seit den Anfängen in den 1880er Jahren hatte sich einerseits das Spektrum an publizierten Büchern stark verbreitert, andererseits legten die Publizisten und Autoren ein gewachsenes Selbstbewusstsein an den Tag. Wie die oben beschriebenen Organisationsgründungen aus den Kriegsjahren verdeutlichten, verstand man sich im Vergleich zum europäischen Judentum nicht mehr als kulturell rückständig, sondern sah die USA als neues kulturelles Zentrum. Salman Schockens Idee, alle existierenden Judaika-Verlage in den USA aufzukaufen, um die kulturell wichtigen Titel zu übernehmen, musste scheitern. Er wollte ein neues Programm starten, in dem er die bedeutendsten Judaika in englischer Übersetzung herausbringen wollte; sein Ziel war es, eine intellektuelle Renaissance des Judentums zu initiieren. ${ }^{16}$ Ob Schocken sich bewusst war, dass 1915 die JPS mit der Schiff Library of Jewish Classics ein fast identisches Programm auf den Markt gebracht hatte, ist heute nicht mehr zu rekonstruieren. Aus dieser Zeit sind keine schriftlichen Äußerungen aus Salman Schockens Hand überliefert. Lediglich die Briefwechsel unter den Bekannten von Schocken und die Memoiren von Nahum N. Glatzer ${ }^{17}$ stehen als Quellen zur Verfügung. Glatzer war in den früheren 1920er Jahren Assistent von Martin Buber und Franz Rosenzweig bei deren Bibel-Projekt. 1933 verließ er gemeinsam mit seiner Frau Anna Deutschland. Das junge Paar ließ sich vorerst in London nieder, bevor sie kurz darauf nach Haifa übersiedelten. Da ihm dort eine akademische Karriere verwehrt blieb, migrierte die Familie nach Amerika, wo Glatzer an unterschiedlichen jüdischen Institutionen unterrichtete und wissenschaftliche Texte publizierte. 1945 wurde er von Salman Schocken angefragt, in seinem

15 Vgl. Sarna: Jewish Culture Comes to America, S. 57.

16 Vgl. Michael A. Fishbane/Judith Glatzer Wechsler (Hrsg.): The Memoirs of Nachum N. Glatzer. Detroit: Wane State UP 1997, S. 98.

17 Der von Nahum Glatzers Tochter in Zusammenarbeit mit Michael Fishbane, Professor für Jüdische Studien, herausgegebene Text, setzt sich aus Ausschnitten aus den publizierten Memoiren Glatzers zusammen. Glatzer schrieb in den Jahren 1971, 1972, 1978 und 1980 Teile seiner Erinnerungen nieder, als Grundlage dazu dienten seine Tagebücher. Vgl. ebd., S.7. 
neuen Verlag die Position des leitenden Lektors zu übernehmen. Er lehnte das Angebot ab, da er seine akademische Arbeit nicht aufgeben wollte. ${ }^{18}$ Schocken und Glatzer kannten sich bereits aus Deutschland, als Glatzer Ludwig Strauß bei den Vorbereitungen zum Lesebuch Sendung und Schicksal ${ }^{19}$ assistierte. Glatzers Erfahrungen im Lektorat wissenschaftlicher Texte und seine profunde Kenntnis des jüdischen Schrifttums veranlassten Schocken, ihm die Position im Verlag anzubieten. Als Glatzer ablehnte, konnte Schocken Max Strauß, den Bruder von Ludwig Strauß, für die Leitung des Verlages gewinnen. ${ }^{20}$ Glatzer war dem Verlag im ersten Jahr als Autor und Berater verbunden, 1946 übernahm er dann die Verantwortung für das hebräische und judaistische Programm im Verlag. Dadurch hatte er einen direkten Einblick in die Entwicklungen der ersten Jahre.

Glatzer erinnert sich in seinen Memoiren an Salman Schockens Plan, ganze Verlage aufzukaufen und die ,kulturell wertvollen' Titel zu übernehmen. Er hielt auch fest, dass die kontaktierten Verlage durchgehend ablehnend reagierten und dass Schocken ob dieser Reaktionen mehr als erstaunt war. ${ }^{21}$ Schocken hatte also tatsächlich erwartet, dass die Verleger ohne Zögern ihr Werk aufgeben würden, damit er seinen Verlag aufbauen konnte. Es scheint fast so, als ob Schocken, der sonst alle seine geschäftlichen Pläne erst nach minutiösen Abklärungen anging, in den USA seinen Verlag ohne große Vorbereitungen gründete. Möglicherweise war er tatsächlich davon überzeugt, dass nur er als Europäer die wirklichen Kulturschätze erkennen könnte und die amerikanischen Verleger ihm dankbar für seine Initiative wären. In jedem Fall ignorierte er nicht nur die heterogene Publikationslandschaft, sondern auch das Selbstverständnis der amerikanisch-jüdischen Eliten: Denn die Zeiten, in denen man neidvoll nach Europa schaute und sich an den dortigen Standards orientierte, waren vorüber. Das amerikanische Judentum hatte sich vom europäischen emanzipiert und schaute selbstbewusst in die Zukunft. Der Holocaust war dafür nicht der einzige Grund. Bereits vor dem Krieg und vor der Vernichtung des Judentums auf dem europäischen Festland entwickelte sich eine

18 Vgl. Fishbane/Wechsler (Hrsg.): The Memoirs of Nachum N. Glatzer, S. 16-18. 19 Nahum N. Glatzer / Ludwig Strauss (Hrsg.): Sendung und Schicksal. Aus dem Schrifttum des nachbiblischen Judentums. Ein jüdisches Lesebuch. Berlin: Schocken 1931.

20 Vgl. Fishbane / Glatzer Wechsler: The Memoirs of Nachum N. Glatzer, S. 97-99.

21 Vgl. ebd., S. 98. 
dezidiert amerikanisch-jüdische Kultur und Wissenschaft, die bis zu einem gewissen Grad unabhängig von jener in Europa war.

Die zahlreichen jüdischen Exilanten, die vor dem Hitlerregime aus Europa nach Amerika flohen, konnten das Selbstbewusstsein der amerikanisch-jüdischen Elite nur mit Mühe akzeptieren. Nicht ohne Überheblichkeit werteten sie die Errungenschaften des europäischen Judentums höher als jene des amerikanischen. Gerne wurden die Amerikaner als kulturlos und ungebildet dargestellt. In dieser Reaktion ist sicherlich auch ein Schutzmechanismus wirksam: Die Exilanten, oft angesehene Intellektuelle, Wissenschaftler und Autoren mussten nicht nur mit dem Verlust der Heimat und der Sprache umgehen, sondern auch mit der mehr oder weniger offenen Ablehnung im Exil. Nur wenige schafften es, in das amerikanische Establishment aufgenommen zu werden oder die akademische Karriere fortzuführen. Die Angst der Einheimischen vor der Konkurrenz durch die Zugewanderten, aber auch deren fehlende sprachliche und kulturelle Kompetenzen erschwerten die Integration. In New York und in anderen nordamerikanischen Städten bildeten sich Gruppen von Exilanten; diese konstituierten eigene, sprachlich und kulturell determinierte gesellschaftliche Räume. Bekannt war z. B. der Kreis um Hannah Arendt, die 1941 gemeinsam mit ihrem zweiten Mann und ihrer Mutter nach New York floh, wo bereits zahlreiche andere Intellektuelle aus Deutschland verkehrten. Eigene Publikationsorgane, wie z. B. das deutsch-jüdische Magazin Der Aufbau, für das Arendt tätig war, die Gründung von Hilfsorganisationen, aber auch gegenseitige Unterstützung waren kennzeichnend für diese Räume des Exils.

Salman Schocken bewegte sich zwar nur am Rande dieser Zirkel - er und seine Frau schienen zu keinem fest dazuzugehören -, dennoch war er Teil der Exilgemeinschaft. Bereits bei seinen Verhandlungen mit den amerikanischen Körperschaften, die er als Schatzmeister der Universität führte, zeigte sich, dass er die dortigen Gepflogenheiten nicht richtig verstand. Vor allem wurde aber deutlich, dass er sich nicht als Teil der amerikanisch-jüdischen Gesellschaft sah, sondern dass seine Identität stark auf seiner europäischen Herkunft fußte. Die Überheblichkeit, mit der er in den US-amerikanischen Verlagsmarkt einstieg, ist in diesem Kontext zu verstehen. Er war wie viele andere Exilanten davon überzeugt, dass die deutsch-jüdische Kultur der amerikanisch-jüdischen überlegen war. So ist auch sein etwas befremdliches Vorpreschen im Jahr 1945 seinem Selbstverständnis als Exilant geschuldet. Auch nach dem Scheitern der 
Verhandlungen war er weiterhin davon überzeugt, den amerikanischen Lesern die zentralen Texte des Judentums vorlegen zu müssen, um ihnen die ihnen fehlende kulturell-religiöse Bildung zugänglich zu machen. Zu finden waren diese Texte in seinem Berliner Verlag. Damit wandte er das Geschäftsmodell an, mit dem er bereits in Deutschland erfolgreich war.

Im Frühjahr 1945 wurde der Verlag schließlich gegründet, Max Strauß als Lektor eingestellt und ein Büro in der Fifth Avenue 565 angemietet. Als Theodor Schocken Ende 1945 aus der amerikanischen Armee entlassen wurde, ${ }^{22}$ ließ er sich gemeinsam mit seiner Frau Dora in New York nieder und übernahm offiziell die Leitung des Verlages. Glatzer schreibt, dass Salman Schocken wünschte, im Hintergrund zu bleiben, er habe aber nie aufgehört, aktiv an der Arbeit teilzunehmen. Er habe, so seine schmeichelnden Worte, den Verlag mit „seiner Weisheit, seinem artistischen Urteilsvermögen sowie seiner technischen Expertise in Fragen der Drucktechnik “23 unterstützt. Wie aber die Korrespondenz, sowohl zwischen Salman Schocken und seinen Bekannten und Söhnen wie auch jene über Salman Schocken, zeigt, war er zu Beginn sehr viel stärker involviert als dies von außen den Anschein hatte.

Da die Idee der Übernahme bestehender amerikanischer Judaika-Verlage scheiterte, musste Salman Schocken in der Anfangszeit Manuskripte aus anderen Quellen akquirieren. Aus diesem Grund kontaktierte Schocken im Frühjahr 1945 nach oft jahrelangem Schweigen einige seiner früheren Autoren, die ihm einst nahegestanden hatten.

Noch vor der Verlagsgründung schrieb er an Karl Wolfskehl. Ohne große Vorrede eröffnet Schocken dem Schriftsteller, dass er ihm sagen könne,

22 Leider sind kaum Informationen über Theodor Schockens Zeit in der US Army überliefert. Bekannt ist, dass er in Frankreich gegen die deutsche Armee kämpfte. Vgl. Salman Schocken an Karl Wolfskehl, 03.04.1945. Archiv der Schocken Books (SchB), New York. Das Archiv der Schocken Books wurde größtenteils bei der Übernahme des Verlages durch Random House aufgelöst. Ein kleiner Teil - im Umfang von ca. sechs Archivschachteln - wurde im Verlag behalten. Die Akten sind weder geordnet noch erschlossen. Ich bin der heutigen Direktorin von Schocken Books, Altie Karper, zu großem Dank verpflichtet, dass ich die Akten frei einsehen und kopieren durfte. Da die Akten weder in einer logischen Reihenfolge abgelegt sind noch über Signaturen verfügen, kann hier nur auf Verfasser, Empfänger und Datum verwiesen werden.

23 Glatzer, 80. Geburtstag, S. II. 
dass die Voraussetzung für eine Veröffentlichung einer englisch-deutschen Ausgabe der ,Stimme $\left[{ }^{24}\right]$ besteht. Zum Teil ist dieses Ergebnis entstanden aus Erörterungen mit Kurt Wolff $\left[{ }^{25}\right]$, der in alter Freundschaft oft Ihrer gedenkt, und mit Rat und Tat gern mithelfen will. ${ }^{26}$

Nach Abklärungen mit Kurt Wolff schien es Schocken am sinnvollsten, so schreibt er, wenn die Übersetzungsarbeiten unter der Mitarbeit von Wolfskehl in Neuseeland geleistet würden. Die Kosten würden vom „zukünftigen Verlag gern übernommen“ und die Veröffentlichung „hier wäre in kurzer, normaler Zeit gesichert, wenn das Manuskript druckfertig vorliegt. ${ }^{\text {“27 }}$ Falls eine Übersetzung in Neuseeland nicht machbar wäre, könnte man in New York einen geeigneten Übersetzer oder eine geeignete Übersetzerin finden. Schocken brachte dabei Carol North Valhope, also Olga Marx Perlzweig, ${ }^{28}$ ins Gespräch, die für Wolffs Pantheon Books einen Band von Stefan George übersetzte. Schocken plante, zeitgleich mit der Wolfskehl-Übersetzung zwei, drei andere

24 Gemeint ist Die Stimme spricht, erstmals 1934 als Band 17 der Schocken-Bibliothek erschienen, die zweite Auflage folgte 1936, im selben Jahr im allgemeinen Programm in einer erweiterten Auflage publiziert.

25 Kurt Wolff (1887-1963) war ein deutsch-jüdischer Verleger. 1908 war er erst stiller Teilhaber im Verlag von Ernst Rowohlt, dort rief er die bibliophile Reihe Drugulin-Drucke ins Leben. 1912 verließ er aufgrund von Unstimmigkeiten mit Rowohlt das Unternehmen und gründete 1913 den Kurt Wolff Verlag, der sich auf deutsche expressionistische Literatur spezialisierte. Zu den verlegten Autoren gehörte u. a. Franz Werfel. 1924 gründete er in Florenz den kunstwissenschaftlichen Verlag Pantheon Casa Editrice S. A. 1930 begann Wolff aus finanziellen Gründen seinen Verlag zu liquidieren. 1933 ließ er sich kurz nach der Heirat mit Helen Mosel mit ihr in der Nähe von Nizza nieder. 1935 zog das Ehepaar mit ihrem einjährigen Sohn nach Italien, von dort aus flohen sie 1938 wieder nach Nizza und, nachdem es ihnen gelang, die nötigen Reisepapiere zu erlangen, 1940 weiter nach New York. Dort gründeten Helen und Kurt Wolff 1942 den Verlag Pantheon Books, der vor allem deutsche Literatur in englischer Übersetzung verlegte. 1960 verließ er den Verlag und kehrte nach Deutschland zurück. Vgl. Helen Wolff: Kurt Wolff. Lebensdaten. Aus den Tagebuchaufzeichnungen, Notizen, Briefen und Vorträgen zusammengestellt. In: Kurt Wolff: Autoren, Bücher, Abenteuer. Betrachtungen und Erinnerungen eines Verlegers. Berlin: Wagenbach 1965, S. 103-112. Zum Leben und Schaffen Wolffs vgl. auch Helmut Frielinghaus (Hrsg.): Kurt Wolff zum Hundertsten. Hamburg: Kellner 1987; Barbara Weidle (Hrsg.): Kurt Wolff. Ein Literat und Gentleman. Bonn: Weidle 2007.

26 Salman Schocken an Karl Wolfskehl, 03.04.1945. SchB.

27 Ebd.

28 Vgl. Anm. 37. 
Werke erscheinen zu lassen, unter anderem eine erweiterte Ausgabe von Scholems Kabbala-Buch. ${ }^{29}$ Schocken muss zu dieser Zeit schon seit längerem mit Kurt Wolff in Kontakt gestanden haben, da er in seinem Brief eine mögliche Zusammenarbeit mit Pantheon Books ansprach.

Wolfskehl zeigte sich erfreut über Schockens Brief und die Idee einer englischsprachigen Ausgabe von Die Stimme spricht im New Yorker Schocken Verlag. Der im gedruckten Briefwechsel über fünfseitige Antwortbrief enthält zahlreiche Überlegungen, wie das Projekt angegangen werden könne. ${ }^{30} \mathrm{Im}$ Dezember 1946 wurde der Vertrag unterzeichnet. ${ }^{31}$ Die Übersetzung dauerte länger, als Schocken sich das vorgestellt hatte, aber kam zustande. Von Januar 1947 ist ein Brief Hannah Arendts, die 1946 zum Verlag stieß, überliefert, der auf die zu diesem Zeitpunkt vorliegende Übersetzung Bezug nimmt. ${ }^{32}$

Außer mit Wolfskehl nahm Schocken auch mit Martin Buber wieder Kontakt auf. Er beauftragte seinen Sohn Gustav herauszufinden, ob Buber daran interessiert wäre, seine Werke in englischer Übersetzung in seinem neuen Verlag zu publizieren.

Ich schreibe Ihnen heute in einer anderen Angelegenheit: Gestern bekam ich ein Telegramm meines Vaters, aus dem hervorgeht, dass er in Amerika einen SchockenVerlag aufbauen will in Zusammenarbeit mit Kurt Wolff. Unter den ersten Büchern, die mein Vater herausgeben möchte, nennt er eine Auswahl Ihrer chassidischen Bücher, wobei man Vater wohl daran denkt, dass die Übersetzungsarbeit und die Auswahl drüben geschehen würde. Als Honorar schlägt er vor: $7 \frac{1}{2} \%$ für die ersten 3.000, später $10 \%$ - was offenbar der normale Satz für übersetzte Bücher in Amerika ist. $^{33}$

Buber war für den Berliner Verlag von großer Bedeutung, im besonderen Maß als Berater, aber auch als Autor. Seine Bücher sollten ins Englische übertragen

29 Vgl. Anm. 37.

30 Vgl. Karl Wolfskehl an Salman Schocken, 30.04.1945. In: Blasberg: Karl Wolfskehls Briefwechsel aus Neuseeland 1938-1948, Bd. 1, S.209-214.

$31 \mathrm{Vgl}$. Agreement between Karl Wolfskehl and Schocken Books Inc. of New York, 06.12.1945. SchB.

32 Vgl. Hannah Arendt an Karl Wolfskehl, 21.01.1947. In: Blasberg: Karl Wolfskehls Briefwechsel aus Neuseeland 1938-1948, Bd. 1, S.214-215.

33 Gustav Schocken an Martin Buber, 29.05.1945. NLI, Buber Archiv, Ms. Var. 350/705. 
im neuen Schocken Verlag erscheinen. Die Antwort Bubers ist nicht überliefert, aber aus späteren Briefen und der Bibliographie der Schocken Books ist ersichtlich, dass die Zusammenarbeit zustande gekommen ist und die Werke Bubers in englischer Übersetzung erschienen. ${ }^{34}$

Kurt Wolff und der Pantheon Verlag fanden sowohl im Brief an Kurt Wolfskehl wie auch in jenem an Martin Buber Erwähnung. In beiden Fällen deutete Schocken an, dass die Verlagsgründung in Zusammenarbeit mit Wolff geplant sei. Diese kam jedoch aus unbekannten Gründen nicht zustande. Weder in den überlieferten Briefen aus dem Archiv der Schocken Books noch in den Aufzeichnungen Glatzers, den publizierten Briefen Hannah Arendts oder in Schockens Briefwechsel finden sich Hinweise auf eine Kooperation zwischen den beiden Verlagshäusern. Zudem wird in keiner Publikation über Kurt Wolff eine Zusammenarbeit mit Salman Schocken oder mit den Schocken Books erwähnt, auch wenn für Schocken das Interesse an einer Kooperation plausibel scheint, denn Wolff verfolgte ein ähnliches Ziel mit seinem Verlag: deutsche Bücher in englischer Übersetzung für das amerikanische Lesepublikum herauszubringen. Der Unterschied war, dass Schocken ein dezidiert jüdisches Programm vorsah. Er war es jedoch gewohnt, unabhängig zu sein, und bereits in der Vergangenheit hatte sich gezeigt, dass er große Mühe damit hatte, wenn er nicht die alleinige Entscheidungsgewalt besaß. Es erstaunt daher wenig, dass er den Verlag ohne Kooperationspartner gründete. Ein weiterer möglicher Grund, warum sich Schocken gegen eine formelle Zusammenarbeit entschied, ist, dass mehrere Investoren bei der Gründung von Pantheon Books involviert waren. ${ }^{35}$ Schocken hatte bislang alle seine Firmen mit eigenem Kapital gegründet und weigerte sich, fremdes Geld anzunehmen.

34 Vgl. Salman Schocken an Martin Buber, 06.06.1946. NLI, Buber Archiv, Ms. Var. 350/705; Glatzer: 80. Geburtstag; [Hannah Arendt (Hrsg.)]: Schocken Reader II. Excerpts From New Publications and Books in Preparation. Winter 1947/48. New York: Schocken Books 1947, S. 39, 44. Hannah Arendt war die ungenannte Herausgeberin des Readers, vgl. Elisabeth Young-Bruehl: Hannah Arendt. For Love of the World. New Haven: Yale College 1982, S. 189-191.

35 Vgl. Katherine McNamara: A Conversation About Schocken Books Part I With Altie Karper and the Editor of Archipelago. In: Archipelago. An International Journal of Literature, the Arts, and Opinion 5,2 (2001), S.63-82, hier S.70; Wolff: Autoren, Bücher, Abenteuer. Betrachtungen und Erinnerungen eines Verlegers, S. 109-111. 
In den ersten Jahren war Schocken Books ein Übersetzungsverlag, der bis auf wenige Ausnahmen englische Übertragungen des Berliner Programms publizierte. Glatzers Begründung dafür war die Qualität des deutschen SchockenVerlagsprogramms: Die hier herausgebrachten Texte wären derart zentral, dass sie in keiner Bibliothek eines amerikanischen Juden fehlen dürften. ${ }^{36}$ Das Vorgehen war aber sicherlich auch der Tatsache geschuldet, dass die Manuskripte bereits vorlagen und nur noch übersetzt werden mussten. Die Publikation neuer Texte hätte sehr viel mehr zeitliche und finanzielle Ressourcen in Anspruch genommen. Ähnlich war Schocken bereits in Berlin vorgegangen, wo er als Erstes das Lesebuch, das von Ludwig Strauß und Nahum Glatzer ediert wurde, auf den Markt brachte - eine Arbeit, die bereits in den 1920er Jahren in Angriff genommen wurde -, und anschließend hauptsächlich Texte von Buber publizierte, die er aus anderen Verlagen übernommen hatte. Durch diese Praxis gewann Schocken Zeit, das Verlagsprogramm aufzubauen, auch in den USA. Bezeichnenderweise brachte Schocken Books im Jahr 1946 als erstes Buch In Time and Eternity. A Jewish Reader, die englische Übersetzung und Adaption des Lesebuches Sendung und Schicksal auf den Markt. Olga Marx Perlzweig ${ }^{37}$ war als Übersetzerin gewonnen worden und Glatzer übernahm die Adaption und Ergänzung des Materials für den US-amerikanischen Markt. ${ }^{38}$ Schocken startete also sein Programm in New York mit demselben Werk wie in Berlin. Nicht alle waren von Schockens Vorgehen begeistert. Hannah Arendt äußerte sich kritisch über das geplante Programm, und schrieb im März 1945 an Scholem, dass Schocken „Gott und der Welt ${ }^{\text {“39 }}$ erzähle, dass er sie kennenlernen möchte, dazu aber keinen Schritt unternehme. In dem Brief benennt sie als ihr Anliegen die Publikation von Walter Benjamins Schriften - damit werde sie Schocken, so kündigte sie an, „zu löchern beginne[n]“40, sobald sie ihn sehe. Irgendwann zwischen Anfang April und Ende Juli traf Arendt dann tatsächlich mit Schocken zusammen, das Gespräch nahm aber nicht den Ausgang, den sich

36 Vgl. Glatzer: 80. Geburtstag, S. II.

37 Die Übersetzerin Perlzweig, geboren 1894, übersetzte einige Texte für Schocken. Sie war auch unter dem Pseudonym Carol North Valhope bekannt.

38 Vgl. Fishbane / Glatzer Wechsler: The Memoirs of Nachum N. Glatzer, S. 99; Schocken Reader II 1947/48, S. 39.

39 Hanna Blücher an Gerhard Scholem, 31.03.1945. In: Knott (Hrsg.): Hannah Arendt und Gershom Scholem. Der Briefwechsel, S. 65-70, hier S. 66.

40 Ebd. 
Arendt erhofft hatte. In einem Brief an Kurt Blumenfeld lässt sie sich über die Arbeit des Verlages aus. Schocken und Strauß „machen ihren Verlag“, kritisiert die Philosophin, „unter genauster Umgehung von allen Dingen, die über den Horizont des 19. Jahrhunderts hinausgehen könnten. “41

Arendts Kritik stellt sich als etwas ungerecht dar: Zwar zeigte sich Schocken mit der Auswahl an Autoren und Texten für den Verlag nicht sehr innovativ, insofern es sich zum Großteil um Wiederholungen aus dem Berliner Verlag handelte. Betrachtet man aber die Publikationen aus den ersten drei Jahren, wird auch deutlich, dass Schocken nicht bloß ,Verstaubtes' aus dem 19. Jahrhundert publizierte. Neben Scholem und Buber, die nun auch nicht zum 19. Jahrhundert zu zählen sind, findet sich hier Kafka in englischer Übersetzung sowie eine von Bella Chagall herausgegebene Ausgabe mit 36 Zeichnungen Marc Chagalls. ${ }^{42}$

Auch im weiteren Verlauf des Briefwechsels äußerte sich Arendt wenig schmeichelhaft über Schocken, ebenso wenig hielt sich Blumenfeld, der Schocken seit langer Zeit kannte, mit Sticheleien zurück. Im Antwortschreiben an Arendt bemerkte er, dass es „mit Max Strauß [...] ein schlimmes Ende nehmen [wird] “43, da Schocken ihn bald entlassen werde. Schocken selbst sei

interessant, aber entschlusslos und ein typischer Sammler. Ihn interessieren im Grunde genommen nur Kuriositäten, auf die er durch Fachleute aufmerksam gemacht wird. Als Verleger hat er dennoch Verdienste. Dass er Scholem herausgibt, rechne ich ihm nicht so hoch an, da Scholem bereits anerkannt ist. ${ }^{44}$

Blumenfelds harsche Kritik an seinem langjährigen zionistischen Weggefährten ist nicht nur als private Spitze gegen Schocken zu verstehen, sondern muss im Kontext der Stimmung in Jerusalem gesehen werden. Im Herbst 1945 war Schocken in den Jerusalemer Kreisen wohl beinahe eine Persona non grata. Er hatte schon immer den Ruf, ein schwieriger Mensch zu sein, ihn aber als

41 Hannah Arendt an Kurt Blumenfeld, 02.08.1945. In: Ingeborg Nordmann / Iris Pilling (Hrsg.): Hannah Arendt, Kurt Blumenfeld. ,... in keinem Besitz verwurzelt'. Die Korrespondenz. Hamburg: Rotbuch 1995, S.23-26, hier S. 25.

42 Vgl. Schocken Reader II 1947/48.

43 Kurt Blumenfeld an Hannah Arendt, 19.09.1945. In: Nordmann / Pilling (Hrsg.): Hannah Arendt, Kurt Blumenfeld, S. 26-30, hier S. 29.

44 Ebd. 
Sammler von Kuriositäten, die er nicht einmal selber zu entdecken wisse, zu bezeichnen und damit auf seine fehlende formelle Bildung anzuspielen, ist schon fast boshaft. Im Briefwechsel zwischen Blumenfeld und Arendt wird deutlich, dass Schocken seinen Platz in der deutsch-jüdischen Gemeinschaft in den USA ebenso wie den in der Jerusalemer Gesellschaft verloren hatte. Blumenfeld brachte stellvertretend für viele in Palästina die Enttäuschung und den Ärger darüber zum Ausdruck, dass Schocken während des Krieges Palästina den Rücken kehrte. Arendt wiederum spricht für die deutsch-jüdische Exilgesellschaft in New York, die voller Tatendrang versuchte, sich eine neue kulturelle und intellektuelle Heimat zu schaffen. Schockens Festhalten an der Vorkriegszeit in Deutschland wurde von diesen Kreisen kritisch betrachtet.

Dennoch nahm Hannah Arendt im August 1946 Schockens Angebot an, als Lektorin für moderne Literatur für den Verlag zu arbeiten. Strauß wurde nicht entlassen; er musste nach einem Herzinfarkt aus gesundheitlichen Gründen seine Stelle bei Schocken Books aufgeben. ${ }^{45}$ An seiner Stelle wurden Arendt und Nahum Glatzer, er als verantwortlicher Lektor für hebräische und jüdische Literatur, eingestellt. ${ }^{46}$ Der Verlag zog zeitgleich in größere Räumlichkeiten im selben Gebäude an der Fifth Avenue 565 um. ${ }^{47}$ Trotz Arendts Vorbehalten Schocken gegenüber startete sie voller Energie in ihre neue Arbeit. So schrieb sie an Karl Jaspers, dass diese ihr Freude bereite. Schocken, den sie in einem früheren Brief an Jaspers als „Bismarck “48 bezeichnete, erscheint in diesem Brief in einem ganz anderen Licht. Arendt beschreibt ihn als Mann „mit einem ausgesprochenen Sinn für Humor“, zudem habe er noch nicht versucht, sie zu „tyrannisieren “49. Möglicherweise resultierte ihr Umdenken daraus, dass sich Schocken im Sommer 1946 voller Tatendrang zeigte. In einem Brief an Martin Buber schrieb er im Juni 1946: „Ich stehe seit meiner Ankunft hier in einer dauernden Spannung, so wie es in den früheren Jahren, in den Zeiten des Aufbaus des Schocken-Konzerns oft gewesen ist. ${ }^{\text {"50 }}$

45 Vgl. Young-Bruehl: Hannah Arendt, S. 189.

46 Vgl. Glatzer: 80. Geburtstag, S. III.

47 Vgl. ebd., S.II.

48 Hannah Arendt an Karl Jaspers, 09.07.1946. In: Lotte Köhler / Hans Saner (Hrsg.): Hannah Arendt, Karl Jaspers. Briefwechsel 1926-1969. München / Zürich: Piper 1985, S. 83-88, hier S. 87.

49 Hannah Arendt an Karl Jaspers, 11.11.1946. In: Ebd., S. 100-103, hier S. 102.

50 Salman Schocken an Martin Buber, 06.06.1946. NLI, Buber Archiv, Ms. Var. 350/705. 
Arendts Biographin, Elisabeth Young-Bruehl, beschreibt Arendts Büro in den Verlagsräumlichkeiten als „Verkehrszentrum ${ }^{\text {“51 }}$, in dem deutsch- und englischsprachige Autoren und Editoren ein- und ausgingen. Dort habe sie, ein Jahr nach Ende des Krieges, endlich die Welt außerhalb ihres Emigrantenzirkels kennengelernt. So traf sie unter anderen T. S. Eliot, der für ein Treffen mit Salman und Theodor Schocken in den Verlag eingeladen wurde. Zu Arendts großer Enttäuschung konnte sich Schocken, wie so oft, nicht dazu entschließen, die Werke des späteren Nobelpreisträgers ins Verlagsprogramm aufzunehmen. ${ }^{52}$ Schocken verpasste durch sein oft langwieriges Abwägen viele Chancen, wichtige zeitgenössische Autorinnen und Autoren, aber auch Klassiker zu publizieren. ${ }^{53}$ Dennoch gelang es Schocken Books in den ersten drei Jahren des Bestehens, 21 Bücher auf den Markt zu bringen und die Reihe Schocken Library zu lancieren. Fünf weitere Bücher waren in Vorbereitung. Martin Buber war ebenso wie Gershom Scholem wichtig für den Verlag. Das erste Werk Scholems im New Yorker Verlag war Major Trends in Jewish Mysticism, das aus dem Hebräischen ins Englische übertragen wurde. ${ }^{54}$ Im April 1946 schloss der Verlag mit Scholem einen Vertrag, der nicht nur die Vereinbarung über das nächste Buch - die englische Ausgabe von Die sabbatianische Bewegung - umfasste, sondern auch Unterstützung für eine Reise in die USA. ${ }^{55}$ Die Korrespondenz im Nachlass Scholems in der israelischen Nationalbibliothek zeigt, dass die Beziehung zwischen Scholem und dem New Yorker Verlag über den Tod Salman Schockens hinaus Bestand hatte, auch wenn sie nicht immer frei von Spannungen war. Solange Arendt für den Verlag arbeitete, war sie für die ScholemPublikationen zuständig. Ihr wichtigstes und gleichzeitig zeitaufwändigstes Projekt bei Schocken Books waren jedoch die Kafka-Ausgaben.

Auch mit Kafka knüpfte Schocken an seine verlegerische Arbeit im Vorkriegsdeutschland an. 1934 zeigte sein Berliner Verlag in einem Prospekt die Publikation mehrerer Erzählungen Kafkas in Einzelausgaben an. Die Bestände und

51 Young-Bruehl: Hannah Arendt, S. 189.

52 Vgl. ebd., S. 190.

53 Vgl. u. a. Fishbane / Glatzer Wechsler: The Memoirs of Nachum N. Glatzer, S. 104.

54 Vgl. Gershom Scholem an Hannah Arendt, 16.12.1945. In: Itta Schedletzky (Hrsg.): Gershom Scholem. Briefe I, 1914-1947. München: Beck 1994, S. 305-309, hier S. 306.

55 Vgl. Vertrag zwischen Schocken Books Inc. New York und Gershom Scholem, 03.04.1946. NLI, Scholem Archiv, Arc 4 1599, 01 3050, Bd. 2. 
Veröffentlichungsrechte wurden von den Verlagen von Kurt Wolff und von Gustav Kiepenheuer übernommen. Diese Ausgaben wurden aus dem Verkauf genommen, als die Gesammelten Schriften erschienen. Es war Moritz Spitzers Idee, eine Gesamtausgabe Kafkas in das Verlagsprogramm aufzunehmen. Schocken war begeistert und schloss im Februar 1934 mit Max Brod, dem Verwalter des Kafka-Nachlasses, einen Vertrag. Brod wurde als Leiter der Herausgabe des Gesamtwerkes eingesetzt und Schocken bzw. seinen Nachkommen die Weltrechte am Werk Kafkas zugestanden. ${ }^{56}$ Noch im selben Jahr erschien Vor dem Gesetz als Band 19 der Schocken-Bibliothek und weniger als ein Jahr später brachte der Schocken Verlag die ersten vier Bände des Gesamtwerkes heraus, nämlich die Romane Amerika, Der Prozess und Das Schloss, sowie einen Band mit Erzählungen und kleinen Prosastücken. Jedoch verbot kurz nach Erscheinen der Bücher das Propagandaministerium den weiteren Verkauf, da das Werk Franz Kafkas auf die am 25. April 1935 erstellte ,Liste des schädlichen und unerwünschten Schrifttums gesetzt wurde. ${ }^{57}$ Schocken leistete dem Befehl nicht sofort Folge, wie ein Schreiben aus dem Büro des Präsidenten der Reichsschriftumskammer an die Geheime Staatspolizei vom 22. Juli 1935 zeigt. Die Reichsschrifttumskammer verlangte die sofortige Beschlagnahmung der im „Verlag noch vorhandenen Druckschriften dieses Verfassers “58. Der Verlag konnte erwirken, dass die Bestände nicht konfisziert, sondern für den Export freigegeben wurden. Moritz Spitzer reiste nach Prag, wo er den mit Brod abgeschlossenen Verlagsvertrag auf den Rechtsanwalt Josef Schlesinger übertrug. ${ }^{59}$ Der Vertrag zwischen Brod und Schlesinger wurde am 23. Mai 1936 abgeschlossen und beinhaltete auch das Verlagsrecht für alle noch nicht veröffentlichten Werke und Schriften. ${ }^{60}$ Schlesinger fungierte als Strohmann; er vereinbarte mit

56 Vgl. Dahm: Das jüdische Buch im Dritten Reich, S. 349. Eine Kopie des Vertrages zwischen dem Schocken Verlag Berlin, Max Brod und Julie Kafka liegt im Archiv der Schocken Books. Ebenfalls befindet sich dort eine Kopie des am 11. Juli 1924 ausgestellten Vertrags über den literarischen Nachlass Kafkas zwischen den Erben Franz Kafkas, also Hermann und Julie Kafka, und Max Brod. Dieser setzt Brod als Herausgeber des literarischen Nachlasses ein, regelt aber auch, dass bei Vertragsabschlüssen mit Verlegern die Zustimmung der Erben einholt werden muss. Zudem wurde die Aufteilung von Honoraren und Tantiemen geregelt.

57 Vgl. ebd., S.349-350.

58 Präsident der Reichsschrifttumskammer [Signatur unleserlich] an das Geheime Staatspolizeiamt, 22.07.1935. BArch, R58/1023.

59 Vgl. Dahm: Das jüdische Buch im Dritten Reich, S. 352.

$60 \mathrm{Vgl}$. Memo to Mr. S. Schocken from Max Strauss, 24.09.1946. SchB. 
der Prager Druck- und Verlagsanstalt Heinrich Mercy Sohn, dass der Verlag die Bücher übernehmen und die restlichen Bände drucken würde. Der Export wurde 1936 abgewickelt und 1937 erschienen bei Mercy die Bände fünf und sechs der Gesamtausgabe sowie die Kafka-Biographie von Max Brod ${ }^{61}$ Laut Akten im Archiv der Schocken Books trat Schlesinger am 28. Februar 1939 sämtliche Rechte aus dem Vertrag mit Brod an Schocken Publishing Ltd., also an Schockens Verlag in Palästina, ab. ${ }^{62}$

Die Weltrechte an sämtlichen bereits publizierten wie auch an den nicht publizierten Werken Kafkas lagen also beim Schocken Verlag Jerusalem, mit dem Schocken Books New York in der Folge Vereinbarungen über die Publikation in den USA traf. ${ }^{63}$ Basierend auf diesen Verträgen begannen wohl bereits Ende 1945 im New Yorker Verlag die ersten Vorbereitungen zur Übersetzung von Kafkas Werk. Im Zuge dieser Arbeit zeigte sich jedoch, dass in der Kriegszeit der in London beheimatete Verlag Secker \& Warburg, der ein dezidiert antifaschistisches und antikommunistisches Verlagsprogramm anbot, einige Werke Kafkas, u. a. The Castle publiziert hatte. ${ }^{64}$ Martin Secker hatte die Rechte von Kurt Wolff erworben, damit war der Verlag berechtigt, das Werk zu verlegen. Als Frederic Warburg und Roger Senhouse im Jahr 1936 die Restbestände des insolventen und daher liquidierten Verlages Martin Secker in den Secker \& Warburg-Verlag übernahmen, gingen die britischen Rechte an Kafkas Roman The Castle und an einem Band mit Kurzgeschichten, The Great Wall of China, an den neuen Verlag. Insofern war die englische Übersetzung von Das Schloss juristisch unproblematisch. Problematisch war jedoch die Beanspruchung von Rechten am restlichen Werk Franz Kafkas. Dessen waren sich Warburg und Senhouse zwar bewusst, dennoch wählten sie ab 1938 einen juristisch fragwürdigen Umgang damit.

Bis 1938 war die englische Ausgabe von Das Schloss bei der Leserschaft nicht sehr gefragt, aber dann begann sich das Buch immer besser zu verkaufen, sodass 1939 eine neue Auflage gedruckt werden musste. Dabei bemerkte Senhouse,

61 Vgl. Dahm: Das jüdische Buch im Dritten Reich, S.352. Auch Max Brods Schriften wurden indiziert.

62 Vgl. Memo to Mr. S. Schocken from Max Strauss, 24.09.1946. SchB.

63 Vgl. ebd.

64 Vgl. die Copyright-Angaben zu den unterschiedlichen englischen Übersetzungen des Werkes Kafkas in: John Hoyles: The Literary Underground. Writers and the Totalitarian Experience, 1900-1950. New York: St. Martin’s 1991, S.ix-xi. 
dass eine neue ,definitive' deutsche Version des Manuskriptes vorlag, die 66 Seiten mehr zählte als jene, die der englischen Übersetzung zugrunde lag. Es gelang den Verlegern, diese Version zu finden. Damit stellte sich jedoch die Frage, wer die Rechte an Kafka besaß. Es war zu dieser Zeit wohl nicht bekannt, dass Schocken die Weltrechte besaß. Der Aufenthalt Brods war nach dessen Flucht aus Prag im Jahr 1938 auch nicht zu eruieren, sodass man sich an den Kafka-Übersetzer Edwin Muir wandte. Aber Muir klärte die Sachlage nicht, obwohl er sich, wie er später eingestand, durchaus bewusst war, dass Schocken die Weltrechte besaß. Senhouse und Warburg entschlossen sich zu einer unorthodoxen Lösung, als sie 1941 erklärten, dass sie alle britischen Rechte an Kafkas publiziertem und nicht-publizierten Werk innehätten und sie eine definitive und komplette Ausgabe des Werkes zu publizieren beabsichtigen. Diese Erklärung publizierten die Verleger nach eigenen Angaben im Times Literary Supplement. ${ }^{65}$ Es gelang ihnen, die Rechte an The Trial, America und The Metamorphosis von verschiedenen Verlagen zu erwerben, die sich bei ihnen meldeten. Ansonsten wurden sie jedoch von niemandem kontaktiert. Erst 1944 trat Brod mit den Verlegern in Kontakt, der klarstellte, dass Salman Schocken sämtliche Rechte an Kafka besaß. Brod und Schocken waren erzürnt über das Verhalten der beiden Verleger, zumal sie sich erst im Januar 1945 direkt mit Schocken in Verbindung setzten. Als Schocken im Sommer 1945 nach London reiste, um dort an Sitzungen teilzunehmen, kam es zu einem Treffen zwischen ihm und Senhouse, das wenig erfolgreich verlief. ${ }^{66}$

Als Schocken Ende 1945 bei Edwin Muir, der Kafka bereits für Warburg \& Secker ins Englische übertrug, die Übersetzung der ,kleinen Erzählungen' in Auftrag gab, eskalierten die Auseinandersetzungen. Muir, der 1943 verschwieg, dass er von Schockens Vertrag mit Brod wusste, stellte sich auf die Seite von Senhouse und Warburg. Zudem weigerte er sich, an der Übersetzung zu arbeiten, solange sich die beiden Verlage nicht über die Publikationspläne verständigt hätten. ${ }^{67}$ Die Korrespondenz zwischen Schocken Books New York und Secker \& Warburg, die im Archiv des New Yorker Verlages einzusehen ist, dokumentiert die Verhandlungen, die sich bis ins Jahr 1947 hinzogen. Die

65 Diese Anzeige ließ sich nicht auffinden.

66 Vgl. Frederic Warburg: All Authors Are Equal. The Publishing Life of Frederic Warburg, 1936-1971. London: Hutchinson 1973, S. 59-70.

67 Vgl. Edwin Muir an Salman Schocken, 18.01.1946. SchB. 
Einigung, zu der man kam, sah vor, dass die beiden Verlage bei gewissen Werken kooperierten, die Rechte jedoch bei Schocken blieben.

Schocken Books strebte die Herausgabe sämtlicher Werke und Schriften Kafkas an. Man ließ nicht nur die bekannten Werke übersetzen, ${ }^{68}$ sondern begann auch aktiv nach der Korrespondenz Franz Kafkas zu suchen. Von Brod wusste Salman Schocken, dass Kafkas frühere Verlobte, Felice Bauer ${ }^{69}$ noch Briefe besaß, und er nahm an, dass auch Kafkas Familie einen Teil seiner Korrespondenz aufbewahrte. Zudem erfuhr er, dass ein Konvolut von Briefen an eine ,tschechische Schauspielerin - es sollte sich herausstellen, dass es sich dabei um den Briefwechsel zwischen Kafka und der tschechischen Journalistin und Übersetzerin Milena Jesenká ${ }^{70}$ handelte - in einem Prager Safe liege. Kafka und Jesenká lernten sich 1920 kennen und schnell entwickelte sich eine intensive Freundschaft. Erst der Briefwechsel zeigte jedoch, wie tief die Beziehung zwischen den beiden ging. Willy Haas ${ }^{71}$, dem Jesenká die Briefe von Kafka anvertraut und der diese aufbewahrt hatte, war der Editor der englischen Übersetzung der Briefe und der spätere Herausgeber der deutschen Originale. Er schrieb, dass sich in den Briefen „ein Liebesroman, eine Orgie an Verzweiflung, Seligkeit, Selbstzerfleischung und Selbsterniedrigung "72 offenbare. Schocken war sich sicher, dass Willy Haas ihm gerne die Briefe überlassen würde. ${ }^{73} \mathrm{Im}$ Juni 1947 schrieb Haas an Kurt Wolff, dass die Briefe in London eingetroffen seien, dass jedoch Ernst Pollack, Jesenkás erster Mann, mit dem sie während der Beziehung mit Kafka verheiratet war, Einwände gegen die Publikation erhoben hätte. ${ }^{74}$ Hannah Arendt, die im Verlag mit Kafkas Schriften betraut war, stand in den nächsten Monaten im konstantem Kontakt mit Wolff und Haas. Letzteren beauftragte sie mit der Edition des Materials, obwohl weiterhin nicht klar war, wann und in welchem Umfang die Briefe würden publiziert werden

68 Vgl. Salman Schocken an Edwin Muir, 06.06.1946. SchB.

69 Kafkas Briefe an Felice erschienen 1967.

70 Milena Jesenká (1896-1944) war Publizistin, Journalistin und Übersetzerin, auch von Texten Kafkas. Jesenká starb 1944 im Konzentrationslager Ravensbrück.

71 Willy Haas (1891-1973) war u. a. Herausgeber der Herder-Blätter in Prag und später Kritiker in Berlin und Verleger von Die literarische Welt (gemeinsam mit Ernst Rowohlt), er gehörte zu jenem Kreis in Prag, dem auch Franz Kafka und Max Brod angehörten.

72 Willy Haas (Hrsg.): Franz Kafka. Briefe an Milena. Berlin: S. Fischer 1975, Klappentext.

73 Vgl. Salman Schocken an Edwin Muir, 06.06.1946. SchB.

74 Vgl. Kopie des Briefes von Willy Haas an Kurt Wolff, 27.07.1947. SchB. 
können. ${ }^{75}$ Nach längeren Verhandlungen wurden sich Haas und Arendt einig und Haas begann mit der Auswahl der zu publizierenden Briefe. ${ }^{76}$ Die Übersetzungsarbeiten wurden jedoch erst nach Arendts Zeit bei Schocken Books 1951 in Auftrag gegeben. Warum es zu dieser langen Verzögerung kam, ist auf Grundlage des überlieferten Materials nicht mehr zu eruieren. Nach Beratungen mit Secker \& Warburg wurde James Stern mit der Übersetzung der Briefe beauftragt. ${ }^{77}$ Die beiden Verlage brachten die Briefe in Kooperation heraus, wobei die Rechte bei Schocken lagen. ${ }^{78} 1952$ erschienen die Briefe in Deutsch und ein Jahr später in englischer Übersetzung von James und Tania Stern bei Schocken Books New York. ${ }^{79}$

Kafka war zentral für Schocken Books New York und Salman Schocken blieb bis zu seinem Tod in die Herausgabe der Schriften involviert - auch dann noch, als er sich im Laufe der 1950er Jahre sukzessive aus dem Verlag zurückzog. Als dieser zwischen 1956 und 1958 in Kooperation mit Kurt Wolff und dem Verlag Secker \& Warburg Description of a Struggle ${ }^{80}$ in der Übersetzung von Tania und James Stern vorbereitete, brachte sich Schocken vor allem in Fragen der Typographie und des Drucks ein. Wie in seinem Berliner Verlag legte er Wert auf eine dem Text entsprechende Type, auf die Qualität des Schriftbildes und auf hochwertiges Papier. ${ }^{81}$ Im Archiv des Verlages sind Druckfahnen überliefert, in denen Salman Schocken handschriftlich Korrekturen anbrachte. Warum Kafka für Salman Schocken so wichtig war, ist aus der Korrespondenz nicht zu eruieren, wir können nur Vermutungen anstellen.

Der Autor erinnerte ihn sicherlich an seinen Berliner Verlag, der Kafka erstmals in einem größeren Umfang herausgab. Wie viele Bücher, die zu Lebzeiten Salman Schockens bei Schocken Books erschienen, waren auch die Hauptwerke

75 Vgl. Hannah Arendt an Willy Haas, 10.11.1947. SchB.

76 Vgl. Willy Haas an Hannah Arendt, 18.04.1948. SchB.

77 Vgl. James Stern an Salman Schocken, 16.01.1951. SchB.

$78 \mathrm{Vgl}$. Briefwechsel zwischen Salman Schocken, James Stern und Frederic Warburg, 07.03.1951 bis 20.01.1952. SchB.

79 Haas wählte für die ersten Ausgaben die Briefe aus, die publiziert wurden. Erst in die deutsche Ausgabe von 1986 und die englische Neuübersetzung von 1990 wurden alle Briefe aufgenommen.

80 Erschienen 1958.

81 Vgl. die Korrespondenz zwischen Salman Schocken, Regina Klapper, Kurt Wolff und Klaus Gemming, 15.11.1956 bis 20.02.1958. SchB. 
Kafkas ein Zurückblicken auf seine deutsche Verlegerlaufbahn. Dass Schocken die Weltrechte am Werk Kafkas besaß, spielte in den Publikationsplänen sicherlich eine weitere zentrale Rolle. Als Geschäftsmann muss es ihn gereizt haben, mit unterschiedlichen Personen zu verhandeln, um schließlich seine Vision umsetzen zu können: die Publikation sämtlicher Schriften Kafkas. Schocken war aber auch ein Sammler, dem daran lag, Manuskripte ausfindig zu machen. Dass er dabei wie beim Erwerb von Büchern für seine Bibliothek auf Spezialisten angewiesen war, störte ihn kaum. Bei der Suche nach bislang unbekannten Manuskripten und Briefen, aber auch durch seine verlegerische Arbeit wurde Schocken Mitglied des informellen Kreises von Kafka-Spezialisten. Schocken, der zu dieser Zeit von seinen bisherigen Weggefährten entfremdet war, war wieder Teil eines Netzwerkes. Die Vorbereitung der Publikationen Kafkas ermöglichte ihm die Art von Kontakten, die ihm so wichtig war. Darüber hinaus muss Schocken fasziniert von Kafkas Texten gewesen sein. Seine Bewunderung für den tschechischen Autor wird unter anderem von Frederic Warburg erwähnt. $^{82}$

Das hohe Maß an Entscheidungskraft und Energie, die Schocken in die Publikation der Kafka-Texte steckte, kontrastierte mit dem Zögern und Herausschieben anderer Projekte im Verlag. Arendt kritisierte ihn diesbezüglich gegenüber Jaspers sogar als „unerträglich untüchtig “ ${ }^{83}$. Diese Bemerkung stammte aus der Zeit, nachdem sie ihre Arbeit bei Schocken bereits niedergelegt hatte. Schocken war zwar 1946 noch voller Tatendrang und initiierte neben der Publikation von Kafkas Werk auch die der Schocken Library, also der englischen Version der erfolgreichen Schocken-Bibliothek. Sonst konnte er sich aber kaum dazu durchringen, Neues anzugehen. Arendts Trennung von Schocken Books beruhte schließlich auf Schockens Weigerung, das Werk Benjamins herauszubringen.

Walter Benjamin, der sich am 26. September 1940 im spanischen Grenzort Portbou das Leben nahm, war ein enger Freund Hannah Arendts. Die Publikation von Benjamins Werk war ihr ein großes Anliegen und sie hoffte, mit Schocken einen Verleger gefunden zu haben, der diesen Wunsch erfüllen würde.

82 Vgl. Warburg: All Authors Are Equal, S. 68.

83 Hannah Arendt an Gertrud und Karl Jaspers, 04.12.1948. In: Köhler / Saner (Hrsg.): Hannah Arendt, Karl Jaspers, S. 160. 
Die Problematik bei Arendts Veröffentlichungsplänen war nicht nur Schockens Zögern, das später in deutliche Ablehnung umschlug, sondern auch die zahlreichen Unklarheiten, was die Geschichte und die Rechte an Benjamins Nachlass anbelangten. Arendt ging davon aus, dass Benjamin seinen Nachlass dem Institut für Sozialforschung testamentarisch vermachte. Die Arbeit des Frankfurter Instituts wurde von Max Horkheimer, Theodor W. Adorno und anderen an der Columbia University fortgeführt. Der Nachlass sei, so schreibt sie an Scholem, in New York angekommen und dort habe „niemand [...] ihn je zu Gesicht bekommen. [...] Horkheimer behauptet, ihn in einem Safe zu haben; nur wo der Safe ist, ist nicht festzustellen. ${ }^{\text {“84 }}$ Sie weiß zu diesem Zeitpunkt noch nicht, dass es Benjamins Schwester gelang, den Anweisungen ihres Bruders folgend, den bedeutendsten Teil des Nachlasses ${ }^{85}$ über den Rechtsanwalt Martin Domke Adorno zukommen zu lassen. ${ }^{86}$

In der unmittelbaren Nachkriegszeit schien auch nicht klar gewesen zu sein, wer die Rechte am unveröffentlichten Material Benjamins hatte, das nicht im Besitz des Instituts, sondern sich in den Händen Scholems, Arendts und anderer befand. ${ }^{87}$ Arendt und Adorno schienen um gewisse Teile des Nachlasses zu konkurrieren. Arendt wollte im Schocken Verlag die ,geschichtsphilosophischen Thesen 'veröffentlichen. ${ }^{88}$ Sie war im Besitz einer handschriftlichen Fassung und offenbar auch eines Typoskripts seiner Thesen Über den Begriff der

84 Hannah Arendt an Gershom Scholem, 22.09.1945. In: Knott (Hrsg.): Hannah Arendt und Gershom Scholem, S.78.

85 Benjamin hat seinen Nachlass aufgeteilt, ein Teil ging über seine Schwester zu Adorno nach New York, einen weiteren Teil ließ er in seiner letzten Wohnung in Paris zurück. Dieser wurde von der Gestapo beschlagnahmt, nach Kriegsende von der Roten Armee nach Moskau gebracht, 1957 an das Deutsche Staatsarchiv der DDR und 1972 an die Akademie der Künste (Ost) gegeben. Erst 1996 kam dieser Nachlassteil nach Frankfurt am Main ins Institut für Sozialforschung. Wichtige Manuskripte und Typoskripte zum Passagenwerk und zu Baudelaire ließ Benajmin vor seiner Flucht von Georges Bataille in der Bibliothèque Nationale verstecken. Außerdem hat Scholem bereits zu Benjamins Lebzeiten viele seiner Manuskripte bekommen und bewahrte sie auf (heute in der NLI als Teil des Scholem-Nachlasses archiviert, NLI, ARC. 4 1598). Ich danke Nadine Werner für diese wichtigen Hinweise.

86 Vgl. Rolf Tiedemann / Hermann Schweppenhäuser: Editorischer Bericht. In: Walter Benjamin: Gesammelte Schriften, Bd. I.2, hrsg. v. Rolf Tiedemann / Hermann Schweppenhäuser. Frankfurt am Main: Suhrkamp 1991, S.751-796, hier S.759.

87 Vgl. Gershom Scholem an Hanna Arendt, 16.12.1945. In: Knott (Hrsg.): Hannah Arendt und Gershom Scholem, S. 82-83.

88 Vgl. Hannah Arendt an Gershom Scholem, 21.04.1946. In: Ebd., S. 105. 
Geschichte. Das Typoskript übergab sie 1941 Adorno zur Abschrift. Während die Abschrift überliefert ist, ging Arendts Typoskript verloren. ${ }^{89}$ Der dortige Umgang mit Benjamins Material beunruhigte Hannah Arendt zutiefst. Ursprünglich wollte Arendt Kopien des Manuskripts an Schocken schicken. Sie hatte die Hoffnung, dass dieser es im Jerusalemer Verlag herausbringen würde. Da der Krieg die Postverbindung zwischen den USA und Palästina unterbrach, beschloss sie, zunächst das Ende des Krieges abzuwarten. ${ }^{90}$ Nach dem Krieg versuchte sie, Schocken davon zu überzeugen, die ,Thesen' und weitere Schriften Benjamins zu publizieren. Sie schrieb an Scholem:

Ich hatte eine kleine Hoffnung, dass Schocken sich vielleicht doch zur Herausgabe entschließt und ich dann einen Druck auf sie [gemeint sind Adorno und Horkheimer, Anm. der Verf.] ausüben kann. Schocken aber, wie Sie wissen, beschäftigt sich ausschließlich mit den, ewigen Werten' des Judentums, rechnet Benjamin nicht darunter und erklärte mir wörtlich, dass für ihn selbst Kafka schon ein borderline case wäre. ${ }^{91}$

Als sie ihre Aufgabe im Verlag begann, war sie zunächst noch ganz positiver Stimmung. „Im Verlag geht es gut“, schrieb sie wiederum an Scholem, „das heißt es macht mir einen ungeheuren Spaß.“92 So nahm sie neben ihren anderen Verpflichtungen im Verlag die Arbeit an Benjamin auf. Im Januar 1946 schrieb sie an Scholem, dass sie „mitten drin in der Arbeit“ ${ }^{\text {“93 }}$ sei. Schocken stand inzwischen hinter dem Projekt, auch wenn er es verschieben wollte, was Arendt entgegenkam, da weiteres, ihr unbekanntes Material am Institut für Sozialforschung vorhanden sei. ${ }^{94}$ In der Zwischenzeit zeigte sich auch Adorno begeistert davon, dass Schocken Books eine Ausgabe der Schriften Benjamins plante. Jedoch verdeutlichte er, dass er sich als „qualifizierter für die Aufgabe ${ }^{\text {(95 }}$

89 Vgl. Walter Benjamin: Werke und Nachlaß. Kritische Gesamtausgabe, Bd. 19, hrsg. v. Gérard Raulet. Berlin: Suhrkamp 2010, S. 168.

90 Vgl. Young-Bruehl: Hannah Arendt, S. 166-167.

91 Hannah Arendt an Gershom Scholem, 22.09.1945. In: Knott (Hrsg.): Hannah Arendt und Gershom Scholem, S. 78.

92 Hannah Arendt an Gershom Scholem, 09.09.1946. In: Ebd., S. 126-128, hier S. 126.

93 Hannah Arendt an Gershom Scholem, 07.01.1947. In: Ebd., S. 149-150, hier S. 149.

94 Vgl. Hannah Arendt an Gershom Scholem, 25.02.1947. In: Ebd., S. 151-152, hier S. 151.

95 Kopie des Briefes von Theodor Adorno an Hannah Arendt, 01.03.1947. NLI, Scholem Archiv, Arc. 4159910080. 
als Arendt betrachtete. In diesem Brief tritt auch die Konkurrenz um den Nachlass zutage. Er schreibt:

Vielleicht ist es nicht unwichtig für den Plan, zu wissen, dass Walter Benjamin mir seinen gesamten literarischen Nachlass anvertraut hat. [...] Noch als ich Benjamin zum letzten Male sah, Januar 1938 in San Remo, war zwischen uns vereinbart, dass ich eine grössere Gesamtdarstellung seiner philosophischen Intentionen geben sollte. Mir erscheint die Ausführung dieses Plans, den wir bis in Einzelheiten erörtert hatten, nicht bloss die Erfüllung einer bindenden Pflicht, sondern ich glaube überdies nicht unbescheiden zu sein, wenn ich mich als qualifizierter für die Aufgabe betrachte denn irgendeinen anderen - sowohl wegen meiner intimen Vertrautheit mit Benjamins geistiger Landschaft wie wegen der zentralen Übereinstimmung unserer Philosophie. Vielleicht würde die Ausgabe den Anlass bieten, jenen Plan zu verwirklichen. ${ }^{96}$

Arendt war bereit, eine Einleitung von Adorno aufzunehmen, da sie damit rechnete, sonst die Druckrechte nicht zu erhalten. ${ }^{97}$ Scholem stimmte Arendt zu; er wies aber darauf hin, dass man Adorno nicht zu viel Platz einräumen solle. ${ }^{98}$ Während Arendt und Scholem fest damit rechneten, dass die Ausgabe bei Schocken Books erscheinen würde, hatte Salman Schocken andere Pläne. Da man im Verlag „mit unserem eigentlichen jüdischen Programm um viele Monate um Rückstand [ist], verschieben sich auch die Termine für dieses zweite Gebiet des Schocken Verlages. “ ${ }^{99}$ Er habe aber mit großem Interesse die ihm aus Palästina zugesandten Benjamin-Aufsätze gelesen, ${ }^{100}$ und glaube, dass das Buch über Benjamin „bedeutend sein werde und ein für den Verlag wichtiges Buch werden

96 Kopie des Briefes von Theodor Adorno an Hannah Arendt, 01.03.1947. NLI, Scholem Archiv, Arc. 4159910080.

97 Vgl. Hannah Arendt an Gershom Scholem, 25.02.1947. In: Knott (Hrsg.): Hannah Arendt und Gershom Scholem, S. 152.

98 Vgl. Gershom Scholem an Hannah Arendt, 16.03.1946. In: Ebd., S. 153.

99 Salman Schocken an Gershom Scholem, 24.03.1947. NLI, Scholem Archiv, Arc. 4 1599, 013050, Bd. 10.

100 Scholem hatte unveröffentlichtes Material aus seinem Besitz an Arendt gesandt. Vgl. Gershom Scholem an Hannah Arendt, 25.02.1947. In: Knott (Hrsg.): Hannah Arendt und Gershom Scholem, S. 151. 
kann. “101 Schocken fügte aber hinzu, dass viele der Aufsätze gekürzt werden müssten, zumal das US-amerikanische Lesepublikum nicht mit allen Themen vertraut sei. Und schließlich seien die Fragen des Copyrights noch nicht geklärt. ${ }^{102}$

Bei Schocken muss um diesen Zeitpunkt herum ein Umdenken stattgefunden haben, denn schon im Mai 1947 zweifelte Arendt daran, ob er den BenjaminBand überhaupt noch bringen würde. ${ }^{103}$ Im Januar kam dann die Ernüchterung: Schocken hatte beschlossen, Benjamin nicht zu drucken. Sie schrieb an Scholem, der offizielle Grund sei, dass er „zu high-brow ist und vermutlich nicht ,jüdisch ' genug. “" ${ }^{104}$ Sie vermutete Ranküne gegen sich selbst, aber wichtiger noch sei, dass

der Alte naturgemäß Benjamin nicht richtig verstehen kann; ist einfach zu schwer; und dass er gegen Leute die so schreiben, dass er sie nicht versteht, und wäre es Kant persönlich, eine starke Ranküne hat und vermutet, das selbige das nur getan haben, um ihm eins auszuwischen. ${ }^{105}$

Nach diesen für Hannah Arendt niederschmetternden Entwicklungen verlor sie jegliches Interesse, für Schocken zu arbeiten. Bereits Ende 1947 klagte sie gegenüber Jaspers über mangelnden Gestaltungsspielraum im Verlag. „Der Alte ${ }^{\text {"106 }}$ sei schwierig und zudem unterdrücke er seine Söhne. Benjamin war

101 Salman Schocken an Gershom Scholem, 24.03.1947. NLI, Scholem Archiv, Arc. 4 1599, 013050, Bd. 10.

102 Ebd.

103 Vgl. Hannah Arendt an Gershom Scholem, 14.05.1947. In: Knott (Hrsg.): Hannah Arendt und Gershom Scholem, S. 168.

104 Hannah Arendt an Gershom Scholem, 26.01.1948. In: Ebd., S. 184-185.

105 Ebd. Zu einem früheren Zeitpunkt gab Schocken gegenüber Scholem zu verstehen, dass er Benjamins Texte größtenteils nicht verstehe, vgl. Gershom Scholem an Walter Benjamin, 11.04.1934. In: Walter Benjamnin - Gershom Scholem. Briefwechsel 1933-1940, S. 47. Benjamin versuchte 1934 durch die Vermittlung von Scholem im Schocken Verlag zu publizieren. Trotz des großen Einsatzes von Scholem, so schrieb er in der Sache auch direkt an Moritz Spitzer, vgl. Gershom Scholem an Walter Benjamin, 19.04.1934. In: Ebd., S. 135, ließ sich Schocken nicht davon überzeugen. Vgl. Walter Benjamin an Gershom Scholem, 06.05.1934. In: Ebd., S. 141.

106 Hannah Arendt an Karl Jaspers, 04.09.1947. In: Köhler/Saner (Hrsg.): Hannah Arendt, Karl Jaspers, S. 135. 
nicht das einzige Projekt, das Arendt bei Schocken nicht durchbringen konnte, wenn auch das für sie wichtigste. Etwas früher im Jahr 1947 wies Schocken den Vorschlag zurück, Eugen Kogons Der SS-Staat auf Englisch zu verlegen. ${ }^{107}$ Auch Spinoza wollte er nicht publizieren, da "Spinoza kein Jude war. ${ }^{108}$ Ihre anfängliche Freude über ihre Arbeit bei Schocken Books schlug durch diese Erfahrungen in Frustration um, sodass Arendt sich im Sommer 1948 dazu entschloss, den Verlag zu verlassen.

$\mathrm{Zu}$ Lebzeiten Salman Schockens war Schocken Books eine Hommage an den Berliner Verlag. Schocken hielt an seinen Ideen fest und publizierte, wie bereits in Deutschland, klassische jüdische Texte unterschiedlicher Herkunft - jetzt nur in englischer Übersetzung -, darunter die Werke von Buber, Scholem, Kafka und Agnon, aber auch Editionen von Midraschim und anderen religiösen Texten. ${ }^{109}$

Schocken Books war ein Neuanfang für Schocken in New York. Nach dem Ausschluss aus seinem bisherigen sozialen Netzwerken brachte die Verlagsarbeit ihn mit Menschen zusammen, die ähnliche Interessen verfolgten: die Herausgabe von jüdischen Bücher. Vor allem das Kafka-Projekt brachte ihn zeitweilig wieder ins Zentrum eines Netzwerkes. Seine finanziellen Mittel erlaubten ihm, Manuskripte zu erwerben, Übersetzer einzustellen und die Bücher zu publizieren, die ihn interessierten. Noch einmal konnte er seine Interessen verfolgen jedoch hatte, was im Deutschland der 1930er Jahre innovativ und mutig war, in den USA der Nachkriegszeit eine andere Bedeutung. Sein Verlagsprogramm wurde zwar als interessant, zugleich aber als wenig innovativ wahrgenommen. Neuen Autorinnen und Autoren sowie Texten gegenüber zeigte er sich verschlossen. Hannah Arendt kämpfte als Lektorin vergebens darum, Texte auf den Markt zu bringen, von deren Relevanz für die Leser der Nachkriegszeit sie überzeugt war. Schocken blieb in seiner deutschen Vergangenheit gefangen und schaffte sich mit dem Verlag eine Insel, die sein Werk in Berlin bewahrte und fortsetzte. Der New Yorker Schocken Verlag war kein Relikt aus dem 19. Jahrhundert, wie Arendt 1945 spöttisch bemerkte, sondern aus einer anderen verlorenen Zeit: dem Berlin der 1930er Jahre.

107 Vgl. Hannah Arendt an Karl Jaspers, 03.05.1947. In: Köhler / Saner (Hrsg.): Hannah Arendt, Karl Jaspers, S. 123.

108 Hannah Arendt an Karl Jaspers, 07.09.1952. In: Ebd., S.236.

109 Die Gesamtbibliographie bis 1957 findet sich im Anhang. 


\subsection{Schocken / Merkur. Ein kurzes Gastspiel in Deutschland}

Ein zweites Nachkriegsprojekt Schockens war sein Konzern, den er 1938 unter Zwang verkaufte. Zu diesem Zeitpunkt umfasste Salman Schockens Konzern 19 Filialen, eine Einkaufszentrale, die I. Schocken Söhne GmbH in Zwickau, zahlreiche Eigenfabrikationsstätten wie die Strumpffabrik oder die Rollladenmanufaktur, eine Baufirma, ein technisches Warenprüflabor, die Feina Feinkostund Nahrungsmittel GmbH in Berlin, ein Einkaufshaus für Lebensmittel, ein Erholungsheim in Rautenkranz sowie wertvolle Grundstücke. ${ }^{110} 1938$ kam es durch die Vermittlung der beiden Amsterdamer Banken Rhodius Koenigs und Hollandsche Koopmansbank zum Verkauf an eine deutsche Bankengruppe. Der Preis, den die deutsche Bankengruppe für die Übernahme zahlte, lag weit unter dem eigentlichen Wert des Konzerns. Nach dem Verkauf wurde der Name der vormaligen Eigentümer aus der Firmenbezeichnung entfernt und durch ,Merkur' ersetzt. ${ }^{111}$

Zwar wurde Schockens Name im Unternehmen ausgelöscht, die von ihm aufgebaute Konzernstruktur sowie das von ihm angeregte Erscheinungsbild als Teil der Unternehmensidentität überdauerten jedoch die sogenannte Arisierung ${ }^{112}$. Bereits 1934 hatte Salman Schocken den rassisch nicht verfolgten Wilhelm Fonk, ein Volkswirtschaftler und ehemaliges Mitglied des Reichstages für die Zentrumspartei, in den Konzern berufen. Fonk war Leiter der Verwaltung und zuständig für die Repräsentanz des Konzerns gegenüber den Behörden. ${ }^{113}$ Nach

110 Vgl. Fuchs: Ein Konzern aus Sachsen, S. 177-178, 262.

111 Zur Geschichte des Konzerns in den Jahren 1938 bis 1949 vgl. Mahrer: Schocken und Merkur. In: Fischer / Riemer / Schüler-Springorum (Hrsg.): Juden und Nicht-Juden nach der Schoah.

112 Die Problematik des Begriffes ,Arisierung haben u. a. Benno Nietzel und Christoph Kreutzmüller dargelegt. Die Forschung hat mit dem Begriff eine rassistische Terminologie der nationalsozialistischen Herrschaft als Forschungs- und Untersuchungsbegriff übernommen. Der Begriff war bereits in den 1920er Jahren in völkischen Kreisen in Gebrauch und wurde ab 1936 von Partei- und Staatsstellen für die Übertragung von, jüdischem ' in , arisches Vermögen und Besitz verwendet. Es kam nie zu einer rechtlich verbindlichen Definition. Vgl. Nietzel: Die Vernichtung der wirtschaftlichen Existenz der deutschen Juden 1933-1945; Christoph Kreutzmüller: Vernichtung der jüdischen Gewerbetätigkeit im Nationalsozialismus. Abläufe, Blickwinkel und Begrifflichkeiten. In: Docupedia-Zeitgeschichte, 04.11.2016. https://docupedia.de/zg/Kreutzmueller_vernichtung_der_juedischen_Gewerbetaetigkeit_ v1_de_2016 (Zugriff am 12.02.2020). In der vorliegenden Untersuchung wird der Begriff im Wissen um die Problematik stets als Zitat, nicht als Analysebegriff verwendet.

113 Vgl. Fuchs: Ein Konzern aus Sachsen, S.228. 
einem Bericht des Vorstands der Merkur Aktiengesellschaft aus dem Jahr 1945 trug die Wahl Fonks maßgeblich dazu bei, dass Schockens Visionen den Nationalsozialismus weitgehend überdauerten. Fonk und das übrige Direktorium, das ebenfalls von Schocken mit nichtjüdischen Vertrauensmännern unterschiedlicher Herkunft besetzt wurde, hielten nicht nur an Schockens Philosophie fest, sondern verhinderten ebenfalls die Aufnahme von NS-Funktionären in den Betrieb. ${ }^{114}$

Nach Ende des Krieges zweifelten die Direktoren der Merkur auch nicht daran, dass die ursprünglichen Besitzverhältnisse wiederherzustellen wären. Diese Rückerstattung erwies sich als höchst komplexer Prozess, da das Bankenkonsortium unter der Führung der Deutschen Bank und der Reichs-KreditGesellschaft den Aktienbesitz weiterverkauft hatte. Enteignungen der in Sachsen liegenden Häuser und die Quasi-Enteignung der restlichen, sich in der sowjetischen Besatzungszone befindenden Filialen, die Zerstörung weiterer Häuser im Krieg, aber auch die Zerstreuung des Aktienbesitzes erschwerten eine reibungslose Rückgabe des Konzerns. ${ }^{115}$ Schließlich wurden die in der amerikanischen Zone liegenden Überreste der einstigen Warenhauskette im September 1949 der Familie Schocken zurückerstattet. ${ }^{116}$

In 40 Prozent der Fälle, in denen in Deutschland ein jüdischer Betrieb im Zuge der Enteignungspolitik auf einen nichtjüdischen Inhaber überging - laut

114 Vgl. Bericht des Vorstandes der Merkur Aktiengesellschaft an den Aufsichtsrat, Ende 1945. SchA, Konzern, M 2, S.3-4.

115 Vgl. Fuchs: Ein Konzern aus Sachsen, S. 268-287. Die finanzielle Entschädigung für die verlorenen Geschäfte in der sowjetischen Zone wurde erst nach der Wiedervereinigung erlangt, resp. vor Gericht erstritten. Im Juni 2014 sprach die 4. Kammer des Verwaltungsgerichts Berlin den Erben von Salman Schocken 30 Millionen Euro Entschädigung sowie 20 Millionen Euro entgangener Zinsen zu. Bereits in den 1990er Jahren erhielt die Erbengemeinschaft 30 Millionen D-Mark an Entschädigung für das Chemnitzer Kaufhaus Schocken im Zuge der Privatisierung von ehemaligem DDR-Staatseigentum. Mit dem Berliner Urteil von 2014 fand das Verfahren nach über 20 Jahren einen Abschluss. Vgl. David Böcking: Deutschland muss Erben von Kaufhauskette entschädigen. In: Spiegel Online, 12.06.2014. http://www.spiegel.de/wirtschaft/unternehmen/schocken-deutschland-musserben-von-kaufhauskette-entschaedigen-a-974796.html (Zugriff am 19.02.2020); Marcus Jung: Kaufhaus Schocken. Prozessrechtler Schmitz erreicht Entschädigung für Erben. In: juve. Neues aus dem Wirtschaftsanwaltsmarkt, 16.06.2014. http:/www.juve-verlag.at/nachrichten/ verfahren/2014/06/kaufhaus-schocken-prozessrechtler-schmitz-erreicht-entschadigung-furerben (Zugriff am 31.01.2017).

116 Vgl. Fuchs: Ein Konzern aus Sachsen, S. 272. 
Benno Nietzel wurden nach Schätzungen 70 bis 80 Prozent der jüdischen Betriebe nicht verkauft, sondern liquidiert ${ }^{117}$-, bereicherten sich die neuen Eigentümer und Geschäftsführer. Dies gelang aufgrund der Verfolgungssituation der vorigen jüdischen Eigentümer. Nur ein Teil der Fälle, in denen nichtjüdische Nachfolger die Notlage der jüdischen Geschäftsleute ausnutzten, wurden nach dem Krieg vor amerikanischen, britischen und französischen Gerichten verhandelt. Knapp 20 Prozent der Käufer verhielten sich gegenüber den jüdischen Besitzern juristisch und moralisch korrekt. ${ }^{118}$ Einer davon war Wilhelm Fonk, der, nach dem Verkauf des Schocken-Konzerns an eine deutsche Bankengruppe, die Geschäftsleitung des Konzerns übernahm. Fonk wurde, wie die übrigen Mitglieder der Geschäftsführung, von Salman Schocken, noch während dieser mehrheitlich die Besitzrechte hatte, gewählt und eingearbeitet, und er bemühte sich, den Konzern im Sinne seines Gründers weiterzuführen.

Die grundlegende und bewährte Struktur des Betriebes mit seiner zentralen Verwaltung in Zwickau wurde von Fonk belassen. Laut Fuchs, dem besten Kenner der Geschichte des Schocken-Konzerns, verstanden sich Fonk und die restlichen Geschäftsleiter der Merkur AG als Verwalter von Schockens Unternehmen. Dementsprechend zeigte sich auch im Umgang mit dem Personal eine bemerkenswerte Kontinuität. Zwar verließen noch unter Salman Schocken sämtliche jüdische Geschäftsleitungsmitglieder und Angestellte den Betrieb, dennoch zeigten sich klare Parallelen zwischen Schocken und Merkur. Salman Schocken verstand sich als Patron, der von seinen Mitarbeiterinnen und Mitarbeitern ein Höchstmaß an Einsatzbereitschaft verlangte, ihnen aber im Gegenzug in schwierigen Situationen beistand. Ganz ähnlich verhielt sich die Geschäftsleitung des Merkur-Konzerns gegenüber den Angestellten. Trotz großem Druck, der von den NS-Behörden auf den Konzern ausgeübt wurde, weigerte sich die Geschäftsleitung, ,politisch unerwünschte' Mitarbeitende zu entlassen. Solche Loyalität den eigenen Mitarbeiter*innen gegenüber war in dieser Zeit eine große Ausnahme. Sie zeigte sich auch darin, dass den Mitarbeitenden, die von den Nationalsozialisten inhaftiert wurden und schlimmstenfalls in einem Konzentrationslager interniert, ihr Gehalt weiter ausbezahlt wurde.

117 Vgl. Nietzel: Die Vernichtung der wirtschaftlichen Existenz der deutschen Juden 1933-1945, S. 585.

118 Vgl. Bajohr: ,Arisierung' in Hamburg, S. 315-319. 
Damit übernahm die Geschäftsleitung nicht nur die moralische Verantwortung, sondern ermöglichte den Familien auch das finanzielle Überleben.

Etwas weniger moralisch aufgeladen, aber ebenso wichtig war das Festhalten an der visuellen Identität des Konzerns. Salman Schocken legte größten Wert auf die typographische und architektonische Sprache seines Unternehmens. Dass Fonk die modernistische Gestaltung der Printsachen und der Innenarchitektur beibehielt, und sich nicht der völkischen Ästhetik der Machthaber anbiederte, zeigt den starken Willen, das Erbe des ehemaligen Inhabers zu bewahren.

Es bleibt zu fragen, warum gerade im Fall des Schocken-Konzerns in diesen zentralen Aspekten der Konzernidentität ein derart hohes Maß an Kontinuität zu verzeichnen ist. In den Quellen finden sich dazu keine expliziten Antworten. Überliefert ist die Aussage, dass die Mitglieder der Geschäftsleitung, die Salman Schocken als Vertrauensleute eingesetzt hatte,

die im Ausland lebenden Teilhaber, solange das möglich war, durch persönliche und schriftliche Berichte informierten. Die Herren Schocken wussten aus der jahrzehntelangen Zusammenarbeit, dass sie keine Nazis waren und auch nicht den Anschluss an die Nazis suchten. ${ }^{119}$

Die Antwort auf die Frage liegt in dieser Aussage verborgen. Die Schocken entgegengebrachte Loyalität und der darin begründete Versuch, den Konzern im Sinne des Gründers und ehemaligen Inhabers weiterzuführen, lag in der Charakterstärke Wilhelm Fonks und der restlichen Mitglieder der Geschäftsleitung. Die Gesamtgeschäftsleitung widerstand der Versuchung, Profit aus der Unrechtssituation zu schlagen. Sie bewahrte sich Menschlichkeit, Anstand und Charakterstärke in Zeiten der allgemeinen Entfesselung. Der Fall des Schocken-Konzerns resp. der Merkur AG verdeutlicht, dass die historischen Akteure - anders, als es oft dargestellt wird -, ein, wenn auch begrenztes, Maß an Handlungsspielraum besaßen. Dies war jedoch eher die Ausnahme; ein typisches Beispiel stellte der Wertheim-Konzern dar. Georg Wertheim schenkte sein Vertrauen dem NSDAP-Mitglied Emil Georg von Stauß und hoffte, dass dessen gute Verbindungen zur Regierung sich positiv auf seinen Konzern auswirken würden. Von Stauß aber drängte nicht nur Wertheim aus seinem

119 Bericht des Vorstandes der Merkur Aktiengesellschaft an den Aufsichtsrat, Ende 1945. Konzern, SchA, M 2, S.3-4. 
Konzern, er sorgte auch dafür, dass Grundstücke massiv unter Wert verkauft wurden. ${ }^{120}$ Der Wertheim-Konzern wurde 1937 für ,deutsch ‘ erklärt, nachdem Georg Wertheim den Konzern verließ. Bereits 1934 hatte er, auf Anraten von Emil Georg von Stauß - dem Generaldirektor der Deutschen Bank, Sympathisant der NSDAP schon vor 1933 und angeblicher Freund der Familie -, die Mehrheit der Aktien auf seine nichtjüdische Frau Ursula überschrieben, sie ließ sich später scheiden. ${ }^{121}$ Es war auch von Stauß, der Wertheim davon überzeugte, dass der Aktienübertrag das Bankenkonsortium, das dem stark defizitären Betrieb 1932 Kredite gewährte, ${ }^{122}$ nicht zufrieden stellte und daher ein Kuratorium den Konzern treuhänderisch verwalten solle. Ursula Wertheim zeigte sich im Geschäft nicht aktiv und überließ die Führung des Konzerns dem Kuratorium. Von Stauß, der dem Aufsichtsrat angehörte, forcierte in den nächsten Jahren den Verkauf eines großen Grundstückes an der Leipziger Straße, auf dem ein Regierungsgrundstück errichtet werden sollte. ${ }^{123}$ Schließlich trat Georg Wertheim am 1. Januar 1937 auf Druck seines angeblichen Freundes Emil Georg von Stauß als Aufsichtsratsvorsitzender zurück, gleichzeitig musste auch sein Neffe Fritz Sternberg seinen Posten als Syndikus aufgeben. Damit schied die Gründerfamilie aus dem Konzern aus. ${ }^{124}$

Zehn Jahre nach der Enteignung, im Jahr 1948, stellte Salman Schocken einen Rückerstattungsantrag beim Zentralamt Bad Nauheim. ${ }^{125}$ Dies geschah, nachdem die Merkur AG bereits zwei Jahre zuvor in einem Brief zum Ausdruck brachte, dass eine Rückerstattung wünschenswert sei, da sich „die leitenden Herren [...] immer als Treuhänder des Herrn Schocken gefühlt [hätten]. ${ }^{126}$ In den zehn Jahren zwischen Enteignung und diesem Schreiben schrumpfte der Konzern dramatisch. Der größte Teil der Warenhäuser und des Grundbesitzes lag nicht in der amerikanischen, sondern in der sowjetischen Zone und wurde

120 Vgl. Erica Fischer / Simone Ladwig-Winters: Die Wertheims. Geschichte einer Familie. Berlin: Rowohlt 2004, S.297.

121 Vgl. ebd., S.286-288.

122 Für Details vgl. ebd., S.257-258.

123 Vgl. ebd., S. 287-289.

124 Vgl. ebd., S. 295.

125 Vgl. Fuchs: Ein Konzern aus Sachsen, S. 270.

126 Fonk im Bericht für die US-Besatzung, die bis zum 1. Juli 1945 in Zwickau war, Zwickau, 08.05.1945. Konzern, SchA, M5, S.3, zit. n. ebd., S. 267. 
Ende Juni 1945, also direkt nach Kriegsende, verstaatlicht. ${ }^{127} 1949$ schließlich wurden die im amerikanischen Sektor liegenden Teile des Schocken-Konzerns an den ursprünglichen Inhaber zurückerstattet. Die Familie Schocken erhielt 51 Prozent des Grundkapitals der Merkur AG. ${ }^{128}$

Salman Schocken nahm keine exekutive Funktion mehr ein. Der bereits 72jährige Patron hatte sich aus sämtlichen operativen Geschäften in Palästina und den USA zurückgezogen. Von seiner neuen Heimat New York aus stand er den Geschäftsführern als Berater und Ideengeber zur Seite. Er kümmerte sich jedoch nur noch um Dinge, die ihn persönlich stark interessierten. Im MerkurKonzern beließ Schocken nach der Restitution die Führungskräfte, die er in den 1930er Jahren eingesetzt hatte, in ihren Positionen. Wilhelm Fonk stieß 1948, nachdem er frühzeitig aus der sowjetischen Kriegsgefangenschaft entlassen wurde, ${ }^{129}$ wieder zum Unternehmen. ${ }^{130}$ Er entschloss sich, obwohl er nach eigenen Angaben zahlreiche Angebote von weitaus größeren Firmen hatte, aus Loyalität zu Salman Schocken zur Rückkehr.

In einem Brief schrieb er an Schocken, dass sich ein Abschied für ihn als „Fahnenflucht ${ }^{\text {"131 }}$ anfühlen würde. Er wollte dem Unternehmen helfen, eine neue Zentrale aufzubauen, den Konzern zu sanieren und Schockens Restitutionsanspruch unterstützen. Der ausschlaggebende Grund sei seine Beziehung zu Schocken und dessen Familie. Schocken habe ihn 1934 in Zeiten der Not in den Konzern geholt, nun herrsche wieder eine Notsituation, wenn auch eine andere. ${ }^{132}$ Schocken, der seine Ausgaben stets vorsichtig plante und selten Geschenke verteilte, honorierte Fonks Loyalität und Einsatz für die Firma mit 5 Prozent der Ansprüche, die die Familie aus den Rückerstattungszahlungen erhielt. Weitere

127 Vgl. Fonk im Bericht für die US-Besatzung, die bis zum 1. Juli 1945 in Zwickau war, Zwickau, 08.05.1945. Konzern, SchA, M5, S. 270-271. Zur Problematik der Restitution jüdischen Eigentums nach 1945 vgl. u. a. Constantin Goschler / Philipp Ther (Hrsg.): Raub und Restitution. ,Arisiserung und Rückerstattung jüdischen Eigentums in Europa. Frankfurt am Main: Fischer 2003.

128 Vgl. Fuchs: Ein Konzern aus Sachsen, S. 271.

129 Fonk wurde wahrscheinlich 1941, das Datum wird nirgends belegt, einberufen. Während des Krieges lehnte er die Beförderung zum Offizier ab. Vgl. Herbert Hörnig: Brüning. Politiker ohne Auftrag. Zwischen Weimarer und Bonner Republik. Paderborn: Schöningh 2005, S. 138-139.

130 Vgl. Fuchs: Ein Konzern aus Sachsen, S. 274.

131 Wilhelm Fonk an Salman Schocken, 23.12.1948. SchA, M6, S. 2. Hier zit. n. ebd.

132 Vgl. ebd. 
5 Prozent wurden ihm in Aussicht gestellt, wenn er weitere fünf Jahre für den Merkur-Konzern, der auch nach der Rückerstattung diesen Namen trug, tätig sei. ${ }^{133}$ Damit sorgte Schocken - trotz der Einschnitte durch Kriegsende und durch die Restitution - für Kontinuität. Das Wachstum seines Konzerns und das Weiterbestehen seiner Geschäftsideale sollten damit wohl gesichert werden. Warum er sich dann 1953 dazu entschloss, seine Anteile am Konzern an den Kaufhauskonzern Horten zu verkaufen, ist auf Basis der vorliegenden Quellen nicht zu rekonstruieren. Sein fortgeschrittenes Alter oder die Tatsache, dass keines seiner Kinder die Geschäfte in Deutschland übernehmen wollte, könnten Gründe für diese Entscheidung gewesen sein. Mit dem Verkauf hatte Salman Schockens wirtschaftliche Betätigung in Deutschland ein Ende gefunden.

Anders als bei seinem New Yorker Verlag brachte sich Schocken also kaum in die Geschäfte seines Konzernes ein. Zwar reiste er einige Male nach Deutschland und traf dort mit den Geschäftsführern zusammen, Einfluss auf deren Entscheidungen übte er jedoch keinen. Zu einem Neuanfang in Deutschland kam es nicht. Möglicherweise fehlte ihm die Energie, den Konzern neu aufzubauen - was nötig gewesen wäre, da nach dem Wegfall der Teile, die in der sowjetischen Zone lagen, das Unternehmen enorm geschrumpft war. Auch das Desinteresse der Söhne und Töchter, sich wirtschaftlich im Nachkriegsdeutschland zu betätigen, mag zu Schockens Zurückhaltung geführt haben. So sind die vier Jahre bis zum endgültigen Verkauf des Konzerns mehr als Epilog einer Erfolgsgeschichte denn als Neuanfang zu verstehen. Es war ein letzter Blick zurück auf ein Lebenswerk, dass von den Nationalsozialisten zwar nicht gänzlich zerstört, aber doch erheblich gestört wurde.

\subsection{Die Erfüllung eines Traums: Die Schocken-Baruch-Type}

Salman Schockens Sinn für Ästhetik wurde bereits mehrfach thematisiert. Seinen Wunsch nach typographisch fehlerfreien und ästhetisch ansprechenden Büchern formulierte er ebenso deutlich wie seine Kritik an der oftmals schlechten Qualität jüdischer Bücher in Deutschland. Bereits 1927 schrieb er an Agnon, als dessen Werk zur Drucklegung vorbereitet wurde, dass „die verschiedenen Typenvorschläge der uns in Deutschland zur Verfügung stehenden

133 Vgl. Entwurf für einen Brief Theodor Schockens im Auftrag Salman Schockens an Wilhelm Fonk, 01.11.1948. SchA, M 2. S. 1; Theodor Schocken an Wilhelm Fonk, 29.04.1948. SchA, M33, zit. n. ebd., S. 275. 
Firmen: W. Drugulin, Kreysing, Teubner, Priess, nicht genügen. ${ }^{\text {134 }}$ Nach einigem Abwägen gab Schocken den Druck, wie wir wissen, bei der Offizin Drugulin in Leipzig in Auftrag. Tatsächlich war das Angebot an hebräischen Typen nicht überwältigend. Zwar lag mit der vom Leipziger Kantor Rafael Frank entworfenen und 1910 gegossenen ,Frank-Rühl' eine moderne hebräische Type vor. ${ }^{135}$ Jedoch spielte Salman Schocken bereits früh mit dem Gedanken, eine eigene hebräische Schrift entwerfen zu lassen, die moderner Literatur optisch eher entspräche. Erst in den 1940er Jahren, als er bereits in New York lebte, wurden diese Pläne ernsthaft verfolgt. Die Geschichte der 1947 veröffentlichten und 1949 erstmals in einem Buch zur Verwendung kommenden ,Schocken-Type‘, hat ihren Beginn in der zweiten Hälfte der 1930er Jahre und wird im Folgenden rekonstruiert.

1935 schreibt Franziska Baruch, mit der Salman Schocken auf Vermittlung von Moses Marx bereits in Deutschland in Kontakt stand und die für einige Ausgaben in Schockens Bibliothek Buchrücken gestaltete, an Schocken. Es ging darum, dass sie ihm kürzlich einige hebräische Schrifttypen zeigte und sie gerne eine neue Schrift zeichnen würde. Sie wolle aber zuerst nachfragen, „welche Möglichkeiten dafür sind, eine neue Schrift zu machen. “136 Baruch hatte sich bereits als junge Studentin intensiv mit der Form der hebräischen Schrift befasst. Sie studierte ab 1919 Buchkunst und Graphik an der Unterrichtsanstalt des staatlichen Kunstgewerbemuseums bei Emil Orlik, bevor sie 1922 an die Abteilung Gebrauchsgraphik und damit zu Ernst Böhm wechselte. Ihr Zugang zur hebräischen Schrift, die Sprache wird sie erst sehr viel später lernen, war ein historischer. Sie studierte mittelalterliche Handschriften und frühe Drucke und entwickelte daraus eine Serie hebräischer Kalligraphie. Mit der von der Berliner Gießerei H. Berthold gegossenen Stam-Type schuf sie zudem 1925 eine Drucktype, die auf der Schrift einer Haggada des frühen 16. Jahrhunderts basiert. ${ }^{137}$ Das Berlin der Weimarer Republik war dabei ein fruchtbarer Ort für die junge Schriftkünstlerin. Die Stadt war in den 1920er Jahren ein Zentrum für typographische Experimente.

134 Salman Schocken an S.J. Agnon, 12.08.1927. NLI, Agnon Archiv, Arc. 4, 1270.

135 Vgl. Philipp Messner: Hebrew Type Design in the Context of the Book Art Movement and New Typography. In: Wardi (Hrsg.): New Types, S. 21-33, hier S.26-27.

136 Franzisca Baruch an Salman Schocken, 03.04.1935. SchA, Privates, 844/2, Bd. 1.

137 Vgl. Messner: Hebrew Type Design in the Context of the Book Art Movement and New Typography. In: Wardi (Hrsg.): New Types, S. 24-26. 
Neben zahlreichen anderen Aufgaben übernahm Franzisca Baruch für Salman Schocken auch die Neubeschriftung neugebundener, bibliophiler Ausgaben. ${ }^{138}$ Als sie 1933 nach Palästina emigrieren wollte, bestätige Schocken gegenüber dem Palästina-Amt, dass Baruch bei ihm als "Schrift-Kunstgewerblerin “139 gearbeitet hätte. Er empfahl, ihr ein Zertifikat auszustellen, das ihr die Einreise ermöglichen würde. ${ }^{140}$ Nachdem Schocken die Tageszeitung Haaretz übernahm, suchte er jemanden, der den Titel und das Layout neu entwarf: Das äußere Erscheinungsbild sollte der unter ihm modernisierten Zeitung entsprechen. Für diesen Auftrag konnte er Baruch gewinnen. ${ }^{141}$ Zufrieden mit Baruchs Arbeit für Haaretz - so entwarf sie den bis heute unveränderten Titel -, blieben sie in Kontakt.

Jedoch blieb Franzisca Baruchs oben erwähntes Schreiben vom April 1935 zunächst unbeantwortet. Sie versuchte es zwei Jahre später nochmals und sandte Schocken, unaufgefordert, Proben für eine hebräische Type. Schocken antwortete ihr, dass er seit einiger Zeit entschlossen sei, „die lange von mir vorbereitete Arbeit zur Schaffung einer neuen hebräischen Type fortzuführen. " ${ }^{142}$ Er glaube aber, dass für ein solches Projekt die selbständige Arbeit von Buchkünstlern ungeeignet sei und dass er daher entschlossen sei, mit der Unterstützung von Grafikern, die für Hilfsarbeiten herangezogen würden, selber am Entwurf mitzuarbeiten. ${ }^{143}$ Es kam in der Folge zu einigen Besprechungen zwischen Baruch und Schocken, und sie wurde beauftragt, „Vorschläge für Änderungen

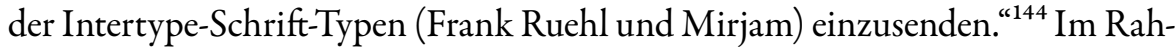
men dieser Zusammenarbeit kam es zu Missstimmungen wegen der Entlohnung Baruchs für ihre Entwürfe, die sie als zu niedrig kritisierte. Sie erhielt in Palästina zwar immer wieder Aufträge, unter anderem von Schocken, litt aber wie viele Einwanderinnen und Einwanderer zeitweilig unter Armut. Schocken

138 Noch heute finden sich in den Regalen der Schocken-Bibliothek in Jerusalem einige Bände, die in hellem Leder eingefasst und mit der sorgfältigen Schrift Baruchs versehen sind.

139 Salman Schocken an das Palästina-Amt Berlin, 29.05.1933. Israel Museum Jerusalem (IMJ), Central Archives, Franzisca Baruch.

140 Vgl. ebd.

141 Vgl. Gesprächsnotizen, Salman Schocken und Franzisca Baruch, 28.10.1936. IMJ, Central Archives, Franzisca Baruch.

142 Salman Schocken an Franzisca Baruch, 27.05.1937. SchA, Privates, 844/2, Bd. 1.

143 Vgl. ebd.

144 Sekretariat Schocken an Franzisca Baruch, 15.05.1938. SchA, Privates, 844/2, Bd. 1. 
vertrat den Standpunkt, dass die Arbeit an Entwürfen weniger hoch entlohnt werden sollte als jene am finalen Produkt. ${ }^{145}$ Die Zusammenarbeit blieb zwar bestehen, jedoch materialisierten sich die Pläne erst 1943, als Salman Schocken bereits in New York lebte und sein Sohn Gustav ohne die Einmischung seines Vaters die Geschäfte des Jerusalemer Verlages führte.

Als Leiter des Schocken Verlages Jerusalem / Tel Aviv suchte Gustav Schocken nach einer neuen Schrift für den Maschinensatz, ${ }^{146}$ die Baruch entwerfen sollte. Man entschied sich für einen Einzelbuchstabenguss für das System der Monotype Company, die einen ausgezeichneten Ruf für ihre hochwertigen Schriften genoss. Gustav Schocken wollte die Angelegenheit nicht weiter herauszögern und trat im November über einen Mittelsmann mit der Firma in London in Kontakt. Der Krieg verzögerte die Kommunikation enorm, dennoch wurde das Projekt nicht unterbrochen. ${ }^{147}$ Baruch arbeitete an den Entwürfen und der Vertrag vom Februar 1945 zwischen der Typographin und dem Verlag ist Zeuge davon, dass man sicher davon ausging, dass man die Type realisieren könne. ${ }^{148}$ Jedoch erreichte die erste Monotype-Maschine Palästina erst Ende 1946; danach konnte endlich an den technischen Anpassungen gearbeitet werden. Darüber hinaus verzögerten die Schwierigkeiten nach Kriegsende die Arbeit bei Monotype, sodass die erste Lieferung von Matrizen im Jahre 1947 nur in der Grundgröße von sieben Punkt möglich war. Erst 1955 konnten die fünf gebräuchlichsten Größen geliefert werden. ${ }^{149}$ Das erste Buch, dass in der Schocken-Type gesetzt wurde, die hebräische Autobiographie von Chaim Weizmann, dem ersten Präsidenten des neugegründeten Staates Israel, kam 1949 auf

145 Vgl. Briefwechsel zwischen Salman Schocken (Sekretariat Schocken) und Franzisca Baruch, 13.06.-01.08.1938. SchA, Privates, 844/2, Bd. 1.

146 Zur Problematik des Druckens in Palästina vgl. Gustav Schocken: Printing and Publishing. In: Joseph B. Hobman (Hrsg.): Palestine's Econonomic Future. London: Percey Lund Humphries 1947, S. 244-252.

147 Vgl. Philipp Messner: שוקן-ברוך': אות-ספר עברית חדשה [,Schocken-Baruch'. Eine neue

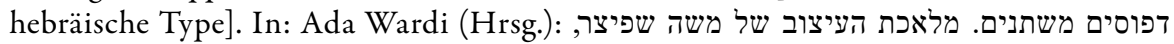
דפרים [The Graphic Design of Moshe Spitzer, Franzisca Baruch and Henri Friedlaender]. Jerusalem: Israel Musem Jerusalem 2016, S. 239-255.

148 Vgl. Vertrag zwischen Schocken Publishing Hose Ltd. und Franzisca Baruch, 05.02. und 11.02.1945. IMJ, Central Archives, Franzisca Baruch.

149 Vgl. Philipp Messner: ,Schocken-Baruch', S. 239-255. 
den Markt. Die Type konnte sich jedoch bei Verlegern nicht durchsetzen; sie wurde fast ausschließlich in Publikationen des Schocken Verlages verwendet. ${ }^{150}$ Auch wenn nach 1940 Gustav Schocken das Zepter im Jerusalemer Verlag übernahm und damit auch für die Schaffung der neuen hebräischen Drucktype die Hauptverantwortung trug, ist dies als letztes Projekt Salman Schockens in Palästina zu bezeichnen. Trotz der zeitweilig unterbrochenen Postwege schaltete er sich schriftlich in den Entwicklungsprozess ein. Im Februar 1944 schrieb er an Gustav: „Das Ergebnis Eurer Arbeit macht einen vorzüglichen Eindruck auf mich. Ich habe die verschiedenen Vorlagen mit Fachleuten besprochen "151, um dann in der Folge über mehrere Seiten sehr detaillierte Anmerkungen zu einzelnen Buchstaben zu machen. Für Salman Schocken war die Schaffung der Type, die seinen Namen trug, sein Projekt, auch wenn die Umsetzung sein Sohn übernahm.

Mit dem Druck des ersten Buches realisierte sich nicht nur ein jahrzehntelanger Wunsch, es schloss sich darüber hinaus ein Kreis. Schocken hatte als Verleger jüdischer Literatur in Deutschland, in Palästina und später in New York vieles erreicht. Er brachte die für ihn relevanten jüdischen Schriften auf den Markt und arbeitete, vor allem in Deutschland, mit unterschiedlichen Fachleuten an der Ästhetisierung des jüdischen Buches. Die Schaffung einer eigenen Type - ein Wunsch, den er bereits in Deutschland hegte - wurde erst in den Nachkriegsjahren Realität. Damit war auch dieses letzte hier besprochene Projekt kein Neuanfang, sondern eine endlich zum Abschluss gekommene Idee: ein letzter Blick zurück auf Deutschland und gleichzeitig ein letztes Projekt in Palästina.

\subsection{Bruch mit Palästina - ein Schluss}

Nach fünfähriger Abwesenheit kehrten Salman und Lili Schocken im Herbst 1945 auf Besuch nach Palästina zurück. Es war keine Heimkehr; die Villa war vermietet, Salmans Stellung bei der Universität aufgelöst und die früheren Freunde entfremdet. Kurt Blumenfelds Beschreibung über Schockens Aufenthalt in Jerusalem steht exemplarisch für den kühlen Empfang, der ihm bereitet wurde:

150 Vgl. ebd.

151 Brief (Kopie) Salman Schocken an Gustav Schocken, 13.02.1944. IMJ, Central Archives, Franzisca Baruch. 
Schocken wird [...] als ein sehr enttäuschter das Land verlassen. Man vergisst ihm nicht, dass über ihn bei Ausbruch des Krieges das Witzwort in Palästina verbreitet werden konnte, er habe gekabelt: „Kann Amerika in der Stunde der Not nicht verlassen. S. Schocken." Wir stehen persönlich gut, ich habe ihn aber nur während der ganzen Zeit nur flüchtig gesprochen. Alle behandeln ihn höflich, aber niemand nimmt von ihm Notiz. Wie viel Korruption es auch geben mag, Geltung im öffentlichen Leben und Geldbesitz fallen nicht zusammen. ${ }^{152}$

Schocken, dem Einfluss und Anerkennung so wichtig waren, wurde zu einer marginalen Figur. Er hielt zwar einige Vorträge über seine Erfahrungen in Amerika, aber auch damit knüpfte er nicht an seine vorherige Stellung an. In seiner letzten Rede vor seiner Abreise, die er anlässlich des zehnjährigen Jubiläums von Jacob Katzenstein als Bibliothekar in der Schocken-Bibliothek hielt, thematisierte er die Entfremdung zwischen dem Diaspora-Judentum, er meinte damit das US-amerikanische Judentum, und dem Jischuv: Er beschreibt die Arbeit seiner Verlage als Brücke zwischen den beiden Kulturen, die durch die Vermittlung der jahrhundertealten Textkultur, die dem Judentum überall zugrunde liege, dessen Auseinanderdriften zu verhindern vermöge. ${ }^{153}$ Entgegen dieser Beschreibung muss festgehalten werden, dass die Verlage sicherlich wichtige Arbeit leisteten, jedoch keine Brücken zu bauen vermochten, schon gar nicht, was Schockens eigene Stellung im vorstaatlichen Israel anbelangte. In den folgenden Jahren reiste Schocken immer wieder nach Palästina resp. Israel und traf dort frühere Bekannte und Weggefährten, die Stimmung blieb jedoch kühl. 1946 ernannte er seinen Sohn Gustav (Gershom) zu seinem rechtmäßigen Vertreter in allen Angelegenheiten in Palästina. ${ }^{154}$ Wenige Jahre später äußerte er Buber gegenüber, dass er im Tel Aviver Verlag längst keinen Einfluss mehr hätte, die neue Generation hätte übernommen. Zu runden Geburtstagen wurde er in der Presse zwar mit freundlichen Beiträgen bedacht - man erinnerte an seine großen Verdienste in Deutschland -, eine Kontroverse um eine Verleihung der Ehrendoktorwürde verdeutlicht aber, wie gering sein Rückhalt

152 Kurt Blumenfeld an Hannah Arendt, 04.01.1946. In: Nordmann / Pilling (Hrsg.): Hannah Arendt, Kurt Blumenfeld, S. 35.

153 Vgl. Ansprache des Herrn Salman Schockens anlässlich des 10-jährigen Jubiläums des Herrn Katzenstein im Hause Schocken, 12.01.1946. SchA, Privates, 803/82.

154 Schreiben Salman Schocken, 24.07.1946. SchA, Privates, 823, Bd. 33. 
nunmehr in Israel war. Diese Episode aus dem Jahr 1952 soll abschließend etwas genauer beleuchtet werden, da sie Einblick in die zerrütteten Verhältnisse zwischen Schocken und seinen früheren Freunden und Bekannten gibt. Mitte August 1952 kontaktierte Werner Senator, der noch immer im Dienst der Hebräischen Universität stand, Gershom Scholem: Das Permanent Committee der Universität hatte in seiner Sitzung vom 13. August 1952 beschlossen, Salman Schocken zu seinem 75. Geburtstag einzuladen und im Kreis der Universität mit ihm zu feiern. Bereits im zweiten Abschnitt des Briefes an Scholem erwähnt Senator die Schocken-Bibliothek, deren „Schicksal“ die Universität sehr interessiere, denn „schließlich und endlich wird Schocken jetzt 75 Jahre alt, und nach menschlichem Ermessen wird ja einmal der Zeitpunkt kommen, wo die Frage der Zukunft der Bibliothek und des Instituts akut wird. “155 Es bestehe der Wunsch, dass die Bibliothek der Universität „zufalle, bzw. von Herrn Schocken schon bei seinen Lebzeiten übereignet wird, d. h. Bücher und Haus [...]. “156 Man sei gleichzeitig der Ansicht, dass die Hebräische Universität

die Verdienste eines Mannes wie Schocken um die hebräische Literatur, um das hebräische Buch und um jüdische Wissenschaft ehren sollte, und dass es in diesem Falle zu rechtfertigen wäre, dass die Universität, die bisher nur Dr. Magnes, Dr. Weizmann und Prof. Einstein den doctor hon.causa verliehen hat, Schocken den Doktortitel verleiht. ${ }^{157}$

Für die Verhandlungen mit Schocken wollte man Scholem, der selbst nicht im Gremium vertreten war, zu Schocken schicken, denn man war sich bewusst, dass die Situation sehr, delikat' sei. Einerseits wisse man, dass der Titel für Schocken sehr erstrebenswert sei, vermutete aber andererseits „außerordentliche Widerstände“, den Doktortitel „zu kaufen“ - „kaufen“ wurde von Senator unterstrichen. ${ }^{158}$ Scholem wurde also gebeten, mit Schocken eine „klare Vereinbarung $^{\text {“159 }}$ zu treffen, dass die Universität ihm die Würden eines Ehrendoktors

155 Werner Senator an Gershom Scholem, 14.08.1952. NLI, Scholem Archiv, Arc 4159901 2407.

156 Ebd.

157 Ebd.

158 Ebd.

159 Ebd. 
verleihe, wenn er sich im Gegenzug dazu verpflichte, seine Bibliothek, also die Bücher und das Gebäude, sowie das Forschungsinstitut der Universität zu stiften. Das Institut würde auf alle Zeiten seinen Namen tragen und die Universität würde sich verpflichten, es zu unterhalten. In Klammer merkte Senator dann noch an, dass es "natürlich gut [wäre], wenn er uns noch etwas Geld zum Unterhalt für einige Jahre geben bezw. testamentarisch vermachen würde. “160 Senator sprach in seinem Brief an Scholem die Problematik bei dem erhofften Deal an: Die Universität wollte Schocken nicht an sich für sein Verdienst an der jüdischen Kultur ehren, sondern sich die wertvolle Bibliothek in einem Tauschgeschäft sichern. Schocken, der, seit er zu Reichtum gekommen war, immer fürchtete, als reicher Mann wahrgenommen und ausgenutzt zu werden, lehnte das nicht sehr respektvolle Angebot der Universität ab.

Scholem unterbreitete es ihm nach vorherigen geheimen Absprachen mit Lili Schocken anscheinend recht taktvoll. Es kam laut Scholem zu „keiner Explo-

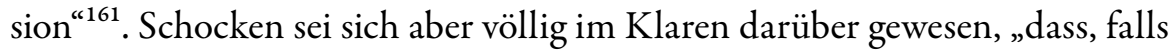
er eine Ehrung der Universität annehme, - was er, wenn sie ihm angeboten wird selbstverständlich tun wird - dies ihn seinerseits moralisch verpflichte. " ${ }^{162}$ Schocken spielte mit der Idee, die Bibliothek unter die gemeinsame Verwaltung der Familie und der Universität zu stellen, insistierte aber, dass er „auf keinen Fall eine Ehrung durch eine vorherige Schenkung erkaufen [könne]. ${ }^{163} \mathrm{Er}$ bestand darauf, dass man ihm erstens vertrauen müsse, und dass zweitens das, was er als „deutscher Jude für das jüdische Buch in den 3 Verlägen [sic] Deutschland, Palästina und Amerika geleistet habe, [...] der Universität genügen [müsse] ${ }^{\text {“164 }}$, und dass, wenn die Universität nach seinen Vorgaben handle, ihr dies nicht schaden würde. Schocken fügte weiterhin an, dass er sich bewusst sei, was man ihm vorwerfe, dass er sich aber absolut unschuldig fühle. ${ }^{165}$ Schocken meinte damit das Zerwürfnis mit der Universität, das durch seine Abwesenheit

160 Werner Senator an Salman Schocken, 14.08.1952. NLI, Scholem Archiv, Arc 4159901 2407.

161 Gershom Scholem an Werner Senator, 05.09.1952. NLI, Scholem Archiv, Arc 4159901 2407.

162 Ebd.

163 Ebd.

164 Ebd.

165 Vgl. ebd. 
während der Kriegsjahre ausgelöst wurde. Aber genau dies hielt man ihm in der Universitätsleitung vor.

Senator schrieb daraufhin an Scholem, dass man sich an der Universität sehr intensiv mit der Sache beschäftigte, die Leistungen seiner Verlage jedoch nicht als ausreichend ansehen würde, um ihm die Würde eines Ehrendoktors zu verleihen. Zudem sei „die Leistung von Schocken in der Universität [...] nicht allgemein anerkannt, und in jedem Falle hat er sie mit der schweren Hypothek seiner Abreise aus Palästina in der Kriegszeit belastet. "166 Ohne schriftliche Bestätigung Schockens, dass er der Universität die Bibliothek vermache, würde der Senat der Ehre darum keinesfalls zustimmen. Senator war sich bewusst, dass es damit mutmaßlich zu keinem Abkommen kommen würde. Er spielte noch mit dem Gedanken, dass Schocken der Universität die Bibliothek anlässlich seines 75. Geburtstages schenken und den Ehrendoktor erst ein Jahr später erhalten würde, machte sich aber keine großen Hoffnungen, dass dieser Vorschlag angenommen würde. ${ }^{167}$ Auch Scholem betrachtete das Projekt als gescheitert. Er war sich sicher, dass Schocken unter keinen Umständen eine Schenkungsabsicht schriftlich festhalten würde, bevor ihm nicht der Titel verliehen würde. ${ }^{168}$ Mangelndes Vertrauen und das Unvermögen beider Seiten, die Sicht der anderen nachzuvollziehen, führten zum Abbruch der Verhandlungen. Schocken feierte seinen 75. Geburtstag nicht mit einer offiziellen, von der Universität ausgerichteten Feier, sondern im Kreise seiner Familie. ${ }^{169}$

Die Zerrüttung mit der Universität im Jahr 1945 führte zu einem nicht zu kittenden Bruch mit dem Jischuv. Die wenigen Zeilen Senators verdeutlichen, wie schwer man es Schocken anlastete, die Gefahren des Krieges nicht mit seinen Mitstreitern ausgestanden zu haben. Man warf ihm vor, in der sicheren Ferne ein angenehmes Leben verbracht zu haben. Bis heute haftet ihm dies an. Seine Rolle beim Aufbau des vorstaatlichen Israels und seine Arbeit in der Universitätsleitung fanden keinen Eingang in die Geschichtsbücher. Sein Name wird

166 Werner Senator an Gershom Scholem, 18.09.1952. NLI, Scholem Archiv, Arc 4 1599, 01 2407.

167 Vgl. ebd.

168 Vgl. Gershom Scholem an Werner Senator, 01.10.1952. NLI, Scholem Archiv, Arc 4 1599, 012407.

169 Vgl. Salman Schocken an Gershom Scholem, 29.10.1953. NLI, Scholem Archiv, Arc. 4 1599, 013050 , Bd. 10. 
zwar mit der Tageszeitung und dem Verlag in Verbindung gebracht, ansonsten geriet er mit Ausnahme eines kleinen Kreises in Vergessenheit.

Trotz des reservierten Verhaltens ihm gegenüber verbrachte er bis zu seinem Tod fast jedes Jahr ein paar Monate in Israel. Dies geschah jedoch als Privatmann und ohne Teil der Gesellschaft zu werden, der er in Berlin und Jerusalem einst angehörte. Der Zugang zu seinem ehemaligen Netzwerk war zerbrochen. Er stand noch in sporadischem Kontakt mit Scholem und wechselte auch mit anderen ehemaligen Wegbegleitern und Mitstreitern vereinzelt Briefe, aber weiter gingen die Beziehungen nicht mehr. Sein Lebensmittelpunkt befand sich in den USA; in Israel und Europa wurde er zu einer marginalen Figur, an die man sich anlässlich von Geburtstagen erinnerte, die aber nicht mehr Teil der Gegenwart war. 


\section{3 \\ Blicke auf Verpasstes}

\section{Ein Epilog}

Salman Schockens Lebenswerk darf als beachtlich bezeichnet werden. Man könnte seinen Werdegang mit dem Sprichwort vom Tellerwäscher, der zum Millionär wird, beschreiben. Als zehntes Kind einer einfachen, frommen jüdischen Familie in Posen gelang ihm der soziale Aufstieg zum Inhaber der fünftgrößten Warenhauskette Deutschlands, zum einflussreichen Zionisten und zu einem der wichtigsten Männer des jüdischen Literaturbetriebs seiner Zeit. Das Erbe seines Schaffens ist bis heute in Deutschland, Israel und den USA auffindbar, auch wenn sein Name in weiten Kreisen in Vergessenheit geriet. Dies steht im starken Gegensatz zu seiner gewichtigen Position im deutschen wie transnationalen Netzwerk des jüdischen Kulturzionismus und Kulturschaffens in den 1920er und 1930er Jahren, als er als Entscheidungsträger auf unterschiedlichen Ebenen Einfluss auf das innerjüdische Geschehen seiner Zeit nahm. Er pflegte berufliche und private Beziehungen mit den Geistesgrößen seiner Zeit ebenso wie mit Politikern und Wirtschaftsfachleuten. Mit seinem Weggehen aus Jerusalem im Jahr 1940, seiner zeitweilig harschen Kritik an langjährigen Weggefährten (man denke an seinen Streit mit Robert Weltsch über die Deutschsprachigkeit der Jüdischen Weltrundschau) und durch seine Schreibfaulheit verspielte er geschäftliche Beziehungen wie zahlreiche Freundschaften. Selbst seine engste Familie tat sich schwer mit Salmans Charakter und entfremdete sich zunehmend von ihm. Zudem trennte er sich Anfang der 1950er Jahre 
von seiner Frau Lili. ${ }^{1}$ In den letzten Jahren vor seinem Tod begann der sonst so analytisch denkende Mann, wehmütig auf Verpasstes zurückzuschauen. Nach der Trennung von Lili alleine, hoffte er einerseits, vergangene Freundschaften wiederzubeleben, und andererseits, sein Leben und sein Werk (auto-) biographisch aufzuarbeiten.

1956, drei Jahre vor seinem Tod, unternahm Salman Schocken den ersten Versuch, eine Biographie schreiben zu lassen. Im Sinn hatte er keine traditionelle Biographie, die sein Leben und sein Wirken nachzeichnen und damit der Nachwelt zugänglich machen sollte, sondern eine, wie er es nannte, „Bio-Bibliographie“2 Im Zentrum der Schrift sollte nicht ein Hauptcharakter - also Salman Schocken - stehen, sondern zwei: Schocken und sein Verlag. Das jüdische Buch, in dessen Dienst er sich als junger Mann erstmals stellte und das ihn sein Leben lang begleitet hatte, war nicht bloßes Objekt, sondern Subjekt in seiner eigenen Lebensgeschichte. Schocken stellte sich eine kommentierte Bibliographie seines Berliner Verlages vor, die auf sein Wirken und seine wichtigsten Erfolge ausgelegt sein sollte. Das Gesprächsprotokoll weist darauf hin, dass Spitzer mit der Arbeit bereits begonnen hatte und sie in enger Absprache mit Schocken weiterführen sollte. Ein Manuskript ist jedoch nicht überliefert. Mit Spitzer beauftragte Schocken einen Mann, der sowohl die Arbeit des Berliner Schocken Verlages wie auch den Menschen Salman Schocken bestens kannte. Auch wenn die Beziehung zwischen den Männern zeitweise sehr schwierig war - Spitzer fühlte sich nach seiner Ankunft in Jerusalem von Schocken verstoßen -, ${ }^{3}$ blieb er Schocken, wie dieser Plan zeigt, dennoch verbunden.

Ein Jahr später und damit wenige Monate vor seinem unerwarteten Tod äußerte Schocken seinem langjährigen Autor und zeitweiligem Vertrauten

1 Vgl. Gespräch der Autorin mit Racheli Edelman.

2 Besprechungsprotokoll Salman Schocken mit Dr. Spitzer, 16.04.1958. SchA, Verlag, 303.

3 Moritz Spitzer erzählte seinen Kindern, dass Salman Schocken ihn des Hauses verwies, als er 1939 aus Deutschland nach Jerusalem flüchtete. Die Akten im Schocken Archiv widerlegen diese Darstellung der Ereignisse (es sind Briefe und Protokolle überliefert, die belegen, dass Spitzer und Schocken in Kontakt standen und Schocken Spitzer weiterhin beschäftigen wollte). In der Familie Spitzer ist jedoch bis heute eine andere Version präsent. Dies lässt vermuten, dass es aus nicht näher bekannten Gründen zu einem Bruch zwischen den beiden Männern kam. Spitzer scheint darunter auf eine Weise gelitten zu haben, die seine Erinnerung an die Anfangszeit in Jerusalem bestimmt. 


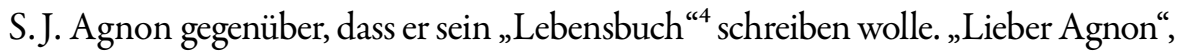
schrieb er,

wir schreiben uns keine Briefe. Ich war und bin von jeher ein schlechter Briefeschreiber. Das Schicksal rächt sich dazu ironisch: Bemüht mein Lebensbuch zu schreiben und auf der Suche nach einer richtigen Form hierfür, bin ich[,] ohne es eigentlich geplant zu haben, dazu gekommen, literarische Briefe zu schreiben, die einmal zusammengestellt, Teile meines Lebens repräsentieren [...] können. ${ }^{5}$

Wie Schocken, der seine Briefe mit ganz wenigen Ausnahmen, in einem geschäftlichen, kurz angebundenen Ton zu verfassen pflegte, und auch sonst wenig schriftstellerisches Talent zeigte, darauf kam, literarische Briefe zu verfassen und diese zu einer Autobiographie zusammenzufügen, erschließt sich aus seinem Nachlass nicht. Es verwundert jedenfalls nicht, dass auch dieses Projekt nicht über die Absichtserklärung hinausging. Die Idee steht wie jene der BioBibliographie für Schockens Wunsch, der Nachwelt einen persönlich gehaltenen Einblick in sein Schaffen zu geben, und damit in Erinnerung zu bleiben. Die beiden nicht verwirklichten Anläufe zu einer Biographie legen aber nahe, dass Schocken am Ende seines Lebens den Eindruck hatte, bestimmte Chancen verpasst zu haben. Sie verweisen darüber hinaus auf seine Angst, nach dem Tod in Vergessenheit zu geraten. Vielleicht konnte er sich nicht vorstellen, wer sich an ihn erinnern sollte. Entfremdet von seinen ehemaligen Weggefährten und von seiner Familie, in Israel durch sein eigenes Verhalten in den Kriegsjahren in die Vergessenheit gedrängt, musste er selbst dafür sorgen, dass sein Vermächtnis in Erinnerung behalten würde.

Er sollte nicht Unrecht behalten. Nach seinem unerwarteten Tod an einem Herzinfarkt in einem Hotelzimmer in Pontresina in den Schweizer Alpen, wo er den Sommer verbrachte, erschienen zwar zahlreiche wohlmeinende Nachrufe von ehemaligen Weggefährten und es wurde ihm ein stattliches Begräbnis in Jerusalem ausgerichtet, wo er neben Lili begraben wurde. Jedoch widmete man sich schon bald anderen Dingen. Erst viele Jahre nach seinem Tod erwachte ein Interesse an diesem Mann, der für das jüdische Buch, den Zionismus und das jüdische Gemeinwesen in Palästina viel geleistet hatte. Lambert Schneider, mit

4 Salman Schocken an S. J. Agnon, 03.04.1959. NLI, Agnon Archiv, Arc. 41270.

5 Ebd. 
dem Salman Schocken nach dem Krieg keinen Kontakt halten wollte, ${ }^{6}$ schrieb 1966 an Gershom Scholem, dass es ihn bedrücke, dass es niemanden gäbe, der über den Schocken Verlag schreiben könne, denn eine „solche Arbeit wäre sehr wichtig. ${ }^{\text {"7 }}$ Schneider selbst hatte in seinem Almanach 1965 seine Geschichte mit Schocken und damit auch die Geschichte des Schocken Verlages in Ansätzen niedergeschrieben. Dabei, so gesteht er Scholem gegenüber, sei es ihm nicht leichtgefallen, da

seine garstigen Seiten [...] noch erheblich grösser [waren], als ich sie angedeutet hatte. Doch er verdient es trotzdem, dass man ihm hier in Deutschland ein Denkmal setzt, denn dass es den Schocken Verlag in dieser Zeit gab, reicht dafür alleine aus. ${ }^{8}$

Das Denkmal sollte dem Verleger Schocken gesetzt werden, nicht dem Menschen. Vielleicht lag Schockens Enkelin Racheli Edelman, die den Schocken Verlag Tel Aviv heute führt, richtig, als sie in einer persönlichen Erinnerung schrieb, dass er sich den Büchern näher gefühlt hätte als den Menschen. ${ }^{9}$

6 Salman Schocken schrieb im März 1946 folgende Zeilen an Robert Weltsch: „Dr. Schneider war der letzte Arier, den ich aus dem Bereich meiner deutschen Tätigkeit gesehen habe [...]. Es mag sein, dass mein Erinnerungsbild z. T. daher stammt, dass man damals doch schon recht misstrauisch war gegen jeden Deutschen. Die menschlichen Beziehungen hatten jedenfalls schon manchen Stoss erlitten. [...] Ich muss schon sagen, dass ich im allgemeinen wenige Sehnsucht habe, deutsche Freunde wiederzusehen." (Salman Schocken an Robert Weltsch, 28.02.1946. SchA, Privates, 844, Bd.8.)

7 Lambert Schneider an Gershom Scholem, 04.05.1966. NLI, Scholem Archiv, Arc. 41599 012341.

8 Lambert Schneider an Gershom Scholem, 12.08.1965. NLI, Scholem Archiv, 4159901 2341.

9 Vgl. Racheli Edelman: Rediscovering Grandpa Schocken. A Tribute on the Occasion of the $130^{\text {th }}$ Anniversary of Salman Schocken's Birth. In: Haaretz, 08.11.2007. https://www.haaretz. com/israel-news/rediscovering-grandpa-schocken-1.232839 (Zugriff am 23.10.2017). 


\section{4 \\ Schlusswort}

Es verwundert kaum, dass die ersten biographischen Arbeiten zu Schocken sich mit seinem Verlag und seiner Bibliothek befassten, oder im Fall von Siegfried Moses mit seinen wirtschaftlichen und zionistischen Betätigungen. Die Lebensgeschichte Schockens wurde erstmals in den 2000er Jahren von Anthony Davis niedergeschrieben, diese Arbeit bewegte sich aber hauptsächlich in Sphären der Vermutung und des Unbelegbaren. Erst eine Konferenz, die 2013 in Chemnitz anlässlich der damals noch geplanten, und inzwischen eröffneten Ausstellung zu Salman Schockens Biographie im ehemaligen Kaufhaus Schocken Chemnitz ${ }^{1}$ stattfand, interessierte sich für Schockens Biographie in all ihren Nuancen. Sie vermochte jedoch viele Lücken nicht schließen.

Es ist keinesfalls Ziel der vorliegenden Studie, sämtliche Leerstellen zu füllen, da die lückenlose Chronologie eines Lebens nie das Ziel einer wissenschaftlichen Biographie sein kann. Vielmehr geht es darum, den Menschen Salman Schocken im Licht seiner zahlreichen Beziehungen zu Menschen, Institutionen und Dingen zu betrachten und zu untersuchen, wie er sich im Netzwerk der Beziehungen und im Kontext seiner Zeit bewegte.

Die Studie ist mit Topographien eines Lebens überschrieben. Es war das Ziel, Schockens Weg durch den Raum, den geographischen und den gesellschaftlichen,

1 Das Kaufhaus Schocken Chemnitz beherbergt heute das Staatliche Museum für Archäologie, in dem zwei kleinere Ausstellungen Salman Schocken und Erich Mendelsohn gewidmet sind. 
darzustellen und dabei die Zwischenräume auszuloten. Schocken bewegte sich in vielen gesellschaftlichen Räumen, die sich teilweise überschnitten: So war sein verlegerisches Arbeiten nicht von seinem zionistischen zu trennen, und seine Versuche, gesellschaftlichen und politischen Einfluss auszuüben, waren eng mit seinem Mäzenatentum verbunden. Schockens Leben war, um an Foucault anzuschließen, „ein Netz, das seine Punkte verknüpft und sein Gewirr durchkreuzt. “2 Dieses ,Netz des Lebens sollte hier aufgespannt werden und dessen Betrachtung an einigen Punkten vertieft werden.

Wirtschaftliches Denken, die Beziehung zum Buch, Machtbewusstsein, Migration und Exil sowie brüchige zwischenmenschliche Beziehungen waren die Punkte, die immer wieder aufgegriffen und unter unterschiedlichen politischen und gesellschaftlichen Vorzeichen analysiert wurden. Rückblickend kann gesagt werden, dass sich die Exilerfahrung einschneidend auf Schockens Leben auswirkte. Bei Schocken zeigt sich, dass auch eine scheinbar erfolgreiche Emigration ein Leben bis in seine Tiefe erschüttern kann. Aus Deutschland verstoßen zu werden, die Vertreibung aus dem geographischen, wirtschaftlichen und kulturellen Raum seiner Heimat, hatte weitreichende Konsequenzen für sein weiteres Leben. Er wurde nirgendwo mehr heimisch, seine Versuche, an Vergangenes anzuknüpfen, sollten ihm nicht richtig gelingen. Er lebte in einem Dazwischen, in einer Rückwärtsgewandtheit und durch seine Erinnerungen, ohne wieder Wurzeln schlagen zu können. Er wurde zum schwierigen, unzuverlässigen Mann, der zwar viele Ideen hatte, sich aber kaum mehr durchringen konnte, diese zu verwirklichen. ,Zauderer' wurde er von Hannah Arendt genannt, „eine merkwürdige Figur“3 von Scholem. Ein Leben im Dazwischen, ein Bewegen in mehreren Räumen gleichzeitig war nur möglich, solange er seiner gefühlten Heimat angehörte. Das Exil machte ihn zum Heimatlosen, zu einem Nomaden, wie ihn sein Sohn Gershom in seinen Erinnerungen, die er nach dem Tod des Vaters verfasste, bezeichnete. ${ }^{4}$

2 Foucault: Andere Räume, S.34.

3 Gershom Scholem an Hannah Arendt, 16.12.1946. In: Schedletzky (Hrsg.): Gershom Scholem. Briefe I, 1914-1947, S. 305-309, hier S. 308.

4 Vgl. Schocken: Salman Schocken, S. 30. 


\section{Dank}

Während meiner Arbeit durfte ich auf die Unterstützung zahlreicher Menschen zählen, ohne die diese Untersuchung kaum nicht möglich gewesen wäre. Als Erstes gilt mein Dank Alfred Bodenheimer (Basel), der mich mit der historischen Person Salman Schocken in Kontakt brachte und diese Arbeit wissenschaftlich begleitete. Danken möchte ich auch Yfaat Weiss (Jerusalem / Leipzig), die mich während dreier Jahre als Fellow am Franz-Rosenzweig-MinervaForschungszentrum der Hebräischen Universität willkommen hieß. Ohne den wissenschaftlichen Austausch mit den anderen Fellows am Zentrum sowie die Einbindung in die Wissenschaftsgemeinschaft in Jerusalem hätte die Studie nie diese Form gefunden. Dank gebührt dabei vor allem Caroline Jessen, Elisabeth Gallas, Irene Aue-Ben-David sowie Arndt Engelhardt für die Gespräche und Diskussionen.

Ada Wardi, die mich zur Mitarbeit am Ausstellungsprojekt New Types. Three Pioneers of Hebrew Graphic Design ${ }^{1}$ am Israel-Museum in Jerusalem einlud, sowie den weiteren Projektmitarbeitenden Liron Lavi Turkenich und Philipp Messner danke ich für den Einblick in die Welt der Typographie, die sich mir sonst kaum erschlossen hätte.

In der Schweiz gebührt mein Dank Anatol Schenker, der die wahrscheinlich größte Privatsammlung an Publikationen des Schocken Verlages besitzt, mir freien Zugang zu dieser gewährte und mich schließlich mit seiner Freude am Sammeln ansteckte! Des Weiteren danke ich den Mitarbeiter*innen des Zentrums für Jüdische Studien der Universität Basel für ihre Kollegialität. Den Kolleg*innen in Deutschland und in der Schweiz danke ich für die Anfertigung zahlreicher Kopien von Texten, die in Israel nicht erhältlich waren.

Eine Historikerin kann nicht ohne Quellen und Bücher arbeiten. In diesem Feld geht mein erstes großes Dankeschön an die Lesesaalmitarbeitenden der Nationalbibliothek in Jerusalem, die während dreier Jahre meine Bücherstapel schleppten und mir beim Lokalisieren von nur schwer auffindbaren Texten

1 Ada Wardi (Kuratorin): New Types. Three Pioneers of Hebrew Graphic Design. Moshe Spitzer, Franzica Baruch, Henri Friedlaender. The Israel Museum Jersualem, 22.10.2015-07.06.2016. http://www.imj.org.il/en/exhibitions/new-types (Zugriff am 19.02.2020). 
behilflich waren. Die Bibliothek wurde in dieser Zeit zu meinem zweiten Zuhause. Daher gilt ein weiterer großer Dank den Mitarbeiterinnen und Mitarbeitern der Archivabteilung der Bibliothek, insbesondere natürlich Oded Fluss, meinem (jetzigen) Mann, dem ich nicht nur zahlreiche Hinweise sondern viel mehr verdanke. Nach den drei Jahren verbanden mich Freundschaften und mehr mit diesem Ort.

Ein anderer zentraler Ort für meine Forschung war das Schocken Archiv in Jerusalem, wo ich lange Monate im Lesesaal über Salman Schockens Akten saß. Dass mir dies in dieser Form möglich war, verdanke ich der Großzügigkeit der Familie Schocken, vor allem aber Racheli Edelman, die mir nahezu unbeschränkten Zugang zum Material gewährte. Ohne die Hilfe von Rabbi Baruch Yonin, dem Leiter des Archivs, wäre meine Arbeit nicht möglich gewesen. Unermüdlich suchte er die von mir bestellten Schachteln zusammen und teilte sein reiches Wissen über Salman Schocken mit mir.

Auch den Archivar*innen der übrigen besuchten Archive sei zu danken. Namentlich zu nennen ist Altie Karper, nicht Archivarin, sondern Lektorin der Schocken Books New York. Ihr ist es zu verdanken, dass ich während mehrerer Tage die Akten des Verlages studieren und kopieren durfte. Schließlich gebührt mein Dank auch Dvorah Schocken und nochmals Racheli Edelman, die sich bereit erklärten, mir ihre persönlichen Eindrücke von Salman Schocken zu schildern.

Ein solches Projekt ist nicht nur von Quellen und Büchern, sondern auch von finanzieller Unterstützung abhängig. Zu danken ist in dieser Hinsicht dem Schweizerischen Nationalfonds, der mit einem dreijährigen Projektstipendium einen gewichtigen Beitrag leistete. Des Weiteren wurde ich teilweise mit namhaften Beträgen der Freiwilligen Akademischen Gesellschaft Basel, des Franz-Rosenzweig-Minerva-Forschungszentrums in Jerusalem, des Da'at Hamakom - Center for the Study of Cultures of Place in the Modern Jewish World, des Deutschen Literaturarchivs Marbach, der Gerald Westheimer Foundation, New York, der Rothschild Foundation (Hanadiv), London, der Schweizerischen Akademie für Geisteswissenschaften, des Forschungsfonds der Universität Basel, des Reisefonds der Universität Basel, der Jetty, Aron und Simon Blum-Stiftung, Zürich, der Gretel und Walter Picard-Weil Stiftung, Zürich, des Pierre-André und Marly Haas Fonds, Basel, der René und Susanne BraginskyStiftung, Zürich, der Ruth und Paul Wallach Stiftung, Basel und der Adolf und 
Mary Mil-Stiftung, Zürich gefördert. Vielen Dank! Dass Pierre-André Haas z"l und Marly Haas z"l den Abschluss der vorliegenden Studie nicht mehr erleben durften, bedauere ich sehr. Die beiden haben mich seit Beginn meiner Dissertation immer wieder unterstützt.

Salman Schocken sammelte und verlegte schöne Bücher, daher war es für mich als Autorin seiner Biografie Pflicht, dass das Buch über sein Leben seinen ästhetischen und verlegerischen Ansprüchen genügt hätte. Der Neofelis Verlag Berlin entsprach diesen Wünschen. Mein großer Dank geht an den Inhaber des Verlages, Matthias Naumann, für sein Engagement für das Buch und die OpenAccess-Publikation, an die Graphikerin Marija Skara für die Gestaltung des Buchumschlages, an Joachim Schlör, dass er das Buch in die Reihe Jüdische Kulturgeschichte in der Moderne aufnahm, und schließlich an Nadine Werner für ihr genaues Lektorat und die angenehme Zusammenarbeit.

Und schließlich geht mein Dank an meine Familie - ohne euch wäre dies nicht möglich. 

ANhang 


\section{Abbildungsverzeichnis}

Abb. 1: Die Hauptverwaltungs-Gebäude des Schocken Konzerns, Zwickau S. A. Aus: Die Zentrale. Mitteilungen der Schocken Kommandit-Gesellschaft auf Aktien Zwickau S.A., 8, hrsg. v. Ewald Schäfer. (C) The Schocken Institute for Jewish Research.

Abb. 2: Martin Buber: Die Geschichten des Rabbi Nachman. Frankfurt am Main: Rütten \& Loening 1906.

Abb. 3: Darntons Kommunikationskreislauf. Aus: Robert Darnton: What Is the History of Books? In: Deadalus 111,3 (1982), S.68. (C) The MIT Press.

Abb.4: Theodor Herzl: Sechs Kongressreden. Leipzig: Drugulin 1914. Bibliothek der Israelitischen Cultusgemeinde Zürich, Signatur Q90.

Abb. 5: Beispiele aus der ,Schocken-Bücherei', Schocken Verlag Berlin, 1933-1938. Sammlung Stefanie Mahrer.

Abb. 6: Prospekt der Bücherei des Schocken Verlags, erste Seite, Typographie Max Malte Müller, 1935. Sammlung Stefanie Mahrer.

Abb.7: Die Tröstung Israels in der Verdeutschung von Martin Buber und Franz Rosenzweig. Bücherei des Schocken Verlags, Bd. 1. Berlin: Schocken 1933, S.4-5.

Abb. 8: Alfred Bernheim: Lesesaal der Schocken Bibliothek, 1937. (C) The Schocken Institute for Jewish Research.

Abb. 9: Luftaufnahme der Villa Schocken und der Schocken-Bibliothek, 1937. (C) The Schocken Institute for Jewish Research.

Abb. 10: Erich Mendelsohn (links) und Salman Schocken anlässlich der Eröffnung des Hadassah-Krankenhauses, 1939. (C) The Schocken Institute for Jewish Research.

Abb. 11: Swimmingpool der Villa Schocken, 1937. (C) The Schocken Institute for Jewish Research.

Abb. 12: Teilansicht des Gartens, 1937. (c) The Schocken Institute for Jewish Research.

Abb. 13: Alfred Bernheim: Esszimmer mit Blick auf die Terrasse und den Swimmingpool. Möblierung von Erich Mendelsohn, 1937. (C) The Schocken Institute for Jewish Research.

Abb. 14: Alfred Bernheim: Esszimmer mit Blick auf die Terrasse und den Swimmingpool. Möblierung von Erich Mendelsohn, 1937. (C) The Schocken Institute for Jewish Research.

Abb. 15: Alfred Bernheim: Empfangshalle mit Sessel von Erich Mendelsobn, 1937. (C) The Schocken Institute for Jewish Research.

Abb. 16: Alfred Bernheim: Empfangshalle mit Sessel aus dem Berliner Haushalt, 1937. (C) The Schocken Institute for Jewish Research.

Abb. 17: Alfred Bernheim: Sitzecke vor Kamin. Möblierung von Erich Mendelsohn, 1937. (C) The Schocken Institute for Jewish Research.

Abb. 18: Schocken Reader Winter 1947-48. New York: Schocken Publishing House. Sammlung Stefanie Mahrer.

Ich danke den besitzenden Institutionen für die freundliche Genehmigung, die Bilder verwenden zu dürfen. 


\section{Abkürzungsverzeichnis}

BArch Bundesarchiv der Bundesrepublik Deutschland

CZA Central Zionist Archives, Jerusalem

DLA Deutsches Literaturarchiv Marbach

DVA Deutsche Verlags-Anstalt

dtv Deutscher Taschenbuchverlag

EJGK Enzyklopädie jüdischer Geschichte und Kultur

EMA Erich Mendelsohn Archiv

Gestapo Geheime Staatspolizei

IMJ Israel-Museum, Jerusalem

JPS Jewish Publication Society

JWR Jüdische Weltrundschau

KH Keren Hayesod (Gründungs-Fonds). Sammelt Spenden für Israel.

KKL Keren Kayemeth LeIsrael (Jüdischer Nationalfonds, auch JNF)

LBIYB Leo Baeck Institute Year Book

$£ P \quad$ Palästina-Pfund

NLI National Library Archive (Archiv der Nationalbibliothek, Jerusalem)

NSDAP Nationalsozialistische Deutsche Arbeiterpartei

NZZ Neue Zürcher Zeitung

OPAC Online Public Access Catalogue

RGB Reichsbürgergesetz

RM Reichsmark

SchA Schocken Archiv, Jerusalem

SchB Archiv der Schocken Books, New York

WIZO Akronym von Women's International Zionist Organization

ZVfD Zionistische Vereinigung für Deutschland 


\section{Glossar}

Alija

Av

Bezalel

Bnai Brit

Brit Schalom

Chalutz

Chassid

Cheder

Eretz Israel

Galut

Genisa

Haaretz

Ha'avara

Hachscharat ha-Jischuv
Hebr. „Aufstieg“. Bezeichnet die Einwanderung von Juden und Jüdinnen nach $\rightarrow$ Eretz Israel.

Der fünfte Monat des religiösen jüdischen Kalenders.

Hebr. „Im Schatten Gottes“. Eine biblische Gestalt, die namensgebend für die 1906 in Jerusalem gegründete Kunstgewerbeschule (heute Kunstakademie) wurde.

Hebr. „Söhne des Bundes“. Ein jüdischer Orden, der ähnlich den Freimaurern in Logen gegliedert ist .

Hebr. „Bund des Friedens“. Ein 1926 von europäischen Intellektuellen gegründeter politischer Verband in Palästina und Israel, der sich die Förderung der Verständigung zwischen Juden und Arabern zum Ziel gesetzt hat.

Hebr. „Pionier“. Bezeichnung für einen jüdischen Immigranten in Palästina, der in der Land- oder Forstwirtschaft arbeitet.

Hebr. „der Fromme“. Strenggläubiger Jude.

Hebr. „Zimmer“. Traditionelle jüdische Schule für Knaben im Primarschulalter.

Hebr. „das Land Israel“. Traditionelle Bezeichnung für das biblische Heimatland der Juden.

Hebr. Bezeichnung für die jüdische Diaspora.

Hebr. „Depot, Speicher“. Raum, in dem nicht mehr verwendete religiöse jüdische Texte aufbewahrt werden, die eine Bezeichnung Gottes enthalten und daher nicht zerstört werden dürfen.

Hebr. „das Land“. Name der von Salman Schocken aufgebauten linksliberalen israelischen Tageszeitung.

Hebr. „Transfer“. Bezeichnung für das im Jahr 1933 abgeschlossene Wirtschaftsabkommen zwischen der $\rightarrow$ Jewish Agency, der Zionistischen Vereinigung für Deutschland und dem deutschen Reichsministerium für Wirtschaft.

Hebr. „Vorbereitung für den $\rightarrow$ Jischuv“. Ausbildungsstätten des ZVfD in Deutschland, in denen junge Zionistinnen und Zionisten berufliche wie sprachliche Kompetenzen für ihr Leben in Palästina erwerben konnten. 
Hadassah

Haggada

haggadisch

Hanotea

Histadrut

Hotza’a

Jecke

Jewish Agency

Jirmijahu

Jischuv

Joint

Kabbala

Kabbalistica

Kibbutz

Kraal

Makkabäer

Machsor

Mapai

Mesusa

Mesusot

Midrasch

Misrad
Hebr. „Myrte“ und Name der von Henrietta Szold gegründeten zionistischen Frauenorganisation in den USA, die sich insbesondere für das Gesundheitswesen in Israel einsetzte und einsetzt.

Hebr. „Erzählen“ und Handlungsanweisung für den Seder am Vorabend des $\rightarrow$ Pessachfestes.

Adj. zu $\rightarrow$ Haggada.

Hebr. „der Pflanzer“. Zitruspflanzunternehmen.

Hebr. „Zusammenschluss“. Der „Allgemeine Verband der Arbeiter Israels": Dachverband der Gewerkschaften in Palästina / Israel.

Hebr. „Verlag“.

Despektierliche Bezeichnung für die in den 1930er Jahren eingewanderten Juden aus Deutschland.

Vertretung der Juden im Völkerbundsmandat für Palästina (historische Funktion).

Hebr. Transliteration von „Jeremia“. Gemeint ist das Prophetenbuch Jeremia.

Jüdisches Gemeinwesen in Palästina vor der Staatsgründung Israels.

Kurzform für American Jewish Joint Distribution Committee, eine 1914 gegründete jüdische Hilfsorganisation mit Sitz in New York.

Hebr. „Überlieferung“. Mystische Tradition des Judentums.

Kabbalistische Literatur.

Hebr. „Sammlung“. Ländliche Kollektivsiedlung in Israel.

Afrikaans: urspr. kreisförmige Siedlung mit einer klar geregelten sozialen Struktur im südlichen Afrika, heute Bezeichnung für ein Viehgehege. Name des von Else Lasker-Schüler 1942 gegründeten literarischen Zirkels in Jerusalem.

Anführer eines jüdischen Aufstands gegen das Seleukidenreich.

Hebr. „Zyklus, Wiederholung“. Bezeichnet ein Gebetbuch.

Akronym für Mifleget Póalei Eretz („Partei der Arbeiter Eretz Israels“), politische Partei, die 1930-1968 existierte.

Schriftkapsel am Türrahmen eines jüdischen Hauses.

Plural von $\rightarrow$ Mesusa.

Auslegung religiöser Texte, zunächst in mündlicher Form, die später verschriftlicht und tradiert wurden.

Hebr. „Büro“. 
Mo'atzat Po'alim Hebr. „Arbeiterrat“.

Moschav Hebr. „Siedlung, Sitz“. Genossenschaftliche ländliche Siedlungsform in Israel.

Mussar Hebr. „Moral, Ethik“. Philosophische und religiöse Texte mit ethisch-moralischem Inhalt ab dem 13. Jahrhundert.

Nevi'im Hebr. „Propheten“. Bezeichnung der Prophetenbücher im $\rightarrow$ Tanach.

Paltreu Akronym für Palästina-Treuhandstelle zur Beratung deutscher Juden, eine GmbH.

Paraschiot Plural von „Parascha“, Hebr. für „Einteilung“. Bezeichnung des Wochenabschnittes der Tora, der an Schabbat gelesen wird.

Pentateuch Griech. Bezeichnung für die ersten fünf Bücher der jüdischen Bibel.

Pessach Jüdisches Fest im Frühjahr, an dem an den Auszug der Israeliten aus Ägypten erinnert wird.

Rosch ha-Schana Hebr. „Kopf des Jahres“. Jüdisches Neujahrsfest.

Schoa Holocaust.

Schuk Markt.

Talmud

Auslegung des biblischen Gesetzestextes durch Rabbiner.

talmudisch

Adj. zu $\rightarrow$ Talmud.

Tanach

Akronym, setzt sich aus den hebräischen Anfangsbuchstaben der drei Hauptteile der im Judentum kanonischen Bibeltexte - Torah, Propheten und Schriften - zusammen.

Tchija Organisation des ZVfD zur Unterstützung notleidender jüdischer Schriftsteller.

Tisch'a be-Av Fasten- und Trauertag, an dem der Zerstörung des jüdischen Tempels in Jerusalem gedacht wird.

Wa'ad ha-po'el im Kontext der vorliegenden Studie: Exekutivkomitee der Hebräischen Universität Jerusalem. 


\section{Veröffentlichungen der Schocken Books New York 1946-1957}

1946

Mikraot Gedolot: Ketuvim, 622 Seiten. Offset-Druck, korrigiert von Judah Rosenthal, beruhend auf der Erstausgabe mit Kommentaren von Joel Lewinsohn, Warschau 1832-1866.

Chagall, Bella: Burning Lights. Thirty-Six Drawings by Marc Chagall, 266 Seiten. Übersetzt aus dem Jiddischen von Norbert Guterman.

Kafka, Franz: The Great Wall of China. Stories and Reflections, 313 Seiten. Übersetzt aus dem Deutschen von Willa und Edwin Muir.

Glatzer, Nahum N.: In Time and Eternity. A Jewish Reader, 255 Seiten. Überarbeitete und von Olga Marx übersetzte Ausgabe von Sendung und Schicksal. Ein jüdisches Lesebuch des Berliner Schocken Verlages.

Yamim Noraim, ediert von S. Y. Agnon, 415 Seiten. Erste Ausgabe der klassischen Anthologie von Texten zu den Hohen Feiertagen, erstmals publiziert 1938 im Schocken Verlag Berlin mit einer neuen Einleitung von S. Y. Agnon.

Schocken Reader, Winter 1946, illustriert, 48 Seiten. Exzerpte von neuen Publikationen und von Büchern in Vorbereitung.

\section{7}

Scholem, Gershom G.: Major Trends in Jewish Mysticism, 454 Seiten. Überarbeitete Ausgabe, erstmals publiziert im Schocken Verlag Jerusalem.

Kafka, Franz: Gesammelte Schriften, Volumes 1 to 5, ediert von Max Brod, 300 Seiten. Zweite, überarbeitete Ausgabe von Kafkas Gesamtausgabe in Deutsch mit neuem Material. Band 1: Erzählungen und kleine Prosa. Band 2: Amerika. Band 3: Der Prozess. Band 4: Das Schloss. Band 5: Beschreibung eines Kampfes.

Brod, Max: Franz Kafka - A Biography, 250 Seiten, 12 Illustrationen. Übersetzt aus dem Deutschen von G. Humphrey Roberts.

Buber, Martin: Tales of the Hasidim. The Early Masters, 335 Seiten. Übersetzt von Olga Marx, teilweise aus den deutschen Originalausgaben, teilweise aus dem Manuskript des Autors.

Rosner, Jacob: A Palestine Picture Book, 142 Seiten. Über 120 Fotografien vom Leben, Arbeiten und den Menschen im modernen jüdischen Palästina.

1 Die Liste basiert auf der Aufstellung von Nahum N. Glatzer (Herrn Salman Schocken zum 80. Geburtstag. SchA, Verlag, 30), mit Ergänzungen der Autorin. 
Olsvanger, Immanuel: Roÿte Pomerantsen, 206 Seiten. Eine Auswahl von humoristischen Geschichten in Jiddisch gedruckt in lateinischen Buchstaben mit Erklärungen in Englisch. Teile davon wurden in Band 23 der Schocken-Bibliothek (Rêjte Pomeranzen. Ostjüdische Schwänke und Erzählungen. Gesammelt von Immanuel Olsvanger, 1935) veröffentlicht.

Mikraot Gedolot: Neviim - Ketuvim, 1986 Seiten. Reduzierte Ausgabe in einem Band, enthält die drei Bände der Schocken-Ausgabe der Mikraot Gedolot, sorgfältig ediert mit dem Basler Ibn-Esra-Kommentar zu Isiah (1618).

Baeck, Leo: The Pharisees and Other Essays, 164 Seiten. Erschienen zu Ehren Leo Baecks anlässlich seiner Befreiung aus dem Konzentrationslager Theresienstadt. Übersetzt aus dem Deutschen, ausgewählt aus dem Band Aus drei Jahrtausenden, erschienen beim Schocken Verlag Berlin. 1938 war der Großteil des Bestandes von der Gestapo zerstört worden. ${ }^{2}$ Der titelgebende Essay erschien erstmals im Band 6 der Schocken-Bibliothek (Die Pharisäer. Ein Kapitel jüdischer Geschichte, 1934).

Vishniac, Roman: Polish Jews - A Pictorial Record, 80 Seiten. Mit einem einführenden Essay von Abraham Joshua Heschel.

Wolfskehl, Karl: 1933 - A Poem Sequence, 123 Seiten. In Deutsch und Englisch, übersetzt von Carol North Valope und Ernst Morwitz. Der Gedichtband erschien erstmals $1936 \mathrm{im}$ Schocken Verlag Berlin unter dem Titel Die Stimme spricht.

Rembrandt: Thirty-Two Drawings for the Bible. Originalgetreue Reproduktionen in der Originalgröße, hergestellt durch Lichtdruck-Verfahren.

Glatzer, Nahum N. (Hg.): The Language of Faith. Selected Jewish Prayers, ca. 128 Seiten (Schocken Library, Band 1). Mehrsprachige Sammlung von hebräischen, jiddischen und aramäischen Gebeten mit Übersetzungen von Jacob Sloan und Olga Marx.

Baer, Yitzhak F.: Galut, ca. 128 Seiten (Schocken Library, Band 2). Übersetzt aus dem Deutschen von Robert Warshow. Erschien erstmals 1936 unter dem gleichen Titel als Band 61 der Schocken-Bibliothek.

The Land of Sheba. Tales of the Jews of Yemen. Zusammengestellt und herausgegeben von S. D. Goitein, ca. 128 Seiten (Schocken Library, Band 3). Neu angeordnet und übersetzt aus dem Deutschen von Christopher Fremantle. Erschien erstmals als Band 13 der Schocken-Bibliothek (Von den Juden Jemens. Eine Anthologie. Gesammelt, übersetzt und herausgegeben von S.D. F. Goitein, 1934).

Heine, Heinrich: The Rabbi of Bacherach. A Fragment, ca. 128 Seiten (Schocken Library, Band 4). Mit einer Auswahl von Briefen Heinrich Heines und einem Nachwort von Erich Loewenthal. Übersetzt aus dem Deutschen von E. B. Ashton. Erschien auch als Band 80 in der Schocken-Bibliothek, 1937.

2 Den Angaben bei Dahm zufolge wurde das Werk am 12.04.1939 fertiggestellt, eventuell wurden die Bestände und deren Vertrieb durch den Verlag des Jüdischen Kulturbunds in Deutschland e.V. übernommen. Heute sind nur wenige Ausgaben erhalten. 
Maimon, Solomon: An Autobiography, ca. 128 Seiten (Schocken Library, Band 5). Bearbeitet und mit einem Nachwort versehen von Moses Hadas. Die vorliegende englische Ausgabe basiert auf der englischen Übersetzung von S. Clark Murray (1888). Erschien 1935 in einer kommentierten Ausgabe als Doppelband 33/34 der Schocken-Bibliothek.

Bickermann, Elias: The Maccabees, ca. 128 Seiten (Schocken Library, Band 6). Übersetzt aus dem Deutschen von Moses Hadas. Erschien als Band 47 der Schocken-Bibliothek (Bickermann, Elias: Die Makkabäer. Eine Darstellung ihrer Geschichte von den Anfängen bis zum Untergang des Hasmonäerhauses, 1935).

Kafka, Franz: Parables, ca. 128 Seiten (Schocken Library, Band 7). Zweisprachige Ausgabe in Deutsch und Englisch; englische Übersetzung von Willa und Edwin Muir und Clement Greenberg.

Schocken Reader, Winter 1947-1948, 46 Seiten, illustriert. Exzerpte von bereits erschienenen und in Kürze erscheinenden Texten des Verlages, sowie dem Originalbeitrag The Jewish Book in America von Ludwig Lewinsohn.

\section{8}

Kafka, Franz: Diaries 1910-1913, 345 Seiten. Ediert von Max Brod und übersetzt von Joseph Kresh; erster Band von zweien. Erste englischsprachige Ausgabe der Tagebücher.

Kafka, Franz: The Penal Colony. Stories and Short Pieces, 320 Seiten. Übersetzt aus dem Deutschen von Willa und Edwin Muir.

Agnon, S. Y.: Days of Awe, 300 Seiten. Übersetzt von Maurice T. Galpert und Jacob Sloan; gekürzte Ausgabe von Agnons Yamim Noraim. Das Buch wurde 1948 mit dem Lamed Prize ausgezeichnet.

Buber, Martin: Tales of the Hasidim. The Later Masters, 352 Seiten. Fortsetzung des Bandes zu den frühen Meistern, mit einer Einführung von Martin Buber und einem Anhang mit einem detaillierten Glossar und den Genealogien der chassidischen Meister.

Sartre, Jean-Paul: Anti-Semite and Jew, 153 Seiten. Übersetzung aus dem Französischen von Goerge J. Becker. Erstmals erschienen 1946 unter dem Titel Réflexions sur la question juive.

Buber, Martin: Israel and the World. Essays in a Time of Crisis, 255 Seiten. Eine Auswahl von Bubers Essays mit einer Einleitung des Autors. Der größte Teil der Texte erschien im Schocken Verlag Berlin (Kampf um Israel. Reden und Schriften [1921-1932] 1933; Die Stunde und die Erkenntnis. Reden und Aufsätze [1933-1935] 1936; Die Schrift und ibre Verdeutschung, 1936).

Baeck, Leo: The Essence of Judaism. A Guide to the Great Ideas and Teachings of Judaism, 288 Seiten. Überarbeitete Ausgabe. 
Buber, Martin: Ten Rungs. Hasidic Sayings, ca. 128 Seiten (Schocken Library, Band 8). Übersetzt aus dem Deutschen von Olga Marx.

Agnon, S. Y.: In the Heart of the Seas, ca. 128 Seiten (Schocken Library, Band 9). Übersetzt aus dem Hebräischen von I. M. Lask, mit Zeichnungen von Herzl Rome.

Lazare, Bernard: Job's Dungheap. Essays on Jewish Nationalism and Social Revolution, ca. 128 Seiten (Schocken Library, Band 10). Übersetzt aus dem Französischen von Harry Lorin Binsse und ediert von Hannah Arendt, mit einem Portrait von Bernard Lazare angefertigt von Charles Péguy.

Aleichem, Shalom: Inside Kasilevke, ca. 128 Seiten (Schocken Library, Band 11). Übersetzt aus dem Jiddischen von Isidore Goldstick.

Gregorovius, Ferdinand: The Ghetto and the Jews of Rome, ca. 128 Seiten (Schocken Library, Band 12). Kurze Geschichte der Juden in Rom, verfasst 1853, übersetzt aus dem Deutschen von Moses Hadas, sowie einem Gedicht zu Ehren der Juden Roms hier übersetzt von Randall Jarrell. Erschien 1935 als Band 46 der Schocken-Bibliothek (Gregorovius, Ferdinand: Das Ghetto und die Juden in Rom. Mit einem Geleitwort von Leo Baeck).

Shenberg (Shenhar), Yitzhak: Under the Fig Tree, ca. 128 Seiten (Schocken Library, Band 13). Übersetzt aus dem Hebräischen von I. M. Lask.

Wilhelm, Kurt: Roads to Zion. Four Centuries of Travelers' Reports, ca. 128 Seiten (Schocken Library, Band 14). Übersetzt aus dem Hebräischen von I. M. Lask.

Babel, Isaak: Benya Krik. The Gangsters and Other Stories, ca. 128 Seiten (Schocken Library, Band 15). Ediert und teilweise übersetzt von Avrahm Yarmolinsky.

Glatzer, Nahum N. (ed.): Hammer on the Rock. A Midrash Reader, ca. 128 Seiten (Schocken Library, Band 16). Anthologie aus zweihundert Passagen aus Talmud und Midrasch in Übersetzung von Jacob Sloan.

The First Book of Maccabees. Commentary by H. A. Fischel, ca. 128 Seiten (Schocken Library, Band 17). Übersetzt von W.O.E. Oesterley, mit kurzen Erklärungen.

\section{9}

Kafka, Franz: Diaries 1914-1923, 344 Seiten. Ediert von Max Brod und übersetzt von Martin Greenberg in Kooperation mit Hannah Arendt; zweiter Band von zweien.

Heller, Joseph: The Zionist Idea, 246 Seiten. Erstmals 1947 veröffentlicht in Großbritannien, überarbeitet für den amerikanischen Markt von Carl Alpert in Zusammenarbeit mit dem Autor.

Jacob, Heinrich Eduard: The World of Emma Lazarus, 222 Seiten. Mit Illustrationen. 
Olsvanger, Immanuel: L'Chayim!, 192 Seiten. Eine Fortsetzung von Roÿte Pomerantsen (1947).

Ruppin, Arthur: Building Israel. Selected Essays 1907-1935, 342 Seiten. Die englische Originalausgabe wurde erstmals 1936 unter dem Titel Three Decades of Palestine veröffentlicht, die hebräische und die deutsche Version jeweils 1937 bei Schocken Jerusalem resp. beim Schocken Verlag Berlin.

Seforim, Mendele Mosher: The Travels and Adventures of Benjamin III, ca. 128 Seiten (Schocken Library, Band 18). Übersetzt von Moshe Spiegel. Erschien 1937 als Band 85 der Schocken-Bibliothek (Mendele Mocher Sfarim: Die Fabrten Binjamins des Dritten. Eine Erzählung. Aus der jiddischen Sprache ins Deutsche übersetzt von Efraim Frisch).

Zohar. The Book of Splendor, ausgewählt und ediert von Gershom G. Scholem, ca. 128 Seiten (Schocken Library, Band 19). Gekürzte Ausgabe in englischer Übersetzung.

Ayalti, Hanan J.: Yiddish Proverbs, ca. 128 Seiten (Schocken Library, Band 20). Zweisprachige Ausgabe: Jiddischer Text in Transliteration und Übersetzung ins Deutsche von Isidore Goldstick, mit sechs Holzschnitten von Bernard Reder.

\section{0}

Rosenberg, Isaac: Collected Poems, ediert von Gordon Bottomley und Denys Harding, 240 Seiten. Mit einem Vorwort von Siegried Sassoon.

Maletz, David: Young Hearts. A Novel of Modern Israel, 237 Seiten. Übersetzung aus dem Hebräischen von Solomon N. Richards.

Halkin, Simon: Modern Hebrew Literature. Trends and Values, 238 Seiten.

Levin, Harry: I Saw the Battle of Jerusalem, 288 Seiten. Tagebuch des Autors über die Belagerung Jerusalems im Jahr 1948.

Rubin, Ruth: A Treasury of Jewish Folksongs, 224 Seiten. Sammlung von Liedern, Fassung für Klavier von Ruth Post; Anpassung der Gedichte von Isaac Schwartz, Jacob Sloan und der Herausgeberin. Mit Zeichnungen von Herzl Rome.

Reifenberg, Adolf: Ancient Hebrew Arts, 171 Seiten. Über 200 Bilder aus dem jüdischen Altertum, mit einleitenden Texten.

\section{2}

Kafka, Franz: Briefe an Milena, 287 Seiten. Ediert und mit einer Einleitung von Willy Haas. Haas nahm die chronologische Anordnung der größtenteils undatierten Briefe Kafkas vor. 
1953

Franz Rosenzweig. His Life and Thought. Presented by Nahum N. Glatzer, 400 Seiten. Mit Illustrationen.

Glatzer, Nahum N.: Passover Haggadah, 1933. Kommentierte, zweisprachige und gekürzte Ausgabe der Goldschmidt Haggadah in englischer Übersetzung von Jacob Sloan und einer Einleitung. Die Goldschmidt Haggadah wurde 1936 in einer zweisprachigen Ausgabe als Band 54 der Schocken-Bibliothek und 1947 im Jerusalemer Schocken Verlag publiziert.

Kafka, Franz: Hochzeitsvorbereitungen auf dem Lande und andere Prosa aus dem Nachlass, 457 Seiten.

\section{4}

Kafka, Franz: Letters to Milena, ediert von Willy Haas, 238 Seiten. Englische Übersetzung von Tania und James Stern.

Kafka, Franz: Dearest Father. Stories and Other Writings, ediert von Max Brod, 409 Seiten. Englische Ausgabe der Hochzeitsvorbereitungen auf dem Lande, übersetzt aus dem Deutschen von Ernst Kaiser und Eithne Wilkins.

\section{5}

Goitein, Shlomo Dov: Jews and Arabs. Their Contacts Through the Ages, 257 Seiten. Mit chronologischen Tabellen und einer Bibliographie im Anhang.

Rosenzweig, Franz: On Jewish Learning, ediert von Nahum N. Glatzer, 128 Seiten. Englische Ausgabe der Texte Zeit ist's, Bildung und kein Ende sowie Die Bauleute. Anhang bestehend aus Rosenzweigs Vortrag anlässlich der Eröffnung des Jüdischen Lehrhauses sowie der Korrespondenz zwischen Rosenzweig und Martin Buber über Die Bauleute.

Scholem, Gershom: Major Trends in Jewish Mysticism, 456 Seiten. Dritte, überarbeitete Ausgabe mit einer aktualisierten Bibliographie.

\section{7}

Kafka, Franz: Description of a Struggle, 240 Seiten. Übersetzung aus dem Deutschen von Tania und James Stern. 


\section{Literatur- und Quellennachweise}

\section{Ungedruckte Quellen, Bestandsverzeichnisse und Archivsiglen}

\section{Archiv der Israelischen Nationalbibliothek (NLA)}

Akibah Ernst Simon Archiv

Arc 41751013007

Arc 4 1751/3008 (Korrespondenz mit Schocken Books)

Else Lasker-Schüler Archiv

Arc Ms. Var. 50105265 (Korrespondenz mit Salman Schocken)

Gershom Scholem Archiv

Arc $41599013050 \quad$ (Korrespondenz mit Salman Schocken)

Arc 4x $1599012341 \quad$ (Korrespondenz mit Lambert Schneider)

Arc $4159910080 \quad$ (Korrespondenz mit Hannah Arendt)

Arc 4x 1599012407 (Korrespondenz mit Werner Senator)

Hugo Bergmann Archiv

Arc 4 1502/2905 (Korrespondenz mit Schocken Books)

Arc 4 1502/2907 (Korrespondenz mit Salman Schocken)

Martin Buber Archiv

Arc Ms. Var 35011174

Arc Ms. Var. 350/880 (Korrespondenz mit Robert Weltsch)

Arc Ms. Var. 350/752 (Korrespondenz mit Moritz Spitzer)

Arc Ms. Var. 350/750(i) (Korrespondenz mit Salman Schocken)

Arc Ms. Var. 350/524 (Korrespondenz mit Malte Müller)

\section{Archiv der Schocken Books New York (SchB)}

Unterlagen zu den Rechten am Werk Franz Kafkas

Korrespondenz Salman Schocken

\section{Bundesarchiv Berlin (BArch)}

Abteilung Deutsches Reich (R)
BArch R 58/1023
(Reichssicherheitshauptamt)
BArch R 87/8211
(Reichskommissar für die Behandlung feindlichen Vermögens)
BArch R 87/8966
(Reichskommissar für die Behandlung feindlichen Vermögens)
BArch R 3101/34695
(Reichswirtschaftsministerium: Personalakten)
BArch R 9361-V/35529 (Sammlung Berlin Document Center) 
Central Zionist Archives (CZA)

$\mathrm{Z} 3 / 1128$

(Zeitschrift Der Jude, 1915-1920)

$\mathrm{Z} / 1129$

(Zeitschrift Der Jude, 1915-1920)

Erich Mendelsohn Archiv (EMA)

Briefe (Korrespondenz zwischen Erich und Louise Mendelsohn)

Habima Administrative Archive

82.1.8. (Brief Salman Schocken)

Hebräische Universität

Departement of Oral Documentation. Instititute for Contemporary Jewry

Project 41: The Reaction of German Jewry to Nazi Persecution

\section{Israel Museum Jerusalem Archives (IMJ)}

Archiv von Franzisca Baruch

Haaretz (1936-1938)

Schocken - Baruch (1943-1951)

\section{Leo Baeck Institute Jerusalem Archive}

Ernst Markowicz Collection

LBIJER 193/folder 6 (Materials pertaining Salman Schocken, 1924-1971)

\section{Leo Baeck Institute New York Archive}

LBI AR 256C (Salman Schocken Clipping Collection)

\section{Museum of Modern Art Archives (MoMA) \\ Manhattan Special Collection M36 M361m (My Life in a Changing World)}

\section{Schocken Archiv Jerusalem (SchA)}

Jüdisches und Zionistisches

$517 / 491$

$531 / 4$

$531 / 5$

$531 / 6$

$531 / 66$

$532 / 1$
(Schocken Darlehenskasse, 1930-1932)

(Rede Salman Schocken am Delegiertentag der ZVfD, 1918)

(Zentralkomitee)

(Organisationskomitee)

(Antisemitismus-Kommission)

(Zionistische Vereinigung für Deutschland) 
$533 / 1$

$535 / 61$

554

Konzern

$111 / 191$

$111 / 192$

$111 / 714$

$112 / 113$

$115 / 11$

$115 / 21$

$115 / 224$

$121 / 714$

$149 / 225$

$183 / 278 / 2$

Korrespondenz

$844 / 2$

Privates

$801 / 2$

$803 / 82$

$807 / 1$

$807 / 2$

821

822

823

$835 / 2$

$835 / 3$

$835 / 4$

$842 / 1$

$842 / 211$

$842 / 212$

$842 / 22$

$842 / 23$

$842 / 35$

$842 / 3$

870
(KKL)

(Haavara)

(Mitwirkung des Herrn Schocken an dem Aufbau der Palästina-Wirtschaft, 1921-1928)

(Eröffnungsdaten, wichtige Ereignisse, Geschäftsentwicklung 1901-1931)

(Wirtschaftswissenschaftliche Anfragen)

(Rede Salman Schocken anlässlich der Eröffnung in Nürnberg)

(Die wirtschaftliche Entwicklung der Firma I. Schocken im Jahr 1920)

(Der Schocken-Konzern im politischen Kampf bis zum Eintritt der englischen Gruppe)

(Der Schocken-Konzern im politischen Kampf)

(Exposé Dr. Landauer)

(Aus früheren Hauszeitungen)

(Sammlung sämtlicher Referate den Schocken-Konzern betreffend)

(Entwurf einer Systematik der Schocken-Auswahllisten 1922-23)

(Korrespondenz mit Freunden und Bekannten und wichtige Korrespondenz)

(Tagebücher)

(Reden Salman Schocken)

(Zeitungsausschnitte und Pressenotizen)

(Biographien Salman Schocken in Lexika)

(Haus in Zwickau)

(Haus in Zehlendorf)

(Haus in Jerusalem)

(Palästinareisen)

(Reisen)

(Reisen in die USA)

(Einladungen)

(Adressbücher)

(Rosenzweig-Feier, 1936)

(Empfang für Erich Mendelsohn, 1937)

(Veranstaltungen und Empfänge in der Schocken-Bibliothek)

(Vortragsreihe in hebräischer Sprache in der Bibliothek)

(Empfänge im Wohnhaus)

(Geschichte und frühe Ankäufe der Schocken-Bibliothek) 
$871 / 52$

$871 / 53$

$871 / 72$

$871 / 73$

$871 / 9$

Universität

00

011

$013 / 7$

013/11

$013 / 19$

$016 / 16$

$021 / 1$

$021 / 32$

$021 / 42$

$023 / 2$

$023 / 4$

024/1

029

$031 / 4$

$031 / 5$

$042 / 61$

$052 / 4$

$053 / 12$

$058 / 33$

$058 / 35$

$058 / 5$

$061 / 1$

$061 / 3$

071

071/1

$071 / 32$

$072 / 2$

$072 / 22$

$072 / 33$

072/41

$074 / 220$

$074 / 221$

$074 / 222$

$074 / 223$

075
(Verschicken der Bibliothek von Deutschland nach Jerusalem) (Einrichtung der Bibliothek)

(Einlagerung von Büchern und Kunstgegenständen in Safes in der Schweiz)

(Verschiffung Teile der Bibliothek nach Südafrika; Sicherheit) (Artikel über die Bibliothek)

(Eröffnung der Universität)

(Sitzungen Kuratorium)

(Prof. Bodezky [President], 1949-1950)

(Kompetenzen Magnes)

(Briefe und Dubletten)

(President's Fonds)

(Waad Hapoel. Allg. Fragen Kompetenzen)

(Waad Hapoel, Tagesordnungen und Sitzungen)

(Verhältnis Salman Schocken mit Vad Hapoel 1942-1946)

(Reorganisation Prof. Toeplitz)

(Bewerbungen um akademische Posten)

(Reorganisation, Organisations-Komitee und Reorganisationsfragen)

(Reden Salman Schocken)

(Verrechnung mit Sochnut, KH und KKL)

(Finanzen, Finanzverwaltung, Zahlungen Salman Schocken an die Universität)

(Mendelsohn und Büro Mendelsohn)

(Deutsche Professoren)

(Naturwissenschaftliche Fakultät Prof. Weizmann)

(Studenten, soziale Einrichtungen, Kupath Milwe)

(Studenten, soziale Einrichtungen, Student's Hostel)

(Prassim und Stipendien)

(Universitätsbibliothek Allgemein)

(Universitätsbibliothek Prof. Weil)

(Propagandaabteilung Allgemein)

(Propaganda, Gesellschaften der Freunde)

(Propaganda, Besprechungsprotokolle Kurt Blumenfeld)

(Schocharei HaUniversita)

(Arbeitskreis Deutschland Einnahmen und Ausgaben)

(American Friends, Finkel Director)

(English Friends of the University)

(Reise Salman Schocken nach Amerika, Vorbereitung)

(Erste Reise nach Amerika)

(Zweite Reise Salman Schocken nach Amerika)

(Reden Salman Schocken in Amerika)

(Inkunabeln) 
$075 / 24$

$075 / 5$

$078 / 3$

085

Verlag

303

$311 / 211$

312

$331 / 12$

$331 / 14$

$331 / 41$

$331 / 42$

$331 / 43$

$331 / 44$

$331 / 47$

$331 / 51$

$331 / 6$

$331 / 91$

$331 / 95$

32

$332 / 148$

$332 / 33$

$332 / 6$

$332 / 61$

$333 / 11$

$335 / 1$

$336 / 123$

$351 / 15$

$351 / 16$

$351 / 222$

$351 / 821$

(Propaganda Tabellen)

(Broschüren)

(American Friends, Warburg)

(Eröffnung des Medical Centers)

(Geschichte des Verlags)

(Vier Bände Agnon)

(Martin Buber, 1914-1929)

(Besprechungen S. Schocken)

(Interne Korrespondenz und Notizen)

(Personal)

(Dr. Lambert Schneider)

(Dr. Spitzer)

(Frage Nachfolge Spitzer)

(Büro)

(Propaganda)

(Theodor Schocken)

(Ausgliederung Verlag)

(Verlegung und Liquidation)

(Bibelübersetzung Martin Buber)

(Karl Wolfskehl)

(Schocken-Bibliothek)

(Peel Bericht)

(Manuldrucke)

(Arbeitsberichte und Halbmonatsberichte)

(Lesehefte)

(Moses Marx)

(Haim, 1937/39)

(Gründung des Schocken Verlags Jerusalem - Schocken

Publishing House T. A.)

(Verlag Tel Aviv - Druck des Katalogs 1940)

(Pläne - Druckerei Palästina)

Ohne Signatur

Kataloge

Fotos Bücherabteilung

Fotos Konzern

Lose Prospekte und Warenpackungen Konzern

\section{Universitätsbibliothek Basel (UB Basel)}

NL 144

Nachlass Edgar Salin 


\section{Gedruckte Quellen}

Agnon, Shmuel Yosef: ספר האותיות [Buch der Buchstaben]. Tel Aviv: Schocken 1983.

Herrn Lublins Laden, aus d. Hebr. v. Inken Kraft. Leipzig: Kiepenheuer 1993.

Schira, aus d. Hebr. v Tuvia Rübner. Frankfurt am Main: Jüdischer Verlag 1998 [1971].

/ Salman Schocken: ש"י עגנון - ש"ז שוקן: חילופי עגרות (תרש"ו - תש"ט) [S. J. Agnon Sch. Z. Schocken: Briefwechsel (1916-1958)]. Jerusalem: Schocken 1991.

Arendt, Hannah: Menschen in finsteren Zeiten. München / Zürich: Piper 1989.

Auerbach, Elias: Joab - Ein Heldenleben, hrsg. v. Ausschuss für jüdische Kulturarbeit. Berlin: Jüdischer Verlag 1920.

Bergmann, Schmuel Hugo: Tagebücher und Briefe, Bd. 1: 1901-1948, hrsg. v. Miriam Sambursky. Königstein: Jüdischer Verlag 1985.

Blasberg, Cornelia (Hrsg.): Karl Wolfskehls Briefwechsel aus Neuseeland 1938-1948. Mit einem Vorwort von Paul Hoffmann, Bd. 1. Darmstadt: Luchterhand 1988.

Blumenfeld, Kurt: Erinnerungen an Salman Schocken. In: Mitteilungsblatt des Irgun Olej Merkas Europa 27,37 (1959), S.3-4.

Erlebte Judenfrage. Ein Vierteljahrhundert deutscher Zionismus. Veröffentlichung des

Leo Baeck Instituts. Stuttgart: DVA 1962.

Böhm, Adolf: Die Zionistische Bewegung 1918 bis 1925. Jerusalem: Hotza’a Ivrit 1937.

Bornstein, David Josef: Einführung in das Hebräische der Gegenwart. Methodische Texte und Erläuterungen, hrsg. v. der ZVfD. Berlin: Verlag der Jüdischen Rundschau 1927.

Breslauer, Bernhard: Die Abwanderung der Juden aus der Provinz Posen. Denkschrift im Auftrage des Verbandes der Deutschen Juden gefertigt von seinem ersten Schriftü̈hrer. Berlin: Berthold Levy 1909.

Brody, Heinrich: Aus den Berichten des Institutsleiters Heinrich Brody. In: Moritz Spitzer (Hrsg.): Almanach des Schocken Verlags auf das Jahr 5697. Berlin: Schocken 1936/37, S. 176-181.

Buber, Martin: Die Losung. In: Der Jude 1,1 (1916), S. 1-3.

Ich und Du. In: Die Kreatur 3,2 (1929), S.201-222.

Der jüdische Mensch von heute. In: Moritz Spitzer (Hrsg.): Almanach des Schocken Verlags auf das Jahr 5694. Berlin: Schocken 1933/34, S. 5.

Die Tröstung Israels mit der Verdeutschung von Martin Buber und Franz Rosenzweig. Bücherei des Schocken Verlages, Bd. 1. Berlin: Schocken 1933.

Zwiesprache. Bücherei des Schocken Verlages, Bd. 16. Berlin: Schocken 1934, S.64-65. 
Erkenntnis tut not. In: Moritz Spitzer (Hrsg.): Almanach des Schocken Verlags auf das Jahr 5696. Berlin: Schocken 1935/36, S. 11-14.

Aus den Tiefen Rufe ich dich. 23 Psalmen in der Urschrift mit der Verdeutschung von Martin Buber. Bücherei des Schocken Verlages, Bd.51. Berlin: Schocken 1936.

Die Stunde und die Erkenntnis. Reden und Aufsätze 1933-1935. Berlin: Schocken 1936.

Briefwechsel aus sieben Jahrzehnten. In drei Bänden, hrsg. v. Grete Schaeder. Heidelberg: Lambert Schneider 1972.

/ H[elena] H[anna] Cohn / C[heskel] Z[wi] Klötzel: Drei Legenden. Jüdische Jugendbücherei, Bd. 1. Berlin: Jüdischer Verlag 1920.

/ Berthold Feiwel / Chaim Weizmann: Das Projekt einer jüdischen Hochschule. Berlin: Jüdischer Verlag 1902.

Calvary, Moses: Durch Palästina. Jüdische Jugendbücherei, Bd. 5. Berlin: Jüdischer Verlag 1920.

Christie, Manson \& Woods International Inc. (Hrsg.): Important Hebrew Manuscripts From the Salman Schocken Collection. New York: Christie's 2005.

Cohen, Erich: German Papers in Palestine. Reader's Letters. In: Palestine Post, 20.04.1939, S.6.

Cohen, Hermann: Erklärung. In: Handels-Zeitung des Berliner Tagblattes. Beiblatt, 05.02.1914, o.P.

Die hebräische Universität in Jerusalem anlässlich der Eröffnung am siebenten Nissan 5656 / ersten April 1925, hrsg. v. dem vorbereitenden Komitee. Berlin: Marx 1925.

Dienemann, Max: Midraschim der Klage und des Zuspruchs. Bücherei des Schocken Verlages, Bd.36. Berlin: Schocken 1935.

Edelman, Racheli: Rediscovering Grandpa Schocken. A Tribute on the Occasion of the $130^{\text {th }}$ Anniversary of Salman Schocken's Birth. In: Haaretz, 08.11.2007. https:// www.haaretz.com/israel-news/rediscovering-grandpa-schocken-1.232839 (Zugriff am 23.10.2017).

Ein Gang durch die Bibliothek der Berliner Gemeinde. In: Berliner israelitisches Familienblatt, 19.10.1933, S.9.

Feilchenfeld, Werner: FünfJahre deutsche Palästinawanderung und Haavara-Transfer, 1933-1938. Tel-Aviv: Trust and Transfer Office „Haavara“ 1938.

Fichte, Johann Gottlieb: Reden an die deutsche Nation. Berlin: Realschulbuchhandlung 1808 .

Fishbane, Michael A. / Judith Glatzer Wechsler (Hrsg.): The Memoirs of Nachum N. Glatzer. Detroit: Wane State UP 1997. https://doi.org/10.2307/j.ctt17mvhm4 
Fröhlich, Elke (Hrsg.): Die Tagebücher von Joseph Goebbels. Sämtliche Fragmente. Teil I: Aufzeichnungen, 1924-1941, Bd.2: 01.01.1931-31.12.1936. München: Saur 1987.

Glanz-Sohar, Heinrich: Elisa und Jonadab. Jüdische Jugendbücherei, Bd. 8. Berlin: Jüdischer Verlag 1920.

Glaser, Karl: Gibborim. Jüdische Jugendbücherei, Bd. 4. Berlin: Jüdischer Verlag 1920.

Glatzer, Nahum N. / Ludwig Strauss (Hrsg.): Sendung und Schicksal. Aus dem Schrifttum des nachbiblischen Judentums. Ein jüdisches Lesebuch. Berlin: Schocken 1931.

Goldstein, Moritz: Deutsch-jüdischer Parnass. In: Kunstwart 25,11 (1912), S.281-294.

Kulturghetto? In: Jüdische Rundschau, 28.01.1933, S. 373.

Guttmann, Julius: Jüdische Wissenschaft. Die Akademie für die Wissenschaft des Judentums. In: Der Jude. Eine Monatsschrift 7,7-8 (1923), S. 489-493.

„Haavara“ Misrad Neemanut: Bedingungen für den Bautransfer der,Haavara' Ltd. Tel Aviv: typ. B. Ortner 1937.

Hausedewell, Ernst / Ernst Nolte: Die Bibliotheken Salman Schocken und Karl Wolfskehl. Auktion Dr. Ernst Hausedewell \& Ernst Nolte, Antiquariat und Aktionshaus. 2 Teile. Hamburg: Hausedewell \& Nolte 1975-1976.

Herzberg, H.: The 'No German' Campaign. To the Editor of the Palestine Post. Reader's Letters. In: Palestine Post, 09.05.1939, S. 6.

Herzl, Theodor: Sechs Kongressreden. Leipzig: Drugulin 1914.

Hillel, Bath: In Bene Berak. Und andere Erzählungen. Jüdische Jugendbücherei, Bd. 3. Berlin: Jüdischer Verlag 1920.

Historien und Legenden. Berlin: Jüdischer Verlag 1922[?].

Hübner, Reinhard: Arabisches Wirtschaftsleben. Heidelberg / Berlin: Vowinckel 1943.

Im Morgenlande. Berlin: Jüdischer Verlag 1922[?].

[Über die Arbeit und die Wirtschaft im Land [Israel]. Ein Gespräch mit H. Schocken]. In: Haaretz, 18.05.1922, S. 2.

Kaufmann, Fritz Mordechai (Hrsg.): Die schönsten Lieder der Ostjuden. 47 ausgewählte Volkslieder. Schriften des Ausschusses für jüdische Kulturarbeit. Berlin: Jüdischer Verlag 1920.

Kestenbaum \& Co. (Hrsg.): Catalogue of Important Hebrew Printed Books From the Library of the Late Salman Schocken (1877-1959). To Be Offered for Sale by Auction on Tuesday, $2^{\text {nd }}$ June, 2003. New York: Kestenbaum 2003.

Klötzel, C[heskel] Z[wi]: In Saloniki. Jüdische Jugendbücherei 6. Berlin: Jüdischer Ver$\operatorname{lag} 1920$. 
Knott, Marie Luise (Hrsg.): Hannah Arendt und Gershom Scholem. Der Briefwechsel. Frankfurt am Main: Jüdischer Verlag 2010.

Köhler, Lotte / Hans Saner (Hrsg.): Hannah Arendt, Karl Jaspers. Briefwechsel 1926-1969. München / Zürich: Piper 1985.

Krupnik, Baruch: Hebräische Phraseologie. Dreitausend Redewendungen, deutsch-hebräisch, hebräisch-deutsch. Berlin: Rubin Mass 1932.

Lasker-Schüler, Else: Konzert. Berlin: Rowohlt 1932.

Das Hebräerland. Zürich: Oprecht 1937.

יום כיפור [Der Versöhnungstag], aus d. Deutsch. v. Tuvia Rübner. In: Proza 35-37 (1980), S. 18-19.

,Was soll ich hier?' Exilbriefe an Salman Schocken. Heidelberg: Lambert Schneider 1986.

Literarische Neuorientierung. Jüdische Schreiber und Leser in der Zeitenwende. In: Israelitisches Familienblatt, 02.06.1933, S. 13.

Mendelsohn, Erich: Palestine and the World of Tomorrow. Jerusalem: Jerusalem Press 1940.

Briefe eines Architekten, hrsg. v. Oskar Beyer. München: Prestel 1961.

/ Bruno Zevi: Neues Haus, neue Welt [1932]. Berlin: Gebr. Mann 1997.

Meyer, Erna: Wie kocht man in Erez-Israel?, hrsg. im Auftrag der Women's International Zionist Organization (WIZO), dreisprachig Hebräisch, Deutsch, Englisch. Tel Aviv: Histadrut Naschim Zioniot 1936.

Nordmann, Ingeborg / Iris Pilling (Hrsg.): Hannah Arendt, Kurt Blumenfeld. ,...in keinem Besitz verwurzelt. Die Korrespondenz. Hamburg: Rotbuch 1995.

Palestine Personalities. Salmann Schocken. In: Palestine Review, 21.08.1936, S. 375.

Phiebig, Albert J.: Statistische Tabellen. In: Moritz Spitzer (Hrsg.): Schocken Almanach auf das Jahr 5699. Berlin: Schocken 1938/39, S. 137-153.

Picard, Jakob: Unsere Dichtung in diesen Tagen. In: Jüdische Rundschau, 22.11.1935, S.6. Rader Marcus, Jacob: New Literary Responsibility. In: American Jewish Yearbook 43 (1941/42), S.784-791.

Rosenberg, Ada: Jerusalem's Private Gardens. In: The Palestine Tribune, 23.05.1946, S. 11. Shedletzky, Itta (Hrsg.): Gershom Scholem. Briefe I, 1914-1947. München: Beck 1994.

/ Thomas Sparr (Hrsg.): Betty Scholem - Gershom Scholem. Mutter und Sohn im Briefwechsel 1917-1946. München: Beck 1989.

Schneider, Lambert: Rechenschaft über vierzig Jahre Verlagsarbeit 1925-1965. Ein Almanach. Heidelberg: Lambert Schneider 1965. 
Schocken, Gershom: Salman Schocken. Ich werde seinesgleichen nicht mehr sehen. In: Der Monat 242 (1968), S. 15.

Schocken, Gustav: Printing and Publishing. In: Joseph B. Hobman (Hrsg.): Palestine's Econonomic Future. London: Percey Lund Humphries 1947, S. 244-252.

Schocken, Salman: Eine Maccabäerrede. Gehalten am 29. Dezember in Chemnitz. Leipzig: Poeschel \& Trepte [1913].

Zwischen Produktion und Konsum. Berlin: Schocken 1931.

Philosophie und Politik. Hermann Cohen und der Zionismus. In: Jüdische Rundschau, 20.03.1914, S. 123.

Hermann Cohen. In: Jüdische Rundschau, 05.11.1915, S.361-362.

Schockens Referat. In: Jüdische Rundschau, 05.01.1917, S.3.

Palästinensische Wirtschaftspolitik. Bericht auf der Jahreskonferenz in Karlsbad am 23. August 1922. Zionistische Broschüren-Bibliothek. Berlin: Verlag des Berliner Büros der Zionistischen Organisation 1922.

Zur Eröffnung des Kaufhauses Schocken in Nürnberg. Ansprache des Herrn Salman Schocken an die Gäste am 11. Oktober 1926. In: Aus früheren Schocken Hauszeitungen, 1926, S. 1.

Zwischen Produktion und Konsum. Berlin: Schocken 1931.

Über das Forschungsinstitut für Hebräische Dichtung. Vorwort zur ersten Veröffentlichung. In: Moritz Spitzer (Hrsg.): Almanach des Schocken Verlags auf das Jahr 5697. Berlin: Schocken 1936/37, S. 175-176.

Schocken Reader II. Excerpts From New Publications and Books in Preparation. Winter 1947/48, hrsg. v. Hannah Arendt. New York: Schocken Books 1947.

Scholem, Gershom: Von Berlin nach Jerusalem. Jugenderinnerungen. Frankfurt am Main: Suhrkamp 1978.

Walter Benjamnin - Gershom Scholem. Briefwechsel 1933-1940, hrsg. v. Gershom Scholem. Frankfurt am Main: Suhrkamp 1980.

Simon, Ernst: Der Schocken Verlag. In: Jüdische Rundschau, 12.11.1937, S.9.

Eine Bemerkung über Leopold Zunz. Bruchstück einer Arbeit über die westjüdische Aufklärung im 19. Jahrhundert. In: Moritz Spitzer (Hrsg.): Almanach des Schocken Verlags auf das Jahr 5699. Berlin: Schocken 1938/1939, S.65-68.

Sotheby's: Important Hebrew Books From the Library of the Late Salman Schocken. Catalogue of Auction Held in London on Monday, $6^{\text {th }}$ December, 1993. London: Sotheby's 1993.

Steinberg, Jehuda: Der Soldat des Zaren. Jüdische Jugendbücherei 2. Berlin: Jüdischer Verlag 1920. 
Stern, Gerson: Jüdischer Roman in Deutschland. In: Israelitisches Familienblatt, 28.04.1938, S.28.

The Commission on European Jewish Cultural Reconstruction: Tentative List of Jewish Cultural Treasures in Axis-Occupied Countries. In: Jewish Social Studies 8,1 Supplement (1946), S. 1-103.

Verband Deutscher Volksbibliothekare: Zum Umbau des deutschen Volksbüchereiwesens. In: Bücherei und Bildungspflege 13 (1933), S. 169-170.

Weizmann, Chaim: Aus der Rede von Chaim Weizmann anlässlich der Grundsteinlegung der hebräischen Universität auf dem Skopusberg am 24. Juli 1918. In: Zionist Organization / University Committee: Die Hebräische Universität in Jerusalem anlässlich der Eröffnung am siebenten Nissan 5685, ersten April 1925. Berlin: Marx 1925, S. 12-13.

Weltsch, Robert: Schluss der Jahreskonferenz. Erstes Resumé. Von unserem Berichterstatter. In: Jüdische Rundschau, 05.09.1922, S. 467.

Fanal und Besinnung. In: Jüdische Rundschau, 12.05.1933, S. 187-190.

[Weltsch, Robert / Siegmund Kaznelson]: An unsere Leser. In: Jüdische Weltrundschau, 10.03.1939, S. 1.

Wolff, Helen: Kurt Wolff. Lebensdaten. Aus den Tagebuchaufzeichnungen, Notizen, Briefen und Vorträgen zusammengestellt. In: Kurt Wolff: Autoren, Bücher, Abenteuer. Betrachtungen und Erinnerungen eines Verlegers. Berlin: Wagenbach 1965, S. 103-112.

Wolff, Kurt: Autoren, Bücher, Abenteuer. Betrachtungen und Erinnerungen eines Verlegers. Berlin: Wagenbach 1965.

Wünsche, August: Der Midrasch Echa Rabbati. Das ist die Haggadaische Auslegung der Klagelieder. Zum ersten Male ins Deutsche übertragen. Leipzig: Schulze 1881.

Yaari, Abraham: Schocken-Sammlung hebräischer Inkunablen der Jüdischen Nationalund Universitätsbibliothek. In: Mitteilungsblätter der Hebräischen Universität Jerusalem 4 (1938), S. 39-41.

Zobel, Moritz: Das Jahr der Juden in Brauch und Liturgie. Bücherei des Schocken Verlages, Bd. 55/56. Berlin: Schocken 1936.

Zusammenstellung der Anträge, die vom XIII. Delegiertentag zum Beschluss erhoben wurden. In: Jüdische Rundschau, 14.06.1912, S. 222.

Zweig, Stefan: Salman Schocken - 70 Jahre. In: Mitteilungsblatt der Alijah Chadaschah 11,44 (1947), S. 5-6. 


\section{Forschungsliteratur}

Aigner, Dietrich: Die Indizierung, schädlichen und unerwünschten Schrifttums' im Dritten Reich. Sonderdruck aus dem Archiv für Geschichte des Buchwesens. Bd.XI, Lieferung 3-5. Frankfurt am Main: Buchhändler-Vereinigung 1971.

Akademie der Künste (Hrsg.): Geschlossene Vorstellung. Der Jüdische Kulturbund in Deutschland, 1933-1941. Berlin: Hentrich 1992.

Anderson, Benedict: Imagined Communities. Reflections on the Origin and Spread of Nationalism [1983]. London: Verso 2006.

Aue-Ben-David, Irene: Deutsch-jüdische Geschichtsschreibung im 20. Jahrhundert. Zu Werk und Rezeption von Selma Stern. Göttingen: Vandenhoeck \& Ruprecht 2017. https://doi. org/10.13109/9783666370519

Bachmann-Medick, Doris: Cultural Turns. Neuorientierung in den Kulturwissenschaften. Hamburg: Rowohlt 2006.

Bade, Klaus J.: Sozialhistorische Migrationsforschung. Göttingen: V\&R unipress 2004.

Bajohr, Frank: ,Arisierung ' in Hamburg. Die Verdrängung der jüdischen Unternehmer in Hamburg 1933-1945. Hamburg: Christians 1998.

Barbian, Jan-Pieter: Literaturpolitik im,Dritten Reich`. Institutionen, Kompetenzen, Betätigungsfelder. Überarb. u. akt. Aufl. München: dtv 1995.

Literaturpolitik im NS-Staat. Von der, Gleichschaltung'bis zum Ruin. Überarb. Ausg. Frankfurt am Main: Fischer 2010.

Barkai, Avraham: German Interests in the Haavara-Transfer Agreement 1933-1939. In: LBIYB 35,1 (1990), S.245-266. https://doi.org/10.1093/leobaeck/35.1.245

Barnai, Jacob: Jüdische National- und Universitätsbibliothek. In: EJGK, Bd. 3, hrsg. v. Dan Diner. Stuttgart / Weimar: Metzler 2012, S.249-251.

Barzilay, Isaac E.: Hayyim (Jefim) Schirmann (1904-1981). In: Proceedings of the American Academy for Jewish Reserearch 49 (1982), S. xxv-xxxi.

Basu, Paul / Simon Coleman: Introduction. Migrant Worlds, Material Cultures. In: Mobilities 3,3 (2008), S.313-330. https://doi.org/10.1080/17450100802376753

Bauer, Yehuda: Jews for Sale? Nazi-Jewish Negotiations, 1933-1945. New Haven: Yale UP 1994. https://doi.org/10.1080/03612759.1995.9949198

Bauschinger, Sigrid: Else Lasker-Schüler. Ihr Werk und ihre Zeit. Heidelberg: Stiehm 1980.

Else Lasker-Schüler. Biographie. Göttingen: Wallstein 2004.

/ Hermann, Helmut G: Einleitung. In: Else Lasker-Schüler: ,Was soll ich hier?'Exilbriefe an Salman Schocken. Heidelberg: Lambert Schneider 1986, S. 13-35. 
Beer, Mathias / Dittmar Dahlmann: Einleitung. In: Dies.(Hrsg.): Über die trockene Grenze und über das offene Meer. Binneneuropäische und transatlantische Migration im 18. und 19. Jahrhundert. Essen: Klartext 2004, S.7-14.

Beling, Eva: Die gesellschaftliche Eingliederung der deutschen Einwanderer in Israel. Eine soziologische Untersuchung der Einwanderung aus Deutschland zwischen 1933 und 1945. Frankfurt am Main: EVA 1967.

Ben Elissar, Eliahu: La diplomatie du IIIème Reich et les juifs (1933-1939). Paris: Julliard 1969.

Ben-David, Joseph: Universities in Israel. Dilemmas of Growth, Diversifiction and Administration. In: Studies in Higher Education 11,2 (1986), S. 105-130. https://doi.org/ 10.1080/03075078612331378340

Benjamin, Walter: Werke und Nachlaß. Kritische Gesamtausgabe, Bd. 19, hrsg. v. Gérard Raulet. Berlin: Suhrkamp 2010.

Bertaux, Pierre: Die Bücherverbrennung in Berlin am 10. Mai 1933. In: Hermann Haarmann / Walter Huder / Klaus Siebenhaar (Hrsg.): ,Das war ein Vorspiel nur.... Bücherverbrennung Deutschland 1933. Voraussetzungen und Folgen. Ausstellungskatalog Akademie der Künste. Berlin: Medusa 1983, S.228-231.

Bischoff, Doerte: Exile, Trauma and the Modern Jewish Experience. The Example of Else Lasker-Schüler. In: Bernhard Greiner (Hrsg.): Placeless Topographies. Jewish Perspectives on the Literature of Exile. Tübingen: Niemeyer 2003, S. 127-159.

/ Joachim Schlör: Dinge des Exils. Zur Einleitung. In: Exilforschung. Ein internationales Jahrbuch 31 (2013): Dinge des Exils, S.9-20.

Black, Edwin: The Transfer Agreement. The Dramatic Story of the Pact Between the Third Reich and Jewish Palestine. Überarb. Aufl. New York: Carroll \& Graf 2001.

Böcking, David: Deutschland muss Erben von Kaufhauskette entschädigen. In: Spiegel Online, 12.06.2014. http://www.spiegel.de/wirtschaft/unternehmen/schockendeutschland-muss-erben-von-kaufhauskette-entschaedigen-a-974796.html (Zugriff am 19.02.2020).

Bödeker, Hans Erich: Biographie. Annäherung an den gegenwärtigen Forschungs- und Diskussionsstand. In: Ders. (Hrsg.): Biographie schreiben. Göttingen: Wallstein 2003, S.9-63.

Bodenheimer, Alfred: Die auferlegte Heimat. Else Lasker-Schülers Emigration in Palästina. Tübingen: Niemeyer 1995. https://doi.org/10.1515/9783110964844

Borrmann, Antje / Doreen Mölders / Sabine Wolfram (Hrsg.): Konsum und Gestalt. Leben und Werk von Salman Schocken und Erich Mendelsohn vor 1933 und im Exil. Berlin: Hentrich \& Hentrich 2016. 
Bourdieu, Pierre: Die feinen Unterschiede. Kritik der gesellschaftlichen Urteilskraft, aus d. Franz. v. Bernd Schwibs / Achim Russer. Frankfurt am Main: Suhrkamp 1987.

Die biographische Illusion. In: Ders.: Praktische Vernunft. Zur Theorie des Handelns, aus d. Franz. v. Hella Beister. Frankfurt am Main: Suhrkamp 1998, S.75-83.

Praktische Vernunft. Zur Theorie des Handelns, aus d. Franz. v. Hella Beister. Frankfurt am Main: Suhrkamp 1998.

Die Regeln der Kunst. Genese und Struktur des literarischen Feldes. Frankfurt am Main: Suhrkamp 2001.

Die verborgenen Mechanismen der Macht, aus d. Franz. v. Jürgen Bolder. Hamburg: VSA 2005.

Bourel, Dominique: Martin Buber. Was es heisst, ein Mensch zu sein. Gütersloh: Gütersloher Verlagshaus 2017.

Braese, Stephan: Deutsche Sprache, jüdisches Exil - Optionen von ,Identität' nach 1933. In: Hans Otto Horch / Hanni Mittelmann / Karin Neuburger (Hrsg.): Exilerfahrung und Konstruktionen von Identität 1933 bis 1945. Berlin: de Gruyter 2013, S. 7-16.

Brandes, Detlef: Die Sudetendeutschen im Krisenjahr 1938. München: Oldenbourg 2008. Brenner, Hildegard: Die Kunstpolitik des Nationalsozialismus. Reinbek: Rowohlt 1963.

Brenner, Michael: Rezension zu Anthony David. The Patron: A Life of Salman Schocken, 1877-1959. In: Jewish 2uarterly Review 96,3 (2006), S. 457-460. https://doi.org/10.1353/ jqr.2006.0023

Brinkmann, Tobias: Migration und Transnationalität. Paderborn: Schöningh 2012. https://doi.org/10.30965/9783657771646

Brody, Heinrich (R. Salomonsohn, Chaim Brody). In: Handbuch österreichischer Autorinnen und Autoren jüdischer Herkunft 18. bis 20. Jahrhundert, hrsg. v. d. Österreichischen Nationalbibliothek. Oldenburg: de Gruyter Saur 2002, S. 173-174.

Burgess, Greg: The League of Nations and the Refugees From Nazi Germany. James G. McDonald and Hitler's Victims. London: Bloomsbury Academic 2016.

Carassus, Émilien: Bibliothèque-Fiction. In: Littératures. Études de littérature moderne. Annales publiées par la Faculté des lettres de Toulouse 11 (1984), S. 97-105. https://doi. org/10.3406/litts.1984.1307

Castles, Stephen: The Age of Migration. International Population Movements in the Modern World. Basingstoke: Palgrave Macmillan 2009.

Centre d'études guerres et sociétés contemporaines / Frank Caestecker / Bob Moore (Hrsg.): Refugees From Nazi Germany and the Liberal European States. New York: Berghahn 2010. 
Dachs, Gisela (Hrsg.): Die Jeckes. Frankfurt am Main: Jüdsicher Verlag 2005.

Dahm, Volker: Das jüdische Buch im Dritten Reich. Frankfurt am Main: BuchhändlerVereinigung 1979.

Anfänge und Ideologie der Reichskulturkammer. Die ,Berufsgemeinschaft‘ als Instrument kulturpolitischer Steuerung und sozialer Reglementierung. In: Vierteljabreszeitschrift für Zeitgeschichte 34,1 (1986), S. 53-84.

Salman Schocken. In: Saskia Schreuder / Claude Weber (Hrsg.): Der Schocken-Verlag/ Berlin. Jüdische Selbstbehauptung in Deutschland 1931-1938. Berlin: Akademie 1994, S. 15-35.

Dak, Michael: Israelis aus Not. Über die unsanfte Landung im Lande der Verheissung. In: Moshe Zimmermann / Yotam Hotam (Hrsg.): Zweimal Heimat. Die Jeckes zwischen Mitteleuropa und Nahost. Frankfurt am Main: beerenverlag 2005, S. 125-131.

Darnton, Robert: What Is the History of Books? In: Deadalus 111,3 (1982), S.65-83.

David, Anthony: The Patron. A Life of Salman Schocken, 1877-1959. New York: Metropolitan Books 2003.

Davidowicz, Klaus S.: Rückführung zum Judentum. Der ,jüdische Mensch von heute und die Tradition. In: Saskia Schreuder / Claude Weber (Hrsg.): Der Schocken-Verlag/Berlin. Jüdische Selbstbehauptung in Deutschland 1931-1938. Berlin: Akademie 1994, S. 115-128.

Dean, Martin: Robbing the Jews. The Confiscation of Jewish Property in the Holocaust 1933-1945. New York: Cambridge UP 2008.

Denkler, Horst / Eberhard Lämmert (Hrsg.): ,Das war ein Vorspiel nur.... Berliner Colloquium zur Literaturpolitik im ,Dritten Reich'. Berlin: Akademie der Künste 1985.

Diamant, Adolf: Zur Chronik der Juden in Zwickau. Dem Gedenken einer kleinen jüdischen Gemeinde in Sachsen. Frankfurt am Main: Selbstverlag 1971.

Chronik der Juden in Leipzig. Chemnitz: Heimatland Sachsen 1993.

Dieckhaut, Kirsten: Verkehrte Bücherwelten. Eine kulturgeschichtliche Studie über deformierte Bibliotheken in der französischen Literatur. München: Fink 2004.

Diner, Dan: Einleitung. In: Ders. (Hrsg.): Historische Migrationsforschung. Gerlingen: Bleicher 1998, S. 1 -4.

Jeckes. Ursprung und Wandel einer Zuschreibung. In: Moshe Zimmermann / Yotam Hotam (Hrsg.): Zweimal Heimat. Die Jeckes zwischen Mitteleuropa und Nahost. Frankfurt am Main: beerenverlag 2005, S. 100-103.

Divine, Donna Robinson: Exiled in the Homeland. In: Shofar. An Interdisciplinary Journal of Jewish Studies 21,2 (2003), S.66-81. https://doi.org/10.1353/sho.2002.0140

Exiled in the Homeland. Zionism and the Return to Mandate Palestine. Austin: U of Texas P 2009. 
Dolev, Diana: The Planning and Building of the Hebrew University, 1919-1948. Facing the Temple Mount. Lanham / Boulder / New York / London: Lexington 2016.

/ Haim Gordon: The Architectural Challenge of a Jewish Studies House at the Hebrew University. A Lost Opportunity. In: Shofar. An Interdisciplinary Journal of Jewish Studies 11,1 (1992), S. 1-11. https://doi.org/10.1353/sho.1992.0063

Döring, Jörg / Tristan Thielmann: Einleitung. Was lesen wir im Raume? Der Spatial Turn und das geheime Wissen der Geographen. In: Dies. (Hrsg.): Spatial Turn. Das Raumparadigma in den Kultur-und Sozialwissenschaften. Bielefeld: Transcript 2008, S.9-45. https://doi.org/10.14361/9783839406830

Durkheim, Émile: Die elementaren Formen des religiösen Lebens, aus d. Franz. v. Ludwig Schmidts. Frankfurt am Main: Suhrkamp 1981.

Ettinger, Shmuel: Drittes Buch. Vom 17. Jahrhundert bis zur Gegenwart. Die Neuzeit. In: Haim Hillel Ben Sasson (Hrsg.): Geschichte des jüdischen Volkes. Von den Anfängen bis zur Gegenwart. 5. erw. Ausg. München: Beck 2007, S. 887-1348.

Faber, David: Munich. The 1938 Appeasement Crisis. London: Pocket Books 2009.

Febvre, Lucien / Henri-Jean Martin: L'apparition du livre. Paris: Albin Michel 1958.

Feilchenfeld, Werner / Dolf Michaelis / Ludwig Pinner (Hrsg.): Haavara-Transfer nach Palästina und Einwanderung deutscher Juden 1933-1939. Tübingen: Mohr Siebeck 1972.

Finkel, Samuel B.: American Jews and the Hebrew University. In: American Jewish Yearbook 39 (1938), S. 193-201.

Fischer, Erica / Simone Ladwig-Winters: Die Wertheims. Geschichte einer Familie. Berlin: Rowohlt 2004.

Fischer, Ernst: Zerstörung einer Buchkultur. Die Emigration jüdischer Büchersammler aus Deutschland. In: Imprimatur. Ein Jahrbuch für Bücherfreunde XVII (2002), S. 176-195.

Fleury, Michèle / Valérie Boillat: Die Schweiz und die Flüchtlinge zur Zeit des Nationalsozialismus. Zürich: Chronos 2001.

Flint, Peter B.: Gershom G. Schocken, 78, Editor of Israeli Newspaper for 50 Years. In: The New York Times, 24.12.1990, S. 48.

Foucault, Michel: Andere Räume, aus d. Franz. v. Walter Seitter. In: Karlheinz Barck / Peter Gente / Heidi Paris / Stefan Richter (Hrsg.): Aisthesis. Wahrnebmung heute oder Perspektiven einer anderen Ästhetik. Essais. Leipzig: Reclam 1992, S.34-46.

Freeden, Herbert: Requiem für die Jekken. In: Alice Schwarz-Gardos (Hrsg.): Heimat ist anderswo. Freiburg i. Br.: Herder 1983, S. 18-30. 
Frielinghaus, Helmut (Hrsg.): Kurt Wolff zum Hundertsten. Hamburg: Kellner 1987.

Fuchs, Konrad: Zur Geschichte des Warenhaus-Konzerns I. Schocken Söhne. Unter besonderer Berücksichtigung der Jahre seit 1933. In: Zeitschrift für Unternehmensgeschichte 33,4 (1988), S. 232-252. https://doi.org/10.1515/zug-1988-0403

Ein Konzern aus Sachsen. Das Kaufhaus Schocken als Spiegelbild deutscher Wirtschaft und Politik 1901 bis 1953. Stuttgart: DVA 1990.

Gallas, Elisabeth: Das Leichenhaus der Bücher. Kulturrestitution und jüdisches Geschichtsdenken nach 1945. Göttingen: Vandenhoeck \& Ruprecht 2013. https://doi.org/10.13109/ 9783666369575

Gebel, Ralf: ,Heim ins Reich!' Konrad Henlein und der Reichsgau Sudetenland (1938-1945). München: Oldenbourg 2000.

Geisel, Eike / Henryk M. Broder (Hrsg.): Premiere und Pogrom. Der Jüdische Kulturbund 1933-1941. Texte und Bilder. Berlin: Siedler 1992.

Gelber, Yoav: המדיניות הציונית והסכם ההעברה [Zionistische Grundsätze und das Ha'avaraAbkommen]. In: Yalkut Moreshet 1,XVII (1974), S. 97-152.

המדיניות הציונית והסכם ההעברה [Zionistische Grundsätze und das Ha'avara-Abkommen]. In: Yalkut Moreshet 2,XVIII (1974), S.23-100.

Goren, Arthur A.: The View From Scopus. Judah L. Magnes und the Early Years of the Hebrew University. In: Modern Jewish Studies 45,2 (1996), S. 203-224.

Goschler, Constantin / Philipp Ther (Hrsg.): Raub und Restitution. ,Arisiserung und Rückerstattung jüdischen Eigentums in Europa. Frankfurt am Main: Fischer 2003.

Greif, Gideon / Colin McPherson / Laurence Weinbaum (Hrsg.): Die Jeckes. Deutsche Juden aus Israel erzählen. Mit einem Geleitwort von Dan Diner. Köln: Böhlau 2000.

Haas, Willy (Hrsg.): Franz Kafka. Briefe an Milena. Berlin: S. Fischer 1975.

Habermas, Jürgen: Theorie des kommunikativen Handelns. Zur Kritik der funktionalistischen Vernunft. Frankfurt am Main: Suhrkamp 1981.

Das Konzept der Lebenswelt und der hermeneutische Idealismus der verstehenden Soziologie. In: Ders. (Hrsg.): Theorie des kommunikativen Handelns. Zur Kritik der funktionalistischen Vernunft. Frankfurt am Main: Suhrkamp 1995, S. 190-209, 222-228.

Hambrock, Matthias: Das, jüdische Buch' und seine Verlage im deutschsprachigen Raum. In: Handbuch der deutsch-jüdischen Literatur, hrsg. v. Hans Otto Horch. Berlin: de Gruyter 2015, S. 539-554. https://doi.org/10.1515/9783110282566-034 
Haumann, Heiko: Lebensweltlich orientierte Geschichtschreibung in den Jüdischen Studien. Das Basler Beispiel. In: Klaus Hödl (Hrsg.): Jüdische Studien. Reflexionen und Praxis eines wissenschaftlichen Feldes. Innsbruck: Studienverlag 2003, S. 105-122.

Geschichte, Lebenswelt, Sinn. Über die Interpretation von Selbstzeugnissen. In: Brigitte Hilmer / Georg Lohmann / Tilo Wesche (Hrsg.): Anfang und Grenzen des Sinns. Weilerswist: Velbrück Wissenschaft 2006, S.42-54.

Heim, Susanne: International Refugee Policy and Jewish Immigration Under the Shadow of National Socialism. In: Frank Caestecker / Bob Moore (Hrsg.): Refugees From Nazi Germany and the Liberal European States. New York: Berghahn 2010, S. 17-47.

Heinze-Greenberg, Ita: Erich Mendelsohn. Bauten und Projekte in Palästina (1934-1941). München: Scaneg 1986.

,Ich bin ein freier Bauer.' Bauen in Palästina 1934-1941. In: Regina Stephan (Hrsg.): Erich Mendelsohn. Architekt 1887-1953. Gebaute Welten. Arbeiten für Europa, Palästina und Amerika. Ostfildern-Ruit: Hatje 1998.

Erich Mendelsohn. ,Bauen ist Glückseligkeit‘. Berlin: Hentrich \& Hentrich 2011.

„Palästina verpflichtet!!!“. Der Jerusalemer Emigrantenkreis um Else Lasker-Schüler, Salman Schocken, Erich Mendelsohn. In: Burcu Dogramaci / Karin Wimmer (Hrsg.): Netzwerke des Exils. Künstlerische Verflechtung, Austausch und Patronage nach 1933. Berlin: Gebr. Mann 2011, S.31-49.

/ Regina Stephan (Hrsg.): Erich Mendelsohn. Gedankenwelten. Unbekannte Texte zu Architektur, Kulturgeschichte und Politik. Ostfildern-Ruit: Hatje Cantz 2000.

Herbert, Ulrich: Über Nutzen und Nachteil von Biographien in der Geschichtswissenschaft. In: Beate Böckem / Olaf Peters / Barbara Schellewald (Hrsg.): Die Biographie - Mode oder Universalie? Zu Geschichte und Konzept einer Gattung in der Kunstgeschichte. Berlin: de Gruyter 2015, S.3-15. https://doi.org/10.1515/9783110404425-002

Hessing, Jakob: Else Lasker-Schüler. Biographie einer deutsch-jüdischen Dichterin. Karlsruhe: Loeper 1985.

Heyd, Werner P.: Marx, Leopold. In: Neue deutsche Biographie. Bd. 16, hrsg. v. Otto zu Stolberg-Wernigerode. Berlin: Maly-Melanchthon 1990, S. 347.

Hilberg, Raul: Die Vernichtung der europäischen Juden, Bd. 1, aus d. Amer. v. Christian Seeger / Harry Maor / Walle Bengs / Wilfried Szepan. 9. erw. Aufl. Frankfurt am Main: Fischer 1998.

Hinrichs, Tomke: Fluchthilfe. Der Ankauf der Bibliothek von Karl Wolfskehl durch Salman Schocken. In: Medaon - Magazin für jüdisches Leben in der Forschung und Bildung 13 (2013), S. 1-4.

Hirschfeld, Ariel: Schocken und Agnon. Münz und Masal. In: Saskia Schreuder / Claude Weber (Hrsg.): Der Schocken-Verlag/Berlin. Jüdische Selbstbehauptung in Deutschland 1931-1938. Berlin: Akademie 1994, S. 191-200. 
Hoffmann, Adina: Till We Have Built Jerusalem. Architects of a New City. New York: Farrar, Straus \& Giroux 2016.

Högerle, Heinz / Träger- und Förderverein Ehemalige Synagoge Rexingen (Hrsg.): Ort der Zuflucht und Verheissung. Shavei Zion 1938-2008. Darmstadt: WBG Theiss 2008.

Hölter, Achim: Kritische Marginalie. Zum Motiv der Bibliothek in der Literatur. In: Arcadia. Zeitschrift für Vergleichende Literaturwissenschaft 28,1 (1993), S. 65-72. https:// doi.org/10.1515/arca.1993.28.1.65

Hoppe, Heinz-Hermann: Zur Buchgestaltung des Schocken Verlages. In: Saskia Schreuder / Claude Weber (Hrsg.): Der Schocken-Verlag/Berlin. Jüdische Selbstbehauptung in Deutschland 1931-1938. Berlin: Akademie 1994, S. 321-326.

Hörner, Unda: Orte jüdischen Lebens in Berlin. Literarische Spaziergänge durch die Mitte. Berlin: Insel 2010.

Hörnig, Herbert: Brüning. Politiker ohne Auftrag. Zwischen Weimarer und Bonner Republik. Paderborn: Schöningh 2005.

Howsam, Leslie: Old Books and New Histories. An Orientation to Studies in Book and Print Culture. Toronto: U of Toronto P 2006.

Hoyles, John: The Literary Underground. Writers and the Totalitarian Experience, 1900-1950. New York: St. Martin's 1991.

Hübner, Reinhard: Arabisches Wirtschaftsleben. Heidelberg/Berlin: Vowinckel 1943.

Husserl, Edmund: Die Phänomenologie der Lebenswelt. Ausgewählte Texte II. Überarb. Aufl. Stuttgart: Reclam 2007.

Iggers, Georg G.: Geschichtswissenschaft im 20. Jahrhundert. Ein kritischer Überblick im internationalen Zusammenhang. Berlin: Vandenhoeck \& Ruprecht 2007.

Iggers, Wilma: Herrmann, Leo. In: YIVO Encyclopedia of Jews in Eastern Europe, Bd. 1, hrsg. v. Gershon David Hundert. New Haven / London: Yale UP 2008, S. 713-714.

Iram, Yaacov: Higher Education in Transition - The Case of Israel. A Comparative Study. In: Higher Education 9 (1980), S. 81-95. https://doi.org/10.1007/BF00149137

Jacobson, Manfred R. / Jacobson Evelyn M: Max Horkheimer. A Life in Letters. Selected Correspondence. Lincoln, NE: U of Nebraska P 2007.

Jansen, Dorothea: Einführung in die Netzwerkanalyse. Grundlagen, Methoden, Forschungsbeispiele. 3. überarb. Aufl. Wiesbaden: VS 2006.

/ Rainer Diaz-Bone: Netzwerkstrukturen als soziales Kapital. In: Johannes Weyer (Hrsg.): Soziale Netzwerke. Konzepte und Methoden der sozialwissenschaftlichen Netzwerkforschung. München: Oldenbourg 2011, S.73-108. 
Jessen, Caroline: My Blue Piano. Else Lasker-Schüler's Last Poetry Volume, Jerusalem 1943. In: Ada Wardi (Hrsg.): New Types. Three Pioneers of Hebrew Graphic Design. Jerusalem: Israel Museum Jerusalem 2016, S. 167-171.

Das problematische Bild der geretteten Kultur. Büchersammlungen deutsch-jüdischer Einwanderer in Israel. In: Tel Aviver Jahrbuch für deutsche Geschichte 41 (2013): Deutsche(s) in Palästina und Israel. Alltag, Kultur, Politik, S. 179-194.

Franzisca Baruch's Marzipan Biscuits From Jerusalem. In: Ada Wardi (Hrsg.): New Types. Three Pioneers of Hebrew Graphic Design. Jerusalem: Israel Museum Jerusalem 2016, S. 214-217.

Der Sammler Karl Wolfskehl. Berlin: Jüdischer Verlag 2018.

Jung, Marcus: Kaufhaus Schocken. Prozessrechtler Schmitz erreicht Entschädigung für Erben. In: juve. Neues aus dem Wirtschaftsanwaltsmarkt, 16.06.2014. http://www. juve-verlag.at/nachrichten/verfahren/2014/06/kaufhaus-schocken-prozessrechtlerschmitz-erreicht-entschadigung-fur-erben (Zugriff am 31.01.2017).

Jurt, Joseph: Die Theorie des literarischen Feldes von Pierre Bourdieu. In: LiTheS. Zeitschrift für Literatur- und Theatersoziologie 1 (2008), S. 5-14.

Jütte, Robert: Die Emigration der deutschsprachigen, Wissenschaft des Judentums.' Die Auswanderung jüdischer Historiker nach Palästina 1933-1945. Stuttgart: Steiner 1991.

Kawałko, Anna: The Dual Dynamics of Postwar Cultural Restoration. On the Salvage and Destruction of the Breslau Rabbinical Library. In: Dies. / Yfaat Weiss / Caroline Jessen / Elisabeth Gallas (Hrsg.): Contested German Jewish Cultural Property After 1945. The Sacred and the Profane. Göttingen: Vandenhoeck \& Ruprecht 2019, S.92-102.

From Breslau to Wrocław: Transfer of the Saraval Collection to Poland and the Restitution of Jewish Cultural Property After WWII. In: Naharaim 9,1-2 (2015), S. 48-72. https://doi.org/10.1515/naha-2015-0006

Kilcher, Andreas: Deutsche Sprachkultur in Palästina und Israel im 20. Jahrhundert. Historisch-politischer Kontext und literarische Kultur. In: Ders. / Eva Edelmann-Ohler (Hrsg.): Deutsche Sprachkultur in Palästina / Israel. Geschichte und Bibliographie. Berlin: de Gruyter 2016, S.9-63. https://doi.org/10.1515/9783110441758-002

Kirchhoff, Markus: Looted Texts. Restituting Jewish Libraries. In: Dan Diner / Gotthart Wunberg (Hrsg.): Restitution and Memory. Material Restoration in Europe. New York / Oxford: Berghahn 2007, S. 161-188.

Knaupe, Henk / Ulrich G. Wurzel: Die Jewish Agency und die IG Farben. Das HaavaraAbkommen und die wirtschaftliche Entwicklung Palästinas. Berlin: Schwarz 1994.

Köstler, Eberhard: Bücher Bücher Bücher Bücher. Aus der Blütezeit der Münchner Bibliophilie. In: Imprimatur. Ein Jahrbuch für Bücherfreunde XXII (2009), S. 259-286. 
Kotzin, Daniel P.: Judah L. Magnes. An American Nonconformist. New York: Syracuse UP 2010.

Kraft, Christian: Aschkenas in Jerusalem. Die religiösen Institutionen der Einwanderer aus Deutschland im Jerusalemer Stadtviertel Rechavia (1933-2004). Transfer und Transformation. Göttingen: Vandenhoeck \& Ruprecht 2014. https://oi.org/10.13109/ 9783666570346

Kreft, Gerald: Zürich und die Notgemeinschaft Deutscher Wissenschaftler im Ausland. In: Schriftenreihe der Deutschen Gesellschaft für Geschichte der Nervenheilkunde 18 (2012), S. 101-129.

Kreutzmüller, Christoph: Vernichtung der jüdischen Gewerbetätigkeit im Nationalsozialismus. Abläufe, Blickwinkel und Begrifflichkeiten. In: Docupedia-Zeitgeschichte, 04.11.2016. docupedia.de/zg/Kreutzmueller_vernichtung_der_juedischen_Gewerbe taetigkeit_v1_de_2016 (Zugriff am 12.02.2020).

Krohn, Carsten: Hoffnung für die Schocken-Villa. In Israel wird der Umgang mit Erich Mendelsohns Bauten neu diskutiert. In: NZZ, 15.03.2013, S. 50.

Kroyanker, David: Die Architektur Jerusalems. 3000 Jabre Heilige Stadt. Mit einer Einleitung von Teddy Kollek. Stuttgart: Kolhammer 1994.

Rechavia. Das ,Jeckenland' von Jerusalem. In: Moshe Zimmermann / Yotam Hotam (Hrsg.): Zweimal Heimat. Die Jeckes zwischen Mitteleuropa und Nahost. Frankfurt am Main: beerenverlag 2005, S. 260-266.

Lappin, Eleonore: Der Jude 1916-1928. Jüdische Moderne zwischen Universalismus und Partikularismus. Tübingen: Mohr Siebeck 2000.

Laqueur, Walter: Der Weg zum Staat Israel. Geschichte des Zionismus, aus d. Engl. v. Heinrich Jelinek. Wien: Europa 1975.

A History of Zionism. With a New Preface by the Author. New York: Schocken Books 1989.

Lässig, Simone: Jüdische Wege ins Bürgertum. Kulturelles Kapital und sozialer Aufstieg im 19. Jahrhundert. Göttingen: Vandenhoeck \& Ruprecht 2004.

Die historische Biographie auf neuen Wegen? In: Geschichte in Wissenschaft und Unterricht 10 (2009), S. 540-553.

Le Déaut, Roger: A propos d'une définition du midrash. In: Biblica 50,3 (1969), S.395-413.

Lehnhardt, Peter S.: Das Forschungsinstitut für hebräische Dichtung und sein Beitrag zur Kenntnis der hebräischen Dichtung des Mittelalters. In: Saskia Schreuder / Claude Weber (Hrsg.): Der Schocken-Verlag/Berlin. Jüdische Selbstbehauptung in Deutschland 1931-1938. Berlin: Akademie 1994, S.299-320. 
Leuenberger, Stefanie: Schrift-Raum Jerusalem. Identitätsdiskurse im Werk deutschjüdischer Autoren. Köln: Böhlau 2007.

Loewenstein, Kurt: Die innerjüdische Reaktion auf die Krise der deutschen Demokratie. In: Werner E. Mosse (Hrsg.): Entscheidungsjahr 1932. Zur Judenfrage in der Endphase der Weimarer Republik. Tübingen: Mohr Siebeck 1966, S. 349-404.

Löhr, Isabella: Solidarity and the Academic Community. The Support Networks for Refugee Scholars in the 1930s. In: Journal of Modern European History 12,2 (2014): Ideas, Practices and Histories of Humanitarianism, S. 231-246. https://doi.org/10.17104/ 1611-8944_2014_2_231

Löwinger, Samuel / Bernard D. Weinryb: Catalogue of the Hebrew Manuscripts in the Library of the Jüdisch-Theologisches Seminar in Breslau. Wiesbaden: Harrassowitz 1965.

Lüdi, Regula: Dwindling Options. Seeking Asylum in Switzerland 1933-1939. In: Frank Caestecker / Bob Moore (Hrsg.): Refugees From Nazi Germany and the Liberal European States. New York: Berghahn 2013, S. 82-102.

Madison, Charles A.: Jewish Publishing in America. The Impact of Jewish Writing on American Culture. New York: Sanhedrin 1976.

Mahrer, Stefanie: Handwerk der Moderne. Jüdische Uhrmacher und Uhrenunternehmer im Neuenburger Jura 1800-1914. Köln: Böhlau 2012. https://doi.org/10.7788/ boehlau. 9783412215408

'Much More than Just another Private Collection'. The Schocken Library and Its Rescue From Nazi Germany in 1945. In: Naharaim. Zeitschrift für deutsch-jüdische Literatur und Kulturgeschichte 9,1 (2015), S. 4-24. https://doi.org/10.1515/naha2015-0003

Salman Schockens Lebensjahre in Palästina. In: Antje Borrmann / Doreen Mölders / Sabine Wolfram (Hrsg.): Konsum und Gestalt. Leben und Werk von Salman Schocken und Erich Mendelsohn vor 1933 und im Exil. Berlin: Hentrich \& Hentrich 2016, S. 103-122.

Schreiben aus den Katakomben. Bücher als Widerstand. Der Schocken Verlag Berlin in den Jahren 1933 bis 1938. In: Julius H. Schoeps / Dieter Bingen / Gideon Botsch (Hrsg.): Jüdischer Widerstand in Europa (1933-1945). Formen und Facetten. Berlin: de Gruyter 2016, S. 222-239.

Tradition and Modernity. Salman Schocken and the Aestheticisation of Everyday Life. In: Ada Wardi (Hrsg.): New Types. Three Pioneers of Hebrew Graphic Design. Jerusalem: Israel Museum Jerusalem 2016, S. 58-71.

Texts and Objects. The Books of the Schocken Publishing Houses in the Context of Their Time. In: Rachel Seelig / Amir Eschel (Hrsg.): The German-Hebrew. Dialogue Studies of Encounter and Exchange. Berlin: de Gruyter 2017, S. 121-141. https://doi. org/10.1515/9783110473384-007 
Schocken und Merkur. Kontinuitäten des Unternehmens von der NS-Zeit bis in die Nachkriegszeit. In: Stefanie Fischer / Nathanael Riemer / Stefanie Schüler-Springorum (Hrsg.): Juden und Nicht-Juden nach der Schoah. Begegnungen in Deutschland. Berlin: de Gruyter 2019, S. 95-115. https://doi.org/10.1515/9783110570083-008

The Uncanny of the Schocken Villa. Interior Design and Objects of Exile. In: Yfaat Weiss / Caroline Jessen / Anna Kawałko / Elisabeth Gallas (Hrsg.): Contested German Jewish Cultural Property After 1945. The Sacred and the Profane. Göttingen: Vandenhoeck \& Ruprecht 2019, S. 185-193. https://doi.org/10.13109/9783666310836.185

Marrus, Michael R.: Evian. In: EJGK, Bd.2, hrsg. v. Dan Diner. Stuttgart / Weimar: Metzler 2012, S. 289-295.

Maschke, Manuela: Die israelische Arbeiterorganisation Histadrut. Vom Staat im Staate zur unabbängigen Gewerkschaft. Frankfurt am Main: Haag + Herchen 2003.

McDonald, Peter D.: British Literary Culture and Publishing Practice 1880-1914. Cambridge: Cambridge UP 1997.

McNamara, Katherine: A Conversation About Schocken Books Part I With Altie Karper and the Editor of Archipelago. In: Archipelago. An International Journal of Literature, the Arts, and Opinion 5,2 (2001), S.63-82.

Meinen, Insa: Verfolgt von Land zu Land. Jüdische Flüchtlinge in Westeuropa 1938-1944. Paderborn: Schöningh 2013.

Mendelssohn, Peter de: S. Fischer und sein Verlag. Frankfurt am Main: S. Fischer 1959.

Mendes-Flohr, Paul R.: Martin Buber. A Life of Faith and Dissent. New Haven / London: Yale UP 2019. https://doi.org/10.2307/j.ctvdlc9hk

Mertens, Heinrich A.: Die Schocken-Bibliothek in Jerusalem. In: Börsenblatt für den deutschen Buchhandel 13,61 (1957), S. 1047-1049.

Messner, Philipp: Von der Form der Sprache. Hebräische Renaissance und typographischer Diskurs in Deutschland zur Zeit der Weimarer Republik. In: Karin Bürger / Ines Sonder / Ursula Wallmeier (Hrsg.): Soncino-Gesellschaft der Freunde des jüdischen Buches. Ein Beitrag zur Kulturgeschichte. Berlin: de Gruyter 2014, S.42-74.

דפיפ: I,Schocken-Baruch'. Eine neue hebräische Type]. In: Ada Wardi (Hrsg.): דפוסים משתנים. מלאכת העיצוב של משה שפיצר, פרנציסקה ברוך והנרורי פThe Graphic Design of Moshe Spitzer, Franzisca Baruch and Henri Friedlaender]. Jerusalem: Israel Musem Jerusalem 2016, S. 239-255.

Hebrew Type Design in the Context of the Book Art Movement and New Typography. In: Ada Wardi (Hrsg.): New Types. Three Pioneers of Hebrew Graphic Design. Jerusalem: Israel Museum Jerusalem 2016, S.21-33. 
Meyer, Michael A.: German-Jewish Identity in Nineteenth-Century America. In: Jacob Katz (Hrsg.): Toward Modernity: The European Jewish Model. New Brunswick: Routledge 1987, S. 247-267. https://doi.org/10.4324/9781351318006-10

Judaism Within Modernity. Essays on Jewish History and Religion. Detroit: Wayne State UP 2001.

Michaeli, Ilana / Irmgard Klönne (Hrsg.): Gut Winkel. Die schützende Insel. Hachschara 1933-1941. Berlin: Lit 2007.

Michaelis, Dolf: Die wirtschaftliche und politische Entwicklung der Auswanderungs-und Transferfrage im nationalsozialistischen Deutschland. In: Ders. / Werner Feilchenfeld / Ludwig Pinner (Hrsg.): Haavara-Transfer nach Palästina und Einwanderung deutscher Juden 1933-1939. Tübingen: Mohr Siebeck 1972, S. 15-33.

Milton, John: Areopagitica, hrsg. mit Einführung und Anm. v. John M. Hales. Oxford: Clarendon 1904.

Moore, Bob: Jewish Refugees in the Netherlands 1933-1940. The Structure and Pattern of Immigration From Nazi Germany. In: LBIYB 29,1 (1984), S.73-101. https://doi.org/ 10.1093/leobaeck/29.1.73

Refugees From Nazi Germany in the Netherlands, 1933-1940. Dordrecht / Boston / Lancaster: Nijhoff 1986.

Moses, Siegfried: Salman Schocken. His Economic and Zionist Activities. In: LBIYB 5,1 (1960), S.73-104. https://doi.org/10.1093/leobaeck/5.1.73

Salman Schocken. Seine Betätigung in der Wirtschaft und als Zionist. In: Bulletin des Leo Baeck Instituts (Tel Aviv) 13,4 (1961), S. 1-43.

Mosley, James: The Technologies of Print. In: Michael F. Suarez/Henry R. Woudhuysen (Hrsg.): The Book. A Global History. Oxford: Oxford UP 2013, S. 130-153.

Mosse, George L.: Die Bildungsbürger verbrennen ihre eigenen Bücher. In: Horst Denkler / Eberhard Lämmert (Hrsg.): ,Das war ein Vorspiel nur.... Berliner Colloquium zur Literaturpolitik im ,Dritten Reich'. Berlin: Akademie der Künste 1985, S. 35-50.

Murken Barbara: Tom Seidmann-Freud. In: Kinder-und Jugendliteratur. Ein Lexikon. 32. Ergänzungslieferung, hrsg. v. Kurt Franz / Günter Lange / Franz-Josef Payrhuber. Meitinge: Corian 2008, S. 1-21.

Myers, David N.: Re-Inventing the Jewish Past. European Jewish Intellectuals and the Zionist Return to History. New York: Oxford UP 1995.

A New Scholarly Colony in Jerusalem. The Early History of Jewish Studies. In: Judaism 45,2 (1996), S. 142-159. 
Niederland, Doron: The Emigration of Jewish Academics and Professionals in the First Years of Nazi Rule. In: LBIYB 33,1 (1988), S. 285-300. https://doi.org/10.1093/leobaeck/ 33.1.285

Nietzel, Benno: Die Vernichtung der wirtschaftlichen Existenz der deutschen Juden 1933-1945. Ein Literatur- und Forschungsbericht. In: Archiv für Sozialgeschichte 49 (2009), S. 561-613.

Nora, Pierre: Entre Mémoire et Histoire. In: Ders.: Les Lieux de Mémoire, Bd. 1: La République. Paris: Gallimard 1984, S.XVII-XLII.

Oelkers, Jürgen: Biographik - Überlegungen zu einer unschuldigen Gattung. In: Neue politische Literatur 19,3 (1974), S. 296-309.

Ofrat, Gideon: Berlin - Jerusalem. Kulturhelden. In: Moshe Zimmermann / Yotam Hotam (Hrsg.): Zweimal Heimat. Die Jeckes zwischen Mitteleuropa und Nahost. Frankfurt am Main: beerenverlag 2005, S. 137-146.

Ovink, Gerrit Willem: Die Gesinnung des Typographen. Laudatio anlässlich der Verleibung des Gutenberg-Preises 1971 der Stadt Mainz am 21. Juni 1971 an Henri Friedlaender. Mainz: Gutenberg-Gesellschaft 1973.

Panter, Sarah: Jüdische Erfahrungen und Loyalitätskonflikte im Ersten Weltkrieg. Göttingen: Vandenhoeck \& Ruprecht 2014. https://doi.org/10.13109/9783666101342

Pasdermadjian, Hrant: Das Warenhaus. Entstehung, Entwicklung und wirtschaftliche Struktur. Köln / Opladen: Westdeutscher Verlag 1954. https://doi.org/10.1007/978-3322-96298-0

Perec, Georges: Träume von Räumen, aus d. Franz. v. Eugen Helmlé. Zürich: Diaphanes 2013.

Perrenoud, Marc: La place financière et les banques suisses à l'époque du national-socialisme. Les relations des grandes banques avec l'Allemagne (1931-1946). Zürich: Chronos 2002.

Poppel, Stephen M.: Writing and Reading About Salman Schocken. In: Medaon - Magazin für jüdisches Leben in der Forschung und Bildung 8,14 (2014), S. 1-15.

Salman Schocken and the Schocken Verlag. A Jewish Publisher in Weimar and Nazi Germany. In: Harvard Library Bulletin 11,1 (1973), S. 20-49.

Zionism in Germany 1897-1933. The Shaping of a Jewish Identity. Philadelphia: Jewish Publication Society of America 1976.

Porton Gary G.: Defining Midrash. In: Jacob Neusner (Hrsg.): The Study of Ancient Judaism. New York: Ktav 1981, S. 55-92.

Purkert, Walter: Otto Toeplitz (1881-1940). In: Birgit Bergmann / Moritz Epple (Hrsg.): Jüdische Mathematiker in der deutschsprachigen akademischen Kultur. Berlin / Heidelberg: Springer 2009, S. 103-109. 
Ratzabi, Shalom: Between Zionism and Judaism. The Radical Circle in Brith Shalom 1925-1933. Leiden / Boston / Köln: Brill 2002.

Ratzaby, Jehuda: Zulay Menahem. In: Encyclopaedia Judaica. 2. Aufl, hrsg. v. Michael Berenbaum / Fred Skolnik. Detroit: Macmillan Reference 2007, S. 683.

Rautenberg-Alianov, Viola: Schlagsahne oder Shemen-Öl? Deutsch-jüdische Hausfrauen und ihre Küche in Palästina 1936-1940. In: Tel Aviver Jahrbuch für deutsche Geschichte 41 (2013): Deutsche(s) in Palästina und Israel. Alltag, Kultur, Politik, S. 82-96.

Reinharz, Jehuda: Consensus and Conflict Between Zionists and Liberals in Germany Before World War I. In: Michael A. Fishbane / Paul R. Mendes-Flohr (Hrsg.): Texts and Responses. Studies Presented to Nahum N. Glatzer on the Occasion of His Seventieth Birthday by His Students. Leiden: Brill 1975, S. 226-238.

Fatherland or Promised Land. The Dilemma of the German Jew, 1893-1914. Ann Arbor: U of Michigan P 1975.

Richter, Tilo / Evangelisches Forum Chemnitz (Hrsg.): Erich Mendelsobns Kaufhaus Schocken. Jüdische Kulturgeschichte in Chemnitz. Leipzig: Passage 1998.

Roschewski, Heinz: Rothmund und die Juden. Eine historische Fallstudie des Antisemitismus in der schweizerischen Flüchtlingspolitik 1933-1957. Basel: Helbing \& Lichtenhahn 1997.

Rosenblum, Keshet: Mendelsohn Building Spurs Monumental Dilemma. In: Haaretz, 19.12.2012. https://www.haaretz.com/.premium-where-there-s-a-villa-there-s-a-way1.5275518 (Zugriff am 10.02.2020).

Rosenstock, Werner: Exodus 1933-1939. A Survey of Jewish Emigration From Germany. In: LBIYB 1,1 (1956), S.373-390. https://doi.org/10.1093/leobaeck/1.1.373

Sarna, Jonathan: JPS. The Americanization of Jewish Culture, 1888-1988. Philadelphia: Jewish Publication Society 1989.

Sarna, Jonathan D.: Jewish Culture Comes to America. In:Jewish Studies 42 (2003-2004), S. $45-57$.

Sartre, Jean-Paul: Les mots. Paris: Gallimard 1964.

Sauder, Gerhard (Hrsg.): Die Bücherverbrennung. Zum 10. Mai 1933. München: Hanser 1983.

Der Germanist Goebbels als Redner bei der Berliner Büchervebrennung. In: Horst Denkler / Eberhard Lämmert (Hrsg.): ,Das war ein Vorspiel nur .... Berliner Colloquium zur Literaturpolitik im ,Dritten Reich`. Berlin: Akademie der Künste 1985, S. 56-81.

Sauer, Paul: Für Recht und Menschenwürde. Lebensbild von Otto Hirsch (1885-1941). Gerlingen: Bleicher 1985. 
Schaeper, Silke: Bibliophilie als kultureller Auftrag. Die Geschichte der Schockenbibliothek. In: Saskia Schreuder / Claude Weber (Hrsg.): Der Schocken-Verlag/Berlin. Jüdische Selbstbehauptung in Deutschland 1931-1938. Berlin: Akademie 1994, S.347-360.

Goldadern wertvollen jüdischen Lebens. Salman Schocken und seine HebraicaSammlung. In: Jakob Hessing (Hrsg.): Jüdischer Almanach 1995. Frankfurt am Main: Jüdischer Verlag 1995, S.328-330.

The History of the Book Collection of Salman Schocken. Unveröffentlichte Masterarbeit, Hebrew University Jerusalem, 1995.

Von Zwickau nach Jerusalem. Der Kulturzionist Salman Schocken. In: Heiko Haumann (Hrsg.): Der Erste Zionistenkongress von 1897. Ursachen, Bedeutung, Aktualität. Basel: Karger 1997.

S'ridei Schocken. ,Einbandfragmente' of Hebrew Incunabula at the Schocken Institute for Jewish Reserach. In: Judit Targarona Borrás / Angel Sáenz-Badillos (Hrsg.): Jewish Studies at the Turn of the $20^{\text {th }}$ Century. Proceedings of the $6^{\text {th }}$ EAJS Congress Toledo 1998. Leiden / Boston / Köln: Brill 1999, S. 627-635.

Schedletzky, Itta: Existenz und Tradition. Zur Bestimmung des ,Jüdischen 'in der deutschsprachigen Literatur. In: Dies. / Hans Otto Horch (Hrsg.): Deutsch-jüdische Exil- und Emigrationsliteratur im 20. Jahrhundert. Tübingen: Niemeyer 1993, S.3-14. https://doi. org/10.1515/9783110944624

Der Ort der Jeckes in der Literatur von Palästina / Israel. Über Else Lasker-Schüler und Ludwig Strauss. In: Moshe Zimmermann / Yotam Hotam (Hrsg.): Zweimal Heimat. Die Jeckes zwischen Mitteleuropa und Nahost. Frankfurt am Main: beerenverlag 2005, S. 194-203.

Scheibelhofer, Elisabeth: Raumsensible Migrationsforschung. Methodologische Überlegungen und ihre empirische Relevanz für die Migrationssoziologie. Wiesbaden: Spinger VS 2011. https://doi.org/10.1007/978-3-531-94007-6_4

Schenker, Anatol: Der jüdische Verlag 1902-1938. Zwischen Aufbruch, Blüte und Vernichtung. Tübingen: Niemeyer 2003. https://doi.org/10.1515/9783110963274

Schidorsky, Dov: Das Schicksal jüdischer Bibliotheken im Dritten Reich. In: Peter Vodosek / Manfred Komorowsky (Hrsg.): Bibliotheken während des Nationalsozialismus. Wiesbaden: Harrassowitz 1992, S. 189-222.

Schliebs, Siegfried: Verboten, verbrannt, verfolgt ... Wolfgang Herrmann und seine ,Schwarze Liste. Schöne Literatur' vom Mai 1933. Der Fall des Volksbibliothekars Dr. Wolfgang Herrmann. In: Hermann Haarmann / Walter Huder / Klaus Siebenhaar (Hrsg.): , Das war ein Vorspiel nur.... Büchervebrennung Deutschland 1933. Voraussetzungen und Folgen. Ausstellungskatalog Akademie der Künste. Berlin: Medusa 1983, S.442-444.

Schlögel, Karl: Im Raume lesen wir die Zeit. Über Zivilisationsgeschichte und Geopolitik. Frankfurt am Main: Fischer 2016. 
Schlör, Joachim (Hrsg.): Endlich im Gelobten Land? Deutsche Juden unterwegs in eine neue Heimat. Berlin: Aufbau 2003.

Schmerbach, Folker: Das, Gemeinschaftslager Hanns Kerrl'für Referendare in Jüterbog 1933-1945. Tübingen: Mohr Siebeck 2008.

Schmid, Christian: Stadt, Raum und Gesellschaft. Henri Lefebvre und die Theorie der Produktion des Raumes. Wiesbaden: Steiner 2005.

Schneider, Lambert: Salman Schocken. In: Imprimatur. Ein Jahrbuch für Bücherfreunde 6 (1969), S. 189-202.

Schreuder, Saskia / Claude Weber (Hrsg.): Der Schocken-Verlag/Berlin. Jüdische Selbstbehauptung in Deutschland 1931-1938. Berlin: Akademie 1994.

,Inmitten aller Not und aller Angriffe‘. Der Schocken Verlag im Spiegel der jüdischen Kritik. In: Ebd., S. 377-395.

Würde im Widerspruch. Jüdische Erzählliteratur im nationalsozialistischen Deutschland 1933-1938. Tübingen: Niemeyer 2002.

Schulze, Hagen: Die Biographie in der ,Krise der Geschichtswissenschaft'. In: Geschichte in Wissenschaft und Unterricht 29,8 (1978), S. 508-518.

Schütz, Alfred: Strukturen der Lebenswelt, hrsg. v. Thomas Luckmann. Stuttgart: UTB 2003.

Schwartz, Philip / Helge Peukert: Notgemeinschaft. Zur Emigration deutscher Wissenschaftler nach 1933 in die Türkei. Marburg: Metropolis 1995.

Schwarz-Gardos, Alice (Hrsg.): Heimat ist anderswo. Deutsche Schriftsteller in Israel. Erzählungen und Gedichte. Freiburg i. Br.: Herder 1983.

Shapira, Anita: Israel. A History. Waltham, MA: Brandeis UP 2012. https://doi.org/ $10.2307 /$ j.ctv102bfrj

Sheffi, Naama: The Hebrew Absorption of German Literature in the Yishuv. In: Efraim Karsh (Hrsg.): The First Hundred Years. London: Cass 2000, S. 158-171. https://doi. org/10.1080/13537129908719535

Sieder, Reinhard: Sozialgeschichte auf dem Weg zu einer historischen Kulturwissenschaft. In: Geschichte und Gesellschaft. Zeitschrift für historische Sozialwissenschaft 20,3 (1994), S. 446-468.

Simmons, Erica: Hadassah. The Women's Zionist Organization of America. In: Encyclopaedia Judaica. 2. Aufl., hrsg. v. Michael Berenbaum / Fred Skolnik. Detroit: Macmillan Reference 2007, S. 185-188.

Jewish Adult Education in Nazi Germany as Spiritual Resistance. In: $L B I Y B$ 1,1 (1956), S.68-104. https://doi.org/10.1093/leobaeck/1.1.68 
Aufbau im Untergang. Jüdische Erwachsenenbildung im nationalsozialistischen Deutschland als geistiger Widerstand. Tübingen: Mohr 1959.

Singerman, Robert: Judaica Americana. A Bibliography of Publications to 1900. New York: Greenwood 1990.

Soja, Edward W.: Postmodern Geographies. The Reassertion of Space in Critical Social Theory. New York: Verso 1989.

Thirdspace. Journeys to Los Angeles and Other Real-and-Imagined Places. Oxford: Blackwell 1997.

Sparr, Thomas: Grunewald im Orient. Das deutsch-jüdische Jerusalem. Berlin: Berenberg 2018.

Spengler, Oswald: Die Symbolik des Weltbildes und das Raumproblem. In: Ders.: Der Untergang des Abendlandes. Umrisse einer Morphologie der Weltgeschichte. München: dtv 1972 , S. 231-234.

Spranger, Albrecht: Theodor Zlocisti. Die multiplen Zugehörigkeiten eines Zionisten. Berlin: Neofelis 2020.

Steinweis, Alan E.: Hans Hinkel and German Jewry, 1933-1941. In: LBIYB 38,1 (1993), S.209-219. https://doi.org/10.1093/leobaeck/38.1.209

Stemberger, Günter: Einleitung in Talmud und Midrasch. 8. neubearb. Aufl. München: Beck 1992.

Steinschneider Moritz. In: Österreichisches Biographisches Lexikon 1815-1950, Bd. 13.

Wien: Österreichische Akademie der Wissenschaften 2007-2010, S. 198-199.

Stephan, Regina (Hrsg.): Erich Mendelsohn. Architekt 1887-1953. Gebaute Welten. Arbeiten für Europa, Palästina und Amerika. Ostfildern-Ruit: Hatje 1998.

,Denken von Tag zu Tag, wo Geschichte große Kurven schlägt und Hunderttausende unbefriedigt lässt.' Frühe expressionistische Bauten in Luckenwalde, Berlin und Gleiwitz. In: Ebd., S.44-63.

Sternhell, Ziva: Zwischen den Bergen Jerusalems und den Stränden Tel Avivs. Die deutsche Kultur und die Ausformung der israelischen Kunst. In: Moshe Zimmermann / Yotam Hotam (Hrsg.): Zweimal Heimat. Die Jeckes zwischen Mitteleuropa und Nahost. Frankfurt am Main: beerenverlag 2005, S. 147-152.

Stopka, Katja: Zeitgeschichte, Literatur und Literaturwissenschaft. In: DocupediaZeitgeschichte (2010), S. 1-17.

Surall, Frank: Dienemann Max. Rabbiner und jüdischer Theologie. In: BiographischBibliographisches Kirchenlexikon, Bd.XXXI, hrsg. v. Friedrich-Wilhelm Bautz/Traugott Bautz. Nordhausen: Bautz 2010, Sp. 354-365. 
Szöllösi-Janze, Margit: Lebens-Geschichte - Wissenschafts-Geschichte. Vom Nutzen der Bigraphie für Geschichtswissenschaft und Wissenschaftsgeschichte. In: Berichte zur Wissenschaftsgeschichte 23 (2000), S. 17-35. https://doi.org/10.1002/bewi.20000230104

Tamari, Ittai Jospeh: Hebräische Typographie des Schocken Verlags. In: Saskia Schreuder / Claude Weber (Hrsg.): Der Schocken-Verlag/Berlin. Jüdische Selbstbehauptung in Deutschland 1931-1938. Berlin: Akademie 1994, S.327-346.

Das Volk der Bücher. Eine Bücherreise durch sechs Jahrhunderte jüdischen Lebens. München: Oldenbourg 2012.

Tel Aviver Jahrbuch für deutsche Geschichte 41 (2013): Deutsche(s) in Palästina und Israel. Alltag, Kultur, Politik, hrsg. v. José Brunner.

Tiedemann, Rolf/ Hermann Schweppenhäsuer: Editorischer Bericht. In: Walter Benjamin: Gesammelte Schriften, Bd. I.2, hrsg. v. RolfTiedemann / Hermann Schweppenhäuser. Frankfurt am Main: Suhrkamp 1991, S.751-796.

Tilly, Charles: Transplanted Networks. In: Virginia Yans-McLaughlin (Hrsg.): Immigration Reconsidered. History, Sociology, and Politics. New York / Oxford: Oxford UP 1990, S.79-95.

Triendl-Zadoff, Miriam: Nächstes Jahr in Marienbad. Gegenwelten jüdischer Kulturen der Moderne. Göttingen: Vandenhoeck \& Ruprecht 2007. https://doi.org/10.13109/ 9783666569951

Tylor, Edward Burnett: Primitive Culture. London: Murray 1871.

Vierhaus, Rudolf: Die Rekonstruktion historischer Lebenswelten. Probleme moderner Kulturgeschichtsschreibung. In: Hartmut Lehmann (Hrsg.): Wege zu einer neuen Kulturgeschichte. Göttingen: Wallstein 1995, S.6-28.

Völpel, Annegret / Ran HaCohen: Deutsch-jüdische Kinder-und Jugendliteratur von der Haskala bis 1945. Die deutsch-und hebräischsprachigen Schriften des deutschsprachigen Raums. Ein bibliographisches Handbuch in zwei Bänden. Stuttgart: Metzler 2016.

Warburg, Frederic: All Authors Are Equal. The Publishing Life of Frederic Warburg, 1936-1971. London: Hutchinson 1973.

Wardi, Ada (Hrsg.): New Types. Three Pioneers of Hebrew Graphic Design. Jerusalem: Israel Museum Jerusalem 2016.

Wassermann, Henry: Bibliographie des Jüdischen Schrifttums in Deutschland 1933-1943. München: Saur 1989.

Weber, Claude: ,Halt und Richte‘. Zur Programmatik des Schocken Verlags. In: Saskia Schreuder / Claude Weber (Hrsg.): Der Schocken-Verlag/Berlin. Jüdische Selbstbehauptung in Deutschland 1931-1938. Berlin: Akademie 1994, S.39-54.

Weidle, Barbara (Hrsg.): Kurt Wolff. Ein Literat und Gentleman. Bonn: Weidle 2007. 
Weigel, Sigrid: Zum ,topographical turn'. Kartographie, Topographie und Raumkonzepte in den Kulturwissenschaften. In: KulturPoetik 2,2 (2002), S. 151-165.

Albrecht Weisker: Rezension zu: Karl Schlögel: Im Raume lesen wir die Zeit. Über Zivilisationsgeschichte und Geopolitik. München 2003. In: H-Soz-Kult, 13.03.2004. www. hsozkult.de/publicationreview/id/reb-4847 (Zugriff am 12.02.2020).

Weiss, Yfaat: The Transfer Agreement and the Boycott Movement. A Jewish Dilemma on the Eve of the Holocaust. In: Yad Vashem Studies 26 (1998), S. 129-171.

Wiechemann, Dietmar: Traum vom Frieden. Das bi-nationale Konzept des Brith-Schalom zur Lösung des jüdisch-arabischen Konfliktes in der Zeit von 1925-1933. Schwalbach a.T.: Wochenschau 1998.

Witzthum, David: Deutsche Presse in hebräischer Sprache. Drei Wenden und ihre Bedeutung. In: Moshe Zimmermann / Yotam Hotam (Hrsg.): Zweimal Heimat. Die Jeckes zwischen Mitteleuropa und Nahost. Frankfurt am Main: beerenverlag 2005, S. 187-294.

Yisraeli, David: The Third Reich and the Transfer Agreement. In: Journal of Contemporary History 6,2 (1971), S. 129-148. https://doi.org/10.1177/002200947100600207

[Das deutsche,Reich“ und Eretz Israel]. Ramat Gan: Bar Ilan UP 1974.

Young-Bruehl, Elisabeth: Hannah Arendt. For Love of the World. New Haven: Yale College 1982.

Zadoff, Miriam: Der rote Hiob. Das Leben des Werner Scholem. München: Hanser 2014.

Zadoff, Noam: Gershom Scholem. From Berlin to Jerusalem and Back. An Intellectual Biography. Waltham, MA: Brandeis UP 2018.

Zarusky, Jürgen / Institut für Zeitgeschichte (Hrsg.): Das Münchener Abkommen von 1938 in europäischer Perspektive. München: Oldenbourg 2013. https://doi.org/10.1524/ 9783486719291

Zeitlin, Rose: Henrietta Szold. Record of a Life. New York: Dial Press 1952.

Zelinsky, Wilbur: The Hypothesis of the Mobility Transition. In: Geographical Review 60,2 (2003), S. 219-249.

Zimmermann, Moshe / Yotam Hotam (Hrsg.): Zweimal Heimat. Die Jeckes zwischen Mitteleuropa und Nabost. Frankfurt am Main: beerenverlag 2005. https://doi.org/ $10.2307 / 213996$

Vorwort. In: Ebd., S. 10-13. 


\section{Index}

Fundstellen in Fußnoten sind durch Kursivschrift gekennzeichnet, Quellen- und Literaturnachweise sind nicht berücksichtigt.

A

Adler, Karl 362

Adorno, Theodor W. 412-414

Agnon, Samuel Joseph (alternativ Shmuel Yosef Agnon) 12, 29, 67, 98-99, 107, $110-111,117-119,125,128,138,141$, $155-157,164,183,186,244-246,252$, $270,273,312,352,361,373,416,423$, 434-435

Allenby, Edmund Lord 282

Alperovich, Moses 394

An-Ski, Salomon 123

Arendt, Hannah 16, 30, 378, 380, 397, 400-405, 409-416, 438

Arndtheim, Erna 344

B

Balfour, Arthur James Lord 282

Baruch, Franzisca 30, 306, 351, 352, 390, 424-426

Bataille, Georges 412

Bauer, Felice 409

Ben Gurion, David 219, 268

Ben Yitzhak, Avraham 352, 363

Ben-Chorin, Schalom 361

Benjamin, Walter 356, 378, 402, 411-415
Bentwich, Norman 285

Berger, Julius 104

Bergmann, Hugo 29, 108, 124, 281, 294, 296, 361, 366

Bernheim, Alfred 190, 265-267

Bialik, Chaim Nachman 281

Bin Gorion, Emanuel 131

Bin Gorion, Micha Josef 123, 164

Birnbaum, Lucie 137

Bloch, Herr 141

Blumenfeld, Kurt 15, 18, 26, 75-77, 95 , 98, 108, 199, 309, 403-404, 427

Böhm, Ernst 424

Brod, Max 108, 406-409

Brody, Heinrich (alternativ Chaim Brody) $126,245,247,273$

Buber, Martin 29-30, 63-64, 67, 70-71, 76, 99-108, 110-111, 117, 119, 121-125, 127-128, 136-144, 146-147, 157, 159-164, 166-167, 171, 175-176, $186,246,267,270,273,280-281,287$, 294-295, 309, 311-312, 352, 355, 361-362, 395, 400-405, 416, 428

Buber, Paula 267, 270, 295

Bullwachter, M. S. 334, 337, 340 
C

Calvary, Moses 108

Cassirer, Paul 203

Chagall, Bella 403

Chagall, Marc 255, 403

Chamberlain, Arthur Neville 321-322

Cohen, Dvorah 42

Cohen, Hermann 65, 85-86

Cohen, Sam 225

Cohn, Ernst 137, 252-254

Cohn, Helene Hanna 106

Czaczkes, Samuel Joseph (d. i. Samuel Joseph Agnon) 98

\section{D}

Daladier, Édouard 321

de Rothschild, Edmond 282

Dienemann, Max 168-171

Diesendruck 124

E

Edelman, Racheli 30, 42, 118, 312, 436, 440

Ehrlich, Paul 282

Ehrmann, Zerline s. Schocken, Lily

Einstein, Albert 284-285, 429

Eliot, T.S. 405

Engelke, Karl 230

Eskuchen, Karl 319
F

Feiwel, Berthold 100-101, 281

Finkel, Samuel B. 270-271, 376-377, 382

Fonk, Wilhelm 46-47, 385, 417-420, 422-423

Frank, Rafael 424

Fränkel, David 244

Freeden, Herbert 193

Freimann, Aron 245

Freud, Martha s. Seidmann-Freud, Tom

Friedenthal, Herbert s. Freeden, Herbert

Friedländer, Henri 149

Frohknecht, R. 305, 342-343

G

George, Stefan 399

Ginzberg, Louis 123

Glatzer, Anna 395

Glatzer, Nahum N. 119, 127, 391, 395-396, 398, 401-402, 404

Glazer, Julius S. 42

Goebbels, Joseph 129, 151-152, 155

Goldmann, Moschawa 55

Goldstein, Moritz 181-182

Greenberg, Uri Zwi 361

Gregorovius, Ferdinand 131

Guggenheim, Sylvain 355 
H

Ha'am, Achad 281-282, 303

Haas, Willy 409-410

Habermann, Abraham Meir 245-246, 252-254

Halevi, Jehuda 164

Hartog, Philip 287, 293

Hegner, Jakob 148-149

Heine, Heinrich 146, 178, 247, 357

Heinze, Willy 210-211, 220, 230, 236

Henlein, Konrad 321

Herder, Johann Gottfried 131

Herrmann, Leo 70, 102, 104

Herrmann, Wolfgang 153-154

Herz, Alina 343-345

Herz, Horst 343-344

Herz, Isaak 341-344

Herzl, Theodor 72, 75-76, 96-97, 107, 303

Hinkel, Hans 59, 152, 175-176

Hirsch, Otto 362

Hitler, Adolf 135, 153, 159, 215, 259, 288, 321,323

Hoffmann, Ernst 253

Hoofien, Sigmund 225

Horkheimer, Max 322, 412-413

Hünecke, Hedwig 137

Hushi, Aba 309
I

Igersheimer, Hermann 322

J

Jabotinsky, Vladimir Ze'ev 282, 303

Jacobsohn, Victor 102-103

Jaspers, Karl 404, 411, 415

Jellicoe, Geoffrey 236

Jesenká, Milena 409

Joseph, Bernhard (alternativ Dov Yosef) 268

K

Kafka, Franz 30, 148, 403, 405-411, 413, 416

Kafka, Hermann 406

Kafka, Julie 406

Katzenstein, Jacob 428

Kauffmann, Richard 197-198, 208

Kaznelson, Siegmund 105-106, 124, 306, 307-308

Kellner, Ernst 147, 149

Kiepenheuer, Gustav 406

Klausner, Israel 281

Knopf, Lucy 137

Kochanowski, Erich 175

Kohn, Hans 303, 385

Kook, Abraham Isaak Oberrabbiner 361

Kraft, Werner 361

Krakauer, Grete 352

Krakauer, Leopold 352 
$\mathbf{L}$

Landauer, Dora 42, 59, 137, 325, 398

Landauer, Dr. 54

Landauer, Georg 225, 309

Landauer, Gustav 148

Lang, Erwin 374

Lasker-Schüler, Else 12, 29, 235, 351, 354-361, 363-364

Leeser, Isaac 392

Levi, Selma 340

Levin, Maurice 340

Lilien, Ephraim Moses 101

Loewenstein-Rosenthal, Frau 137

Luzzatto, Samuel David 178, 241

M

Magnes, Judah Leon 195, 281-288, 294-296, 301-302, 328, 429

Mann, Golo 152

Mann, Thomas 23

Maly, Eva (geb. Eva Marbach) 345-346

Marbach, Eva s. Maly, Eva

Marbach, Herr 346

Marcus Rader, Jacob 394

Markowicz, Ernst 30, 336-339

Marx Perlzweig, Olga 399, 402

Marx, Ephraim 362

Marx, Erich Jehoshua 362

Marx, Leopold 362-363

Marx, Moses 245-246, 424

Mendelsohn, Erich 28, 45, 60, 136, 195, 198-213, 215-216, 220, 236, 249 , 264-267, 273, 301, 352, 363, 382, 437
Mendelsohn, Louise 205-206, 209, 212-213, 216

Michelsen, Edith 336-337

Michelsen, Jost 336

Mombert, Alfred 177

Mommsen, Theodor 131

Moses, Siegfried 49-50, 53, 58, 74, 75, $109,121,125,231,248,253,309,437$

Mosse, Rudolf 136

Motzkin, Leo 101

Muir, Edwin 408

Müller, Max Malte 132, 148-149

Mussolini, Benito 248, 321

$\mathbf{N}$

Nossing, Alfred 101

Nussbaum, Miriam 64, 168

$\mathbf{O}$

Orlik, Emil 424

$\mathbf{P}$

Parsitz, Shulamit 42

Pelz, Elise 248-249, 252-254

Phiebig, Albert J. 191

Picard, Fritz 137

Pollack, Ernst 409

Polotsky, Jacob H. 294

Pozen, Robert (Pseudonym Gershom (Gustav) Schocken) 42

Präger, Max 106 
$\mathbf{R}$

Reichmann-Fromm, Frau 335

Robinsohn, Abraham 106

Rome Herzl, Theodore 42

Roosevelt, Franklin D. 347, 349

Rosenberg, Ada 235

Rosenberg, Alfred Ernst 250, 252

Rosenblüth, Felix 102, 309

Rosenzweig, Franz 125, 127, 142, 164, $166,186,203,256,272,395$

Roth, Leon 382-383

Rowohlt, Ernst 399, 409

Ruppin, Arthur 83, 309, 385

\section{S}

Salaman, Redcliffe N. 287

Salin, Edgar 262

Samuel, Herbert 282, 292

Saravan, Leon Vita 240

Schiff, Frieda 283

Schiff, Otto W. 345

Schiller, Hety 333, 335-336

Schiller, Robert 333-337, 340

Schirmann, Chaim Jefim 126, 273-274

Schlesinger, Josef 406-407

Schneider, Lambert 29, 30, 125, 131, $136-138,142,144,146-147,148$, $155-156,160,162-164,175-176,180$, 245-246, 287, 330, 354, 435-436

Schocken, Amos 42

Schocken, Chava 42
Schocken, Dora s. Dora Landauer

Schocken, Dvorah 30, 42, 440,

Schocken, Eva (Tochter Salman Schockens) 42, 194, 329, 334, 374

Schocken, Eva (Mutter Salman Schockens) 35

Schocken, Gershom (Gustav) 26, 42, 47, 52, 65, 118, 155, 195, 230, 267, 277, 289, 305-306, 310-313, 338, 363, 365, 379, 386-387, 389, 390, 400, 426-428, 438

Schocken, Gideon 30, 42, 194, 264

Schocken, Hermann 342

Schocken, Isaak 35, 39, 43

Schocken, Julius 67

Schocken, Lili (geb. Zerline Ehrmann) 12, 30, 42, 59, 60, 78, 80-82, 194, 202, $210,212-216,255,263-264,269$, 272, 302, 317-319, 325-326, 328-330, 371-374, 378, 397, 427, 430, 434-435

Schocken, Mischa 194

Schocken, Simon 43-45, 66, 83, 103

Schocken, Theodor 42, 46, 59-60, 116, 134-135, 137, 194, 248, 252, 322, 329, 334-335, 346, 349, 374, 398, 405

Scholem, Betty 371-373

Scholem, Erich 372

Scholem, Fania 372

Scholem, Gershom 29-30, 95, 124, 138, 145, 156-157, 178, 199, 246-247, 272-273, 294, 311, 319-320, 356, 361, 371-372, 378-380, 400, 402-403, 405, 412-416, 429-432, 436, 438

Scholem, Reinhold 372

Scholem, Werner 372 
Schudt, Johann Jakob 131

Schwager, Lipa 244

Seidmann, Jakob 117

Seidmann-Freud, Tom 117

Senator, Werner 30, 292, 302, 309, 371,

$373,375,380,383,429-431$

Senhouse, Roger 407-408

Silber, Blume 37

Simon, Ernst 29, 138, 145, 167-168, 171, 175, 178-180, 199, 272-273, 361

Smoira, Moses 202

Sonne, Abraham, s. Ben Yitzhak, Avraham

Sonne, Isaia 245

Spanier, Arthur 245

Spiro, Adon 235

Spiro, Georg 337, 340

Spitzer, Moritz (Moshe) 30, 59, 116, $128,130,134-138,144-146,149,156$, 159, 164, 175-180, 245-246, 303-304, $320-327,330,332,337,340,356,406$, 415,434

Steinhardt, Jakob 363

Steinhoff, Frau 137

Steinschneider, Moritz 241-243

Stern, Gerson 183

Stern, James 410

Stern, Tania 410

Sternberg, Fritz 421

Stifter, Adalbert 131, 247

Strauss, Ludwig 146

Struck, Herman 352
Swet, Judith 355

Szold, Henrietta 380, 381

\section{$\mathbf{T}$}

Ticho, Abraham 50, 309, 352

Ticho, Anna 50, 309, 352

Toeplitz, Otto 298-300

Trietsch, Davis 101

Turnowsky, Walter 306

$\mathbf{U}$

Ury, Dora 346

Ury, George 346

Ussischkin, Menachem 81, 199, 281

V

Valhope North, Carol s. Marx Perlzweig, Olga

von Droste-Hülshoff, Annette 131

von Stauß, Emil Georg 420-421

von Weizsäcker, Viktor 160

W

Warburg, Aby 252

Warburg, Felix Moritz 283, 375

Warburg, Frederic 407-408, 410-411

Weizmann, Chaim 100-101, 280-288, 293, 302, 327-328, 380, 383, 426, 429

Weltsch, Robert 83, 127, 182, 306, 307-308, 310, 433, 436

Weltsch, Simon 29

Werfel, Franz 399 
Wertheim, Georg 420, 421

Wertheim, Ursula 421

Wiepking-Jürgensmann, Heinrich 236

Wilson, Harris 342

Wise Mayer, Isaac 392

Wittig, Joseph 160

Wolff, Helen (geb. Helen Mosel) 399

Wolff, Kurt 399-401, 406-407, 409-410

Wolfskehl, Karl 124, 138, 183-184, 247-250, 255, 262, 373, 398-341

Y

Yellin, David 281

Yosef, Dov s. Joseph, Bernhard

Z

Zobel, Moritz 303

Zulay, Menachem 126, 138, 245, 273-274

Zunz, Leopold 178-179, 241-243

Zweig, Stefan 49-50 



\title{
Jüdische Kulturgeschichte im Neofelis Verlag
}

\author{
Theodor Zlocisti \\ Die multiplen Zugebörigkeiten eines Zionisten \\ - Einblicke in die ambivalenten Lebenswelten eines zionistischen Pioniers - \\ von Albrecht Spranger \\ Jüdische Kulturgeschichte in der Moderne, Bd. 23 \\ ISBN: 978-3-95808-322-6 \\ 424 S., $35 €$
}

\section{Heinemann Stern. Jüdische Jugend im Umbruch}

Briefe nach Berlin und Rio de Janeiro, 1937-1953

- Über ein weltweites Netzwerk der deutsch-jüdischen Emigration -

hrsg. von Aubrey Pomerance / Eva Rohland / Joachim Schlör

Jüdische Kulturgeschichte in der Moderne, Bd. 20

ISBN: 978-3-95808-242-7

mit 1 Farb- u. 24 S/W-Abbildungen

364 S., $32 €$

\section{Lotte Cohn}

Eine schreibende Architektin in Israel

Bd. 1: Ausgewäblte Schriften (1934-1982)

Bd. 2: Ausgewählte Briefe (1921-1982)

- Eine Architekturpionierin und Zionistin reflektiert ihre Berufspraxis und Emigration -

hrsg. von Ines Sonder

Jüdische Kulturgeschichte in der Moderne, Bd. 14.1 / 14.2

ISBN: 978-3-95808-118-5 / 978-3-95808-125-3

188 S., $24 € / 202$ S., $24 €$ 


\title{
Deutsche und zentraleuropäische Juden in Palästina und Israel Kulturtransfers, Lebenswelten, Identitäten - Beispiele aus Haifa
}

- Die ,Jeckes' neu verhandelt: Plädoyer für ein vielfarbiges Mosaik -

hrsg. von Anja Siegemund

Jüdische Kulturgeschichte in der Moderne, Bd. 11

ISBN: 978-3-95808-027-0

mit 17 Farb- u. 161 S/W-Abbildungen

541 S., $34 €$

\author{
Hegels Juden \\ Reformer, Sozialisten, Zionisten \\ - Zur jüdischen Rezeption Hegels - \\ von Micha Brumlik \\ Jüdische Kulturgeschichte in der Moderne, Bd. 17 \\ ISBN: 978-3-95808-211-3 \\ 184 S., $22 €$
}

\section{Zwischen allen Bühnen \\ Die Jeckes und das hebräische Theater 1933-1948}

- Ein Kampf um Anerkennung und einen Platz auf der Bühne: Der Werdegang von deutschsprachigen jüdischen Theaterschaffenden im britischen Mandatsgebiet Palästina -

von Thomas Lewy

aus dem Hebräischen von Sebastian Schirrmeister

Jüdische Kulturgeschichte in der Moderne, Bd. 10

ISBN: 978-3-95808-019-5

mit 15 Farb- u. $35 \mathrm{~S} / \mathrm{W}$-Abbildungen

352 S., $26 €$

Leseproben zu all unseren Titeln unter: www.neofelis-verlag.de 
Publiziert mit Unterstützung des Schweizerischen Nationalfonds zur Förderung der wissenschaftlichen Forschung.

Bibliografische Information der Deutschen Nationalbibliothek

Die Deutsche Nationalbibliothek verzeichnet diese

Publikation in der Deutschen Nationalbibliografie;

detaillierte bibliografische Daten sind im Internet über http://dnb.d-nb.de abrufbar.

(C) 2021 Neofelis Verlag GmbH, Berlin

www.neofelis-verlag.de

This work is licensed under a

Creative Commons Attribution-NonCommercial-NoDerivatives 4.0 International License.

Umschlaggestaltung: Marija Skara

Lektorat \& Satz: Neofelis Verlag (nw/vf)

Druck: Drusala s.r. o., Frýdek-Místek (CZ)

Gedruckt auf FSC-zertifiziertem Papier.

ISBN (Print): 978-3-95808-327-1

ISBN (PDF): 978-3-95808-378-3

DOI: https://doi.org/10.52007/9783958083783 
Salman Schocken war ein Selfmademan. Aufgewachsen in bescheidenen Verhältnissen in der Nähe von Posen, folgte er dem Ruf seines Bruders in die sächsische Stadt Zwickau, wo beide 1904 eine Warenhauskette gründeten. Die Geschäfte verliefen derart erfolgreich, dass sie in die Kreise der führenden Kaufleute aufstiegen. Gleichzeitig begann Salman Schocken, sich für die zionistische Arbeit zu interessieren.

Als Kulturzionist, Verleger, Mäzen und Bibliophiler wurde Schocken zum Zentrum eines Netzwerks bedeutender jüdischer Intellektueller. Nach der Machtergreifung der Nationalsozialisten verließ er mit seiner Familie Deutschland und ließ sich in Jerusalem nieder, blieb aber auch nach seiner Emigration geschäftlich und zionistisch in Europa tätig. In Jerusalem war er als Vorsteher der Hebräischen Universität, Besitzer einer bedeutenden hebräischen Tageszeitung und seines zweiten Verlagshauses federführend am Aufbau eines deutsch-jüdischen Kulturlebens des Jischuv beteiligt - Salman Schocken bleibt auch dort Zentrum des Netzwerks. Erst mit seiner Emigration nach New York im Jahr 1940 verliert er seinen Einfluss, gründet dort aber noch einmal einen neuen Verlag.

Die Annäherung an Schocken erfolgt auf dem Weg der Topographie, also den Ortsbeziehungen in seinem Leben von Posen über Berlin nach Zwickau und dann von Berlin über Jerusalem nach New York. Das Buch stellt Schockens Lebensweg durch die detaillierte Analyse von tausenden von Primärquellen im Zusammenhang und in der Wechselbeziehung mit der Zeitgeschichte dar. So ist die Arbeit mehr als die Schilderung seines Lebens, sie ist auch eine Analyse, wie sich der Kulturraum des deutschen Judentums nach 1933 außerhalb Deutschlands konstituierte und veränderte.
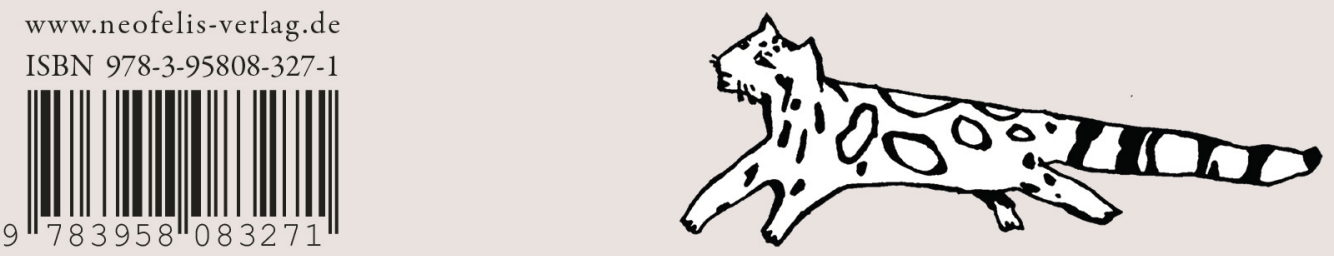